\title{
ANÁLISE DO INSTRUMENTO VISTORIA TÉCNICA HOSPITALAR
}

TÂNIA REGINA G. BOTELHO PUPO

Tese de Doutorado a ser apresentada ao

Departamento de Prática de Saúde Pública da Faculdade de Saúde Pública da Universidade de São Paulo, para obtenção do grau de Doutor.

Área de Concentração:

Administração Hospitalar

ORIENTADOR:

PROF. DR. MARCOS KISIL

São Paulo

2004

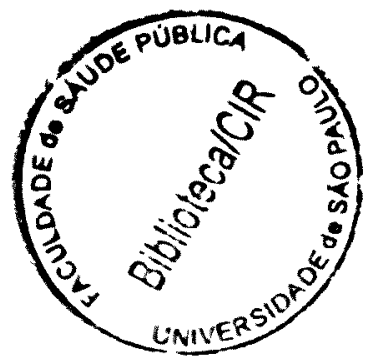




\section{AGRADECIMENTOS}

Ao Prof. Dr. Marcos Kisil pela orientação prestada durante a realização deste trabalho.

Aos membros da banca de qualificação, Professores Drs. Olimpio J. V. Bittar e Vitória Kedy Cornetta pelas orientações, sugestões e acompanhamento.

À Diretoria dos Hospitais selecionados pela autorização e disponibilidade em participar deste estudo.

A meus familiares e amigos pelo apoio e incentivo.

E em especial, a Celso Fiszbeyn, companheiro de todas as horas, colaborador das várias fases deste trabalho, pelas atitudes de solidariedade, respeito e carinho que me possibilitaram crescimento pessoal e profissional. 


\section{RESUMO}

Pupo TRGB. Análise do Instrumento Vistoria Técnica-Hospitalar. São Paulo 2004 [Tese de Doutorado - Faculdade de Saúde Pública da USP]

Este estudo foi realizado em amostra constituída por Instituições Hospitalares, públicas e privadas do Estado de São Paulo, com o objetivo de analisar um instrumento elaborado para categorização de hospitais.

A pesquisa de campo com desenvolvimento de software específico, foi realizada no período de dezembro de 2002 a dezembro de 2003, em nove hospitais selecionados intencionalmente, utilizando-se como critério fundamental a capacidade ou lotação, mediante aplicação de um Roteiro de Vistoria Técnica Hospitalar voltado para análise da estrutura física, equipamentos, recursos humanos e indicadores hospitalares.

Este instrumento foi baseado no Roteiro de Inspeção de Hospitais da Coleção Saúde \& Cidadania (1998), modificado pela autora em função de novos Instrumentos e de novas Resoluções, Portarias e Normas Técnicas do Ministério da Saúde, específicas para cada setor do hospital.

O Roteiro de Vistoria Técnica Hospitalar foi utilizado por dois vistoriadores, um médico e uma enfermeira (própria autora), previamente treinados para sua aplicação. O método de pesquisa foi o quali-quantitativo e a estratégia metodológica para a pesquisa de campo foi a Vistoria Técnica, que corresponde à inspeção de estabelecimentos de saúde por profissionais devidamente habilitados, a ser realizada segundo roteiro elaborado de acordo com normas técnicas e padrões (exigidos pelo Ministério da Saúde, Agências Reguladoras e órgãos de classe), bem como à obtenção dos dados referentes aos indicadores de qualidade, produtividade e dimensionamento quantitativo de recursos humanos. 
A duração das vistorias foi de 4 horas para hospitais de pequeno porte, 06 horas para hospitais de médio porte, 8 horas para hospitais de grande porte e 16 horas para o especial. O instrumento mostrou-se adequado à coleta de dados e os resultados encontrados possibilitaram a categorização dos hospitais, além da identificação dos pontos fortes e fracos de cada instituição vistoriada. 


\section{SUMMARY}

Pupo TRGB. Analysis of the Instrument Inspects Technique-Hospital. São Paulo 2004 [Doctorate Thesis - Faculty of Public Health of the University of São Paulo (USP)]

This study aims at developing an instrument to categorize hospitals and it was based on the analysis of public and private health institutions in São Paulo state.

The field research, which included the development of specific software, was conducted in nine hospitals selected for this purpose, and the main criterion used was each institution's number of beds.

The analysis was based on Itinerary of Inspection of Hospitals of the Colection Saúde\&Cidadania, an inspection guideline issued by the Health Ministry in 1998 and which was modified by the author following the issue of new rules for each hospital sector.

This study looks into the physical structure, human resources and hospital indicators of several institutions between December 2002 and December 2003, and it was conducted by two observers previously trained to utilize this research instrument - a doctor and a nurse (the author).

The method utilized by the researchers was the quali-quantitative one and the methodological strategy used in the field research was a Technical Survey - an inspection of health establishments carried out by qualified professionals, following the guidelines issued by the Health Ministry and by the health sector regulator - and an analysis of each hospital's quality, productivity and human resource quantitative data. 
Each inspection visit lasted four hours in small hospitals, six hours in medium hospitals, eight hours for large hospitals and sixteen hours in so-called 'special' hospitals.

The instrument proved efficient for data collection and the results obtained enabled the researchers to categorize the hospitals and to identify the strong and weak points of each institution studied. 


\section{ÍNDICE}

Página

1. Introdução 01

1.1. Avaliação-Conceitos 01

1.2. Avaliação em Saúde 03

1.3. Implantação do SUS no Brasil e Avaliação de Hospitais 08

1.4. A rede hospitalar: dimensões e características 16

1.5. Métodos de avaliação da qualidade implantados em hospitais 21 brasileiros

1.6. Categorização de Hospitais 32

1.7. Instrumentos de Avaliação de Hospitais utilizados pelos 42 gestores na atualidade

$\begin{array}{ll}\text { 2. Justificativa } & 48\end{array}$

3. Objetivos 52

4. Método 53

4.1. Estratégia de Pesquisa 53

4.2. Determinação da Amostra 56

4.3. Instrumento e Coleta de Dados 57

4.4. Pesquisa de Campo 59

4.5. Descrição do Método dẻ Análise Qualitativa e Quantitativa 61

5. Resultados e Discussão 69

6. Considerações Finais 155

7. Referências Bibliográficas 162

8. Bibliografia Consultada 173 
Anexo 1 - Autorização

Anexo 2 - Roteiro de Vistoria Técnica Hospitalar

Anexo 3 - Roteiro de Pontuação

Anexo 4 - Vistoria Técnica Hospitalar-Hospital A

Anexo 5 - Vistoria Técnica Hospitalar-Hospital B

Anexo 6 - Vistoria Técnica Hospitalar-Hospital C

Anexo 7 - Vistoria Técnica Hospitalar-Hospital D

Anexo 8 - Vistoria Técnica Hospitalar-Hospital E

Anexo 9 - Vistoria Técnica Hospitalar-Hospital F

Anexo 10 - Vistoria Técnica Hospitalar-Hospital G

Anexo 11 - Vistoria Técnica Hospitalar-Hospital H

Anexo 12 - Vistoria Técnica Hospitalar-Hospital I

Anexo 13 - Execução Orçamentária e Financeira - Ministério da

Saúde, 2002

Anexo 14 - Execução Orçamentária e Financeira - Ministério da

Saúde, 2003 


\section{INTRODUÇÃO}

\section{1- Avaliação - Conceitos}

Segundo Worthen, Sanders e Fitzpatrick, citados por MALIK e SCHIESARI (1998), qualquer discussão a respeito de qualidade traz, implícita ou explícita, a noção de avaliação. O processo de avaliação determina o valor de algo. Um julgamento é então realizado e a explicitação dos critérios utilizados aumenta a legitimidade da avaliação. O conhecimento dos critérios permite saber se o julgamento pode ou não ser considerado válido pelo observador. ${ }^{85}$

AGUILAR (1995) relata que para a Real Academia Espanhola, avaliar é “assinalar o valor de uma coisa”. E se tomarmos a definição genérica de um dos principais autores em matéria de pesquisa avaliativa, Scriven, verificamos que, para ele, "avaliar é um processo pelo qual estimamos o mérito ou valor de algo". Assim, pois, e sempre, como uma primeira aproximação, podemos dizer que avaliar é uma forma de estimar, apreciar, calcular. Em sentido lato, a palavra avaliação se refere ao termo valor e supõe um juízo sobre algo. Trata-se, pois, de um juízo que envolve uma avaliação de "algo" (objeto, situação ou processo) de acordo com determinados critérios de valor com que se emite o juízo ${ }^{3}$.

Outros autores definiram avaliação na área de saúde: CHAMPAGNE $^{48}(1985)$ e JAMES (1969) consideram que a meta da avaliação de programas é fazer juízo sobre uma atividade, um recurso ou um resultado. Desta definição derivarão, de acordo com esses autores, três tipos de avaliação: de estrutura, processo e impacto. $\mathrm{Na}$ mesma linha que os anteriores, se expressa DONABEDIAN ${ }^{57}(1966)$, ao indicar 
que a função primeira da avaliação é determinar o valor ou grau de êxito na consecução de um objetivo determinado. ${ }^{3}$

No campo do trabalho social ou do desenvolvimento comunitário, encontramos definições que contêm um forte elemento prático face à solução de problemas: "a avaliação é a análise dos efeitos e das conseqüências dos diferentes modos de atuação sobre uma situação, para definir num prazo quais são os que trazem mais soluções" (DUTRENIT, 1984) ${ }^{3}$. Portanto, a avaliação, no campo das tecnologias sociais, é entendida como um mecanismo de regulação de ações e políticas sociais, que pode permitir uma notável diminuição das possibilidades de fracasso de um programa de interesse social (MARETTE, 1980; REZSOHAZY, $1988)^{3}$. Isto é, “a avaliação só será útil se for utilizada como meio para melhorar um programa. É necessário conhecer as qualidades e as fraquezas de um programa para poder modificá-lo à medida que for preciso". ${ }^{3}$.

Estas definições precedentes mostram-nos claramente a utilidade da avaliação como meio para corrigir erros e modificar cursos de ação. Em outras palavras, a avaliação só tem sentido na medida em que serve para tomar decisões concretas. Assim se expressam autores como Stufflebeam: a avaliação é um estudo sistemático, dirigido e realizado com o fim de ajudar um grupo de clientes e julgar e ou aperfeiçoar o valor e ou mérito de algum objeto (STUFFLEBEAM, SKINKFIELD, 1987). Ou: "processo sistemático de coleta e valoração de informação útil para uma eventual tomada de decisões" ${ }^{3}$.

SCRIVENS (1995), por sua vez, define a avaliação como uma atividade metodológica que "consiste simplesmente na coleta e combinação de dados de trabalho mediante a definição de metas que proporcione escalas comparativas ou 
numéricas, com o fim de justificar: 1. Os instrumentos de coleta de dados; 2. as valorações; 3. a seleção das metas" 104 .

Para SUCHMAN (1967), a avaliação é um "conjunto de procedimentos para a coleta e análise de dados que aumentam mais a possibilidade de provar do que de afirmar o valor de uma atividade social" ${ }^{3}$.

LIMA JR. et alii (1978), consideram o processo de avaliação como “a análise crítica do programa (política) com o objetivo de apreender, principalmente, em que medida as metas estão sendo alcançadas, a que custos, quais os processos ou efeitos colaterais que estão sendo ativados (previstos ou não previstos, desejáveis ou não desejáveis) indicando novos cursos de ação mais eficazes"'.

A Organização das Nações Unidas (ONU) definiu avaliação como “processo que se destina a determinar sistemática e objetivamente a pertinência, eficiência, eficácia e impacto de todas as atividades à luz de seus objetivos”. Trata-se de um processo organizacional para melhorar as atividades que estão em andamento e auxiliar a administração no planejamento, programação e decisões futuras ${ }^{3}$.

\section{2- Avaliação em Saúde}

O processo saúde-doença constituiu-se num fenômeno complexo, cuja gênese envolve determinações de ordem biológica, econômica, social, cultural e psicológica (BREILH, 1991; BREILH \& GRANDA, 1986; LAUREL1, 1983), sendo que as necessidades de saúde a ele relacionadas dizem respeito a essas diversas dimensões do real. Também as ações que tomam como objeto o processo saúde-doença, embora possuam características técnicas evidentes, têm se organizado, historicamente, enquanto práticas sociais (DONANGELO, 1976), podendo ou não guardar relação 
com as necessidades de saúde ou, mesmo, com as necessidades de serviços de saúde (PAIM, 1982). Dessa forma, nem as necessidades de saúde nem as práticas a elas referidas existem em abstrato, possuindo historicidade a ser buscada por quem pretende investigá-las ${ }^{105}$.

As relações entre as práticas e as necessidades de saúde podem ser apreendidas a partir de duas vertentes principais. A primeira delas consiste na busca dos seus significados econômicos, políticos e ideológicos, bem como da especificidade dessas relações em sociedades concretas. A segunda diz respeito à capacidade de as práticas modificarem uma dada situação de saúde, atendendo ou não às necessidades de saúde de determinada população, ou seja, refere-se à discussão sobre suas características e seus efeitos. ${ }^{105}$

Nesta última perspectiva, a temática da avaliação ganha relevância, por um lado associada à possibilidade e necessidade de intervenções capazes de modificar certos quadros sanitários, e, por outro, pela verificação das dificuldades enfrentadas por essas mesmas práticas para alterarem indicadores de morbi-mortalidade em outras circunstâncias $^{105}$.

Sob o rótulo de "avaliação" reúnem-se diversas atividades, cujo espectro varia desde um julgamento subjetivo do desenvolvimento de determinada prática social, até a chamada pesquisa avaliativa que busca responder a perguntas semelhantes entre si, recorrendo a métodos e técnicas que apresentam maior objetividade.

As práticas de saúde, à semelhança de outras práticas sociais, podem constituir-se em objeto de avaliação nas suas diversas dimensões, seja enquanto 
cuidado individual $\mathbf{1}$ seja nos seus níveis mais complexos de intervenção e de organização, como:aslíticas, programas, serviços ou sistema ${ }^{105}$.

A avaliaçã : em saúde é um instrumento chave para a condução e administração dos iasstemas de Saúde. "Só avaliando é que assumimos a consciência de suas ações" (PALł́́N LASSO, 1994) .

A Organizধ́lăo Mundial de Saúde (OMS) em 1981 elaborou a seguinte definição, aplicadaarao campo da saúde: "a avaliação é um meio sistemático de aprender empiricare ınte e de utilizar as lições aprendidas para o melhoramento das atividades em cursa e para o fomento de um planejamento mais satisfatório mediante uma seleção rigoroe : entre as diferentes possibilidades de ação futura. Deve ser, pois, um processo permı qente que busca aumentar a pertinência, a eficiência e a eficácia das atividades de š. de" ${ }^{3}$.

Para quem ebcá trabalhando em programas e/ou serviços de saúde, a avaliação é um processo téadico-administrativo destinado à tomada de decisão. Envolve momentos de medip comparar e emitir juízo de valor. No contexto de programas e serviços de saúde, bæom base no juízo de valor emitido a partir da avaliação que será tomada a decisão ${ }^{10:}$

Nesse sentiva, a avaliação deve constituir-se em um instrumento fundamental para a gerência, : til e facilitador das mudanças pretendidas, que incorporado sistematicamente al nível dos Sistemas Locais de Saúde, revelará se as atividades desenvolvidas no sbu âmbito são adequadas e compatíveis em relação à realidade sanitária local e qua io seu impacto sobre o nível de saúde da população ${ }^{1}$.

Para a avaldıção de serviços de saúde, DONABEDIAN ${ }^{60}$ (1980), um dos principais estudioe $\mathrm{s}$ de avaliação nesse campo, desenvolveu um modelo de 
avaliação baseado em três características: estrutura, processo e resultado. A área de estrutura corresponde aos aspectos de recursos físicos, materiais e humanos e aos da organização dos serviços, como disponibilidade de equipamentos, manutenção predial, limpeza, quantidade e qualificação de recursos humanos. O processo envolve todas as atividades desenvolvidas entre os profissionais de saúde e o paciente: relações entre ambos, ética profissional, condutas e tratamentos adequados, períodos de espera. Os resultados são relativos às mudanças observadas no estado de saúde do paciente, atribuíveis à assistência prestada, e ao grau de satisfação do paciente e seus familiares. Entretanto, uma boa estrutura e processos adequados, embora aumentem a probabilidade de se atingirem melhores resultados, não podem garanti-los; por outro lado, uma estrutura inadequada pode interferir no processo, mas não inviabiliza um resultado satisfatório. Ainda não foram construídos indicadores que possam medir a importância relativa de cada um desses fatores no resultado final da assistência, porém já existem progressos nesse sentido ${ }^{60}$.

DONABEDIAN $^{60}$ (1980) fez uma série de comentários a respeito das características da avaliação em saúde, dividindo a qualidade do cuidado em três dimensões: técnica, interpessoal e amenidades. A dimensão técnica diz respeito à aplicação dos conhecimentos e tecnologias médicas e de outras ciências da saúde no atendimento ao paciente, incluindo diagnóstico e tratamento adequados, de maneira a maximizar seus benefícios sem aumentar os riscos; a dimensão interpessoal engloba o relacionamento, comportamentos e comunicação dos profissionais de saúde com o paciente e seus familiares. A qualidade deve envolver transformações no nível do paciente, considerando conhecimentos, atitudes e comportamentos, implicando, assim, as ações curativas e também as promocionais e preventivas; as amenidades 
correspondem às circunstancias sob as quais o cuidado é prestado, envolvendo aspectos como conforto e estética das instalações, privacidade, cortesia entre $\operatorname{outros}^{60}$.

Da mesma forma que Donabedian, SILVA e FORMIGLI (1994), atribuíram três dimensões à qualidade: conhecimento técnico-científico, relações interpessoais entre profissionais e o paciente, e amenidades, isto é, condições de conforto e estética das instalações e equipamentos no local onde a prestação ocorre. ${ }^{105}$

A avaliação somente poderá ser conduzida dentro de critérios, padrões e normas preestabelecidos, tendo em vista a notável variabilidade da prática de saúde, o que implica, por exemplo, que a metodologia desenvolvida para avaliação da atividade médica num hospital de determinada complexidade médica não possa ser utilizada para avaliar o desempenho de uma prática alternativa de saúde $e^{60}$.

A avaliação pode ser ainda conduzida segundo critérios implícitos ou explícitos, ou seja, predeterminados. Este aspecto relaciona-se também à utilização de instrumentos abertos, envolvendo um componente subjetivo maior, ou fechados, mais objetivos, mas também limitados em seu alcance. Os critérios podem ainda ser de determinação normativa, e neste caso corresponder a um ideal desejado, ou ser empiricamente estabelecidos, ou seja, resultantes do estudo das características observadas numa realidade ${ }^{83}$.

A avaliação de serviços de saúde em geral e de sua forma mais complexa, os serviços hospitalares, apresenta dificuldades que têm sido comentadas amplamente na literatura. A organização hospitalar é complexa, com especificidades que tornam mais difícil a aplicação dos conceitos de qualidade, pois o serviço é produzido e consumido simultaneamente, na relação do fornecedor com o cliente, e erros podem 
causar conseqüências impossíveis de serem corrigidas ou compensadas. Além disso, o usuário interfere no processo produtivo e o resultado do atendimento prestado depende também da sua aceitação e do seguimento das recomendações recebidas, ou seja, do vínculo estabelecido entre paciente e profissional de saúde ${ }^{86}$.

Para entendermos como o processo de avaliação foi implantado nos serviços hospitalares, é necessária uma revisão, mesmo que breve, sobre a evolução histórica da implantação do Sistema Único de Saúde no Brasil (SUS) e da avaliação de hospitais.

\section{3- Implantação do SUS no Brasil e Avaliação de Hospitais}

Em 1565, foi fundado o primeiro hospital brasileiro, a Santa Casa de Santos, por padres jesuítas que vieram ao país para a catequese dos índios. Este modelo, baseado em similares portugueses, reproduziu-se em grande quantidade, a tal ponto que praticamente todas as cidades de médio porte têm ou tiveram a sua Santa Casa. Este modelo estava baseado na proposta de outros hospitais europeus, que viam a tarefa do hospital mais como uma atividade religiosa do que como uma atividade médica propriamente $\operatorname{dita}^{47}$.

Da fundação do primeiro hospital no Brasil até a década de 1930, os serviços de saúde, disponibilizados à população, eram constituidos por Santas Casas, de cunho religioso, e de ações da Vigilância Sanitária, originada esta, nos séculos XVIII e XIX, com funções de regulamentar o exercício da profissão, combater o charlatanismo, exercer o saneamento da cidade, fiscalizar as embarcações, os cemitérios e o comércio de alimentos, com o objetivo de vigiar a cidade para evitar a propagação das doenças ${ }^{73}$. 
Com o passar dos anos, as Santas Casas assumiram mais a cura dos doentes, exercendo papel preponderante no desenvolvimento da Medicina e na vida das comunidades e as irmandades religiosas foram as abandonando, ficando em mãos do poder médico local e das lideranças políticas ${ }^{47}$.

Esse periodo coincide também com a modernização da Medicina, incorporação de tecnologia sofisticada e influência do modelo médico americano, fazendo surgir vários outros tipos de hospitais, com destaque para os hospitais universitários e os hospitais da Previdência Social ${ }^{47}$.

Na década de 1930, com o aparecimento dos hospitais construídos pelo Sistema de Previdência dos Institutos de Aposentadoria e Pensão, identificados por agrupamentos profissionais, as primeiras tentativas conhecidas de classificação de hospitais ocorreram por sugestão do professor Odair Pacheco Pedroso e foram feitas pelo Departamento de Assistência Médica do Instituto de Aposentadoria e Pensão dos Comerciários (IAPC), cujo estudo passou a ser implementado em $1959 .^{102}$

Em 1941, foi criada a Divisão de Organização Hospitalar (DOH), dentro do Departamento Nacional de Saúde, que era vinculado ao Ministério de Educação. Cabia à DOH, entre outras competências, o incentivo ao desenvolvimento e melhoria das instituições e serviços de assistência; o estabelecimento de normas e padrões para instalações; organização e funcionamento dos vários serviços técnicos e administrativos de hospitais; a organização e manutenção do cadastro dos estabelecimentos hospitalares. ${ }^{102}$

A DOH realizou em 1941, o primeiro censo-cadastro nacional dos hospitais que continha informações gerais sobre o hospital, especialidades implantadas, 
edificações, instalações e equipamentos, funcionamento e administração, financiamento e assistência.

Em 1961, o instrumento “Credenciamento de Hospitais para Convênio com o Instituto da Previdência dos Comerciários" incluía a observação de três tópicos: planta fisica, equipamentos e organização.

Em 1962, é publicado o documento "Padrões Mínimos Exigíveis dos Hospitais para a prestação de Assistência Cirúrgica aos Beneficiários do Instituto de Aposentadoria e Pensão dos Industriários". Continha 25 itens para dois tipos de hospitais. Estes dois institutos estabeleceram padrões para credenciamento de hospitais e contavam com quadro técnico especializado. ${ }^{102}$

Em 1966, com a unificação dos Institutos pela criação do Instituto Nacional de Previdência Social (INPS), o aumento dos recursos disponíveis de forma centralizada contribuiu para o aumento da pressão para ampliação de cobertura dos benefícios. Isto levou à expansão da rede de serviços e ampliação da cobertura da assistência médico-hospitalar do país. Acreditava-se que o critério a ser adotado deveria ser amplo, considerando-se, além das condições técnicas, administrativas e éticas, a qualidade dos serviços de natureza hoteleira e, conseqüentemente, o preço final do serviço.

Em 1968, na Tabela de Classificação de Hospitais, foram estabelecidas as normas para aplicação de instrumento destinado a avaliar a eficiência, por meio de pontuação, considerando: a) planta física; b) equipamento, os utensílios e as instalações; c) a administração. Esta tabela contemplava hospitais de clínica médica, cirurgia e obstetrícia, tisiologia e psiquiatria ${ }^{102}$. 
Em 1974, através da portaria da Secretaria de Assistência Médico-Social do Ministério do Trabalho - SAMES-8 foram aprovados os modelos de "Formulário de Classificação Hospitalar", do "Relatório de Classificação Hospitalar (RECLAR)", e de "Comprovante de Classificação Hospitalar". No RECLAR, "classificação hospitalar" é definida como "a sistemática de avaliação global ou parcial de um hospital (ou serviço) instalado". Esta avaliação era feita por meio de um Formulário de Classificação Hospitalar, que constava de exigências e parâmetros instituídos pelo Instituto Nacional de Assistência Médica da Previdência Social (INAMPS). Tinha por finalidade estabelecer classes de referência para o pagamento das internações hospitalares. O objetivo era habilitar o hospital para a contratação de leitos pelo INAMPS; estabelecer unidades de referência para o pagamento das internações; promover a uniformidade da avaliação, com a padronização de critérios de julgamento e sistematização das informações emitidas pelos classificados; fornecer à rede contratada orientação quanto aos padrões de assistência hospitalar adotados pelo INAMPS $^{102}$

Neste caso, está claramente colocada a finalidade de estabelecer classes de referência para o pagamento e ainda habilitar hospitais para a venda de leitos ao INAMPS. Com este intuito, o termo "classificação" parece contemplar a preocupação com a avaliação. Avaliar a qualidade, no entanto, não aparece de forma explícita, embora fosse esta uma das intenções dos idealizadores da iniciativa.

A habilitação para a venda de leitos leva ao credenciamento, isto é, o hospital é credenciado para esse fim. Naquele momento histórico da saúde no país, poucos eram os compradores de serviços hospitalares. O INAMPS era, certamente, o maior deles. Ser credenciado era a intenção de boa parte dos prestadores de serviços,

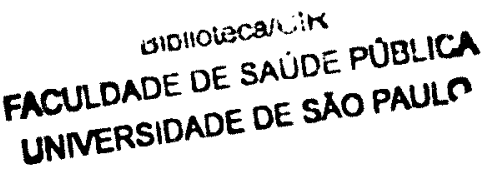


motivo de distinção do estabelecimento de saúde, já que estava garantida a possibilidade de venda de serviços.

Em 1982, a Portaria $n^{\circ} 833$ da Presidência do INAMPS, definia comissão destinada a proceder aos estudos necessários para recadastramento e reclassificação dos hospitais que mantivessem contrato ou convênio com o INAMPS.

Em 1986, com a criação do Sistema Unificado e Descentralizado de Saúde (SUDS), com a extinção do INAMPS e a transferência dos hospitais próprios para a esfera estadual e, ainda, com mudanças de competências governamentais, o credenciamento de prestadores de serviços, a avaliação e o controle passaram a ser responsabilidade da esfera estadual ${ }^{107}$.

Em 1988, com a promulgação da Constituição e criação do Sistema Único de Saúde com as diretrizes de universalidade, equidade, integralidade, descentralização e participação da comunidade, modifica-se o cenário do Setor Saúde. Os serviços são organizados para atender estas diretrizes e o hospital deixa de ser o centro das atenções para fazer parte de um Sistema Local de Saúde ${ }^{21}$.

Em 1990, as Leis no 8080 e n⿳ 8142 são regulamentadas e a implantação do SUS ocorre fundamentada em instrumentos normativos e legais denominados Normas Operacionais Básicas (NOBs) ${ }^{22,23}$.

A Norma Operacional Básica-SUS/ 01-93 definia como competência de estados e municípios "controle e avaliação efetivos sobre a qualidade e quantidade dos serviços prestados pela rede", incluindo todos os serviços desde a atenção básica à hospitalar ${ }^{24}$.

A Norma Operacional Básica - SUS/ 01-96 avançou na reordenação do modelo assistencial à saúde e definiu a "prática do acompanhamento, controle e 
avaliação do SUS, superando os mecanismos tradicionais, centrados no faturamento de serviços produzidos, e valorizando os resultados advindos de programações com critérios epidemiológicos e desempenho de qualidade", sendo essa prática função a ser exercida pelas Unidades de Avaliação e Controle dos Municípios e Estados. ${ }^{25}$

A Norma Operacional de Assistência à Saúde (NOAS) foi editada em 2001, com a finalidade de estabelecer o processo de regionalização como estratégia de hierarquização dos serviços de saúde e de busca de maior eqüidade ${ }^{29}$.

Esse processo de regionalização deve contemplar uma lógica de planejamento integrado, compreendendo as noções de territorialidade na identificação de prioridades de intervenção e de conformação de sistemas funcionais de saúde, não necessariamente restritos à abrangência municipal, mas respeitando seus limites como unidade indivisível, de forma a garantir o acesso dos cidadãos a todas as ações e serviços necessários para a resolução de seus problemas de saúde, otimizando os recursos disponíveis, incluindo os serviços hospitalares. ${ }^{29}$

Com a Constituição de 1988, a Lei Federal n 8080 e a NOB-SUS-01/ 96, a definição de Vigilância Sanitária também foi modificada: "Entende-se por Vigilância Sanitária um conjunto de ações capazes de eliminar, diminuir ou prevenir riscos à saúde e de intervir nos problemas sanitários decorrentes do meio ambiente, da produção e circulação de bens e da prestação de serviços de interesse da saúde abrangendo: I - o controle de bens de consumo que direta ou indiretamente, se relacionem com a saúde, compreendidas todas as etapas e processos, da produção ao consumo e II - o controle da prestação de serviços que se relacionam direta ou indiretamente com a saúde" 
É a Vigilância Sanitária que habilita os hospitais, através das inspeções periódicas para a obtenção da licença de funcionamento ou Alvará Sanitário ${ }^{73}$.

Com a descentralização, o gestor estadual e os gestores municipais em gestão plena de sistema, ficaram com as atribuições de inspecionar os hospitais e emitir licença de funcionamento através da Vigilância Sanitária e, permanentemente, realizar avaliação, controle e auditoria, por meio das Unidades de Avaliação e Controle, em relação aos prestadores de serviços públicos, filantrópicos e privados, no que tange à assistência ambulatorial e hospitalar. O hospital passou a ser pensado dentro do contexto dos sistemas locais de saúde ${ }^{25}$.

Em relação ao Setor Privado no Brasil, em 1988, com o objetivo de proceder à sua regulamentação, a Agência Nacional de Saúde Suplementar (ANS), através da Lei $\mathrm{n}^{\circ} 9656,{ }^{27}$ de $03 / 06 / 98$, com os dispositivos alterados de acordo com a MP 197624, de 09/03/2000, definiu que as Operadoras de Planos Privados de Assistência à Saúde devem satisfazer os seguintes requisitos:

- descrição pormenorizada dos serviços de saúde próprios a serem oferecidos e daqueles a serem prestados por terceiros;

- descrição das instalações e equipamentos destinados à prestação de serviços;

- especificação dos recursos humanos qualificados e habilitados com responsabilidade técnica de acordo com as leis que regem a matéria. ${ }^{27}$

A Resolução Normativa $n^{\circ} 42$, de 04 de Julho de $2003,{ }^{38}$ estabelece os requisitos para a celebração dos instrumentos jurídicos firmados entre as operadoras de planos de assistência à saúde e prestadores de serviços hospitalares e define: 
Art. $2^{\circ}$

Parágrafo único - São cláusulas obrigatórias em todo instrumento jurídico as que estabeleçam:

I- qualificação específica:

a. registro da operadora na ANS;

b. registro da entidade hospitalar no Cadastro Nacional de Estabelecimentos de Saúde, instituído pela Portaria SAS n ${ }^{\circ} 376$, de 3 de outubro de 2000, e pela Portaria SAS n 511 , de 2000;

II- objeto e natureza do ajuste, bem como descrição de todos os serviços contratados, ou seja:

a- definição detalhada do objeto;

b- perfil assistencial e especialidade contratada, serviços contratados, inclusive o Apoio ao Diagnóstico e Terapia;

c- procedimento para o qual a entidade hospitalar é indicada, quando a prestação do serviço não for integral;

d- regime de atendimento oferecido pela entidade: hospitalar, ambulatorial, médico-hospitalar e urgência 24h.; e

e- padrão de acomodação.

V- informação da produção assistencial, com a obrigação da entidade hospitalar disponibilizar às operadoras contratantes os dados assistenciais dos atendimentos prestados aos beneficiários, observadas as questões éticas e o sigilo profissional, quando requisitados pela ANS, em atendimento ao disposto no inciso XXXI do art. $4^{\circ}$ da Lei ${ }^{\circ} 9.961$, de 2000; e 
VI- direitos e obrigações, relativos às condições gerais da Lei 9.656, de 1998, e às estabelecidas pelo Conselho de Saúde Suplementar (CONSU) e pela ANS, contemplando:

a. a fixação de rotinas para pleno atendimento ao disposto no art. 18 da lei acima citada;

b. a prioridade no atendimento para os casos de urgência ou emergência, assim como às pessoas com mais de sessenta e cinco anos de idade, as gestantes, lactantes, lactentes e crianças até cinco anos de idade, ${ }^{37}$

O mesmo processo foi estendido também aos prestadores de serviços auxiliares de diagnóstico e terapia e clínicas ambulatoriais através da Resolução Normativa $54 .^{39}$

\subsection{A Rede Hospitalar: Dimensões e Características}

A conceituação de hospital, ainda que expressa de forma diferente, mantém pontos comuns. De acordo com o Manual Brasileiro de Acreditação Hospitalar, o hospital é "todo estabelecimento dedicado à assistência médica, de caráter estatal ou privado, de alta ou baixa complexidade, com ou sem fins lucrativos"42.

A definição de hospital proposta pela Organização Pan-Americana de Saúde (OPAS), diz: "São todos os estabelecimentos com pelo menos 5 leitos, para internação de pacientes, que garantem um atendimento básico de diagnóstico e tratamento, com equipe clínica organizada e com prova de admissão e assistência permanente prestada por médicos. Além disso, considera-se a existência de serviço de enfermagem e atendimento terapêutico direto ao paciente, durante 24 horas, com disponibilidade de serviços de laboratório e radiologia, serviço de cirurgia e/ou parto, 
bem como registros médicos organizados para a rápida observação e acompanhamento dos casos" $"$.

Quanto à diferenciação dos cuidados prestados, os hospitais são classificados em gerais, especializados e com especialidades. Estes últimos diferem dos gerais no sentido de já possuírem áreas de atendimento especializado, mas sem a prioridade que lhe é conferida no especializado.

Adotando um enfoque sistêmico, os hospitais formam parte de uma rede de serviços de atenção à saúde, associados geográficamente, seja por uma organização planejada ou como conseqüência de uma organização espontânea dos elementos assistenciais existentes. Esse critério, que abrange a totalidade da oferta de serviços disponiveis em um território determinado, é integrado nos sistemas locais de saúde. Neste contexto, deve ser enunciado o papel específico que os estabelecimentos hospitalares devem cumprir, no amplo sentido caracterizado anteriormente:

- assistência médica continuada: concentrar uma grande quantidade de recursos de diagnóstico e tratamento para, no menor tempo possível, reintegrar rapidamente o paciente no seu meio;

- assistência médica integrada: constitui um lugar intermediário dentro de uma rede de serviços de complexidade crescente;

- assistência médica integral: quando o estabelecimento pertence a uma rede que garante a disponibilidade de todos os recursos para resolver cada caso;

- área de programação: o estabelecimento tem uma área de influência a qual fornece seus serviços e sobre cuja população os resultados de suas ações devem ser avaliados; 
- provedor dos programas de saúde: o estabelecimento também executa programas preventivos e de promoção da saúde, promovidos pela autoridade sanitária ${ }^{92}$.

Segundo o IBGE: Pesquisa de Assistência Médico-Sanitária (Tabela 1), em 2002 havia no Brasil, em funcionamento, 7397 estabelecimentos, distribuídos conforme sua natureza em Públicos: Federal 147 (1,98\%), Estadual 610 (8,25\%), Municipal 1831 (24,75\%); Privados: Privados/ SUS 3357 (45,39\%) e Privados não conveniados ao SUS: $1452(19,63 \%) .^{78}$

Se considerarmos o total de estabelecimentos com internações segundo sua distribuição em públicos e privados, observamos que $65,02 \%$ são privados e apenas 34,98\% são públicos. Portanto, o papel regulador do sistema por parte do Estado deve levar em consideração esta característica.

Tabela 1 - Hospitais segundo natureza, Brasil, 2002.

\begin{tabular}{cccc}
\hline Hospitais & Natureza & Número & $\%$ \\
\hline Públicos & Federal & 147 & 1,98 \\
& Estadual & 610 & 8,25 \\
& Municipal & 1831 & 24,75 \\
Sub-Total & & 2588 & 34,98 \\
Privados & Privado/ SUS & 3357 & 45,39 \\
& Privado & 1452 & 19,63 \\
Sub-Total & & 4809 & 65,02 \\
\hline Total & & 7397 & 100,00 \\
\hline
\end{tabular}

Fonte: IBGE: Pesquisa de Assistência Médico-Sanitária 1976/2002

Segundo a Organização Nacional de Acreditação - ONA, abril de 2004, 31 hospitais $(0,41 \%)$ apresentavam certificados válidos de acreditação, ${ }^{93}$ e segundo o Programa de Controle de Qualidade Hospitalar do Estado de São Paulo (CQH), no 
mesmo período, $125(1,68 \%)$ estavam com termos de adesão ao Programa ${ }^{6}$, totalizando $156(2,09 \%)$ dos hospitais com avaliação da qualidade implantados no Brasil (Tabela 2).

Tabela 2 - Número de hospitais com avaliação da qualidade no Brasil, 2004.

\begin{tabular}{lcc}
\hline \multicolumn{1}{c}{ Hospitais Avaliados } & Número & $\%$ \\
\hline Acreditados & 19 & 0,25 \\
Acreditados Pleno & 10 & 0,13 \\
Acreditados Excelência & 02 & 0,02 \\
Total de Hospitais com Certificados Válidos - ONA & 31 & 0,41 \\
Termo de Adesão CQH & 125 & 1,68 \\
\hline Total de Hospitais - Brasil & 7397 & 100,00 \\
\hline
\end{tabular}

Fonte IBGE: Pesquisa de Assistência Médico-Sanitária 1976/2002; ONA, 04/ 2004 e CQH, 04/ 2004.

De acordo com o IBGE: Pesquisa de Assistência Médico-Sanitária (Tabela 3), em 2002 havia em funcionamento no Estado de São Paulo, 1402 estabelecimentos hospitalares, distribuídos conforme sua natureza em Públicos: Estadual 62 (4,42\%), Municipal 119 (8,49\%); Privados: Privados/ SUS 445 (31,74\%), Privados não conveniados ao SUS: $776(55,35 \%){ }^{78}$

Se considerarmos o total de estabelecimentos com internações segundo sua distribuição em públicos e privados, observamos que $87,09 \%$ são privados e apenas $12,91 \%$ são públicos. Portanto, o papel regulador do sistema por parte do Estado de São Paulo deve ser ainda maior, frente a este elevado percentual de hospitais privados. 
Tabela 3 - Hospitais segundo natureza, Estado de São Paulo, 2002

\begin{tabular}{cccc}
\hline Hospitais & Natureza & Número & $\%$ \\
\hline Públicos & Estadual & 62 & 4,42 \\
& Municipal & 119 & 8,49 \\
Sub-Total & & 181 & 12,91 \\
Privados & Privado/ SUS & 445 & 31,74 \\
& Privado & 776 & 55,35 \\
Sub-Total & & 1221 & 87,09 \\
\hline Total & & 1402 & 100,00 \\
\hline
\end{tabular}

Fonte: IBGE: Pesquisa de Assistência Médico-Sanitária 1976/2002

Para identificar a importância da assistência médico-hospitalar em relação ao total de gastos com saúde no Brasil, buscou-se analisar a representatividade desse gasto na execução financeira do Ministério da Saúde, nos anos de 2002 e 2003.

A execução financeira do Ministério da Saúde em 2002 foi de R\$ 28.293.330.622,00. Destes recursos, foram destinados à assistência médicohospitalar (AIH/SIASUS) R $\$ 11.749 .218 .945,00$, representando $41,53 \%$ do total de gastos. Em 2003, a execução financeira do Ministério da Saúde foi de R\$ 30.226.280.425,00 e os recursos destinados à assistência médico-hospitalar (AIH/SIASUS) foram da ordem de R\$ 13.253.642.093,00, representando 43,85\% do total de gastos (Anexos 13 e 14). ${ }^{40}$

Estes percentuais são bastante representativos em relação ao total de gastos e, se acrescentarmos outras despesas com Hospitais Próprios, Instituto Nacional do Câncer e Pioneiras Sociais, os percentuais passam a representar 43,39\%, em 2002, e $45,85 \%$, em $2003 .^{40}$

Esses dados demonstram a importância do papel regulador do sistema por parte do Estado em relação aos serviços hospitalares, pois é de sua responsabilidade 
a habilitação, avaliação, controle, auditoria e pagamento dos prestadores de serviços médico-hospitalares. E, para tanto, necessita utilizar instrumentos de avaliação para que o recurso financeiro, que lhe é destinado, seja aplicado adequadamente em função da representatividade do gasto.

Tabela 4 - Execução Financeira do Ministério da Saúde referente à Assistência Hospitalar, 2002 e 2003.

\begin{tabular}{|c|c|c|c|c|}
\hline Denominação & $\begin{array}{c}\text { Executado } 2002 \\
\text { R\$ }\end{array}$ & $\%$ & $\begin{array}{c}\text { Executado } 2003 \\
\text { R\$ }\end{array}$ & $\%$ \\
\hline Hospitais Próprios & 197.704 .224 & 0,7 & 206.920 .959 & 0,68 \\
\hline Instituto Nacional do Câncer & 83.454 .987 & 0,29 & 154.660 .883 & 0,51 \\
\hline Pioneiras Sociais & 245.000 .000 & 0,87 & 245.000 .000 & 0,81 \\
\hline AIH/SIA SUS & 11.749 .218 .945 & 41,53 & 13.253 .642 .093 & 43,85 \\
\hline Sub-Total & 12.275 .378 .156 & 43,39 & 13.860 .223 .935 & 45,85 \\
\hline Total Geral - MS & 28.293 .330 .622 & 100,00 & 30.226 .280 .425 & 100,00 \\
\hline
\end{tabular}

Fonte: Ministério da Saúde, Subsecretaria de Planejamento e Orçamento - Execução Orçamentária e Financeira 2003 e 2004.

\subsection{Métodos de Avaliação da Qualidade implantados em Hospitais}

\section{Brasileiros}

A constante avaliação da qualidade dos serviços de saúde é vital para o sucesso das organizações. É fundamental que esta avaliação seja feita com critérios objetivos, ou seja, utilize indicadores que permitam "medir" a qualidade dos serviços. $^{74}$

Mas, o que é qualidade em cuidados de saúde e serviços de saúde? Profissionais que lidam com garantia de qualidade tendem a usar a definição de qualidade técnico-científica: a aplicação apropriada do conhecimento médico 
disponível, bem como da tecnologia, no cuidado com o paciente. Uma vez mais é necessário ressaltar que qualidade tem muitas facetas e autores diferentes podem empregar significados distintos para esse termo. Hoje em dia, o termo qualidade geralmente denota um grande espectro de características desejáveis de cuidados. Estas incluem: efetividade (a relação entre o impacto real e o impacto potencial em uma situação real), eficácia (ser capaz de produzir o efeito desejado), eficiência (relação entre o impacto real e seus custos de produção), eqüidade (a distribuição do serviço de acordo com os objetivos e necessidades de saúde percebidas pela população), aceitabilidade (oferecimento de serviços que estejam de acordo com a cultura, normas e expectativas sociais do usuário), acessibilidade (remoção dos obstáculos físicos, financeiros, etc para a utilização de serviços confiáveis pela população), adequação (número suficiente de serviços em relação à necessidade e demanda) e qualidade técnico-científica do cuidado (nível de aplicação do conhecimento e tecnologia). ${ }^{113}$

Para VUORI, "a noção de qualidade varia com o interesse de grupos diferentes: planejadores de saúde, administradores, prestadores de serviços e os consumidores que podem ter diferentes visões do que constitue a melhor qualidade ou, no mínimo podem enfatizar diferentes aspectos da qualidade. Se por um lado os planejadores desejam enfatizar a equidade e a adequacidade, por outro o que mais interessa aos administradores é a eficiência. Os prestadores de serviços de saúde e os consumidores têm maior interesse na efetividade e na qualidade da alta tecnologia científica, mas a acessibilidade e aceitabilidade são muito mais importantes para os consumidores do que para os prestadores". 113 
Para a implementação de Programas de Qualidade, QUINTO e BITTAR (2003) ressaltam a importância de se conhecer a cultura organizacional, que dará respaldo às mudanças que se fizerem necessárias. Cultura é todo complexo que inclui os saberes, as crenças, a arte, as leis, a moral, os costumes e todas as outras aptidões e hábitos adquiridos pelo homem enquanto membro de uma sociedade (AKTOUF,1991). Qualidade é uma propriedade, atributo ou condição capaz de distinguir programas, serviços, pessoas entre seus pares e lhes determinar a natureza e, numa escala de valores, permite avaliar e, conseqüentemente, aprovar, aceitar ou recusar qualquer coisa. ${ }^{99}$

Para a implantação da qualidade, BONATO (2003) classificou os métodos de avaliação da qualidade aplicados em hospitais brasileiros, segundo quatro tipos de avaliação: Acreditação, Certificação, Selo e Premiação. ${ }^{18}$

\section{Acreditação Hospitalar}

"Acreditação é um procedimento de avaliação dos recursos institucionais, voluntário, periódico e reservado, que tende a garantir a qualidade da assistência por meio de padrões previamente aceitos. São estabelecidos padrões, em grau de complexidade crescente, os quais orientam a avaliação dos diversos serviços do hospital. O status de acreditado conota sempre confiança no hospital por parte dos clientes internos e externos, bem como da comunidade em geral. Constitui, essencialmente, um programa de educação continuada e, jamais, uma forma de fiscalização". ${ }^{42}$

Em relação à Acreditação Hospitalar, BONATO (2003) caracterizou a Joint

Comission on Accreditation of Healthcare Organizations (JCAHO), o Consórcio 
Brasileiro de Acreditação (CBA) e o Manual Brasileiro de Acreditação Hospitalar (MBAH) como instrumentos para essa acreditação com área de abrangência institucional. $^{18}$

A acreditação hospitalar é o único modelo desenvolvido especificamente para a área de saúde. A estruturação dos manuais de acreditação leva em conta as peculiaridades dos serviços de saúde.

\section{Joint Comission on Accreditation of Healthcare Organizations (JCAHO)}

O processo de acreditação hospitalar originou-se nos Estados Unidos por iniciativa da corporação médica, em 1910, onde foi desenvolvido um sistema de padronização hospitalar baseado na avaliação do resultado final (end-result system of hospital standardization) por meio do qual se verificava a efetividade do tratamento médico. ${ }^{102}$

Em 1917, o Colégio Americano de Cirurgiões estabeleceu as bases para a padronização hospitalar a partir das constatações da necessidade de melhorar as condições de trabalho nos hospitais e a qualidade da assistência prestada ao paciente.

Em 1919, foram adotados os padrões mínimos, considerados essenciais para a assistência adequada, dando uma forma inicial ao processo de acreditação. A evolução desse processo levou, em 1951, à criação da Joint Comission on Acreditation of Hospitals (JCAH), com a participação de outras associações profissionais, mantendo os princípios estabelecidos anteriormente de voluntariedade, confidencialidade, padrões de consenso entre os profissionais de saúde, avaliação, educação e consultoria. ${ }^{102}$ 
Em 1970, uma vez que a grande maioria dos hospitais norte-americanos já havia atingido os padrões mínimos, estes foram adaptados para representar padrões ótimos de qualidade, constituindo-se em novo desafio para os hospitais (ROBERTS et al.; 1987). Com a expansão de suas atividades, em 1987, a JCAH mudou seu nome para Joint Comission on Accreditation of Healthcare Organizations (JCAHO) com ênfase em um processo de acreditação mais moderno e sofisticado. Nesse processo são usados padrões ótimos para a verificação dos hospitais, através de indicadores quantitativos clínicos e banco de dados incorporados ao processo de acreditação. ${ }^{102}$

A partir da experiência americana, incorporaram essa prática outros países, como o Canadá e Austrália e, a partir da década de 80, o Brasil, Espanha, Itália, Suécia, Reino Unido, Japão, China, Tailândia, Israel, África do Sul, Arábia Saudita, República Tcheca, Hungria, entre outros.

\section{Consórcio Brasileiro de Acreditação (CBA)}

O Consórcio Brasileiro de Acreditação de Serviços de Saúde (CBA) foi criado em 1997, integrado pela Fundação CESGRANRIO, por sua experiência em avaliação educacional; pela Universidade Estadual do Rio de Janeiro, através do Instituto de Medicina Social; pelo Colégio Brasileiro de Cirurgiões e pela Academia Nacional de Medicina. Na avaliação do CBA são usados padrões mínimos para a verificação de hospitais, por meio de indicadores quantitativos que estão em fase de construção e testagem em hospitais federais do Rio de Janeiro. O CBA vem trabalhando para adequar os padrões da Joint Comission on Accreditation of Healthcare Organizations (JCAHO) à cultura brasileira e refletir sobre a melhor forma de aplicação dos stândares para nossa realidade..$^{52}$ 


\section{Manual Brasileiro de Acreditação Hospitalar}

A primeira proposta de acreditação hospitalar na América Latina foi desenvolvida por iniciativa da Organização Pan-Americana de Saúde, em 1989, que no ano seguinte firmou convênio com a Federação Latino-Americana de Hospitais para a elaboração de um manual de "Padrões de Acreditação para América Latina e Caribe”. O manual foi publicado em 1991 em espanhol, sendo traduzido para o português em 1992.

No Brasil, as primeiras iniciativas relacionadas à acreditação hospitalar surgiram em 1990, a partir de discussões realizadas pela Associação Paulista de Medicina, Sociedade Médica Paulista de Administração em Saúde, Conselho Regional de Medicina do Estado de São Paulo, entre outras entidades da área de saúde, dando origem ao Programa de Controle de Qualidade Médico-Hospitalar no Estado de São Paulo (CQH). O primeiro seminário nacional ocorreu em abril de 1992, em Brasília, com a participação de representantes de diversas entidades nacionais da área de saúde, como órgãos de classe profissionais, provedores de serviços e órgãos com função reguladora, sob o patrocínio da OPAS. No final deste ano, essas entidades constituíram um conselho e uma comissão técnica, formando o Grupo Técnico de Acreditação Hospitalar. ${ }^{102}$

Outras iniciativas foram surgindo no Rio de Janeiro, Rio Grande do Sul e Paraná e, em 1997, o Ministério da Saúde contratou um consultor para tentar unificar os vários esforços existentes no país. Em 1998, o Manual Brasileiro de Acreditação Hospitalar foi lançado oficialmente e, em 1999, constituída juridicamente a Organização Nacional de Acreditação (ONA), responsável pelo monitoramento do processo de acreditação realizado pelas instituições acreditadoras. ${ }^{102}$ 
Os manuais da Organização Pan-Americana da Saúde (OPAS) ${ }^{92}$ do Grupo Técnico de Acreditação Hospitalar (1992) e o Manual Brasileiro de Acreditação Hospitalar do Ministério da Saúde (1998) ${ }^{42}$ estabelecem os padrões de qualidade a serem atingidos, contemplando aspectos de estrutura, processo e resultado e propõem-se a avaliar hospitais públicos, privados, filantrópicos e universitários, de pequeno, médio e grande porte, e de qualquer nível de complexidade, mesmo reconhecendo as diferenças existentes entre eles.

Em 1992, a OPAS, no Manual Acreditação de Hospitais para América Latina e Caribe, definiu que "acreditação é o procedimento de avaliação dos recursos institucionais, voluntário, periódico e reservado, que tende a garantir a qualidade da assistência prestada através de padrões previamente aceitos" ${ }^{92}$; nesse caso, o manual é concebido como instrumento de avaliação técnica, explícita e objetiva, da qualidade.

Os padrões podem ser mínimos ou mais elaborados e exigentes. O hospital acredita ou é acreditado quando a disposição e a organização dos seus recursos e atividades conformam um processo cujo resultado final é uma assistência médica de qualidade considerada satisfatória.

Outras definições são apresentadas no Manual da OPAS e no Manual Brasileiro de Acreditação Hospitalar: "categorização", objeto deste estudo, a ser definida em item específico; "habilitação" procedimento executado pela autoridade sanitária que tem por objetivo identificar se a organização encontra-se de acordo com os instrumentos legais; o "licenciamento ou alvará de funcionamento" constitui-se no passo inicial para que uma organização de saúde esteja apta a iniciar seu atendimento à população/ usuários; "auto-avaliação": são métodos utilizados para monitoramento 
do desempenho hospitalar. Por exemplo: reuniões anatomo-patológicas postmortem, discussões de casos clínicos, revisões de registros médicos, etc. ${ }^{92}$

O processo de acreditação busca classificar os hospitais em níveis estabelecidos a partir de padrões conforme os itens de verificação. $O$ instrumento construído estabelece o padrão e os itens de verificação que devem ser considerados.

Cada padrão apresenta uma definição e uma lista de itens de verificação que permitem a identificação precisa do que se busca avaliar e a concordância com o padrão estabelecido. O método de coleta de dados é a observação no local e contatos com os profissionais dos diversos serviços. ${ }^{42}$

Todos os padrões são organizados por graus de satisfação ou complexidade crescente, definidos em:

Nível 1 - As exigências deste nível contemplam o atendimento aos requisitos básicos da qualidade na assistência prestada ao cliente, nas especialidades e serviços do hospital, com os recursos humanos compativeis com a complexidade, qualificação adequada (habilitação) dos profissionais e responsável técnico com habilitação correspondente para as áreas de atuação institucional.

Princípios orientadores:

- habilitação do corpo funcional;

- atendimento aos requisitos fundamentais de segurança para o cliente nas ações de assistenciais e de procedimentos médico-sanitários;

- estrutura básica (recursos) capaz de garantir assistência orientada para a execução coerente. $^{42}$

Nível 2 - Evidências de adoção do planejamento na organização da assistência hospitalar, referentes à documentação, corpo funcional (força de trabalho), 
treinamento, controle, estatísticas básicas para a tomada de decisão clínica e gerencial e práticas de auditoria interna.

Princípios orientadores:

- existência de normas, rotinas e procedimentos documentados e aplicados;

- evidências da introdução e utilização de uma lógica de melhoria dos processos nas ações de assistência e nos procedimentos médico-sanitários;

- evidências de atuação focalizada no cliente/ paciente. ${ }^{42}$

Nível 3 - Evidências de políticas institucionais de melhoria contínua em termos de estrutura, novas tecnologias, atualização técnico-profissional, ações assistenciais e procedimentos médico-sanitários. Evidências objetivas de utilização da tecnologia da informação, disseminação global e sistêmica de rotinas padronizadas e avaliadas com foco na busca de excelência.

Princípios orientadores:

- evidências de vários ciclos de melhoria em todas as áreas, atingindo a organização de modo global e sistêmico;

- utilização de um sistema de informação institucional consistente, baseado em taxas e indicadores, que permitam análises comparativas com referenciais adequados e a obtenção de informação estatística que mostrem tendências positivas e sustentação de resultados;

- utilização de sistema de aferição do grau de satisfação dos clientes (internos e externos) e existência de um programa institucional da qualidade e produtividade implantado, com evidências de impacto sistêmico. ${ }^{42}$ 


\section{- Certificação}

PRAZERES (1996) conceituou certificação como a atividade de comprovação da qualificação de itens, materiais, produtos, serviços, procedimentos, processos, pessoal ou de sistema da qualidade, no todo ou em parte. ${ }^{95}$

A certificação da qualidade necessariamente será executada por entidade especificamente designada para tal (organismo certificador), com base em requisitos previamente estabelecidos e documentados, podendo ou não resultar em emissão de certificado. $^{18}$

Certificação pelas normas ISO (International Standardization Organization) permite garantir o sistema de qualidade, através da verificação das normas estabelecidas pela ISO, com área de abrangência setorial.

As normas ISO têm sido adotadas com mais freqüência em serviços isolados dentro dos hospitais ou ainda em estruturas menores, como laboratórios, serviços de hemoterapia, entre outros.

BONATO (2003) relata que no Setor Saúde, 167 instituições foram certificadas segundo dados da Associação Brasileira de Normas Técnicas (ABNT), que representa no Brasil a Organização Internacional para Normalização. ${ }^{18}$

\section{Selo}

Segundo BONATO (2003), para este tipo de avaliação, o instrumento utilizado é o Programa de Qualidade Hospitalar que se baseia no registro e análise de dados e aferição da adequação dos serviços às suas normas e critérios, com área de abrangência institucional. ${ }^{18}$ 
Para a implementação do programa, é necessário verificar e analisar as condições da estrutura hospitalar, a capacidade profissional e técnica, os processos, os resultados do atendimento, as opiniões dos consumidores e prestadores dos serviços. Por exemplo: o CQH, administrado pela Associação Paulista de Medicina (APM) e Conselho Regional de Medicina do Estado de São Paulo possui um sistema de captação, validação e registro de dados de hospitais. Atualmente, 121 hospitais possuem termo de adesão ao Programa (CQH, abril de 2004). ${ }^{6}$

\section{Premiação}

A Premiação busca estimular a melhoria da qualidade e produtividade da gestão das organizações produtoras de bens e serviços.

No Brasil, dois programas foram implantados: o Programa Nacional de Qualidade (PNQ), que busca estimular a melhoria da qualidade e produtividade da gestão das organizações produtoras de bens e serviços, estabelecendo 07 critérios e itens de avaliação que permitem o diagnóstico baseado em metas de pontuação, sendo que este instrumento não é prescritivo; e o Prêmio de Qualidade do Governo Federal (PQGF), que é um instrumento de transformação da gestão pública, no campo específico da promoção da qualidade dos serviços prestados aos cidadãos.

O Prêmio Nacional de Qualidade (PNQ) e o Prêmio de Qualidade do Governo Federal (PQGF) vêm sendo utilizados por hospitais e serviços como um modelo de gestão da qualidade aplicado à organização como um todo, portanto com área de abrangência institucional. ${ }^{75}$ 


\subsection{Categorização de Hospitais}

O termo "Classificação" significa distribuir em classes e ou grupos, segundo sistema ou método de classificação. Determinar as categorias em que se divide ou subdivide um conjunto (AURÉLIO, 1994).

A classificação dos serviços de saúde vem ocupando, há tempo, um espaço bem significativo, dentro da literatura voltada à saúde, pela relevância do tema.

Segundo o Manual da OPAS (1998) e o Manual Brasileiro de Acreditação Hospitalar (1999): "Categorização" é o procedimento relacionado à classificação de serviços hospitalares e ambulatoriais de acordo com o critério adotado (complexidade, riscos de atenção e outros) que permite definir os níveis, concentrar atividades, classificar os beneficios de acordo com sua viabilidade, segundo o tipo de estabelecimento analisado e tornando-se, no futuro, em uma rede de serviços integrados aos Sistemas Locais de Saúde. ${ }^{92,42}$

SCHIESARI (1999) relata que a necessidade de classificar os hospitais surgiu em diferentes países por motivos diversos. Apresenta, como exemplo, os Estados Unidos da América, onde a classificação obedeceu, inicialmente, à necessidade de informar o público em geral sobre a idoneidade das instituições, do ponto de vista técnico-profissional, administrativo e ético, valorizando as organizações em que a Medicina era praticada com seriedade e pondo em evidência aquelas que não estavam em condições de oferecer assistência de nível recomendável. O objetivo final do processo era a garantia da qualidade dos serviços prestados pelas instituições hospitalares. ${ }^{102}$ 
No Brasil, a classificação de hospitais vem ocorrendo há quase oito décadas e surgiu da necessidade de qualificar os hospitais para a cobrança diferenciada dos serviços prestados.

O processo histórico da implantação do SUS e da avaliação dos hospitais no Brasil, relatado no item 1.3 deste estudo, demonstra que o objetivo principal da classificação dos hospitais foi o estabelecimento de classes de referência para o pagamento das internações hospitalares, inicialmente, pelos Institutos de Aposentadoria e Pensão, e posteriormente, pelo INPS e pelo INAMPS.

Em decorrência disso, os instrumentos elaborados para a classificação de hospitais foram surgindo, dependendo das necessidades destes Institutos, relacionadas à compra de serviços hospitalares e do conhecimento técnico-científico incorporado pelos profissionais de saúde e instituições hospitalares.

Como vimos anteriormente, são estes os instrumentos que foram utilizados ao longo do tempo:

- Década de 1930, primeiras tentativas para classificação de hospitais foram feitas pelo Departamento de Assistência Médica do Instituto de Aposentadoria e Pensão dos Comerciários (IAPC).

- Em 1941, a Divisão de Organização Hospitalar foi criada para o estabelecimento de normas e padrões para instalações, organização e funcionamento dos vários serviços técnicos e administrativos de hospitais e a organização e manutenção do cadastro de estabelecimentos hospitalares.

- Em 1959, o IAPC, implementa a classificação de hospitais, por meio de instrumento, com relação sumária de requisitos relativos ao prédio e ao equipamento. (Associação Paulista de Hospitais, 1966). ${ }^{102}$ 
- Em 1961, o instrumento utilizado para credenciamento de hospitais para convênio com o IAPC, incluía três tópicos principais: planta física, equipamento e organização. Era um instrumento genérico, com tópicos amplos e vagos e explicitava que "o critério na determinação dos pontos visa o custo do serviço representado pela planta física e pelo equipamento e mais a facilidade de obtenção de pessoal”. Os responsáveis pela aplicação do instrumento defendiam que a pontuação obtida pelos hospitais não deveria ser inferior a $70 \%$ dos pontos indicados, a fim de garantir que os padrões mínimos exigidos fossem cumpridos. ${ }^{102}$

- Em 1962, o IAPI, passou a utilizar o instrumento Padrões Mínimos Exigíveis dos Hospitais para a Prestação de Assistência Cirúrgica aos Beneficiários do Instituto de Aposentadoria e Pensão dos Industriários (IAPI), com 25 ítens de observação para dois tipos de hospitais (clínicos e obstétricos), que continha normas técnicas mínimas a serem cumpridas relacionadas a diretrizes clínicas. $^{102}$

- Em 1962, uma comissão técnica constituída pelo Conselho de Medicina da Previdência Social, composta por representantes do IAPC, IAPI e do Instituto de Aposentadoria dos Bancários (IAPB), elaborou uma proposta para classificação de hospitais, resultando, num primeiro momento, no estudo meticuloso dos centros de custos hospitalares, e posteriormente, na elaboração de uma lista dos elementos mais importantes para a prestação de cinco tipos de assistência hospitalar: clínica, cirúrgica, obstétrica, tisiológica e psquiátrica. ${ }^{102}$ 
- Em 1966, com a unificação dos institutos pela criação do INPS, surgiu a necessidade de classificar os hospitais no Brasil em função de estabelecer valores monetários pela contraprestação de serviços pelos hospitais particulares. $^{102}$

- Em 1968, na Tabela de Classificação de Hospitais, foram estabelecidas as normas para sua aplicação para avaliação da eficiência hospitalar. Eram atribuídos pontos separadamente para planta física; equipamento, utensílios e instalações; administração para hospitais de clínica médica; cirurgia e obstetrícia; tisiologia e psiquiatria. ${ }^{102}$

- Em 1974, o RECLAR pretendia uniformizar o processo de avaliação para fornecer à rede contratada orientação quanto aos padrões de assistência médico-hospitalar adotados pelo INAMPS para hospitais: gerais, cirúrgicos, obstétricos, tisiopneumológicos, psiquiátricos e pediátricos. Avaliava os hospitais, mediante tabela, nos seguintes setores: planta fisica; equipamentos, utensílios e instalações e organização e apresentava também Tabela Suplementar. Estes setores recebiam pontuação, sendo que a planta física apresentava 92 ítens, sendo responsável por $29,4 \%$ do total de pontos; para equipamentos, utensílios e instalações, 128 itens, correspondendo a $39 \%$ dos pontos; organização apresentava 69 ítens, representando $31,5 \%$ dos pontos. ${ }^{102}$ Com a implantação do RECLAR, vinculado ao Departamento de Controle e Avaliação do INAMPS (nível central) e Coordenadoria de Controle e Avaliação (nível regional), legitimou-se a existência de vários padrões de hospitais, atrelando mais uma vez o pagamento à classificação do hospital. 
Nesse período, a finalidade da classificação foi reduzida ao credenciamento, predominando critérios políticos. ${ }^{102}$

Independentemente deste uso distorcido, o RECLAR merece destaque pelo componente técnico que apresentava e por ter sido aplicado por profissionais do INAMPS treinados e de reconhecida competência técnica.

A partir da década de 1980, com a crise da Previdência, associada ao processo de democratização do país, o setor saúde passa por um processo de mudança iniciando a descentralização, transferindo as atividades de avaliação para os níveis estaduais e municipais.

Com a implantação do SUS a partir de 1988, as competências dos três níveis de governo são redefinidas, ficando as funções de habilitação, avaliação e controle para as esferas estaduais e municipais.

Para a categorização de hospitais, o Ministério da Saúde editou a Portaria $\mathrm{n}^{\circ}$ 2224/GM, de 05 de dezembro de 2002, “Considerando que a classificação hospitalar se dará a partir do agrupamento de hospitais com características semelhantes, sistematizando, desta forma, o conhecimento sobre grupos de hospitais e facilitando a adoção de políticas e de planejamento".35

A classificação será aplicada aos hospitais integrantes do SUS, ordenando-os, de acordo com suas características, em um dos seguintes portes:

- Hospital Porte I

- Hospital Porte II

- Hospital Porte III

- Hospital Porte IV 
Determinou-se que o enquadramento de cada hospital em um dos portes estabelecidos na referida Portaria, se dará respeitando o intervalo de pontos atribuídos para cada porte, considerando a somatória da pontuação alcançada como resultado da aplicação dos itens de avaliação, definidos pela seguinte Tabela de Pontuação:

\begin{tabular}{|c|c|c|c|c|c|c|c|c|}
\hline \multirow{3}{*}{$\begin{array}{c}\text { Pontos } \\
\text { por } \\
\text { item }\end{array}$} & \multicolumn{7}{|c|}{ Itens de Avaliação } & \multirow{3}{*}{$\begin{array}{l}\text { Pontos } \\
\text { Totais }\end{array}$} \\
\hline & A & B & $\mathrm{C}$ & $\mathrm{D}$ & $\mathrm{E}$ & $\mathrm{F}$ & $\mathrm{G}$ & \\
\hline & $\begin{array}{l}\mathrm{N}^{\circ} \mathrm{de} \\
\text { leitos }\end{array}$ & $\begin{array}{c}\text { Leitos de } \\
\text { UTI }\end{array}$ & $\begin{array}{l}\text { Tipo de } \\
\text { UTI }\end{array}$ & $\begin{array}{c}\text { Alta } \\
\text { Complexidade }\end{array}$ & $\begin{array}{l}\text { Urgência/ } \\
\text { Emergência }\end{array}$ & $\begin{array}{l}\text { Gestação de } \\
\text { Alto Risco }\end{array}$ & $\begin{array}{c}\text { Salas } \\
\text { Cirúrgicas }\end{array}$ & \\
\hline 1 & 0 a 49 & 01 a 04 & --- & 1 & Pronto-atendimento & $---\cdots--$ & Até 02 & Mínimo 1 \\
\hline 2 & 0 a 149 & 05 a 09 & Tipo II & 2 & $\begin{array}{c}\text { Serviço de } \\
\text { Urgência/Emergência }\end{array}$ & Nivel I & 03 e 04 & \\
\hline 3 & 50 a 299 & 10 a 29 & ------- & 3 & $\begin{array}{c}\text { Referência Nível I ou } \\
\text { II }\end{array}$ & Nivel II & 05 e 06 & Máximo 27 \\
\hline 4 & 300 ou + & $30 \mathrm{ou}+$ & Tipo III & 4 ou mais & Referência Nível III & ----- & $>8$ & \\
\hline
\end{tabular}

A verificação do cumprimento dos itens de avaliação estabelecidos na Tabela de Pontuação e sua respectiva pontuação serão realizadas pela Secretaria de Assistência à Saúde (SAS), no momento da classificação hospitalar, por meio de consulta ao Banco de Dados Nacional de Estabelecimentos de Saúde, criado pela Portaria SAS/ MS n 511 , de 29 de dezembro de 2000.

A avaliação e enquadramento dos hospitais, no momento da classificação hospitalar em cada um dos itens de avaliação, dar-se-á de acordo com os seguintes entendimentos estabelecidos, discriminados a seguir:

Leitos Cadastrados (Coluna A): será considerado o quantitativo total de leitos existentes nos hospitais, cadastrados no Cadastro Nacional de Estabelecimentos de Saúde, contratados ou não pelo SUS; 
Leitos de UTI (Coluna B): será considerado o quantitativo de leitos cadastrados em Unidade(s) de Terapia Intensiva (Adulto, Neonatal e Pediátrica), independentemente da classificação de tipo de UTI;

Tipo de UTI (Coluna C): será considerado o cadastramento de UTI no Sistema Único de Saúde de acordo com seu Tipo II ou III (conforme Portaria GM/MS n 3432, de 12 de agosto de 1998, sendo que na hipótese da existência de mais de uma unidade cadastrada, será pontuada apenas uma delas - aquela que corresponder ao maior número de pontos);

Alta Complexidade (Coluna D): será considerado o quantitativo de serviços de alta complexidade existentes no hospital e devidamente cadastrados/contratados pelo SUS, podendo ser computados para tanto: Serviços/Centros de Alta Complexidade em Assistência Cardiovascular (não serão computados Hospitais Gerais com Serviço de Implante de Marcapasso Permanente), tratamento das Lesões Lábio Palatais e Implante Coclear, Neurocirurgia, Traumato-Ortopedia, Tratamento Cirúrgico da Epilepsia, Assistência a Queimados, Oncologia, Cirurgia Bariátrica e Transplantes (considerar como 1 sistema o cadastro para realização de transplante de cada tipo de órgão);

Urgência/Emergência (Coluna E): será considerada a existência: (1) de Serviço de Pronto-atendimento nas 24 horas do dia com equipe presente, pelo menos, de urgências em Pediatria e Clínica Médica, ou Equipe da(s) Especialidade(s) oferecida(s) no caso de hospitais especializados; (2) de Serviço de Urgência e Emergência com atendimento nas 24 horas do dia, com equipe presente, de urgências e emergências em Pediatria, Clínica Médica, Cirurgia Geral, Ortopedia e Anestesia, todos disponíveis para o SUS; ou ainda (3): a existência de Serviço de Urgência e 
Emergência cadastrado pelo Ministério da Saúde segundo a Portaria GM/MS nº 479, de 15 de abril de 1999, em Hospital integrante do Sistema Estadual de Referência Hospitalar em Atendimento de Urgências e Emergências, de acordo com seus respectivos Níveis I, II ou III;

Gestação de Alto Risco (Coluna F): será considerada a existência de Serviço de Atendimento de Gestação de Alto Risco cadastrado pelo Ministério da Saúde segundo a Portaria GM/MS n ${ }^{\circ} 3477$, de 20 de agosto de 1988, como Hospital integrante do Sistema Estadual de Referência Hospitalar em Atendimento à Gestação de Alto Risco, de acordo com seus respectivos Níveis I e II;

Salas Cirúrgicas (Coluna $G$ ): será considerado o quantitativo total de salas cirúrgicas existentes no hospital. ${ }^{35}$

A Portaria $\mathrm{n}^{\circ}$ 2224/ GM, de 05 de dezembro de 2002, estabelece que o total de pontos obtidos, resultantes da aplicação da Tabela de Pontuação, levará ao enquadramento dos hospitais no Sistema de Classificação Hospitalar do Sistema Único de Saúde em seu correspondente Porte, em conformidade com o que segue:

Porte I - de 01 a 05 pontos

Porte II - de 06 a 12 pontos

Porte III - de 13 a 19 pontos

Porte IV - de 20 a 27 pontos

Para a estruturação técnico-administrativa dos hospitais, outra Portaria foi editada, a de $n^{\circ} 2225 / G M$, de 5 de dezembro de $2002,{ }^{36}$ que estabeleceu exigências mínimas para os hospitais, que são apresentadas a seguir:

Hospital de Porte I

Um responsável pela Direção Geral - profissional com nível superior, com 
curso de aperfeiçoamento em Administração Hospitalar, com no mínimo 180 horas/aula, realizado em instituição de ensino superior legalmente reconhecida.

Um responsável pela Direção Técnica - profissional médico, a quem compete zelar pela qualidade da assistência prestada.

Observação: Se o responsável pela Direção Geral for profissional médico, o mesmo poderá acumular as funções de responsável pela Direção Técnica.

Hospital de Porte II

Um responsável pela Direção Geral - profisssional de nível superior, com curso de aperfeiçoamento em Administração Hospitalar, com no mínimo 180 horas/aula, realizado em instituição de ensino superior legalmente reconhecida.

Um responsável pela Direção Técnica - profissional médico, a quem compete zelar pela qualidade da assistência prestada.

Um responsável pela Direção Administrativa - profissional de nível superior, preferencialmente com formação em administração hospitalar ou administração, com curso de aperfeiçoamento em Administração Hospitalar, com no mínimo 180 horas/aula, em instituição de ensino legalmente reconhecida.

\section{Hospital de Porte III}

Um responsável pela Direção Geral - profissional com nível superior, experiência comprovada de dois anos na função gerencial em unidade hospitalar e curso de especialização em Administração Hospitalar com no mínimo 360 horas/aula, realizado em instituição de ensino superior legalmente reconhecida.

Um responsável pela Direção Técnica - profissional médico a quem compete zelar pela qualidade da assistência prestada, com curso aperfeiçoamento em Administração Hospitalar, com no mínimo 180 horas/aula, realizado em instituição 
de ensino superior legalmente reconhecida.

Um responsável pela Direção Administrativa - Profissional de nível superior, preferencialmente com formação em administração hospitalar ou administração, com experiência comprovada de dois anos na função gerencial em unidade hospitalar e com curso de aperfeiçoamento em Administração Hospitalar, com no mínimo 180 horas/aula, realizado em instituição de ensino legalmente reconhecida.

Hospital de Porte IV

Um responsável pela Direção Geral - profissional de nível superior, com dois anos de experiência comprovada na função gerencial em unidade hospitalar, com curso de especialização em Administração Hospitalar, com no mínimo 360 horas/aula, realizado em instituição de ensino superior legalmente reconhecida. Um responsável pela Direção Técnica - profissional médico, a quem compete zelar pela qualidade da assistência prestada, com experiência de um ano na função gerencial em unidade hospitalar e com curso de especialização em Administração Hospitalar, com no mínimo 360 horas/aula, realizado em instituição de ensino superior legalmente reconhecida.

Um responsável pela Direção Administrativa - profissional de nível superior, preferencialmente com formação em administração hospitalar, ou administração, com experiência de dois anos na função gerencial em unidade hospitalar e com curso de especialização em Administração Hospitalar, com no mínimo 360 horas/aula, realizado em instituição de ensino superior legalmente reconhecida.

Essas exigências foram estabelecidas de acordo com o porte do hospital e são válidas para a totalidade dos hospitais cadastrados e que prestam serviços ao Sistema Único de Saúde, independentemente de sua situação jurídica. 


\subsection{Instrumentos de Avaliação de Hospitais utilizados pelos gestores na} atualidade

\section{Para avaliação da Qualidade}

Os gestores do Setor Saúde contam com os instrumentos elaborados para avaliação da qualidade institucional ou setorial, já descritos anteriormente, que são os da Joint Comission on Accreditation of Healthcare Organizations (1951); os do Programa de Controle de Qualidade do Atendimento Médico-Hospitalar da Associação Paulista de Medicina e Conselho Regional de Medicina do Estado de São Paulo - CQH (1990); os do Manual de Acreditação de Hospitais para América Latina e Caribe da OPAS (1992), os do Consórcio Brasileiro de Acreditação de Serviços de Saúde - CBA (1997); os de avaliação de hospitais para Acreditação Hospitalar da ONA (1998); os do Programa Nacional de Qualidade e do Programa de Qualidade do Governo Federal; os de entrega de Selo e os de Certificação ISO.

\section{Para a Gestão do Sistema Único de Saúde}

\section{Cadastro Nacional de Estabelecimentos de Saúde (CNES)}

O cadastro compreende o conhecimento dos Estabelecimentos de Saúde nos aspectos de área física, recursos humanos, equipamentos e serviços ambulatoriais e hospitalares. É a base para os sistemas de Informações em Saúde, sendo estes imprescindíveis ao gerenciamento eficaz e eficiente. Propiciam ao gestor o conhecimento da rede assistencial existente e suas potencialidades, visando auxiliar no planejamento em saúde, em todos os níveis de governo, bem como dar maior visibilidade ao controle social pela população. ${ }^{44}$ 
O CNES visa disponibilizar informações das atuais condições de infraestrutura e funcionamento dos Estabelecimentos de Saúde em todas as esferas: federal, estadual e municipal.

O cadastramento prevê as estapas:

- fornecimento da informação através de preenchimento dos formulários por parte do responsável pelo Estabelecimento de Saúde por internet, disquetes, formulário, etc.; esta etapa é utilizada de modo opcional pelo gestor responsável pelo cadastramento, o qual deve orientar os estabelecimentos localizados em seu território, sobre a forma de preenchimento;

- verificação, "in loco", de competência do gestor, validando as informações prestadas pelos Estabelecimentos de Saúde;

- encaminhamento dos dados pelo gestor ao Departamento de Informação e Informática do Sistema Único de Saúde (DATASUS) que inclui a unidade no CNES;

- certificação do processo de cadastramento do Estado, sob responsabilidade do Ministério da Saúde. ${ }^{44}$

\section{Programa Nacional de Avaliação de Serviços de Saúde (PNASS)}

Instrumento criado para avaliar serviços de saúde do Sistema Único de Saúde a partir dos serviços priorizados pelo Cadastro Nacional de Estabelecimentos de Saúde, publicado pelo Ministério da Saúde em $2004 .^{43}$ 
A metodologia utilizada baseia-se em Roteiro de Padrões de Conformidade, Indicadores de Produção, Pesquisa de Satisfação dos Usuários e Pesquisa das Condições e Relações de Trabalho.

É feita uma auto-avaliação inicial pelo hospital, que depois é conferida pelo gestor local. Os indicadores hospitalares são retirados das fontes: CNES (Cadastro Nacional de Estabelecimentos de Saúde), SIA (Sistema de Informação Ambulatorial), SIH (Sistema de Informação Hospitalar) e APAC (Autorização de Procedimentos de Alta Complexidade) e submetidos à análise. A pesquisa de satisfação dos usuários e das condições e relações de trabalho é feita pelo gestor local, utilizando-se questionários padronizados, em amostra de usuários e funcionários, respectivamente.

Os critérios utilizados destinam-se à avaliação da gestão organizacional, do apoio técnico logístico e da atenção da saúde do paciente. São 22 critérios, com itens que o gestor local classifica em imprescindível, necessário e recomendável. ${ }^{43}$

\section{Instrumento Nacional para Inspeção de Serviços de Saúde da Agência Nacional} de Vigilância Sanitária

Instrumento desenvolvido para inspeção de serviços de saúde dentro de metodologia que facilita a aplicação da legislação vigente, publicado em 2004. Apresenta parâmetros para se avaliarem as condições sanitárias e a qualidade dos serviços de saúde disponibilizados em um hospital, abrangendo as quatro clínicas básicas: médica, cirúrgica, pediátrica e gineco-obstetrícia, além dos serviços de apoio técnico, administrativo e diagnóstico. ${ }^{41}$ 
O instrumento é aplicado pela autoridade sanitária competente, nos âmbitos federal, estadual e municipal, durante a realização de inspeções para quaisquer finalidades nos Serviços de Saúde e deve ser utilizado pelos responsáveis dos serviços como roteiro de auto-inspeção.

Para fins de liberação do Alvará Sanitário, que é expedido pela Vigilância Sanitária estadual ou municipal, o serviço de saúde deve atender a todos os ítens classificados como imprescindíveis no roteiro.

O instrumento foi dividido em quatro módulos: Dados Gerais, Organização e Atenção ao Paciente, Apoio Técnico e Administrativo e Apoio Diagnóstico e Terapia $\mathrm{Na}$ elaboração utilizaram-se portarias, normas técnicas e resoluções específicas de cada área do hospital. ${ }^{41}$

Devido à especificidade e à complexidade da instituição hospitalar é freqüente a publicação de portarias e normas técnicas com as exigências legais para o hospital como um todo ou para parte dele, que são utilizadas pelos gestores.

Segundo BITTAR (1996), apesar dos avanços que vêm ocorrendo na administração da área de saúde, ainda se identificam poucos hospitais brasileiros mobilizados para discussão da qualidade, dos indicadores gerenciais e de serviço, das metas institucionais e do estabelecimento de mecanismos de avaliação e acreditação no seu ambiente. ${ }^{17}$

AKERMAN (1996), em pesquisa realizada com dirigentes de organizações que congregam um grande número de hospitais, apresentou os três principais fatores apontados como obstáculo para a implementação de programas de qualidade: o não envolvimento da alta direção, a falta de comprometimento da gerência e a baixa 
remuneração dos profissionais. Além destes fatores, existe resistência, individual e de setores, em aceitar os princípios e técnicas dos programas de qualidade. ${ }^{4}$

MALIK e TELES (1999) investigaram as atividades de qualidade em 97 hospitais do Estado de São Paulo, públicos, filantrópicos, não filantrópicos e universitários, dos quais $23 \%$ afirmaram ter alguma iniciativa desse teor. Os $77 \%$ que afirmaram não ter atividades de qualidade, atribuíram esse fato aos custos dos programas, à demora na obtenção de resultados e à falta de necessidade. Muitos dos que desenvolviam tais atividades, conheciam mal os custos incorridos e outros tipos de conseqüências. Quase todos os que responderam positivamente, afirmaram monitorar indicadores gerenciais. ${ }^{83}$

TERRA (2000), em estudo sobre mudança organizacional e implantação de um programa de qualidade em hospital do Município de São Paulo, observou que ainda não existe um consenso sobre o significado exato do termo qualidade, principalmente pelos aspectos de subjetividade implícitos no conceito. Tais aspectos encerram em si um juízo de valor, próprio da apreciação ou opinião pessoal. A definição de qualidade deve variar segundo o ponto de vista do produtor, do fornecedor e do usuário final, de acordo com os critérios estabelecidos pelos diferentes atores submetidos ao processo em avaliação. ${ }^{110}$

CYPRIANO (2004), em estudo para analisar o nível de incorporação das práticas de qualidade em nove hospitais, que atestavam o Selo de Conformidade do CQH no ano de 2003, situados na Região Metropolitana da Grande São Paulo, constatou pluralidade de entendimento de conceitos da qualidade e programas de avaliação da gestão hospitalar. A depender da visão dos entrevistados na pesquisa (gestores do programa ou comissão de qualidade), qualidade expressa um atributo 
relacionado desde a aquisição de equipamentos, a ampliação da estrutura física, o desenvolvimento e a capacitação de recursos humanos até a incorporação de um modelo de gestão da qualidade. Essa diversidade de compreensão tornou complexa a tarefa de identificar atividades comuns que possam configurar um padrão de melhoria da qualidade nos hospitais em estudo. ${ }^{55}$ 


\section{JUSTIFICATIVA}

Ao analisarmos as mudanças ocorridas no Setor Saúde no período de 1988 até os dias atuais, identificamos que os gestores públicos e privados necessitam de instrumentos que possibilitem avaliação sistemática dos serviços de saúde e, em especial, dos hospitais. No caso de gestores públicos, são de sua responsabilidade a habilitação para o funcionamento, a avaliação, o controle e o pagamento de prestadores de serviços hospitalares, além da avaliação dos riscos que estes serviços oferecem à população em geral. No caso de gestores privados, a situação é semelhante. São eles que colocam, mediante credenciamento dos serviços e dos contratos de prestação de serviços, os hospitais qualificados em suas redes assistenciais a fim de não oferecer riscos e atender às necessidades da clientela, frente às exigências cada vez maiores do consumidor e do mercado competitivo.

A questão da garantia da qualidade dos serviços de atenção à saúde e da assistência médico-hospitalar que é oferecida à população tem sido uma preocupação intrinsicamente ligada à atividade dos gestores.

Entretanto, a variabilidade das atividades que compõem os processos de atenção à saúde (promover saúde, prevenir doenças, recuperar e reabilitar sistemas e funções) e a quantidade e diversidade dos recursos envolvidos na sua execução, fazem com que haja uma grande distância entre os serviços planejados e aquilo que efetivamente é realizado em termos de assistência, pois nem sempre conseguem atender as reais necessidades de assistência dos pacientes, independentemente de quão boas tenham sido as intenções do prestador dos serviços. ${ }^{45}$

Quanto maior a complexidade da organização responsável pela concretização da atenção planejada, maiores os riscos de perdas e ruídos durante o processo de 
prestação dos serviços. Assim, seja,, por modelos de auto-regulação do exercício profissional por parte dos responsáveis pela saúde dos pacientes, seja pela crescente tomada de consciência destes últimos quanto aos seus direitos de cidadãos e consumidores, seja ainda pela crescente competição intra-setorial, a qualidade dos serviços prestados pelas organizações responsáveis pela assistência médicohospitalar vem sendo alvo de ações e de investimentos crescentes de seus gestores.

Junto com a necessidade de prover mecanismos que garantam a qualidade da assistência médico-hospitalar, não se deve deixar de considerar a pressão sofrida pelos hospitais e demais instituições de saúde - principalmente através da mídia com relação a todos os assuntos que possam pôr em dúvida a efetividade do tratamento dispensado aos seus pacientes. ${ }^{45}$

A autora, mobilizada pela necessidade de contribuir para a melhoria da qualidade da assistência médico-hospitalar e considerando: a baixa adesão dos hospitais ao processo de qualidade $(2,09 \%$ deles $){ }^{93,6}$; o alto percentual de hospitais no Brasil ( $75 \%$ deles com menos de 70 leitos) que funcionam sem medidas básicas de avaliação da assistência médica, com um número insuficiente de pessoal e sem instrumentos normativos (NOVAES, 1999) ${ }^{91}$; os gastos com assistência médicohospitalar bastante representativos (variando de $43,39 \%$ do total de gastos em 2002 a $45,85 \%$ em 2003$)^{40}$, entendeu ser extremamente oportuna a organização de um instrumento capaz de fornecer informações fidedignas sobre qualidade hospitalar.

Para a verificação de graus de excelência, observou que há instrumentos de avaliação de qualidade hospitalar adequados, enquanto que para a avaliação de padrões mínimos de funcionamento, não se encontram instrumentos que possibilitem a avaliação do hospital como um todo; para cada serviço hospitalar foram 
estabelecidos padrões, ou seja, o nível de atenção, prática ou método esperado, definido por especialistas e/ou associações profissionais. Como um hospital não é constituído por serviços independentes e isolados, é necessária a organização de instrumentos que possibilitem sua avaliação global.

Este cenário motivou a autora a cogitar a organização ou reengenharia de um novo instrumento que fosse capaz de agregar as variáveis ou itens de observação de cada área hospitalar em relação aos padrões mínimos exigidos e que tivesse as seguintes características: exatidão, confiabilidade, simplicidade, pertinência, validade e sensibilidade. Considerando ser possível mudar a gestão e a forma de regulação do sistema avaliando produtos e serviços a partir da análise de parâmetros determinados por meio de protocolos e rotinas, verificar-se-ia, dessa forma, o grau de conformidade das organizações de saúde aos padrões preestabelecidos por especialistas.

Esses instrumentos de avaliação de conformidade devem atender às necessidades de análise e apoio para a tomada de decisão, tendo em vista sua capacidade de fornecer aos gestores conhecimento sobre as muitas particularidades e respostas aos desafios enfrentados na administração de suas organizações, desde procedimentos técnicos e relações interpessoais até amenidades (que fazem parte da atenção, mesmo que de forma indireta). Tais particularidades são avaliadas - como demonstrativo mensurável da qualidade da assistência médico-hospitalar prestada - a partir de itens de estrutura, processo e resultado, que de forma direta (nos indicadores de resultados) ou indireta (nos indicadores de estrutura) permitem inferir a qualidade existente. $^{45}$ 
Dessa forma, considerando a necessidade de tomada de decisão por parte dos gestores, e considerando os conceitos e normas definidos para a avaliação dos serviços hospitalares, públicos e privados, explicitados nos Manuais de Acreditação Hospitalar como categorização, buscou-se construir um instrumento - Vistoria Técnica Hospitalar - apto a realizar diagnósticos de serviços e de rede a fim de identificar o tipo de prestador, sua localização, seu perfil de atendimento, para que os gestores possam, com maior segurança, definir suas estratégias no atendimento às necessidades de saúde da população ou de usuários de planos de saúde e eleger as prioridades na alocação de recursos.

A Vistoria Técnica Hospitalar corresponde à inspeção de estabelecimentos de saúde por profissionais devidamente habilitados, a ser realizada segundo roteiro elaborado de acordo com normas técnicas e padrões (exigidos pelo Ministério da Saúde, Agências Reguladoras e órgãos de classe), bem como à obtenção dos dados referentes aos indicadores de qualidade, produtividade e dimensionamento quantitativo de recursos humanos. ${ }^{88}$

Neste estudo, procurou-se verificar se o instrumento Vistoria Técnica Hospitalar é adequado para a avaliação e categorização da rede de serviços hospitalares, uma vez que todos os estabelecimentos vistoriados serão observados/ inspecionados, comparados com padrões de conformidade de acordo com critérios técnicos preestabelecidos e metodologia própria. 


\section{OBJETIVOS}

- Propor e analisar instrumento para categorização de hospitais.

- Aplicar o instrumento numa amostra intencional de hospitais. 


\section{MÉTODO}

\subsection{Estratégia de Pesquisa}

Segundo CASTRO (1977), citado por CIPRIANO (2004), metodologia pode ser definida como o interesse por princípios e técnicas, chamados consequentemente de métodos.

Métodos são técnicas suficientemente gerais para se tornarem comuns a todas as ciências ou a uma significativa parte delas. O objetivo da metodologia é ajudarnos a compreender, nos mais amplos termos, não os produtos da pesquisa, mas o próprio processo. ${ }^{54}$

Dessa maneira, fica evidente a importância da metodologia na prática da pesquisa e do trabalho científico, o que a torna indispensável para a boa qualidade e confiabilidade dos mesmos.

Para a classificação da pesquisa realizada, tomaram-se como base os critérios apresentados por VERGARA (1998), que a qualifica quanto aos fins (objetivos da pesquisa) e aos meios (métodos empregados). ${ }^{12}$

Quanto aos fins, a pesquisa apresentou características que possibilitou:

- a análise do instrumento Vistoria Técnica Hospitalar para categorização de hospitais de pequeno, médio, grande e especial portes;

- identificar se os itens de verificação contemplados no instrumento apresentam as seguintes características descritas para um indicador por SARACENO e LEVAV (1992): ${ }^{103}$

- exatidão: o indicador deve apresentar a mínima possibilidade de erro cada vez que é registrado; 
- confiabilidade: mesmas medidas podem ser obtidas por diferentes pesquisadores, frente a um mesmo evento;

- simplicidade: deve apresentar poucas dificuldades quanto ao seu registro;

- pertinência: deve estar correlacionado ao fenômeno ou critério que está sendo examinado;

o validade: deve medir efetivamente o fenômeno ou parâmetro que se examina;

- sensibilidade: $\mathrm{o}$ indicador deve detectar as variações no comportamento do fenômeno que se examina.

Pode-se classificar esta pesquisa como de campo, pois foi realizada onde ocorre o fato, sendo que os dados foram coletados por meio de um instrumento (Roteiro de Vistoria Técnica Hospitalar) aplicado por dois vistoriadores, um médico e uma enfermeira (própria autora). A pesquisa é também bibliográfica, pois recorreu ao uso de referencial teórico, desenvolvido a partir de material publicado em livros, teses, dissertações, revistas especializadas, artigos, normas técnicas e meios eletrônicos sobre avaliação de hospitais, visando à categorização.

Utilizaram-se nesta pesquisa tanto o método qualitativo quanto o quantitativo, por entender que, para enriquecer a análise do fenômeno estudado, são imprescindiveis as duas abordagens. ${ }^{87}$

MINAYO (1994) argumenta que o método qualitativo possibilita "incorporar a questão do Significado e Intencionalidade como inerentes aos atos, às relações, e às estruturas sociais; sendo estas últimas tomadas tanto no seu advento quanto na sua transformação, como construções humanas significativas". ${ }^{87}$ 
GOLDENGERG (2000), citado por CIPRIANO (2004), parte do princípio de que o ato de compreender está ligado ao universo existencial humano, diz que as abordagens qualitativas não se preocupam em fixar leis para produzir generalizações. Enfatizam as particularidades de um fenômeno em termos de seu significado para o grupo pesquisado. ${ }^{54}$

Para LEFÈVRE F e LEFÈVRE AMC (2003), a pesquisa quantitativa é a classe de pesquisa que deve ter sempre por objetivo verificar quanto ou em que proporção um determinado atributo está presente por população pesquisada. Estabelece as prováveis causas a que estão submetidos os objetos de estudo, assim como descreve em detalhes o padrão de ocorrência dos eventos observados; permite abordar uma grande variedade de áreas de investigação com um mesmo entrevistado, validar estatisticamente as variáveis em estudo e seus resultados podem ser extrapolados para o universo pesquisado. ${ }^{81}$

MINAYO (1994) refere que as pesquisas qualitativas e quantitativas são inseparáveis e interdependentes. ${ }^{87}$ 


\subsection{Determinação da amostra}

A pesquisa de campo foi desenvolvida em nove hospitais selecionados intencionalmente pela capacidade instalada e complexidade, característica necessária para a análise do instrumento. Foram escolhidos hospitais situados no Estado de São Paulo, pela facilidade da coleta dos dados e do relacionamento com as equipes gestoras, sendo 01 especial (acima de 500 leitos), dois de grande porte (hospital com capacidade instalada de 151 a 500 leitos), três de médio porte (hospital com capacidade instalada de 51 e 150 leitos) e três de pequeno porte (hospital com capacidade instalada até 50 leitos), segundo o Ministério da $S_{a u ́ d e}{ }^{20}$, distribuídos segundo sua natureza em: um universitário ou de ensino, dois privados não lucrativos e seis privados. Para garantir o sigilo acordado com eles, os mesmos foram identificados pelas letras A, B, C, D, E, F, G, H e I. Aos Hospitais selecionados foi enviado Termo de Consentimento (Anexo 1).

\begin{tabular}{|c|c|c|}
\hline \multicolumn{3}{|c|}{ Hospital acima de 500 leitos } \\
\hline Hospital & Estado & $N^{\circ}$ leitos \\
\hline $\mathrm{A}$ & São Paulo & 700 \\
\hline \multicolumn{3}{|c|}{ Hospitais acima de 150 leitos } \\
\hline Hospital & Estado & $\mathrm{N}^{\circ}$ leitos \\
\hline $\mathrm{B}$ & São Paulo & 220 \\
\hline $\mathrm{C}$ & São Paulo & 201 \\
\hline \multicolumn{3}{|c|}{ Hospitais de 51 a 150 leitos } \\
\hline Hospital & Estado & $N^{\circ}$ leitos \\
\hline $\mathrm{D}$ & São Paulo & 95 \\
\hline E & São Paulo & 70 \\
\hline $\mathrm{F}$ & São Paulo & 130 \\
\hline
\end{tabular}




\begin{tabular}{llc}
\hline \multicolumn{3}{c}{ Hospitais abaixo de $\mathbf{5 0}$ leitos } \\
\hline Hospital & Estado & $\mathrm{N}^{\circ}$ leitos \\
\hline $\mathrm{G}$ & São Paulo & 48 \\
$\mathrm{H}$ & São Paulo & 38 \\
$\mathrm{I}$ & São Paulo & 30 \\
\hline
\end{tabular}

\subsection{Instrumento e Coleta de Dados}

Para a coleta de dados da pesquisa de campo, utilizou-se como instrumento o Roteiro de Vistoria Técnica Hospitalar (Anexo 2), baseado no Roteiro de Inspeção de Hospitais do Manual de Vigilância Sanitária da Coleção Saúde e Cidadania (1998) ${ }^{73}$, modificado pela autora, utilizando-se: o Instrumento Nacional para Inspeção de Serviços de Saúde da Agência Nacional de Vigilância Sanitária (2004) ${ }^{41}$; a Resolução RDC $n^{\circ} 50$, de 21 de fevereiro de $2002,{ }^{30}$ que dispõe sobre o regulamento técnico para planejamento, programação, elaboração e avaliação de projetos físicos de estabelecimentos assistenciais, cujas especificações técnicas foram contempladas no roteiro; a Resolução - RDC n 307 , de 14 de novembro de $2002,{ }^{34}$ que altera a RDC n $n^{\circ} 50 / 02$; a Resolução RDC n 33 , de 25 de fevereiro de $2003,{ }^{37}$ sobre tratamento de resíduos; a Portaria Federal $n^{\circ} 453$, de 1 de junho de $1998,{ }^{26}$ que trata de radioionizantes; a Portaria $\mathrm{n}^{\circ} 3432 / \mathrm{GM}$, de 12 de Agosto de 1998, ${ }^{28}$ que estabelece critérios de classificação para as Unidades de Tratamento Intensivo - UTI; a Resolução CFM no $1451 / 95,{ }^{50}$ que trata da estrutura dos Pronto-Socorros para atendimento de Urgência/Emergência; a Portaria n ${ }^{\circ}$ 2048/GM, de 05 de novembro de 2002, ${ }^{33}$ que trata de Urgência e Emergência; a Resolução do Conselho Federal de Medicina $n^{\circ} 1.638$, de 10 de Julho de $2002,{ }^{50}$ que define prontuário médico e torna obrigatória a criação da Comissão de Revisão de Prontuários nas instituições de 
saúde; a Portaria $\mathrm{n}^{\circ} 2.224 / \mathrm{GM}$, de 5 de dezembro de $2002,{ }^{35}$ que trata da classificação de hospitais; a Portaria $\mathrm{n}^{\circ}$ 1101/GM, de 12 de Junho de $2002^{32}$; a Resolução COFEN n $189 / 2003,{ }^{49}$ que estabelece parâmetros para dimensionamento do quadro de profissionais de Enfermagem nas instituições de saúde ${ }^{48}$; a Resolução Conjunta SS/SMA-1, de 2-5-96, publicada no DOE de 03.05.96, ${ }^{101}$ que trata de Lixo Hospitalar; Indicadores CQH-APM/CREMESP $-1^{\circ}$ Trimestre de $2003^{8}$ para dimensionamento do quadro de profissionais de enfermagem e indicadores de produtividade e qualidade hospitalares.

O Roteiro de Vistoria Técnica Hospitalar versou sobre:

Parte I - Dados Gerais do hospital (Identificação, Classificação, Tipo de Serviço, Abrangência, Organização e Funcionamento, Recursos Humanos, Estatística, Indicadores Hospitalares e Estrutura física/Infra-estrutura);

Parte II - Organização e Atenção ao Paciente (Hotelaria/Unidades de Internação Médico-Cirúrgica, Pediátrica, Obstétrica, Pronto-Socorro, Unidade(s) de Terapia Intensiva(s), Maternidade, Centro Obstétrico, Berçário, Centro Cirúrgico e Recuperação Pós-Anestésica);

Parte III - Apoio Diagnóstico e Terapia (Serviços de Apoio Diagnóstico e Terapia básicos e acessórios);

Parte IV - Apoio Técnico e Administrativo (Farmácia, Serviço de Nutrição e Dietética, Lavanderia, Almoxarifado, Manutenção, Segurança, Serviço de Arquivo Médico e Estatística e Central de Esterilização de Materiais).

Os itens de verificação apontam as fontes nas quais os vistoriadores podem procurar a documentação e ou observação que comprovem o cumprimento do padrão exigido, segundo os critérios técnicos. 
Após sua elaboração, o instrumento foi testado antes da aplicação definitiva em quatro hospitais, escolhidos aleatoriamente, com características semelhantes aos hospitais da amostra. Realizado o pré-teste, verificaram-se as falhas e procedeu-se à necessária reformulação.

No exame de qualificação, esse roteiro foi apresentado e a banca examinadora sugeriu modificações quanto ao agrupamento das áreas que compõem cada parte do instrumento.

Posteriormente, o roteiro foi programado para uso em computador de mão (Pocket PC) para agilizar a coleta de informações.

\subsection{Pesquisa de Campo}

O período da pesquisa de campo estendeu-se de dezembro de 2002 a dezembro de 2003.

As vistorias técnicas hospitalares foram realizadas por dois profissionais treinados para a aplicação do instrumento, um médico e uma enfermeira (própria autora) com o seguinte perfil: currículo qualificado em área específica, experiência profissional como gestores de serviços e sistema de saúde, compromisso de sigilo e ética profissional.

$\mathrm{Na}$ fase preparatória, os hospitais que haviam preenchido o Termo de Consentimento foram comunicados a respeito da Vistoria Técnica Hospitalar por contato telefônico e correio eletrônico (e-mail) e definiram a data e horário para a sua realização. Foi solicitado aos Diretores Técnicos que designassem dois profissionais para acompanharem a vistoria técnica e que preparassem a seguinte documentação: cópia xerográfica do Alvará da Vigilância Sanitária, CRM Institucional, CRM do 
Diretor Técnico; que deixassem disponibilizados: Regimento e Regulamento do Hospital, Normas, Rotinas e Manuais, os Livros de Atas das Comissões de Ética Médica, Comissão de Controle de Infecção Hospitalar (CCIH), Revisão de Prontuários e Óbitos, Comissão Interna de Prevenção de Acidentes (CIPA) e outras que estivessem constituídas.

$\mathrm{Na}$ fase de execução, os vistoriadores compareceram aos hospitais e, mediante a utilização do Roteiro de Vistoria Técnica Hospitalar, acompanhados pelos profissionais designados, vistoriaram todas as áreas do hospital, observando o cumprimento ou não dos itens de verificação, previamente definidos.

A duração da vistoria foi variável: para hospitais de pequeno porte, em média 4 horas; para hospitais de médio porte, em média 6 horas; para os de grande porte, em média 8 horas e para o especial, 16 horas.

Após a realização das vistorias, o computador de mão era acoplado ao computador móvel (laptop) e as informações nele contidas eram transferidas ao servidor, gerando um relatório técnico e pontuando cada área vistoriada, emitindo a classificação por área e total, obtida da média ponderada do percentual de todas as áreas vistoriadas.

Posteriormente, os vistoriadores elaboraram o parecer técnico relativo aos problemas identificados e às propostas de mudanças necessárias ao cumprimento do padrão técnico preestabelecido. Foi possível comparar os hospitais entre seus pares, identificando-se o grau de proximidade/distanciamento dos padrões predefinidos.

A comparação de hospitais será feita entre os de mesmo porte, com características semelhantes. 


\subsection{Descrição do Método de Análise Qualitativa e Quantitativa}

Os dados foram organizados segundo aspectos qualitativos e quantitativos. Os dados qualitativos compreenderam variáveis relativas aos Dados Gerais, à Organização e Atenção ao Paciente, aos Serviços de Apoio Diagnóstico e Terapia e aos Serviços de Apoio Técnico e Administrativo, já descritos anteriormente.

O modelo de pontuação utilizado foi aplicado atribuindo-se valor às variáveis qualitativas relacionadas no Roteiro de Vistoria Técnica Hospitalar, específicas de cada área vistoriada, observando se o hospital cumpre ou não cumpre, atinge ou não atinge o padrão exigido. Para itens obrigatórios ou imprescindíveis foram atribuídos 3 pontos; aos necessários, 2 pontos e aos recomendáveis, 1 ponto. Cada área obteve um número total de pontos que, cumpridos na totalidade, atingiu os $100 \%$. Para a classificação final, calculou-se a média ponderada do percentual de pontos atingidos em cada área. O modelo de pontuação encontra-se no Anexo 3 e o quadro resumo de pontuação está descrito a seguir. 
Tabela 5 - Resumo de pontuação atribuída às áreas hospitalares vistoriadas.

\begin{tabular}{lcc}
\hline Item avaliado & Total de pontos & Pontos obtidos \% Pontos atingidos \\
\hline Organização e funcionamento & 44 \\
Estrutura Física e Infra Estrutura & 45 \\
Hotelaria & 88 \\
Pronto Socorro & 46 \\
UTI Geral & 45 \\
UTI Cardiológica & 45 \\
UTI Pediátrica & 45 \\
UTI Neonatal & 45 \\
Maternidade & 43 \\
Berçário & 29 \\
Centro-Cirúrgico & 44 \\
Recuperação Pós Anestésica & 18 \\
SADT Básico & 29 \\
SADT Acessório & 44 \\
Serviços de Apoio & 113 \\
\hline Total (Média ponderada) &
\end{tabular}

Em relação aos dados quantitativos, para análise do dimensionamento dos Recursos Humanos, utilizaram-se como parâmetros os Indicadores de Produtividade estudados por BITTAR (1993 e 1994) ${ }^{116,117}$, os Indicadores do Programa CQH-APM - CREMESP-1 ${ }^{\circ}$ Trimestre $2003^{8}$, a Resolução COFEN 189/2003 ${ }^{49}$ sobre Parâmetros de Dimensionamento de Tabela de Pessoal de Enfermagem.

Relação Servidores/Leito

Hospitais Privados Secundários (BITTAR, 1993)

○ Mínimo 5,10

○ Máximo 5,20

- Mediana 5,15 
Hospitais Privados Terciários (BITTAR, 1993)

- Mínimo 6,60

○ Máximo 9,00

- Mediana 6,95

Hospitais de Ensino (BITTAR, 1994)

○ Mínimo 5,40

○ Máximo 9,40

- Mediana 7,00

Proporção de Funcionários de Enfermagem/leito (APM/CREMESP-CQH $1^{\circ}$ Trimestre 2003)

Hospitais Secundários

- 1,63 ou mais - Adequado

- Menor que 1,63 - Inadequado

Hospitais Terciários e Quaternários

○ 2,68 ou mais - Adequado

○ Menor que 2,68 - Inadequado

Enfermeiros/Leito (Resolução COFEN nº189/2003)

Hospitais Secundários

$\circ \quad 0,27$ ou mais - Adequado

○ Menor que 0,27 - Inadequado

Hospitais Terciários e Quaternários

○ 0,33 ou mais - Adequado

- Menor que 0,33 - Inadequado 
Técnicos e Auxiliares de Enfermagem/Leito (Resolução COFEN nº 189/2003)

Hospitais Secundários

- 1,36 ou mais - Adequado

- Menor que 1,36 - Inadequado

Hospitais Terciários e Quaternários

- 2,53 ou mais - Adequado

- Menor que 2,53 - Inadequado

Para análise dos Indicadores Hospitalares de Qualidade foram utilizados como parâmetros os do Programa CQH-APM/CREMESP - $1^{\circ}$ Trimestre de 2003.

Indicadores Hospitalares de Qualidade

- Taxa de Mortalidade Institucional:

- Mínimo-0\%;

- Máximo - 13,11\%;

- $\quad$ Mediana -1,95\%;

- Taxa de Mortalidade Operatória:

- Mínimo-0\%;

- $\quad$ Máximo - 1,42\%;

- $\quad$ Mediana-0,15\%;

- Taxa de Cesárea:

- $\quad$ Mínimo - 23,90\%;

- Máximo - 100\%;

- $\quad$ Mediana-79,46\%; 
- Taxa de Infecção Hospitalar:

- Mínimo - 0\%;

- Máximo - 7,82\%;

- Mediana-2,35\%;

Para análise dos indicadores hospitalares de produtividade foram utilizados os Indicadores do Programa CQH-APM/CREMESP-1 $1^{\circ}$ Trimestre de 2003 e os dados obtidos por BITTAR ${ }^{116}$ em cinco hospitais de ensino (1994), quatro hospitais privados terciários, dois hospitais privados secundários e dois hospitais públicos secundários (agosto de 1993), ${ }^{117,118}$ relacionados na Tabela 6.

Indicadores Hospitalares de Produtividade (APM/CREMESP-CQH - $1^{\circ}$ Trimestre de 2003):

Taxa de Ocupação:

- Mínimo - 22,97\%;

- Máximo - 98,22\%

- $\quad$ Mediana-64,10\%;

Para a análise da Média de Permanência e Giro de Rotatividade foram utilizados os dados da Tabela 6. 
Tabela 6. Comparação entre indicadores hospitalares, hospitais de ensino (1994), hospitais privados terciários e secundários e hospitais públicos secundários (agosto de 1993), Estado de São Paulo, Brasil.

\begin{tabular}{lccc}
\hline Tipo de hospital e no de hospitais analisados & Mínimo & Máximo & Mediana \\
\hline Hospital Público Secundário (2) & & & \\
Média de Permanência (dias) & 5,70 & 6,80 & 6,25 \\
Índice de Renovação (pacientes/mês) & 3,70 & 3,90 & 3,80 \\
Número de Funcionários por leito & 7,10 & 15,60 & 11,35 \\
Hospital Privado Secundário (2) & & & \\
Média de Permanência (dias) & 3,50 & 5,70 & 4,60 \\
Índice de Renovação (pacientes/mês) & 4,60 & 6,68 & 5,60 \\
Número de Funcionários por leito & 5,10 & 5,20 & 5,15 \\
Hospital Privado Terciário (4) & & & \\
Média de Permanência (dias) & 3,10 & 5,60 & 4,60 \\
Índice de Renovação (pacientes/mês) & 4,40 & 6,60 & 5,10 \\
Número de Funcionários por leito & 6,60 & 9,00 & 6,95 \\
Hospital de Ensino (5) & & & \\
Média de Permanência (dias) & 3,90 & 8,30 & 7,00 \\
Índice de Renovação (pacientes/mês) & 2,80 & 5,50 & 3,70 \\
Número de Funcionários por leito & 5,40 & 9,40 & 7,00 \\
\hline
\end{tabular}

Fonte:BITTAR, OJNV- agosto de 1993 e 1994.

Para a classificação dos Hospitais vistoriados por nível de complexidade utilizaram-se os itens de avaliação da Portaria $n^{\circ} 2224 / M S,{ }^{35}$ acrescidos dos itens organização e funcionamento, recursos humanos, estatística e indicadores hospitalares, estrutura física e infra-estrutura, Hotelaria/Unidades de Internação, Pronto-Socorro, UTIs, Maternidade, Centro Obstétrico, Berçário, Centro Cirúrgico, RPA, Serviços de Apoio Diagnóstico e Terapia: básicos e acessórios e Serviços de Apoio Técnico e Administrativo: Farmácia, Serviço de Nutrição e Dietética, Lavanderia, Almoxarifado, Manutenção, Segurança, SAME e Central de Esterilização de Materiais, construindo-se a seguinte categorização: 
Grupo 0

Hospitais Gerais ou Especializados, com nível de complexidade primário, cuja média percentual de pontos obtidos foi inferior a $50 \%$.

Grupo I

Hospitais Gerais ou Especializados, com nível de complexidade primário, cuja média percentual de pontos obtidos foi superior a $50,0 \%$.

Grupo II

Hospitais Gerais ou Especializados, com nível de complexidade secundário, com até 04 procedimentos de alta complexidade conforme Portaria $\mathrm{n}^{\circ} 2224 / \mathrm{GM}$, de 05 de dezembro de 2002, do Ministério da $\mathrm{Saúde}^{35}$, cuja média percentual de pontos obtidos foi superior a $63,0 \%$.

Grupo III

Hospitais Gerais ou Especializados, com nível de complexidade terciário na assistência, incluindo de 05 a 08 procedimentos de alta complexidade conforme Portaria $n^{\circ}$ 2224/GM, de 05 de dezembro de 2002, do Ministério da Saúde, ${ }^{35}$ e cuja média percentual de pontos obtidos foi superior a $75,0 \%$.

\section{Grupo IV}

Hospitais Gerais e Especializados, com nível de complexidade terciário e quaternário na assistência, incluindo mais de 08 procedimentos de alta complexidade conforme Portaria $n^{\circ}$ 2224/GM, de 05 de dezembro de 2002, do Ministério da Saúde, ${ }^{35}$ e cuja média percentual de pontos obtidos foi superior a $89,0 \%$.

Foram considerados procedimentos de alta complexidade: Serviços/Centros de Alta Complexidade em Assistência Cardiovascular (não foram computados Hospitais Gerais com Serviço de Implante de Marcapasso Permanente), Tratamento 
das Lesões Lábio Palatais e Implante Coclear, Neurocirurgia, Traumato-Ortopedia, Tratamento Cirúrgico da Epilepsia, Assistência a Queimados, Oncologia, Cirurgia Bariátrica e Transplantes (considerar como 1 sistema o cadastro para realização de transplante de cada tipo de órgão). ${ }^{35}$ 


\section{RESULTADOS E DISCUSSÃO}

No Brasil, temos utilizado instrumentos de avaliação de hospitais em função das necessidades organizacionais do Sistema de Saúde, do conhecimento técnicocientífico apreendido e das exigências cada vez maiores dos compradores e usuários de serviços de saúde.

Esses instrumentos, elaborados para a classificação de hospitais, serviram inicialmente para a avaliação dos serviços visando ao pagamento diferenciado das internações hospitalares pelos Institutos de Aposentadoria e Pensão, Instituto Nacional de Previdência Social (INPS) e Instituto Nacional de Assistência Médica da Previdência Social (INAMPS).

Embora o objetivo inicial tenha sido esse pagamento diferenciado, os itens de avaliação neles contidos possibilitaram, também, realizar:

- o primeiro censo hospitalar com informações gerais sobre os hospitais;

- a avaliação de planta física, equipamentos e organização dos hospitais;

- a verificação das condições técnicas, administrativas, éticas, qualidade dos serviços de natureza hoteleira e preço final do produto;

- o cadastro nacional dos serviços hospitalares;

- a análise da distribuição dos hospitais e respectivos leitos, pelas regiões brasileiras;

- classificar por portes e complexidade as instituições hospitalares.

No momento atual, os gestores do Setor Público de Saúde, de Estados e Municípios em gestão plena de sistema são os responsáveis pela habilitação, credenciamento, avaliação, controle, auditoria e pagamento de prestadores de serviços hospitalares públicos, filantrópicos e privados. 
Em relação aos gestores do Setor Privado, é a partir de 1998, com a Lei ${ }^{\circ}$ 9656, que a Agência Nacional de Saúde Suplementar passa a exigir que as Operadoras de Planos de Saúde avaliem os serviços que compõem sua rede de prestadores.

Na década de 90, sob influência das experiências americanas de Acreditação Hospitalar, observamos o surgimento, no Brasil, de iniciativas de avaliação da qualidade; posteriormente, sob orientação da Organização Panamericana de Saúde, surgem métodos e instrumentos criados para avaliação da qualidade hospitalar. Esses métodos e instrumentos serviram de subsídios para os programas de qualidade que vêm sendo implementados no Brasil.

Os instrumentos de avaliação de qualidade e os desenvolvidos para a gestão do SUS são utilizados pelos gestores, dependendo do tipo de avaliação a ser realizada e dos objetivos que se pretende atingir.

Para a gestão hospitalar, os instrumentos mais utilizados são os de qualidade e para a gestão do Sistema de Saúde, os de gestão do SUS.

Quando pensamos na criação de um instrumento de avaliação denominado Vistoria Técnica Hospitalar, buscamos agregar em um único roteiro as normas técnicas exigidas pelos órgãos competentes, relacionadas aos serviços hospitalares, organizando-o com aspectos qualitativos e quantitativos dos hospitais.

$\mathrm{O}$ instrumento foi desenvolvido em meio magnético para facilitar a coleta das informações, agilizar a elaboração dos relatórios técnicos e dar suporte aos gestores no exercício de suas funções de planejamento, avaliação e controle, possibilitando o direcionamento de recursos aos serviços hospitalares de acordo com suas 
necessidades, bem como subsidiar a área de avaliação, controle e auditoria frente aos problemas detectados quando da sua aplicação.

Pensou-se, também, na criação de um banco de dados que, dependendo da necessidade dos serviços e/ou dos gestores, poderá ser acessado para subsidiar o processo de tomada de decisão.

O teste do Instrumento Vistoria Técnica Hospitalar para sua validação ocorreu no período de dezembro de 2002 a dezembro de 2003, numa amostra intencional de hospitais do Estado de São Paulo.

Os resultados do teste serão apresentados em tabelas que contêm o resumo dos itens de verificação elaborados em função das normas técnicas e utilizados como parâmetros para as vistorias técnicas hospitalares.

A Tabela 07 apresenta a caracterização dos hospitais selecionados intencionalmente de acordo com sua personalidade jurídica, tipo segundo a natureza da assistência, número de leitos para identificar a capacidade ou lotação e área de abrangência.

Tabela 7 - Caracterização dos Hospitais do Estado de São Paulo, selecionados intencionalmente, 2002 e 2003.

\begin{tabular}{cccccc}
\hline Hospital & Personalidade Jurídica & Tipo & $\mathbf{N}^{\circ}$ de leitos & Lotação & Abrangência \\
\hline A & Fundação/Público & Geral & 700 & Especial & Estadual/Regional \\
B & Privado sem fins lucrativos & Geral & 220 & Grande & Regional \\
C & Privado sem fins lucrativos & Geral & 201 & Grande & Regional \\
D & Privado & Geral & 95 & Médio & Regional \\
E & Privado & Geral & 70 & Médio & Regional \\
F & Privado & Geral & 130 & Médio & Regional \\
G & Privado & Geral & 48 & Pequeno & Regional \\
H & Privado & Geral & 38 & Pequeno & Regional \\
I & Privado & Geral & 30 & Pequeno & Regional \\
\hline
\end{tabular}

Fonte: Diretoria dos Hospitais, 2002 e 2003. 
Hospital A

- Hospital geral filantrópico (Fundação), Universitário, com 700 leitos, sendo 60 para convênios, com nível de atendimento terciário e quaternário. Realiza transplantes: cardíaco, renal, medula óssea, fígado, ossos e córnea.

- Estrutura fisica: vertical, planejada, com sinalização adequada e em boas condições de higiene e limpeza, iluminação adequada. Com pronto-socorro geral, UTI geral, Cardiológica, Adulto, Pediátrica e Neonatal, Centro Cirúrgico com 21 salas, RPA, Centro Obstétrico, Maternidade, Hemodinâmica, Hemodiálise, Hemocentro, Unidades de Internação.

- Estrutura básica: 03 geradores que dão suporte a todas as áreas críticas, cabine primária de força, central de gases, sistema de prevenção de incêndios com hidrantes e extintores, ar condicionado central, 05 poços artesianos, 12 elevadores, pára-raios e posto de abastecimento de diesel.

- Hotelaria: suítes e apartamentos confortáveis com TV, telefone, frigobar, ar condicionado central, com 01 bico de oxigênio, 01 de ar comprimido e 01 de vácuo. Suítes e apartamentos com pias para lavagem das mãos. Sanitários: portas abrindo para dentro, contrariando a RDC $n^{\circ} 50 / 02$, com box e barras de apoio. Enfermarias com o mesmo padrão, porém sem telefone. Enfermarias SUS simples.

- Serviços de apoio: farmácia com 03 farmacêuticos, dispensação por sistema individualizado. SND com 04 nutricionistas. Serviço de Limpeza terceirizado para os usuários de convênios. Lavanderia com fluxos incorretos, Serviços de Segurança, Manutenção e Almoxarifado próprios e organizados. Central de 
Esterilização de Materiais em área pequena para dar suporte às necessidades, em fase inicial de reforma e ampliação.

- SADT: Anatomia Patológica, Angiografia Digital, Audiometria, Cintilografia, ECG, EEG, Eletromiografia, Endoscopia, Ergometria, Fisioterapia, Hemodiálise, Hemodinâmica, Hemoterapia, Holter, Litotripsia, Mamografia, Patologia Clínica, Quimioterapia, Ressonância Magnética, RX Simples e Contrastados, Tomografia e USG.

- Organização e funcionamento: Regulamento Interno, Normas, Rotinas, Setor de Recrutamento e Seleção de Pessoal, Programas de Educação Continuada, Indicadores Hospitalares, Relatórios Gerenciais, Informatização em rede, exceto o prontuário eletrônico, Serviço Social, Psicologia Hospitalar e Setor de Saúde Ocupacional. Todas as Comissões existentes e funcionantes.

- Recursos Humanos

- Servidores/leito: 3,93

○ Funcionários da Enfermagem/Total de Leitos: 1,55

- Enfermeiros/leito: 0,19

- Técnicos e Auxiliares de Enfermagem/leito: 1,32

- Atendentes/leito: 0,03

- Indicadores de Qualidade

- Taxa de Mortalidade Institucional: $0,46 \%$

- Taxa de Cesárea: $89,33 \%$

- Indicadores de Produtividade

- Taxa de Ocupação: $72,36 \%$

- Taxa de Permanência: 3,0 dias 
- Giro de Rotatividade: 7,33 pacientes/mês

\section{Hospital B}

- Hospital: geral privado sem fins lucrativos, com 220 leitos operacionais, com nivel de atendimento terciário.

- Estrutura física: vertical, adaptada, com sinalização adequada, sem estacionamento, em boas condições de higiene e limpeza. Pronto-socorro geral, Maternidade, UTI geral com isolamento sem antecâmara, UTI cardiológica e UTI neonatal sem isolamento. Centro Cirúrgico com 16 salas, 07 operacionais. RPA em área física inadequada, com recursos humanos e materiais inadequados.

- Estrutura básica: gerador com suporte às áreas críticas, 02 cabines primárias de força, central de gases, sistema de prevenção de incêndios com extintores e hidrantes, pára-raios e 03 elevadores.

- Hotelaria: apartamentos que podem ser transformados em enfermarias de 02 leitos, confortáveis, com TV, telefone, ar condicionado, cadeira de descanso, 01 bico de oxigênio, 01 de ar comprimido e 01 de vácuo. Sanitários: porta abrindo para fora, box, sem barras/apoios, contrariando a $\mathrm{RDC} \mathrm{n}^{\circ} 50 / 02.04$ apartamentos com frigobar. Posto de enfermagem central com área de prescrição. Enfermarias SUS simples.

- Serviços de apoio: farmácia com 02 farmacêuticos, dispensação por sistema individualizado e padronização de medicamentos. SND com 02 nutricionistas, cardápio afixado semanalmente. Serviço de limpeza próprio com normas e rotinas e participação da $\mathrm{CCIH}$. Manutenção própria. 
Lavanderia em área física inadequada, com fluxo cruzado e equipamentos inadequados. Central de Esterilização de Materiais em reforma, área física inadequada.

- SADT: Audiometria, Cintilografia, EEG, ECG, Endoscopia, Fisioterapia, Angiografia Digital/Hemodinâmica, Holter, Quimioterapia, Ecografia, Ergometria, Litotripsia, Patologia Clínica, Mamografia, Ressonância Magnética, RX Simples e Contrastado, Tomografia e USG.

- Organização e funcionamento: Normas, Rotinas e Manuais, Regimento/Regulamento Interno, Recrutamento e Seleção de Pessoal, Educação Continuada, Indicadores Hospitalares, Relatórios Gerenciais, Informatização em rede exceto prontuário eletrônico, Saúde Ocupacional. Comissões de Ética Médica, CCIH, Revisão de Prontuários e de Óbitos, CIPA, Ensino, Residência Médica, Farmácia e Medicamentos e Controle de Gestão de Qualidade.

- Recursos Humanos:

○ Servidores/leito: 5,17

- Proporção de funcionários de enfermagem/leito: 1,8

- Enfermeiros/leito: 0,13

- Técnicos e Auxiliares de Enfermagem/leito: 1,65

- Atendentes/leito: 0,02

- Indicadores de Qualidade:

- Taxa de Mortalidade Institucional: $3,83 \%$

- Taxa de Cesárea: $30,23 \%$

○ Taxa de Infecção Hospitalar: 2,7\% 
- Indicadores de Produtividade:

○ Taxa de Ocupação: $64,9 \%$

- Taxa de permanência: 4,46 dias

- Giro de Rotatividade: 4,42 pacientes/mês

\section{Hospital C}

- Hospital geral privado sem fins lucrativos, com 201 leitos operacionais, 26 leitos para convênios, com nível de atendimento terciário.

- Estrutura física: vertical, adaptada, com sinalização adequada e em boas condições de higiene e limpeza. Pronto-socorro geral, UTI geral, UTI Neurológica, Centro Cirúrgico com 07 salas cirúrgicas, RPA com 06 leitos e recursos adequados e Unidades de Internação.

- Estrutura básica: 02 geradores automáticos para suporte às áreas críticas, cabine primária de força, central de gases, sistema de prevenção de incêndios com extintores, pára-raios e 04 elevadores.

- Hotelaria: não há recepção diferenciada para pacientes de convênios. Apartamentos e ou enfermarias de 02 leitos confortáveis com TV, telefone, frigobar, com 02 bicos de oxigênio e 02 de ar comprimido. Sanitários: porta de correr, sem barras/apoios, contrariando a $\mathrm{RDC} \mathrm{n}^{\circ}$ 50/02. Sofá-cama para acompanhantes, cadeira de descanso. Enfermaria SUS simples.

- Serviços de apoio: farmácia com 02 farmacêuticos, dispensação por dose unitária, com padronização dos medicamentos. SND com 01 nutricionista e cardápio afixado semanalmente. Serviço de limpeza com normas e rotinas e participação da CCIH. Manutenção própria. Lavanderia necessitando trocar 
piso, com fluxos corretos, equipamentos em regular estado de conservação.

Central de Esterilização de Materiais com fluxo cruzado

- SADT: Ecografia, Endoscopia, Mamografia, ECG, Quimioterapia, Radioterapia. Terceirizados: Anatomia Patológica, Patologia Clínica, RX Simples e Contrastado, USG, Hemodinâmica, Ergometria, Holter, MAPA, Tomografia.

- Organização e funcionamento: Regimento Interno, Regulamento, Normas, Rotinas, Setor de Recrutamento e Seleção de Pessoal, Indicadores Hospitalares, Relatórios Gerenciais, Informatização em Rede exceto prontuário eletrônico, Serviço Social, Psicologia Hospitalar e Setor de Saúde Ocupacional. Comissões de Ética Médica, CCIH, Revisão de Prontuários e Óbitos, Ensino e Pesquisa, Residência Médica, CIPA, Farmácia e Medicamentos.

- Recursos Humanos

○ Servidores/leito: 5,28

○ Proporção funcionários de enfermagem/ leito: 2,18

○ Enfermeiros/leito: 0,20

- Técnicos e Auxiliares de Enfermagem/leito: 1,97

- Atendentes/leito: 0,004

Observamos a necessidade de reduzir o número de auxiliares de enfermagem, aumentando-se o número dos demais membros que compõem a equipe de enfermagem a fim de melhorar a assistência prestada ao paciente.

- Indicadores de Qualidade

- Taxa de Mortalidade Institucional: 5,5\% 
○ Taxa de Cesáreas: $43,07 \%$

- Taxa de Mortalidade Operatória: 2,6\%

○ Taxa de Infecção Hospitalar: 6,2\%

Observação: A Maternidade, Berçário e UTI neonatal foram transferidos para outro Hospital em outubro de 2003.

- Indicadores de Produtividade

○ Taxa de Ocupação: $74,8 \%$

○ Taxa de Permanência: 5,1 dias

- Giro de Rotatividade: 5,1 pacientes/mês

Hospital D

- Hospital geral privado com 95 leitos operacionais, com nível de atendimento secundário.

- Estrutura fisica: vertical, adaptada, com sinalização adequada e em boas condições de higiene e limpeza. Pronto-atendimento geral com sala de urgência montada, necessitando de respirador adequado. Maternidade, Berçário, UTI geral, Pediátrica e Neonatal, Centro Cirúrgico com 07 salas, RPA com 10 leitos com recursos adequados e Unidades de Internação.

- Estrutura básica: gerador para suporte às áreas críticas, cabine primária de força, central de gases, sistema de prevenção de incêndios com extintores e hidrantes, pára-raios e 02 elevadores.

- Hotelaria: apartamentos confortáveis com TV, telefone, frigobar, ar condicionado, com 01 bico de oxigênio, 01 de ar comprimido e 01 de vácuo. Sanitários: porta abrindo para fora, box/cortina, sem barras/apoios, 
contrariando a RDC $\mathrm{n}^{\circ}$ 50/02. Enfermarias confortáveis com TV, telefone e ventilador, com 01 bico de oxigênio e 01 de vácuo. Sanitários: porta abrindo para fora, box/cortina, sem barras/apoios, contrariando a $R D C n^{0} 50 / 02$.

- Serviços de apoio: farmácia com 01 farmacêutico, dispensação por sistema individualizado, com padronização dos medicamentos. SND com 01 nutricionista e cardápio afixado semanalmente. Serviço de limpeza com normas e rotinas e participação da CCIH. Manutenção Própria. Lavanderia terceirizada. Manutenção própria. Central de Esterilização de Materiais adequada.

- SADT: Angiografia Digital, Ecocardiografia, ECG, Hemoterapia, Quimioterapia, Mamografia, Patologia Clínica, Radiologia, Tomografia e USG.

- Organização e funcionamento: Regulamento Interno, Normas, Rotinas, Setor de Recrutamento e Seleção de Pessoal, Indicadores Hospitalares, Relatórios Gerenciais, Informatização em Rede (exceto o prontuário eletrônico), Setor de Saúde Ocupacional, Serviço Social. Comissões de Ética Médica, CCIH, Ensino e Pesquisa, CIPA, Farmácia e Medicamentos, Controle e Gestão de Qualidade, Marketing, Informática e Plano Diretor. Hospital acreditado pela ONA.

- Recursos Humanos

o Servidores/leito: 4,10

○ Proporção funcionários de enfermagem/ leito: 2,27

o Enfermeiros/leito: 0,25

○ Técnicos e Auxiliares de Enfermagem/leito: 2,02 
- Indicadores de Qualidade

o Taxa de Mortalidade Institucional: $0,9 \%$

o Taxa de Cesáreas: $89 \%$

o Taxa de Infecção Hospitalar: 2,96\%

- Indicadores de Produtividade

O Taxa de Ocupação: $83,18 \%$

o Taxa de Permanência: 2,76 dias

o Giro de Rotatividade: 6,44 pacientes/mês

\section{Hospital E}

- Hospital geral privado com 70 leitos operacionais, com nível de atendimento secundário.

- Estrutura física: vertical, adaptada (2 pavimentos), com sinalização adequada, estacionamento, em boas condições de higiene e limpeza. Pronto-atendimento geral, Maternidade, Berçário, UTI Geral, Centro Cirúrgico com 07 salas cirúrgicas, RPA com 07 leitos e recursos adequados e Unidades de Internação.

- Estrutura básica: gerador para suporte às áreas críticas, cabine primária de força, central de gases, sistema de prevenção de incêndios com extintores e hidrantes, pára-raios e 01 elevador.

- Hotelaria: apartamentos com cama elétrica, campainha viva-voz, TV, ar condicionado, telefone e frigobar, 01 bico de oxigênio, 01 de ar comprimido e 01 de vácuo. Sanitários: porta abrindo para fora e com barras/apoios. Enfermarias com TV, telefone e ar condicionado, 01 bico de oxigênio, 01 de 
ar comprimido e 01 de vácuo. Sanitários: porta abrindo para fora e com barras/apoios.

- Serviços de apoio: farmácia com 01 farmacêutico, dispensação por sistema unitário, com padronização dos medicamentos. SND com 01 nutricionista e cardápio afixado semanalmente. Serviço de limpeza próprio com normas e rotinas e participação da $\mathrm{CCIH}$. Lavanderia terceirizada, porém ainda lavando roupas novas, local sem ventilação. Almoxarifado próprio em área adequada. Manutenção própria (operacional) e terceirizada através de engenheiro clínico e técnico para equipamentos e coordenação geral. Central de Esterilização de Materiais adequada.

- SADT: ECG, Hemodiálise (01 máquina), Densitometria Óssea, Ecocardiografia, Patologia Clínica, Radiologia, RX Simples e Contrastado, USG, ECO, Tomografia e Hemoterapia.

- Organização e funcionamento: Regulamento Interno, Normas e Rotinas, Recrutamento e Seleção de Pessoal, Treinamento, Educação Continuada, Indicadores Hospitalares, Relatórios Gerenciais, Informatização em Rede exceto o prontuário eletrônico, Serviço Social e Saúde Ocupacional. Comissões de Ética Médica, $\mathrm{CCIH}$, Revisão de Prontuários, Revisão de Óbitos, CIPA, Farmácia e Medicamentos e Controle e Gestão de Qualidade, visando receber Selo do Programa APM/CREMESP-CQH.

- Recursos Humanos

o Servidores/leito: 3,84

o Proporção funcionários de enfermagem/ leito: 1,86

o Enfermeiros/leito: 0,22 
o Técnicos e Auxiliares de Enfermagem/leito: 1,62

- Indicadores de Qualidade

o Taxa de Mortalidade Institucional: 1,13\%

o Taxa de Mortalidade Operatória: 0,08\%

○ Taxa de Infecção Hospitalar: $1,98 \%$

o Taxa de Cesáreas: $76,40 \%$

- Indicadores de Produtividade

○ Taxa de Ocupação: $59 \%$

o Taxa de Permanência: 2,38 dias

o Giro de Rotatividade: 4,25 pacientes/mês

\section{Hospital F}

- Hospital geral privado com 130 leitos, 112 leitos operacionais, nível de atendimento secundário.

- Estrutura física: vertical, adaptada, com sinalização adequada e em boas condições de higiene e limpeza. Pronto-socorro geral, Maternidade, Berçário, UTI Geral, Pediátrica e Neonatal, Centro Cirúrgico com 06 salas cirúrgicas, RPA com 07 leitos e Unidades de Internação.

- Estrutura básica: gerador automático para suporte às áreas críticas, cabine primária de força, central de gases, sistema de prevenção de incêndios com extintores e hidrantes, pára-raios.

- Hotelaria: suíte: 01 sofá-cama, 01 mesa com 02 cadeiras, 01 bico de ar comprimido e 01 de vácuo. Ante-sala, frigobar, TV e telefone. Sanitário: porta abrindo para dentro, com box, sem barras/apoio. 
- Apartamentos/Enfermarias: com TV, 01 bico de ar comprimido e 01 de vácuo. Sanitário: porta abrindo para dentro, com box, sem barras/apoio. Concentrador portátil de oxigênio (Millenium Respironics) em todas as unidades.

- Serviços de apoio: farmácia com 01 farmacêutico, dispensação por sistema individualizado e unitário, com padronização dos medicamentos. SND com 02 nutricionistas e cardápio afixado semanalmente, em reforma, com área física e fluxos inadequados. Serviço de limpeza terceirizado com normas e rotinas e participação da $\mathrm{CCIH}$. Manutenção própria e terceirizada para equipamenos. Lavanderia em reforma. Central de Esterilização de Materiais adequada.

- SADT: ECG, Endoscopia, Patologia Clínica, Hemoterapia, RX Simples e Contrastado, Ecografia, Ergometria, Holter, Litotripsia.

- Organização e funcionamento: Regulamento Interno, Normas, Rotinas, Setor de Recrutamento e Seleção de Pessoal, Programa de Treinamento, Educação Continuada, Indicadores Hospitalares, Relatórios Gerenciais, Informatização em Rede exceto prontuário eletrônico, Saúde Ocupacional, Serviço Social. Comissões de Ética Médica, CCIH, Revisão de Óbitos, CIPA, Controle e Gestão de Qualidade, visando a acreditação pela ONA.

- Recursos Humanos o Servidores/leito: 4,19

o Proporção funcionários de enfermagem/ leito: 2,20

o Enfermeiros/leito: 0,13

o Técnicos e Auxiliares de Enfermagem/leito: 2,07 
Observamos a necessidade de contratação de mais enfermeiros para alterar a composição da equipe de enfermagem e melhorar a assistência de enfermagem prestada ao paciente.

- Indicadores de Qualidade

○ Taxa de Mortalidade Institucional: $1,6 \%$

○ Taxa de Cesárea: $67,20 \%$

○ Taxa de Infecção Hospitalar: 0,61\%

- Indicadores de Produtividade

○ Taxa de Ocupação: $64,66 \%$

o Taxa de Permanência: 2,63 dias

o Giro de Rotatividade: 2,57 pacientes/mês

Hospital G

- Hospital geral privado, com 48 leitos, 30 leitos operacionais, com nível de atendimento primário.

- Estrutura física: horizontal, adaptada, com sinalização adequada e em boas condições de higiene e limpeza. Pronto-atendimento de adulto e Pediatria, Maternidade, Berçário, Sala erroneamente denominada UTI geral com 02 leitos, Centro Cirúrgico com 02 salas cirúrgicas, sem RPA. Unidades de Internação.

- Estrutura básica: sem gerador para suporte às áreas críticas, cabine primária de força, central de gases, sistema de prevenção de incêndios com extintores, sem pára-raios. 
- Hotelaria: apartamentos confortáveis com TV, telefone, frigobar, ar condicionado, com 01 bico de oxigênio. Sanitários: porta abrindo para dentro, com box, sem barras/apoios, contrariando a $\mathrm{RDC} \mathrm{n}^{\circ} 50 / 02$. Isolamento com 02 apartamentos, com sanitários privativos com portas abrindo para dentro, com box, sem barras/apoio e sala de paramentação comum aos dois apartamentos. Enfermaria com 04 leitos. Para cada 02 leitos, 01 bico de oxigênio. Sanitário: 01 para os 04 leitos, com porta abrindo para dentro, com box, sem barras/apoios contrariando a $\mathrm{RDC} \mathrm{n}^{\circ} 50 / 02$.

- Serviços de apoio: farmácia com 01 farmacêutico, dispensação por sistema convencional, com padronização dos medicamentos. SND sem nutricionista e cardápio afixado semanalmente. Limpeza própria com normas e rotinas, a CCIH não participa da elaboração de normas. Lavanderia própria, com área física e fluxos corretos. Serviço de Manutenção próprio para o hospital e terceirizado para os equipamentos. Sem Serviço de Vigilância. Central de Esterilização de Materiais em área física inadequada com fluxo cruzado.

- SADT: ECG, Mamografia, RX Simples e Contrastado e Tomografia, Endoscopia, Fisioterapia. Patologia Clínica externa e terceirizada.

- Organização e funcionamento: Regulamento Interno, Normas, Rotinas, Indicadores Hospitalares, Relatórios Gerenciais, Informatização em Rede exceto prontuário eletrônico e Saúde Ocupacional. Comissões: de Ética Médica (sem Livro Ata) e CIPA.

- Recursos Humanos

- Servidores/leito: 2,23

- Proporção funcionários de enfermagem/ leito: 0,5 
○ Enfermeiros/leito: 0,03

- Técnicos e Auxiliares de Enfermagem/leito: 0,46

Observamos a necessidade de contratação de mais enfermeiros para alterar a composição da equipe de enfermagem e melhorar a assistência de enfermagem prestada ao paciente.

- Indicadores de Qualidade

○ Taxa de Mortalidade Institucional: $1,01 \%$

○ Taxa de Cesárea: $91 \%$

- Indicadores de Produtividade

○ Taxa de Ocupação: $42,66 \%$

- Taxa de Permanência: 1,83 dias

- Giro de Rotatividade: 6,63 pacientes/mês

Hospital H

- Hospital geral com 38 leitos, com nível de atendimento primário.

- Estrutura física: vertical (3 pavimentos), adaptada, com sinalização adequada e em boas condições de higiene e limpeza. Pronto-Socorro Geral, Maternidade, Berçário de baixo risco, Sala de Sustentação de Vida (erroneamente chamada de Semi-Intensiva), Centro Cirúrgico com 03 salas, sem RPA. Unidades de Internação.

- Estrutura básica: gerador para suporte às áreas críticas, cabine primária de força, central de gases (torpedos), sistema de prevenção de incêndios com extintores, sem pára-raios e sem elevadores. 
- Hotelaria: enfermarias masculina e feminina com divisórias entre os leitos. Sanitário: 03 boxes para banho, 03 boxes com vasos sanitários, TV, Ventilador, 01 bico de oxigênio e 01 de ar comprimido/leito. Pediatria: 01 enfermaria com 03 leitos e 03 berços. 01 bico de oxigênio e 01 de ar comprimido/leito. Utilizam o banheiro coletivo da enfermaria feminina. Copa para preparo de refeições.

Maternidade: 02 enfermarias de 02 leitos com sanitário coletivo. Sanitário: porta abre para dentro, sem barras de apoio. 03 apartamentos com 01 leito, 01 sofá-cama, TV, 01 bico de oxigênio, 01 de ar comprimido. A porta do sanitário abre para dentro, com barra de apoio no chuveiro.

Unidade de Internação Geral: 07 apartamentos com 02 leitos, 01 bico de oxigênio com 02 saídas. TV e Ar condicionado em 06 apartamentos. Telefone em 01 apartamento. Sanitário: porta abrindo para dentro com barras de apoio no chuveiro, sem box.

- Serviços de apoio: farmácia com 01 farmacêutico, dispensação por sistema individualizado, sem padronização dos medicamentos. SND com 01 nutricionista e cardápio afixado mensalmente. Serviço de Limpeza próprio com normas e rotinas e participação da $\mathrm{CCIH}$. Manutenção própria. Lavanderia com fluxos corretos. Central de Esterilização de Materiais em área física inadequada com fluxo cruzado.

- SADT: Hemoterapia, USG, Tomografia em instalação, Endoscopia, RX Simples e Contrastado e Patologia Clínica.

- Organização e funcionamento: Regulamento Interno, Normas, Rotinas, Setor de Recrutamento e Seleção de Pessoal, Programa de Treinamento, 
Indicadores Hospitalares, Relatórios Gerenciais, Informatização parcial, Serviço Social, Psicologia Hospitalar e Saúde Ocupacional. Comissões de Ética Médica, CCIH e CIPA.

- Recursos Humanos

- Servidores/leito: 3,11

○ Proporção funcionários de enfermagem/ leito: 1,32

- Enfermeiros/leito: 0,11

- Técnicos e Auxiliares de Enfermagem/leito: 1,21

- Indicadores de Qualidade

- Taxa de Mortalidade Institucional: 1,07\%

○ Taxa de Cesáreas: $89,72 \%$

○ Taxa de Infecção Hospitalar: $1,37 \%$

- Indicadores de Produtividade

○ Taxa de Ocupação: $41,81 \%$

○ Taxa de Permanência: 2,5 dias

○ Giro de Rotatividade: 5,08 pacientes/mês

\section{Hospital I}

- Hospital Geral privado, com 28 leitos, nível de atendimento primário.

- Estrutura física: vertical, planejada, identificação e sinalização adequadas e em boas condições de higiene e limpeza. Pronto Socorro sem condições de suporte de vida, local erroneamente denominado UTI com 03 leitos em área inadequada, Centro Cirúrgico com 02 salas, sem RPA. Unidades de Internação. 
- Estrutura básica: 01 elevador, gerador manual, cabine primária de força, central de gases, local exclusivo para lixo, pára-raios e reservatório de água.

- Hotelaria: sala de espera com TV e som ambiente, rouparia, expurgo. 09 apartamentos com TV, telefone, ar condicionado, frigobar e secretária eletrônica, com 02 bicos de oxigênio, 01 de ar comprimido e 01 de vácuo. Sanitários: portas abrindo para dentro, sem barras/apoios.

- Serviço de apoio: farmácia com 01 farmacêutico, dispensação por sistema individualizado e em área inadequada. SND com 01 nutricionista, em área inadequada, equipamentos necessários e conservados, cardápio afixado. Serviço de limpeza próprio com normas e rotinas. Manutenção própria. Lavanderia terceirizada. Almoxarifado em área inadequada. Central de Esterilização de Materiais em área física inadequada, com fluxo cruzado.

- SADT: ECG, Fisioterapia, Radiologia, Ultra-sonografia, Endoscopia. Patologia Clínica externa e terceirizada.

- Organização e funcionamento: Normas, Rotinas, Regulamento Interno, Recrutamento e Seleção de Pessoal, Indicadores Hospitalares. Comissões de Ética Médica, CCIH e CIPA.

- Recursos Humanos

- Servidores/leito: 4,4

○ Funcionários de enfermagem/leito: 1,83

- Enfermeiros/leito: 0,26

- Técnicos e Auxiliares de Enfermagem/leito 1,56

- Indicadores de Qualidade:

- Taxa de mortalidade Institucional: $1,47 \%$ 
- Taxa de Mortalidade Operária: 0,07\%

○ Taxa de Cesáreas: $87,84 \%$

○ Taxa de Infecção Hospitalar: $0,35 \%$

- Indicadores de Produtividade:

○ Taxa de ocupação: $29 \%$

- Média de Permanência: 1,04 dias

- Giro de Rotatividade: 7,84 pacientes/mês

Para avaliarmos a organização e funcionamento dos hospitais da amostra: um especial (A), dois grandes (B e C), três médios (D, E e F) e três pequenos ( $G, H$ e I), utilizamos as informações contidas na Tabela 08 , na qual observamos que $100 \%$ dos hospitais da amostra apresentavam Normas, Rotinas e Manuais e Regimento Interno/ Regulamento (A, B, C, D, E, F, G, H, I), instrumentos necessários aos gestores de hospitais de qualquer complexidade e porte; em relação a Recrutamento e Seleção de Pessoal, 88,89\% dos hospitais (A, B, C, D, E, F, H e I) a apresentavam, apenas o Hospital G $(11,11 \%)$ não possuía esta área instalada; quanto a Programas de Treinamento, 77,77\% dos Hospitais (A, B, C, D, E, F e H) apresentavam programas organizados com atividades definidas e não os apresentavam os Hospitais G e I; em relação à Educação continuada, 66,66\% dos Hospitais (A, B, C, D, E e F) definiram responsáveis pela área que coordenavam esta atividade nas instituições, enquanto $\mathrm{G}$, H, I (Hospitais com menos de 50 leitos) não a apresentavam; 100\% dos hospitais apresentavam Indicadores Hospitalares e Relatórios Gerenciais, demonstrando preocupação dos gestores com o desempenho organizacional. Os hospitais A, B, C, 
D, E, F e G $(77,77 \%)$ estavam informatizados, em rede, exceto o prontuário eletrônico, enquanto H e I ainda não haviam priorizado a informatização.

O Serviço Social, órgão responsável por atividades relativas à assistência sócio-econômica aos pacientes e seus familiares em regime de internação ou ambulatorial, ${ }^{97}$ estava instalado em $77,77 \%$ dos hospitais da amostra (A, B, C, D, E, F e H), nos demais G e I $(22,22 \%)$ não havia serviços instalados nem profissionais contratados, ficando esta atribuição a cargo do pessoal de enfermagem ou da área administrativa.

O Serviço de Psicologia Hospitalar, órgão responsável pelas atividades relativas à assistência psicológica aos pacientes e seus familiares em regime de internação e ambulatorial, ${ }^{97}$ estava instalado em $44,44 \%$ dos hospitais da amostra (A, B, C e H), um especial, dois grandes e um pequeno. Nos demais (D, E, F, G e I), representando $55,55 \%$ dos hospitais, as atribuições desta área também ficavam a cargo do serviço de enfermagem.

O Setor de Saúde Ocupacional estava organizado em 100\% dos hospitais estudados (A, B, C, D, E, F, G, H e I), com as Comissões Internas de Prevenção de Acidentes (CIPAs) funcionando regularmente.

A Comissão de Ética Médica exigida pela Resolução CFM nº 1215/85 estava constituida e funcionante em $100 \%$ dos hospitais da amostra (A, B, C, D, E, F, G, H e I); a Comissão de Controle de Infecção Hospitalar exigida pela Portaria MS no $2616 / 98$ estava constituída em $88,89 \%$ dos hospitais (A, B, C, D, E, F, H e I), e não funcionante no Hospital G (11,11\%); a Comissão de Revisão de Prontuários exigida pela Resolução CFM n ${ }^{\circ}$ 1638/02 estava constituída e funcionante em 55,55\% dos hospitais (A, B, C, D e E) e não constituída nos demais (F, G, H e I), representando 
44,44\% da amostra, e a de Revisão de Óbitos estava constituída em 66,66\% dos hospitais (A, B, C, D, E e F) e não constituida nos demais ( $G, H$ e I), representando $33,33 \%$ da amostra.

Outras comissões, como a de Farmácia e Medicamentos, estavam constituídas em 55,55\% dos hospitais (A, B, C, D e E); a de Gestão e Controle da Qualidade, também em $55,55 \%$ dos hospitais da amostra (A, B, D, E e F), que busvavam melhoria da qualidade da assistência prestada ao paciente, sendo que o hospital $\mathrm{E}$ estava investindo esforços para o recebimento do selo do Programa APM/CREMESP-CQH, o hospital D era acreditado pela ONA e o F estava sendo organizado para a acreditação pela ONA. As Comissões de Ensino e Pesquisa e a de Residência Médica estavam presentes em apenas 33,33\% dos hospitas (A, B, C) devido ao fato de estarem eles ligados a Instituições de Ensino, e destes, apenas $11,11 \%$ (A) apresentava Comissão de Pós-Graduação.

Observamos que quanto mais complexo é o hospital, maior é a preocupação com a organização hospitalar. 
Tabela 8 - Organização e funcionamento dos nove hospitais, Estado de São Paulo, 2002 e 2003.

\begin{tabular}{|c|c|c|c|c|c|c|c|c|c|}
\hline Organização e Funcionamento & A & B & $\mathrm{C}$ & $\mathrm{D}$ & $\mathbf{E}$ & $\mathrm{F}$ & $\mathrm{G}$ & $\mathrm{H}$ & I \\
\hline Normas, Rotinas e Manuais & $\mathrm{X}$ & $\mathrm{X}$ & $\mathrm{X}$ & $X$ & $\mathbf{X}$ & $\mathrm{X}$ & $\mathrm{X}$ & $\mathbf{X}$ & $X$ \\
\hline Regimento Interno/Regulamento & $X$ & $\mathrm{X}$ & $\mathrm{X}$ & $\mathrm{X}$ & $\mathrm{X}$ & $\mathrm{X}$ & $\mathrm{X}$ & $\mathrm{X}$ & $\mathrm{X}$ \\
\hline Recrutamento e Seleção de Pessoal & $X$ & $\mathrm{X}$ & $\mathrm{X}$ & $X$ & $X$ & $X$ & $\mathrm{~N}$ & $\mathbf{X}$ & $\mathrm{X}$ \\
\hline Programas de Treinamento & $\mathrm{X}$ & $\mathrm{X}$ & $X$ & $\mathrm{X}$ & $X$ & $\mathrm{X}$ & $\mathrm{N}$ & $\mathrm{X}$ & $\mathrm{N}$ \\
\hline Educação Continuada & $X$ & $\mathrm{X}$ & $\mathrm{X}$ & $\mathrm{X}$ & $X$ & $X$ & $\mathrm{~N}$ & $\mathbf{N}$ & $\mathbf{N}$ \\
\hline Indicadores Hospitalares & $\mathrm{X}$ & $\mathrm{X}$ & $\mathrm{X}$ & $\mathrm{X}$ & $\mathrm{X}$ & $\mathrm{X}$ & $\mathrm{X}$ & $\mathrm{X}$ & $\mathrm{X}$ \\
\hline Relatórios Gerenciais & $\mathrm{X}$ & $\mathrm{X}$ & $\mathrm{X}$ & $X$ & $X$ & $X$ & $X$ & $X$ & $X$ \\
\hline Informatização & $X$ & $\mathrm{X}$ & $\mathrm{X}$ & $\mathrm{X}$ & $\mathrm{X}$ & $\mathrm{X}$ & $\mathrm{X}$ & $\mathrm{N}$ & $\mathrm{N}$ \\
\hline Informatização em rede & $X$ & $\mathrm{X}$ & $\mathrm{X}$ & $\mathrm{X}$ & $X$ & $\mathrm{X}$ & $\mathrm{X}$ & $\mathbf{N}$ & $\mathrm{N}$ \\
\hline Serviço Social & $\mathrm{X}$ & $\mathrm{X}$ & $X$ & $\mathrm{X}$ & $X$ & $\mathrm{X}$ & $\mathrm{N}$ & $X$ & $\mathbf{N}$ \\
\hline Psicologia Hospitalar & $X$ & $\mathrm{X}$ & $X$ & $\mathbf{N}$ & $\mathrm{N}$ & $\mathbf{N}$ & $\mathrm{N}$ & $X$ & $\mathrm{~N}$ \\
\hline Saúde Ocupacional & $\mathrm{X}$ & $X$ & $X$ & $\mathrm{X}$ & $\mathrm{X}$ & $\mathrm{X}$ & $\mathrm{X}$ & $X$ & $X$ \\
\hline Comissão de Ética Médica & $X$ & $X$ & $\mathrm{X}$ & $\mathrm{X}$ & $\mathrm{X}$ & $\mathrm{X}$ & $\mathrm{X}$ & $\mathrm{X}$ & $X$ \\
\hline $\mathrm{CCIH}$ & $X$ & $\mathrm{X}$ & $\mathrm{X}$ & $\mathrm{X}$ & $X$ & $X$ & $\mathrm{~N}$ & $\mathrm{X}$ & $\mathrm{X}$ \\
\hline Comissão Revisão de Prontuários & $\mathbf{X}$ & $X$ & $X$ & $\mathrm{X}$ & $\mathrm{X}$ & $\mathbf{N}$ & $\mathbf{N}$ & $\mathbf{N}$ & $\mathbf{N}$ \\
\hline Comissão Revisão de Óbitos & $\mathrm{X}$ & $\mathrm{X}$ & $\mathrm{X}$ & $\mathrm{X}$ & $\mathrm{X}$ & $\mathrm{X}$ & $\mathbf{N}$ & $\mathbf{N}$ & $\mathbf{N}$ \\
\hline CIPA & $\mathrm{X}$ & $X$ & $\mathrm{X}$ & $\mathbf{X}$ & $X$ & $\mathbf{X}$ & $\mathrm{X}$ & $X$ & $X$ \\
\hline Comissão Farmácia e Medicamentos & $\mathrm{X}$ & $\mathrm{X}$ & $\mathrm{X}$ & $\mathrm{X}$ & $\mathrm{X}$ & $\mathbf{N}$ & $\mathrm{N}$ & $\mathbf{N}$ & $\mathrm{N}$ \\
\hline Controle e Gestão de Qualidade & $X$ & $X$ & $\mathbf{N}$ & $X$ & $X$ & $\mathrm{X}$ & $\mathbf{N}$ & $\mathbf{N}$ & $\mathbf{N}$ \\
\hline Comissão Ensino e Pesquisa & $\mathrm{X}$ & $\mathrm{X}$ & $X$ & $\mathbf{N}$ & $\mathbf{N}$ & $\mathrm{N}$ & $\mathrm{N}$ & $\mathbf{N}$ & $\mathbf{N}$ \\
\hline Comissão Residência Médica & $\mathrm{X}$ & $\mathbf{X}$ & $X$ & $\mathbf{N}$ & $\mathbf{N}$ & $\mathbf{N}$ & $\mathrm{N}$ & $\mathbf{N}$ & $\mathrm{N}$ \\
\hline Comissão de Pós Graduação & $X$ & $\mathbf{N}$ & $\mathbf{N}$ & $\mathbf{N}$ & $\mathbf{N}$ & $\mathbf{N}$ & $\mathbf{N}$ & $\mathbf{N}$ & $\mathrm{N}$ \\
\hline
\end{tabular}

(X) Apresenta (N) Não apresenta 


\section{Indicadores de Produtividade}

Para BITTAR (1996) e HIGASHI (2001), a produtividade global pode ser medida segundo alguns indicadores hospitalares como média de permanência, índice ou giro de rotatividade, taxa de ocupação e relação de funcionários por leito. ${ }^{77}$

Média Permanência (MP) - relação numérica entre o total de pacientes-dia em um determinado período e o total de doentes saídos (altas e óbitos) no mesmo período. $^{20}$

Índice de Renovação ou Giro de Rotatividade - relação entre o número de pacientes saídos (altas e óbitos) durante determinado período e o número de leitos postos à disposição dos pacientes no mesmo período. ${ }^{20}$

Taxa de Ocupação - relação entre o número de pacientes-dia em um determinado período e o número de leitos-dia no mesmo período. ${ }^{20}$

Relação funcionários por leito - relação entre o número de funcionários em um determinado período e o número de leitos em operação no mesmo período. Segundo a Portaria $n^{\circ} 312$, de 02 de maio de 2002, não são considerados leitos hospitalares de internação os leitos de observação, incluindo os leitos de pré-parto e os de recuperação pós-anestésica, os berços de alojamento conjunto, os leitos de berçário para recém-nascidos sadios, as camas destinadas a acompanhantes e funcionários do hospital e os leitos de serviços diagnósticos. Os leitos de tratamento intensivo e semi-intensivo devem ser considerados leitos hospitalares de internação. $^{31}$

A complexidade que envolve o hospital faz com que seja impossivel medir produtividade com um único índice, tornando-se necessária a utilização de um conjunto de indicadores. BROWN, citado por BITTAR, refere que a produção no 
hospital é um agregado de processos independentes, ainda mais complicados quando esta mesma produção ora se utiliza intensivamente de capital, ora do trabalho. No primeiro caso, temos a enorme gama de equipamentos concentrados principalmente nos serviços complementares, e no segundo, o trabalho da enfermagem. ${ }^{16}$

\section{Média de Permanência}

Segundo FÁVERO, citado por BITTAR, a média de permanência (MP) varia com o diagnóstico, idade, sexo, sistema de financiamento e distância do domicílio ao hospital. $^{16}$

Em relação à MP, ZUCCHI e BITTAR (1997), em estudo sobre produtividade em hospitais de ensino no Estado de São Paulo ${ }^{116}$, encontraram valores de MP para hospitais de ensino com variação de 3,90 a 8,30, com mediana de 7,00 dias. A Tabela 09 apresenta o valor encontrado da MP para o hospital A, que foi de 3,00 dias; valor inferior ao observado nos hospitais de ensino por eles estudados.

Em relação aos hospitais $\mathrm{B}$ e $\mathrm{C}$, os valores de $\mathrm{MP}$ encontrados para o Hospital B foi de 4,46 dias e para o C, de 4,97 dias, dentro dos valores encontrados por BITTAR (1993) em estudo realizado em hospitais privados terciários, que apresentaram variação de 3,10 a 5,60, com mediana 4,60 dias.

Encontramos nos Hospitais D, E e F a MP de 2,76, 2,38 e 2,63 dias, respectivamente, que, comparados com dados do estudo de BITTAR para hospitais privados secundários que apresentaram variação de 3,50 a 5,70 e mediana de 4,60 dias, foram inferiores aos encontrados no estudo em hospitais com as mesmas características. 
Encontramos nos Hospitais G, H e I a Média de Permanência de 1,83, 2,5 e 1,04 dias, respectivamente. Como são hospitais de pequeno porte, com baixa complexidade, não encontramos estudos anteriores que servissem de parâmetros para efetuarmos as devidas comparações.

\section{Giro de Rotatividade}

Em relação ao Giro de Rotatividade, BITTAR (1994), em estudo sobre produtividade em hospitais de ensino no Estado de São Paulo, encontrou valores para este tipo de hospital que variaram de 2,80 a 5,50, com mediana de 3,70 pacientes/mês. O valor encontrado do Giro de Rotatividade para o Hospital A foi de 7,00 pacientes/mês; valor superior à maior variação observada em hospitais de ensino estudados por BITTAR.

BITTAR (1993), em estudo sobre produtividade em hospitais privados terciários no Estado e São Paulo, encontrou valores para Giro de Rotatividade com variação de 4,40 a 6,60, com mediana de 5,10 pacientes/mês. O valor encontrado do Giro de Rotatividade para o hospital B foi de 4,42 pacientes/mês e para o C, de 5,10 pacientes/mês; valores que se encontram dentro da faixa de variação observada por BITTAR em estudo de indicadores hospitalares em hospitais com o mesmo perfil.

Encontramos nos Hospitais D, E e F o Giro de Rotatividade de 6,44, de 4,25 e 2,56 pacientes/mês, respectivamente, que comparado com dados do estudo de BITTAR (1994) para hospitais privados secundários cuja variação foi de 4,60 a 6,68, com mediana de 5,60 pacientes/mês, revela que o Hospital D encontrava-se dentro do intervalo de variação, enquanto os valores de $E$ e $F$ foram inferiores aos encontrados por BITTAR em hospitais com o mesmo perfil. 
Encontramos nos Hospitais G, H e I o Giro de Rotatividade de 6,63, 5,08 e 7,84 pacientes/mês. Como referimos anteriormente, não encontramos estudos anteriores para este grupo de hospitais que servissem de parâmetros para efetuarmos as comparações.

\section{Taxa de Ocupação}

Em relação à Taxa de Ocupação, utilizaremos os Indicadores do Programa CQH-APM/CREMESP-1 ${ }^{\circ}$ Trimestre de $2003^{8}$ cuja mediana da taxa de ocupação foi de $64,10 \%$ para compararmos com os resultados obtidos. A mediana encontrada na amostra dos nove hospitais estudados foi de $64,66 \%$, com variação de $29,0 \%$ a $83,77 \%$ (Tabela 9 ).

Tabela 9 - Taxa de Ocupação, Média de Permanência e Giro de Rotatividade dos nove hospitais estudados, Estado de São Paulo, 2002 e 2003.

\begin{tabular}{|c|c|c|c|c|c|c|c|c|c|}
\hline $\begin{array}{l}\text { Indicadores de } \\
\text { Produtividade }\end{array}$ & A & B & $\mathrm{C}$ & $\mathrm{D}$ & $\mathrm{E}$ & $\mathrm{F}$ & G & $\mathrm{H}$ & I \\
\hline $\begin{array}{l}\text { Média de Permanência } \\
\text { (dias) }\end{array}$ & 3,00 & 4,46 & 4,97 & 2,76 & 2,38 & 2,63 & 1,83 & 2,5 & 1,04 \\
\hline $\begin{array}{l}\text { Giro de Rotatividade } \\
\text { do leito/mês }\end{array}$ & 7,3 & 4,42 & 5,1 & 6,44 & 4,25 & 2,56 & 6,63 & 5,08 & 7,84 \\
\hline Taxa de Ocupação/ano & 72,36 & 64,9 & 83,77 & 83,18 & 59,0 & 64,66 & 42,66 & 41,81 & 29,0 \\
\hline
\end{tabular}

Fonte: Pesquisa de Campo, 2002 e 2003.

Para a análise da proporção de recursos humanos, separamos os hospitais em função de sua complexidade.

Encontramos no Hospital A a proporção de 3,93 servidores por leito (incluindo médicos); comparada com dados de BITTAR (1994) para hospitais de 
ensino que apresentaram variação de 5,40 a 9,40 , com mediana de 7,0 servidores por leito, essa proporção foi inferior aos valores encontrados. ${ }^{116}$

Em relação à Equipe de Enfermagem, observamos que a proporção de funcionários de enfermagem/leito do Hospital A foi de 1,55 que, comparada com os parâmetros do Programa CQH $1^{\circ}$ trimestre de 2003, foi inadequada; a proporção de Enfermeiros/leito foi de 0,19; a de Técnicos e Auxiliares de Enfermagem/leito foi de 1,32 que comparadas com os parâmetros da Resolução COFEN n 189/2003, essas proporções foram consideradas inadequadas devido à complexidade do hospital (quaternário/terciário, de ensino, realiza procedimentos de alta complexidade, incluindo transplantes, com serviços de apoio diagnóstico e terapia complexos).

Tabela 10 - Recursos Humanos do Hospital A (Especial), Estado de São Paulo, 2003.

\begin{tabular}{lc}
\hline Proporção de RH & $\mathrm{A}$ \\
\hline Servidores/leito & 3,93 \\
Funcionários de enfermagem/Total de leitos & 1,55 \\
Enfermeiros/leito & 0,19 \\
Técnicos e Auxiliares de Enfermagem/leito & 1,32 \\
\hline
\end{tabular}

Fonte: Pesquisa de Campo, 2003.

Encontramos nos Hospitais B e C a proporção de 5,17 e 5,28 servidores por leito (com médico), respectivamente. BITTAR (1994) reproduz alguns dados sobre a relação funcionários/leito, informando que ela variava em hospitais privados terciários de 6,60 a 9,00 com mediana 6,95 , incluindo médicos. ${ }^{116}$ Observamos que os resultados encontrados foram inferiores aos valores encontrados por BITTAR em hospitais privados terciários. 
Em relação à Equipe de Enfermagem, a proporção de funcionários de enfermagem/leito do Hospital $\mathrm{B}$ foi de 1,18 e a do C, 2,18, que comparadas com os parâmetros do Programa CQH $1^{\circ}$ trimestre de 2003 foram inadequadas; as proporções de Enfermeiros/leito foram de 0,13 no Hospital $\mathrm{B}$ e 0,20 , no C; de Técnicos e Auxiliares de Enfermagem/leito foram de 1,65 no Hospital B e de 1,97 no C; comparadas com os parâmetros da Resolução COFEN n 189/2003, essas proporções foram consideradas inadequadas devido à complexidade do hospital (terciários).

Tabela 11 - Recursos Humanos dos Hospitais B e C (acima de 150 leitos), Estado de São Paulo, 2003.

\begin{tabular}{lcc}
\hline Proporção de RH & B & C \\
\hline Servidores/leito & 5,17 & 5,28 \\
Funcionários de enfermagem/Total de leitos & 1,18 & 2,18 \\
Enfermeiros/leito & 0,13 & 0,20 \\
Técnicos e Auxiliares de Enfermagem/leito & 1,65 & 1,97 \\
\hline Fonte: Fonte: Pesquisa de Campo, 2003.
\end{tabular}

Fonte: Fonte: Pesquisa de Campo, 2003.

Encontramos nos Hospitais D, E e F as proporções de 4,10, 3,84 e 4,19 servidores por leito (incluindo médico), respectivamente, que, comparadas com dados de BITTAR (1994), que encontrou em hospitais privados secundários a variação de 5,10 a 5,20, com mediana de 5,15 servidores por leito, foram inferiores às proporções por ele observadas para este grupo de hospitais.

Em relação à Equipe de Enfermagem, a proporção de funcionários de enfermagem/leito do Hospital D foi de 2,27, a do E foi de 1,86, e a do F, 2,20; que comparadas com os parâmetros do Programa CQH - $1^{\circ}$ trimestre de 2003, foram consideradas adequadas; a proporção de Enfermeiros/leito foi de 0,25 no Hospital D, 
0,22 no Hospital E, e 0,13 no F; de Técnicos e Auxiliares de Enfermagem/leito foi de 2,02 no Hospital D, de 1,62 no E, e de 2,07 no F; que comparadas com os parâmetros da Resolução COFEN n 189/2003 foram consideradas adequadas.

Tabela 12 - Recursos Humanos dos Hospitais D, E e F (de 51 a 150 leitos), Estado de São Paulo, 2002 e 2003.

\begin{tabular}{lccc}
\hline Proporção de RH & D & E & F \\
\hline Servidores/leito & 4,10 & 3,84 & 4,19 \\
Funcionários de enfermagem/Total de leitos & 2,27 & 1,86 & 2,20 \\
Enfermeiros/leito & 0,25 & 0,22 & 0,13 \\
Técnicos e Auxiliares de Enfermagem/leito & 1,10 & 0,84 & 0,41 \\
\hline
\end{tabular}

Fonte: Fonte: Pesquisa de Campo, 2002 e 2003.

Encontramos nos Hospitais G, H e I a proporção de 2,$23 ; 3,10$ e 4,4 servidores/leito (incluindo médico), respectivamente.

Em relação à Equipe de Enfermagem, a proporção de funcionários de enfermagem/leito do Hospital $G$ foi de 0,5 , no Hospital $H$ foi 1,32, e a do Hospital I 1,83; comparadas com os parâmetros do Programa CQH $1^{\circ}$ trimestre de 2003, foram consideradas inadequadas para os Hospitais $\mathrm{G}$ e $\mathrm{H}$ e adequada para o Hospital I; a proporção de Enfermeiros/leito foi de 0,03 no Hospital G, 0,11 no H, e 0,26 no I ; a proporção de Técnicos e Auxiliares de Enfermagem/leito foi de 0,46 no Hospital G, 1,21 no H, e de 1,56 no I; comparadas com os parâmetros da Resolução COFEN n ${ }^{\circ}$ 189/2003 foram consideradas inadequadas para os Hospitais G e H e adequada para o Hospital I. 
Tabela 13 - Recursos Humanos dos Hospitais G, H e I (com menos de 50 leitos), Estado de São Paulo, 2002 e 2003.

\begin{tabular}{lccc}
\hline Proporção de RH & G & H & I \\
\hline Servidores/leito & 2,23 & 3,10 & 4,4 \\
Funcionários de enfermagem/Total de leitos & 0,5 & 1,32 & 1,83 \\
Enfermeiros/leito & 0,03 & 0,11 & 0,26 \\
Técnicos e Auxiliares de Enfermagem/leito & 0,46 & 1,21 & 1,56 \\
\hline
\end{tabular}

Fonte: Fonte: Pesquisa de Campo, 2002 e 2003.

\section{Indicadores de Qualidade}

Taxa de Mortalidade Institucional - relação percentual entre o número de óbitos após $48 \mathrm{~h}$ de internação e o número de saídas (altas e óbitos). ${ }^{20}$

Taxa de Mortalidade Operatória - relação percentual entre o número de óbitos operatórios ocorridos até 10 dias da cirurgia durante determinado período e o número total de atos cirúrgicos no mesmo período. ${ }^{20}$

Taxa de Cesárea - relação percentual entre o número de cesáreas ocorridas durante determinado periodo e o número de partos no mesmo período. ${ }^{20}$

Taxa de Infecção Hospitalar - relação percentual entre o número de infecções atribuíveis ao hospital durante determinado período e o número de saídas (altas e óbitos) no mesmo período. ${ }^{20}$

Para análise dos indicadores hospitalares de qualidade utilizaremos os Indicadores do Programa CQH-APM/CREMESP-1 ${ }^{\circ}$ Trimestre de $2003,{ }^{8}$ referentes à informação de 150 hospitais gerais de pequeno, médio e grande porte, públicos e privados, da capital e interior do Estado de São Paulo, cujas medianas foram: Mortalidade Institucional 1,95\%; Infecção Hospitalar 2,35\%; Taxa de Cesárea $79,46 \%$ e Mortalidade Operatória $0,15 \%$. 
Em relação à Taxa de Mortalidade Institucional, a variação observada na amostra foi de $0,46 \%$ a $5,5 \%$, com mediana de $1,13 \%$, que foi inferior à mediana do Programa CQH-APM/CREMESP-1 ${ }^{\circ}$ Trimestre de $^{2003}$ (1,95\%).

Em relação à Taxa de Mortalidade Operatória, a variação observada na amostra foi de $0,07 \%$ a $2,6 \%$, com mediana de $0,09 \%$, que foi inferior à mediana do Programa CQH-APM/CREMESP-1 ${ }^{\circ}$ Trimestre de $2003(0,15 \%)$.

Em relação à Taxa de Cesárea, a variação observada na amostra foi de $30,23 \%$ a $91,00 \%$, com mediana de $87,28 \%$, que foi superior à mediana do Programa CQH-APM/CREMESP-1 ${ }^{\circ}$ Trimestre de 2003 (79,46\%).

Em relação à Taxa de Infecção Hospitalar, a variação observada na amostra foi de $0,35 \%$ a $6,2 \%$, com mediana de $1,98 \%$, que foi inferior à do Programa CQHAPM/CREMESP-1 ${ }^{\circ}$ Trimestre de 2003 (2,35\%).

Tabela 14 - Indicadores de Qualidade dos nove hospitais estudados, Estado de São Paulo, 2002 e 2003.

\begin{tabular}{lccccccccc}
\hline $\begin{array}{l}\text { Indicadores de } \\
\text { Qualidade }\end{array}$ & A & B & C & D & E & F & G & H & I \\
\hline $\begin{array}{l}\text { Taxa de Mortalidade } \\
\text { Institucional (\%) }\end{array}$ & 0,46 & 3,83 & 5,5 & 0,9 & 1,13 & 1,6 & 1,01 & 1,07 & 1,47 \\
$\begin{array}{l}\text { Taxa de Mortalidade } \\
\text { Operatória (\%) }\end{array}$ & - & - & 2,6 & 0,1 & 0,08 & - & - & - & 0,07 \\
$\begin{array}{l}\text { Taxa de Cesáreas } \\
(\%)\end{array}$ & 89,33 & 30,23 & 43,06 & 89,0 & 76,40 & 67,20 & 91,0 & 89,72 & 87,84 \\
$\begin{array}{l}\text { Taxa de Infecção } \\
\text { Hospitalar (\%) }\end{array}$ & - & 2,7 & 6,2 & 2,96 & 1,98 & 0,61 & - & 1,37 & 0,35 \\
\hline Fonte: Pesquisa de Campo, 2002 e 2003. & & & & & & & & & \\
\hline
\end{tabular}

Em relação à estrutura física e infra-estrutura, observamos na Tabela 15 que o Hospital A (11,11\%) apresenta edificação planejada; os demais: B, C, D, E, F, G, H e I $(88,89 \%)$ apresentam edificações adaptadas. A estrutura vertical está presente em 
$88,89 \%$ dos hospitais (A, B, C, D, E, E, F, H e I) cujos números de pavimentos variaram de 2 a 12; o Hospital G $(11,11 \%)$ apresentava edificação horizontal.

Segundo CARVALHO (2002), o ideal seria a construção de hospitais horizontais, em grandes áreas, com micro-clima adequado para facilitar o tratamento do paciente e o seu contato com a natureza, com humanização do atendimento, porém as variáveis que definem o desenho do projeto são: localização relacionada à disponibilidade de espaço urbano, o custo deste espaço e o valor da obra a ser construída. Segundo engenheiros e arquitetos, o valor da obra é menor na edificação vertical, em alguns itens importantes do projeto, e esse tipo de edificação reduz o tempo de deslocamento dos funcionários que atuam no processo assistencial. ${ }^{46}$

Tabela 15 - Estrutura Física e Infra-Estrutura: Edificação dos nove hospitais estudados, Estado de São Paulo, 2002 e 2003.

\begin{tabular}{lccccccccc}
\hline \multicolumn{1}{c}{ Edificação } & A & B & C & D & E & F & G & H & I \\
\hline Planejada & X & N & N & N & N & N & N & N & N \\
Adaptada & N & X & X & X & X & X & X & X & X \\
Vertical & X & X & X & X & X & X & N & X & X \\
Horizontal & N & N & N & N & N & N & X & N & N \\
Número de Pavimentos & 12 & 03 & 02 & 03 & 02 & 02 & 01 & 03 & 02 \\
\hline
\end{tabular}

Fonte: Pesquisa de Campo, 2002 e 2003.

(X) Apresenta (N) Não apresenta

A Tabela 16 apresenta o resumo da avaliação da estrutura física e infraestrutura dos hospitais da amostra. Nela observamos que $100 \%$ dos hospitais (A, B, C, D, E, E, F, G, H e I) apresentavam identificação adequada, facilitando o acesso ao serviço hospitalar no município; 44,44\% (A, E, G e H) disponibilizavam estacionamento para funcionários e usuários; os demais $55,55 \%$ (B, C, D, F e I) não contavam com estacionamento suficiente, contrariando as normas técnicas para 
edificação de hospitais; em $88,89 \%$ (A, B, C, D, E, F, G e I), foi observada sinalização adequada que permitia a localização dos setores hospitalares pelos funcionários e usuários; $100 \%$ dos hospitais (A, B, C, D, E, E, F, G, H e I) contavam com área específica para manutenção e descarga. Dos oito hospitais com edificação verticalizada, 75\% (A, B, C, D, E e I) apresentavam elevadores em número suficiente para atender as necessidades, $25 \%$ ( $\mathrm{F}$ e $\mathrm{H})$ não apresentavam elevadores em número suficiente.

Em relação ao lixo hospitalar, 100\% (A, B, C, D, E, F, G, H e I) apresentava local próprio para destino do lixo hospitalar, com coleta seletiva do mesmo; $100 \%$ (A, B, C, D, E, F, G, H e I) contavam com Central de Gases Medicinais e atendiam a NBR 12.188; quanto ao Ar Condicionado Central, 88,89\% (B, C, D, E, F, G, H e I) não contavam com este sistema de climatização, $11,11 \%$ (A) o apresentava e atendia as exigências da ABNT/NBR 6401 e NBR 7256; observamos que a maioria dos hospitais optou por sistema individualizado de climatização.

Quanto ao Sistema de Tratamento de Resíduos, $88,89 \%$ (A, B, C, D, E, G, H, e I) não contavam com este sistema contrariando a Resolução RDC n. ${ }^{\circ} 33$, de 25 de fevereiro de 2003 , enquanto $11,11 \%$ (F) oferecia tratamento aos resíduos através de empresa terceirizada. O Sistema de Tratamento de Esgoto não estava implantado em nenhum hospital da amostra; enquanto $100 \%$ apresentava Sistema de Prevenção de Incêndios. Em relação à proteção contra descargas atmosféricas (pára-raios) encontramos $77,77 \%$ dos hospitais (A, B, C, D, E, F e I) com proteção instalada e $22,22 \%(\mathrm{G}$ e $\mathrm{H})$ não a apresentando, em descumprimento às normas técnicas para edificação de hospitais. Observamos que estes dois hospitais ( $\mathrm{G}$ e $\mathrm{H}$ ) também não contavam com gerador para suporte elétrico alternativo, contrariando a NBR-13.534; 
dos demais, 33,33\% (A, F e H) tinham suporte alternativo para todo o hospital e 44,44\% (B, C, D e E) apenas para as áreas críticas. Em relação à Cabine Primária de Força e Reservatório de Água todos os hospitais os possuíam.

Em relação à Caldeira, 33,33\% (A, B e D) a apresentavam e cumpriam a NR 13/TEM; os demais 77,77\% (C, E, F, G, H e I) não a apresentavam.

Tabela 16 - Estrutura Física e Infra-Estrutura dos nove hospitais estudados, Estado de São Paulo, 2002 e 2003.

\begin{tabular}{|c|c|c|c|c|c|c|c|c|c|}
\hline $\begin{array}{l}\text { Estrutura Física e } \text { Infra- } \\
\text { Estrutura }\end{array}$ & A & B & $\mathrm{C}$ & $\mathrm{D}$ & $\mathbf{E}$ & $\mathrm{F}$ & G & $\mathbf{H}$ & I \\
\hline $\begin{array}{l}\text { Identificação adequada e } \\
\text { visível }\end{array}$ & $\mathrm{X}$ & $X$ & $\mathrm{X}$ & $\mathrm{X}$ & $\mathrm{X}$ & $\mathrm{X}$ & $\mathrm{X}$ & $\mathrm{X}$ & $X$ \\
\hline Estacionamento suficiente & $\mathrm{X}$ & $\mathbf{N}$ & $\mathbf{N}$ & $\mathbf{N}$ & $\mathrm{X}$ & $\mathbf{N}$ & $\mathrm{X}$ & $\mathrm{X}$ & $\mathrm{N}$ \\
\hline Sinalização adequada e visível & $\mathrm{X}$ & $\mathrm{X}$ & $\mathrm{X}$ & $X$ & $\mathrm{X}$ & $\mathrm{X}$ & $\mathrm{X}$ & $\mathrm{N}$ & $\mathrm{X}$ \\
\hline Área para manutenção/descarga & $\mathrm{X}$ & $\mathrm{X}$ & $X$ & $\mathrm{X}$ & $\mathrm{X}$ & $\mathrm{X}$ & $\mathrm{X}$ & $X$ & $\mathrm{X}$ \\
\hline Elevadores em $n^{\circ}$ suficiente & $\mathrm{X}$ & $X$ & $X$ & $X$ & $\mathrm{X}$ & $\mathrm{N}$ & $\mathrm{H}$ & $\mathrm{N}$ & $X$ \\
\hline Local exclusivo para lixo & $\mathbf{X}$ & $\mathrm{X}$ & $\mathrm{X}$ & $\mathrm{X}$ & $\mathrm{X}$ & $\mathrm{X}$ & $X$ & $\mathbf{X}$ & $\mathrm{X}$ \\
\hline Central de Gases & $\mathrm{X}$ & $\mathrm{X}$ & $\mathrm{X}$ & $\mathrm{X}$ & $\mathrm{X}$ & $\mathrm{X}$ & $\mathrm{X}$ & $\mathrm{X}$ & $\mathrm{X}$ \\
\hline Ar condicionado Central & $\mathrm{X}$ & $\mathrm{N}$ & $\mathrm{N}$ & $\mathrm{N}$ & $\mathrm{N}$ & $\mathrm{N}$ & $\mathrm{N}$ & $\mathrm{N}$ & $\mathrm{N}$ \\
\hline Sistema de Resíduos & $\mathrm{N}$ & $\mathrm{N}$ & $\mathbf{N}$ & $\mathbf{N}$ & $\mathbf{N}$ & $\mathrm{X}$ & $\mathrm{N}$ & $\mathbf{N}$ & $\mathrm{N}$ \\
\hline Sistema de Esgotos & $\mathrm{N}$ & $\mathrm{N}$ & $\mathrm{N}$ & $\mathrm{N}$ & $\mathbf{N}$ & $\mathrm{N}$ & $\mathrm{N}$ & $\mathrm{N}$ & $\mathrm{N}$ \\
\hline $\begin{array}{l}\text { Sistema de Prevenção de } \\
\text { Incêndios }\end{array}$ & $X$ & $X$ & $\mathrm{X}$ & $X$ & $X$ & $\mathrm{X}$ & $X$ & $\mathrm{X}$ & $\mathrm{X}$ \\
\hline Pára-raios & $X$ & $X$ & $X$ & $\mathrm{X}$ & $X$ & $X$ & $\mathrm{~N}$ & $\mathrm{~N}$ & $X$ \\
\hline $\begin{array}{l}\text { Gerador automático áreas } \\
\text { criticas }\end{array}$ & $X$ & $X$ & $\mathrm{X}$ & $X$ & $X$ & $X$ & $\mathbf{N}$ & $X$ & $\mathbf{N}$ \\
\hline $\begin{array}{l}\text { Gerador automático todo } \\
\text { hospital }\end{array}$ & $X$ & $\mathrm{~N}$ & $\mathbf{N}$ & $\mathbf{N}$ & $\mathbf{N}$ & $X$ & $\mathrm{~N}$ & $\mathrm{X}$ & $\mathrm{N}$ \\
\hline Caldeira & $X$ & $X$ & $\mathrm{~N}$ & $X$ & $\mathrm{~N}$ & $\mathrm{~N}$ & $\mathrm{~N}$ & $\mathrm{~N}$ & $\mathbf{N}$ \\
\hline Cabine primária de força & $\mathrm{X}$ & $\mathrm{X}$ & $X$ & $X$ & $\mathrm{X}$ & $\mathrm{X}$ & $\mathrm{X}$ & $\mathrm{X}$ & $\mathrm{X}$ \\
\hline Reservatório de Água & $X$ & $\mathrm{X}$ & $\mathrm{X}$ & $\mathrm{X}$ & $\mathrm{X}$ & $\mathrm{X}$ & $\mathrm{X}$ & $\mathrm{X}$ & $X$ \\
\hline
\end{tabular}

Fonte: Pesquisa de Campo, 2002 e 2003.

(X) Apresenta (N) Não apresenta (H) Horizontal. 
Em relação à organização e atenção ao paciente, a recepção dos hospitais é o local onde se dá o primeiro contato do usuário/ paciente com a estrutura hospitalar.

Na Tabela 17 observamos que 88,89\% dos hospitais (A, B, D, E, F, G, H e I) investiram na recepção dos hospitais. Elas eram adequadas e confortáveis nos oito hospitais que a possuíam em sua estrutura física; $33,33 \%$ (A, D e E) estavam em condições ótimas de limpeza, 55,55\% (B, F, G, H e I) em boas condições de limpeza. Em relação à conservação predial, $22 \%$ dos hospitais (A e E) estavam em ótimo estado de conservação e $66 \%$ (B, D, F, G, H e I) em bom estado de conservação predial. Nos hospitais com recepção instalada, havia sanitários para ambos os sexos, conforme $\mathrm{RDC} \mathrm{n}^{\circ}$ 50/02.

Tabela 17 - Organização e Atenção ao Paciente - Hotelaria dos nove hospitais, Estado de São Paulo, 2002 e 2003.

\begin{tabular}{lccccccccc}
\hline Hotelaria/ Recepção & A & B & C & D & E & F & G & H & I \\
\hline Adequada e confortável & S & S & N & S & S & S & S & S & S \\
Limpeza & O & B & N & O & O & B & B & B & B \\
Higiene & O & B & N & O & O & B & B & B & B \\
Conservação predial & O & B & N & B & O & B & B & B & B \\
Sanitário para ambos & S & S & N & S & S & S & S & S & S \\
\hline Fonte: Pesquisa de Campo, 2002 e 2003. & & & & & & & &
\end{tabular}

(O) Ótima (B) Boa (R) Regular (I) Insuficiente (N) Não apresenta

Na Tabela 18, apresentamos os itens observados nas unidades de internação, que demonstram que os hospitais vêm buscando melhorar a qualidade da hotelaria oferecida aos pacientes, sejam eles públicos ou privados e procurando adequá-las às exigências da $R D C n^{\circ} 50 / 02$.

Em relação às acomodações, buscam ofertá-la de forma diferenciada, conforme o tipo de paciente. Para pacientes oriundos de convênios ou particulares oferecem suítes, presentes nos Hospitais A e F $(22,22 \%)$, apartamentos, presentes em 
$100 \%$ da amostra de hospitais (A, B, C, D, E, F, G, H e I) e enfermarias diferenciadas de 2 leitos presentes em 88,89\% dos hospitais (A, B, C, D, E, F, H e I), enquanto para pacientes SUS oferecem enfermarias simples de 02 a 04 leitos, com estrutura fisica, recursos humanos e materiais adequados ao atendimento geral e de urgência e emergência. Em 100\% das acomodações dos hospitais da amostra (A, B, C, D, E, F, G, H e I) observamos bicos de oxigênio instalados; em 66,66\% deles (A, $\mathrm{B}, \mathrm{C}, \mathrm{E}, \mathrm{H}$ e I) bicos de ar comprimido instalados e em $66,66 \%$ (A, B, D, E, F e I) bicos de vácuo instalados.

Para dar suporte à vida, em casos de emergência, as unidades hospitalares de $77,77 \%$ dos hospitais (A, C, D, E, F, G e I) contam com carrinho para atendimento de urgência e emergência, enquanto $22,22 \%$ (B e H) não o apresentam; torpedos de oxigênio reserva para eventuais problemas que possam ocorrer na rede de gases foram encontrados em $55,55 \%$ dos hospitais (C, D, E, F e G), nos demais $44,44 \%$ (A, B, H e I) não. Em relação aos sanitários, $44,44 \%$ dos hospitais (B, C, D e E) apresentavam portas abrindo para fora ou de correr, em cumprimento à RDC $\mathrm{n}^{\circ}$ $50 / 02$, enquanto a maioria, $55,55 \%$ ( $A, F, G, H$ e I) não cumpriam esta exigência técnica; em 77,77\% dos hospitais (B, C, D, F, G, H e I) não encontramos barras de apoio instaladas nos sanitários para segurança dos pacientes em cumprimento à RDC $\mathrm{n}^{\mathrm{0}} 50 / 02$; nos demais $22,22 \%$ (A e E) elas estavam instaladas. 
Tabela 18 - Organização e Atenção ao Paciente - Unidades de Internação dos nove hospitais, Estado de São Paulo, 2002 e 2003.

\begin{tabular}{llllllllll}
\hline Unidades de Internação & A & B & C & D & E & F & G & H & I \\
\hline Suíte & X & N & N & N & N & X & N & N & N \\
Apartamento & X & X & X & X & X & X & X & X & X \\
Enfermaria de 2 leitos & X & X & X & X & X & X & N & X & X \\
Enfermaria de 3 leitos & N & N & N & N & N & N & N & N & N \\
Enfermaria de 4 leitos & N & N & N & N & N & N & X & N & N \\
Enfermaria de 5 leitos & N & N & N & N & N & N & N & X & N \\
Bico de oxigênio/ leito & X & X & X & X & X & X & X & X & X \\
Bico ar comprimido/leito & X & X & X & N & X & N & N & X & X \\
Bico de vácuo/ leito & X & X & N & X & X & X & N & N & X \\
Carrinho de emergência na & X & N & X & X & X & X & X & N & X \\
unidade & & & & & & & & & \\
Torpedo de oxigênio & $\mathrm{N}$ & $\mathrm{N}$ & X & X & X & X & X & N & N \\
reserva & & & & & & & & & \\
$\begin{array}{l}\text { Sanitário porta abrindo } \\
\text { para fora/ correr }\end{array}$ & $\mathrm{N}$ & $\mathrm{X}$ & $\mathrm{X}$ & $\mathrm{X}$ & $\mathrm{X}$ & $\mathrm{N}$ & $\mathrm{N}$ & $\mathrm{N}$ & $\mathrm{N}$ \\
$\begin{array}{l}\text { Sanitário com barras de } \\
\text { apoio }\end{array}$ & $\mathrm{X}$ & $\mathrm{N}$ & $\mathrm{N}$ & $\mathrm{N}$ & $\mathrm{X}$ & $\mathrm{N}$ & $\mathrm{N}$ & $\mathrm{N}$ & $\mathrm{N}$ \\
\hline
\end{tabular}

Fonte: Pesquisa de Campo, 2002 e 2003.

(X) Apresenta (N) Não apresenta

Continuando a análise da organização e atenção ao paciente, a Tabela 19 apresenta o resumo das observações feitas nos pronto-socorros (PS) e prontoatendimentos (PA) dos hospitais da amostra, relativos ao atendimento de urgência e emergência. Encontramos $66,66 \%$ de hospitais (A, B, C, F, H e I), com prontosocorros instalados, sendo cinco gerais e um especializado (atendimento exclusivo para adultos) e $33,33 \%$ (D, E e G) com pronto-atendimentos gerais instalados.

Em relação à área física, $100 \%$ dos hospitais apresentavam salas exclusivas para atendimentos de urgência/emergência (A, B, C, D, E, F, G, H e I). Destas, 
apenas $44,44 \%$ (A, E, G e I) estavam equipadas adequadamente, $55,56 \%$ (B, C, D, F e H) não possuiam equipamentos para suporte e manutenção de vida, como por exemplo, respiradores adequados, desfibriladores. A totalidade da amostra (A, B, C, D, E, F, G, H e I) apresentava bicos de oxigênio; os hospitais A, B, C, D, E, F, G e I $(88,88 \%)$ apresentavam bicos de vácuo instalados e $88,89 \%$ (A, B, C, D, E, F, H e I) contavam também com bicos de ar comprimido.

Os hospitais A, B, C, D, E, F e I (77,77\%) tinham leitos de observação instalados, sendo: A- 04 mistos; B- 06 mistos; C- 06 masculinos, 05 femininos e 04 mistos; D- 03 mistos; E- 03 mistos; F- 03 masculinos, 03 femininos e 02 pediátricos e I- 04 masculinos e 04 femininos; G e H $(22,23 \%)$ não dispunham deste tipo de leito. Os medicamentos de urgência e emergência estavam presentes em qualidade e quantidade todos os hospitais.

Em relação à garantia de transporte dos pacientes graves, $77,77 \%$ dos hospitais (A, B, C, D, E, H e I) possuiam ambulâncias e UTIs móveis para remoção de pacientes; os hospitais $\mathrm{F}$ e $\mathrm{G}$, representando $22,23 \%$ da amostra não possuiam ambulâncias.

A equipe médica estava de acordo com a Portaria GM n² 2048, de 05 de novembro de 2002 , em $22,23 \%$ dos hospitais (A e C).

Observamos Enfermeiras contratadas para todos os turnos de trabalho em $33,33 \%$ dos hospitais da amostra, A e C com PS e E com PA; os demais 66,67\% (B, D, F, G, H e I) não contavam com estas profissionais em todos os turnos de trabalho, sendo o período noturno o mais comprometido, ficando a assistência de urgência e emergência a cargo de enfermeiras que realizavam a supervisão do hospital. 
Tabela 19 - Organização e Atenção ao Paciente - Pronto-Socorro e ProntoAtendimento dos nove hospitais, Estado de São Paulo, 2002 e 2003.

\begin{tabular}{|c|c|c|c|c|c|c|c|c|c|}
\hline Pronto-Socorro & A & B & $\mathrm{C}$ & $\mathrm{D}$ & $\mathrm{E}$ & $\mathrm{F}$ & $\mathrm{G}$ & $\mathbf{H}$ & I \\
\hline Pronto-Socorro Geral & $X$ & $X$ & $X$ & PA & PA & $X$ & PA & $\mathrm{X}$ & A \\
\hline $\begin{array}{l}\text { Pronto-Socorro } \\
\text { Especializado }\end{array}$ & $\mathrm{N}$ & $\mathrm{N}$ & $\mathrm{N}$ & $\mathrm{N}$ & $\mathbf{N}$ & $\mathrm{N}$ & $\mathrm{N}$ & $\mathbf{N}$ & $\mathrm{N}$ \\
\hline $\begin{array}{l}\text { Sala exclusiva para } \\
\text { urgências }\end{array}$ & $\mathrm{X}$ & $\mathrm{X}$ & $\mathrm{X}$ & $\mathrm{X}$ & $\mathrm{X}$ & $X$ & $\mathrm{X}$ & $\mathrm{X}$ & $X$ \\
\hline $\begin{array}{l}\text { Equipamentos } \\
\text { Adequados }\end{array}$ & $X$ & $\mathrm{~N}$ & $\mathrm{~N}$ & $\mathrm{~N}$ & $\mathrm{X}$ & $\mathrm{N}$ & $\mathrm{X}$ & $\mathbf{N}$ & $\mathrm{X}$ \\
\hline $\begin{array}{l}1 \text { bico de oxigênio/ leito } \\
\text { (mínimo) }\end{array}$ & $\mathrm{X}$ & $X$ & $X$ & $X$ & $\mathrm{X}$ & $\mathrm{X}$ & $X$ & $X$ & $X$ \\
\hline $\begin{array}{l}1 \text { bico de ar } \\
\text { comprimido/leito }\end{array}$ & $X$ & $X$ & $\mathrm{X}$ & $\mathrm{X}$ & $\mathrm{X}$ & $\mathrm{X}$ & $\mathbf{N}$ & $\mathrm{X}$ & $\mathrm{X}$ \\
\hline 1 bico de vácuo/ leito & $\mathrm{X}$ & $\mathrm{X}$ & $\mathrm{X}$ & $\mathbf{X}$ & $\mathbf{X}$ & $\mathrm{X}$ & $\mathrm{X}$ & $\mathbf{N}$ & $\mathrm{X}$ \\
\hline $\begin{array}{l}\text { Leitos de observação } \\
\text { masculinos }\end{array}$ & $\mathrm{N}$ & $\mathrm{N}$ & 06 & $\mathrm{~N}$ & $\mathrm{~N}$ & 03 & $\mathbf{N}$ & $\mathbf{N}$ & 04 \\
\hline $\begin{array}{l}\text { Leitos de observação } \\
\text { femininos }\end{array}$ & $\mathrm{N}$ & $\mathrm{N}$ & 05 & $\mathrm{~N}$ & $\mathrm{~N}$ & 03 & $\mathrm{~N}$ & $\mathrm{~N}$ & 04 \\
\hline $\begin{array}{l}\text { Leitos de observação } \\
\text { mistos }\end{array}$ & 04 & 06 & 04 & 03 & 03 & $\mathrm{~N}$ & $\mathrm{~N}$ & $\mathrm{~N}$ & $\mathrm{~N}$ \\
\hline $\begin{array}{l}\text { Leitos de observação } \\
\text { pediátricos }\end{array}$ & $\mathbf{N}$ & $\mathbf{N}$ & $\mathrm{N}$ & $\mathrm{N}$ & $\mathbf{N}$ & 02 & $\mathrm{~N}$ & $\mathrm{~N}$ & $\mathbf{N}$ \\
\hline $\begin{array}{l}\text { Ambulância para } \\
\text { remoção }\end{array}$ & $X$ & $X$ & $X$ & $X$ & $X$ & $\mathrm{~N}$ & $\mathrm{~N}$ & $X$ & $X$ \\
\hline UTI móvel & $X$ & $\mathrm{X}$ & $X$ & $X$ & $X$ & $\mathrm{~N}$ & $\mathrm{~N}$ & $X$ & $X$ \\
\hline $\begin{array}{l}\text { Equipe médica } \\
\text { conforme PortGM 2048/02 }\end{array}$ & $X$ & $\mathbf{N}$ & $X$ & $\mathrm{~N}$ & $\mathbf{N}$ & $\mathrm{N}$ & $\mathbf{N}$ & $\mathrm{N}$ & $\mathrm{N}$ \\
\hline $\begin{array}{l}\text { Enfermeira em todos os } \\
\text { turnos }\end{array}$ & $\mathrm{X}$ & $\mathrm{N}$ & $X$ & $\mathrm{~N}$ & $X$ & $\mathrm{~N}$ & $\mathrm{~N}$ & $\mathrm{~N}$ & $\mathrm{~N}$ \\
\hline $\begin{array}{l}\text { Medicamentos de } \\
\text { Urgência }\end{array}$ & $X$ & $X$ & $X$ & $X$ & $X$ & $X$ & $X$ & $X$ & $X$ \\
\hline
\end{tabular}

Fonte: Pesquisa de Campo, 2002 e 2003.

(X) Apresenta (N) Não apresenta A (Adulto) PA (Pronto-Atendimento) 
Em relação aos cuidados intensivos, a Tabela 20 demontra que $66,66 \%$ dos hospitais (A, B, C, D, E e F) estavam com Unidades de Terapia Intensiva Geral instaladas; destes, 22,22\% (A e B) também contavam com Unidade Coronariana, 33,33\% (A, D e F) com Unidade de Terapia Intensiva Pediátrica, 44,44\% (A, B, D e F) com Unidade de Terapia Neonatal e $11,11 \%$ (C) com Unidade de Terapia Neurológica. Apesar de os hospitais G, H e I referirem possuir Unidade de Terapia Intensiva observou-se que neles estavam instalados de dois a três leitos para atendimento de pacientes mais graves, porém não possuíam área física, equipamentos e recursos humanos que caracterizassem uma Unidade de Terapia Intensiva, conforme Portaria GM n⿳3 3432, de 12 de agosto de 1988.

Tabela 20 - Organização e Atenção ao Paciente - Unidades de Terapia Intensiva dos nove hospitais, Estado de São Paulo, 2002 e 2003.

\begin{tabular}{lccccccccc}
\hline UTI & $\mathrm{A}$ & $\mathrm{B}$ & $\mathrm{C}$ & $\mathrm{D}$ & $\mathrm{E}$ & $\mathrm{F}$ & $\mathrm{G}$ & $\mathrm{H}$ & $\mathrm{I}$ \\
\hline UTI Geral & $\mathrm{X}$ & $\mathrm{X}$ & $\mathrm{X}$ & $\mathrm{X}$ & $\mathrm{X}$ & $\mathrm{X}$ & $02 \mathrm{~L}$ & $02 \mathrm{~L}$ & $03 \mathrm{~L}$ \\
UCO & $\mathrm{X}$ & $\mathrm{X}$ & $\mathrm{N}$ & $\mathrm{N}$ & $\mathrm{N}$ & $\mathrm{N}$ & $\mathrm{N}$ & $\mathrm{N}$ & $\mathrm{N}$ \\
UTI Pediátrica & $\mathrm{X}$ & $\mathrm{N}$ & $\mathrm{N}$ & $\mathrm{X}$ & $\mathrm{N}$ & $\mathrm{X}$ & $\mathrm{N}$ & $\mathrm{N}$ & $\mathrm{N}$ \\
UTI Neonatal & $\mathrm{X}$ & $\mathrm{X}$ & $\mathrm{N}$ & $\mathrm{X}$ & $\mathrm{N}$ & $\mathrm{X}$ & $\mathrm{N}$ & $\mathrm{N}$ & $\mathrm{N}$ \\
Neurológica & $\mathrm{N}$ & $\mathrm{N}$ & $\mathrm{X}$ & $\mathrm{N}$ & $\mathrm{N}$ & $\mathrm{N}$ & $\mathrm{N}$ & $\mathrm{N}$ & $\mathrm{N}$ \\
\hline
\end{tabular}

Fonte: Pesquisa de Campo, 2002 e 2003.

(X) Apresenta (N) Não apresenta

Observamos na Tabela 21 as características da Unidade de Terapia Intensiva (UTI) Geral dos hospitais A, B, C, D, E e F.

Segundo a Portaria GM 3432 de 12 de agosto de 1988, UTI é unidade hospitalar destinada ao atendimento de pacientes graves ou de risco que dispõe de assistência médica e de enfermagem ininterruptas, com equipamentos específicos 
próprios, recursos humanos especializados e que tenha acesso a outras tecnologias destinadas a diagnóstico e terapia.

Em relação aos aspectos organizacionais das UTIs gerais, dos seis hospitais que a apresentavam, 100\% das UTIs gerais (A, B ,C, D, E e F) apresentavam um médico para cada 10 leitos; 83,34\% (A, B, C, D e E) tinham normas e rotinas para a área; $100 \%$ participava da Comissão de Controle de Infecç̧ão Hospitalar; em 100\% havia acompanhamento de visita aos pacientes com orientação aos componentes da equipe. Os hospitais G, H e I não possuíam UTI.

Em relação à área física, $66,68 \%(\mathrm{~A}, \mathrm{C}, \mathrm{D}$ e $\mathrm{F})$ encontrava-se em área física adequada conforme a $\mathrm{RDC} \mathrm{n}^{\mathrm{o}} 50 / 02,33,32 \%$ (B e E) em área inadequada; em $83,34 \%$ delas (A, C , D , E e F) o posto de enfermagem permitia boa visão dos leitos, enquanto em 16,66\% (B) ele estava mal localizado; em 100\% (A, B, C, D, E e F) havia boa circulação de funcionários e pacientes, leitos para isolamento de pacientes, quarto para médicos plantonistas e para cada leito estavam instalados dois bicos de oxigênio, um de ar comprimido, um de vácuo e dez tomadas elétricas. Nenhuma contava com área de descanso para a enfermagem.

Todas apresentavam equipamentos em quantidade e qualidade.

Em relação aos recursos humanos, $83,34 \%$ (A, B, C, D e E) possuía médico diarista, 16,66\% não contava com este profissional; mesmo assim, 100\% (A, B, C, D, E e F) possuia equipe médica, equipe de enfermagem treinada e enfermeira em todos os turnos. 
Tabela 21 - Características da Unidade de Terapia Intensiva dos nove hospitais, Estado de São Paulo, 2002 e 2003.

\begin{tabular}{|c|c|c|c|c|c|c|c|c|c|}
\hline UTI Geral- Port GM 3432/1998 & A & $\mathrm{B}$ & $\mathrm{C}$ & $\mathrm{D}$ & $\mathrm{E}$ & $\mathrm{F}$ & $\mathrm{G}$ & $\mathrm{H}$ & I \\
\hline 01 médico para cada 10 leitos & $\mathrm{X}$ & $\mathrm{X}$ & $\mathrm{X}$ & $\mathrm{X}$ & $\mathrm{X}$ & $\mathrm{X}$ & $\mathrm{N}$ & $\mathrm{N}$ & $\mathrm{N}$ \\
\hline Há normas e rotinas para a área & $X$ & $\mathrm{X}$ & $\mathrm{X}$ & $X$ & $\mathrm{X}$ & $\mathrm{N}$ & $\mathbf{N}$ & $\mathrm{N}$ & $\mathrm{N}$ \\
\hline A UTI participa da $\mathrm{CCIH}$ & $\mathrm{X}$ & $X$ & $\mathrm{X}$ & $\mathrm{X}$ & $X$ & $X$ & $\mathrm{~N}$ & $\mathbf{N}$ & $\mathrm{N}$ \\
\hline $\begin{array}{l}\text { Há acompanhamento de visita } \\
\text { com orientação }\end{array}$ & $X$ & $X$ & $\mathrm{X}$ & $X$ & $\mathrm{X}$ & $X$ & $\mathbf{N}$ & $\mathbf{N}$ & $\mathrm{N}$ \\
\hline $\begin{array}{l}\text { Encontra-se em área física } \\
\left.\text { adequada ( } R D C \mathrm{n}^{\circ} 50 / 02\right)\end{array}$ & $X$ & $\mathrm{~N}$ & $\mathrm{X}$ & $\mathrm{X}$ & $\mathbf{N}$ & $X$ & $\mathrm{~N}$ & $\mathbf{N}$ & $\mathrm{N}$ \\
\hline $\begin{array}{l}\text { De acordo com a legislação } \\
\left.\text { (RDC } n^{\circ} 50 / 02\right)\end{array}$ & $\mathrm{X}$ & $\mathbf{N}$ & $X$ & $X$ & $\mathbf{N}$ & $\mathrm{X}$ & $\mathbf{N}$ & $\mathbf{N}$ & $\mathbf{N}$ \\
\hline $\begin{array}{l}\text { Posto de enfermagem permite } \\
\text { boa visão dos leitos }\end{array}$ & $\mathrm{X}$ & $\mathrm{N}$ & $\mathrm{X}$ & $\mathrm{X}$ & $\mathrm{X}$ & $\mathrm{X}$ & $\mathrm{N}$ & $\mathbf{N}$ & $\mathrm{N}$ \\
\hline $\begin{array}{l}\text { Há boa circulação de } \\
\text { funcionários e pacientes }\end{array}$ & $X$ & $X$ & $X$ & $X$ & $\mathrm{X}$ & $\mathbf{X}$ & $\mathbf{N}$ & $\mathbf{N}$ & $\mathrm{N}$ \\
\hline Possui médico diarista & $X$ & $X$ & $X$ & $X$ & $X$ & $\mathbf{N}$ & $\mathbf{N}$ & $\mathbf{N}$ & $\mathrm{N}$ \\
\hline $\begin{array}{l}\text { Possui equipe médica em todos } \\
\text { os turnos }\end{array}$ & $X$ & $X$ & $X$ & $\mathrm{X}$ & $\mathrm{X}$ & $X$ & $\mathbf{N}$ & $\mathbf{N}$ & $\mathbf{N}$ \\
\hline $\begin{array}{l}\text { Equipe de enfermagem treinada } \\
\text { e completa }\end{array}$ & $X$ & $X$ & $X$ & $X$ & $\mathrm{X}$ & $X$ & $\mathrm{~N}$ & $\mathbf{N}$ & $\mathbf{N}$ \\
\hline Enfermeira em todos os turnos & $\mathbf{X}$ & $\mathrm{X}$ & $X$ & $X$ & $X$ & $\mathbf{X}$ & $\mathbf{N}$ & $\mathbf{N}$ & $\mathbf{N}$ \\
\hline Há leitos para isolamento & $X$ & $X$ & $X$ & $X$ & $X$ & $X$ & $\mathbf{N}$ & $\mathrm{N}$ & $\mathrm{N}$ \\
\hline Quarto para médico plantonista & $X$ & $\mathrm{X}$ & $X$ & $X$ & $X$ & $X$ & $\mathbf{N}$ & $\mathbf{N}$ & $\mathrm{N}$ \\
\hline $\begin{array}{l}\text { Área de descanso para } \\
\text { enfermagem }\end{array}$ & $\mathbf{N}$ & $\mathbf{N}$ & $\mathbf{N}$ & $\mathbf{N}$ & $\mathbf{N}$ & $\mathbf{N}$ & $\mathbf{N}$ & $\mathbf{N}$ & $\mathrm{N}$ \\
\hline 2 bicos de oxigênio/leito & $X$ & $X$ & $X$ & $\mathrm{X}$ & $\mathrm{X}$ & $X$ & $\mathbf{N}$ & $\mathbf{N}$ & $\mathbf{N}$ \\
\hline 1 bico de ar comprimido/leito & $X$ & $\mathrm{X}$ & $X$ & $X$ & $X$ & $X$ & $\mathbf{N}$ & $\mathbf{N}$ & $\mathrm{N}$ \\
\hline 1 bico de vácuo/leito & $X$ & $X$ & $X$ & $X$ & $X$ & $X$ & $\mathbf{N}$ & $\mathbf{N}$ & $\mathbf{N}$ \\
\hline 10 tomadas elétricas & $X$ & $\mathrm{X}$ & $X$ & $X$ & $X$ & $X$ & $\mathbf{N}$ & $\mathbf{N}$ & $\mathrm{N}$ \\
\hline $\begin{array}{l}\text { Equipamentos em quantidade e } \\
\text { qualidade }\end{array}$ & $X$ & $X$ & $X$ & $X$ & $X$ & $X$ & $\mathbf{N}$ & $\mathbf{N}$ & $\mathrm{N}$ \\
\hline
\end{tabular}

Fonte: Pesquisa de Campo, 2002 e 2003.

(X) Apresenta (N) Não apresenta 
A Tabela 22 apresenta resumo dos aspectos organizacionais das UTIs Cardiológicas dos hospitais A, B e D onde observamos que $100 \%$ delas apresentavam um médico para cada 10 leitos; $100 \%$ (A, B e D) estavam com normas e rotinas para a área; $100 \%$ (A, B e D) participavam da Comissão de Controle de Infecç̧ão Hospitalar; em 100\% (A, B e D) havia acompanhamento de visita aos pacientes com orientação aos componentes da equipe.

Em relação à área física, 66,66\% (A e D) encontravam-se em área física adequada conforme a $\mathrm{RDC} \mathrm{n}^{\circ} 50 / 02$ e $33,33 \%$ (B) em área inadequada; em $100 \%$ delas (A, B e D) o posto de enfermagem permitia boa visão dos leitos; em 100\% (A, B e D) havia boa circulação de funcionários e pacientes, leitos para isolamento de pacientes, quarto para médicos plantonistas e para cada leito estavam instalados dois bicos de oxigênio, um de ar comprimido, um de vácuo e dez tomadas elétricas. Nenhuma contava com área de descanso para a enfermagem.

Todas apresentavam equipamentos em quantidade e qualidade.

Em relação aos recursos humanos, $100 \%$ (A, B e D) possuia médico diarista, equipe médica, equipe de enfermagem treinada e enfermeira em todos os turnos. 
Tabela 22 - Características das Unidades de Terapia Intensiva Cardiológicas dos hospitais A, B e D, Estado de São Paulo, 2003.

\begin{tabular}{|c|c|c|c|}
\hline UTI Cardiológica Port GM 3432/1998 & A & B & D \\
\hline 01 médico para cada 10 leitos & $\mathrm{X}$ & $\mathrm{X}$ & $\mathrm{X}$ \\
\hline Há normas e rotinas para a área & $\mathrm{X}$ & $\mathrm{X}$ & $\mathrm{X}$ \\
\hline A UTI participa da CCIH & $\mathbf{X}$ & $X$ & $\mathrm{X}$ \\
\hline Há acompanhamento de visita com orientação & $\mathbf{X}$ & $\mathrm{X}$ & $\mathbf{X}$ \\
\hline Encontra-se em área física adequada ( $\left.\mathrm{RDC}^{\circ} 50 / 02\right)$ & $X$ & $\mathbf{N}$ & $X$ \\
\hline De acordo com a legislação (RDC nº 50/02) & $\mathbf{X}$ & $\mathbf{N}$ & $\mathbf{X}$ \\
\hline Posto de enfermagem permite boa visão dos leitos & $X$ & $X$ & $X$ \\
\hline Há boa circulação de funcionários e pacientes & $\mathbf{X}$ & $\mathbf{X}$ & $\mathrm{X}$ \\
\hline Possui médico diarista & $X$ & $X$ & $X$ \\
\hline Possui equipe médica em todos os turnos & $\mathbf{X}$ & $\mathrm{X}$ & $X$ \\
\hline Equipe de enfermagem treinada e completa & $\mathbf{X}$ & $X$ & $\mathbf{X}$ \\
\hline Enfermeira em todos os turnos & $\mathrm{X}$ & $X$ & $X$ \\
\hline Há leitos para isolamento & $X$ & $X$ & $X$ \\
\hline Quarto para médico plantonista & $\mathbf{X}$ & $\mathbf{X}$ & $\mathrm{X}$ \\
\hline Área de descanso para enfermagem & $\mathrm{N}$ & $\mathrm{N}$ & $\mathrm{N}$ \\
\hline 2 bicos de oxigênio/leito & $X$ & $X$ & $\mathrm{X}$ \\
\hline 1 bico de ar comprimido/leito & $X$ & $\mathbf{X}$ & $\mathbf{X}$ \\
\hline 1 bico de vácuo/leito & $\mathrm{X}$ & $\mathrm{X}$ & $\mathrm{X}$ \\
\hline 10 tomadas elétricas & $\mathrm{X}$ & $X$ & $\mathrm{X}$ \\
\hline Equipamentos em quantidade e qualidade & $\mathrm{X}$ & $\mathrm{X}$ & $\mathrm{X}$ \\
\hline
\end{tabular}

Fonte: Pesquisa de Campo, 2003.

(X) Apresenta (N) Não apresenta

Em relação aos aspectos organizacionais das UTIs Pediátricas dos hospitais A

e F, observamos na Tabela 23, que $100 \%$ (A e F) delas apresentavam um médico para cada 10 leitos; $50 \%$ (A) estava com normas e rotinas para a área e 50\% (F) não estava com as normas e rotinas elaboradas; $100 \%$ (A e F) participava da Comissão de Controle de Infecç̧ão Hospitalar; em 100\% (A e F) havia acompanhamento de visita aos pacientes com orientação aos componentes da equipe. 
Em relação à área física, $100 \%$ (A e F) encontrava-se em área física adequada conforme a RDC $\mathrm{n}^{\circ}$ 50/02; em $100 \%$ delas (A e F) o posto de enfermagem permitia boa visão dos leitos; em $100 \%$ (A e F) havia boa circulação de funcionários e pacientes, leitos para isolamento de pacientes, quarto para médicos plantonistas e para cada leito estavam instalados dois bicos de oxigênio, um de ar comprimido, um de vácuo e dez tomadas elétricas. Nenhuma contava com área de descanso para a enfermagem.

Todas apresentavam equipamentos em quantidade e qualidade.

Em relação aos recursos humanos, $50 \%$ (A) possuia médico diarista e 50\% (F) não contava com este profissional; $100 \%$ ( $\mathrm{A}$ e F) possuia equipe médica, equipe de enfermagem treinada e enfermeira em todos os turnos. 
Tabela 23 - Características das Unidades de Terapia Intensiva Pediátricas dos hospitais A e F, Estado de São Paulo, 2002 e 2003.

\begin{tabular}{lll}
\hline UTI Pediátrica Port GM 3432/1998 & $\mathrm{A}$ & $\mathrm{F}$ \\
\hline 01 médico para cada 10 leitos & $\mathrm{X}$ & $\mathrm{X}$ \\
Há normas e rotinas para a área & $\mathrm{X}$ & $\mathrm{N}$ \\
A UTI participa da CCIH & $\mathrm{X}$ & $\mathrm{X}$ \\
Há acompanhamento de visita com orientação & $\mathrm{X}$ & $\mathrm{X}$ \\
Encontra-se em área física adequada & $\mathrm{X}$ & $\mathrm{X}$ \\
De acordo com a legislação (Port MS 2918) & $\mathrm{X}$ & $\mathrm{X}$ \\
Posto de enfermagem permite boa visão dos leitos & $\mathrm{X}$ & $\mathrm{X}$ \\
Há boa circulação de funcionários e pacientes & $\mathrm{X}$ & $\mathrm{X}$ \\
Possui médico diarista & $\mathrm{X}$ & $\mathrm{N}$ \\
Possui equipe médica em todos os turnos & $\mathrm{X}$ & $\mathrm{X}$ \\
Equipe de enfermagem treinada e completa & $\mathrm{X}$ & $\mathrm{X}$ \\
Enfermeira em todos os turnos & $\mathrm{X}$ & $\mathrm{X}$ \\
Há leitos para isolamento & $\mathrm{X}$ & $\mathrm{X}$ \\
Quarto para médico plantonista & $\mathrm{X}$ & $\mathrm{X}$ \\
Área de descanso para enfermagem & $\mathrm{N}$ & $\mathrm{N}$ \\
2 bicos de oxigênio/leito & $\mathrm{X}$ & $\mathrm{X}$ \\
1 bico de ar comprimido/leito & $\mathrm{X}$ & $\mathrm{X}$ \\
1 bico de vácuo/leito & $\mathrm{X}$ & $\mathrm{X}$ \\
10 tomadas elétricas & $\mathrm{X}$ & $\mathrm{X}$ \\
Equipamentos em quantidade e qualidade & $\mathrm{X}$ & $\mathrm{X}$ \\
\hline Font:Pesqusa Campo, 2002e & & \\
\hline
\end{tabular}

Fonte: Pesquisa de Campo, 2002 e 2003.

(X) Apresenta (N) Não apresenta

Em relação aos aspectos organizacionais das UTIs neonatais dos hospitais A, D e F, observamos na Tabela 24 que $100 \%$ delas (A, D e F) apresentavam um médico para cada 10 leitos; 100\% (A, D e F) estava com normas e rotinas para a área; $100 \%$ (A, D e F) participava da Comissão de Controle de Infeccção Hospitalar; em $100 \%$ (A, D e F) havia acompanhamento de visita aos pacientes com orientação aos componentes da equipe. 
Em relação à área física, $66,66 \%$ (A e F) encontrava-se em área física adequada conforme a $\mathrm{RDC} \mathrm{n}^{\circ} 50 / 02$ e 33,33\% (D) em área física inadequada; em $100 \%$ delas (A, D e F) o posto de enfermagem permitia boa visão dos leitos; em $100 \%$ (A, D e F) havia boa circulação de funcionários e pacientes, leitos para isolamento de pacientes, quarto para médicos plantonistas e para cada leito estavam instalados dois bicos de oxigênio, um de ar comprimido, um de vácuo e dez tomadas elétricas. Nenhuma contava com área de descanso para a enfermagem.

Todas apresentavam equipamentos em quantidade e qualidade.

Em relação aos recursos humanos, $100 \%$ (A, D e F) possuia médico diarista; $100 \%$ ( $\mathrm{A}, \mathrm{D}$ e $\mathrm{F}$ ) possuia equipe médica, equipe de enfermagem treinada $\mathrm{e}$ enfermeira em todos os turnos. 
Tabela 24 - Características das Unidades de Terapia Intensiva Neonatais dos hospitais A, D e F, Estado de São Paulo, 2002 e 2003.

\begin{tabular}{llll}
\hline UTI Neonatal Port GM 3432/1998 & $\mathrm{A}$ & $\mathrm{D}$ & $\mathrm{F}$ \\
\hline 01 médico para cada 10 leitos & $\mathrm{X}$ & $\mathrm{X}$ & $\mathrm{X}$ \\
Há normas e rotinas para a área & $\mathrm{X}$ & $\mathrm{X}$ & $\mathrm{X}$ \\
A UTI participa da CCIH & $\mathrm{X}$ & $\mathrm{X}$ & $\mathrm{X}$ \\
Há acompanhamento de visita com orientação & $\mathrm{X}$ & $\mathrm{X}$ & $\mathrm{X}$ \\
Encontra-se em área física adequada & $\mathrm{X}$ & $\mathrm{N}$ & $\mathrm{X}$ \\
De acordo com a legislação & $\mathrm{X}$ & $\mathrm{N}$ & $\mathrm{X}$ \\
Posto de enfermagem permite boa visão dos leitos & $\mathrm{X}$ & $\mathrm{X}$ & $\mathrm{X}$ \\
Há boa circulação de funcionários e pacientes & $\mathrm{X}$ & $\mathrm{X}$ & $\mathrm{X}$ \\
Possui médico diarista & $\mathrm{X}$ & $\mathrm{X}$ & $\mathrm{X}$ \\
Possui equipe médica em todos os turnos & $\mathrm{X}$ & $\mathrm{X}$ & $\mathrm{X}$ \\
Equipe de enfermagem treinada e completa & $\mathrm{X}$ & $\mathrm{X}$ & $\mathrm{X}$ \\
Enfermeira em todos os turnos & $\mathrm{X}$ & $\mathrm{X}$ & $\mathrm{X}$ \\
Há leitos para isolamento & $\mathrm{X}$ & $\mathrm{X}$ & $\mathrm{X}$ \\
Quarto para médico plantonista & $\mathrm{X}$ & $\mathrm{X}$ & $\mathrm{X}$ \\
Área de descanso para enfermagem & $\mathrm{N}$ & $\mathrm{N}$ & $\mathrm{N}$ \\
2 bicos de oxigênio/leito & $\mathrm{X}$ & $\mathrm{X}$ & $\mathrm{X}$ \\
1 bico de ar comprimido/leito & $\mathrm{X}$ & $\mathrm{X}$ & $\mathrm{X}$ \\
1 bico de vácuo/leito & $\mathrm{X}$ & $\mathrm{X}$ & $\mathrm{X}$ \\
10 tomadas elétricas & $\mathrm{X}$ & $\mathrm{X}$ & $\mathrm{X}$ \\
Equipamentos em quantidade e qualidade & $\mathrm{X}$ & $\mathrm{X}$ \\
\hline Fore:Pesqu & & & \\
\hline
\end{tabular}

Fonte: Pesquisa de Campo, 2002 e 2003.

(X) Apresenta (N) Não apresenta.

Em relação aos aspectos organizacionais da UTI Neurológica do Hospital C, observamos na Tabela 25 que ela apresentava um médico para cada 10 leitos; estava com normas e rotinas para a área; participava da Comissão de Controle de Infeccção Hospitalar e havia acompanhamento de visita aos pacientes com orientação aos componentes da equipe. 
Em relação à área física, encontrava-se em área inadequada em desacordo à RDC $n^{\circ} 50 / 02$; o posto de enfermagem não permitia boa visão dos leitos e não havia boa circulação de funcionários e pacientes, não havia quarto para médicos plantonistas, apresentava leitos para isolamento de pacientes e para cada leito estavam instalados dois bicos de oxigênio, um de ar comprimido, um de vácuo e dez tomadas elétricas.

Apresentava equipamentos em quantidade e qualidade.

Em relação aos recursos humanos, possuia médico diarista, equipe médica, equipe de enfermagem treinada e enfermeira em todos os turnos. 
Tabela 25 - Características das Unidades de Terapia Intensiva Neurológica do Hospital C, Estado de São Paulo, 2003.

\begin{tabular}{ll}
\hline UTI Neurológica Port GM 3432/1998 & $\mathrm{C}$ \\
\hline 01 médico para cada 10 leitos & $\mathrm{X}$ \\
Há normas e rotinas para a área & $\mathrm{X}$ \\
A UTI participa da CCIH & $\mathrm{X}$ \\
Há acompanhamento de visita com orientação & $\mathrm{X}$ \\
Encontra-se em área física adequada & $\mathrm{N}$ \\
De acordo com a legislação (Port MS 2918) & $\mathrm{N}$ \\
Posto de enfermagem permite boa visão dos leitos & $\mathrm{N}$ \\
Há boa circulação de funcionários e pacientes & $\mathrm{N}$ \\
Possui médico diarista & $\mathrm{X}$ \\
Possui equipe médica em todos os turnos & $\mathrm{X}$ \\
Equipe de enfermagem treinada e completa & $\mathrm{X}$ \\
Enfermeira em todos os turnos & $\mathrm{X}$ \\
Há leitos para isolamento & $\mathrm{X}$ \\
Quarto para médico plantonista & $\mathrm{N}$ \\
2 bicos de oxigênio/leito & $\mathrm{X}$ \\
1 bico de ar comprimido/leito & $\mathrm{X}$ \\
1 bico de vácuo/leito & $\mathrm{X}$ \\
10 tomadas elétricas & $\mathrm{X}$ \\
Equipamentos em quantidade e qualidade & $\mathrm{X}$ \\
\hline Fonte: Pesquisa de Campo, 2003. &
\end{tabular}
(X) Apresenta (N) Não apresenta

Em relação à Atenção Materna, a Tabela 26 apresenta os resultados das observações feitas nas Maternidades e Centros Obstétricos dos hospitais da amostra, onde verificamos que $44,44 \%$ dos hospitais (E, G, H e I) realizam partos de baixo risco, $44,44 \%$ (A, B, D e F) de médio e alto risco e $11,11 \%$ (C) não possui Maternidade.

Dos oito hospitais com Maternidade, 44,44\% (A, B, D e F) apresentavam Centro-Obstétrico instalado e $44,44 \%$ (E, G, H e I) utilizavam salas do Centro- 
Cirúrgico para tal finalidade; $62,5 \%$ (A, D, G, H e I) possuíam sala de admissão para as parturientes e $37,5 \%(B, E$ e $F)$ não contavam com este recurso; $75 \%(A, B, D, E$, F e H) contavam com sala de pré-parto para o acompanhamento da evolução dos trabalhos de parto, e 25\% (G e I) não; o número de salas de parto normal variou de uma a três salas na amostra de hospitais estudados, sendo que em dois hospitais, representando $25 \%$ da amostra, as salas eram utilizadas tanto para parto normal quanto cirúrgico. Todas as salas contavam com bico de oxigênio, ar comprimido e vácuo instalados.

Os Centros-Obstétricos e Cirúrgicos dos Hospitais A, D, E e F (50\% da amostra) contavam com vestiários com sanitários para ambos os sexos, os hospitais B, G, H e I (50\% da amostra) não apresentavam vestiários diferenciados; 75\% (A, B, D, E, F e G) apresentavam sala de estar e repouso para funcionários e médicos, $25 \%$ (H e I) não; a Recuperação Pós-Anestésica (RPA) estava instalada em 50\% dos hospitais (A, D, E e F), nos demais 50\% (B, G, H e I) não havia RPA. Em 75\% dos hospitais havia sala de reanimação com pia para lavagem das mãos e era feita a identificação do recém-nascido (RN); em 25\% (B e I) a reanimação e a identificação do $\mathrm{RN}$ eram feitas na prória sala de parto.

Os equipamentos eram adequados em todos os hospitais.

Em relação à assistência ao parto, em 100\% dos hospitais $(\mathrm{A}, \mathrm{B}, \mathrm{D}, \mathrm{E}, \mathrm{F}, \mathrm{G}, \mathrm{H}$ e I) ele era realizado por médico obstetra, em $75 \%$ deles (A, B, D, E, F e I) o Obstetra e o Anestesista permaneciam $24 \mathrm{~h}$ de plantão, enquanto em $25 \%$ (G e H) o plantão era à distância; a recepção do RN era feita por Neonatologista em $62,5 \%$ dos hospitais (A, B, D, E e F), em 25\% (G e I) por Anestesistas e em 12,5\% (H) por Pediatra. 
Tabela 26 - Organização e Atenção ao Paciente - Maternidade e Centro Obstétrico dos hospitais A, B, D, E, F, G, H e I, Estado de São Paulo, 2002 e 2003.

\begin{tabular}{|c|c|c|c|c|c|c|c|c|}
\hline Maternidade e CO & A & B & $\mathrm{D}$ & $\mathrm{E}$ & $\mathrm{F}$ & G & $\mathrm{H}$ & I \\
\hline Realiza partos de baixo risco & $\mathbf{N}$ & $\mathbf{N}$ & $\mathbf{N}$ & $X$ & $\mathrm{~N}$ & $X$ & $X$ & $X$ \\
\hline Realiza partos de médio risco & $X$ & $\mathrm{X}$ & $X$ & $\mathrm{~N}$ & $X$ & $\mathrm{~N}$ & $\mathbf{N}$ & $\mathrm{N}$ \\
\hline Realiza partos de alto risco & $X$ & $X$ & $X$ & $\mathbf{N}$ & $X$ & $\mathrm{~N}$ & $\mathrm{~N}$ & $\mathrm{~N}$ \\
\hline Apresenta CO & $X$ & $X$ & $X$ & $\mathrm{CC}$ & $X$ & $\mathrm{CC}$ & $\mathrm{CC}$ & $\mathrm{CC}$ \\
\hline Apresenta sala de admissão & $X$ & $\mathbf{N}$ & $X$ & $\mathbf{N}$ & $\mathbf{N}$ & $X$ & $X$ & $X$ \\
\hline Sala/ Leitos de pré-parto & $X$ & $\mathrm{X}$ & $\mathrm{X}$ & $\mathrm{X}$ & $\mathrm{X}$ & $\mathrm{N}$ & $\mathrm{X}$ & $\mathrm{N}$ \\
\hline Sala de parto normal & 03 & 01 & 01 & $02 *$ & $02 *$ & $\mathrm{CC}$ & $\mathrm{CC}$ & $\mathrm{CC}$ \\
\hline Sala de parto cirúrgico & 02 & 01 & 01 & $02 *$ & $02 *$ & $\mathrm{CC}$ & $\mathrm{CC}$ & $\mathrm{CC}$ \\
\hline $\begin{array}{l}\text { Vestiário com sanitário para ambos } \\
\text { os sexos }\end{array}$ & $\mathrm{X}$ & $\mathbf{N}$ & $X$ & $\mathrm{X}$ & $\mathrm{X}$ & $\mathbf{N}$ & $\mathbf{N}$ & $\mathbf{N}$ \\
\hline $\begin{array}{l}\text { Sala de estar e repouso para } \\
\text { funcionários e médicos }\end{array}$ & $\mathrm{X}$ & $X$ & $\mathrm{X}$ & $\mathrm{X}$ & $\mathrm{X}$ & $\mathrm{CC}$ & $N$ & $\mathrm{~N}$ \\
\hline RPA & $\mathrm{X}$ & $\mathbf{N}$ & $\mathrm{X}$ & $\mathrm{X}$ & $\mathrm{X}$ & $\mathrm{N}$ & $\mathbf{N}$ & $\mathbf{N}$ \\
\hline O parto é realizado por médico & $\mathrm{X}$ & $\mathrm{X}$ & $X$ & $X$ & $\mathrm{X}$ & $X$ & $X$ & $X$ \\
\hline O parto é realizado por obstetriz & $\mathbf{N}$ & $\mathbf{N}$ & $\mathbf{N}$ & $\mathbf{N}$ & $\mathbf{N}$ & $\mathbf{N}$ & $\mathbf{N}$ & $\mathbf{N}$ \\
\hline Há médico obstetra $24 \mathrm{~h}$ & $X$ & $X$ & $X$ & $X$ & $X$ & $\mathbf{N}$ & $\mathbf{N}$ & $X$ \\
\hline Neonatologista recepciona os RNs & $X$ & $X$ & $\mathbf{X}$ & $X$ & $X$ & A & $\mathrm{P}$ & A \\
\hline Há Neonatologista $24 \mathrm{~h}$ & $\mathrm{X}$ & $\mathrm{X}$ & $\mathrm{X}$ & $\mathrm{X}$ & $\mathrm{X}$ & $\mathbf{N}$ & $\mathbf{N}$ & $\mathbf{N}$ \\
\hline $\begin{array}{l}\text { Há disponibilidade de anestesista } \\
24 \mathrm{~h}\end{array}$ & $\mathrm{X}$ & $X$ & $\mathrm{X}$ & $X$ & $X$ & $\mathrm{~N}$ & $\mathrm{~N}$ & $X$ \\
\hline $\begin{array}{l}\text { Há sala de reanimação e } \\
\text { identificação do RN }\end{array}$ & $X$ & $\mathrm{~N}$ & $X$ & $\mathrm{X}$ & $X$ & $X$ & $X$ & $\mathrm{~N}$ \\
\hline $\begin{array}{l}\text { Há pia com água corrente na sala de } \\
\text { reanimação }\end{array}$ & $\mathrm{X}$ & $\mathrm{N}$ & $\mathrm{X}$ & $\mathrm{X}$ & $\mathrm{X}$ & $\mathrm{X}$ & $\mathrm{X}$ & $\mathbf{N}$ \\
\hline Equipamentos adequados no $\mathrm{CO} / \mathrm{CC}$ & $\mathbf{X}$ & $X$ & $X$ & $X$ & $X$ & $\mathbf{X}$ & $X$ & $X$ \\
\hline Bico de oxigênio & $X$ & $X$ & $\mathrm{X}$ & $\mathrm{X}$ & $\mathrm{X}$ & $X$ & $X$ & $\mathrm{X}$ \\
\hline Bico de ar comprimido & $X$ & $X$ & $\mathrm{X}$ & $\mathrm{X}$ & $\mathrm{X}$ & $X$ & $\mathrm{X}$ & $\mathrm{X}$ \\
\hline Bico de vácuo & $\mathrm{X}$ & $\mathrm{X}$ & $\mathrm{X}$ & $\mathrm{X}$ & $\mathrm{X}$ & $\mathrm{X}$ & $\mathrm{X}$ & $\mathrm{X}$ \\
\hline
\end{tabular}

Fonte: Pesquisa de Campo, 2002 e 2003.

(X) Apresenta (N) Não apresenta (A) Anestesista ( P) Pediatra (CC) Centro-Cirúrgico

* 02 salas que são utilizados tanto para Parto Normal quanto Cirúrgico 
Em relação à assistência ao recém-nascido $(\mathrm{RN})$, observamos na Tabela 27 que $87,5 \%$ dos hospitais (A, B, D, E, F, G e I) possuiam berçários de primeiros cuidados, exceto o hospital H (12,5\%); 100\% dos hospitais (A, B, D, E, F, G, H e I) tinham instalado o berçário de baixo risco; $50 \%$ (A, B, D e F) com berçário de médio e alto risco e UTI-Neonatal instalados.

A área física dos berçários era adequada em 75\% dos hospitais (A, D, E, F, G e $\mathrm{H}$ ) e inadequada em $25 \%$ deles (B e I); $50 \%$ ( $\mathrm{A}, \mathrm{B}, \mathrm{D}$ e $\mathrm{H}$ ) contavam com equipamentos adequados à assitência do $\mathrm{RN}$, enquanto nos demais $50 \%(\mathrm{E}, \mathrm{F}, \mathrm{G}$ e I) encontramos equipamentos inadequados.

Os recursos humanos eram adequados em $100 \%$ dos berçários dos hospitais da amostra.

Tabela 27 - Organização e Atenção ao Paciente - Berçário dos hospitais A, B, D, E, F, G, H e I, Estado de São Paulo, 2002 e 2003.

\begin{tabular}{lllllllll}
\hline Berçário & $\mathrm{A}$ & $\mathrm{B}$ & $\mathrm{D}$ & $\mathrm{E}$ & $\mathrm{F}$ & $\mathrm{G}$ & $\mathrm{H}$ & $\mathrm{I}$ \\
\hline $\begin{array}{l}\text { Berçário de primeiros } \\
\text { cuidados }\end{array}$ & $\mathrm{X}$ & $\mathrm{X}$ & $\mathrm{X}$ & $\mathrm{X}$ & $\mathrm{X}$ & $\mathrm{X}$ & $\mathrm{N}$ & $\mathrm{X}$ \\
Berçário de baixo risco & $\mathrm{X}$ & $\mathrm{X}$ & $\mathrm{X}$ & $\mathrm{X}$ & $\mathrm{X}$ & $\mathrm{X}$ & $\mathrm{X}$ & $\mathrm{X}$ \\
Berçário de médio risco & $\mathrm{X}$ & $\mathrm{X}$ & $\mathrm{X}$ & $\mathrm{N}$ & $\mathrm{X}$ & $\mathrm{N}$ & $\mathrm{N}$ & $\mathrm{N}$ \\
Berçário de Alto risco & $\mathrm{X}$ & $\mathrm{X}$ & $\mathrm{X}$ & $\mathrm{N}$ & $\mathrm{X}$ & $\mathrm{N}$ & $\mathrm{N}$ & $\mathrm{N}$ \\
Há UTI Neonatal & $\mathrm{X}$ & $\mathrm{X}$ & $\mathrm{X}$ & $\mathrm{N}$ & $\mathrm{X}$ & $\mathrm{N}$ & $\mathrm{N}$ & $\mathrm{N}$ \\
Área Física Adequada & $\mathrm{X}$ & $\mathrm{N}$ & $\mathrm{X}$ & $\mathrm{X}$ & $\mathrm{X}$ & $\mathrm{X}$ & $\mathrm{X}$ & $\mathrm{N}$ \\
$\begin{array}{l}\text { Equipamentos } \\
\text { Adequados }\end{array}$ & $\mathrm{X}$ & $\mathrm{X}$ & $\mathrm{X}$ & $\mathrm{N} *$ & $\mathrm{~N} *$ & $\mathrm{~N} *$ & $\mathrm{X}$ & $\mathrm{N} *$ \\
$\begin{array}{l}\text { Recursos Humanos } \\
\text { adequados }\end{array}$ & $\mathrm{X}$ & $\mathrm{X}$ & $\mathrm{X}$ & $\mathrm{X}$ & $\mathrm{X}$ & $\mathrm{X}$ & $\mathrm{X}$ & $\mathrm{X}$ \\
\hline
\end{tabular}

Fonte: Pesquisa de Campo, 2002 e 2003.

(X) Apresenta (N) Não apresenta

* berço aquecido por insuflação 
Na Tabela 28, observamos que os Centros-Cirúrgicos dos hospitais eram pequenos, médios e grandes, em função do número de salas instaladas. O número de salas cirúrgicas variou de 02 a 21 , com mediana de 07 salas.

Tabela 28 - Organização e Atenção ao Paciente - Centro-Cirúrgico dos nove hospitais, Estado de São Paulo, 2002 e 2003.

\begin{tabular}{|c|c|c|c|c|c|c|c|c|c|}
\hline Centro-Cirúrgico & A & $\mathrm{B}$ & $\mathrm{C}$ & $\mathrm{D}$ & $\mathrm{E}$ & $\mathrm{F}$ & G & $\mathrm{H}$ & I \\
\hline $\begin{array}{l}\text { Número de salas de } \\
\text { cirurgia especial }\end{array}$ & 02 & 01 & 0 & 01 & 0 & 0 & 0 & 0 & 0 \\
\hline $\begin{array}{l}\text { Número de salas de } \\
\text { grandes cirurgias }\end{array}$ & 06 & 02 & 04 & 02 & 04 & 01 & 0 & 0 & 0 \\
\hline $\begin{array}{l}\text { Número de salas de } \\
\text { médias cirurgias }\end{array}$ & 08 & 04 & 02 & 04 & 03 & 05 & 01 & 02 & 02 \\
\hline $\begin{array}{l}\text { Número de salas de } \\
\text { pequenas cirurgias }\end{array}$ & 05 & 01 & 01 & 0 & 0 & 0 & 01 & 01 & 0 \\
\hline Sala Inoperante & 0 & 04 & 0 & 0 & 0 & 0 & 0 & 0 & 0 \\
\hline $\begin{array}{l}\text { Número Total de salas } \\
\text { cirúrgicas }\end{array}$ & 21 & 12 & 07 & 07 & 07 & 06 & 02 & 03 & 02 \\
\hline
\end{tabular}

Fonte: Pesquisa de Campo, 2002 e 2003.

(X) Apresenta (N) Não apresenta

Para analisarmos as características dos Centros-Cirúrgicos dos hospitais da amostra, a Tabela 29 nos demonstra que, em relação à área física, 77,77\% dos hospitais $(\mathrm{A}, \mathrm{B}, \mathrm{D}, \mathrm{E}, \mathrm{F}, \mathrm{G}$ e H) continham área de recepção do paciente com passamaca, 22,22\% (C e I) não apresentavam; 100\% dos hospitais (A, B, C, D, E, F, G, H e I) contavam com entradas diferenciadas para pacientes e funcionários e área de escovação adequada, $66,66 \%$ dos hospitais (A, B, C, D, E e F) possuiam posto de enfermagem e serviços e 33,33\% (G, H e I) não; em 55,55\% dos hospitais (A, C, D, E e F) observamos vestiário com sanitário para ambos os sexos, enquanto em $44,44 \%$ (B, G, H e I) não havia diferenciação; em 55,55\% dos hospitais ( $A, B, C, D$ e F) encontramos sala de preparo de equipamento e material; em $66,66 \%$ (A, B, C, D, E e F) estavam presentes a sala de depósito de equipamentos e materiais e a sala 
administrativa; $77,77 \%$ (A, B, C, D, E, F e H) tinham Depósito de Material de Limpeza; 77,77\% (A, B, C, D, E, F e G) sala de estar para funcionários; 33,33\% (A, D, F) sala de espera com sanitários para acompanhantes; $88,88 \%$ (A, B, C, D, E, F, G e H) área de guarda de macas e cadeiras de rodas; 33,33\% (A, D e E) sala de biópsia de congelação no Centro-Cirúrgico; 77,77\% (A, B, C, D, E, F e G) conforto médico; $100 \%$ das salas contavam com rede de oxigênio e ar comprimido, $88,88 \%$ (A, B, C, D, E, F, G e I) com rede de vácuo; 77,77\% ( A, B, C, D, E, F e I) com óxido nitroso em rede e $22,22 \%(\mathrm{G}$ e $\mathrm{H})$ em torpedos.

Os equipamentos: carrinhos de anestesia, respiradores, oxímetros e monitores eram adequados em todos os hospitais da amostra.

Em todos os turnos de funcionamentos dos Centros-Cirúrgicos encontramos enfermeiras responsáveis pelo serviço. 
Tabela 29- Características dos Centros - Cirúrgicos dos nove hospitais, Estado de São Paulo, 2002 e 2003.

\begin{tabular}{|c|c|c|c|c|c|c|c|c|c|}
\hline Centro Cirúrgico & $\mathrm{A}$ & B & $\mathrm{C}$ & $\mathrm{D}$ & $\mathrm{E}$ & F & $\mathrm{G}$ & $\mathrm{H}$ & I \\
\hline $\begin{array}{l}\text { Há área de recepção do paciente com } \\
\text { passa-maca }\end{array}$ & $\mathrm{X}$ & $\mathrm{X}$ & $\mathbf{N}$ & $\bar{X}$ & $\mathrm{X}$ & $\mathrm{X}$ & $\mathrm{X}$ & $\mathrm{X}$ & $\bar{N}$ \\
\hline Há área de escovação & $\mathrm{X}$ & $\mathrm{X}$ & $\mathrm{X}$ & $\mathrm{X}$ & $\mathrm{X}$ & $\mathrm{X}$ & $\mathrm{X}$ & $\mathrm{X}$ & $\mathrm{X}$ \\
\hline $\begin{array}{l}\text { Apresenta posto de enfermagem } \\
\text { e serviços }\end{array}$ & $\mathrm{X}$ & $\mathrm{X}$ & $X$ & $X$ & $\mathbf{X}$ & $\mathrm{X}$ & $\mathbf{N}$ & $\mathbf{N}$ & $\mathbf{N}$ \\
\hline $\begin{array}{l}\text { Há vestiários com sanitários para } \\
\text { ambos os sexos com barreira }\end{array}$ & $\mathrm{X}$ & $\mathbf{N}$ & $\mathrm{X}$ & $\mathrm{X}$ & $\mathrm{X}$ & $\mathrm{X}$ & $\mathbf{N}$ & $\mathrm{N}$ & $\mathrm{N}$ \\
\hline $\begin{array}{l}\text { Sala de preparo de equipamento } \\
\text { e material }\end{array}$ & $\mathrm{X}$ & $X$ & $\mathrm{X}$ & $\mathbf{X}$ & $\mathrm{N}$ & $\mathrm{X}$ & $\mathrm{N}$ & $\mathrm{N}$ & $\mathbf{N}$ \\
\hline Depósito de equipamentos e materiais & $\mathrm{X}$ & $X$ & $\mathrm{X}$ & $\mathbf{X}$ & $X$ & $\mathrm{X}$ & $\mathbf{N}$ & $\mathbf{N}$ & $\mathbf{N}$ \\
\hline Sala Administrativa & $X$ & $X$ & $X$ & $\mathrm{X}$ & $\mathrm{X}$ & $\mathrm{X}$ & $\mathbf{N}$ & $\mathbf{N}$ & $\mathbf{N}$ \\
\hline Depósito de Material de Limpeza & $\mathrm{X}$ & $\mathrm{X}$ & $\mathrm{X}$ & $\mathrm{X}$ & $\mathrm{X}$ & $\mathrm{X}$ & $\mathbf{N}$ & $\mathrm{X}$ & $\mathbf{N}$ \\
\hline Sala de Estar para Funcionários & $\mathrm{X}$ & $\mathrm{X}$ & $X$ & $\mathbf{X}$ & $\mathrm{X}$ & $\mathbf{X}$ & $\mathrm{X}$ & $\mathbf{N}$ & $\mathbf{N}$ \\
\hline $\begin{array}{l}\text { Sala de Espera com sanitário para } \\
\text { acompanhantes }\end{array}$ & $\mathrm{X}$ & $\mathbf{N}$ & $\mathbf{N}$ & $X$ & $\mathbf{N}$ & $X$ & $\mathrm{~N}$ & $\mathbf{N}$ & $\mathbf{N}$ \\
\hline $\begin{array}{l}\text { Área de guarda de macas e } \\
\text { cadeira de rodas }\end{array}$ & $\mathrm{X}$ & $\mathrm{X}$ & $X$ & $X$ & $\mathrm{X}$ & $\mathrm{X}$ & $\mathrm{X}$ & $X$ & $\mathbf{N}$ \\
\hline Sala de biópsia de Congelação & $\mathrm{X}$ & $\mathbf{N}$ & $\mathbf{N}$ & $\mathrm{X}$ & $\mathrm{X}$ & $\mathbf{N}$ & $\mathbf{N}$ & $\mathbf{N}$ & $\mathbf{N}$ \\
\hline $\begin{array}{l}\text { Fluxos paciente/ funcionários por } \\
\text { entradas diferentes }\end{array}$ & $\mathrm{X}$ & $\mathrm{X}$ & $\mathrm{X}$ & $\mathrm{X}$ & $\mathbf{X}$ & $\mathrm{X}$ & $\mathrm{X}$ & $\mathrm{X}$ & $\mathrm{X}$ \\
\hline Há sala de conforto médico & $X$ & $\mathrm{X}$ & $\mathrm{X}$ & $X$ & $\mathrm{X}$ & $\mathbf{X}$ & $\mathrm{X}$ & $\mathbf{N}$ & $\mathbf{N}$ \\
\hline Enfermeira em todos os turnos & $\mathrm{X}$ & $\mathrm{X}$ & $\mathrm{X}$ & $\mathrm{X}$ & $\mathrm{X}$ & $\mathrm{X}$ & $\mathrm{X}$ & $\mathrm{X}$ & $\mathrm{X}$ \\
\hline Bico(s) de oxigênio/sala & $\mathrm{X}$ & $\mathrm{X}$ & $\mathbf{X}$ & $\mathrm{X}$ & $X$ & 01 & 01 & 02 & $\mathrm{X}$ \\
\hline Bico(s) de ar comprimido/ sala & $\mathrm{X}$ & $\mathrm{X}$ & $\mathrm{X}$ & $\mathrm{X}$ & $\mathrm{X}$ & 01 & 01 & 02 & $\mathrm{X}$ \\
\hline Bico(s) de vácuo/sala & $\mathrm{X}$ & $\mathrm{X}$ & $\mathbf{X}$ & $\mathbf{X}$ & $\mathbf{X}$ & 01 & 01 & - & $\mathrm{X}$ \\
\hline Oxido Nitroso/sala & $\mathrm{X}$ & $\mathrm{X}$ & $\mathrm{X}$ & $\mathrm{X}$ & $\mathrm{X}$ & 01 & $\mathrm{t}$ & $\mathbf{t}$ & $\mathrm{X}$ \\
\hline $\begin{array}{l}\text { Carrinho de anestesia adequado nas } \\
\text { salas }\end{array}$ & $\mathrm{X}$ & $\mathrm{X}$ & $X$ & $\mathrm{X}$ & $\mathrm{X}$ & $\mathrm{X}$ & $\mathrm{X}$ & $\mathrm{X}$ & $\mathrm{X}$ \\
\hline Respirador adequado em todas as salas & $\mathrm{X}$ & $X$ & $X$ & $\mathrm{X}$ & $\mathrm{X}$ & $\mathrm{X}$ & $\mathrm{X}$ & $\mathrm{X}$ & $\mathrm{X}$ \\
\hline \multirow[t]{2}{*}{ Oxímetro de pulso em todas as salas } & $\mathrm{X}$ & $\mathrm{X}$ & $\mathrm{X}$ & $\mathbf{X}$ & $\mathrm{X}$ & $\mathrm{X}$ & $01 /$ & $01 /$ & $\mathrm{X}$ \\
\hline & & & & & & & $\mathrm{CC}$ & $\mathrm{CC}$ & \\
\hline
\end{tabular}

Fonte: Pesquisa de Campo, 2002 e 2003.

(X) Apresenta (N) Não apresenta ( $($ ) torpedo 
O resultado da observação da Recuperação Pós-Anestésica (RPA) dos hospitais da amostra encontra-se na Tabela 30 , onde observamos que $66,66 \%$ dos hospitais (A, B, C, D, E e F) estão com esta unidade instalada, enquanto 33,33\% (G, H e I) não. Dos hospitais com RPA, 55,55\% (A, C, D, E e F) estavam em área física adequada, com recursos humanos em quantidade e qualidade, $11,11 \%$ (B) estava em área física inadequada, com recursos humanos inadequados. Em 66,66\% dos hospitais (A, B, C, D, E e F) estavam instalados bicos de oxigênio, ar comprimido e vácuo. Os equipamentos das RPAs (desfibrilador, monitor de frequiência cardíaca, oxímetro e material de urgência) eram adequados em $66,66 \%$ dos hospitais (A, B, C, D, E e F).

Tabela 30 - Organização e Atenção ao Paciente - Características das RPAs dos nove hospitais, Estado de São Paulo, 2002 e 2003.

\begin{tabular}{|c|c|c|c|c|c|c|c|c|c|}
\hline RPA & A & B & $\mathrm{C}$ & $\mathrm{D}$ & $\mathrm{E}$ & $\mathrm{F}$ & G & $\mathrm{H}$ & I \\
\hline Número de leitos & 05 & 05 & 06 & 10 & 07 & 07 & 0 & 0 & 0 \\
\hline Área física adequada & $\mathrm{X}$ & $\mathbf{N}$ & $X$ & $X$ & $X$ & $\mathrm{X}$ & $\mathrm{N}$ & $\mathbf{N}$ & $\mathrm{N}$ \\
\hline $\begin{array}{l}\text { Recursos humanos } \\
\text { adequados }\end{array}$ & $\mathrm{X}$ & $\mathbf{N}$ & $\mathrm{X}$ & $\mathrm{X}$ & $\mathrm{X}$ & $\mathrm{X}$ & $\mathbf{N}$ & $\mathbf{N}$ & $\mathrm{N}$ \\
\hline Desfibrilador & $X$ & $X$ & $X$ & $\mathrm{X}$ & $X$ & $X$ & $\mathbf{N}$ & $\mathbf{N}$ & $\mathrm{N}$ \\
\hline $\begin{array}{l}\text { Monitor de Freqüência } \\
\text { Cardíaca }\end{array}$ & $\mathrm{X}$ & $X$ & $X$ & $\mathrm{X}$ & $\mathrm{X}$ & $\mathrm{X}$ & $\mathrm{N}$ & $\mathbf{N}$ & $\mathrm{N}$ \\
\hline Oxímetro & $X$ & $X$ & $X$ & $\mathrm{X}$ & $X$ & $X$ & $\mathbf{N}$ & $\mathbf{N}$ & $\mathrm{N}$ \\
\hline Material de urgência & $\mathrm{X}$ & $X$ & $\mathrm{X}$ & $\mathrm{X}$ & $X$ & $X$ & $\mathbf{N}$ & $\mathbf{N}$ & $\mathrm{N}$ \\
\hline 1 bico de oxigênio/leito & 02 & $\mathbf{X}$ & $\mathrm{X}$ & $\mathrm{X}$ & $X$ & $X$ & $\mathbf{N}$ & $\mathbf{N}$ & $\mathbf{N}$ \\
\hline $\begin{array}{l}1 \text { bico de ar } \\
\text { comprimido/leito }\end{array}$ & 02 & $X$ & $X$ & $X$ & $X$ & $X$ & $\mathbf{N}$ & $\mathrm{N}$ & $\mathrm{N}$ \\
\hline 1 bico de vácuo/ leito & 02 & $X$ & $\mathbf{X}$ & $\mathbf{X}$ & $X$ & $01 / 21$ & $\mathbf{N}$ & $\mathrm{N}$ & $\mathrm{N}$ \\
\hline
\end{tabular}


Os Serviços de Apoio Diagnóstico e Terapia básicos dos hospitais da amostra observados na Tabela 31 foram: Anatomia Patológica e Hemoterapia, presentes em $88,88 \%$ da amostra (A, B, C, D, E, F, G e H), exceto o hospital I (11,11\%); Ultrassonografia em $88,88 \%$ (A, B, C, D, E, F, H e I), exceto o hospital G $(11,11 \%)$; Eletrocardiograma, Endoscopia, Patologia Clínica, RX Simples, RX Contrastado presentes em 100\% dos hospitais (A, B, C, D, E, F, G, H e I).

Tabela 31 - Serviços de Apoio Diagnóstico e Terapia Básicos dos nove hospitais do Estado de São Paulo, 2002 e 2003.

\begin{tabular}{lccccccccc}
\hline SADT Básico & $\mathrm{A}$ & $\mathrm{B}$ & $\mathrm{C}$ & $\mathrm{D}$ & $\mathrm{E}$ & $\mathrm{F}$ & $\mathrm{G}$ & $\mathrm{H}$ & $\mathrm{I}$ \\
\hline Anatomia Patológica & $\mathrm{X}$ & $\mathrm{X}$ & $\mathrm{X}$ & $\mathrm{X}$ & $\mathrm{X}$ & $\mathrm{X}$ & $\mathrm{X}$ & $\mathrm{X}$ & $\mathrm{N}$ \\
ECG & $\mathrm{X}$ & $\mathrm{X}$ & $\mathrm{X}$ & $\mathrm{X}$ & $\mathrm{X}$ & $\mathrm{X}$ & $\mathrm{X}$ & $\mathrm{X}$ & $\mathrm{X}$ \\
Endoscopia & $\mathrm{X}$ & $\mathrm{X}$ & $\mathrm{X}$ & $\mathrm{X}$ & $\mathrm{X}$ & $\mathrm{X}$ & $\mathrm{X}$ & $\mathrm{X}$ & $\mathrm{X}$ \\
Hemoterapia & $\mathrm{X}$ & $\mathrm{X}$ & $\mathrm{X}$ & $\mathrm{X}$ & $\mathrm{X}$ & $\mathrm{X}$ & $\mathrm{X}$ & $\mathrm{X}$ & $\mathrm{N}$ \\
Patologia Clínica & $\mathrm{X}$ & $\mathrm{X}$ & $\mathrm{X}$ & $\mathrm{X}$ & $\mathrm{X}$ & $\mathrm{X}$ & $\mathrm{X}$ & $\mathrm{X}$ & $\mathrm{X}$ \\
RX simples & $\mathrm{X}$ & $\mathrm{X}$ & $\mathrm{X}$ & $\mathrm{X}$ & $\mathrm{X}$ & $\mathrm{X}$ & $\mathrm{X}$ & $\mathrm{X}$ & $\mathrm{X}$ \\
RX contrastado & $\mathrm{X}$ & $\mathrm{X}$ & $\mathrm{X}$ & $\mathrm{X}$ & $\mathrm{X}$ & $\mathrm{X}$ & $\mathrm{X}$ & $\mathrm{X}$ & $\mathrm{X}$ \\
RX portátil & $\mathrm{X}$ & $\mathrm{X}$ & $\mathrm{X}$ & $\mathrm{X}$ & $\mathrm{X}$ & $\mathrm{X}$ & $\mathrm{X}$ & $\mathrm{X}$ & $\mathrm{X}$ \\
USG & $\mathrm{X}$ & $\mathrm{X}$ & $\mathrm{X}$ & $\mathrm{X}$ & $\mathrm{X}$ & $\mathrm{X}$ & $\mathrm{N}$ & $\mathrm{X}$ & $\mathrm{X}$ \\
\hline Fonte: Pesquisa de Campo $2002 \mathrm{e}$ & 2003 & & & & & & & &
\end{tabular}

(X) Apresenta (N) Não apresenta

Em relação aos demais Serviços de Apoio Diagnóstico e Terapia, considerados acessórios, a Tabela 32 apresenta o resultado observado: 44,44\% dos hospitais (A, B, C e D) realizavam exames de Angiografia Digital e ou Hemodinâmica; 22,22\% (A e B) Audiometria; 11,11\% (A) Cintilografia; 33,33\% (A, B e C) Eletroencelalografia; $22,22 \%$ (A e B) Eletroneuromiografia; $11,11 \%$ (A) Distúrbios do Sono; 44,44\% (A, B, C e F) Ergometria; 44,44\% (A, B, G e I) Fisioterapia; 22,22\% (A e E) Hemodiálise; 66,66\% (A, B, C, D, E e F) Ecografia; 44,44\% (A, B, C e F) Holter; 33,33\% (A, B e C) MAPA; 44,44\% (A, B, D e F) 
Litotripsia; 55,55\% (A, B, C, D e G) Mamografia; 44,44\% (A, B, C e D)

Quimioterapia; $11,11 \%$ (C) Radioterapia; 66,66\% (A, B, C, D, E e G ) Tomografia; 22,22\% (A e B) Ressonância Magnética; $11,11 \%$ (A) Neurofisiologia e 0\% Tilt Table Test.

Tabela 32 - Serviços de Apoio Diagnóstico e Terapia Acessórios dos nove hospitais do Estado de São Paulo, 2002 e 2003.

\begin{tabular}{llllllllll}
\hline SADT Acessórios & A & B & C & D & E & F & G & H & I \\
\hline Angiografia & X & X & X & X & N & N & N & N & N \\
Digital/Hemodinâmica & & & & & & & & & \\
Audiometria & X & X & N & N & N & N & N & N & N \\
Cintilografia & X & N & N & N & N & N & N & N & N \\
EEG & X & X & X & N & N & N & N & N & N \\
Eletroneuromiografia & X & X & N & N & N & N & N & N & N \\
Distúrbios do Sono & X & N & N & N & N & N & N & N & N \\
Ergometria & X & X & X & N & N & X & N & N & N \\
Fisioterapia & X & X & N & N & T & N & X & N & X \\
Hemodiálise & X & N & N & N & X & N & N & N & N \\
Ecografia & X & X & X & X & X & X & N & N & N \\
Holter & X & X & X & N & N & X & N & N & N \\
MAPA & X & X & X & N & N & N & N & N & N \\
Litotripsia & X & X & N & X & N & X & N & N & N \\
Mamografia & X & X & X & X & N & N & X & N & N \\
Quimioterapia & X & X & X & X & N & N & N & N & N \\
Radioterapia & N & N & X & N & N & N & N & N & N \\
Tomografia & X & X & X & X & X & N & X & N & N \\
Ressonância Magnética & X & X & N & N & N & N & N & N & N \\
Neurofisiologia & X & N & N & N & N & N & N & N & N \\
Tilt Table Test & N & N & N & N & N & N & N & N \\
\hline Fonte: Pesquisa de Campoo & & & & & & & &
\end{tabular}

(X) Apresenta N (Não apresenta) T (terceirizado) 
A Farmácia Hospitalar é o órgão tecnicamente preparado para armazenar, distribuir, controlar e produzir medicamentos e produtos afins utilizados no hospital. É também responsável pela informação técnica, científica e controle de qualidade de medicamentos e agentes químicos utilizados no hospital. ${ }^{97}$

Na Tabela 33 encontra-se resumo das observações feitas nas farmácias dos hospitais da amostra, onde observamos que $100 \%$ (A, B, C, D, E, F, G, H e I) realiza controle de medicamentos conforme Portaria $n^{\circ} 344 / 98$. Os hospitais da amostra não manipulam NPP; no hospital D $(11,11 \%)$, estava instalada capela de fluxo laminar destinada ao preparo de quimioterápicos; em 77,77\% (A, B, C, E, F, G e H) havia local adequado ao preparo de medicamentos; em $88,88 \%$ (A, B, C, D, E, F, G e H) havia local adequado para dispensação de medicamentos; $100 \%$ contavam com farmacêutico responsável; 77,77\% (A, B, C, D, E, F e G) estavam com os medicamentos padronizados, e quanto à dispensação, era feita de forma convencional em $11,11 \%$ dos hospitais (G), de forma individualizada em $66,66 \%$ (A, B, D, F, H e I) e de forma unitária em 33,33\% dos hospitais (C, E e F). 
Tabela 33 - Serviços de Apoio Técnico e Administrativo - Farmácia dos nove hospitais do Estado de São Paulo, 2002 e 2003.

\begin{tabular}{|c|c|c|c|c|c|c|c|c|c|}
\hline Farmácia & A & B & $\mathrm{C}$ & $\mathrm{D}$ & $\mathrm{E}$ & $\mathrm{F}$ & $\mathrm{G}$ & $\mathrm{H}$ & I \\
\hline $\begin{array}{l}\text { Há controle dos } \\
\text { medicamentos Port. } n^{\circ} 344 / 98\end{array}$ & $\mathrm{X}$ & $\mathrm{X}$ & $X$ & $X$ & $X$ & $\mathrm{X}$ & $\mathrm{X}$ & $\mathrm{X}$ & $\mathrm{X}$ \\
\hline A farmácia manipula NPP & $\mathrm{N}$ & $\mathrm{N}$ & $\mathbf{N}$ & $\mathrm{N}$ & $\mathbf{N}$ & $\mathrm{N}$ & $\mathbf{N}$ & $\mathbf{N}$ & $\mathbf{N}$ \\
\hline $\begin{array}{l}\text { Em área adequada conforme } \\
\text { legislação }\end{array}$ & $\mathrm{N}$ & $\mathrm{N}$ & $\mathrm{N}$ & $\mathrm{N}$ & $N$ & $\mathrm{~N}$ & $\mathbf{N}$ & $\mathbf{N}$ & $\mathbf{N}$ \\
\hline Há capela de fluxo laminar & $\mathrm{N}$ & $\mathrm{N}$ & $\mathrm{N}$ & $X^{*}$ & $N$ & $\mathbf{N}$ & $\mathrm{N}$ & $\mathbf{N}$ & $\mathrm{N}$ \\
\hline $\begin{array}{l}\text { Há local adequado para } \\
\text { preparo dos medicamentos }\end{array}$ & $X$ & $X$ & $\mathrm{X}$ & $\mathbf{N}$ & $X$ & $X$ & $X$ & $X$ & $\mathbf{N}$ \\
\hline $\begin{array}{l}\text { Há local adequado para } \\
\text { dispensação }\end{array}$ & $X$ & $\mathrm{X}$ & $\mathrm{X}$ & $\mathrm{X}$ & $\mathrm{X}$ & $\mathrm{X}$ & $X$ & $X$ & $\mathbf{N}$ \\
\hline$N^{\circ}$ de farmacêutico no local & $X$ & $\mathrm{X}$ & $\mathrm{X}$ & $\mathrm{X}$ & $\mathrm{X}$ & $\mathrm{X}$ & $X$ & $X$ & $\mathrm{X}$ \\
\hline $\begin{array}{l}\text { Há padronização de } \\
\text { medicamentos }\end{array}$ & $X$ & $\mathrm{X}$ & $\mathrm{X}$ & $\mathrm{X}$ & $\mathrm{X}$ & $X$ & $\mathrm{X}$ & $\mathbf{N}$ & $\mathbf{N}$ \\
\hline Dispensação Convencional & $\mathrm{N}$ & $\mathbf{N}$ & $\mathrm{N}$ & $\mathrm{N}$ & $\mathrm{N}$ & $\mathrm{N}$ & $X$ & $\mathrm{~N}$ & $\mathbf{N}$ \\
\hline Dispensação Individualizada & $X$ & $\mathrm{X}$ & $\mathbf{N}$ & $X$ & $N$ & $X$ & $\mathbf{N}$ & $X$ & $X$ \\
\hline Dispensação Unitária & $\mathrm{N}$ & $\mathbf{N}$ & $X$ & $\mathrm{~N}$ & $X$ & $X$ & $\mathbf{N}$ & $\mathbf{N}$ & $\mathbf{N}$ \\
\hline
\end{tabular}

Fonte: Pesquisa de Campo, 2002 e 2003.

(X) Apresenta (N) Não apresenta

* Preparo de Quimioterápicos

O Serviço de Nutrição e Dietética (SND) é responsável pela assistência nutricional do paciente em regime de internação ou ambulatorial. ${ }^{97}$

Na Tabela 34 observamos a organização dos SND dos hospitais da amostra onde observamos que $77,77 \%$ dos serviços referentes aos hospitais A, B, C, D, E, G e $\mathrm{H}$ encontravam-se em área física adequada, com circulação adequada, os demais $22,22 \%$ ( $F$ e I) não se encontravam de acordo com a RDC $\mathrm{n}^{\circ} 50 / 02$; em $100 \%$ estavam instaladas bancadas para manipulação dos alimentos e cardápio afixado com periodicidade definida. Em $88,88 \%$ (A, B, C, D, E, F, H e I) a nutrionista era a responsável técnica pelo serviço, apenas $11,11 \%$ (G) não possuía esta profissional. 
Tabela 34 - Serviços de Apoio Técnico e Administrativo - Serviço de Nutrição e Dietética dos nove hospitais do Estado de São Paulo, 2002 e 2003.

\begin{tabular}{llllllllll}
\hline SND & A & B & C & D & E & F & G & H & I \\
\hline Circulação adequada & $\mathrm{X}$ & $\mathrm{X}$ & $\mathrm{X}$ & $\mathrm{X}$ & $\mathrm{X}$ & $\mathrm{N}$ & $\mathrm{X}$ & $\mathrm{X}$ & $\mathrm{N}$ \\
$\begin{array}{l}\text { Equipamentos necessários e } \\
\text { conservados }\end{array}$ & $\mathrm{X}$ & $\mathrm{X}$ & $\mathrm{X}$ & $\mathrm{X}$ & $\mathrm{X}$ & $\mathrm{X}$ & $\mathrm{X}$ & $\mathrm{X}$ & $\mathrm{X}$ \\
$\begin{array}{l}\text { Área adequada com boa } \\
\text { iluminação e aeração }\end{array}$ & $\mathrm{X}$ & $\mathrm{X}$ & $\mathrm{X}$ & $\mathrm{X}$ & $\mathrm{X}$ & $\mathrm{N}$ & $\mathrm{X}$ & $\mathrm{X}$ & $\mathrm{N}$ \\
$\begin{array}{l}\text { Existe bancada para } \\
\text { manipulação dos alimentos }\end{array}$ & $\mathrm{X}$ & $\mathrm{X}$ & $\mathrm{X}$ & $\mathrm{X}$ & $\mathrm{X}$ & $\mathrm{X}$ & $\mathrm{X}$ & $\mathrm{X}$ & $\mathrm{X}$ \\
$\begin{array}{l}\text { Há cardápio afixado com } \\
\text { periodicidade definida } \\
\text { Há Nutricionista }\end{array}$ & $\mathrm{X}$ & $\mathrm{X}$ & $\mathrm{X}$ & $\mathrm{X}$ & $\mathrm{X}$ & $\mathrm{X}$ & $\mathrm{X}$ & $\mathrm{X}$ & $\mathrm{X}$ \\
\hline $\begin{array}{l}\text { Fonte: Pesquisa de Campo, 2002 e 2003. } \\
\text { 203 }\end{array}$ & $\mathrm{X}$ & $\mathrm{X}$ & $\mathrm{X}$ & $\mathrm{X}$ & $\mathrm{X}$ & $\mathrm{N}$ & $\mathrm{X}$ & $\mathrm{X}$ \\
\hline
\end{tabular}

(X) Apresenta (N) Não apresenta

Na Tabela 35, observamos a organização dos Serviços de Limpeza Hospitalares dos hospitais da amostra onde detectamos que $100 \%$ deles (A, B, C, D, E, F, G, H e I) estavam organizados, com normas e rotinas estabelecidas com participação da Comissão de Controle de Infeç̧ão Hospitalar $(\mathrm{CCIH})$, utilizando produtos próprios, com coleta seletiva do lixo hospitalar e com funcionários da área utilizando equipamentos de proteção. 
Tabela 35 - Serviços de Apoio Técnico e Administrativo - Serviço de Limpeza dos nove hospitais do Estado de São Paulo, 2002 e 2003.

\begin{tabular}{|c|c|c|c|c|c|c|c|c|c|}
\hline Serviço de Higiene Limpeza & A & B & $\mathrm{C}$ & D & $\mathrm{E}$ & $\mathbf{F}$ & $\mathrm{G}$ & $\mathrm{H}$ & I \\
\hline $\begin{array}{l}\text { Há normas e rotinas para } \\
\text { limpeza da unidade }\end{array}$ & $\mathrm{X}$ & $\mathrm{X}$ & $\mathrm{X}$ & $\mathrm{X}$ & $\mathrm{X}$ & $\mathrm{X}$ & $X$ & $X$ & $\mathbf{X}$ \\
\hline $\begin{array}{l}\text { Utilizam produtos próprios } \\
\text { para limpeza }\end{array}$ & $X$ & $\mathrm{X}$ & $\mathrm{X}$ & $X$ & $\mathrm{X}$ & $\mathrm{X}$ & $\mathrm{X}$ & $X$ & $\mathrm{X}$ \\
\hline $\begin{array}{l}\text { A CCIH participa na } \\
\text { elaboração de normas do } \\
\text { setor }\end{array}$ & $X$ & $\mathrm{X}$ & $\mathrm{X}$ & $\mathrm{X}$ & $\mathrm{X}$ & $\mathrm{X}$ & $\mathrm{N}$ & $X$ & $X$ \\
\hline Há coleta seletiva do lixo & $\mathrm{X}$ & $\mathrm{X}$ & $\mathrm{X}$ & $\mathrm{X}$ & $\mathrm{X}$ & $\mathrm{X}$ & $\mathrm{X}$ & $\mathrm{X}$ & $\mathrm{X}$ \\
\hline $\begin{array}{l}\text { Funcionários utilizam } \\
\text { equipamentos de proteção }\end{array}$ & $\mathrm{X}$ & $X$ & $\mathrm{X}$ & $\mathrm{X}$ & $\mathrm{X}$ & $X$ & $\mathrm{X}$ & $\mathrm{X}$ & $\mathrm{X}$ \\
\hline
\end{tabular}

(X) Apresenta (N) Não apresenta

A Lavanderia é o órgão responsável em prover o hospital de roupa limpa. ${ }^{97}$

Em relação à Lavanderia dos hospitais da amostra, a Tabela 36 apresenta o resultado das observações coletadas: $66,66 \%$ dos hospitais (A, B, C, F, G e H) possuiam serviços próprios, $33,33 \%$ (D, E e I) possuiam serviços terceirizados.

Nestes seis hospitais com serviço de lavanderia instalado, observamos que 33,33\% (G e H) estavam em área física apropriada, 66,64\% (A, B, C e F) em área física inapropriada. Encontramos barreiras físicas em 83,33\% dos hospitais (A, C, F, $\mathrm{G}$ e H), exceto no hospital B (16,66\%). Observamos cruzamento de fluxo de roupas limpas e contaminadas em dois hospitais A e B $(33,33 \%)$. Todos posuiam Serviço de Costura e Rouparia.

Os hospitais A, B, C, F, G e H $(66,66 \%)$ apresentavam equipamentos: máquinas de lavar roupas, centrífugas e calandras, sendo que nos Hospitais B e C $(22,22 \%)$, estes não estavam em boas condições de uso. 
Em $100 \%$ (A, B, C, F, G e H) os funcionários utilizavam equipamentos de proteção.

Tabela 36 - Serviços de Apoio Técnico e Administrativo - Lavanderia dos nove hospitais do Estado de São Paulo, 2002 e 2003.

\begin{tabular}{lccccccccc}
\hline Lavanderia & $\mathrm{A}$ & $\mathrm{B}$ & $\mathrm{C}$ & $\mathrm{D}$ & $\mathrm{E}$ & $\mathrm{F}$ & $\mathrm{G}$ & $\mathrm{H}$ & $\mathrm{I}$ \\
\hline $\begin{array}{l}\text { Máquina de lavar modelo } \\
\text { profissional }\end{array}$ & $\mathrm{X}$ & $\mathrm{X}$ & $\mathrm{X}$ & $\mathrm{T}$ & $\mathrm{T}$ & $\mathrm{X}$ & $\mathrm{X}$ & $\mathrm{X}$ & $\mathrm{T}$ \\
Centrífugas apropriadas & $\mathrm{X}$ & $\mathrm{X}$ & $\mathrm{X}$ & $\mathrm{T}$ & $\mathrm{T}$ & $\mathrm{X}$ & $\mathrm{X}$ & $\mathrm{X}$ & $\mathrm{T}$ \\
Calandras & $\mathrm{X}$ & $\mathrm{X}$ & $\mathrm{X}$ & $\mathrm{T}$ & $\mathrm{T}$ & $\mathrm{X}$ & $\mathrm{X}$ & $\mathrm{X}$ & $\mathrm{T}$ \\
Há barreiras físicas & $\mathrm{X}$ & $\mathrm{N}$ & $\mathrm{X}$ & $\mathrm{T}$ & $\mathrm{T}$ & $\mathrm{X}$ & $\mathrm{X}$ & $\mathrm{X}$ & $\mathrm{T}$ \\
Há cruzamento & $\mathrm{X}$ & $\mathrm{X}$ & $\mathrm{N}$ & $\mathrm{T}$ & $\mathrm{T}$ & $\mathrm{N}$ & $\mathrm{N}$ & $\mathrm{N}$ & $\mathrm{T}$ \\
limpo/contaminado & & & & & & & & & \\
Área física apropriada & $\mathrm{N}$ & $\mathrm{N}$ & $\mathrm{N}$ & $\mathrm{T}$ & $\mathrm{T}$ & $\mathrm{N}$ & $\mathrm{X}$ & $\mathrm{X}$ & $\mathrm{T}$ \\
$\begin{array}{l}\text { Equipamentos em boas } \\
\text { condições }\end{array}$ & $\mathrm{X}$ & $\mathrm{N}$ & $\mathrm{N}$ & $\mathrm{T}$ & $\mathrm{T}$ & $\mathrm{X}$ & $\mathrm{X}$ & $\mathrm{X}$ & $\mathrm{T}$ \\
$\begin{array}{l}\text { Funcionários com } \\
\text { equipamentos de proteção }\end{array}$ & $\mathrm{X}$ & $\mathrm{X}$ & $\mathrm{X}$ & $\mathrm{T}$ & $\mathrm{T}$ & $\mathrm{X}$ & $\mathrm{X}$ & $\mathrm{X}$ & $\mathrm{T}$ \\
Serviço de Costura/Rouparia & $\mathrm{X}$ & $\mathrm{X}$ & $\mathrm{X}$ & $\mathrm{T}$ & $\mathrm{T}$ & $\mathrm{X}$ & $\mathrm{X}$ & $\mathrm{X}$ & $\mathrm{T}$ \\
\hline
\end{tabular}

Fonte: Pesquisa de Campo, 2002 e 2003.

(X) Apresenta (N) Não apresenta (T) Terceirizado

* Em reforma

O Serviço de Almoxarifado consiste em supervisionar, coordenar e orientar a recepção, conferência, armazenagem, conservação e distribuição dos materiais do hospital ${ }^{97}$. Na Tabela 37, observamos que $77,77 \%$ dos hospitais (A, C, D, E, F, G e H) estavam com os almoxarifados instalados em área física apropriada, $22,22 \%$ deles (B e I) não; $88,88 \%$ (A, B, C, D, E, F, G e I) encontravam-se com controle de estoques informatizado, exceto $11,11 \%(\mathrm{H})$ e $100 \%$ (A, B, C, D, E, F, G, H e I) deles tinham estoque suficiente para a operacionalização do hospital. 
Tabela 37 - Serviços de Apoio Técnico e Administrativo - Serviço de Almoxarifado dos nove hospitais do Estado de São Paulo, 2002 e 2003.

\begin{tabular}{llllllllll}
\hline Almoxarifado & A & B & C & D & E & F & G & H & I \\
\hline Área apropriada & $\mathrm{X}$ & $\mathrm{N}$ & $\mathrm{X}$ & $\mathrm{X}$ & $\mathrm{X}$ & $\mathrm{X}$ & $\mathrm{X}$ & $\mathrm{X}$ & $\mathrm{N}$ \\
Estoques suficientes & $\mathrm{X}$ & $\mathrm{X}$ & $\mathrm{X}$ & $\mathrm{X}$ & $\mathrm{X}$ & $\mathrm{X}$ & $\mathrm{X}$ & $\mathrm{X}$ & $\mathrm{X}$ \\
Setor informatizado & $\mathrm{X}$ & $\mathrm{X}$ & $\mathrm{X}$ & $\mathrm{X}$ & $\mathrm{X}$ & $\mathrm{X}$ & $\mathrm{X}$ & $\mathrm{N}$ & $\mathrm{X}$ \\
\hline
\end{tabular}

Fonte: Pesquisa de Campo, 2002 e 2003.

(X) Apresenta (N) Não apresenta

O Serviço de Manutenção é responsável pela manutenção e conservação dos imóveis, instalações e equipamentos do hospital colocando-os em condições de operação contínua. $^{97}$

Na tabela 38, observamos que em $100 \%$ dos hospitais da amostra (A, B, C, D, E, F, G, H e I) o serviço de manutenção era próprio, em 33,33\% (E, F e G), havia também, serviço terceirizado para os equipamentos hospitalares.

Tabela 38 - Serviços de Apoio Técnico e Administrativo - Serviço de Manutenção dos nove hospitais do Estado de São Paulo, 2002 e 2003.

\begin{tabular}{lccccccccc}
\hline Manutenção & A & B & C & D & E & F & G & H & I \\
\hline Manutenção Própria & X & X & X & X & X & X & X & X & X \\
Manutenção Terceirizada & N & N & N & N & X & X & X & N & N \\
\hline Fonte: Pesquisa de Campo, 2002 e 2003. & & & & & & & &
\end{tabular}

(X) Apresenta (N) Não apresenta

O Serviço de Segurança Hospitalar é o órgão responsável pelo planejamento, direção e execução de atividades relacionadas com a preservação do patrimônio, controle e operação dos sistemas de comunicações, transportes e elevadores. ${ }^{97}$

Na Tabela 39, encontramos 66,66\% dos hospitais (A, B, C, D, E e F) com Serviço de Segurança Hospitalar próprios, 33,33\% (G, H e I) não possuíam este serviço. O Hospital D $(11,11 \%)$ também terceiriza parte deste serviço. 
Tabela 39 - Serviços de Apoio Técnico e Administrativo - Serviço de Segurança Hospitalar dos nove hospitais do Estado de São Paulo, 2002 e 2003.

\begin{tabular}{llllllllll}
\hline Segurança Hospitalar & A & B & C & D & E & F & G & H & I \\
\hline Próprio & X & X & X & X & X & X & N & N & N \\
Terceirizado & N & N & N & X & N & N & N & N & N \\
Não possui & & & & & & & X & X & X \\
\hline
\end{tabular}

Fonte: Pesquisa de Campo, 2002 e 2003.

(X) Apresenta (N) Não apresenta

O Serviço de Arquivo Médico e Estatística (SAME) tem por finalidade a manutenção da integridade do conjunto de prontuários dos pacientes, por meio de atividades desenvolvidas segundo critérios de guarda, classificação, codificação, controle da circulação e arquivamento dos prontuários, bem como do necessário sigilo no que se refere ao conteúdo dos mesmos, além de elaborar estatísticas de natureza administrativa e técnicas. ${ }^{97}$

Na Tabela 40, verifica-se que os Serviços de Arquivo Médico dos hospitais da amostra estavam organizados e em $77,77 \%$ deles (A, B. C, D, E, H e I) o prontuário do paciente era único, permitindo a análise e acompanhamento da história clínica do paciente, bem como da evolução de cada caso em particular, sem a perda de dados para a tomada de decisão quanto ao tratamento a ser instituído, conforme legislação. Em 22,22\% dos hospitais ( $F$ e $G$ ) cada internação gerava um novo prontuário.

Analisando amostras de prontuários, observamos que eles estavam preenchidos com identificação do paciente, história clínica, antecedentes pessoais e familiares, exame físico, prescrição, evolução clínica, anotações de enfermagem e anexados os exames de apoio diagnóstico realizados.

Em nenhum hospital estava implantado o prontuário eletrônico. 
Tabela 40 - Serviços de Apoio Técnico e Administrativo - SAME dos nove hospitais do Estado de São Paulo, 2002 e 2003.

\begin{tabular}{llllllllll}
\hline SAME & A & B & C & D & E & F & G & H & I \\
\hline Prontuário Único & X & X & X & X & X & N & N & X & X \\
Conforme legislação & X & X & X & X & X & X & X & X & X \\
Prontuário Eletrônico & N & N & N & N & N & N & N & N & N \\
\hline
\end{tabular}

Fonte: Pesquisa de Campo, 2002 e 2003.

(X) Apresenta (N) Não apresenta

A Central de Esterilização de Materiais é responsável pelo processamento, esterilização, guarda e distribuição de material esterilizado às unidades consumidoras de forma centralizada. ${ }^{97}$

Conforme Tabela 41, as Centrais de Esterilização de Materiais (CEM) dos hospitais da amostra em 33,33\% dos hospitais (D, E e F) estavam instaladas em área física adequada, em $66,66 \%$ deles (A, B, C, G, H e I) a área física era inadequada; $100 \%$ (A, B, C, D, E, E, F, G, H e I) contavam com expurgo, 88,88\% (A, B, C, D, E, E, F, G e H) com área para preparo e esterilização de materiais; 77,77\% (A, B, C, D, E, E, F e H) com área para estocagem de materiais esterilizados. Identificamos que em $44,44 \%$ dos hospitais (A, D, E e F) não havia cruzamento de fluxos de materiais contaminados com esterilizados, porém em $55,55 \%$ dos hospitais (B, C, G, H e I) existia cruzamento de fluxos.

Em relação aos equipamentos: 100\% dos hospitais (A, B, C, D, E, E, F, G, H e I) esterilizavam os materiais em autoclaves horizontais e destes, $22,22 \%$ (B e G) também utilizavam estufas. Havia manutenção preventiva destes equipamentos em $55,55 \%$ dos hospitais (A, C, D, E e F). Todas as Centrais realizavam controle biológico para avaliarem o processo de esterilização. 
Encontramos Enfermeira responsável exclusiva para a Central de Esterilização de Materiais em 44,44\% dos hospitais (A, D, E e F); nos demais havia acúmulo de funções pela enfermeira do Centro-Cirúrgico; $77,77 \%$ dos hospitais (A, C, D, E, F, G e I) estavam com normas e rotinas para a área elaboradas e implantadas.

Tabela 41 - Serviços de Apoio Técnico e Administrativo - Central de Esterilização de Materiais dos nove hospitais do Estado de São Paulo, 2002 e 2003.

\begin{tabular}{lccccccccc}
\hline CEM & A & B & C & D & E & F & G & H & I \\
\hline Encontra-se instalado em área & N & N & N & X & X & X & N & N & N
\end{tabular}
física adequada

Tem área para expurgo

Tem área para preparo/esterilização

Tem área para estocagem/distribuição $\begin{array}{lllllllll}X & X & X & X & X & X & X & X & X\end{array}$ $\begin{array}{lllllllll}X & X & X & X & X & X & X & X & N\end{array}$

Há enfermeira resposável exclusiva

Há normatização de procedimentos na área

Há cruzamento de fluxo de circulação entre as áreas

Funcionários paramentados adequadamente

Possui estufas

Possui Autoclave horizontal

Possui Autoclave vertical

Há manutenção preventiva de equipamentos

$\begin{array}{lllllllll}X & X & X & X & X & X & N & X & N\end{array}$

$\begin{array}{lllllllll}X & N & N & X & X & X & N & N & N\end{array}$

$\begin{array}{lllllllll}X & N & X & X & X & X & X & N & X\end{array}$

$\begin{array}{lllllllll}\mathrm{N} & \mathrm{X} & \mathrm{X} & \mathrm{N} & \mathrm{N} & \mathrm{N} & \mathrm{X} & \mathrm{X} & \mathrm{X}\end{array}$

$\begin{array}{lllllllll}X & X & \text { NO } & X & X & X & X & X & X\end{array}$

$\begin{array}{lllllllll}N & X & N & N & N & N & X & N & N\end{array}$

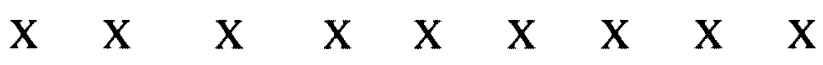

$\begin{array}{lllllllll}N & N & N & N & N & N & N & N & N\end{array}$

$\begin{array}{lllllllll}X & N & X & X & X & X & N & N & N\end{array}$

\begin{tabular}{llllllllll} 
Utiliza Controle Biológico & $\mathrm{X}$ & $\mathrm{X}$ & $\mathrm{X}$ & $\mathrm{X}$ & $\mathrm{X}$ & $\mathrm{X}$ & $\mathrm{X}$ & $\mathrm{X}$ & $\mathrm{X}$ \\
\hline
\end{tabular}

Fonte: Pesquisa de Campo, 2002 e 2003.

(X) Apresenta (N) Não apresenta NO (Não observado) 


\section{Pontuação Atribuída às Áreas Hospitalares Vistoriadas}

O modelo de pontuação utilizado foi aplicado atribuindo-se valor às variáveis qualitativas relacionadas no Roteiro de Vistoria Técnica Hospitalar, conforme descrito anteriormente no item 4.5 sobre descrição do método de análise qualitativa e quantitativa. Para itens obrigatórios ou imprescindíveis foram atribuídos 3 pontos; aos necessários, 2 pontos e aos recomendáveis, 1 ponto. Cada área obteve um número total de pontos que, cumpridos na totalidade, atingiu os $100 \%$. Para a classificação final, calculou-se a média ponderada do percentual de pontos atingidos em cada área.

A atribuição de pontos a cada ítem de avaliação das áreas hospitalares vistoriadas, possibilita a observação objetiva da conformidade. Na tabela 42, observamos que o Hospital A, especial, universitário, de referência regional e estadual, nível de complexidade terciário e quaternário, atendeu na totalidade os ítens de verificação do Centro-Cirúrgico, Recuperação pós-anestésica e os de Serviços de Apoio Diagnóstico e Terapia. Em relação aos demais, necessita ainda de investimentos para a resolução de problemas como adequação de áreas físicas da Lavanderia, Central de Esterilização de Materiais, sanitários das unidades de internação, implantação de sistema de tratamento de resíduos e esgoto. 
Tabela 42 - Pontuação atribuída às áreas hospitalares vistoriadas do Hospital A, 2003.

\begin{tabular}{lccc}
\hline Item avaliado & Total de pontos & Pontos obtidos & \% \\
\hline Organização e funcionamento & 44 & 40 & 90,91 \\
Estrutura física e infra -estrutura & 45 & 39 & 86,67 \\
Hotelaria & 88 & 63 & 81,94 \\
Pronto Socorro & 46 & 42 & 91,30 \\
UTI Geral & 45 & 44 & 97,78 \\
UTI Cardiológica & 45 & 43 & 95,56 \\
UTI Pediátrica & 45 & 44 & 97,78 \\
UTI Neonatal & 45 & 43 & 95,56 \\
Maternidade & 43 & 41 & 95,35 \\
Berçário & 29 & 27 & 93,10 \\
Centro-Cinúrgico & 44 & 44 & 100,00 \\
Recuperação pós-anestésica & 18 & 18 & 100,00 \\
SADT Básico & 29 & 29 & 100,00 \\
SADT Acessório & 44 & 38 & 86,36 \\
Serviços de Apoio & 113 & 96 & 84,96 \\
\hline Total (Média ponderada) & & & $\mathbf{9 3 , 1 5}$
\end{tabular}

Fonte: Pesquisa de Campo, 2003.

No cálculo da Hotelaria do hospital $\mathrm{A}$, foram excluídos os pontos referentes às enfermarias com mais de 4 leitos, pois este hospital nảo apresenta este tipo de acomodaçăn.

Gráfico 1 - Percentual de pontos atingidos pelo Hospital A, por áreas, 2003.

Percentual de pontos atingidos pelo Hospital A, por áreas, 2003

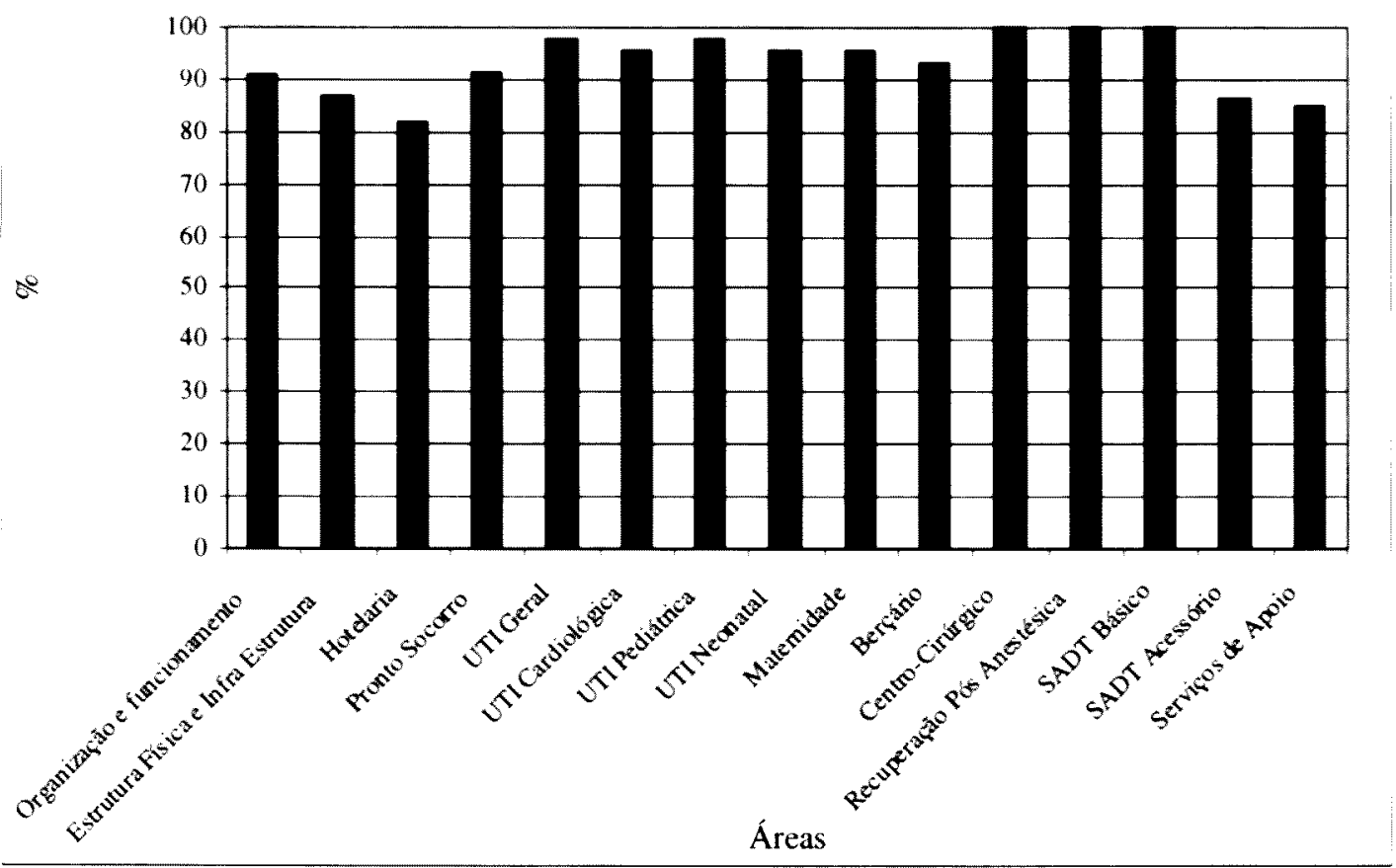

Fonte: Pesquisa de Campo, 2003 
$\mathrm{Na}$ tabela 43, observamos a comparação entre as várias áreas vistoriadas dos hospitais B e C, ambos de grande porte, privados terciários, referência regional. Em função da análise da conformidade ao padrão técnico preestabelecido, podemos afirmar que em uma única área: Recuperação pós-anestésica, o Hospital $\mathrm{C}$ atingiu a totalidade dos pontos; nas demais, os dois hospitais necessitam investimentos para melhoria da organização e funcionamento, estrutura fisica e infra-estrutura, assistência ao paciente, serviços de apoio diagnóstico e terapia e serviços de apoio técnico-administrativo.

O hospital B necessita resolver problemas estruturais relacionados no parecer técnico, que são: adequar sanitários das unidades de internação à $R D C \mathrm{n}^{\circ} 50 / 02$, adequar sala de aplicação de quimioterápicos à RDC $n^{\circ} 50 / 02$ e às Portarias MS $n^{\circ}$ 3535/98 e nº 113/99; instalar sala de reanimação de recém-nascidos; instalar berçário de patológicos e prematuros; instalar isolamento na UTI-neonatal; adequar vestiários do centro-cirúrgico à RDC $\mathrm{n}^{\circ}$ 50/02; mudar a entrada do centro-cirúrgico cardiológico (entrada através da UTI) em cumprimento à RDC $\mathrm{n}^{\circ} 50 / 02$; adequar central de esterilização de materiais à RDC $n^{\circ} 50 / 02$; adequar UTI à RDC no 50/02, bem como à Portaria MS n 3432/98; adequar lavanderia à RDC nº 50/02; implantar sistema de tratamento de resíduos e esgoto; reequipar sala de emergência do prontosocorro para dar condições de sustentação de vida com instalação imediata de respirador adequado; equipar RPA; equipar unidades de internação com carrinho de emergência e torpedo de oxigênio; contratar recursos humanos para compor a equipe médica e de enfermagem do pronto-socorro em atendimento à Portaria GM nº 2048, de 05 de novembro de 2002. 
O Hospital C necessita resolver problemas estruturais que são: adequar sanitários das unidades de internação à RDC $\mathrm{n}^{\circ}$ 50/02; instalar passa-maca no centrocirúrgico ( $\mathrm{RDC} \mathrm{n}^{\circ} 50 / 02$ ); trocar piso da lavanderia ( $\mathrm{RDC} \mathrm{n}^{\circ} 50 / 02$ ); adequar central de esterilização à $\mathrm{RDC} \mathrm{n}^{\circ} 50 / 02$; implantar sistema de tratamento de resíduos e esgoto; reequipar sala de emergência do pronto-socorro para dar condições de sustentação de vida com instalação imediata de respirador adequado; equipar lavanderia com novos equipamentos; analisar o processo assistencial em função das altas taxas de infecção hospitalar e cesáreas.

Tabela 43 - Pontuação atribuída às áreas hospitalares vistoriadas dos hospitais B e C, de grande porte, 2003.

Item avaliado

Total de pontos Pontos obtidos \% Pontos atingidos

\begin{tabular}{lccccc}
\hline Organização e funcionamento & 44 & 42 & 42 & 95,45 & 95,45 \\
Estrutura fisica e infra-estrutura & 45 & 30 & 32 & 66,67 & 71,11 \\
Hotelaria & 88 & 42 & 36 & 73,68 & 63,16 \\
Pronto Socorro & 46 & 30 & 35 & 65,22 & 76,09 \\
UTI Geral & 45 & 37 & 44 & 82,22 & 97,78 \\
UTI Cardiológica & 45 & 37 & - & 82,22 & - \\
UTI Neurológica & 45 & - & 32 & - & 71,11 \\
UTI Pediátrica & 45 & - & - & - & - \\
UTI Neonatal & 45 & 41 & - & 91,11 & - \\
Maternidade & 43 & 28 & - & 65,12 & - \\
Berçário & 29 & 21 & - & 72,41 & - \\
Centro-Cirúrgico & 44 & 40 & 40 & 90,91 & 90,91 \\
Recuperação pós-anestésica & 18 & 12 & 18 & 66,67 & 100,00 \\
SADT Básico & 29 & 25 & 25 & 86,21 & 86,21 \\
SADT Acessório & 44 & 28 & 20 & 63,64 & 45,45 \\
Serviços de Apoio & 113 & 72 & 80 & 63,72 & 70,80 \\
\hline Total (Média ponderada) & & & & $\mathbf{7 6 , 0 9}$ & $\mathbf{7 8 , 9 2}$ \\
\hline
\end{tabular}

Fonte: Pesquisa de Campo, 2003.

No cálculo da Hotelaria dos hospitais $\mathrm{B}$ e $\mathrm{C}$, foram excluídos os pontos referentes à suíte $\mathrm{e}$ enfermarias com mais de 3 leitos, pois estes hospitais não apresentam estes tipos de acomodações. 
Gráfico 2 - Comparação dos pontos obtidos pelos Hospitais B e C, por área vistoriada, 2003.

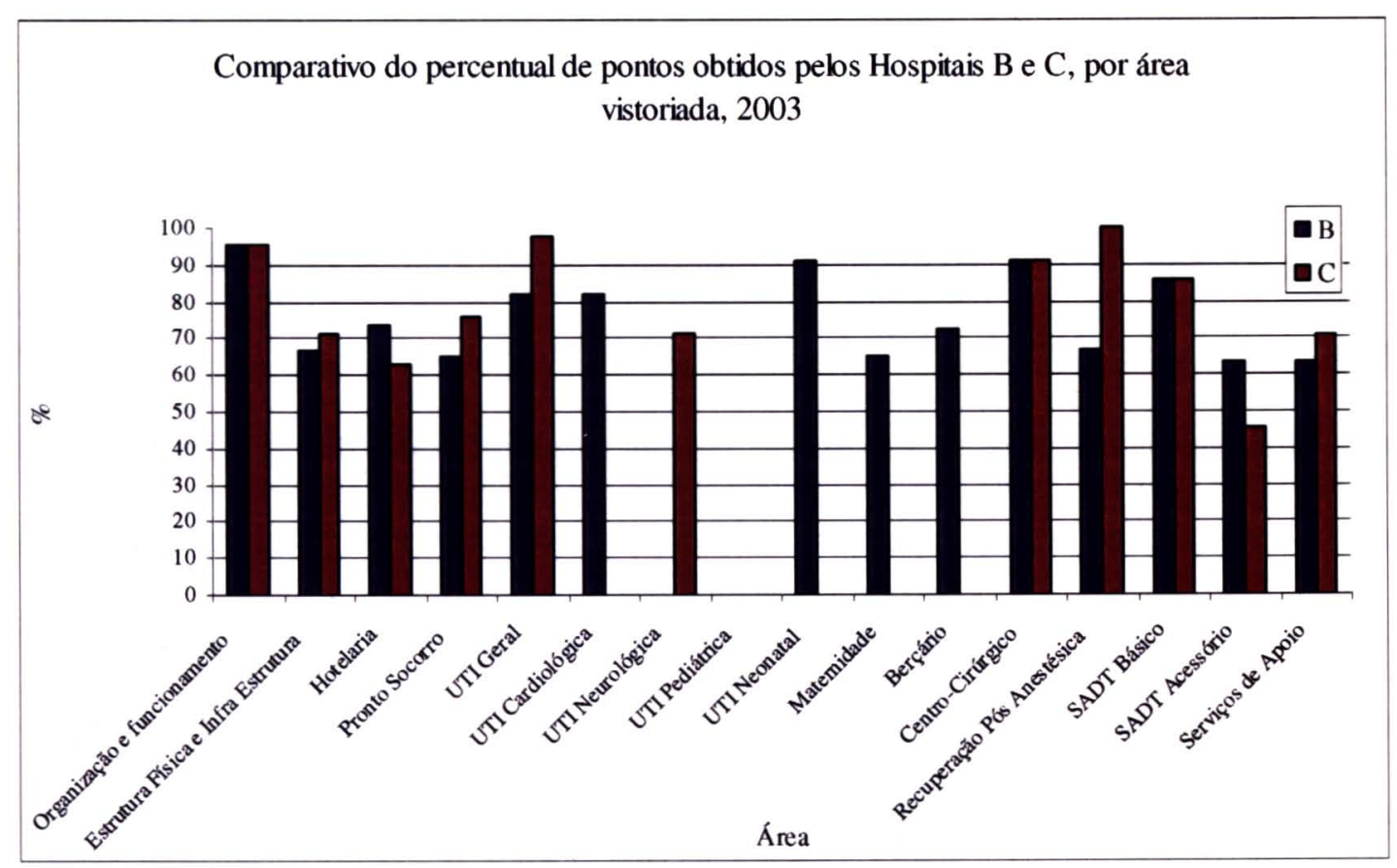

Fonte: Pesquisa de Campo, 2003.

Na tabela 44, observamos a comparação entre as várias áreas vistoriadas dos

hospitais D, E e F de médio porte, privados secundários, referência regional. Em função da análise da conformidade ao padrão técnico preestabelecido, podemos afirmar que em uma única área, a de Recuperação pós-anestésica, os hospitais atingiram a totalidade dos pontos; nas demais áreas os três hospitais necessitam investimentos para melhoria da organização e funcionamento, estrutura física e infraestrutura, assistência ao paciente, serviços de apoio diagnóstico e terapia e serviços de apoio técnico-administrativo.

O hospital D necessita resolver problemas estruturais relacionados no parecer técnico, que são: adequar sanitários das unidades de internação à RDC n 50/02; implantar sistema de tratamento de resíduos e esgoto; adequar área física da UTI Neonatal à $\mathrm{RDC} \mathrm{n}^{\circ} 50 / 02$; reequipar sala de emergência do pronto-atendimento para 
dar condições de sustentação de vida com instalação imediata de respirador adequado.

$\mathrm{O}$ hospital E necessita resolver problemas estruturais, que são: adequar área fisica da UTI à RDC nº 50/02; organizar leitos de observação do Pronto-atendimento geral, separando-os em masculinos, femininos e pediátricos; adequar salas de gesso e curativo do PA à RDC n ${ }^{\circ}$ 50/02 (leito encostado na parede); reequipar sala de emergência do pronto-atendimento para dar condições de sustentação de vida com instalação imediata de respirador adequado. Equipar unidades de internação com torpedo de oxigênio reserva, aspirador elétrico e cardioversor com carga elétrica; retirar berços aquecidos por insuflação do berçário; contratar recursos humanos para compor equipe médica do pronto-atendimento (Resolução CFM no 1451/95 e COFEN n $\left.{ }^{\circ} 189 / 2003\right)$.

$\mathrm{O}$ hospital $\mathrm{F}$ necessita resolver problemas estruturais, que são: adequar sanitários das unidades de internação à RDC n $50 / 02$; adequar Serviços de Nutrição e Lavanderia à $\mathrm{RDC} \mathrm{n}^{\circ} 50 / 02$; reequipar sala de emergência do pronto-socorro para dar condições de sustentação de vida com instalação imediata de respirador adequado. Retirar berços aquecidos por insuflação do berçário; contratar recursos humanos para compor equipe médica e de enfermagem do pronto-socorro (Resolução CFM n ${ }^{\circ}$ 1451/95); contratar médico diarista para a UTI em atendimento à Portaria GM nº 3432/98; instalar Comissão de Revisão de Prontuários e estabelecer normas e rotinas para a UTI; analisar indicadores de qualidade e produtividade em relação às taxas de cesáreas e de ocupação. 
Tabela 44 - Pontuação atribuída às áreas hospitalares vistoriadas dos Hospitais D, E e F, de médio porte, 2002 e 2003.

\begin{tabular}{lcccccccc}
\hline \multirow{2}{*}{ Item avaliado } & Total de pontos & \multicolumn{6}{c}{ Pontos obtidos } & \multicolumn{4}{c}{ Pontos atingidos } \\
\cline { 3 - 8 } & & D & E & F & D & E & F \\
\hline Organização e funcionamento & 44 & 40 & 40 & 39 & 90,91 & 90,91 & 88,64 \\
Estrutura fisica e infra-estrutura & 45 & 33 & 32 & 33 & 73,33 & 71,11 & 76,74 \\
Hotelaria & 88 & 54 & 53 & 52 & 94,74 & 92,98 & 72,22 \\
Pronto-Socorro & 46 & 30 & 36 & 27 & 65,22 & 78,26 & 58,70 \\
UTI Geral & 45 & 44 & 41 & 41 & 97,78 & 91,11 & 91,11 \\
UTI Cardiológica & 45 & 44 & - & - & 97,78 & - & - \\
UTI Neurológica & 45 & - & - & 41 & - & - & 91,11 \\
UTI Pediátrica & 45 & 39 & - & 44 & 86,67 & - & 97,78 \\
UTI Neonatal & 43 & 40 & 37 & 39 & 93,02 & 86,05 & 90,70 \\
Maternidade & 29 & 27 & 21 & 27 & 93,10 & 72,41 & 93,10 \\
Berçário & 44 & 43 & 41 & 42 & 97,73 & 93,18 & 95,45 \\
Centro-Cirúrgico & 18 & 18 & 18 & 18 & 100,0 & 100,0 & 100,0 \\
Recuperação pós-anestésica & 29 & 25 & 25 & 25 & 86,21 & 86,21 & 86,21 \\
SADT Básico & 44 & 13 & 06 & 11 & 29,55 & 13,64 & 25,00 \\
SADT Acessório & 113 & 79 & 93 & 89 & 79,00 & 92,30 & 78,76 \\
\hline Serviços de Apoio & & & & & $\mathbf{8 4 , 6 5}$ & $\mathbf{8 0 , 6 8}$ & $\mathbf{8 1 , 8 2}$
\end{tabular}

Fonte: Pesquisa de Campo, 2002 e 2003.

No cálculo da Hotelaria do hospitais D e E, foram excluídos os pontos referentes à suite, pois estes hospitais não apresentam este tipo de acomodação.

No cálculo dos serviços de apoio técnico-administrativo do hospital $\mathrm{D}$, foram excluídos os pontos referentes à lavanderia, pois ela encontra-se terceirizada e externa ao hospital. Foram considerados os do Hospital E, pois mesmo terceirizada, ela continuava funcionando.

No cálculo da estrutura física e da infra-estrutura do hospital $\mathrm{F}$ (acesso com rampas), foram excluídos os pontos referentes ao elevador. 
Gráfico 3 - Comparação dos pontos obtidos pelos Hospitais D, E e F, por área vistoriada, 2002 e 2003.

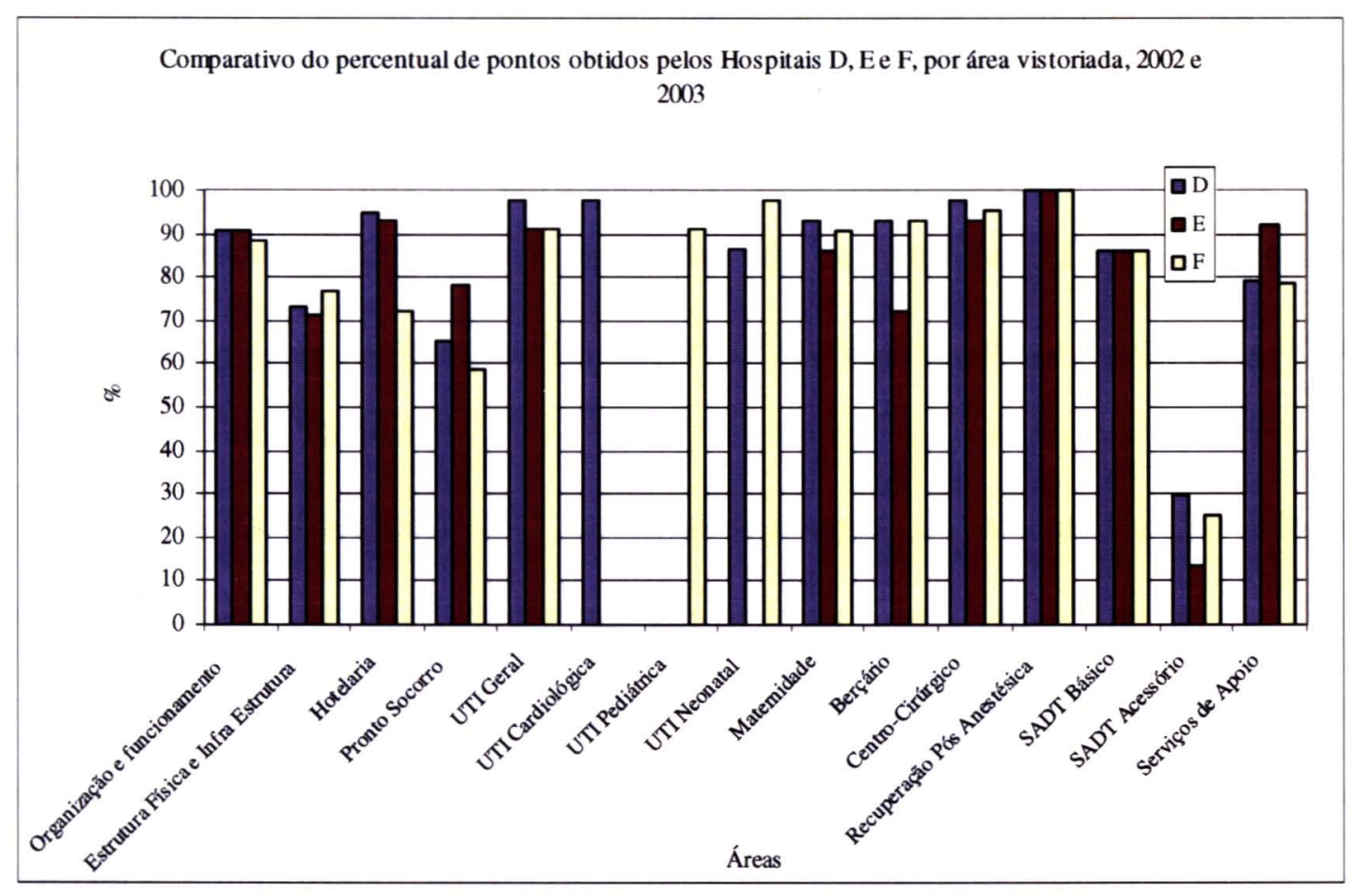

Fonte: Pesquisa de Campo, 2002 e 2003.

Na tabela 45, observamos a comparação entre as várias áreas vistoriadas dos hospitais G, H e I de pequeno porte, privados primários, referência regional. Em função da análise da conformidade ao padrão técnico preestabelecido, observamos que são os hospitais que mais se distanciaram do padrão técnico. Nenhuma área obteve pontuações máximas, demonstrando que os mesmos enfrentam problemas de toda a ordem.

O hospital G necessita resolver problemas estruturais relacionados no parecer técnico, que são: instalar gerador para dar suporte às áreas críticas; adequar sala de endoscopia à RDC n 50/02; adequar sanitários das unidades de internação à RDC n ${ }^{\circ}$ 50/02; adequar vestiários e sanitários do Centro-Cirúrgico à RDC n ${ }^{\circ} 50 / 02$; adequar enfermarias à RDC no 50/02; adequar Central de Esterilização à RDC no 50/02; adequar enfermarias à RDC $\mathrm{n}^{\circ}$ 50/02; instalar RPA; reequipar sala de emergência do 
pronto-atendimento para dar condições de sustentação de vida com instalação imediata de respirador adequado. Retirar berços aquecidos por insuflação do berçário; equipar RPA; contratar recursos humanos para compor equipe médica e de enfermagem do pronto-atendimento (Resolução CFM no 1451/95 e COFEN n ${ }^{\circ}$ 189/2003); contratar nutricionista para o Serviço de Nutrição e Dietética; instalar comissões de $\mathrm{CCIH}$, Revisão de Prontuários e Óbitos; colocar em funcionamento a Comissão de Ética Médica.

O serviço denominado UTI não obedece à legislação, não atendendo nenhum critério técnico preestabelecido, portanto não pode ser considerado como tal.

$\mathrm{O}$ interessante é que mesmo com todos estes problemas apresentados, o hospital conta com tomógrafo, o segundo equipamento instalado neste pequeno município.

O hospital H necessita resolver problemas estruturais, que são: instalar páraraios; adequar área física do pronto-socorro à $\mathrm{RDC} \mathrm{n}^{\circ} 50 / 02$; adequar sala de endoscopia à $\mathrm{RDC} \mathrm{n}^{\circ}$ 50/02; adequar sanitários das unidades de internação à RDC $\mathrm{n}^{\circ}$ 50/02; adequar unidades de internação à $\mathrm{RDC} \mathrm{n}^{\circ}$ 50/02; adequar vestiários do Centro-Cirúrgico à $\mathrm{RDC} \mathrm{n}^{\circ} 50 / 02$; adequar salas cirúrgicas à $\mathrm{RDC} \mathrm{n}^{\circ} 50 / 02$; adequar Central de Esterilização à RDC no 50/02; instalar RPA e melhorar a sinalização interna; reequipar sala de emergência do pronto-socorro para dar condições de sustentação de vida com instalação imediata de respirador adequado; contratar recursos humanos para compor equipe médica e de enfermagem do pronto-socorro (Resoluções CFM no 1451/95 e COFEN 189/2003); contratar pessoal técnico para a agência transfusional no período noturno; padronizar medicamentos; alterar a periodicidade da realização do controle biológico na central de esterilização de 
materiais; instalar comissões de Revisão de Prontuários e Óbitos; registrar em ata as reuniões da Comissão de Ética Médica.

O serviço denominado UTI não obedece à legislação, não atendendo nenhum critério técnico preestabelecido, portanto não pode ser considerado como tal.

O hospital I necessita resolver problemas estruturais, que são: instalar gerador automático para suporte às áreas críticas; adequar centro-cirúrgico à RDC no 50/02; instalar RPA; adequar Farmácia, SND e Almoxarifado à RDC n 50/02; reequipar sala de emergência do pronto-atendimento para dar condições de sustentação de vida com instalação imediata de respirador adequado; retirar berços aquecidos por insuflação do berçário; contratar recursos humanos para compor equipe médica e de enfermagem do pronto-atendimento (Resoluções CFM n $n^{\circ} 1451 / 95$ e COFEN $n^{\circ}$ 189/2003); padronizar medicamentos; organizar prontuários conforme legislação; instalar comissões de Revisão de Prontuários e Óbitos.

O serviço denominado UTI não obedece à legislação, não atendendo nenhum critério técnico preestabelecido, portanto não pode ser considerado como tal. 
Tabela 45 - Pontuação atribuída às áreas hospitalares vistoriadas dos Hospitais $\mathrm{G}, \mathrm{H}$ e I, de pequeno porte, 2002 e 2003.

\begin{tabular}{|c|c|c|c|c|c|c|c|}
\hline \multirow[t]{2}{*}{ Item avaliado } & \multirow[t]{2}{*}{ Total de pontos } & \multicolumn{3}{|c|}{ Pontos obtidos } & \multicolumn{3}{|c|}{$\%$ Pontos atingidos } \\
\hline & & $\mathrm{G}$ & $\mathrm{H}$ & $\mathrm{I}$ & $\mathrm{G}$ & $\mathrm{H}$ & I \\
\hline Organização e funcionamento & 44 & 20 & 26 & 29 & 45,45 & 59,09 & 65,91 \\
\hline Estrutura fisica e infra-estrutura & 45 & 25 & 24 & 31 & 58,14 & 55,81 & 72,09 \\
\hline Hotelaria & 88 & 37 & 39 & 45 & 64,91 & 53,42 & 78,95 \\
\hline Pronto-socorro & 46 & 21 & 23 & 28 & 45,65 & 50,00 & 60,87 \\
\hline UTI Geral & 45 & - & - & - & - & - & - \\
\hline UTI Cardiológica & 45 & - & - & - & - & - & - \\
\hline UTI Pediátrica & 45 & - & - & - & - & - & - \\
\hline UTI Neonatal & 45 & - & - & - & - & - & - \\
\hline Maternidade & 43 & 28 & 29 & 24 & 65,12 & 67,44 & 55,81 \\
\hline Berçário & 29 & 21 & 21 & 15 & 72,41 & 72,41 & 51,72 \\
\hline Centro-Cirúrgico & 44 & 25 & 27 & 24 & 56,82 & 61,36 & 54,55 \\
\hline Recuperação pós-anestésica & 18 & 0 & 0 & 0 & 0 & 0 & 0 \\
\hline SADT Básico & 29 & 21 & 23 & 19 & 72,41 & 79,31 & 65,52 \\
\hline SADT Acessório & 44 & 09 & 0 & 0 & 20,45 & 0 & 0 \\
\hline Serviços de Apoio & 113 & 73 & 80 & 56 & 64,60 & 70,80 & 56,00 \\
\hline Total (Média ponderada) & & & & & 51,45 & 51,79 & 51,04 \\
\hline
\end{tabular}

Fonte: Pesquisa de Campo, 2002 e 2003.

No cálculo de estrutura física e infra-estrutura dos hospitais $\mathrm{G} \mathrm{e} \mathrm{H}$ (acesso com rampas) foram excluídos os pontos referentes ao elevador.

No cálculo da Hotelaria dos hospitais $\mathrm{G}$ e $\mathrm{H}$, foram excluídos os pontos referentes à suíte, pois estes hospitais não apresentam este tipo de acomodação; do hospital I foi excluída, também, pontuação de enfermaria com mais de 4 leitos.

No cálculo dos serviços de apoio técnico-administrativo do hospital I, foram excluídos os pontos referentes à lavanderia, pois ela encontra-se terceirizada e externa ao hospital. 
Gráfico 4 - Comparação dos pontos obtidos pelos Hospitais G, H e I, por área vistoriada, 2002 e 2003.

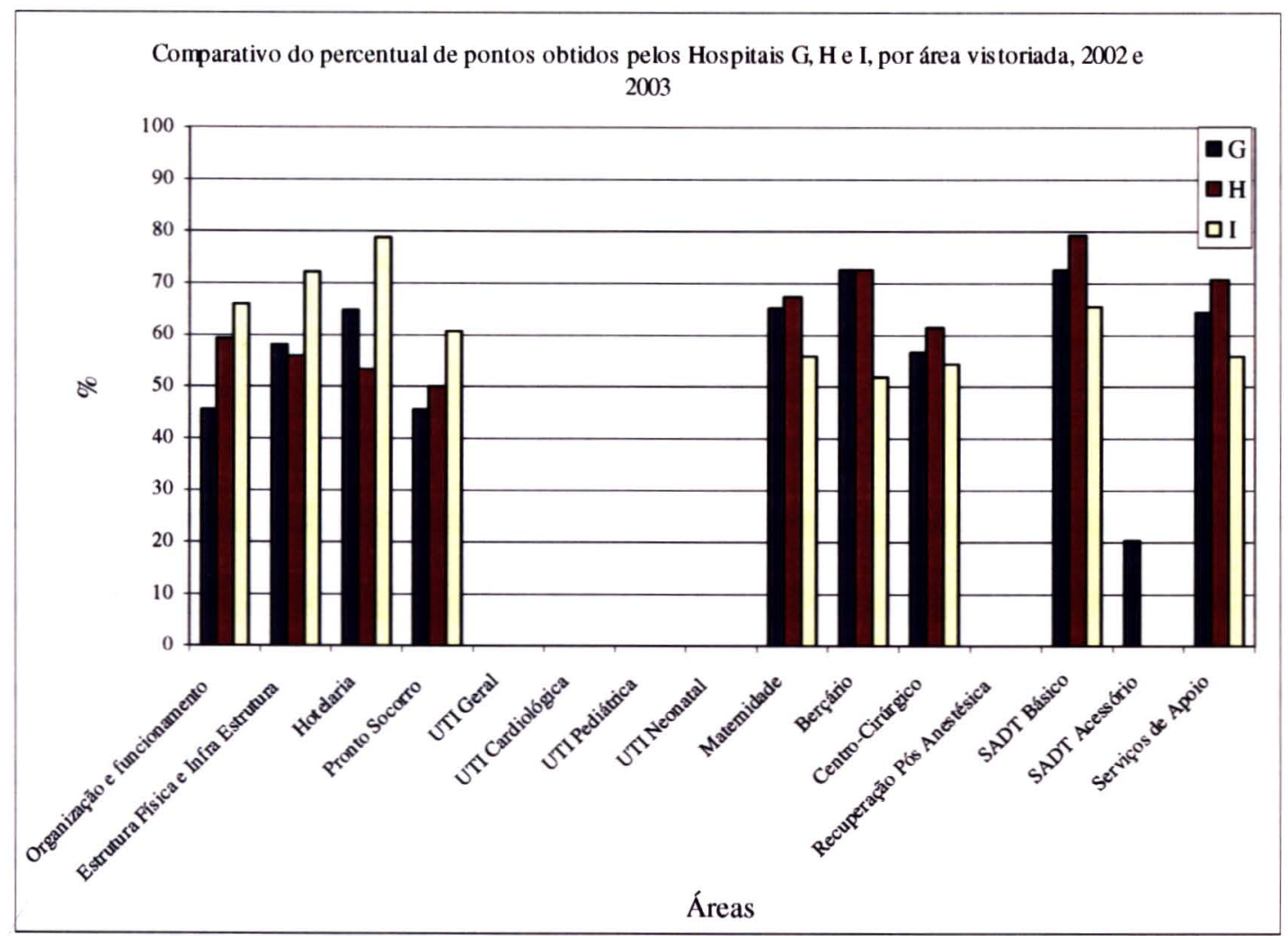

Fonte: Pesquisa de Campo, 2002 e 2003. 


\section{Classificação por Portes}

A Classificação dos Hospitais por grupo, segundo nível de complexidade e média percentual de pontos obtidos, pode ser observada na tabela 46 .

Grupo I

Hospitais Gerais ou Especializados, com nível de complexidade primário, cuja média percentual de pontos obtidos foi superior a 50,0\%. Foram classificados nesse grupo os hospitais G, H e I.

Grupo II

Hospitais Gerais ou Especializados com nível de complexidade secundário, com até 04 procedimentos de alta complexidade, conforme Portaria $n^{\circ} 2224 / G M$, de 05 de dezembro de 2002, do Ministério da Saúde, e cuja média percentual de pontos obtidos foi superior a $63,0 \%$. Foram classificados nesse grupo os hospitais D, F e E.

Grupo III

Hospitais Gerais e Especializados, com nível de complexidade terciário na assistência, incluindo de 05 a 08 procedimentos de alta complexidade, conforme Portaria n ${ }^{\circ}$ 2224/GM, de 05 de dezembro de 2002, do Ministério da Saúde, e cuja média percentual de pontos obtidos foi superior a $75,0 \%$. Foram classificados nesse grupo os hospitais C e B.

\section{Grupo IV}

Hospitais Gerais e Especializados, com nível de complexidade terciário e quaternário na assistência, incluindo mais de 08 procedimentos de alta complexidade, conforme Portaria n $^{\circ}$ 2224/GM, de 05 de dezembro de 2002, do Ministério da Saúde, e cuja média percentual de pontos obtidos foi superior a $89,0 \%$. Foi classificado nesse grupo o hospital A. 
Tabela 46 - Classificação por grupo dos hospitais da amostra, segundo nível de complexidade e média percentual de pontos obtidos, 2002 e 2003.

\begin{tabular}{ccccc}
\hline Hospital & Complexidade & $\begin{array}{c}\text { Procedimentos } \\
\text { Alta complexidade }\end{array}$ & $\begin{array}{c}\text { Média Percentual } \\
\text { Pontos }\end{array}$ & Grupo \\
\hline A & terciário/quaternário & 14 & 93,15 & IV \\
B & terciário & 08 & 76,09 & III \\
C & terciário & 06 & 78,92 & III \\
D & secundário & 04 & 84,65 & II \\
E & secundário & 03 & 80,68 & II \\
F & secundário & 03 & 81,82 & II \\
G & primário & 0 & 51,45 & I \\
H & primário & 0 & 51,79 & I \\
I & primário & 0 & 51,04 & I \\
\hline
\end{tabular}

Fonte: Pesquisa de Campo, 2002 e 2003.

O uso do instrumento Roteiro de Vistoria Técnica para a coleta de dados, visando à categorização de hospitais, apresentou importantes vantagens para a realização do estudo, tais como:

- exatidão: como foi desenvolvido em meio magnético, com perguntas fechadas, cujas respostas eram sim ou não, adequado ou inadequado, apresentou baixa possibilidade de erro no registro das informações;

- confiabilidade: mesmas medidas (pontuação) podem ser obtidas por diferentes pesquisadores, frente à observação das áreas hospitalares vistoriadas;

- simplicidade: apresentou poucas dificuldades quanto ao seu preenchimento;

- pertinência: está correlacionado ao critério (normas técnicas) que está sendo examinado em cada área; 
- validade: é capaz de medir o grau de conformidade ao parâmetro técnico preestabelecido;

- sensibilidade: detecta as variações da conformidade técnica das áreas vistoriadas frente aos padrões preestabelecidos.

Frente aos resultados encontrados, consideramos o instrumento adequado à categorização de hospitais, bem como à comparação entre hospitais de mesmo porte e complexidade. 


\section{CONSIDERAÇÕES FINAIS}

Este estudo se propôs a analisar um instrumento para a categorização de hospitais, em meio magnético, denominado Vistoria Técnica Hospitalar e a testá-lo em amostra intencional de nove hospitais.

Neste sentido, verificamos que os gestores contam com vários instrumentos disponibilizados pelas instituições normatizadoras com finalidades diversas: Cadastro Nacional de Estabelecimentos de Saúde; Programa Nacional de Avaliação de Serviços Hospitalares; Roteiro de Inspeção de Serviços Hospitalares da Agência Nacional de Vigilância Sanitária, Portarias, Normas, Resoluções para Edificação, Classificação, Organização e Funcionamento do hospital e das várias áreas e serviços hospitalares. Estes instrumentos são aplicados ora pela própria equipe do hospital, ora pelos gestores, ora por ambos ou por equipes técnicas específicas quando no credenciamento de procedimentos de alta complexidade ou avaliação de serviços específicos.

Além destes, de caráter normativo, estão disponibilizados os de avaliação de qualidade que foram desenvolvidos para Acreditação Hospitalar, Certificação, Selo e Premiação.

Em função deste estudo, consideramos, a propósito do Instrumento Vistoria Técnica Hospitalar que:

- é adequado para a categorização de hospitais, pois permite classificar os hospitais gerais e especializados, de qualquer porte, de acordo com os critérios adotados (complexidade, riscos de atenção e outros), definindo a rede de serviços integrados aos Sistemas Locais de Saúde; 
- os critérios técnicos estabelecidos possibilitam a avaliação geral do hospital, não sendo adequado para as vistorias de áreas específicas;

- possibilita identificar, por meio da pontuação atribuída a cada área vistoriada, com a construção das tabelas e gráficos, qual delas mais se aproxima ou mais se distancia do padrão técnico pré estabelecido;

- sua construção em meio magnético facilita a coleta dos dados através do uso de computador de mão, reduzindo a possibilidade de erros na coleta das informações e possibilitando a emissão de relatório técnico com rapidez;

- possibilita a construção de banco de dados com as informações de dados gerais contendo: Dados Gerais (Identificação, Classificação, Tipo de Serviço, Abrangência, Organização e Funcionamento, Recursos Humanos, Estatística, Indicadores Hospitalares e Estrutura fisica/Infraestrutura); Organização e Atenção ao Paciente (Hotelaria/Unidades de Internação Médico-Cirúrgica, Pediátrica, Obstétrica, Pronto-Socorro, Unidade(s) de Terapia Intensiva(s), Maternidade, Centro Obstétrico, Berçário, Centro Cirúrgico e Recuperação Pós Anestésica), incluindo descrição de equipamentos de cada área; Apoio Diagnóstico e Terapia (Serviços de Apoio Diagnóstico e Terapêutica básicos e acessórios), incluindo descrição de equipamentos; Apoio Técnico e Administrativo (Farmácia, Serviço de Nutrição e Dietética, Lavanderia, Almoxarifado, Manutenção, Segurança, Serviço de Arquivo Médico e Estatística e Central de Esterilização de Materiais); 
- o tempo de aplicação do instrumento é um ponto forte; o tempo gasto no hospital especial foi del6 horas e no de pequeno porte, de 4 horas; os relatórios técnicos são emitidos logo após a realização das vistorias;

- para os gestores hospitalares, o relatório técnico poderá servir de base para as mudanças que precisarem ser implementadas;

- para os gestores públicos, presta-se à avaliação, controle e auditoria para o diagnóstico de cada instituição e da rede hospitalar de sua área de abrangência, com informações que poderão subsidiar o planejamento estratégico e elaboração dos planos diretores municipais (NOB-SUS 01/96) e planos diretores regionais de saúde (NOAS/ 2001);

- para os gestores privados, presta-se à avaliação, controle e auditoria dos hospitais para o diagnóstico de cada instituição e da rede hospitalar como um todo, com a finalidade de identificar os prestadores de serviços hospitalares, seus perfis e a capacidade instalada frente à demanda por serviços médico-hospitalares, além de cumprir as exigências legais definidas na Lei $n^{\circ}$ 9656/98 e nas Resoluções Normativas (ANS-n ${ }^{\circ} 42$ e ANS-n ${ }^{\circ} 54$ );

- difere dos demais instrumentos por utilizar tecnologia de informação para a coleta de dados no processo de avaliação de serviços hospitalares, agregando as várias normas técnicas, reduzindo tempo de coleta de informações, agilizando a realização dos diagnósticos dos serviços hospitalares e a elaboração dos resultados da avaliação;

- é aplicado por profissionais externos ao hospital e às instituições pagadoras de serviços médico-hospitalares; 
- apresenta características adequadas a um instrumento para categorização de hospitais que são: exatidão, confiabilidade, simplicidade, pertinência, validade e sensibilidade.

Consideramos que a liberdade de escolha dos prestadores de serviços de saúde pelo usuário é um estímulo para a eficiência do sistema de saúde como um todo, e para a busca do aprimoramento qualitativo. No entanto, a complexidade técnica dos serviços que se oferecem dificulta, ao usuário comum, a escolha segundo critérios técnicos.

Devido a esta dificuldade técnica na avaliação do serviço, a legislação brasileira delegou aos gestores públicos e privados a responsabilidade de conformar uma rede de serviços de saúde de acordo com critérios técnicos, de modo que os usuários possam utilizar os serviços ou escolher, com segurança, o prestador que se adeque às suas necessidades.

Assim, estes gestores devem organizar uma rede que seja suficiente e idônea, de maneira a garantir aos seus usuários, adequada qualidade, facilidade de acesso e integralidade dos serviços que recebem. Para isto, devem contar com processos de seleção que avaliem as condições técnicas dos prestadores de serviços (cadastro atualizado com prontuários de cada instituição com descrição da área fisica, equipamentos instalados, serviços oferecidos, recursos humanos, indicadores hospitalares) e ainda o estabelecimento de trabalho conjunto que permita identificar dificuldades para serem corrigidas.

Os gestores devem contar com um processo permanente de planejamento e redimensionamento das necessidades de sua rede (quantidade, tamanho, características), de acordo com: 
- número de usuários (demanda potencial);

- as necessidades dos usuários, de acordo com o perfil populacional e o de morbi-mortalidade;

- a localização geográfica do usuário.

Os gestores devem selecionar seus prestadores de acordo com uma série de critérios explícitos definidos para tal fim, entre os quais:

- garantia de que não se cadastre nenhum prestador que não cumpra com as condições de habilitação;

- indicadores de desempenho e qualidade técnica;

- condições adequadas à prestação de serviços, com exigência de protocolos, normas e rotinas e processos de autorização de serviços, formas de faturamento e condições de auditoria;

- avaliação da tecnologia existente, definição de protocolos para sua utilização e custo/efetividade da utilização da mesma;

- sistema de avaliação dos prestadores, no qual se deve incluir a qualidade técnica dos prestadores e a satisfação do usuário;

- deveres e direitos dos prestadores.

Os gestores devem garantir aos seus prestadores um processo contínuo de informação sobre tópicos relacionados com:

- o que se espera dos prestadores durante o processo da atenção ao usuário;

- os processos organizacionais e o plano de desenvolvimento que dão suporte e impacto sobre a atenção dos usuários;

- os direitos e deveres dos usuários em relação à autorização de serviços; 
- definição de padrões técnicos que possibilitem a melhoria dos serviços dos prestadores e a supervisão, auditoria e monitoramento por parte dos gestores.

Todas estas questões devem estar claramente explicitadas na relação gestores e prestadores de serviços.

O objetivo do estabelecimento e da operacionalização de uma rede assistencial é garantir a integralidade e continuidade da assistência prestada ao usuário. Grande parte dos problemas de qualidade na atenção, resulta da fragmentação dos serviços; devido à especificidade da atenção à saúde que requer trabalho multidisciplinar e diferentes níveis de complexidade, tornam-se necessários excelentes mecanismos de comunicação e coordenação entre profissionais de saúde, prestadores e gestores, evitando-se duplicidade na utilização de métodos diagnósticos e terapêuticos a fim de evitar o aumento do risco de complicações e a insatisfação dos usuários de serviços de saúde.

O desafio das organizações voltadas para a assistência à saúde é saber em que medida os recursos são empregados para atingir os efeitos esperados, em que medida os serviços são adequados para atingir os resultados esperados e se os resultados observados correspondem aos esperados; isto é, aos objetivos que a gestão se propôs atingir.

A atuação no campo da saúde exige uma gestão com visão sistêmica do processo assistencial, pois seus elementos constitutivos são interdependentes e as conseqüências de cada ponto no processo repercutem no resultado geral da organização. É fundamental conhecer permanentemente seus aspectos estruturais e organizacionais, considerando os recursos humanos, físicos e financeiros, 
monitorizar seus processos destacando o conhecimento técnico-científico e acompanhar seus resultados identificando as necessidades de mudanças.

A gestão deve ser pró-ativa para perceber as oportunidades de melhoria e estabelecer, tempestivamente, as soluções adequadas. Daí a importância de se contar com ferramentas gerenciais que permitam o conhecimento sistemático da performance da gestão e se suas ações estão em conformidade com os requisitos estabelecidos para a atuação no Setor Saúde. 


\section{REFERÊNCIAS BIBLIOGRÁFICAS}

1. Acurcio, FA et al. Avaliação de qualidade em serviços de saúde. Saúde em Debate, 33: 50-53, Dez, 1991.

2. Aguilar, MJ \& Ander-Egg, E. Tipos de avaliação. In: Avaliação de serviços e programas sociais. Petrópolis, Vozes, 1994. (40-57)

3. Aguilar, $M J$ et al. Uma primeira aproximação ao conceito de avaliação: a avaliação em sentido lato e sua diferenciação de outros conceitos similares. In: Avaliação de serviços e programas sociais - $2^{a}$ ed. Petrópolis, Vozes, 1995. (17-57).

4. Akerman, M. \& Nadanovsky, P. Avaliação dos serviços de saúde - Avaliar o quê? Cad. Saúde Pública, Rio de Janeiro, 8(4): 361-365, Out/Dez, 1992

5. Associação Brasileira de Normas Técnicas - www.abnt.org.br/

6. Associação Paulista de Medicina - www.apm.org.br/cqh/

7. Associação Paulista de Medicina e Conselho Regional de Medicina. Programa de Qualidade de Atendimento Hospitalar do Estado de São Paulo. Manual de Orientação. ADSAÚDE, 1994.

8. Associação Paulista de Medicina, Conselho Regional de Medicina do Estado de São Paulo - Indicadores CQH- $1^{\circ}$ trimestre de 2003.

9. Azevedo, AC. Avaliação de desempenho de serviços de saúde. Rev. Saúde Pública, 25:64-71, 1991.

10. Indicadores de qualidade e produtividade em serviços de saúde. Departamento de Prática de Saúde Pública - Administração Hospitalar, Faculdade de Saúde Pública da Universidade de São Paulo. [Mimeografado]. Informativo Cqh, v. 2, (6):3, 1993 
11. Banta, HD. Uma abordagem estratégica da avaliação de tecnologias em saúde. Cad. Ciência e Tecnologia-1, Saúde em Debate, 8-16, 1991.

12. Berwick, DM. Melhorando a qualidade dos serviços médicos, hospitalares e da saúde. São Paulo, Brasi 1, Makron Books, 1994.

13. Bittar, OJNV. Aspectos estruturais e de produção em hospitais gerais. Revista Paulista de Hospitais. Vol.XLII (1): 6-11, 1995.

14. Hospital \& Produtividade. São Paulo: Sarvier, 1996.

15. Metodologia para avaliação da produtividade em hospitais.

O Mundo da Saúde, 20 (7): 238-43,1996.

16. . Produtividade em hospitais de acordo com alguns indicadores hospitalares. Rev. Saúde Púb., vol 30, nº 1996

17. Indicadores de qualidade e quantidade em saúde - Parte II,

RAS, vol. 6, n 22, Jan-Mar, 2004

18. Bonato, VL. Programas de Qualidade em Hospitais do Município de São

Paulo. Tese de Doutorado - Faculdade de Saúde Pública da USP, 2003.

19. Brasil, Ministério da Saúde. Instrumento de Avaliação para Hospitais Gerais de Médio Porte. Brasília, Centro de doc., 1986

20. - Ministério da Saúde. Terminologia Básica em Saúde -

Secretaria Nacional de Organização e Desenvolvimento de Serviços de Saúde, 1987.

21. Constituição da República Federativa do Brasil, 1988.

22. Lei 8080 de 19 de Setembro de 1990.

23. . Lei 8142 de 28 de dezembro de 1990.

24. Ministério da Saúde, Norma Operacional Básica - SUS 01-93. 
25. . Ministério da Saúde, Norma Operacional Básica - SUS 01-96

26. . Ministério da Saúde, Agência Nacional de Vigilância Sanitária,

Portaria 453, de 01 de Junho de 1998.

27. . Lei 9656 de 03 de Junho de 1998.

28. - Ministério da Saúde, Portaria 3432/GM, de 12 de Agosto de 1998.

29. - Ministério da Saúde, Norma Operacional de Assistência à

Saúde, 2001.

30. . Ministério da Saúde, Agência Nacional de Vigilância Sanitária, RDC_50, de 21 de Fevereiro de 2002.

31. . Ministério da Saúde, Portaria 312, de 02 de Maio de 2002.

32. . Ministério da Saúde, Portaria 1101/GM, de 12 de Junho de 2002.

33. Ministério da Saúde, Portaria 2048/GM, de 05 de Novembro de 2002.

34. Ministério da Saúde, Agência Nacional de Vigilância Sanitária, RDC_307, de 14 de Novembro de 2002 .

35. . Ministério da Saúde, Portaria 2224/GM, de 05 de Dezembro de 2002.

36. . Ministério da Saúde, Portaria 2225/GM, de 05 de Dezembro de 2002.

37. Ministério da Saúde, Agência Nacional de Vigilância Sanitária, RDC_33, de 25 de Fevereiro de 2003. 
38. - Agência Nacional de Saúde Suplementar, Resolução

Normativa 42, de 04 de Julho de 2003.

39. - Agência Nacional de Saúde Suplementar, Resolução

Normativa 54, de 28 de Novembro de 2003.

40. - Ministério da Saúde, Sub-Secretaria de Planejamento e

Orçamento - Execução Orçamentária e Financeira, 2003/2004 www.saude.gov.br.

41. Ministério da Saúde, Agência Nacional de Vigilância Sanitária,

Instrumento Nacional para Inspeção de Serviços de Saúde, 2004.

42. Ministério da Saúde, Manual Brasileiro de Acreditação das

Organizações Prestadoras de Serviços Hospitalares. $4^{\mathrm{a}}$ ed. Brasília ( DF); 2004.

43. Ministério da Saúde, Secretaria de Atenção à Saúde, Programa

Nacional de Avaliação de Serviços de Saúde, 2004.

44. Cadastro Nacional de Estabelecimentos de Saúde, 2000.

http://cnes.datasus.gov.br.

45. Carap, LJ; Crepaldi,R; Navarro, A. Proposta de Modelo de Acreditação para Operadoras Privadas de Planos de Saúde, RAP, Rio de Janeiro, 37(2):285312, Mar-Abr, 2003.

46. Carvalho, PAC. Temas de Arquitetura de Estabelecimentos Assistenciais de Saúde, Curso de Especialização em Arquitetura em Sistemas de Saúde, Universidade Federal da Bahia, 2002.

47. Castelar, RM; Mordelet, P; Grabois V. Gestão Hospitalar, Um desafio para o Hospital Brasileiro, Rennes (França):pág 38-49, 1995. 
48. Champagne, $\mathrm{F}$ et al. Un cadre conceptuel pour l'evaluation des programmes de santé. Rev. Epidemiol. Santé Publique, 33:173-81, 1985.

49. Conselho Federal de Enfermagem, Resolução COFEN n 189/2003.

50. Conselho Federal de Medicina, Resolução CFM n 1451/95.

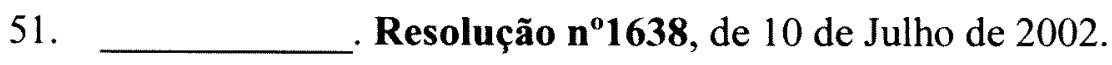

52. Consórcio Brasileiro de Acreditação - www.cbacred.org.br/acreditacao.php

53. $\mathrm{CQH}$ - Controle de Qualidade do Atendimento Médico-Hospitalar - Manual de Orientação aos Hospitais Participantes, Associação Paulista de Medicina Conselho Regional de Medicina, Editora Atheneu, São Paulo, 1998.

54. Cipriano SL.Proposta de um conjunto de indicadores para utilização na Farmácia Hospitalar com foco na Acreditação Hospitalar. São Paulo; 2004. [Dissertação de Mestrado - Faculdade de Saúde Pública da Universidade de São Paulo]

55. Cypriano, AS. Qualidade Hospitalar - Estudo de caso dos hospitais selados pelo CQH - Programa de Qualidade Hospitalar, Dissertação de Mestrado, Faculdade de Saúde Pública da USP, São Paulo, 2004. [Dissertação de Mestrado - Faculdade de Saúde Pública da Universidade de São Paulo]

56. Deslandes, SF. Concepcões em pesquisa social: articulações com o campo da avaliação em serviços de saúde, Cad. Saúde Púb., Rio de Janeiro, 13(1), 103-107, 1997.

57. Donabedian, A. Evaluating the quality of medical care. Milbank Mem. Fund. Q., 44(3):166-206, 1966. 
58. A guide to medical care administration, medical care appraisal: quality and utilization. New York, American Public Health Association, 1969.

59. - Models for organizing the delivery of personal health services and criteria for evaluating them. Milbank Mem. Fund. Q., 50(4):103-54, 1972.

60. The definition of quality and approaches to its assessment, in

Explorations in quality assessment: the definitions of quality and approaches to its assessment. Ann Harbor, Michigan Health Administration Press, 1980.

61. Advantages and limitations of explicit criteria for assessing: the quality of health care. Millbank Mem. Fund. Q., 59(1):99-106, 1981 62. Criteria, norms and standards of quality: what do they mean? Am. J. Public Health, 71(4):409-12, 1981.

63. The criteria and standards of quality. Ann Harbor, Health Administration Press, v. 2, 1982.

64. . Criteria and standards for quality assessment and monitoring. Qual. Rev. Bull., 12(3):99-108, 1986.

65. . Veinte años de investigación en torno a la calidad de la atención médica, 1964-1984. Salud Publica Mex., 30:202-15, 1988.

66. The seven pillars of quality. Arch. Pathol. Lab. Med., 114:1115-8, 1990.

67. La dimensión internacional de la evaluación y garantía de la calidad. Salud Publ. Mex., 32 (2):113-17, 1990. 
68. A qualidade da atenção médica: definição e métodos de avaliação. México, La Prensa Médica Mexicana, 1991. pp.95-157.

69. . The roles of outcomes in quality assessment and assurance.

Qual. Rev. Bull., 18:356-360, 1992.

70. Quality assurance in health care: consumer's role. Quality in Health Care, 1:001-005, 1992.

71. Prioridades para el progreso en la avaluación y monitoreo de la atención. Salud Publ. Mex, 35(1): 94-7, 1993.

72. Donahue, KT; O'Leary, DS. A evolução dos sitemas de acreditação de instituições de saúde, Ensaio, 2000. 8: 5-16.

73. Eduardo, MBP. Vigilância Sanitária. São Paulo, Editora Peirópolis (Série Saúde\&Cidadania, 08),1998.

74. Escrivão, Jr; Carro, ARL. Indicadores hospitalares: um estudo exploratório no Hospital das Clínicas da FMUSP, 2002. Trabalho apresentado no VII Congresso Brasileiro de Saúde Coletiva, promovido pela Abrasco, no período de 29 de julho a 02 de agosto de 2003, Brasília - DF.

75. Fundação Nacional para o Prêmio de Qualidade - www.fpnq.org.br/

76. Goldbaum, M. Epidemiologia e Serviços de Saúde, Cad. Saúde Públ., Rio de Janeiro, 12 (Supl. 2): 95-98, 1996

77. Higashi, EY. Gestão Estratégica de Recusos Humanos no Setor Saúde, Dissertação de Mestrado, Faculdade de Saúde Pública da USP, 2001.

78. IBGE: Pesquisa de Assistência Médico-Sanitária, 1976/2002. 
79. Joint Commission on Accreditation of Healthcare Organizations. Comprehensive Accreditation Manual for Hospitals, Oakbook Terrace, 1997.

80. A Joint Comission International Accreditation Standars for Hospitals, Oakbook Terrace, 1999.

81. Lefèvre F, Lefèvre AMC. O discurso do sujeito coletivo (um novo enfoque em pesquisa qualitativa). Desdobramentos. São Paulo: Editora EDUCS; 2003.

82. Malik, AM. Qualidade em serviços de saúde nos setores público e privado. Cadernos FUNDAP, 19: 7-24, 1996.

83. Malik, AM; Teles, JP. Avaliação, qualidade e gestão. São Paulo, SENAC, 1996.

84. Malik, AM. Qualidade, Profissionais e Organizações de Saúde, Revista de Administração em Saúde, volume 1 número 2, abril/junho 1998

85. Malik, AM; Schiesari, LMC. Qualidade na gestão local de serviços e ações de saúde, São Paulo: Faculdade de Saúde Pública da Universidade de São Paulo Série Saúde \& Cidadania - volume 3, 1998.

86. Malik, AM. Programas de Qualidade em hospitais: um estudo exploratório no Estado de São Paulo, Brasil. Escola de Administração de Empresas de São Paulo - Fundação Getúlio Vargas, Proahsa, 1999.

87. Minayo, MCS. O desafio do conhecimento: pesquisa qualitativa em saúde. São Paulo - Rio de Janeiro: Hucitec-Abrasco, 1992.

88. Motta, ALC. Auditoria de Enfermagem no Processo de Credenciamento Vistoria Básica e Avançada à Rede Credenciada de Hospitais, Editora Erica (08), 2002. 
89. Novaes, HM de; Paganini, JM. Padrões e indicadores de qualidade para hospitais (Brasil), Washington-DC, OPAS, 1994.

90. Epidemiologia e avaliação em serviços de atenção médica: novas tendências na pesquisa. (Epidemiology and assessment of health care services: new research trends). Cad.Saúde Pública, 12(2): 7-12, Rio de Janeiro, 1996.

91. Será que os hospitais latino-americanos e do Caribe já estão na fase da reengenharia?. Revista de Administração em Saúde, vol 1, número 4, Jun 1999.

92. OPAS. Garantia de Qualidade - Acreditação de Hospitais para América Latina e o Caribe, FBH (Série/SILOS, 13), 1992.

93. Organização Nacional de Acreditação - www.ona.org.br

94. Organización Panamericana de La Salud/ Organización Mundial de La Salud. Perfiles de complejidad: método para determinar niveles de atención en estabelecimentos hospitalares. Washington, D.C., 1985-1987. Fasc. III.

95. Prazeres PM. Dicionário de termos de qualidade. São Paulo, Ed. Atlas, 1996.

96. Prêmio de Qualidade do Governo Federal www.pqsp.planejamento.gov.br/pqgf

97. [PROAHSA] Programa de Estudos Avançados em Administração Hospitalar e de Sistemas de Saúde. Manual de Organização e Procedimentos Hospitalares. São Paulo: GV/EAESP/HC/FMUSP; 1987.

98. Quinto Neto, A; Gastal, FL. Acreditação hospitalar: proteção dos usuários, dos profissionais e das instituições de saúde. Porto Alegre: Dacasa/IAHCS; 1997. 
99. Quinto, NA, Bittar, OJNV. Hospitais - Administração da Qualidade e Acreditação de Organizações Complexas, Da Casa Editora, 2003.

100. Ramos, R. O problema de avaliação em Saúde Pública. Rev. Saúde Pública, São Paulo, 8: 305-14, 1974.

101. São Paulo, Governo do Estado, Resolução Conjunta SS/SMA-1, de 02 de Maio de 1996.

102. Schiesari, LMC. Cenário da Acreditação Hospitalar no Brasil e referências externas. São Paulo; 1999. Dissertação de Mestrado - Faculdade de Saúde Pública da USP.

103. Saraceno B, Levav I. La evaluacion de Servicios de Salud Mental em la Comunidad: In: Temas de Salud Mental em la Comunidad. Washington (DC); 1992 (OPS/PALTEX n. 1956, 77).

104. Scrivens, E. Recent development in accreditation, International Journal for Quality in Health Care, vol 7, 4; p427:433, 1995

105. Silva, LMV; Formigli, VLA. Avaliação em saúde: limites e perspectivas. Cad. Saúde Públ., 10(1):80-91, 1994.

106. Siqueira, M M. Atendimento hospitalar: o que importa para o paciente? Rev. Adm. Pública, 22:10-6, 1988

107. SUDS/SES/SP - Manual de Planejamento - Vol I e III; 1988.

108. Tanaka, OU; Melo, C. Avaliação de Programas de Saúde do Adolescente: Um modo de fazer, São Paulo, Editora da USP, 2001.

109. Tanaka, OU. Políticas de saúde: estrutura e avaliação dos serviços. Anais do $1^{\circ}$ Simpósio Franco-Brasileiro de Metodologias de Pesquisa em Saúde 
Perinatal. 3: 3-12 (Série Investigação em Saúde da Mulher, da Criança e Adolescência) ,1999.

110. Terra, V. Mudança organizacional e implantação de um programa de qualidade em hospital do Município de São Paulo - estudo de caso. Tese de Mestrado apresentada à FGV/EAESP, 2000.

111. Tolovi Jr, J. Por que os programas de qualidade falham, Revista de Administração de Empresas, São Paulo, v.34, n 6, p.6-11

112. Vergara SC. Projetos e Relatórios de pesquisa em administração. São Paulo: Atlas; 1998.

113. Vuori, HI. A qualidade da saúde. In: Seminários de Avaliação dos Serviços de Saúde, 1988. - Aspectos Metodológicos. Rio de Janeiro [Trad. M. José Lindgren Alves]. (Revista CEBES/ fev 1991).

114. Vuori, HI. A qualidade da saúde. Divulgação em Saúde para Debate caderno de Ciência e Tecnologia, 1(3): 17-25, Londrina, 1991.

115. Zanon, U. Qualidade da assitência médico-hospitalar: conceito e avaliação de indicadores, RAS, vol. $2, \mathrm{n}^{\circ} 8, \mathrm{Jul} / \mathrm{Set}, 2000$

116. Zucchi, P; Bittar, OJNV; Haddad, N. Produtividade em hospitais de ensino no Estado de São Paulo, Brasil, OPAS, 1997.

117. Zucchi, P. Funcionários por leito: estudo em alguns hospitais públicos e privados, RAP, Rio de Janeiro, 32(3): 65-76, Maio/Jun, 1998.

118. Zucchi, P, Bittar, OJNV. Funcionários por leito: estudo em alguns hospitais públicos e privados, RAS, vol. 4, n 14, Jan/Mar, 2002. 


\section{BIBLIOGRAFIA CONSULTADA}

1. Ahumada, W. et al. Modelos de evaluación y evaluación de programas. Chile, Universidad Católica de Valparaíso, REDUC, 1990.

2. Almeida, PF; Escorel, $\mathrm{S}$. Da avaliação em saúde à avaliação em Saúde Mental: gênese, aproximações teóricas e questões atuais. Saúde em Debate, v.25, $\mathrm{n}^{\circ} 58$, 2001

3. Associação Brasileira de Normas Técnicas. NBR n⿳ 12188, maio de 2003. Central de gases medicinais.

4. NBR n 6401, dezembro de 1980. Ar condicionado central.

5. NBR n⿳0 7256, abril de 1982. Ar condicionado central.

6. . NBR n⿳0 13534, novembro de 1995. Suporte elétrico alternativo.

7. Bertone, AA \& Sbrissia, RR. Um modelo de avaliação democrática de uma instituição: uma proposta inovadora? Saúde em Debate, 23:82-6, 1988.

8. Brasil, Ministério da Saúde, RECLAR, Brasília (DF); 1983.

9. Ministério da Saúde, Portaria no 344, de 12 de maio de 1998. Aprova

o Regulamento Técnico sobre substâncias e medicamentos sujeitos a controle especial.

10. . Ministério da Saúde, Portaria no 3535, de 02 de setembro de 1998.

Critérios para cadastramento de Centros de Atendimento em Oncologia.

11. - Ministério da Saúde, Portaria no 113, de 31 de março de 1999.

Estabelece normas para cadastramento de serviços que realizam procedimentos de alta complexidade em câncer.

12. Ministério da Saúde, Portaria SAS n 376, de 03 de outubro de 2002. 
13. Ministério da Saúde, Portaria SAS no 511, de 29 de dezembro de 2002.

14. Brasil, Ministério do Trabalho. NR no 13/ MTE . Caldeira.

15. Caleman,G et als. - Auditoria, Controle e Programação em Serviços de Saúde. Série Saúde\&Cidadania, 1998.

16. Constanzo, C.A. \& Vertinsky, I. Measuring the quality of health care: a decision oriented typology. Med. Care, 13 (5):417-31, 1975.

17. Contandriopoulos, AP. et al. A avaliação na área da saúde: conceitos e métodos. In: HARTZ, M.A. (org). Avaliação em Saúde. Dos modelos conceituais à prática na análise da implantação de programas. Rio de Janeiro, Fiocruz, 1997.

18. Demo, P. Um ensaio introdutório. In: Avaliação qualitativa. São Paulo, Cortez, 1987, p.13-36.

19. Donabedian, A. Benefits in medical care programs. Boston, Harvard University Press, 1976.

20. Donabedian, A. Contribuitions of epidemiology to quality assessment and monitoring. Infect.Contr.Hosp.Epidemiol., 11(3): 117-121, 1990.

21. Falk, JA; Carvalho, EM. Gestão de Custos para Hospitais: conceitos, metodologias e aplicações - Gestão da Qualidade de Serviços na área de avaliação hospitalar: Conceitos, Critérios e Modelos para avaliação, Editora Atlas, 2001.

22. Lakatos EM. Fundamentos de metodologia científica. $3^{\mathrm{a}}$ ed. São Paulo: Atlas, 1991.

23. Mendes EV. Uma agenda para a saúde. São Paulo. Ed. Hucitec, 1996.

24. Mendes EV. A organização da saúde no nível local. São Paulo. Ed. Hucitec, 1998.

25. Novaes, HMD: Consumo e Demanda em Tecnologia, AdSAude id:5912. São Paulo 
26. Organização Pan-Americana da Saúde. Los Sistemas Locais de Salud. Washington, DC; 273p. (OPAS - Publicação Científica, 540).

27. Rosen G. Uma história da Saúde Pública. São Paulo. Ed. UNESP; 1994. 


\section{ANEXOS}

\section{Anexo 1 - Termo de Consentimento}

Estas instituições foram contatadas e autorizaram a publicação das vistorias técnicas, conforme o modelo do Termo de Consentimento:

\section{Termo de Consentimento}

$\mathrm{Eu}$,

, Diretor do Hospital

, autorizo a Enfermeira Tânia Regina Gasparini Botelho Pupo, doutoranda da Faculdade de Saúde Pública da Universidade de São Paulo a realizar vistoria técnica voltada para a análise da estrutura física, de equipamentos, de recursos humanos e de indicadores hospitalares para fins de pesquisa, nível doutorado, título da pesquisa: Análise do Instrumento Vistoria Téenica Hospitalar, uma vez que a mesma compromete-se a manter sigilo sobre as informações coletadas que serão analisadas em conjunto com as de outros hospitais.

As Instituições selecionadas serão vistoriadas por 02 (dois) profissionais de nível superior (médico e enfermeira), devidamente treinados para a utilização do instrumento.

Assinatura do Diretor do Hospital 


\section{I - Dados Gerais}

\section{Anexo 2 - Roteiro de Vistoria Técnica Hospitalar}

(Identificação, Classificação, Tipo de Serviço, Abrangência,, Organização e Funcionamento, Recursos Humanos, Estatística , Indicadores Hospitalares e Estrutura física / Infra-estrutura)

1.Identificação do Estabelecimento

Nome

Endereço

CEP:

Telefone:

FAX:

Cidade: Estado:

Diretor Clínico:

CRM:

No Alvará / Vigilância Sanitária:

Validade:

$\mathrm{N}^{\circ} \mathrm{CRM}$ Institucional: Validade:

Data da Vistoria

\begin{tabular}{|l|c|}
\hline Acompanhante(s) & Número total de leitos \\
\hline & \\
\hline & Número de leitos operacionais \\
\hline
\end{tabular}

2. Classificação do Estabelecimento Hospital Geral $\square$ Hospital Especializado

Qual:

3. Tipo de Serviço

Filantrópico Privado Público

4. Abrangência do Serviço Municipal Regional Estadual Nacional 
5. Organização / Funcionamento

\begin{tabular}{|c|c|c|c|c|}
\hline \multirow[t]{3}{*}{ Normas e Rotinas e Manuais } & não & & & \\
\hline & $\operatorname{sim}$ & \multirow{2}{*}{\multicolumn{2}{|c|}{ Do conhecimento das partes }} & $\operatorname{sim}$ \\
\hline & & & & não \\
\hline \multirow[t]{3}{*}{ Regime Interno/Regulamento } & não & & & \\
\hline & sim & \multirow{2}{*}{\multicolumn{2}{|c|}{ Do conhecimento das partes }} & $\operatorname{sim}$ \\
\hline & & & & não \\
\hline \multirow[t]{2}{*}{ Recrutamento e Seleção de Pessoal } & não & & & \\
\hline & $\operatorname{sim}$ & & & \\
\hline \multirow[t]{2}{*}{ Programas de Treinamento } & não & & & \\
\hline & $\operatorname{sim}$ & & & \\
\hline \multirow[t]{2}{*}{ Educação Continuada } & não & & & \\
\hline & $\operatorname{sim}$ & & & \\
\hline \multirow[t]{2}{*}{ Indicadores Hospitalares } & não & & & \\
\hline & $\operatorname{sim}$ & & & \\
\hline \multirow[t]{2}{*}{ Relatórios Gerenciais } & não & & & \\
\hline & sim & & & \\
\hline \multirow[t]{2}{*}{ Informatização } & não & \multirow[t]{2}{*}{ Em rede } & Sim & \\
\hline & $\operatorname{sim}$ & & não & \\
\hline \multirow[t]{2}{*}{ Serviço Social } & não & & & \\
\hline & $\operatorname{sim}$ & & & \\
\hline \multirow[t]{2}{*}{ Psicologia Hospitalar } & não & & & \\
\hline & $\operatorname{sim}$ & & & \\
\hline \multirow[t]{2}{*}{ Saúde Ocupacional } & não & & & \\
\hline & $\operatorname{sim}$ & & & \\
\hline \multirow{2}{*}{$\begin{array}{l}\text { Comissão de Ética Médica } \\
\text { (Res. CFM no } 1215 / 85 \text { ) }\end{array}$} & não & \multirow{2}{*}{\multicolumn{2}{|c|}{ Reuniões Regulares/Ata }} & $\operatorname{sim}$ \\
\hline & $\operatorname{sim}$ & & & não \\
\hline \multirow{2}{*}{$\begin{array}{l}\text { CCIH } \\
\text { (Port MS 2616/98) } \\
\end{array}$} & não & \multirow{2}{*}{\multicolumn{2}{|c|}{ Reuniões Regulares/Ata }} & $\operatorname{sim}$ \\
\hline & $\operatorname{sim}$ & & & não \\
\hline \multirow[t]{2}{*}{ Revisão de Prontuários } & não & \multirow{2}{*}{\multicolumn{2}{|c|}{ Reuniões Regulares/Ata }} & $\operatorname{sim}$ \\
\hline & $\operatorname{sim}$ & & & não \\
\hline \multirow[t]{2}{*}{ Revisão de Óbitos } & não & \multirow{2}{*}{\multicolumn{2}{|c|}{ Reuniões Regulares/Ata }} & $\operatorname{sim}$ \\
\hline & $\operatorname{sim}$ & & & não \\
\hline \multirow[t]{2}{*}{ CIPA } & não & Reuniões Regulares/At & & $\operatorname{sim}$ \\
\hline & sim & & & não \\
\hline Farmácia e Medicamentos & não & & & \\
\hline & $\operatorname{sim}$ & & & \\
\hline Controle e Gestão de Qualidade & não & & & \\
\hline & $\operatorname{sim}$ & & & \\
\hline SAME & não & Informatizado & & $\operatorname{sim}$ \\
\hline & $\operatorname{sim}$ & & & não \\
\hline Prontuários conforme Legislação & não & & & \\
\hline & $\operatorname{sim}$ & & & \\
\hline Ensino e Pesquisa & não & & & \\
\hline & $\operatorname{sim}$ & & & \\
\hline Residência Médica/Pós-Graduação & não & & & \\
\hline & $\operatorname{sim}$ & & & \\
\hline Outras & não & & & \\
\hline & $\operatorname{sim}$ & & & \\
\hline
\end{tabular}


6. Recursos Humanos de todo o Hospital (Ano de 200 -- )

\begin{tabular}{|l|l|}
\hline Profissionais & Quantidade \\
\hline Médicos contratados & \\
\hline Enfermeiros & \\
\hline Técnicos de Enfermagem & \\
\hline Auxiliares de Enfermagem & \\
\hline Atendentes de Enfermagem & \\
\hline Outros Funcionários & \\
\hline Total Geral & \\
\hline
\end{tabular}

(Resolução COFEN ñ ${ }^{\circ}$ 189/2003- Parâmetroa de Dimensionamento de Quadro de Pessoal de Enfermagem e Indicadores APM-Cremesp-CQH $1^{\circ}$ trimestre de 2003 para dimensionamento de Quadro de Pessoal).

7. Estatística (Ano de 200-- )

Levantamento de dados anual

\begin{tabular}{|l|l|}
\hline Número de óbitos após 48 horas & \\
\hline Número de saídas (Altas e Óbitos) & \\
\hline Número de óbitos por causas Maternas & \\
\hline Número de pacientes saídos da Obstetrícia & \\
\hline Número de nascidos vivos & \\
\hline Número de nascidos mortos & \\
\hline Número de óbitos neonatais após 48 horas & \\
\hline Número de óbitos operatórios até 10 dias pós-cirurgia & \\
\hline Número de atos cirúrgicos & \\
\hline Número de cesáreas & \\
\hline Número de partos normais & \\
\hline Número total de partos & \\
\hline Número de infecções atribuíveis ao hospital & \\
\hline Número de supurações de feridas cirúrgicas em cirurgias limpas & \\
\hline Número de cirurgias limpas no período & \\
\hline Número de pacientes/dia & \\
\hline Número de leitos/dia & \\
\hline Número de leitos disponíveis no período & \\
\hline
\end{tabular}


8. Indicadores de Qualidade (Ano de 200-- )

\begin{tabular}{|l|l|}
\hline Taxa de Mortalidade Institucional & \\
\hline Taxa de Mortalidade Materna & \\
\hline Taxa de Natimortalidade & \\
\hline Taxa de Mortalidade Neonatal & \\
\hline Taxa de Mortalidade Operatória & \\
\hline Taxa de Cesáreas & \\
\hline Taxa de Infecção Hospitalar & \\
\hline Taxa de Supuração de Ferida Cirúrgica em Cirurgia Limpa & \\
\hline
\end{tabular}

9. Indicadores de Produtividade (Ano de 200-- )

\begin{tabular}{|l|l|}
\hline Taxa de Ocupação & \\
\hline Taxa de Permanência & \\
\hline Giro de Rotatividade do Leito/Ano & \\
\hline
\end{tabular}


10. Estrutura Física / Infra-Estrutura (RDC $\left.n^{\circ} 50 / 02\right)$ :

Edificação

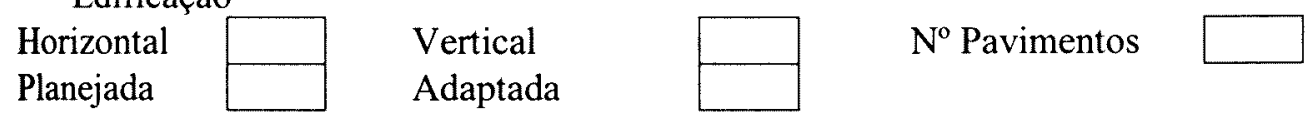

Infra Estrutura

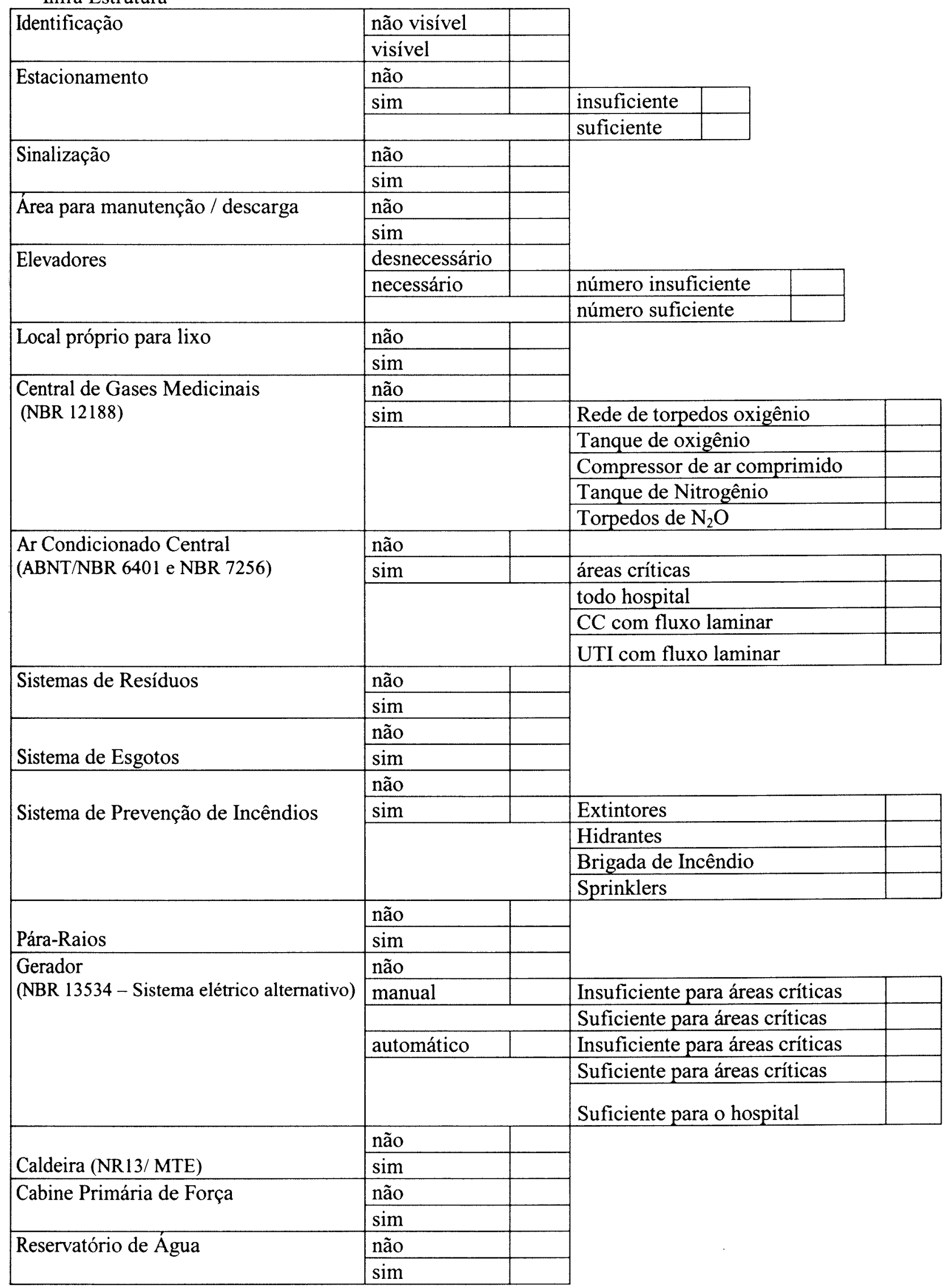




\section{II - Organização e Atenção ao Paciente}

(Hotelaria/ Unidades de Internação médico-cirúrgica, pediátrica, obstétrica, Pronto-Socorro, UTIs, Maternidade, Centro Obstétrico, Berçário, Centro Cirúrgico e RPA)

11. Hotelaria ( $\left.\mathrm{RDC} \mathrm{n}^{\circ} 50 / 02\right)$

\begin{tabular}{|c|c|c|c|}
\hline \multirow{9}{*}{ Recepção } & desconfortável & & \\
\hline & confortável & & \\
\hline & adequada & & \\
\hline & inadequada & & \\
\hline & \multirow{3}{*}{ sanitários } & não & \\
\hline & & \multirow[b]{2}{*}{$\operatorname{sim}$} & único \\
\hline & & & cada sexo \\
\hline & \multirow[t]{2}{*}{ informatizada } & não & \\
\hline & & $\operatorname{sim}$ & \\
\hline \multirow[t]{4}{*}{ Limpeza } & insuficiente & & \\
\hline & regular & & \\
\hline & boa & & \\
\hline & ótima & & \\
\hline \multirow[t]{4}{*}{ Higiene } & insuficiente & & \\
\hline & regular & & \\
\hline & boa & & \\
\hline & ótima & & \\
\hline \multirow[t]{4}{*}{ Conservação Predial } & insuficiente & & \\
\hline & regular & & \\
\hline & boa & & \\
\hline & ótima & & \\
\hline
\end{tabular}


12. Unidades de Internação (RDC $\left.n^{\circ} 50 / 02\right)$

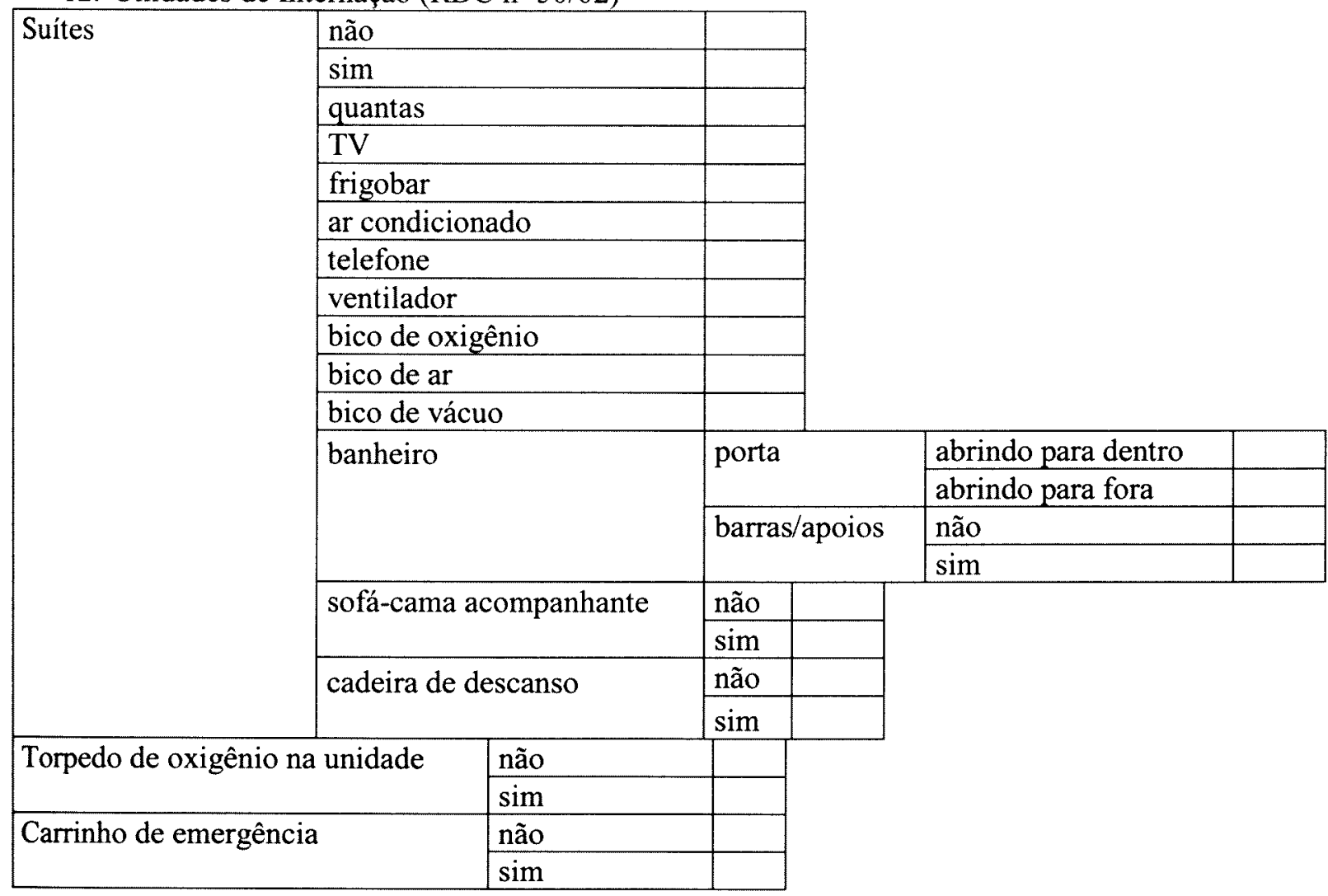

\begin{tabular}{|l|l|l|}
\hline Corredores Livres & não & \\
\cline { 2 - 3 } & sim & \\
\hline \multirow{2}{*}{ Iluminação } & inadequada & \\
\cline { 2 - 3 } & adequada & \\
\hline \multirow{2}{*}{ Ventilação } & inadequada & \\
\cline { 2 - 3 } & adequada & \\
\hline \multirow{2}{*}{ Instalações Elétricas } & inadequada & \\
\cline { 2 - 3 } & adequada & \\
\hline \multirow{2}{*}{ Instalações Hidráulicas } & inadequada & \\
\cline { 2 - 3 } & adequada & \\
\hline
\end{tabular}




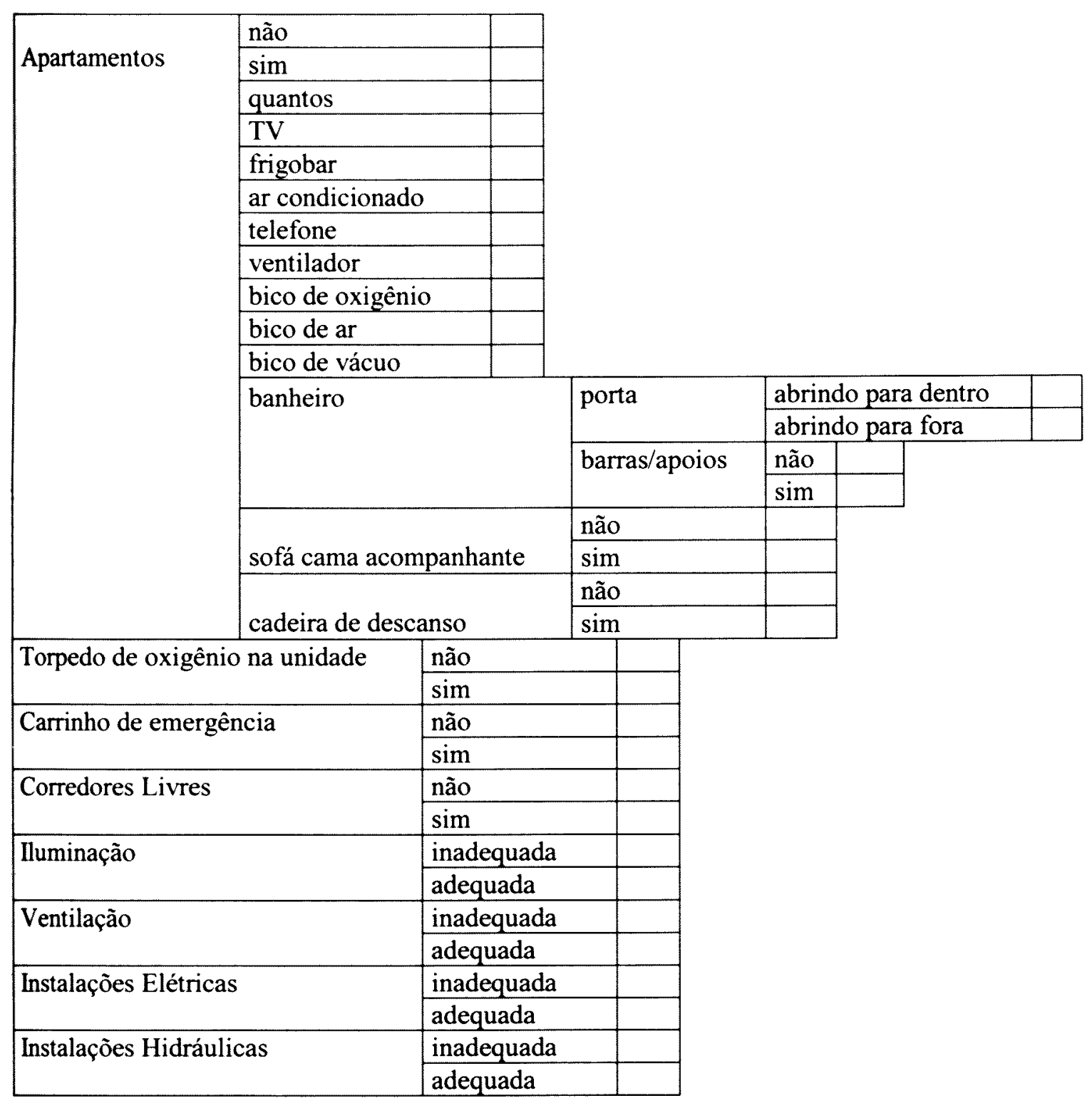




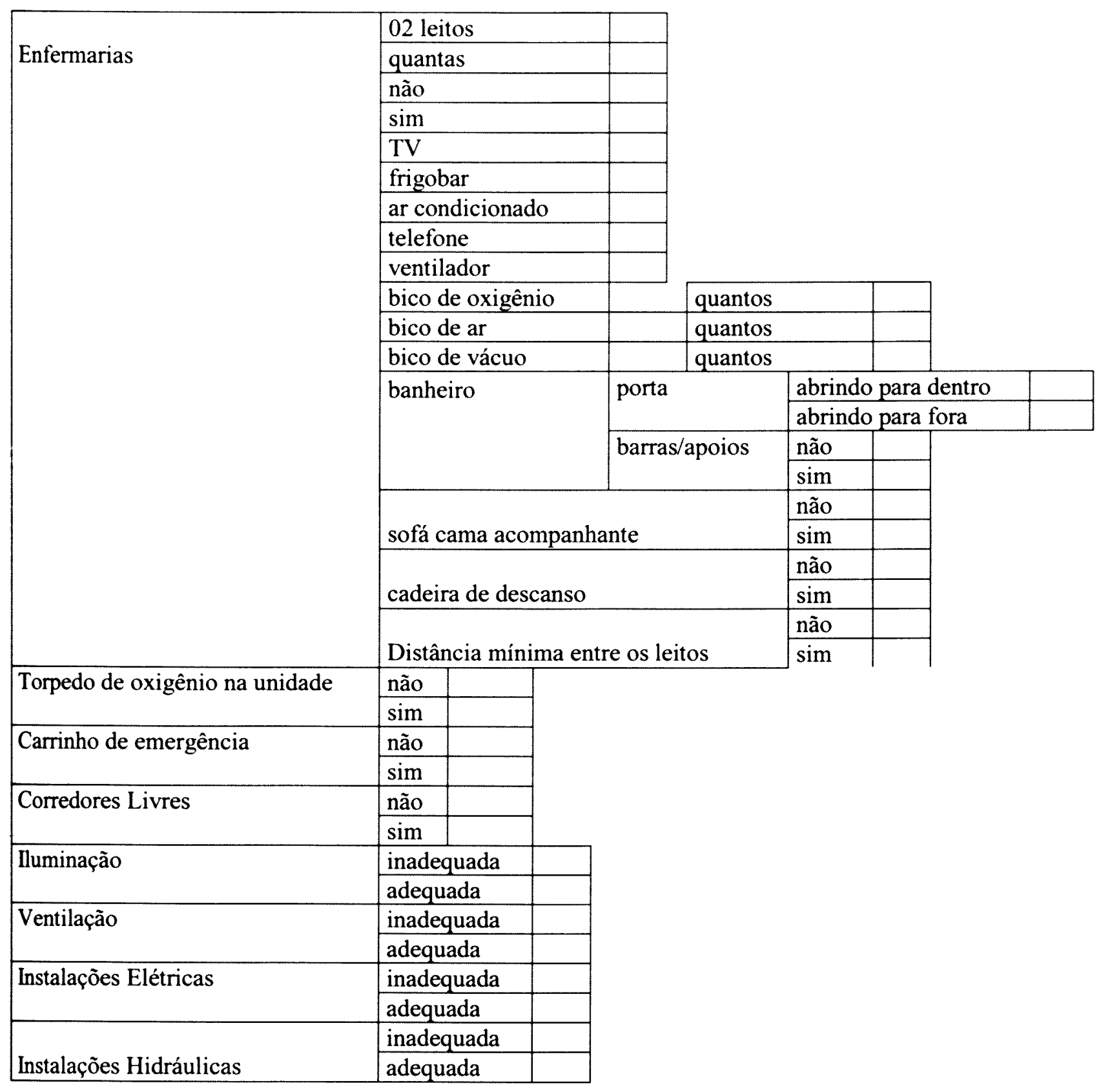




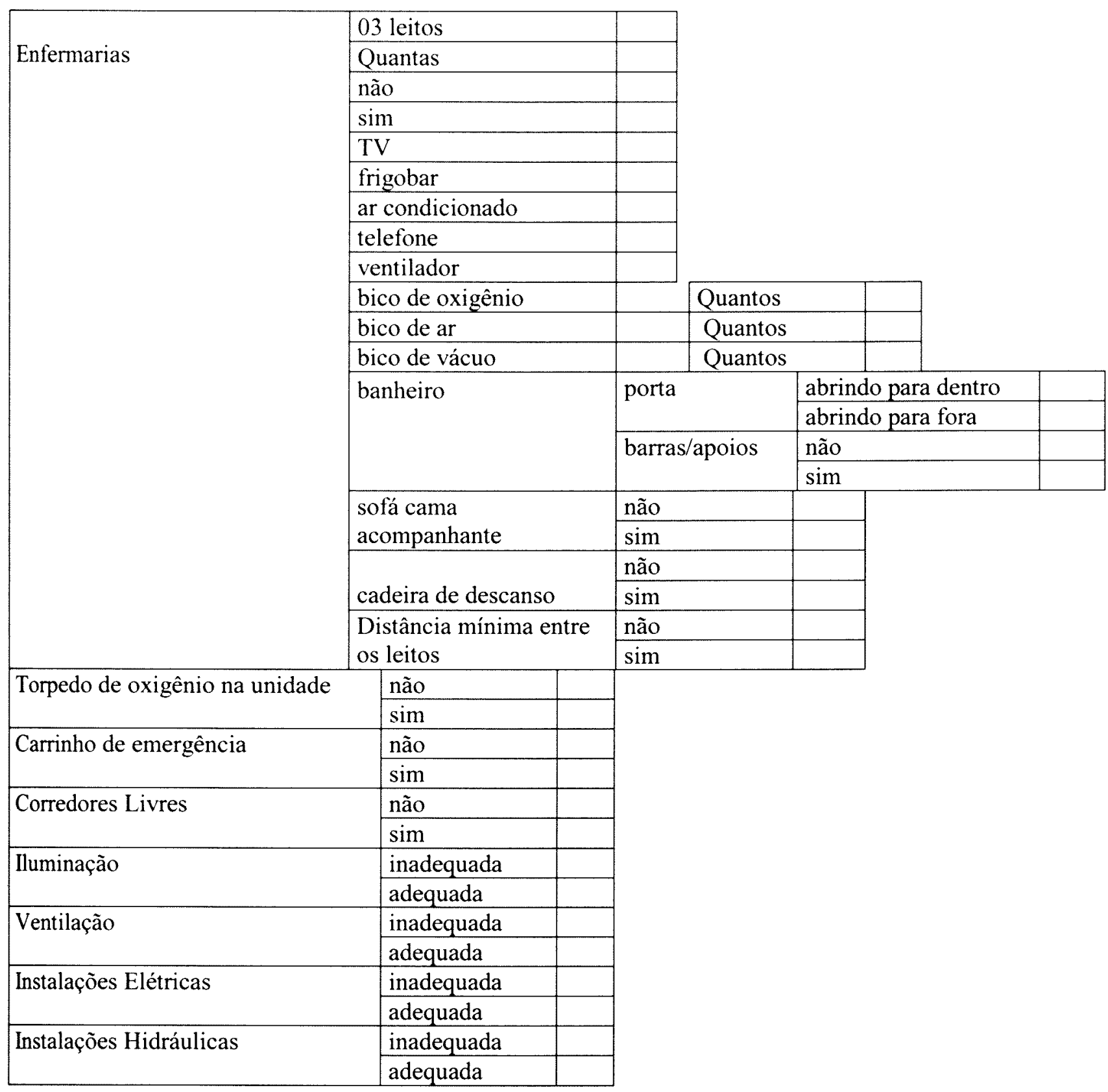




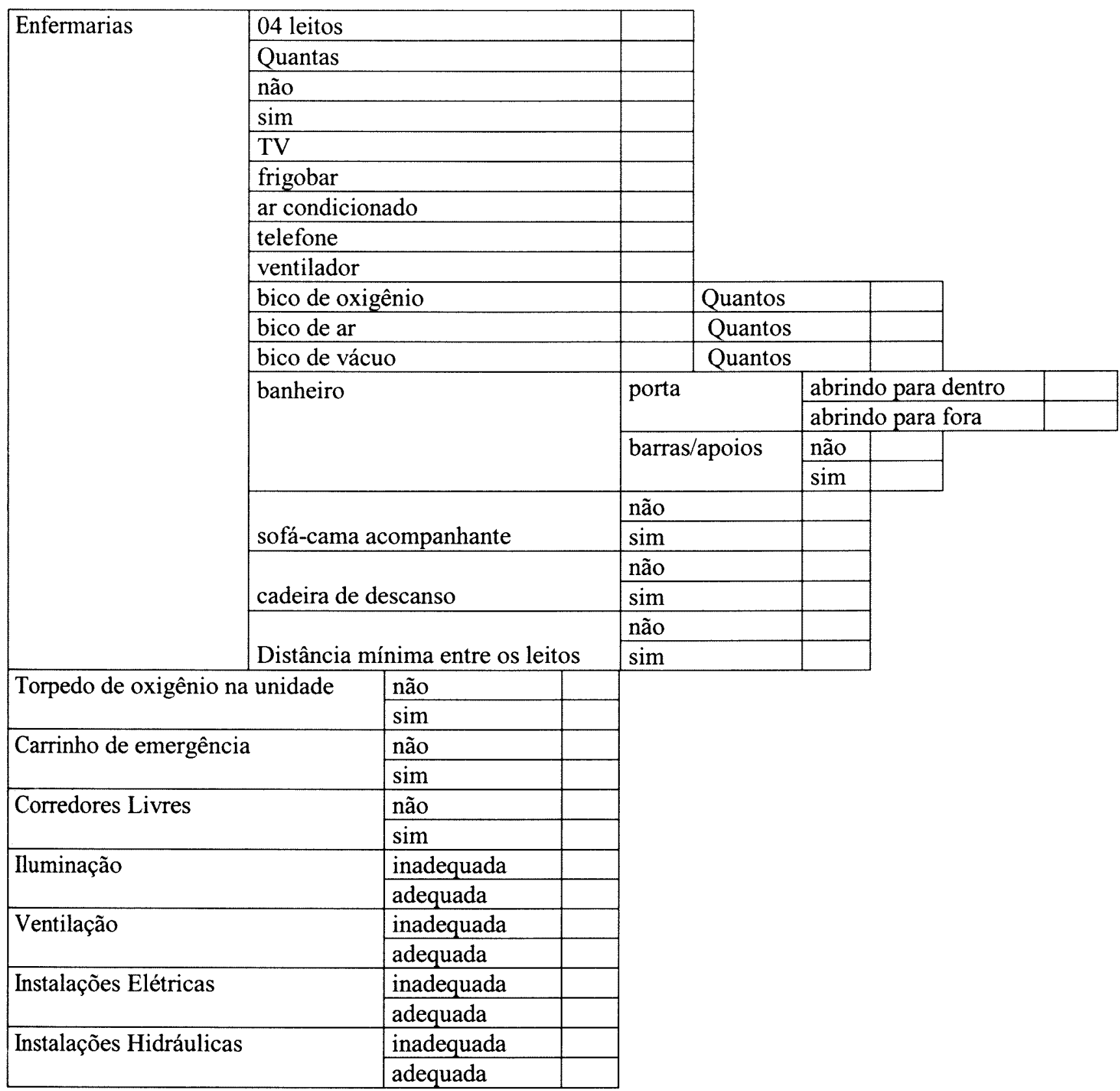


13. Pronto Socorro (RDC $\mathrm{n}^{\circ} 50 / 02$, Port GM n ${ }^{\circ} 2048 / 02$, Res CFM 1451/95)

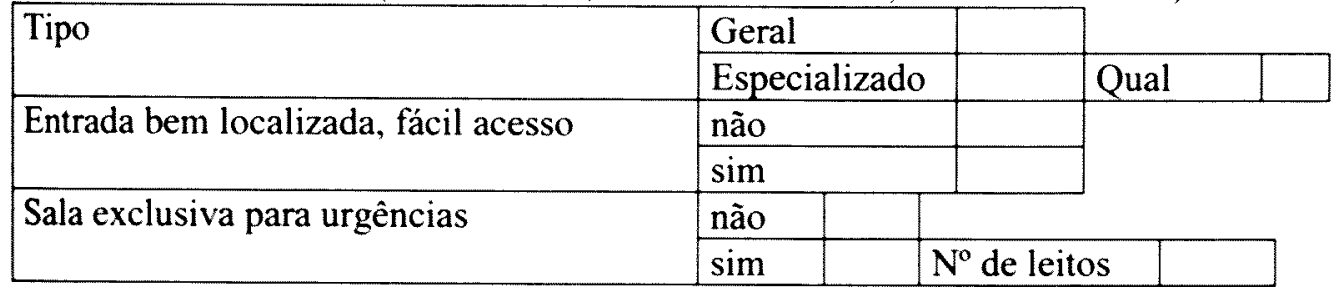

Equipamentos da Urgência

\begin{tabular}{|l|l|l|l|}
\hline Equipamentos & Marca & Modelo & $\mathrm{N}^{\mathbf{0}}$ \\
\hline & & & \\
\hline & & & \\
\hline & & & \\
\hline & & & \\
\hline
\end{tabular}

\begin{tabular}{|l|l|l|}
\hline 1 Bico de Oxigênio/leito & não & \\
\cline { 2 - 3 } & sim & \\
\hline 1 Ar Comprimido/leito & não & \\
\cline { 2 - 3 } & sim & \\
\hline 1 Vácuo/leito & não & \\
\cline { 2 - 3 } & sim & \\
\hline
\end{tabular}

\begin{tabular}{|l|l|l|}
\hline Leitos para observação & não & \\
\hline & sim & \\
\hline & Masculino & \\
\hline & Feminino & \\
\hline & Pediátrico & \\
\hline & Misto & \\
\hline
\end{tabular}

Equipamentos da Observação

\begin{tabular}{|l|l|l|l|}
\hline Equipamentos & Marca & Modelo & $\mathbf{N}^{\mathbf{0}}$ \\
\hline & & & \\
\hline & & & \\
\hline & & & \\
\hline
\end{tabular}

\begin{tabular}{|l|l|l|}
\hline 1 Bico de Oxigênio/leito & não & \\
\cline { 2 - 3 } & sim & \\
\hline \multirow{2}{*}{ I Ar Comprimido/leito } & não & \\
\cline { 2 - 3 } & sim & \\
\hline Ambúcuo/leito & não & \\
\cline { 2 - 3 } & $\operatorname{sim}$ & \\
\hline Possui UTI Móvel & não & \\
\cline { 2 - 3 } & sim & \\
\hline Equipe Médica (CFM 1491/95) & não & \\
\cline { 2 - 3 } & sim & \\
\hline \multirow{2}{*}{ Enfermeira nos turnos } & não & \\
\cline { 2 - 3 } & sim & \\
\hline Medicamentos de urgência & não & \\
\cline { 2 - 3 } & sim & \\
\hline Sala de Inalação & não & \\
\cline { 2 - 3 } & sim & \\
\hline & não & \\
\cline { 2 - 3 } & sim & \\
\hline
\end{tabular}


14. UTI Geral (RDC $n^{\circ} 50 / 02$ e Port MS $n^{\circ} 3432 / 98$ )

\begin{tabular}{|c|c|c|}
\hline \multirow{3}{*}{$\begin{array}{l}\text { Número de Leitos } \\
01 \text { médico para cada } 10 \text { leitos }\end{array}$} & & \\
\hline & não & \\
\hline & $\operatorname{sim}$ & \\
\hline \multirow{2}{*}{ Há normas e rotinas para a área } & não & \\
\hline & $\operatorname{sim}$ & \\
\hline \multirow[t]{2}{*}{ A UTI participa da CCIH } & não & \\
\hline & $\operatorname{sim}$ & \\
\hline \multirow[t]{2}{*}{ Há acompanhamento de visita com orientação } & não & \\
\hline & $\operatorname{sim}$ & \\
\hline \multirow[t]{2}{*}{ Encontra-se em área física adequada } & não & \\
\hline & $\operatorname{sim}$ & \\
\hline \multirow[t]{2}{*}{ De acordo com a legislação (Port MS 3432/ 98) } & não & \\
\hline & $\operatorname{sim}$ & \\
\hline \multirow[t]{2}{*}{ Posto de enfermagem permite boa visão dos leitos } & não & \\
\hline & $\operatorname{sim}$ & \\
\hline \multirow[t]{2}{*}{ Há boa circulação de funcionários e pacientes } & não & \\
\hline & $\operatorname{sim}$ & \\
\hline \multirow[t]{2}{*}{ Possui médico diarista } & não & \\
\hline & $\operatorname{sim}$ & \\
\hline \multirow[t]{2}{*}{ Possui equipe médica em todos os turnos } & não & \\
\hline & $\operatorname{sim}$ & \\
\hline \multirow[t]{2}{*}{ Equipe de enfermagem treinada e completa } & não & \\
\hline & $\operatorname{sim}$ & \\
\hline \multirow[t]{2}{*}{ Enfermeira em todos os turnos } & não & \\
\hline & $\operatorname{sim}$ & \\
\hline \multirow[t]{2}{*}{ Há leitos para isolamento } & não & Quantos \\
\hline & $\operatorname{sim}$ & \\
\hline \multirow[t]{2}{*}{ Quarto para médico plantonista } & não & \\
\hline & $\operatorname{sim}$ & \\
\hline \multirow[t]{2}{*}{ Área de descanso para enfermagem } & não & \\
\hline & $\operatorname{sim}$ & \\
\hline \multirow[t]{2}{*}{2 bicos de oxigênio/leito } & não & \\
\hline & $\operatorname{sim}$ & \\
\hline \multirow[t]{2}{*}{1 bico de ar comprimido/leito } & não & \\
\hline & $\operatorname{sim}$ & \\
\hline \multirow[t]{2}{*}{1 bico de vácuo/leito } & não & \\
\hline & $\operatorname{sim}$ & \\
\hline \multirow[t]{2}{*}{10 tomadas elétricas } & não & \\
\hline & $\operatorname{sim}$ & \\
\hline
\end{tabular}




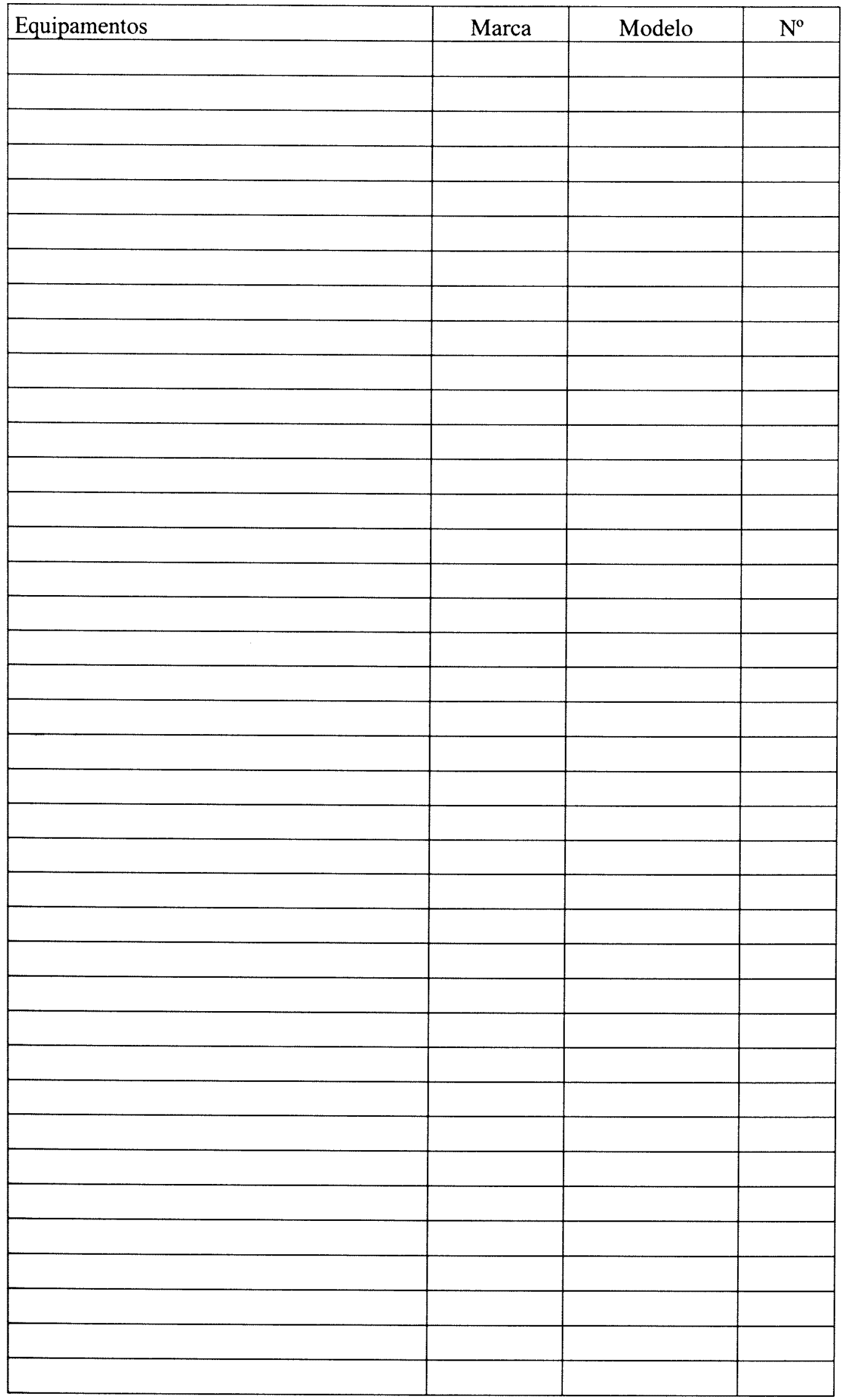


15. UTI Cardiológica (RDC $\mathrm{n}^{\circ} 50 / 02$ e Port MS n ${ }^{\circ} 3432 / 98$ )

\begin{tabular}{|c|c|c|}
\hline \multicolumn{2}{|l|}{ Número de Leitos } & \\
\hline \multirow[t]{2}{*}{01 médico para cada 10 leitos } & não & \\
\hline & $\operatorname{sim}$ & \\
\hline \multirow[t]{2}{*}{ Há normas e rotinas para a área } & não & \\
\hline & $\operatorname{sim}$ & \\
\hline \multirow[t]{2}{*}{ A UTI participa da CCIH } & não & \\
\hline & $\operatorname{sim}$ & \\
\hline \multirow[t]{2}{*}{ Há acompanhamento de visita com orientação } & não & \\
\hline & $\operatorname{sim}$ & \\
\hline \multirow[t]{2}{*}{ Encontra-se em área física adequada } & não & \\
\hline & $\operatorname{sim}$ & \\
\hline \multirow[t]{2}{*}{ De acordo com a legislação (Portaria 3432/ 98) } & não & \\
\hline & $\operatorname{sim}$ & \\
\hline \multirow[t]{2}{*}{ Posto de enfermagem permite boa visão dos leitos } & não & \\
\hline & $\operatorname{sim}$ & \\
\hline \multirow[t]{2}{*}{ Há boa circulação de funcionários e pacientes } & não & \\
\hline & $\operatorname{sim}$ & \\
\hline \multirow[t]{2}{*}{ Possui médico diarista } & não & \\
\hline & $\operatorname{sim}$ & \\
\hline \multirow[t]{2}{*}{ Possui equipe médica em todos os turnos } & não & \\
\hline & $\operatorname{sim}$ & \\
\hline \multirow[t]{2}{*}{ Equipe de enfermagem treinada e completa } & não & \\
\hline & $\operatorname{sim}$ & \\
\hline \multirow[t]{2}{*}{ Enfermeira em todos os turnos } & não & \\
\hline & $\operatorname{sim}$ & \\
\hline \multirow[t]{2}{*}{ Há leitos para isolamento } & não & Quantos \\
\hline & $\operatorname{sim}$ & \\
\hline \multirow[t]{2}{*}{ Quarto para médico plantonista } & não & \\
\hline & $\operatorname{sim}$ & \\
\hline \multirow[t]{2}{*}{ Área de descanso para enfermagem } & não & \\
\hline & $\operatorname{sim}$ & \\
\hline \multirow[t]{2}{*}{2 bicos de oxigênio/leito } & não & \\
\hline & $\operatorname{sim}$ & \\
\hline \multirow[t]{2}{*}{1 bico de ar comprimido/leito } & não & \\
\hline & $\operatorname{sim}$ & \\
\hline \multirow[t]{2}{*}{ I bico de vácuo/leito } & não & \\
\hline & $\operatorname{sim}$ & \\
\hline \multirow[t]{2}{*}{10 tomadas elétricas } & não & \\
\hline & $\operatorname{sim}$ & \\
\hline
\end{tabular}




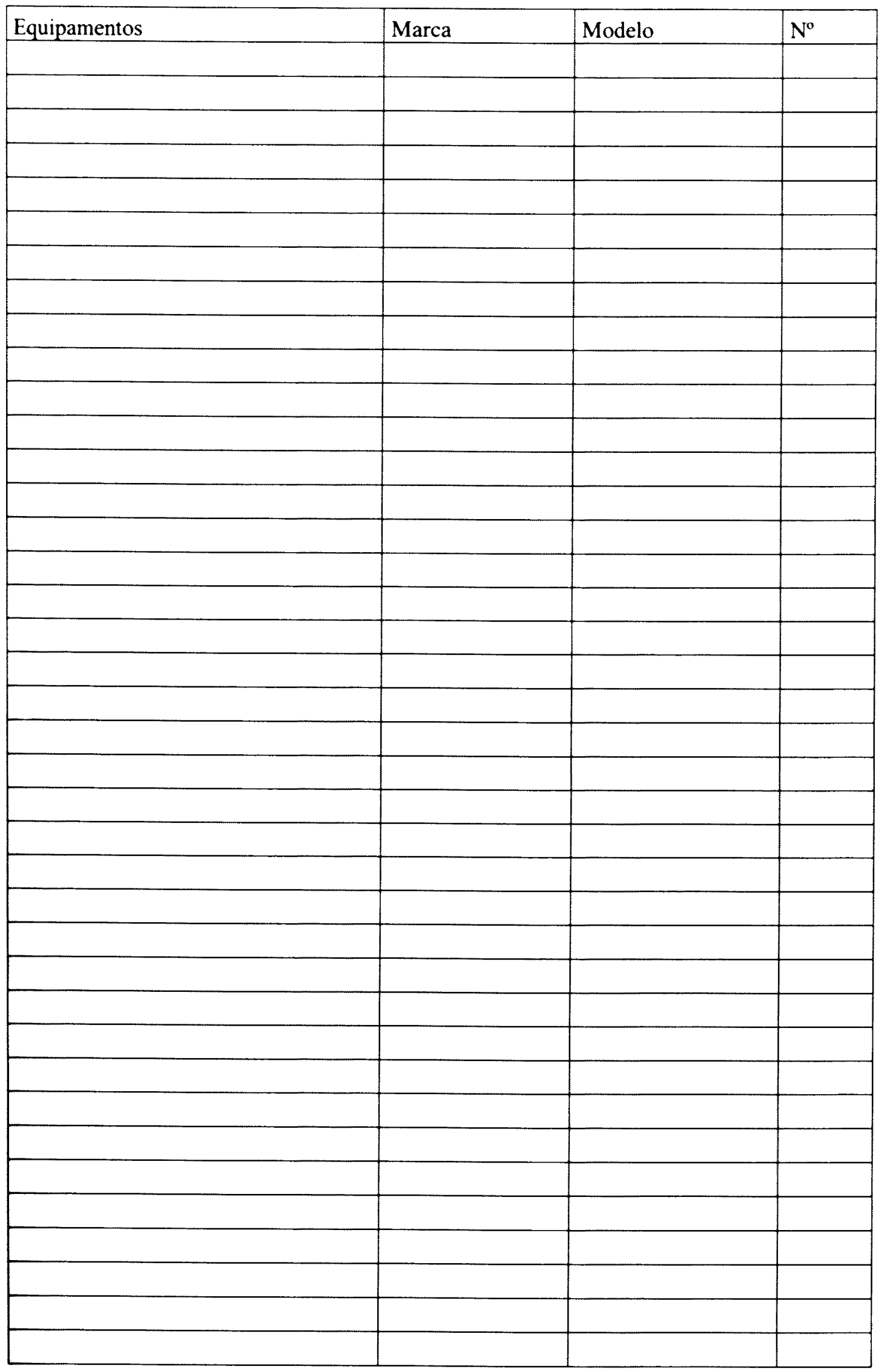


16. UTI Pediátrica ( $\mathrm{RDC} \mathrm{n}^{\circ} 50 / 02$ e Port $\mathrm{MS} \mathrm{n}^{\circ} 3432 / 98$ )

\begin{tabular}{|c|c|c|}
\hline Número de Leitos & & \\
\hline 01 médico para cada 10 leitos & não & \\
\hline & $\operatorname{sim}$ & \\
\hline Há normas e rotinas para a área & não & \\
\hline & $\operatorname{sim}$ & \\
\hline A UTI participa da CCIH & não & \\
\hline & $\operatorname{sim}$ & \\
\hline Há acompanhamento de visita com orientação & não & \\
\hline & $\operatorname{sim}$ & \\
\hline Encontra-se em área fisica adequada & não & \\
\hline & $\operatorname{sim}$ & \\
\hline De acordo com a legislação (Portaria 3432/98) & não & \\
\hline & $\operatorname{sim}$ & \\
\hline Posto de enfermagem permite boa visão dos leitos & não & \\
\hline & $\operatorname{sim}$ & \\
\hline Há boa circulação de funcionários e pacientes & não & \\
\hline & $\operatorname{sim}$ & \\
\hline Possui médico diarista & não & \\
\hline & $\operatorname{sim}$ & \\
\hline Possui equipe médica em todos os turnos & não & \\
\hline & $\operatorname{sim}$ & \\
\hline Equipe de enfermagem treinada e completa & não & \\
\hline & $\operatorname{sim}$ & \\
\hline Enfermeira em todos os turnos & não & \\
\hline & $\operatorname{sim}$ & \\
\hline Há leitos para isolamento & não & Quantos \\
\hline & $\operatorname{sim}$ & \\
\hline Quarto para médico plantonista & não & \\
\hline & $\operatorname{sim}$ & \\
\hline Área de descanso para enfermagem & não & \\
\hline & $\operatorname{sim}$ & \\
\hline 2 bicos de oxigênio/leito & não & \\
\hline & $\operatorname{sim}$ & \\
\hline 1 bico de ar comprimido/leito & não & \\
\hline & $\operatorname{sim}$ & \\
\hline 1 bico de vácuo/leito & não & \\
\hline & $\operatorname{sim}$ & \\
\hline 10 tomadas elétricas & não & \\
\hline & $\operatorname{sim}$ & \\
\hline
\end{tabular}




\begin{tabular}{|c|c|c|c|}
\hline Equipamentos & Marca & Modelo & $\mathrm{N}^{\mathrm{o}}$ \\
\hline & & & \\
\hline & & & \\
\hline & & & \\
\hline & & & \\
\hline & & & \\
\hline & & & \\
\hline & & & \\
\hline & & & \\
\hline & & & \\
\hline & & & \\
\hline & & & \\
\hline & & & \\
\hline & & & \\
\hline & & & \\
\hline & & & \\
\hline & & & \\
\hline & & & \\
\hline & & & \\
\hline & & & \\
\hline & & & \\
\hline & & & \\
\hline & & & \\
\hline & & & \\
\hline & & & \\
\hline & & & \\
\hline & & & \\
\hline & & & \\
\hline & & & \\
\hline & & & \\
\hline & & & \\
\hline & & & \\
\hline & & & \\
\hline & & & \\
\hline & & & \\
\hline & & & \\
\hline & & & \\
\hline & & & \\
\hline & & & \\
\hline
\end{tabular}


17. UTI Neonatal (RDC no 50/02 e Port MS n $\left.{ }^{\circ} 3432 / 98\right)$

\begin{tabular}{|c|c|c|}
\hline \multirow{3}{*}{$\begin{array}{l}\text { Número de Leitos } \\
01 \text { médico para cada } 10 \text { leitos }\end{array}$} & \multirow{2}{*}{\begin{tabular}{|l|} 
não \\
\end{tabular}} & \\
\hline & & \\
\hline & $\operatorname{sim}$ & \\
\hline \multirow[t]{2}{*}{ Há normas e rotinas para a área } & não & \\
\hline & $\operatorname{sim}$ & \\
\hline \multirow[t]{2}{*}{ A UTI participa da CCIH } & não & \\
\hline & $\operatorname{sim}$ & \\
\hline \multirow[t]{2}{*}{ Há acompanhamento de visita com orientação } & não & \\
\hline & $\operatorname{sim}$ & \\
\hline \multirow[t]{2}{*}{ Encontra-se em área física adequada } & não & \\
\hline & $\operatorname{sim}$ & \\
\hline \multirow[t]{2}{*}{ De acordo com a legislação (Portaria 3432/ 98) } & não & \\
\hline & $\operatorname{sim}$ & \\
\hline \multirow[t]{2}{*}{ Posto de enfermagem permite boa visão dos leitos } & não & \\
\hline & $\operatorname{sim}$ & \\
\hline \multirow[t]{2}{*}{ Há boa circulação de funcionários e pacientes } & não & \\
\hline & $\operatorname{sim}$ & \\
\hline \multirow[t]{2}{*}{ Possui médico diarista } & não & \\
\hline & $\operatorname{sim}$ & \\
\hline \multirow[t]{2}{*}{ Possui equipe médica em todos os turnos } & não & \\
\hline & $\operatorname{sim}$ & \\
\hline \multirow[t]{2}{*}{ Equipe de enfermagem treinada e completa } & não & \\
\hline & $\operatorname{sim}$ & \\
\hline \multirow[t]{2}{*}{ Enfermeira em todos os turnos } & não & \\
\hline & $\operatorname{sim}$ & \\
\hline \multirow[t]{2}{*}{ Há leitos para isolamento } & não & Quantos \\
\hline & $\operatorname{sim}$ & \\
\hline \multirow{2}{*}{ Quarto para médico plantonista } & não & \\
\hline & $\operatorname{sim}$ & \\
\hline \multirow{2}{*}{ Area de descanso para enfermagem } & não & \\
\hline & $\operatorname{sim}$ & \\
\hline \multirow[t]{2}{*}{2 bicos de oxigênio/leito } & não & \\
\hline & $\operatorname{sim}$ & \\
\hline \multirow[t]{2}{*}{1 bico de ar comprimido/leito } & não & \\
\hline & $\operatorname{sim}$ & \\
\hline \multirow{2}{*}{1 bico de vácuo/leito } & não & \\
\hline & $\operatorname{sim}$ & \\
\hline \multirow{2}{*}{10 tomadas elétricas } & não & \\
\hline & $\operatorname{sim}$ & \\
\hline
\end{tabular}




\begin{tabular}{|c|c|c|c|}
\hline Equipamentos & Marca & Modelo & $\mathrm{N}^{\mathrm{o}}$ \\
\hline & & & \\
\hline & & & \\
\hline & & & \\
\hline & & & \\
\hline & & & \\
\hline & & & \\
\hline & & & \\
\hline & & & \\
\hline & & & \\
\hline & & & \\
\hline & & & \\
\hline & & & \\
\hline & & & \\
\hline & & & \\
\hline & & & \\
\hline & & & \\
\hline & & & \\
\hline & & & \\
\hline & & & \\
\hline & & & \\
\hline & & & \\
\hline & & & \\
\hline & & & \\
\hline & & & \\
\hline & & & \\
\hline & & & \\
\hline & & & \\
\hline & & & \\
\hline & & & \\
\hline & & & \\
\hline & & & \\
\hline & & & \\
\hline & & & \\
\hline & & & \\
\hline & & & \\
\hline & & & \\
\hline & & & \\
\hline & & & \\
\hline
\end{tabular}


18. Maternidade ( $\left.\mathrm{RDC}^{\circ} 50 / 02\right)$

\begin{tabular}{|c|c|}
\hline \multirow[t]{2}{*}{ Tem sala de admissão } & não \\
\hline & $\operatorname{sim}$ \\
\hline \multirow[t]{2}{*}{ Sala/leitos de pré-parto } & não \\
\hline & $\operatorname{sim}$ \\
\hline \multirow[b]{2}{*}{ Sala de parto normal } & não \\
\hline & $\operatorname{sim}$ \\
\hline \multirow{2}{*}{ Sala de parto cirúrgico } & não \\
\hline & $\operatorname{sim}$ \\
\hline \multirow[t]{2}{*}{ Vestiário com sanitário para ambos os sexos } & não \\
\hline & $\operatorname{sim}$ \\
\hline \multirow[t]{2}{*}{ Sala de estar e repouso para funcionários e médicos } & não \\
\hline & $\operatorname{sim}$ \\
\hline \multirow[t]{2}{*}{ Recuperação pós-anestésica (RPA) } & não \\
\hline & $\operatorname{sim}$ \\
\hline \multirow{2}{*}{ O parto é realizado por: } & Médico \\
\hline & Obstetriz \\
\hline \multirow[t]{2}{*}{ Há médico obstetra no local durante 24 horas } & não \\
\hline & $\operatorname{sim}$ \\
\hline \multirow[t]{2}{*}{ O neonatologista recepciona todos os $\mathrm{RN}$} & não \\
\hline & $\operatorname{sim}$ \\
\hline \multirow[t]{2}{*}{ Há neonatologista no local durante 24 horas } & não \\
\hline & $\operatorname{sim}$ \\
\hline \multirow[t]{2}{*}{ Há disponibilidade de anestesista durante 24 horas } & não \\
\hline & $\operatorname{sim}$ \\
\hline \multirow[t]{2}{*}{ Há sala de reanimação e identificação do $\mathrm{RN}$} & não \\
\hline & $\operatorname{sim}$ \\
\hline \multirow[t]{2}{*}{ Há pia com água corrente na sala de reanimação } & não \\
\hline & $\operatorname{sim}$ \\
\hline
\end{tabular}

\begin{tabular}{|c|c|c|}
\hline Equipamentos do Centro Obstétrico - Sala & Marca & Modelo \\
\hline Bicos de oxigênio & Quantos & \\
\hline Bicos de ar comprimido & Quantos & \\
\hline Bicos de vácuo & Quantos & \\
\hline Torpedo de oxigênio & Quantos & \\
\hline Torpedo de ar comprimido & Quantos & \\
\hline Torpedo de óxido nitroso & Quantos & \\
\hline Torpedo de nitrogênio & Quantos & \\
\hline Torpedo de $\mathrm{CO}_{2}$ & Quantos & \\
\hline
\end{tabular}


19. Berçário (RDC n $\left.{ }^{\circ} 50 / 02\right)$

\begin{tabular}{|l|l|l|}
\hline Há berçário de primeiros cuidados & não & \\
\cline { 2 - 3 } & sim & \\
\hline Área Física & adequada & \\
\hline & inadequada & \\
\hline Há berçário de patológicos & não & \\
\hline & sim & \\
\hline \multirow{4}{*}{ Área Física } & adequada & \\
\hline Há alojamento conjunto & inadequada & \\
\hline Há UTI neonatal & não & \\
\hline & sim & \\
\hline
\end{tabular}

\begin{tabular}{|c|c|c|c|}
\hline Equipamento Berçário de Primeiros Cuidados & Marca & Modelo & $\mathrm{N}^{\circ}$ \\
\hline & & & \\
\hline & & & \\
\hline & & & \\
\hline & & & \\
\hline & & & \\
\hline & & & \\
\hline & & & \\
\hline 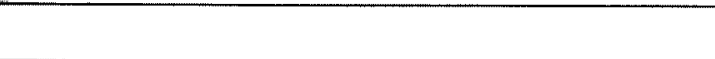 & & & \\
\hline
\end{tabular}

\begin{tabular}{|l|l|l|l|}
\hline Equipamento Berçário de Patológicos/Prematuros & Marca & Modelo & N $^{\mathbf{0}}$ \\
\hline & & & \\
\hline & & & \\
\hline & & & \\
\hline & & & \\
\hline & & & \\
\hline & & & \\
\hline
\end{tabular}


20. Centro Cirúrgico (RDC n ${ }^{\circ} 50 / 02$ )

\begin{tabular}{|c|c|}
\hline \multirow[t]{2}{*}{ Área de recepção de paciente com passa maca } & não \\
\hline & $\operatorname{sim}$ \\
\hline \multirow[t]{2}{*}{ Área de Escovação } & não \\
\hline & $\operatorname{sim}$ \\
\hline \multirow[t]{2}{*}{ Posto de Enfermagem e Serviços } & não \\
\hline & $\operatorname{sim}$ \\
\hline \multirow[t]{2}{*}{ Vestiários com sanitários para funcionários com barreira } & não \\
\hline & $\operatorname{sim}$ \\
\hline \multirow[t]{2}{*}{ Sala de preparo de equipamentos e material } & não \\
\hline & $\operatorname{sim}$ \\
\hline \multirow[t]{2}{*}{ Depósito de equipamentos e materiais } & não \\
\hline & $\operatorname{sim}$ \\
\hline \multirow[t]{2}{*}{ Sala administrativa } & não \\
\hline & $\operatorname{sim}$ \\
\hline \multirow[t]{2}{*}{ Expurgo } & não \\
\hline & $\operatorname{sim}$ \\
\hline \multirow[t]{2}{*}{ Depósito de Material de Limpeza } & não \\
\hline & $\operatorname{sim}$ \\
\hline \multirow[t]{2}{*}{ Sala de estar para funcionários } & não \\
\hline & sim \\
\hline \multirow[t]{2}{*}{ Sala de Espera com sanitário para acompanhantes } & não \\
\hline & $\operatorname{sim}$ \\
\hline \multirow[t]{2}{*}{ Área para guarda de macas e cadeira de rodas } & não \\
\hline & $\operatorname{sim}$ \\
\hline \multirow[t]{2}{*}{ Sala de Biópsia de congelação (Anatomia Patológica) } & não \\
\hline & $\operatorname{sim}$ \\
\hline \multirow[t]{2}{*}{ Fluxos pacientes/funcionários por entradas diferentes } & não \\
\hline & $\operatorname{sim}$ \\
\hline \multirow[t]{2}{*}{ Há Sala de Conforto Médico no Centro Cirúrgico } & não \\
\hline & $\operatorname{sim}$ \\
\hline \multicolumn{2}{|l|}{ Número total de salas cirúrgicas } \\
\hline \multicolumn{2}{|l|}{ Número de salas de pequena cirurgia } \\
\hline \multicolumn{2}{|l|}{ Número de salas de média cirurgia } \\
\hline \multicolumn{2}{|l|}{ Número de salas de grande cirurgia } \\
\hline Número de salas de cirurgia especial & \\
\hline
\end{tabular}




\begin{tabular}{|l|l|l|l|}
\hline Sala & Marca & Modelo & Quantidade \\
\hline Equipamentos & & & \\
\hline & & & \\
\hline & & & \\
\hline & & & \\
\hline & & & \\
\hline & & & \\
\hline Bicos de oxigênio & & & \\
\hline Bicos de ar comprimido & & & \\
\hline Bicos de vácuo & & & \\
\hline Torpedo de oxigênio & & & \\
\hline Torpedo de ar comprimido & & & \\
\hline Torpedo de óxido nitroso & & & \\
\hline Torpedo de nitrogênio & & & \\
\hline Torpedo de CO & & \\
\hline
\end{tabular}

\section{RPA (RDC 50/02)}

\begin{tabular}{|l|l|l|}
\hline Número de leitos & \\
\hline \multirow{2}{*}{ Área Física } & adequada & \\
\cline { 2 - 3 } & inadequada & \\
\hline \multirow{2}{*}{ RH } & adequados & \\
\hline & inadequados & \\
\hline \multirow{2}{*}{ Desfibrilador } & não & \\
\hline \multirow{2}{*}{ Monitor de FC } & sim & \\
\hline \multirow{2}{*}{ Oxímetro } & não & \\
\hline \multirow{2}{*}{01 bico de oxigênio/leito } & sim & \\
\hline \multirow{2}{*}{01 bico ar comprimido/leito } & não & \\
\cline { 2 - 3 } & sim & \\
\hline \multirow{2}{*}{01 bico de vácuo/leito } & não & \\
\hline & não & \\
\hline
\end{tabular}


III - Apoio Diagnóstico e Terapia

(Serviços de Apoio Diagnóstico e Terapia)

22. SADT básico

\begin{tabular}{|l|l|l|l|l|l|}
\hline \multirow{3}{*}{ Anatomia Patológica } & não & & \multicolumn{3}{|l|}{} \\
\cline { 1 - 4 } & sim & & \multirow{2}{*}{ Aparelhos } & adequados & \\
\cline { 2 - 5 } & & & & inadequados & \\
\hline
\end{tabular}

\begin{tabular}{|l|l|l|l|}
\hline Equipamento & Marca & Modelo & Quantidade \\
\hline & & & \\
\hline & & & \\
\hline
\end{tabular}

\begin{tabular}{|l|l|l|l|l|l|}
\hline \multirow{2}{*}{ ECG } & não & & \multicolumn{2}{|l|}{} \\
\cline { 1 - 2 } & sim & & \multirow{2}{*}{ Aparelhos } & adequados & \\
\hline & & & & inadequados & \\
\hline
\end{tabular}

\begin{tabular}{|l|l|l|l|}
\hline Equipamento & Marca & Modelo & Quantidade \\
\hline & & & \\
\hline
\end{tabular}

\begin{tabular}{|c|c|c|c|}
\hline \multirow{7}{*}{ Endoscopia } & não & & \\
\hline & sim & \multirow{2}{*}{ Aparelhos } & adequados \\
\hline & & & inadequados \\
\hline & & \multirow{2}{*}{ Salas } & inadequadas \\
\hline & & & adequadas \\
\hline & & \multirow[t]{2}{*}{ Repouso } & inadequado \\
\hline & & & adequado \\
\hline
\end{tabular}

\begin{tabular}{|l|l|l|l|}
\hline Equipamento & Marca & Modelo & Quantidade \\
\hline & & & \\
\hline & & & \\
\hline & & & \\
\hline
\end{tabular}

\begin{tabular}{|c|c|c|c|}
\hline \multirow{7}{*}{ Hemoterapia } & não & & \\
\hline & $\operatorname{sim}$ & \multirow[b]{2}{*}{ Conforme Legislação } & não \\
\hline & & & $\operatorname{sim}$ \\
\hline & & \multirow[b]{4}{*}{ Realiza } & Tipagem \\
\hline & & & $\mathrm{Rh}$ \\
\hline & & & Coombs \\
\hline & & & Prova Cruzada \\
\hline
\end{tabular}

\begin{tabular}{|l|l|l|l|l|l|}
\hline \multirow{2}{*}{ Patologia Clínica } & não & & \multicolumn{3}{|l|}{} \\
\cline { 2 - 2 } & $\operatorname{sim}$ & & \multirow{2}{*}{ Aparelhos } & adequados & \\
\hline & & & inadequados & \\
\hline
\end{tabular}

\begin{tabular}{|l|l|l|l|}
\hline Equipamento & Marca & Modelo & Quantidade \\
\hline & & & \\
\hline & & & \\
\hline & & & \\
\hline
\end{tabular}


RX

\begin{tabular}{|l|l|l|l|l|}
\hline não & & \multicolumn{3}{|l|}{} \\
\cline { 1 - 1 } $\operatorname{sim}$ & & \multirow{2}{*}{ seriógrafo } & não & \\
\hline & & $\operatorname{sim}$ & \\
\hline
\end{tabular}

\begin{tabular}{|l|l|l|l|}
\hline Equipamento & Marca & Modelo & Quantidade \\
\hline & & & \\
\hline & & & \\
\hline
\end{tabular}

\section{RX Portátil}

\begin{tabular}{|l|l|}
\hline não & \\
\hline $\operatorname{sim}$ & \\
\hline
\end{tabular}

\begin{tabular}{|l|l|l|l|}
\hline Equipamento & Marca & Modelo & Quantidade \\
\hline & & & \\
\hline & & & \\
\hline & & & \\
\hline
\end{tabular}

\section{USG}

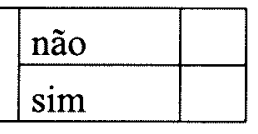

\begin{tabular}{|l|l|l|l|}
\hline Equipamento & Marca & Modelo & Quantidade \\
\hline & & & \\
\hline & & & \\
\hline & & & \\
\hline
\end{tabular}

SADT Acessório

Angiografia Digital/Hemodinâmica
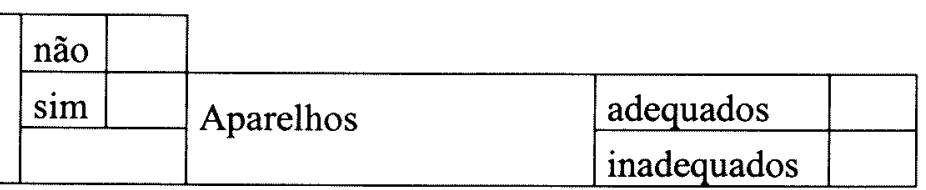

\begin{tabular}{|l|l|l|l|}
\hline Equipamento & Marca & Modelo & Quantidade \\
\hline & & & \\
\hline & & & \\
\hline & & & \\
\hline
\end{tabular}

\begin{tabular}{|l|l|l|l|l|l|}
\hline \multirow{3}{*}{ Audiometria } & não & & \multicolumn{2}{|l|}{} \\
\cline { 2 - 2 } & sim & & \multirow{2}{*}{ Aparelhos } & adequados & \\
\hline & & & & inadequados & \\
\hline
\end{tabular}

\begin{tabular}{|l|l|l|l|}
\hline Equipamento & Marca & Modelo & Quantidade \\
\hline & & & \\
\hline
\end{tabular}

\begin{tabular}{|l|l|l|l|l|l|}
\hline \multirow{4}{*}{ Cintilografia } & não & & \multicolumn{2}{|l|}{} \\
\cline { 4 - 5 } & sim & & \multirow{2}{*}{ Aparelhos } & adequados & \\
\cline { 4 - 5 } & & & inadequados & \\
\cline { 3 - 5 } & & Normas CNEN & não & \\
\hline & & & sim & \\
\hline
\end{tabular}

\begin{tabular}{|l|l|l|l|}
\hline Equipamento & Marca & Modelo $\cdot$ & Quantidade \\
\hline & & & \\
\hline
\end{tabular}


Densitometria óssea

\begin{tabular}{|c|c|c|}
\hline não & & \\
\hline \multirow[t]{2}{*}{$\operatorname{sim}$} & \multirow{2}{*}{ Aparelhos } & adequados \\
\hline & & inadequados \\
\hline
\end{tabular}

\section{Ecografia}

\begin{tabular}{|c|c|c|}
\hline$\frac{\text { não }}{\text { sim }}$ & & \\
\hline \multirow[t]{2}{*}{$\operatorname{sim}$} & \multirow{2}{*}{ Aparelhos } & adequados \\
\hline & & inadequados \\
\hline
\end{tabular}

\section{EEG}

\begin{tabular}{|l|l|l|}
\hline não & & \\
\cline { 1 - 1 } sim & & \multirow{2}{*}{ Aparelhos } \\
\hline
\end{tabular}

\begin{tabular}{|l|l|}
\hline adequados & \\
\hline inadequados & \\
\hline
\end{tabular}

\begin{tabular}{|l|l|l|l|}
\hline Equipamento & Marca & Modelo & Quantidade \\
\hline & & & \\
\hline
\end{tabular}

\begin{tabular}{|l|l|l|l|l|l|}
\hline \multirow{2}{*}{ Eletroneuromiografia } & não & & \multicolumn{3}{|l|}{} \\
\cline { 2 - 3 } & sim & & \multirow{2}{*}{ Aparelhos } & adequados & \\
\cline { 2 - 4 } & & & & inadequados & \\
\hline
\end{tabular}

\begin{tabular}{|l|l|l|l|}
\hline Equipamento & Marca & Modelo & Quantidade \\
\hline & & & \\
\hline
\end{tabular}

\begin{tabular}{|l|l|l|l|l|l|}
\hline \multirow{3}{*}{ Ergometria } & não & & & \multicolumn{2}{|l|}{} \\
\hline & sim & & \multirow{2}{*}{ Aparelhos } & adequados & \\
\hline & & & inadequados & \\
\hline & \multirow{5}{*}{ Vestiários } & adequados & \\
\hline & & inadequados & \\
\hline & Desfibrilador & não & \\
\hline & & sim & \\
\hline
\end{tabular}

\begin{tabular}{|l|l|l|l|}
\hline Equipamento & Marca & Modelo & Quantidade \\
\hline & & & \\
\hline & & & \\
\hline & & & \\
\hline
\end{tabular}

Distúrbios do Sono

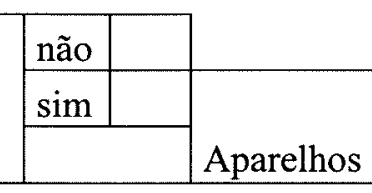

\begin{tabular}{|l|l|}
\hline adequados & \\
\hline inadequados & \\
\hline
\end{tabular}

\begin{tabular}{|l|c|c|c|}
\hline Equipamento & Marca & Modelo & Quantidade \\
\hline & & & \\
\hline
\end{tabular}

Fisioterapia

\begin{tabular}{|c|c|c|}
\hline não & & \\
\hline $\operatorname{sim}$ & \multirow{2}{*}{ Aparelhos } & adequados \\
\hline & & inadequados \\
\hline & \multirow[t]{2}{*}{ Vestiários } & adequados \\
\hline & & inadequados \\
\hline
\end{tabular}




\begin{tabular}{|l|l|l|l|l|l|}
\hline \multirow{3}{*}{ Hemodiálise } & não & & \multicolumn{2}{|l|}{} \\
\cline { 2 - 3 } & sim & & \multirow{2}{*}{ Conforme Legislação } & não & \\
\cline { 5 - 6 } & & & & sim & \\
\hline
\end{tabular}

Holter

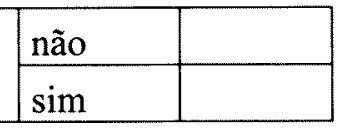

\begin{tabular}{|l|l|l|l|}
\hline Equipamento & Marca & Modelo & Quantidade \\
\hline & & & \\
\hline & & & \\
\hline & & & \\
\hline
\end{tabular}

\begin{tabular}{|c|c|c|c|}
\hline \multirow{5}{*}{ Litotripsia } & não & & \\
\hline & $\operatorname{sim}$ & \multirow{2}{*}{ Aparelhos } & adequados \\
\hline & & & inadequados \\
\hline & & \multirow{2}{*}{ Conforme Legislação } & não \\
\hline & & & $\operatorname{sim}$ \\
\hline
\end{tabular}

\begin{tabular}{|c|c|c|c|}
\hline \multirow{5}{*}{ Mamografia } & não & & \\
\hline & $\operatorname{sim}$ & \multirow{2}{*}{ Aparelhos } & adequados \\
\hline & & & inadequados \\
\hline & & \multirow{2}{*}{ Mamotomia } & não \\
\hline & & & $\operatorname{sim}$ \\
\hline
\end{tabular}

\begin{tabular}{|l|l|l|l|}
\hline Equipamento & Marca & Modelo & Quantidade \\
\hline & & & \\
\hline & & & \\
\hline
\end{tabular}

\section{MAPA}

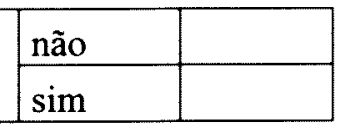

\begin{tabular}{|l|l|l|l|}
\hline Equipamento & Marca & Modelo & Quantidade \\
\hline & & & \\
\hline & & & \\
\hline & & & \\
\hline
\end{tabular}

Neurofisiologia

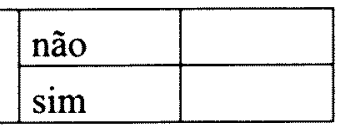

\begin{tabular}{|l|l|l|l|}
\hline Equipamento & Marca & Modelo & Quantidade \\
\hline & & & \\
\hline & & & \\
\hline
\end{tabular}

Quimioterapia

\begin{tabular}{|l|l|l|l|}
\hline não & & \\
\cline { 1 - 1 } $\operatorname{sim}$ & & \multirow{2}{*}{ Conforme Legislação } & não \\
\cline { 1 - 1 } & & $\operatorname{sim}$ \\
\hline
\end{tabular}




\begin{tabular}{|l|l|l|l|l|l|}
\hline \multirow{2}{*}{ Radioterapia } & não & & & \\
& sim & & \multirow{2}{*}{ Conforme Legislação } & não & \\
& & & sim & \\
\hline
\end{tabular}

\section{Ressonância Magnética}

\begin{tabular}{|l|l|l|l|l|}
\hline não & & \multicolumn{3}{|l}{} \\
\hline sim & & \multirow{2}{*}{ Conforme Legislação } & não & \\
\cline { 4 - 5 } & & sim & \\
\hline
\end{tabular}

\begin{tabular}{|l|l|l|l|}
\hline Equipamento & Marca & Modelo & Quantidade \\
\hline & & & \\
\hline & & & \\
\hline
\end{tabular}

\begin{tabular}{|l|l|l|l|l|l|}
\hline \multirow{3}{*}{ Tomografia } & não & & \multicolumn{2}{|l|}{} \\
\cline { 2 - 3 } & sim & & \multirow{2}{*}{ Conforme Legislação } & não & \\
\cline { 5 - 6 } & & & & $\operatorname{sim}$ & \\
\hline
\end{tabular}

\begin{tabular}{|l|l|l|l|}
\hline Equipamento & Marca & Modelo & Quantidade \\
\hline & & & \\
\hline & & & \\
\hline
\end{tabular}

Tilt Table Test

\begin{tabular}{|l|l|}
\hline não & \\
\hline $\operatorname{sim}$ & \\
\hline
\end{tabular}

\begin{tabular}{|l|l|l|l|}
\hline Equipamento & Marca & Modelo & Quantidade \\
\hline & & & \\
\hline & & & \\
\hline & & & \\
\hline
\end{tabular}




\section{IV - Apoio Técnico e Administrativo}

(Farmácia, SND, Lavanderia, Almoxarifado, Manutenção, Segurança, SAME e Central de Esterilização de Materiais)

23. Farmácia ( $\operatorname{RDC~n}^{\circ}$ 50/02)

\begin{tabular}{|c|c|c|}
\hline \multirow[t]{2}{*}{ Há controle dos medicamentos (Port. 344/98) } & não & \\
\hline & $\operatorname{sim}$ & \\
\hline \multirow[t]{2}{*}{ A farmácia manipula NPP } & não & \\
\hline & $\operatorname{sim}$ & \\
\hline \multirow[t]{2}{*}{ Em área adequada conforme } & não & \\
\hline & $\operatorname{sim}$ & \\
\hline \multirow[t]{2}{*}{ Há capela de fluxo laminar } & não & \\
\hline & $\operatorname{sim}$ & \\
\hline \multirow[t]{2}{*}{ Há local adequado para preparo dos medicamentos } & não & \\
\hline & $\operatorname{sim}$ & \\
\hline \multirow[t]{2}{*}{ Há local adequado para dispensação } & não & \\
\hline & $\operatorname{sim}$ & \\
\hline \multirow[t]{2}{*}{ Há farmacêutico no local } & não & Quantos \\
\hline & $\operatorname{sim}$ & \\
\hline \multirow[t]{2}{*}{ Há padronização de medicamentos } & não & \\
\hline & $\operatorname{sim}$ & \\
\hline \multirow[t]{3}{*}{ Dispensação } & \multicolumn{2}{|c|}{ Convencional } \\
\hline & \multicolumn{2}{|c|}{ Individualizada } \\
\hline & \multicolumn{2}{|c|}{ Unitária } \\
\hline
\end{tabular}

24. $\mathrm{SND}\left(\mathrm{RDC} \mathrm{n}^{\circ} 50 / 02\right)$

\begin{tabular}{|c|c|c|}
\hline \multirow[t]{2}{*}{ Circulação adequada } & não & \\
\hline & $\operatorname{sim}$ & \\
\hline \multirow[t]{2}{*}{ Equipamentos necessários e conservados } & não & \\
\hline & $\operatorname{sim}$ & \\
\hline \multirow[t]{2}{*}{ Área adequada com boa iluminação e aeração } & não & \\
\hline & $\operatorname{sim}$ & \\
\hline \multirow[t]{2}{*}{ Existe bancada para manipulação dos alimentos } & não & \\
\hline & $\operatorname{sim}$ & \\
\hline \multirow[t]{2}{*}{ Há cardápio afixado } & não & \\
\hline & $\operatorname{sim}$ & \\
\hline \multirow[t]{2}{*}{ Há Nutricionista } & não & Quantas \\
\hline & $\operatorname{sim}$ & \\
\hline \multirow[t]{2}{*}{ Há Lactário } & não & Adequado \\
\hline & $\operatorname{sim}$ & Inadequado \\
\hline
\end{tabular}

25. Limpeza/Higiene ( $\left.\mathrm{RDC} \mathrm{n}^{\circ} 50 / 02\right)$

\begin{tabular}{|l|l|l|}
\hline Há normas e rotinas para limpeza da unidade & não & \\
\cline { 2 - 3 } & sim & \\
\hline Utilizam produtos próprios para limpeza & não & \\
\cline { 2 - 3 } & sim & \\
\hline A CCIH participa na elaboração de normas do setor & não & \\
\cline { 2 - 3 } & sim & \\
\hline \multirow{2}{*}{ Há coleta seletiva do lixo } & não & \\
\cline { 2 - 3 } & sim & \\
\hline Funcionários utilizam equipamentos de proteção & não & \\
\cline { 2 - 3 } & sim & \\
\hline
\end{tabular}


26. Lavanderia ( $\mathrm{RDC}^{\circ} 50 / 02$ )

\begin{tabular}{|l|l|l|}
\hline \multirow{2}{*}{ Máquina de lavar modelo profissional } & não & \\
\cline { 2 - 3 } & sim & \\
\hline \multirow{2}{*}{ Centrífugas apropriadas } & não & \\
\cline { 2 - 3 } & sim & \\
\hline \multirow{2}{*}{ Há barreiras físicas } & não & \\
\cline { 2 - 3 } & sim & \\
\hline \multirow{2}{*}{ Há cruzamento limpo/contaminado } & não & \\
\cline { 2 - 4 } & sim & \\
\hline \multirow{2}{*}{ Área fisica apropriada } & não & \\
\cline { 2 - 4 } & sim & \\
\hline Equipamentos em boas condições & não & \\
\cline { 2 - 4 } & sim & \\
\hline Funcionários com equipamentos de proteção & não & \\
\cline { 2 - 4 } & sim & \\
\hline Serviço de Costura/Rouparia & não & \\
\cline { 2 - 4 } & sim & \\
\hline & não & \\
\cline { 2 - 4 } & sim & \\
\hline
\end{tabular}

27. Almoxarifado ( $\left.\mathrm{RDC} \mathrm{n}^{\circ} 50 / 02\right)$

\begin{tabular}{|l|l|l|}
\hline Área apropriada & não & \\
\cline { 2 - 3 } & sim & \\
\hline Estoques suficientes & não & \\
\hline & sim & \\
\hline Setor informatizado & não & \\
\hline & sim & \\
\hline
\end{tabular}

28. Manutenção

\begin{tabular}{|l|l|l|l|}
\hline não & & \\
\hline sim & & Própria & \\
\hline \multirow{4}{*}{} & Terceirizada & \\
\hline & Ambas & \\
\cline { 4 - 4 } & &
\end{tabular}

29. Segurança

\begin{tabular}{|l|l|l|l|}
\hline não & & \\
\hline sim & & Própria & \\
\hline \multirow{4}{*}{} & Terceirizada & \\
\cline { 2 - 3 } & Ambas & \\
\hline
\end{tabular}

30. SAME

\begin{tabular}{|l|l|l|}
\hline Prontuário Único & não & \\
\cline { 2 - 3 } & sim & \\
\hline Conforme legislação & não & \\
\cline { 2 - 3 } & sim & \\
\hline Informatizado & não & \\
\cline { 2 - 3 } & sim & \\
\hline
\end{tabular}


31. Central de Esterilização de Materiais (RDC $n^{\circ} 50 / 02$ )

\begin{tabular}{|c|c|c|c|c|c|c|c|}
\hline \multirow[t]{2}{*}{ Encontra-se instalado em área física adequada } & nào & & & & & & \\
\hline & $\operatorname{sim}$ & & & & & & \\
\hline \multirow[t]{2}{*}{ Tem área para expurgo do material } & não & & & & & & \\
\hline & $\operatorname{sim}$ & & & & & & \\
\hline \multirow[t]{2}{*}{ Tem área para preparo/esterilização } & não & & & & & & \\
\hline & $\operatorname{sim}$ & & & & & & \\
\hline \multirow[t]{2}{*}{ Tem área para estocagem/distribuição } & não & & & & & & \\
\hline & $\operatorname{sim}$ & & & & & & \\
\hline \multirow[t]{2}{*}{ Há enfermeira responsável } & não & & & & & & \\
\hline & $\operatorname{sim}$ & & & & & & \\
\hline \multirow[t]{2}{*}{ Há normatização de procedimentos na área } & não & & & & & & \\
\hline & $\operatorname{sim}$ & & & & & & \\
\hline \multirow[t]{2}{*}{ Há fluxo cruzado entre as áreas } & não & & & & & & \\
\hline & sim & & & & & & \\
\hline \multirow[t]{2}{*}{ Funcionários paramentados adequadamente } & não & & & & & & \\
\hline & $\operatorname{sim}$ & & & & & & \\
\hline \multirow[t]{2}{*}{ Possui estufas } & não & Quantas & & & & & \\
\hline & $\operatorname{sim}$ & & & & & & \\
\hline \multirow[t]{2}{*}{ Possui Autoclave horizontal } & não & Quantas & & & & & \\
\hline & $\operatorname{sim}$ & & & & & & \\
\hline \multirow[t]{2}{*}{ Possui Autoclave vertical } & não & Quantas & & & & & \\
\hline & $\operatorname{sim}$ & & & & & & \\
\hline \multirow[t]{2}{*}{ Há manutenção preventiva de equipamentos } & não & & & & & & \\
\hline & $\operatorname{sim}$ & & & & & & \\
\hline \multirow[t]{6}{*}{ É utilizado Controle Biológico } & não & & & & & & \\
\hline & $\operatorname{sim}$ & Periodicidade & 1 & 7 & 15 & 30 & Não \\
\hline & & Attest & & & & & \\
\hline & & Fita teste & & & & & \\
\hline & & Complay & & & & & \\
\hline & & Bowe Dick & & & & & \\
\hline
\end{tabular}


ANEXO 3 - Modelo de Pontuação

I- Dados Gerais - Organização e Funcionamento

\begin{tabular}{|c|c|c|c|c|c|c|c|}
\hline \multirow{2}{*}{ Normas e Rotinas e Manuais } & ก & \multirow{2}{*}{\begin{tabular}{|l|}
0 \\
3
\end{tabular}} & & & & & \\
\hline & nav & & & & & & \\
\hline \multirow{2}{*}{ Regime Interno/regulamento } & não & 0 & & & & & \\
\hline & $\operatorname{sim}$ & 3 & & & & & \\
\hline \multirow[t]{2}{*}{ Recrutamento e Seleção de Pessoal } & não & 0 & & & & & \\
\hline & sim & 1 & & & & & \\
\hline \multirow[t]{2}{*}{ Programas de Treinamento } & não & 0 & & & & & \\
\hline & $\operatorname{sim}$ & 1 & & & & & \\
\hline \multirow[t]{2}{*}{ Educação Continuada } & não & 0 & & & & & \\
\hline & $\operatorname{sim}$ & \multirow{2}{*}{$\frac{1}{0}$} & & & & & \\
\hline \multirow[t]{2}{*}{ Indicadores Hospitalares } & não & & & & & & \\
\hline & $\operatorname{sim}$ & $\frac{0}{3}$ & & & & & \\
\hline \multirow[t]{2}{*}{ Relatórios Gerenciais } & não & 0 & & & & & \\
\hline & $\operatorname{sim}$ & 1 & & & \\
\hline \multirow[t]{3}{*}{ Informatização } & não & 0 & & & & & \\
\hline & $\operatorname{sim}$ & 1 & \multirow[t]{2}{*}{ Em Rede } & $\operatorname{sim}$ & 1 & & \\
\hline & & & & não & 0 & & \\
\hline Serviço Social & não & \multirow{2}{*}{\begin{tabular}{l|}
0 \\
1
\end{tabular}} & & & & & \\
\hline & $\operatorname{sim}$ & & & & & & \\
\hline Psicologia Hospitalar & não & 0 & & & & & \\
\hline & $\operatorname{sim}$ & 1 & & & & & \\
\hline Saúde Ocupacional & não & 0 & & & & & \\
\hline & $\operatorname{sim}$ & 1 & & & & & \\
\hline Comissão de Ética Médica & não & 0 & & & & & \\
\hline & $\operatorname{sim}$ & 3 & Reuniões & lares & & $\operatorname{sim}$ & 1 \\
\hline & & & & & & não & 0 \\
\hline $\mathrm{CCIH}$ & não & 0 & & & & & \\
\hline & $\operatorname{sim}$ & 3 & Reuniões I & llares & & $\operatorname{sim}$ & 1 \\
\hline & & & & & & não & 0 \\
\hline Revisão de Prontuários & não & 0 & & & & & \\
\hline & $\operatorname{sim}$ & 3 & Reuniões I & lares & & $\operatorname{sim}$ & 1 \\
\hline & & & & & & não & 0 \\
\hline Revisão de Óbitos & não & 0 & & & & & \\
\hline & $\operatorname{sim}$ & 3 & Reuniões 1 & lares & & sim & 1 \\
\hline & & & & & & não & 0 \\
\hline CIPA & não & 0 & & & & & \\
\hline & $\operatorname{sim}$ & 3 & Reuniões I & ulares & & $\operatorname{sim}$ & 1 \\
\hline & & & & & & não & 0 \\
\hline Farmácia e Medicamentos & não & 0 & & & & & \\
\hline & $\operatorname{sim}$ & 1 & & & & & \\
\hline Controle e Gestão de Qualidade & não & 0 & & & & & \\
\hline & $\operatorname{sim}$ & 1 & & & & & \\
\hline Ensino e Pesquisa & não & 0 & & & & & \\
\hline & $\operatorname{sim}$ & 1 & & & & & \\
\hline Residência Médica/Pós-Graduação & não & 0 & & & & & \\
\hline & sim & 1 & & & & & \\
\hline
\end{tabular}

Total de pontos $=44$ 
Estrutura Física e Infra-Estrutura

\begin{tabular}{|c|c|c|c|c|c|c|}
\hline \multirow[t]{2}{*}{ Identificação } & \multicolumn{3}{|c|}{ não visível } & 0 & & \\
\hline & \multicolumn{3}{|c|}{ visível } & 3 & & \\
\hline \multirow[t]{3}{*}{ Estacionamento } & \multicolumn{3}{|c|}{ não } & 0 & & \\
\hline & \multicolumn{3}{|l|}{$\operatorname{sim}$} & & insuficiente & 1 \\
\hline & & & & & suficiente & 2 \\
\hline \multirow[t]{2}{*}{ Sinalização } & \multicolumn{3}{|l|}{ não } & 0 & & \\
\hline & \multicolumn{3}{|l|}{$\operatorname{sim}$} & 3 & & \\
\hline \multirow[t]{2}{*}{ Área para manutenção/descarga } & \multicolumn{3}{|l|}{ não } & 0 & & \\
\hline & \multicolumn{3}{|c|}{$\operatorname{sim}$} & 3 & & \\
\hline \multirow[t]{3}{*}{ Elevadores } & \multicolumn{3}{|c|}{ desnecessário } & & & \\
\hline & \multirow{2}{*}{\multicolumn{4}{|c|}{ necessário }} & em número insuficiente & 1 \\
\hline & & & & & em número suficiente & 2 \\
\hline \multirow{2}{*}{ Local próprio para lixo } & não & 0 & & & & \\
\hline & $\operatorname{sim}$ & 3 & & & & \\
\hline \multirow{6}{*}{ Central de Gases } & não & 0 & & & & \\
\hline & $\operatorname{sim}$ & & \multicolumn{3}{|c|}{ Rede de Torpedos oxigênio } & 1 \\
\hline & & & \multicolumn{3}{|c|}{ Usina ou Tanque de oxigênio } & 2 \\
\hline & & & \multicolumn{3}{|c|}{ Compressor de ar comprimido } & 1 \\
\hline & & & \multicolumn{3}{|c|}{ Tanque de Nitrogênio } & 1 \\
\hline & & & \multicolumn{3}{|c|}{ Torpedos de $\mathrm{N}_{2} \mathrm{O}$} & 1 \\
\hline Ar Condicionado Central & não & & & 0 & & \\
\hline & $\operatorname{sim}$ & & & & áreas críticas & 1 \\
\hline & & & & & todo hospital & 2 \\
\hline & & & & & CC com fluxo laminar & 1 \\
\hline & & & & & UTI com fluxo laminar & 1 \\
\hline Sistemas de Resíduos & não & & & 0 & & \\
\hline & $\operatorname{sim}$ & & & 1 & & \\
\hline Sistema de Esgotos & não & & & 0 & & \\
\hline & $\operatorname{sim}$ & & & 1 & & \\
\hline Sistema de Prevenção de Incêndios & não & 0 & & & & \\
\hline & $\operatorname{sim}$ & & & tore & & 1 \\
\hline & & & & ante & & 1 \\
\hline & & & & ida & Incêndio & 1 \\
\hline & & & & gle & & 1 \\
\hline Pára-Raios & não & 0 & & & & \\
\hline & $\operatorname{sim}$ & 3 & & & & \\
\hline Gerador & não & 0 & & & & \\
\hline & $\overline{\text { manu }}$ & & & icie & e para áreas críticas & 0 \\
\hline & & & & ient & para áreas críticas & 1 \\
\hline & auton & tico & & icie & e para áreas críticas & 1 \\
\hline & & & & ent & para áreas críticas & 2 \\
\hline & & & & ent & para o hospital & 3 \\
\hline Caldeira & não & 0 & & & & \\
\hline & sim & 1 & & & & \\
\hline Cabine Primária de Força & não & 0 & & & & \\
\hline & $\operatorname{sim}$ & 3 & & & & \\
\hline Reservatório de Água & não & 0 & & & & \\
\hline & $\operatorname{sim}$ & 3 & & & & \\
\hline
\end{tabular}

Total de pontos $=45$ 


\section{II - Organização e Atenção ao paciente}

Hotelaria

\begin{tabular}{|c|c|c|c|}
\hline \multirow{9}{*}{ Recepção } & confortável & 1 & \\
\hline & desconfortável & 0 & \\
\hline & adequada & 1 & \\
\hline & inadequada & 0 & \\
\hline & \multirow[t]{3}{*}{ Sanitários } & não & 0 \\
\hline & & $\operatorname{sim}$ & único \\
\hline & & & cada sexo \\
\hline & \multirow[t]{2}{*}{ informatizada } & não & 0 \\
\hline & & $\operatorname{sim}$ & 2 \\
\hline \multirow[t]{4}{*}{ Limpeza } & insuficiente & 0 & \\
\hline & regular & 1 & \\
\hline & boa & 2 & \\
\hline & ótima & 3 & \\
\hline \multirow[t]{4}{*}{ Higiene } & insuficiente & 0 & \\
\hline & regular & 1 & \\
\hline & boa & 2 & \\
\hline & ótima & 3 & \\
\hline \multirow[t]{4}{*}{ Conservação Predial } & insuficiente & 0 & \\
\hline & regular & 1 & \\
\hline & boa & 2 & \\
\hline & ótima & 3 & \\
\hline
\end{tabular}

Total de pontos: 15

\begin{tabular}{|l|l|c|}
\hline Torpedo de oxigênio na unidade & não & 0 \\
\cline { 2 - 3 } & sim & 3 \\
\hline Carrinho de emergência & não & 0 \\
\cline { 2 - 3 } & sim & 3 \\
\hline \multirow{2}{*}{ Corredores Livres } & não & 0 \\
\cline { 2 - 3 } & sim & 1 \\
\hline \multirow{2}{*}{ Iluminação } & Inadequada & 0 \\
\cline { 2 - 3 } & Adequada & 1 \\
\hline \multirow{2}{*}{ Ventilação } & Inadequada & 0 \\
\cline { 2 - 3 } & Adequada & 1 \\
\hline \multirow{2}{*}{ Instalações Elétricas } & Inadequada & 0 \\
\cline { 2 - 3 } & Adequada & 1 \\
\hline \multirow{2}{*}{ Instalações Hidráulicas } & Inadequada & 0 \\
\cline { 2 - 3 } & Adequada & 1 \\
\hline
\end{tabular}

Total de Pontos $=11$ 


\begin{tabular}{|c|c|c|c|c|}
\hline \multirow{17}{*}{ Suítes } & \multicolumn{2}{|l|}{ Quantos } & & \\
\hline & TV & 1 & & \\
\hline & frigobar & 1 & & \\
\hline & ar condicionado & 1 & & \\
\hline & telefone & 1 & & \\
\hline & ventilador & 1 & & \\
\hline & bico de oxigênio & 2 & & \\
\hline & bico de ar & 2 & & \\
\hline & bico de vácuo & 2 & & \\
\hline & Sanitário & porta & abrindo para dentro & 0 \\
\hline & & & abrindo para fora & 1 \\
\hline & & barras/apoios & $\operatorname{sim}$ & 1 \\
\hline & & & não & 0 \\
\hline & sofá/cama acompanhante & $\operatorname{sim}$ & 1 & \\
\hline & & não & 0 & \\
\hline & cadeira de descanso & $\operatorname{sim}$ & 1 & \\
\hline & & não & 0 & \\
\hline
\end{tabular}

Total de pontos: 15

\begin{tabular}{|c|c|c|c|c|}
\hline \multirow{17}{*}{ Apartamentos } & Quantos & & & \\
\hline & TV & 1 & & \\
\hline & frigobar & 1 & & \\
\hline & ar condicionado & 1 & & \\
\hline & telefone & 1 & & \\
\hline & ventilador & 1 & & \\
\hline & bico de oxigênio & 2 & & \\
\hline & bico de ar & 2 & & \\
\hline & bico de vácuo & 2 & & \\
\hline & Sanitário & porta & abrindo para dentro & 0 \\
\hline & & & abrindo para fora & 1 \\
\hline & & barras/apoios & sim & 1 \\
\hline & & & não & 0 \\
\hline & sofá/cama acompanhante & $\operatorname{sim}$ & $1 \mid$ & \\
\hline & & não & 0 & \\
\hline & cadeira de descanso & sim & 1 & \\
\hline & & não & 0 & \\
\hline
\end{tabular}

Total de pontos: 15 


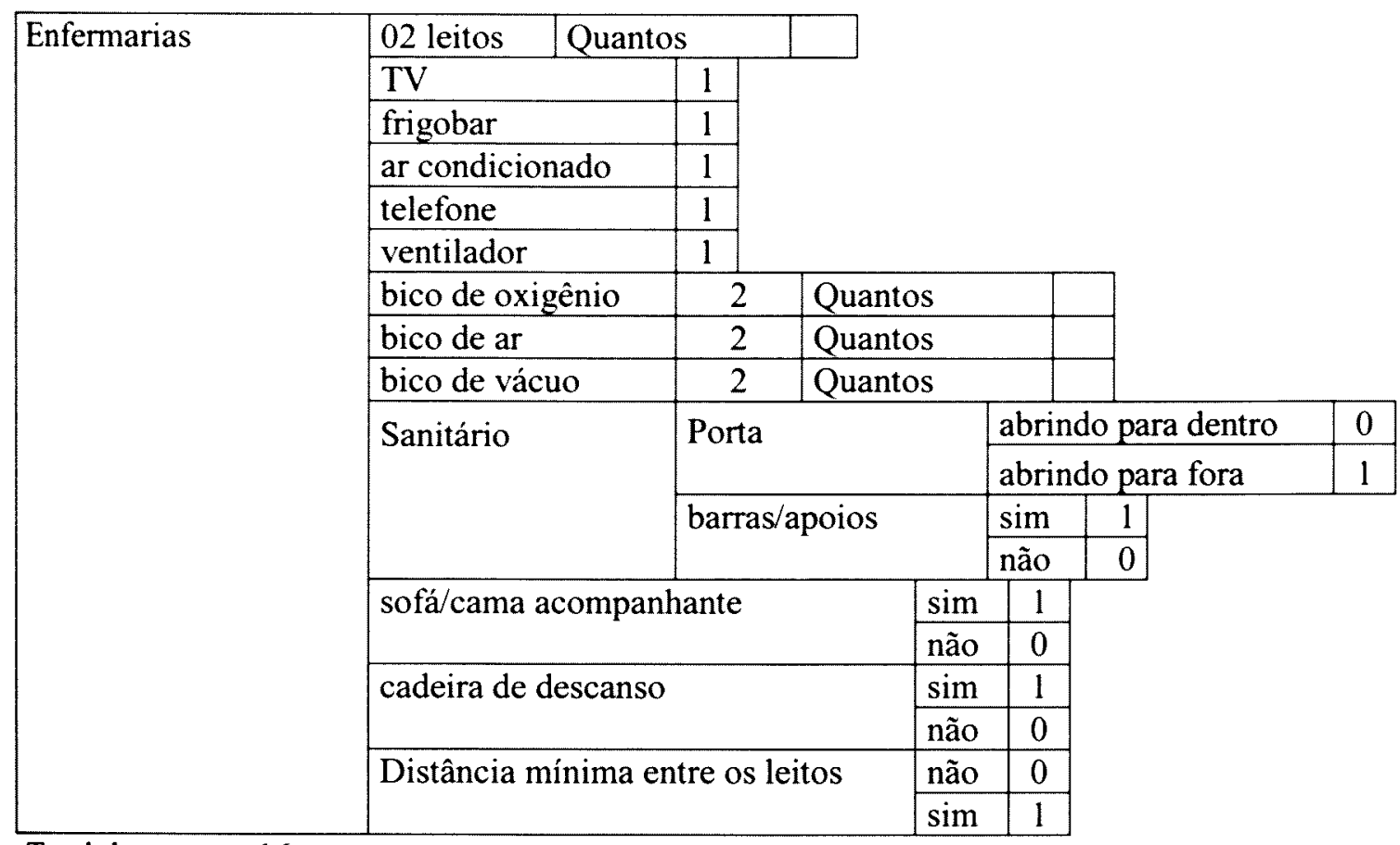

Total de pontos: 16

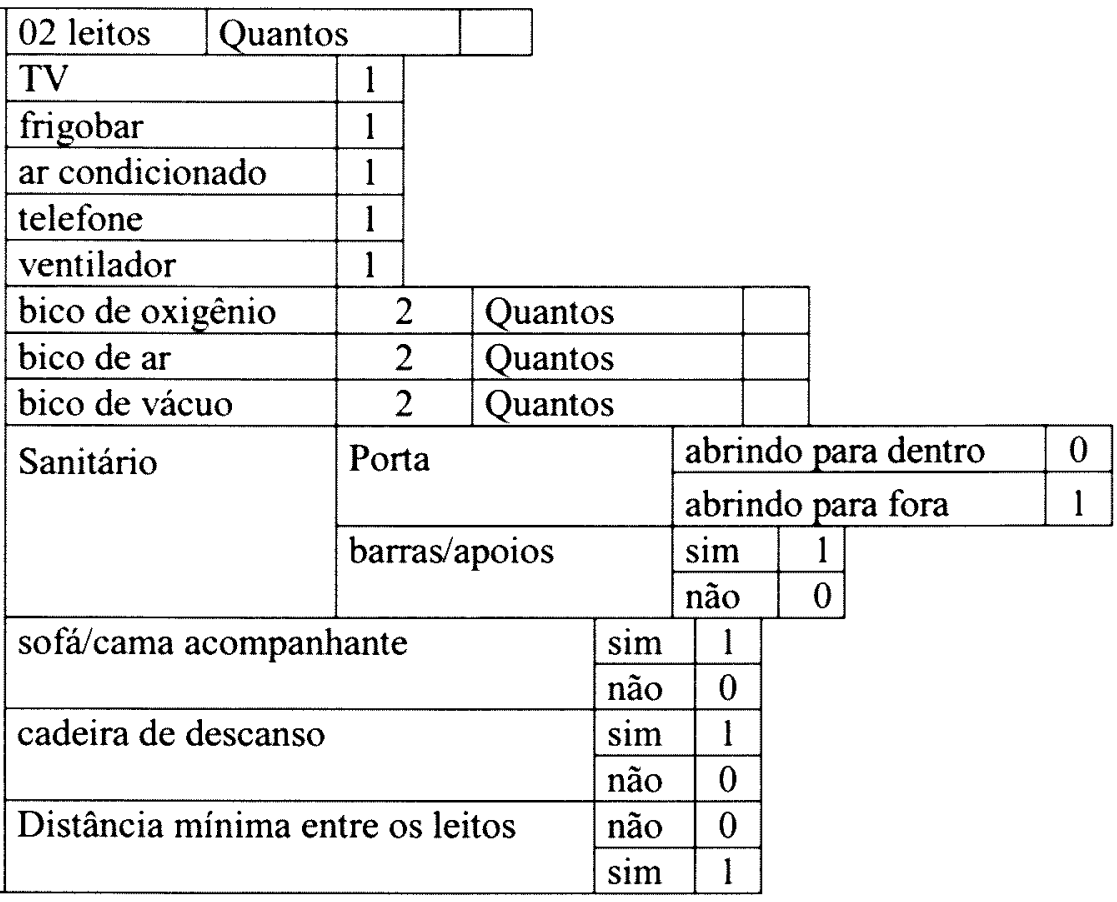

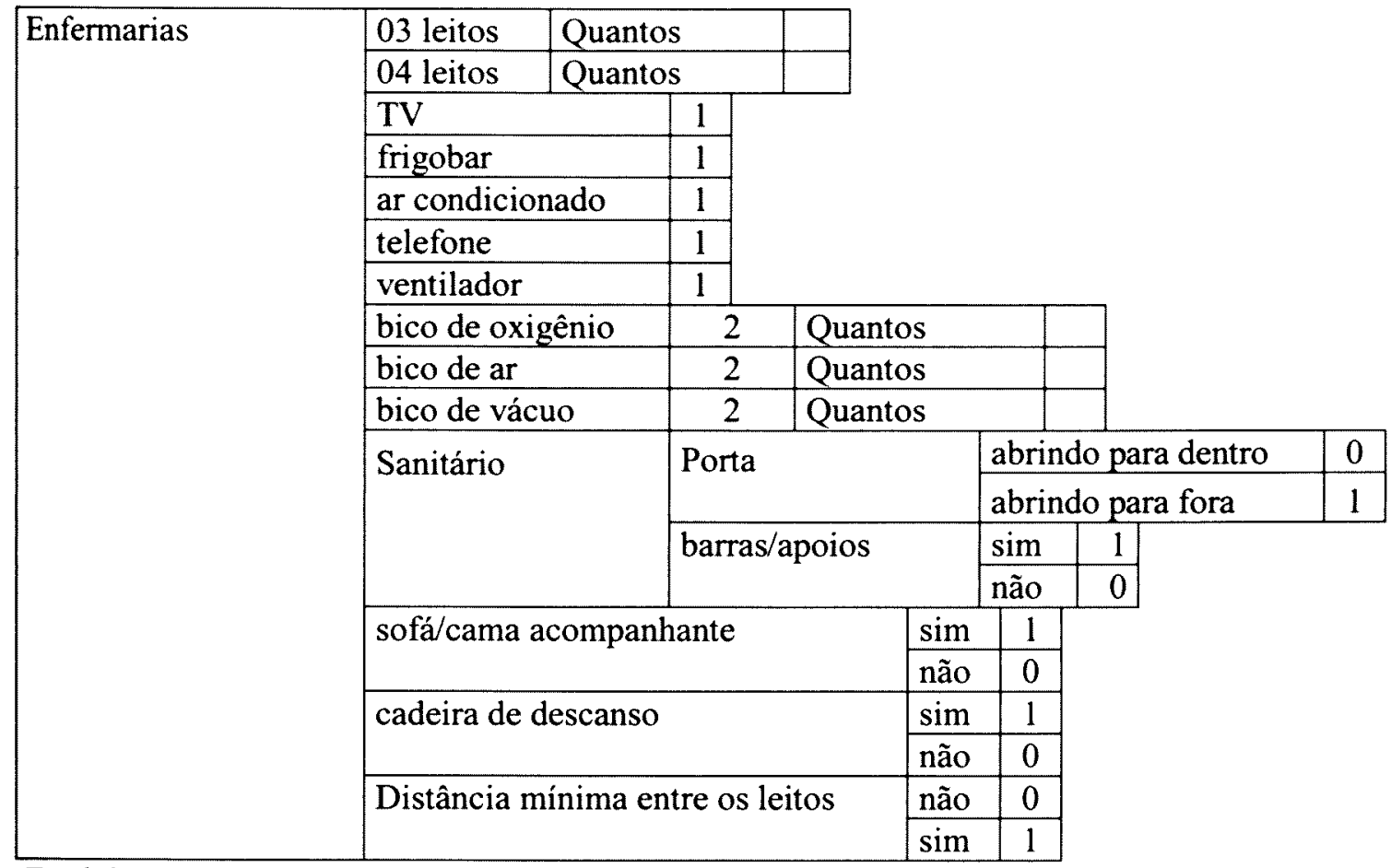

Total de pontos: 16

Máximo de pontos $=88$

sem suite $=88-15=73$

sem enfermaria de 3 e 4 leitos $=88-16=72$

sem suite, mais enfermaria de 3 e 4 leitos $=88-16-15=57$ 
Pronto Socorro

\begin{tabular}{|c|c|c|c|c|}
\hline \multirow[t]{2}{*}{ Tipo } & \multicolumn{2}{|l|}{ Geral } & \multirow[b]{2}{*}{ Oual } & \\
\hline & Especializado & & & \\
\hline \multirow[t]{2}{*}{ Entrada bem localizada, fácil acesso } & $\operatorname{sim}$ & 3 & & \\
\hline & não & 0 & & \\
\hline \multirow[t]{3}{*}{ Sala exclusiva para urgências } & sim & 3 & & \\
\hline & não & 0 & & \\
\hline & $N^{\circ}$ de Leitos & & & \\
\hline \multirow[t]{4}{*}{ Leitos para observação } & Sim & 1 & Masculino & 01 \\
\hline & não & 0 & Feminino & 01 \\
\hline & & & Pediátrico & 01 \\
\hline & & & Misto & 01 \\
\hline \multirow[t]{2}{*}{1 Bico de Oxigênio/leito } & $\operatorname{sim}$ & 3 & & \\
\hline & não & 0 & & \\
\hline \multirow[t]{2}{*}{1 Ar Comprimido/leito } & $\operatorname{sim}$ & 3 & & \\
\hline & não & 0 & & \\
\hline \multirow[t]{2}{*}{ I Vácuo/leito } & $\operatorname{sim}$ & 3 & & \\
\hline & กão & 0 & & \\
\hline \multirow[t]{2}{*}{ Ambulância para remoção } & sim & 1 & & \\
\hline & não & 0 & & \\
\hline \multirow[t]{2}{*}{ Possui UTI Móvel } & $\operatorname{sim}$ & 1 & & \\
\hline & não & 0 & & \\
\hline \multirow[t]{2}{*}{ Equipe Médica conforme legislação } & $\operatorname{sim}$ & 3 & & \\
\hline & não & 0 & & \\
\hline \multirow[t]{2}{*}{ Enfermeira nos turnos } & $\operatorname{sim}$ & 3 & & \\
\hline & não & 0 & & \\
\hline \multirow[t]{2}{*}{ Medicamentos de urgência } & sim & 3 & & \\
\hline & não & 0 & & \\
\hline \multirow[t]{2}{*}{ Sala de Inalação } & $\operatorname{sim}$ & 3 & & \\
\hline & não & 0 & & \\
\hline \multirow[t]{2}{*}{ Desfibrilador ligado } & $\operatorname{sim}$ & 3 & & \\
\hline & não & 0 & & \\
\hline \multirow[t]{2}{*}{ Monitor de FC } & $\operatorname{sim}$ & 3 & & \\
\hline & não & 0 & & \\
\hline \multirow[t]{2}{*}{ Oxímetro } & $\operatorname{sim}$ & 3 & & \\
\hline & não & 0 & & \\
\hline \multirow[t]{2}{*}{ Respirador Adequado } & $\operatorname{sim}$ & 3 & & \\
\hline & não & 0 & & \\
\hline
\end{tabular}

Total de pontos $=46$ 
UTI Geral

\begin{tabular}{|c|c|c|c|}
\hline Número de Leitos & & & \\
\hline \multirow[t]{2}{*}{01 médico para cada 10 leitos } & $\operatorname{sim}$ & 3 & \\
\hline & não & 0 & \\
\hline \multirow[t]{2}{*}{ Há normas e rotinas para a área } & $\operatorname{sim}$ & 3 & \\
\hline & não & 0 & \\
\hline \multirow[t]{2}{*}{ A UTI participa da CCIH } & $\operatorname{sim}$ & 1 & \\
\hline & não & 0 & \\
\hline \multirow{2}{*}{$\begin{array}{l}\text { Há programas de acompanhamento de visita com } \\
\text { orientação }\end{array}$} & $\operatorname{sim}$ & 1 & \\
\hline & não & 0 & \\
\hline \multirow[t]{2}{*}{ Encontra-se em área fisica adequada } & $\operatorname{sim}$ & 3 & \\
\hline & não & 0 & \\
\hline \multirow[t]{2}{*}{ De acordo com a legislação Portaria 2918} & $\operatorname{sim}$ & 3 & \\
\hline & não & 0 & \\
\hline \multirow[t]{2}{*}{ O posto de enfermagem permite boa visão dos leitos } & $\operatorname{sim}$ & 1 & \\
\hline & não & 0 & \\
\hline \multirow[t]{2}{*}{ Há boa circulação de funcionários e pacientes } & $\operatorname{sim}$ & 1 & \\
\hline & não & 0 & \\
\hline \multirow[t]{2}{*}{ Possui médico diarista } & $\operatorname{sim}$ & 3 & \\
\hline & não & 0 & \\
\hline \multirow[t]{2}{*}{ Possui equipe médica em todos os turnos } & $\operatorname{sim}$ & 3 & \\
\hline & não & 0 & \\
\hline \multirow[t]{2}{*}{ Equipe de enfermagem treinada e completa } & $\operatorname{sim}$ & 3 & \\
\hline & não & 0 & \\
\hline \multirow[t]{2}{*}{ Enfermeira em todos os turnos } & $\operatorname{sim}$ & 3 & \\
\hline & não & 0 & \\
\hline \multirow[t]{2}{*}{ Há leitos para isolamento } & $\operatorname{sim}$ & 3 & Quantos \\
\hline & não & 0 & \\
\hline \multirow[t]{2}{*}{ Quarto para médico plantonista } & $\operatorname{sim}$ & 1 & \\
\hline & não & 0 & \\
\hline \multirow[t]{2}{*}{ Área de descanso para enfermagem } & $\operatorname{sim}$ & 1 & \\
\hline & não & 0 & \\
\hline \multirow[t]{2}{*}{2 bicos de oxigênio/leito } & $\operatorname{sim}$ & 3 & \\
\hline & não & 0 & \\
\hline \multirow[t]{2}{*}{1 bico de ar comprimido/leito } & $\operatorname{sim}$ & 3 & \\
\hline & não & 0 & \\
\hline \multirow[t]{2}{*}{1 bico de vácuo/leito } & $\operatorname{sim}$ & 3 & \\
\hline & não & 0 & \\
\hline \multirow[t]{2}{*}{10 tomadas elétricas } & $\operatorname{sim}$ & 3 & \\
\hline & não & 0 & \\
\hline
\end{tabular}

Total de pontos $=45$ 
UTI Cardiológica

\begin{tabular}{|c|c|c|c|}
\hline \multicolumn{3}{|l|}{ Número de Leitos } & \\
\hline \multirow[t]{2}{*}{01 médico para cada 10 leitos } & $\operatorname{sim}$ & 3 & \\
\hline & não & 0 & \\
\hline \multirow[t]{2}{*}{ Há normas e rotinas para a área } & $\operatorname{sim}$ & 3 & \\
\hline & não & 0 & \\
\hline \multirow[t]{2}{*}{ A UTI participa da CCIH } & $\operatorname{sim}$ & 1 & \\
\hline & não & 0 & \\
\hline \multirow{2}{*}{$\begin{array}{l}\text { Há programas de acompanhamento de visita com } \\
\text { orientação }\end{array}$} & $\operatorname{sim}$ & 1 & \\
\hline & não & 0 & \\
\hline \multirow[t]{2}{*}{ Encontra-se em área física adequada } & $\operatorname{sim}$ & 3 & \\
\hline & não & 0 & \\
\hline \multirow[t]{2}{*}{ De acordo com a legislação Portaria 2918} & $\operatorname{sim}$ & 3 & \\
\hline & não & 0 & \\
\hline \multirow[t]{2}{*}{ O posto de enfermagem permite boa visão dos leitos } & $\operatorname{sim}$ & 1 & \\
\hline & não & 0 & \\
\hline \multirow[t]{2}{*}{ Há boa circulação de funcionários e pacientes } & $\operatorname{sim}$ & 1 & \\
\hline & não & 0 & \\
\hline \multirow[t]{2}{*}{ Possui médico diarista } & $\operatorname{sim}$ & 3 & \\
\hline & não & 0 & \\
\hline \multirow[t]{2}{*}{ Possui equipe médica em todos os turnos } & $\operatorname{sim}$ & 3 & \\
\hline & não & 0 & \\
\hline \multirow[t]{2}{*}{ Equipe de enfermagem treinada e completa } & $\operatorname{sim}$ & 3 & \\
\hline & não & 0 & \\
\hline \multirow[t]{2}{*}{ Enfermeira em todos os turnos } & $\operatorname{sim}$ & 3 & \\
\hline & não & 0 & \\
\hline \multirow[t]{2}{*}{ Há leitos para isolamento } & $\operatorname{sim}$ & 3 & Quantos \\
\hline & não & 0 & \\
\hline \multirow[t]{2}{*}{ Quarto para médico plantonista } & $\operatorname{sim}$ & 1 & \\
\hline & não & 0 & \\
\hline \multirow[t]{2}{*}{ Área de descanso para enfermagem } & sim & 1 & \\
\hline & não & 0 & \\
\hline \multirow[t]{2}{*}{2 bicos de oxigênio/leito } & $\operatorname{sim}$ & 3 & \\
\hline & não & 0 & \\
\hline \multirow[t]{2}{*}{ I bico de ar comprimido/leito } & sim & 3 & \\
\hline & não & 0 & \\
\hline \multirow[t]{2}{*}{1 bico de vácuo/leito } & $\operatorname{sim}$ & 3 & \\
\hline & não & 0 & \\
\hline \multirow[t]{2}{*}{10 tomadas elétricas } & $\operatorname{sim}$ & 3 & \\
\hline & não & 0 & \\
\hline
\end{tabular}

Total de pontos $=45$ 
UTI Neonatal

\begin{tabular}{|c|c|c|c|}
\hline Número de Leitos & & & \\
\hline 01 médico para cada 10 leitos & $\operatorname{sim}$ & 3 & \\
\hline & não & 0 & \\
\hline Há normas e rotinas para a área & $\operatorname{sim}$ & 3 & \\
\hline & não & 0 & \\
\hline A UTI participa da CCIH & $\operatorname{sim}$ & 1 & \\
\hline & não & 0 & \\
\hline Há programas de acompanhamento de visita com & $\operatorname{sim}$ & 1 & \\
\hline & não & 0 & \\
\hline Encontra-se em área física adequada & $\operatorname{sim}$ & 3 & \\
\hline & não & 0 & \\
\hline De acordo com a legislação Portaria 2918 & $\operatorname{sim}$ & 3 & \\
\hline & não & 0 & \\
\hline O posto de enfermagem permite boa visão dos leitos & sim & 1 & \\
\hline & não & 0 & \\
\hline Há boa circulação de funcionários e pacientes & $\operatorname{sim}$ & 1 & \\
\hline & não & 0 & \\
\hline Possui médico diarista & sim & 3 & \\
\hline & não & 0 & \\
\hline Possui equipe médica em todos os turnos & $\operatorname{sim}$ & 3 & \\
\hline & não & 0 & \\
\hline Equipe de enfermagem treinada e completa & $\operatorname{sim}$ & 3 & \\
\hline & não & 0 & \\
\hline Enfermeira em todos os turnos & $\operatorname{sim}$ & 3 & \\
\hline & não & 0 & \\
\hline Há leitos para isolamento & sim & 3 & Quantos \\
\hline & não & 0 & \\
\hline Quarto para médico plantonista & $\operatorname{sim}$ & 1 & \\
\hline & não & 0 & \\
\hline Área de descanso para enfermagem & $\operatorname{sim}$ & 1 & \\
\hline & não & 0 & \\
\hline 2 bicos de oxigênio/leito & $\operatorname{sim}$ & 3 & \\
\hline & não & 0 & \\
\hline 1 bico de ar comprimido/leito & $\operatorname{sim}$ & 3 & \\
\hline & não & 0 & \\
\hline 1 bico de vácuo/leito & $\operatorname{sim}$ & 3 & \\
\hline & não & 0 & \\
\hline 10 tomadas elétricas & $\operatorname{sim}$ & 3 & \\
\hline & não & 0 & \\
\hline
\end{tabular}

Total de pontos $=45$ 
UTI Pediátrica

\begin{tabular}{|c|c|c|c|}
\hline Número de Leitos & & & \\
\hline 01 médico para cada 10 leitos & $\operatorname{sim}$ & 3 & \\
\hline & não & 0 & \\
\hline Há normas e rotinas para a área & $\operatorname{sim}$ & 3 & \\
\hline & não & 0 & \\
\hline A UTI participa da CCIH & $\operatorname{sim}$ & 1 & \\
\hline & não & 0 & \\
\hline Há programas de acompanhamento de visita com & $\operatorname{sim}$ & 1 & \\
\hline & não & 0 & \\
\hline Encontra-se em área fisica adequada & $\operatorname{sim}$ & 3 & \\
\hline & não & 0 & \\
\hline De acordo com a legislação Portaria 2918 & $\operatorname{sim}$ & 3 & \\
\hline & não & 0 & \\
\hline O posto de enfermagem permite boa visão dos leitos & $\operatorname{sim}$ & 1 & \\
\hline & não & 0 & \\
\hline Há boa circulação de funcionários e pacientes & $\operatorname{sim}$ & 1 & \\
\hline & não & 0 & \\
\hline Possui médico diarista & $\operatorname{sim}$ & 3 & \\
\hline & não & 0 & \\
\hline Possui equipe médica em todos os turnos & sim & 3 & \\
\hline & não & 0 & \\
\hline Equipe de enfermagem treinada e completa & $\operatorname{sim}$ & 3 & \\
\hline & não & 0 & \\
\hline Enfermeira em todos os turnos & $\operatorname{sim}$ & 3 & \\
\hline & não & 0 & \\
\hline Há leitos para isolamento & sim & 3 & Quantos \\
\hline & não & 0 & \\
\hline Quarto para médico plantonista & $\operatorname{sim}$ & 1 & \\
\hline & não & 0 & \\
\hline Área de descanso para enfermagem & $\operatorname{sim}$ & 1 & \\
\hline & não & 0 & \\
\hline 2 bicos de oxigênio/leito & $\operatorname{sim}$ & 3 & \\
\hline & não & 0 & \\
\hline 1 bico de ar comprimido/leito & $\operatorname{sim}$ & 3 & \\
\hline & não & 0 & \\
\hline 1 bico de vácuo/leito & $\operatorname{sim}$ & 3 & \\
\hline & não & 0 & \\
\hline 10 tomadas elétricas & sim & 3 & \\
\hline & não & 0 & \\
\hline
\end{tabular}

Total de pontos $=45$ 
Maternidade

\begin{tabular}{|c|c|c|}
\hline \multirow[t]{2}{*}{ Tem sala de admissão } & $\operatorname{sim}$ & 3 \\
\hline & não & 0 \\
\hline \multirow[t]{2}{*}{ Sala/leitos de pré-parto } & $\operatorname{sim}$ & 3 \\
\hline & não & 0 \\
\hline \multirow[t]{2}{*}{ Sala de parto normal } & $\operatorname{sim}$ & 3 \\
\hline & não & 0 \\
\hline \multirow[t]{2}{*}{ Sala de parto cirúrgico } & sim & 3 \\
\hline & não & 0 \\
\hline \multirow[t]{2}{*}{ Vestiário com sanitário para ambos os sexos } & $\operatorname{sim}$ & 1 \\
\hline & não & 0 \\
\hline \multirow[t]{2}{*}{ Sala de estar e repouso para funcionários e médicos } & $\operatorname{sim}$ & 1 \\
\hline & não & 0 \\
\hline \multirow[t]{2}{*}{ Recuperação pós-anestésica (RPA) } & $\operatorname{sim}$ & 2 \\
\hline & não & 0 \\
\hline \multirow[t]{2}{*}{ O parto é realizado por: } & Médico & 3 \\
\hline & Obstetriz & 1 \\
\hline \multirow[t]{2}{*}{ Há disponibilidade de médico obstetra no local durante 24 horas } & sim & 2 \\
\hline & não & 0 \\
\hline \multirow[t]{2}{*}{ O neonatologista recepciona todos os $\mathrm{RNs}$} & $\operatorname{sim}$ & 2 \\
\hline & não & 0 \\
\hline \multirow[t]{2}{*}{ Há neonatologista no local durante 24 horas } & $\operatorname{sim}$ & 2 \\
\hline & não & 0 \\
\hline \multirow[t]{2}{*}{ Há disponibilidade de anestesista durante 24 horas } & $\operatorname{sim}$ & 3 \\
\hline & não & 0 \\
\hline \multirow[t]{2}{*}{ Há sala de reanimação e identificação do $\mathrm{RN}$} & $\operatorname{sim}$ & 2 \\
\hline & não & 0 \\
\hline \multirow[t]{2}{*}{ Há pia com água corrente na sala de reanimação } & sim & 1 \\
\hline & não & 0 \\
\hline \multirow[t]{2}{*}{2 bicos de oxigênio/sala } & sim & 3 \\
\hline & não & 0 \\
\hline \multirow[t]{2}{*}{1 bico de ar comprimido/sala } & $\operatorname{sim}$ & 3 \\
\hline & não & 0 \\
\hline \multirow[t]{2}{*}{1 bico de vácuo/sala } & $\operatorname{sim}$ & 3 \\
\hline & não & 0 \\
\hline \multirow[t]{2}{*}{ Torpedo de oxigênio } & $\operatorname{sim}$ & 1 \\
\hline & nào & 0 \\
\hline \multirow[t]{2}{*}{ Aspirador elétrico } & sim & 1 \\
\hline & não & 0 \\
\hline
\end{tabular}

Total de pontos $=43$ 
Berçário

\begin{tabular}{|l|l|l|}
\hline Há berçário de primeiros cuidados & sim & 3 \\
\cline { 2 - 3 } & não & 0 \\
\hline Área Física & adequada & 3 \\
\hline Há berçário de patológicos & inadequada & 0 \\
\hline 2 bicos de oxigênio/leito & sim & 3 \\
\hline não & 0 \\
\hline bico de ar comprimido/leito & sim & 3 \\
\hline I bico de vácuo/leito & não & 0 \\
\hline Torpedo de oxigênio & sim & 3 \\
\hline não & 0 \\
\hline aspirador elétrico & sim & 3 \\
\hline Área Física & não & 0 \\
\hline Há alojamento conjunto & sim & 1 \\
\hline Há UTI neonatal & não & 0 \\
\hline & sim & 1 \\
\hline & não & 0 \\
\hline & adequada & 3 \\
\hline inadequada & 0 \\
\hline & sim & 3 \\
\hline não & 0 \\
\hline & sim & 3 \\
\hline não & 0 \\
\hline
\end{tabular}

Total de pontos: 29 
Centro Cirúrgico

\begin{tabular}{|c|c|c|}
\hline \multirow[t]{2}{*}{ Área de recepção de paciente com passa maca } & $\operatorname{sim}$ & 2 \\
\hline & não & 0 \\
\hline \multirow[t]{2}{*}{ Área de Escovaçào } & $\operatorname{sim}$ & 2 \\
\hline & não & 0 \\
\hline \multirow[t]{2}{*}{ Posto de Enfermagem e Serviços } & sim & 2 \\
\hline & não & 0 \\
\hline \multirow[t]{2}{*}{ Vestiários com sanitários para funcionários com barreira } & $\operatorname{sim}$ & 2 \\
\hline & não & 0 \\
\hline \multirow[t]{2}{*}{ Sala de preparo de equipamentos e material } & $\operatorname{sim}$ & 2 \\
\hline & não & 0 \\
\hline \multirow[t]{2}{*}{ Depósito de equipamentos e materiais } & $\operatorname{sim}$ & 2 \\
\hline & não & 0 \\
\hline \multirow[t]{2}{*}{ Sala administrativa } & sim & 1 \\
\hline & não & 0 \\
\hline \multirow[t]{2}{*}{ Depósito de Material de Limpeza } & $\operatorname{sim}$ & 1 \\
\hline & não & 0 \\
\hline \multirow[t]{2}{*}{ Sala de estar para funcionários } & $\operatorname{sim}$ & 1 \\
\hline & não & 0 \\
\hline \multirow[t]{2}{*}{ Sala de Espera com sanitário para acompanhantes } & $\operatorname{sim}$ & 1 \\
\hline & não & 0 \\
\hline \multirow[t]{2}{*}{ Área para guarda de macas e cadeira de rodas } & sim & 2 \\
\hline & não & 0 \\
\hline \multirow[t]{2}{*}{ Sala de Biópsia de congelação (Anatomia Patológica) } & sim & 1 \\
\hline & não & 0 \\
\hline \multirow[t]{2}{*}{ Fluxos pacientes/funcionários por entradas diferentes } & $\operatorname{sim}$ & 3 \\
\hline & não & 0 \\
\hline \multirow[t]{2}{*}{ Há Sala de Conforto Médico no Centro Cirúrgico } & $\operatorname{sim}$ & 1 \\
\hline & não & 0 \\
\hline \multirow[t]{2}{*}{2 bicos de oxigênio/sala } & $\operatorname{sim}$ & 3 \\
\hline & não & 0 \\
\hline \multirow[t]{2}{*}{1 bico de ar comprimido/sala } & $\operatorname{sim}$ & 3 \\
\hline & não & 0 \\
\hline \multirow[t]{2}{*}{1 bico de vácuo/sala } & $\operatorname{sim}$ & 3 \\
\hline & não & 0 \\
\hline \multirow[t]{2}{*}{ carrinho de anestesia em todas as salas } & $\operatorname{sim}$ & 3 \\
\hline & não & 0 \\
\hline \multirow[t]{2}{*}{ Monitor de FC em todas as salas } & $\operatorname{sim}$ & 3 \\
\hline & não & 0 \\
\hline \multirow[t]{2}{*}{ Oxímetro em todas as salas } & $\operatorname{sim}$ & 3 \\
\hline & nào & 0 \\
\hline \multirow[t]{2}{*}{ Desfibrilador ligado no $\mathrm{CC}$} & $\operatorname{sim}$ & 3 \\
\hline & não & 0 \\
\hline
\end{tabular}

Total de pontos $=44$ 
RPA

\begin{tabular}{|l|l|r|}
\hline Número de leitos & \multicolumn{2}{|c|}{} \\
\hline \multirow{2}{*}{ Área Física } & adequada & 3 \\
\cline { 2 - 3 } & inadequada & 0 \\
\hline \multirow{2}{*}{ RH } & adequados & 3 \\
\cline { 2 - 3 } & inadequados & 0 \\
\hline \multirow{2}{*}{ Desfibrilador } & sim & 3 \\
\cline { 2 - 3 } & não & 0 \\
\hline \multirow{2}{*}{ Monitor de FC } & sim & 3 \\
\cline { 2 - 3 } & não & 0 \\
\hline \multirow{2}{*}{ Oxímetro } & sim & 3 \\
\cline { 2 - 3 } & não & 0 \\
\hline \multirow{2}{*}{01 bico de oxigênio/leito } & sim & 1 \\
\cline { 2 - 3 } & não & 0 \\
\hline \multirow{2}{*}{01 bico ar comprimido/leito } & sim & 1 \\
\cline { 2 - 3 } & não & 0 \\
\hline \multirow{2}{*}{01 bico de vácuo/leito } & sim & 1 \\
\cline { 2 - 3 } & não & 0 \\
\hline
\end{tabular}

Total de pontos $=18$ 
III - Apoio Diagnóstico e Terapia

SADT básico

\begin{tabular}{|c|c|c|c|c|c|}
\hline \multirow{3}{*}{ Anatomia Patológica } & não & 0 & & & \\
\hline & $\operatorname{sim}$ & 3 & \multirow{2}{*}{ Aparelhos } & adequados & 1 \\
\hline & & & & inadequados & 0 \\
\hline \multirow{3}{*}{ ECG } & não & 0 & & & \\
\hline & $\operatorname{sim}$ & 3 & \multirow{2}{*}{ Aparelhos } & adequados & 1 \\
\hline & & & & inadequados & 0 \\
\hline \multirow{7}{*}{ Endoscopia } & não & 0 & & & \\
\hline & sim & 2 & \multirow{2}{*}{ Aparelhos } & adequados & 1 \\
\hline & & & & inadequados & 0 \\
\hline & & & \multirow[t]{2}{*}{ Salas } & inadequados & 0 \\
\hline & & & & adequadas & 1 \\
\hline & & & \multirow{2}{*}{ Repouso } & inadequados & 0 \\
\hline & & & & adequadas & 1 \\
\hline \multirow{3}{*}{ Hemoterapia } & não & 0 & & & \\
\hline & $\operatorname{sim}$ & 3 & \multirow{2}{*}{ Conforme Legislação } & $\operatorname{sim}$ & 1 \\
\hline & & & & não & 0 \\
\hline \multirow{3}{*}{ Patologia Clínica } & não & 0 & & & \\
\hline & $\operatorname{sim}$ & 3 & \multirow{2}{*}{ Aparelhos } & adequados & 1 \\
\hline & & & & inadequados & 0 \\
\hline \multirow{3}{*}{$\mathrm{RX}$} & não & 0 & & & \\
\hline & $\operatorname{sim}$ & 3 & \multirow{2}{*}{ com seriógrafo } & sim & 1 \\
\hline & & & & não & 0 \\
\hline \multirow[t]{2}{*}{ RX Portátil } & $\operatorname{sim}$ & 2 & & & \\
\hline & não & 0 & & & \\
\hline \multirow[t]{2}{*}{ USG } & sim & 2 & & & \\
\hline & não & 0 & & & \\
\hline
\end{tabular}

Total de pontos $=29$ 
SADT acessório

\begin{tabular}{|c|c|c|c|c|c|c|}
\hline \multirow{3}{*}{ Angiografia Digital/Hemodinâmica } & não & 0 & \multirow{3}{*}{ Aparelhos } & \multirow{2}{*}{\multicolumn{2}{|c|}{ adequados }} & \multirow[b]{2}{*}{1} \\
\hline & \multirow{2}{*}{\multicolumn{2}{|c|}{$\operatorname{sim}$}} & & & & \\
\hline & & & & \multicolumn{2}{|c|}{\begin{tabular}{|l} 
inadequados \\
\end{tabular}} & 0 \\
\hline \multirow{3}{*}{ Audiometria } & não & 0 & & & & \\
\hline & sim & 1 & \multirow{2}{*}{ Aparelhos } & \multicolumn{2}{|c|}{ adequados } & 1 \\
\hline & & & & \multicolumn{2}{|c|}{ inadequados } & 0 \\
\hline \multirow{5}{*}{ Cintilografia } & não & 0 & & & & \\
\hline & sim & 1 & \multirow{2}{*}{ Aparelhos } & \multicolumn{2}{|c|}{ adequados } & 1 \\
\hline & & & & \multicolumn{2}{|c|}{ inadequados } & 0 \\
\hline & & & \multirow{2}{*}{ Normas CNEN } & \multicolumn{2}{|c|}{$\operatorname{sim}$} & 1 \\
\hline & & & & \multicolumn{2}{|l|}{ não } & 0 \\
\hline \multirow{3}{*}{ Densitometria Óssea } & não & 0 & & & & \\
\hline & sim & 1 & \multirow{2}{*}{ Aparelhos } & \multicolumn{2}{|c|}{ adequados } & 1 \\
\hline & & & & \multicolumn{2}{|c|}{ inadequados } & 0 \\
\hline \multirow{3}{*}{ Distúrbios do Sono } & não & 0 & & & & \\
\hline & sim & 1 & \multirow{2}{*}{ Aparelhos } & \multicolumn{2}{|c|}{\begin{tabular}{|l|} 
adequados \\
\end{tabular}} & 1 \\
\hline & & & & inac & quados & 0 \\
\hline Ecografia & não & 0 & & & & \\
\hline & $\operatorname{sim}$ & 1 & Aparelhos & ade & ados & 1 \\
\hline & & & & inac & quados & 0 \\
\hline FFG. & não & 0 & & & & \\
\hline LEU & sim & 1 & Aparelhos & adec & $\operatorname{ados}$ & 1 \\
\hline & & & & inad & quados & 0 \\
\hline Eletroneuromiografia & não & 0 & & & & \\
\hline & $\operatorname{sim}$ & 1 & Aparelhos & adec & $\operatorname{ados}$ & 1 \\
\hline & & & & inad & quados & 0 \\
\hline & não & 0 & & & & \\
\hline Ergometria & $\operatorname{sim}$ & 1 & Aparelhos & adec & ados & 1 \\
\hline & & & & inad & quados & 0 \\
\hline & & & Vestiários & adec & $\operatorname{ados}$ & 1 \\
\hline & & & & inad & quados & 0 \\
\hline & & & Desfibrilador & $\operatorname{sim}$ & & 1 \\
\hline & & & & não & & 0 \\
\hline & não & 0 & & & & \\
\hline Fisioterapia & $\operatorname{sim}$ & 1 & Aparelhos & adec & ados & 1 \\
\hline & & & & inad & quados & 0 \\
\hline & & & Vestiários & adec & ados & 1 \\
\hline & & & & inad & quados & 0 \\
\hline L & não & 0 & & & & \\
\hline Hemodialise & $\operatorname{sim}$ & 1 & & & & \\
\hline & & & Conforme Legislação & sim & 1 & \\
\hline & & & & não & 0 & \\
\hline Holter & $\operatorname{sim}$ & 1 & & & & \\
\hline & não & 0 & & & & \\
\hline
\end{tabular}




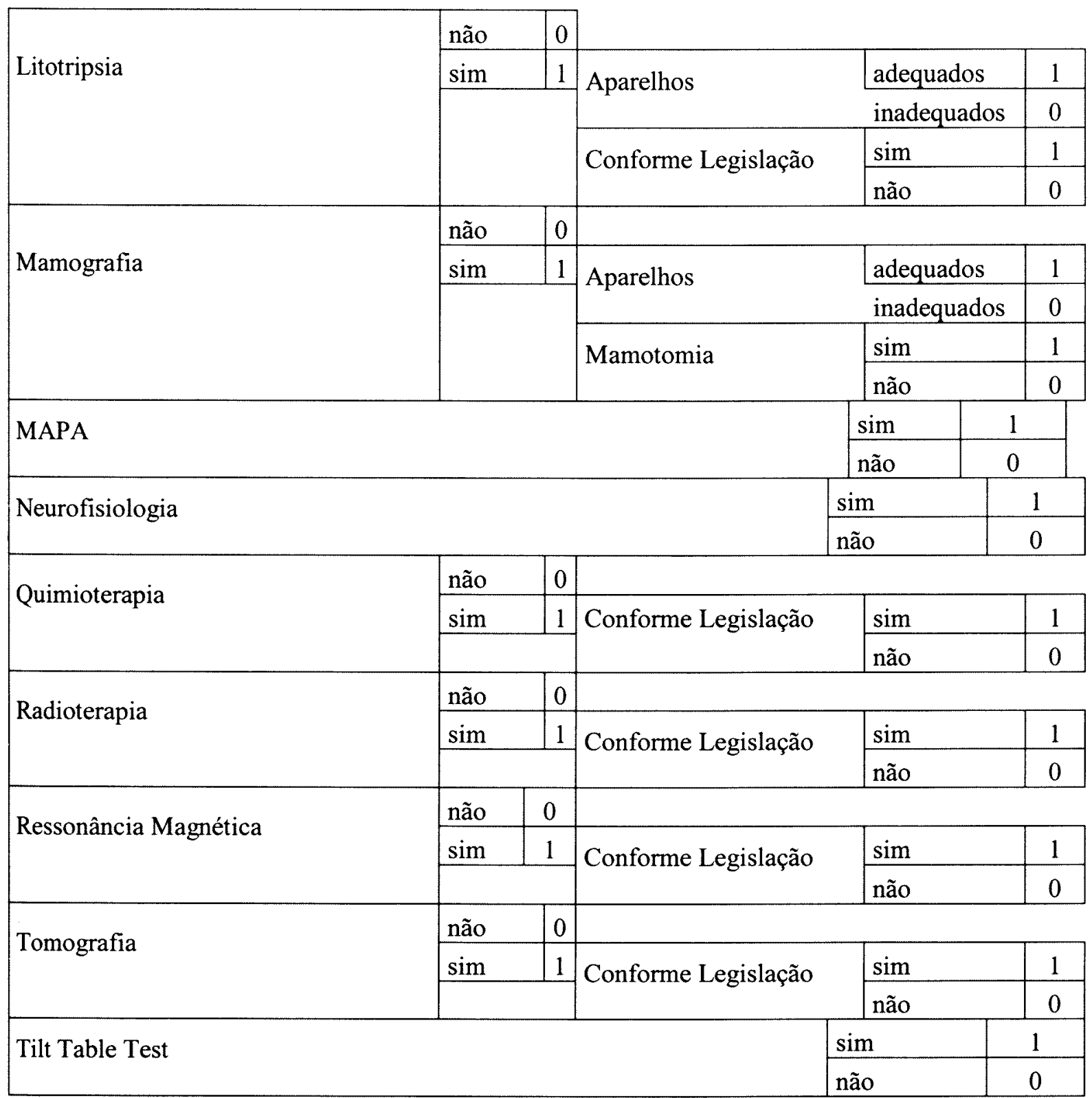

Total de pontos $=44$ 
IV - Apoio Técnico e Administrativo

Farmácia

\begin{tabular}{|c|c|c|c|}
\hline \multirow[t]{2}{*}{ Há controle dos medicamentos Portaria 344} & $\operatorname{sim}$ & 3 & \\
\hline & não & 0 & \\
\hline \multirow[t]{2}{*}{ A farmácia manipula NPP } & $\operatorname{sim}$ & 1 & \\
\hline & não & 0 & \\
\hline \multirow[t]{2}{*}{ Em área adequada conforme legislação } & $\operatorname{sim}$ & 3 & \\
\hline & não & 0 & \\
\hline \multirow[t]{2}{*}{ Há capela de fluxo laminar } & $\operatorname{sim}$ & 1 & \\
\hline & não & 0 & \\
\hline \multirow[t]{2}{*}{ Há local adequado para preparo dos medicamentos } & $\operatorname{sim}$ & 1 & \\
\hline & não & 0 & \\
\hline \multirow[t]{2}{*}{ Há local adequado para dispensação } & $\operatorname{sim}$ & 3 & \\
\hline & não & 0 & \\
\hline \multirow[t]{2}{*}{ Há farmacêutico no local } & $\operatorname{sim}$ & 3 & Quantos \\
\hline & não & 0 & \\
\hline \multirow[t]{2}{*}{ Há padronização de medicamentos } & $\operatorname{sim}$ & 1 & \\
\hline & não & 0 & \\
\hline \multirow[t]{3}{*}{ Dispensação } & Convencional & 1 & \\
\hline & Individualizada & 2 & \\
\hline & Unitária & 3 & \\
\hline
\end{tabular}

Total de pontos: 19

SND

\begin{tabular}{|c|c|c|c|}
\hline \multirow[t]{2}{*}{ Circulação adequada } & $\operatorname{sim}$ & 3 & \\
\hline & não & 0 & \\
\hline \multirow[t]{2}{*}{ Equipamentos necessários e conservados } & sim & 1 & \\
\hline & não & 0 & \\
\hline \multirow[t]{2}{*}{ Área adequada com boa iluminação e aeração } & $\operatorname{sim}$ & 1 & \\
\hline & não & 0 & \\
\hline \multirow[t]{2}{*}{ Existe bancada para manipulação dos alimentos } & $\operatorname{sim}$ & 1 & \\
\hline & não & 0 & \\
\hline \multirow[t]{2}{*}{ Há cardápio afixado } & $\operatorname{sim}$ & 1 & \\
\hline & não & 0 & \\
\hline \multirow[t]{2}{*}{ Há Nutricionista } & sim & 3 & Quantas \\
\hline & não & 0 & \\
\hline
\end{tabular}

Total de pontos: 10

Limpeza/Higiene

\begin{tabular}{|l|l|r|}
\hline Há normas e rotinas para limpeza da unidade & sim & 3 \\
\cline { 2 - 3 } & não & 0 \\
\hline Utilizam produtos próprios para limpeza & sim & 3 \\
\cline { 2 - 3 } & não & 0 \\
\hline \multirow{2}{*}{ A CCIH participa na elaboração de normas do setor } & sim & 3 \\
\cline { 2 - 3 } & não & 0 \\
\hline \multirow{2}{*}{ Há coleta seletiva do lixo } & sim & 3 \\
\cline { 2 - 3 } & não & 0 \\
\hline Funcionários utilizam equipamentos de proteção & sim & 3 \\
\cline { 2 - 3 } & não & 0 \\
\hline
\end{tabular}

Total de pontos: 15 
Lavanderia

\begin{tabular}{|l|l|r|}
\hline \multirow{2}{*}{ Máquina de lavar modelo profissional } & sim & 1 \\
\cline { 2 - 3 } & não & 0 \\
\hline \multirow{2}{*}{ Centrífugas apropriadas } & sim & 1 \\
\cline { 2 - 3 } & não & 0 \\
\hline \multirow{2}{*}{ Há barreiras físicas } & sim & 1 \\
\cline { 2 - 3 } & não & 0 \\
\hline \multirow{2}{*}{ Há cruzamento limpo/contaminado } & sim & 1 \\
\cline { 2 - 3 } & não & 0 \\
\hline \multirow{2}{*}{ Área física apropriada } & sim & 0 \\
\cline { 2 - 3 } & não & 3 \\
\hline Equipamentos em boas condições & sim & 3 \\
\cline { 2 - 3 } & não & 0 \\
\hline Funcionários com equipamentos de proteção & sim & 1 \\
\cline { 2 - 3 } & não & 1 \\
\hline Serviço de Costura/Rouparia & sim & 0 \\
\cline { 2 - 3 } & não & sim \\
\cline { 2 - 3 } & não & \\
\hline
\end{tabular}

Total de pontos: 13 pontos

Almoxarifado

\begin{tabular}{|l|l|r|}
\hline Área apropriada & sim & 1 \\
\cline { 2 - 3 } & não & 0 \\
\hline Estoques suficientes & sim & 1 \\
\cline { 2 - 3 } & não & 0 \\
\hline Setor informatizado & sim & 1 \\
\cline { 2 - 3 } & não & 0 \\
\hline
\end{tabular}

Total de pontos: 3

\begin{tabular}{|l|l|r|l|l|}
\hline \multirow{3}{*}{ Manutenção } & não & 0 & \\
\cline { 2 - 5 } & sim & 2 & Própria & \\
\cline { 2 - 5 } & & Terceirizada & \\
\cline { 3 - 5 } & & Ambas & \\
\cline { 3 - 5 } & &
\end{tabular}

\begin{tabular}{|l|l|r|l|l|}
\hline Segurança & não & 0 & & \\
\cline { 2 - 4 } & sim & 2 & Própria & \\
\cline { 2 - 5 } & & Terceirizada & \\
\cline { 3 - 6 } & & Ambas & \\
\cline { 3 - 5 } & &
\end{tabular}

Total de pontos $=4$

SAME

\begin{tabular}{|l|l|l|}
\hline Prontuário Único & não & \\
\cline { 2 - 3 } & sim & 3 \\
\hline Conforme legislação & não & \\
\cline { 2 - 3 } & $\operatorname{sim}$ & 3 \\
\hline Informatizado & não & \\
\hline & $\operatorname{sim}$ & 3 \\
\hline
\end{tabular}

Total de pontos $=9$ 
Central de Esterilização

\begin{tabular}{|c|c|c|c|c|c|c|}
\hline \multirow[t]{2}{*}{ Encontra-se instalado em área física adequada } & sim & 3 & & & & \\
\hline & não & 0 & & & & \\
\hline \multirow[t]{2}{*}{ Tem área para expurgo do material } & $\operatorname{sim}$ & $\frac{3}{0}$ & & & & \\
\hline & não & 0 & & & & \\
\hline \multirow[t]{2}{*}{ Tem área para preparo/esterilização } & $\operatorname{sim}$ & \multirow{2}{*}{\multicolumn{2}{|c|}{3}} & & & \\
\hline & não & & & & & \\
\hline \multirow[t]{2}{*}{ Tem área para estocagem/distribuição } & $\operatorname{sim}$ & \multirow{2}{*}{\multicolumn{2}{|c|}{3}} & & & \\
\hline & não & & & & & \\
\hline \multirow[t]{2}{*}{ Há enfermeira responsável } & sim & 3 & & & & \\
\hline & não & \multicolumn{2}{|l|}{$\frac{3}{0}$} & & & \\
\hline \multirow[t]{2}{*}{ Há normatização de procedimentos na área } & $\operatorname{sim}$ & \multirow{2}{*}{$\frac{3}{0}$} & & & & \\
\hline & não & & & & & \\
\hline \multirow[t]{2}{*}{ Há cruzamento de fluxo de circulação entre as áreas } & $\operatorname{sim}$ & \multirow{4}{*}{\multicolumn{2}{|c|}{\begin{tabular}{l|}
0 \\
3 \\
1 \\
0 \\
\end{tabular}}} & & & \\
\hline & não & & & & & \\
\hline \multirow[t]{2}{*}{ Funcionários paramentados adequadamente } & $\operatorname{sim}$ & & & & & \\
\hline & não & & & & & \\
\hline \multirow[t]{2}{*}{ Possui Autoclave horizontal } & $\operatorname{sim}$ & 3. & \multicolumn{3}{|c|}{ Quantas } & \\
\hline & não & 0 & & & & \\
\hline \multirow[t]{2}{*}{ Possui Autoclave vertical } & $\operatorname{sim}$ & 1 & \multicolumn{3}{|c|}{ Quantas } & \\
\hline & não & 0 & & & & \\
\hline \multirow[t]{2}{*}{ Há manutenção preventiva de equipamentos } & $\operatorname{sim}$ & 1 & & & & \\
\hline & não & 0 & & & & \\
\hline \multirow[t]{7}{*}{ É utilizado Controle Biológico } & não & 0 & & & & \\
\hline & $\operatorname{sim}$ & 1 & & & & \\
\hline & Peridiocidade & 1 & 7 & 15 & 30 & Não \\
\hline & Fita teste & 3 & & & & 0 \\
\hline & Attest & 3 & 3 & 2 & 1 & 0 \\
\hline & Complay & 3 & 0 & 0 & 0 & 0 \\
\hline & Bowe Dick & 3 & 0 & 0 & 0 & 0 \\
\hline
\end{tabular}

Total de pontos $=40$ 


\section{ANEXO 4-Vistoria Técnica Hospitalar - Hospital A}

\section{Identificação do Estabelecimento}

Nome:

A

Diretor Clínico:

CRM:

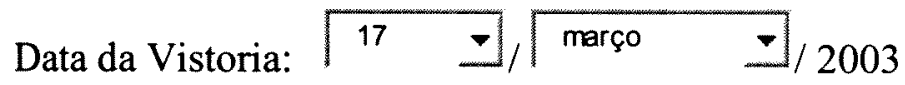

Acompanhantes:

Gisele Maria Giovinazzo

Helena Pavarina Maia
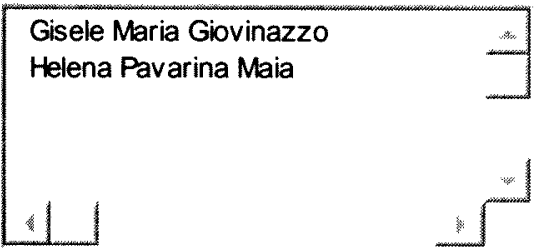

$\mathrm{N}^{\mathrm{o}}$ Total de Leitos:

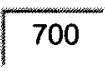

Total de Leitos Operacionais: $\quad 700$

$\mathrm{N}^{\mathrm{o}}$ de Leitos Convênio:

\section{Classificação do Estabelecimento}

Tipo de Hospital:

Geral

Lista de Especializações:

\section{Tipo de Serviço}

Tipo de serviço:

Abrangência do serviço

Filantrópico/Fundação

Abrangência do serviço:

Estadual 


\section{Organização e Funcionamento}

\begin{tabular}{|c|c|c|c|}
\hline & $\Rightarrow \mathrm{Inc}$ & cluir & \\
\hline Regime Interno/regulamento & $\operatorname{sim}$ & & \\
\hline Programas de Treinamento & $\operatorname{sim}$ & & \\
\hline Educação Continuada & $\operatorname{sim}$ & & \\
\hline Informatização & $\operatorname{sim}$ & & \\
\hline Farmácia e Medicamentos & $\operatorname{sim}$ & & \\
\hline Controle e Gestão de Qualidade & $\operatorname{sim}$ & & \\
\hline Ensino e Pesquisa & $\operatorname{sim}$ & & \\
\hline Residência Médica/Pós-Graduação & $\operatorname{sim}$ & & \\
\hline Normas e Rotinas e Manuais & $\operatorname{sim}$ & & \\
\hline Indicadores Hospitalares & $\operatorname{sim}$ & & \\
\hline Relatórios Gerenciais & $\operatorname{sim}$ & & \\
\hline Serviço Social & $\operatorname{sim}$ & & \\
\hline Psicologia Hospitalar & $\operatorname{sim}$ & & \\
\hline Saúde Ocupacional & $\operatorname{sim}$ & & \\
\hline Comissão de Ética Médica & $\operatorname{sim}$ & Reuniões Regulares / Atas & $\operatorname{sim}$ \\
\hline Revisão de Prontuários & $\operatorname{sim}$ & Reuniões Regulares / Atas & $\operatorname{sim}$ \\
\hline $\mathrm{CCIH}$ & $\operatorname{sim}$ & Reuniões Regulares / Atas & $\operatorname{sim}$ \\
\hline Revisão de Óbitos & $\operatorname{sim}$ & Reuniões Regulares / Atas & $\operatorname{sim}$ \\
\hline CIPA & $\operatorname{sim}$ & Reuniões Regulares / Atas & $\operatorname{sim}$ \\
\hline
\end{tabular}

\begin{tabular}{|c|c|c|}
\hline \multicolumn{2}{|c|}{ Recursos Humanos de todo o Hospital (Ano de } & 2003 \\
\hline Profissionais & Quantidade & \\
\hline Médicos contratados & 241 & \\
\hline Enfermeiros & 136 & \\
\hline Técnicos de enfermagem & 58 & \\
\hline Auxiliares de enfermagem & 868 & \\
\hline Atendentes de enfermagem & 26 & \\
\hline Outros Funcionários & 1428 & \\
\hline Total & 2757 & \\
\hline
\end{tabular}


Informações Gerais (Ano de $\sqrt{2002}$

Levantamento de dados anual

Número de óbitos após 48 horas

Números de saídas (Altas e Óbitos)

Números de óbitos por causas maternas

Número de pacientes atendidos em Obstetrícia

Número de nascidos vivos

Número de nascidos mortos

Número de óbitos neonatais após 48 horas

Número de óbitos operatórios até 10 dias pós-cirurgia

Número de atos cirurgicos

Número de cesáreas

Número de partos normais

Número total de partos

\begin{tabular}{|c|c|}
\hline 22 & \\
\hline 5282 & \\
\hline 0 & \\
\hline 0 & \\
\hline 0 & \\
\hline 3 & \\
\hline 1 & \\
\hline 0 & \\
\hline 2861 & \\
\hline 3961 & 61 \\
\hline 347 & \\
\hline 31 & \\
\hline
\end{tabular}

Número de infecções atribuiveis ao hospital

Número de supurações de feridas cirúrgicas em cirurgias limpas

Número de cirurgias limpas do período

Número de pacientes/dia

Número de leitos/dia

Número de leitos disponíveis no período

$\frac{0}{17411}$
0
199

Indicadores de Qualidade (Ano de $\sqrt{2002}$ )

Taxa de mortalidade institucional

Taxa de mortalidade materna

Taxa de natimortalidade

Taxa de mortalidade neonatal

Taxa de mortalidade operatória

Taxa de cesáreas

Taxa de infecção hospitalar

Taxa de supuração de ferida cirúrgica em cirurgia limpa

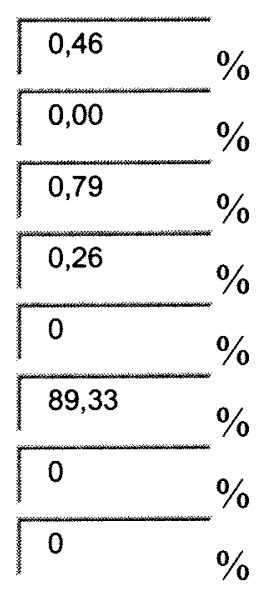

Indicadores de produtividade (Ano de $\sqrt{2002}$ )

Taxa de ocupação $\quad 72,36 \%$

Taxa de permanência 03 dias

Giro de rotatividade 88 vezes 


\section{Estrutura}

Edificação:

$\mathrm{N}^{\circ}$ de Pavimentos:

$\ulcorner$ Horizontal

12

$\nabla$ Planejada

$\nabla$ Vertical

$\mathrm{N}^{\circ}$ de elevadores:

$\ulcorner$ Adaptada

\begin{tabular}{|c|c|c|c|}
\hline & Incluir & & \\
\hline Identificação & visível & & 1 \\
\hline Sinalização & $\operatorname{sim}$ & & 1 \\
\hline Elevadores & necessário & em número suficiente & 1 \\
\hline Local próprio para lixo & $\operatorname{sim}$ & & 1 \\
\hline Reservatório de Água & $\operatorname{sim}$ & & 1 \\
\hline Caldeira & $\operatorname{sim}$ & & 1 \\
\hline Gerador & automático & suficiente para o hospital & 1 \\
\hline Cabine Primária de Força & $\operatorname{sim}$ & & 1 \\
\hline Sistema de Esgotos & não & & 1 \\
\hline Pára-Raios & $\operatorname{sim}$ & & 1 \\
\hline Área para manutenção/descarga & $\operatorname{sim}$ & & 1 \\
\hline Sistema de Prevenção de Incêndios & $\operatorname{sim}$ & Brigada de incêndio & 1 \\
\hline Sistema de Prevenção de Incêndios & $\operatorname{sim}$ & Hidrantes & \\
\hline Sistema de Prevenção de Incêndios & $\operatorname{sim}$ & Extintores & \\
\hline Estacionamento & $\operatorname{sim}$ & suficiente & 1 \\
\hline Central de Gases & $\operatorname{sim}$ & Tanque de oxigênio & 1 \\
\hline Central de Gases & $\operatorname{sim}$ & Compressor de ar comprimido & 1 \\
\hline Central de Gases & sim & Torpedos de N2O & 1 \\
\hline Ar Condicionado Central & $\operatorname{sim}$ & CC com fluxo laminar & 1 \\
\hline Ar Condicionado Central & $\operatorname{sim}$ & UTI com fluxo laminar & 1 \\
\hline
\end{tabular}


Organização e Atenção ao Paciente

\section{Hotelaria}

\begin{tabular}{|ccc|}
\hline & Incluir \\
\cline { 2 - 4 } Recepção & Sanitários sim cada sexo & 0 \\
Recepção & informatizada sim & 0 \\
Limpeza & ótima & 0 \\
Higiene & ótima & 0 \\
Conservação Predial & ótima & 0 \\
Recepção & Confortável & 0 \\
Recepção & Adequada & 0
\end{tabular}

Suítes - Quantos?

bico de oxigênio

bico de ar

bico de vácuo

sofá/cama acompanhante

cadeira de descanso

Sanitário

Sanitário

porta abrindo para dentro

frigobar

sim barras/apoios

ar condicionado

telefone

TV

\section{Suítes}

\begin{tabular}{|c|c|c|}
\hline Instalações Hidráulicas & Adequada & 0 \\
\hline Instalações Elétricas & Adequada & 0 \\
\hline Ventilação & Adequada & 0 \\
\hline Iluminação & Adequada & 0 \\
\hline Corredores Livres & $\operatorname{sim}$ & 0 \\
\hline Carrinho de emergência & $\operatorname{sim}$ & 1 \\
\hline rpedo de oxigênio na unidade & não & 0 \\
\hline
\end{tabular}


Apartamentos - Quantos?

sofá/cama acompanhante

Torpedo de oxigênio na unidade

Sim

Carrinho de emergência

Sim

TV

frigobar

ar condicionado

telefone

bico de oxigênio

bico de vácuo

cadeira de descanso

Sanitário

Sanitário

bico de ar

$\begin{array}{cc}\text { porta } & \text { abrindo para dentro } \\ \text { barras/apoios } & \text { sim }\end{array}$

\section{Apartamentos}

\section{Instalações Hidráulicas}

Instalações Elétricas

Ventilação

Iluminação

Corredores Livres

Carrinho de emergência

Torpedo de oxigênio na unidade

Adequada
Adequada
Adequada
Adequada
sim
sim
sim

Adequada

Adequada

Adequada

$\operatorname{sim}$

$\operatorname{sim}$

0
0
0
0

\section{Enfermaria}

Enfermarias 2 Leitos - Quantos?

Carrinho de emergência Sim

Distância mínima entre os leitos

TV

Torpedo de oxigênio na unidade Sim

bico de vácuo

bico de ar

bico de oxigênio 


\section{Enfermarias 2 Leitos}

Instalações Hidráulicas

Adequada

0 )

Instalações Elétricas

Adequada

0 蛘

Ventilação

Adequada

0 \%

Iluminação

Adequada

0 in

Corredores Livres

$\operatorname{sim}$

0 造

Carrinho de emergência

$\operatorname{sim}$

0 到

Torpedo de oxigênio na unidade

não

0 난 
Pronto Socorro

\begin{tabular}{|c|c|c|c|}
\hline & Incluir & & \\
\hline Tipo & Geral & 0 & * \\
\hline Entrada bem localizada, fácil acesso & $\operatorname{sim}$ & 0 & 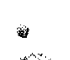 \\
\hline Sala exclusiva para urgências & $\operatorname{sim}$ & 0 & 6 \\
\hline 1 Bico de Oxigênio/leito & $\operatorname{sim}$ & 1 & 의 \\
\hline 1 Ar Comprimido/leito & $\operatorname{sim}$ & 1 & 9 \\
\hline 1 Vácuo/leito & $\operatorname{sim}$ & 1 & $\Leftrightarrow$ \\
\hline Medicamentos de urgência & $\operatorname{sim}$ & 0 & 6 \\
\hline Enfermeira nos turnos & $\operatorname{sim}$ & 0 & w \\
\hline Equipe Médica conforme legislação & $\operatorname{sim}$ & 0 & 到 \\
\hline Possui UTI Móvel & $\operatorname{sim}$ & 0 & 60 \\
\hline Ambulância para remoção & $\operatorname{sim}$ & 0 & 6 \\
\hline Leitos para observação & Masculino & 4 & (3) \\
\hline Leitos para observação & Feminino & 4 & 9 \\
\hline Leitos para observação & Pediátrico & 4 & (6) \\
\hline Sala de Inalação & $\operatorname{sim}$ & 0 & 6 \\
\hline Sala de gesso & $\operatorname{sim}$ & 0 & 6 \\
\hline Sala de pequenas cirurgias & $\operatorname{sim}$ & 0 & 9 \\
\hline
\end{tabular}

\section{Equipamentos da Urgência}

\begin{tabular}{|c|c|c|c|}
\hline & $\rightarrow$ & Incluir & \\
\hline $\mathrm{ECG}$ & Dixtal & EP 3 & 1 \\
\hline Monitor de PANI & Dixtal & & 0 \\
\hline Carrinho de emergência com cardioversor & & & 1 \\
\hline AMBU & & & 1 \\
\hline Foco auxiliar & & & 0 \\
\hline Bisturi elétrico & Medcir & MBJ II & 1 \\
\hline Desfibrilador & TEB & $\mathrm{D}-10$ & 1 \\
\hline Monitor FC + ECG & Dixtal & 920 & 1 \\
\hline & & & 1 \\
\hline
\end{tabular}




\section{Consultórios:}

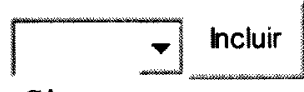

$\begin{array}{lccc}\operatorname{Sim} & \text { Geral } & 0 \\ \operatorname{Sim} & \text { GO } & 0 \\ \operatorname{Sim} & \text { Pediatria } & 0 & \\ \operatorname{Sim} & \text { Cardiologia / Cirurgia Cardiovascular } & 0 & \\ \operatorname{Sim} & \text { Ortopedia } & 0\end{array}$

\section{Outras Salas}

\begin{tabular}{|c|c|c|c|}
\hline & $\Rightarrow$ Incluir & & \\
\hline Sala & Tamanho & Equips. & Excluir \\
\hline Cirurgia & Pequena & 2 & w \\
\hline Curativo & Pequena & $\lambda$ & 9 \\
\hline ORL & Média & 2 & 9 \\
\hline Espirometria & Média & 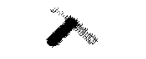 & 67 \\
\hline Urodinâmica & Média & 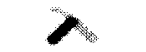 & $\theta$ \\
\hline Gesso & Média & 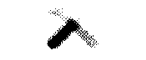 & 5 \\
\hline
\end{tabular}

\section{Sala: Cirurgia}

Equipamentos

\begin{tabular}{|cccc|}
\hline & & & \\
Mesa cirúrgica & Baumer & 1 & \\
Foco auxiliar & & 1 & \\
Bisturi elétrico & Medcir & MBJ II & 1 \\
Lâmpada de fenda & Xenomio & 1 &
\end{tabular}




Incluir

Há normas e rotinas para a área

$\operatorname{sim}$

Há programas de acompanhamento de visita com orientação sim

Encontra-se em área física adequada

$\operatorname{sim}$

De acordo com a legislação vigente

$\operatorname{sim}$

$\operatorname{sim}$

$\operatorname{sim}$

Há normas e rotinas para a área

A UTI participa da CCIH

O posto de enfermagem permite boa visão dos leitos

$\operatorname{sim}$

0 :

0 .

Há boa circulação de funcionários e pacientes

$\operatorname{sim}$

0

Possui médico diarista

$\operatorname{sim}$

0 .

Possui equipe médica em todos os turnos

$\operatorname{sim}$

0 行

Equipe de enfermagem treinada e completa

$\operatorname{sim}$

0

0 (3)

0 㮘

0 解

Enfermeira em todos os turnos

$\operatorname{sim}$

0 \%

Quarto para médico plantonista

$\operatorname{sim}$

0 知

2 bicos de oxigênio/leito

$\operatorname{sim}$

0 㮘

1 bico de ar comprimido/leito

$\operatorname{sim}$

0 镂

1 bico de vácuo/leito

$\operatorname{sim}$

0 列

Há leitos para isolamento

$\operatorname{sim}$

0 解

0 \%

0 의

Número de Leitos

$\operatorname{sim}$

8 鄂

10 tomadas elétricas/leito

$\operatorname{sim}$ 


\section{Equipamentos}

\begin{tabular}{cccc}
\hline & & & \\
Monitor FC + ECG + PANI + oxímetro & Dixtal & DX2010 & 10 \\
Bomba de Infusão & BBraun & Nutrimat II & 28 \\
Bomba de infusão por seringa & Samtronic & ST 680 & 20 \\
Bomba de infusão por seringa & Samtronic & ST MS & 15 \\
Respirador & Benett & 7200 & 15 \\
Respirador & Benett & 8200 & 4 \\
Respirador & Bird & 8400 & 8 \\
Monitor DC SwanGanz & Dixtal & DX 2405 & 4 \\
Monitor de PIC & Bip Camino & Y-420-7 & 5 \\
BEEPAP & Air Way & 302220 & 4 \\
Desfibrilador & HP & OBD-048 & 2 \\
ECG & Dixtal & EP 3 & 2 \\
Monitor multiparâmetro & HP & Philips & 5 \\
Monitor de PANI & Dixtal & DX2710 & 10 \\
Oxímetro & Dixtal & DX 2405 & 10 \\
Colchão térmico & Gaymar Med & Therm II & 3
\end{tabular}




\section{UTI Cardiológica}

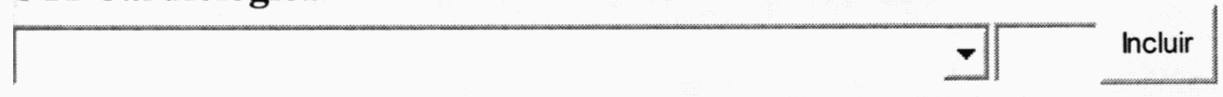

Há normas e rotinas para a área

$\operatorname{sim}$

Há programas de acompanhamento de visita com orientação sim

Encontra-se em área física adequada

$\operatorname{sim}$

De acordo com a legislação vigente

$\operatorname{sim}$

Há boa circulação de funcionários e pacientes

$\operatorname{sim}$

2 bicos de oxigênio/leito

$\operatorname{sim}$

$\operatorname{sim}$

1 bico de ar comprimido/leito

1 bico de vácuo/leito

A UTI participa da CCIH

Possui médico diarista

Possui equipe médica em todos os turnos

Equipe de enfermagem treinada e completa

$\operatorname{sim}$

sim

sim

$\operatorname{sim}$

$\operatorname{sim}$

$\operatorname{sim}$

Enfermeira em todos os turnos

$\operatorname{sim}$

Há leitos para isolamento

Quarto para médico plantonista

$\operatorname{sim}$

$\operatorname{sim}$

01 médico para cada 10 leitos

Número de Leitos

10 tomadas elétricas/leito

$\operatorname{sim}$

\section{Equipamentos}

\begin{tabular}{|c|c|c|c|c|}
\hline & \multirow{2}{*}{ Incluir } & & \\
\hline & -7 & & & \\
\hline Monitor FC + ECG & Dixtal & 920 & 4 & 解 \\
\hline Monitor de FC + oxímetro + PANI & Dixtal & DX2010 & 20 & (2) \\
\hline Respirador & Benett & 7200 & 6 & 通 \\
\hline Respirador & Intermed & Inter 5 & 12 & 6 \\
\hline BEEPAP & Air Way & 302220 & 2 & 8 \\
\hline Oxicapnógrafo & Dixtal & DX 7100 & 1 & 9 \\
\hline Carrinho de emergência com cardioversor & Marquette & STD & 1 & \\
\hline Monitor DC SwanGanz & Dixtal & DX 2405 & 2 & \\
\hline ECG & Dixtal & EP 3 & 3 & \\
\hline Marca-Passo & Biotronik & & 3 & \\
\hline Marca-Passo externo & FEAS & & 3 & \\
\hline Marca-Passo externo & Biotronik & DP 30 bifocal & 5 & \\
\hline Desfibrilador & FAJ & FAJ 200 & 1 & \\
\hline
\end{tabular}




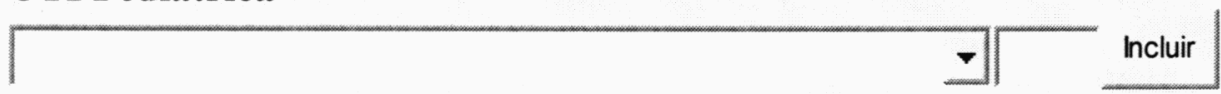

Há normas e rotinas para a área

ação $\begin{array}{ll}\operatorname{sim} & 0 \\ \operatorname{sim} & 0 \\ \operatorname{sim} & 0 \\ \operatorname{sim} & 0 \\ \operatorname{sim} & 0 \\ \operatorname{sim} & 0 \\ \operatorname{sim} & 0 \\ \operatorname{sim} & 0 \\ \operatorname{sim} & 0 \\ \operatorname{sim} & 0 \\ \operatorname{sim} & 0 \\ \operatorname{sim} & 0 \\ \operatorname{sim} & 0 \\ \operatorname{sim} & 0 \\ \operatorname{sim} & 0 \\ \operatorname{sim} & 0 \\ \operatorname{sim} & 2 \\ \operatorname{sim} & 0\end{array}$

Há programas de acompanhamento de visita com orientação Encontra-se em área física adequada

De acordo com a legislação vigente

Há boa circulação de funcionários e pacientes

2 bicos de oxigênio/leito

1 bico de ar comprimido/leito

1 bico de vácuo/leito

01 médico para cada 10 leitos

Há normas e rotinas para a área

A UTI participa da $\mathrm{CCIH}$

O posto de enfermagem permite boa visão dos leitos

Possui médico diarista

Possui equipe médica em todos os turnos

Equipe de enfermagem treinada e completa

Enfermeira em todos os turnos

Há leitos para isolamento

Quarto para médico plantonista

\section{Equipamentos}

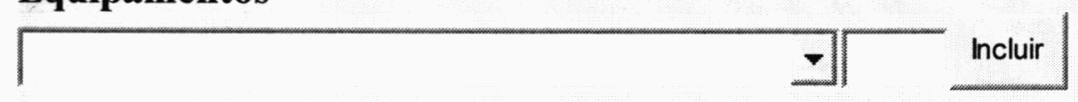

$\begin{array}{cccc}\text { Bomba de infusão por seringa } & \text { Samtronic } & & 10 \\ \text { Respirador } & \text { Intermed } & \text { Inter 5 } & 8 \\ \text { Bomba de Infusão } & \text { BBraun } & \text { Nutrimat II } & 12 \\ \text { Monitor multiparâmetro } & \text { Dixtal } & \text { DX2010 } & 1 \\ \text { Monitor FC + oxímetro } & \text { Dixtal } & 920 & 9 \\ \text { Oxímetro } & \text { Dixtal } & \text { DX2405Oxypleth } & 4\end{array}$




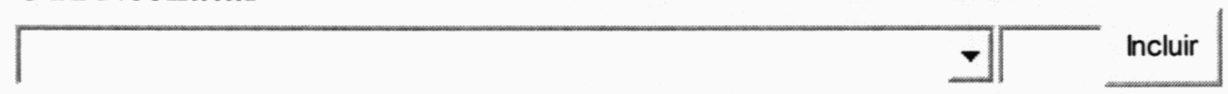

Há normas e rotinas para a área

$\operatorname{sim}$

Há programas de acompanhamento de visita com orientação sim

Encontra-se em área física adequada

$\operatorname{sim} \quad 0$.

De acordo com a legislação vigente

$\operatorname{sim}$

0 的

2 bicos de oxigênio/leito

$\operatorname{sim}$

0 行

1 bico de ar comprimido/leito

$\operatorname{sim}$

0 通

1 bico de vácuo/leito

$\operatorname{sim}$

0 埇

Há leitos para isolamento

A UTI participa da $\mathrm{CCIH}$

$\operatorname{sim}$

$O$ posto de enfermagem permite boa visão dos leitos

$\operatorname{sim}$

0 (4)

Há boa circulação de funcionários e pacientes

$\operatorname{sim}$

Possui médico diarista

$\operatorname{sim}$

0

01 médico para cada 10 leitos

Possui equipe médica em todos os turnos

$\operatorname{sim}$

0 过

Equipe de enfermagem treinada e completa

$\operatorname{sim}$

0 解

$\operatorname{sim}$

0 解

Enfermeira em todos os turnos

$\operatorname{sim}$

0 䅞

Há leitos para isolamento

sim

0 )

10 tomadas elétricas

$\operatorname{sim}$

sim

\section{Equipamentos}

\begin{tabular}{|cccc|}
\hline & & & \\
Respirador & Intermed & Inter 5 & 3 \\
Respirador & Intermed & Inter 3 & 5 \\
Incubadora & Fanem & C186-TS/ST & 22 \\
Bomba de Infusão & BBraun & Nutrimat II & 16 \\
Monitor multiparâmetro & Dixtal & DX2010 & 1 \\
Monitor FC + oxímetro & Dixtal & 920 & 14 \\
Berço aquecido calor irradiante & Fanem & BA-51 TS & 4 \\
Bomba de infusão por seringa & Samtronic & ST 670 infantil & 13 \\
Oxímetro & Dixtal & DX2405Oxypleth & 10
\end{tabular}




\section{Maternidade}

\begin{tabular}{ll}
\hline Tem sala de admissão & $\mathrm{sim}$ \\
Sala/leitos de pré-parto & $\mathrm{sim}$ \\
Vestiário com sanitário para ambos os sexos & $\mathrm{sim}$ \\
Sala de estar e repouso para funcionários e médicos & $\mathrm{sim}$ \\
Recuperação pós-anestésica (RPA) & Médico \\
O parto é realizado por: & $\mathrm{sim}$ \\
Há disponibilidade de médico obstetra no local durante 24 h & $\mathrm{sim}$ \\
O neonatologista recepciona todos os RNs & $\mathrm{sim}$ \\
Há neonatologista no local durante 24 horas & $\mathrm{sim}$ \\
Há disponibilidade de anestesista durante 24 horas & $\mathrm{sim}$ \\
Há sala de reanimação e identificação do RN & $\mathrm{sim}$ \\
Há pia com água corrente na sala de reanimação & $\mathrm{sim}$ \\
02 bicos de oxigênio/sala & $\mathrm{sim}$ \\
02 bicos de ar comprimido/sala & $\mathrm{sim}$
\end{tabular}

Salas

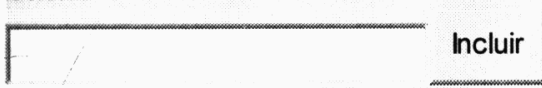

Sala pré-parto

Reanimação do $\mathrm{RN}$

> g

Sala de parto cirúrgico 1

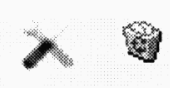

Sala de parto cirúrgico 5

Sala de parto normal 2

Sala de parto normal 3

Sala de parto normal 4
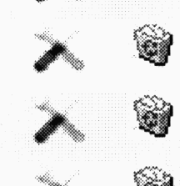

$\lambda$ 範

入

入

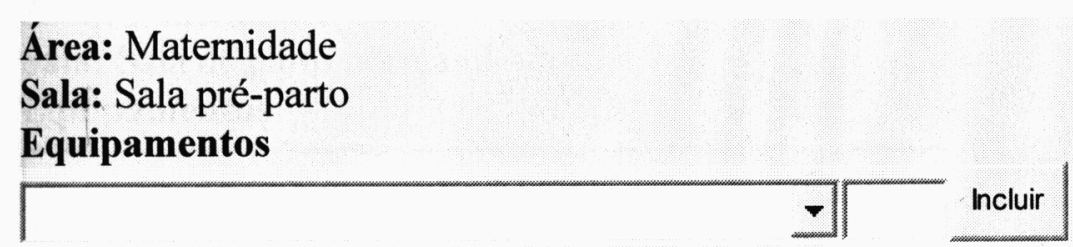

Detector de BCF Imbacrios DF $400 \quad 2$ (2)

Detector de BCF Fetus FD-400 1 is

Monitor de PANI Dixtal DX2710 1 ( 
Área: Maternidade

Sala: Reanimação do RN

Equipamentos

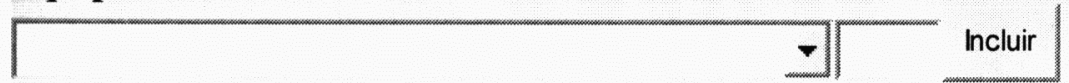

$\begin{array}{ccccc}\begin{array}{c}\text { Berço aquecido calor irradiante } \\ \text { Incubadora de Transporte }\end{array} & \text { Fanem } & \text { AQ-50 } & 2 \\ \text { Oxímetro } & \text { Dixtal } & \text { DX 2405 Oxypleth } & 1 & 1 \\ \text { Balança pesa-bebê } & \text { Filizola } & \text { Baby } & 1\end{array}$

Área: Maternidade

Sala: Sala de parto cirúrgico 1

Equipamentos

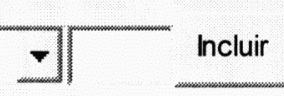

$\begin{array}{ccccc}\text { Bisturi elétrico } & \text { Deltronix } & \text { B 3300 S } & 1 \\ \text { Monitor FC + ECG } & \text { Dixtal } & 920 & 1 \\ \text { Monitor de PANI } & \text { Dixtal } & \text { DX2710 } & 1 \\ \text { Carrinho de anestesia } & \text { Takaoka } & \text { Fuji } & 1\end{array}$

Área: Maternidade

Sala: Sala de parto cirúrgico 5

Equipamentos

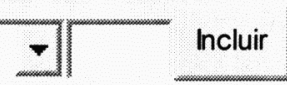

$\begin{array}{ccccc}\text { Bisturi elétrico } & \text { Deltronix } & \text { B 3300 S } & 1 \\ \text { Monitor FC + ECG } & \text { Dixtal } & 920 & 1 \\ \text { Monitor de PANI } & \text { Dixtal } & \text { DX2710 } & 1 & 4 \\ \text { Carrinho de anestesia } & \text { Takaoka } & \text { Fuji } & 1\end{array}$

Área: Maternidade

Sala: Sala de parto normal 2

Equipamentos

Mesa cirúrgica

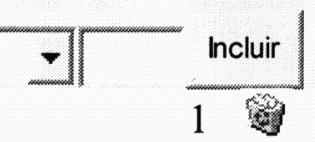


Área: Maternidade

Sala: Sala de parto normal 3

Equipamentos

Incluir

Mesa cirúrgica

1 解

Área: Maternidade

Sala: Sala de parto normal 4

Equipamentos

\begin{tabular}{|c|c|c|}
\hline & $\nabla$ & Incluir \\
\hline Mesa cirúrgica & & 1 歌 \\
\hline Carrinho de anestesia & & 1 行 \\
\hline
\end{tabular}




\section{Berçário}

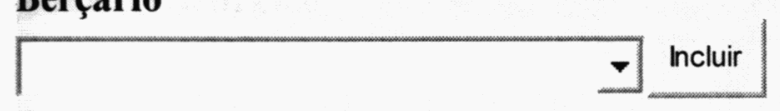

$\begin{array}{lcc}\text { Há berçário de primeiros cuidados } & \operatorname{sim} \\ \text { Há alojamento conjunto } & \operatorname{sim} \\ \text { Há UTI neonatal } & \operatorname{sim} \\ \text { Área Física } & \text { adequada } \\ \text { Há berçário de patológicos } & \operatorname{sim} \\ 2 \text { bicos de oxigênio/leito } & \operatorname{sim} \\ 1 \text { bico de ar comprimido/leito } & \operatorname{sim} \\ 1 \text { bico de vácuo/leito } & \operatorname{sim}\end{array}$

\section{Salas}

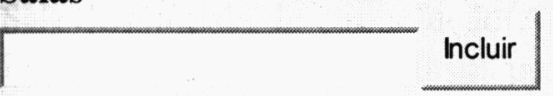

Berçário de Patológicos

Berçário de primeiros cuidados

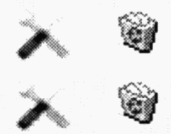

Área: Bercario

Sala: Berçário de Patológicos

\section{Equipamentos}

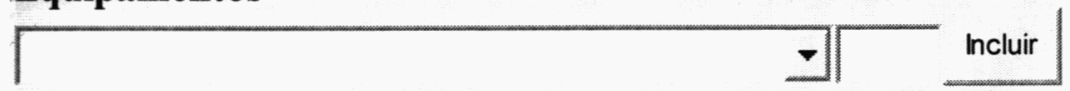

$\begin{array}{lccc}\text { Berço aquecido calor irradiante } & \text { Fanem } & \text { BA-51 TS } & 2 \\ \text { Incubadora } & \text { Fanem } & \text { C186-TS/ST } & 10 \\ \text { Monitor FC + oxímetro } & \text { Dixtal } & 920 & 4 \\ \text { Oxímetro } & \text { Dixtal } & \text { DX2405Oxypleth } & 10 \\ \text { Bomba de Infusão } & \text { BBraun } & \text { Nutrimat II } & 6 \\ \text { Bomba de infusão por seringa } & \text { Samtronic } & & 3\end{array}$

Área: Bercario

Sala: Berçário de primeiros cuidados

\section{Equipamentos}

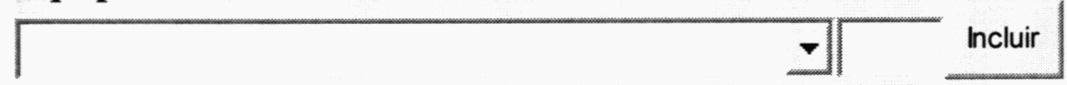

Berço aquecido calor irradiante Fanem AQ-50 10 th

Berço comum 10 筞




\begin{tabular}{|c|c|}
\hline & - Incluir \\
\hline Área de recepção de paciente com passa maca & $\operatorname{sim}$ \\
\hline Área de Escovação & $\operatorname{sim}$ \\
\hline Posto de Enfermagem e Serviços & $\operatorname{sim}$ \\
\hline Vestiários com sanitários para funcionários com barreira & $\operatorname{sim}$ \\
\hline Sala de preparo de equipamentos e material & $\operatorname{sim}$ \\
\hline Depósito de equipamentos e materiais & $\operatorname{sim}$ \\
\hline Sala administrativa & $\operatorname{sim}$ \\
\hline Depósito de Material de Limpeza & $\operatorname{sim}$ \\
\hline Sala de estar para funcionários & $\operatorname{sim}$ \\
\hline Sala de Espera com sanitário para acompanhantes & $\operatorname{sim}$ \\
\hline Área para guarda de macas e cadeira de rodas & $\operatorname{sim}$ \\
\hline Sala de Biópsia de congelação(Anatomia Patológica) & $\operatorname{sim}$ \\
\hline Fluxos pacientes/funcionários por entradas diferentes & $\operatorname{sim}$ \\
\hline Há Sala de Conforto Médico no Centro Cirúrgico & $\operatorname{sim}$ \\
\hline 02 bicos de oxigênio/sala & $\operatorname{sim}$ \\
\hline 02 bicos de ar comprimido/sala & $\operatorname{sim}$ \\
\hline 02 bicos de vácuo/sala & $\operatorname{sim}$ \\
\hline
\end{tabular}




\section{Centro Cirúrgico/Salas}

\begin{tabular}{|c|c|c|c|}
\hline 1 & $\nabla$ Incluir & & \\
\hline Sala & Tamanho & Equips. & Excluir \\
\hline 01 & Grande & $\lambda$ & . \\
\hline 02 & Média & $\lambda$ & . \\
\hline 03 & Média & $\lambda$ & 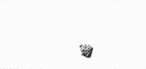 \\
\hline 04 & Pequena & $\lambda$ & . \\
\hline 05 & Pequena & $\lambda$ & की \\
\hline 06 & Pequena & $\lambda$ & 9 \\
\hline 07 & Grande & $\lambda$ & 9 \\
\hline 08 & Média & $\lambda$ & 9 \\
\hline 09 & Média & $\lambda$ & 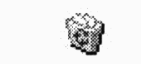 \\
\hline 10 & Pequena & $\lambda$ & 9 \\
\hline 11 & Média & $\lambda$ & 9 \\
\hline 12 & Grande & $\lambda$ & g \\
\hline 13 & Média & $\lambda$ & (2) \\
\hline 14 & Grande & $\lambda$ & gु \\
\hline 15 & Especial & $\lambda$ & 行 \\
\hline 16 & Grande & $\lambda$ & 9 \\
\hline 17 & Pequena & $\lambda$ & (iv \\
\hline 18 & Grande & $\lambda$ & (9) \\
\hline 19 & Especial & $\lambda$ & 4 \\
\hline 20 & Média & $\lambda$ & 9 \\
\hline 21 & Média & $\lambda$ & 9 \\
\hline Recuperação & Grande & $\lambda$ & 约 \\
\hline Reserva & Grande & $\lambda$ & 8 \\
\hline
\end{tabular}


Centro Cirúrgico

Sala: 01

Equipamentos

प Incluir

Carrinho de anestesia Takaoka Samurai III 1 s

Microscópio cirúrgico Zeiss $\quad$ S5 1 (2)

Microscópio neurocirúrgico

Kaps

18

Vitreótomo

Phaco

Lâmpada de fenda Xenomio

1 过

Cadeira Odontológica Atlante

1 )

Monitor FC + ECG

Dixtal

1 ह

Bisturi elétrico

Deltronix B-6600 A 1 的

\section{Centro Cirúrgico}

Sala: 02

Equipamentos

\begin{tabular}{cccc|}
\hline & & \\
Carrinho de anestesia & Takaoka & Samurai III & 1 \\
Oxímetro & Dixtal & DX 2405 & 1 \\
Monitor FC + ECG & Dixtal & 920 & 1 \\
Monitor de PANI & Dixtal & DX2710 & 1 \\
Microscópio cirúrgico & DFVasconcellos & MC M32 & 1 \\
Bisturi elétrico & Deltronix & B-6600 A & 1
\end{tabular}

\section{Centro Cirúrgico}

Sala: 03

Equipamentos

\begin{tabular}{|c|c|c|c|c|}
\hline & & & 7 & \\
\hline Carrinho de anestesia & Takaoka & Samurai III & 1 & 20 \\
\hline Oxímetro & Dixtal & DX 2405 & 1 & 4 \\
\hline Monitor FC + ECG & Dixtal & 920 & 1 & 28 \\
\hline Monitor de PANI & Dixtal & DX2710 & 1 & (2) \\
\hline Microscópio cirúrgico & Kaps & & 1 & 8 \\
\hline Bisturi elétrico & Deltronix & B-6600 S & 1 & 8 \\
\hline
\end{tabular}


Centro Cirúrgico

Sala: 04

Equipamentos

\begin{tabular}{ccccc}
\hline & & & \\
Carrinho de anestesia & Takaoka & Origami & 1 \\
Oxímetro & Dixtal & DX 2405 & 1 \\
Monitor de PANI & Dixtal & DX2710 & 1 \\
Monitor FC + ECG & Dixtal & 920 & 1 \\
Bisturi elétrico & WEM & SS-501 & 1 \\
Microscópio cirúrgico & DFVasconcellos & MC M32 & 1
\end{tabular}

Centro Cirúrgico

Sala: 05

Equipamentos

\begin{tabular}{|ccccc|c|}
\hline & & & & \\
Carrinho de anestesia & Takaoka & 674 & 1 & Incluir \\
Oxímetro & Dixtal & DX 2405 & 1 & \\
Monitor de PANI & Dixtal & DX2710 & 1 & \\
Monitor FC + ECG & Dixtal & 920 & 1 & \\
Bisturi elétrico & Deltronix & B-6600 S & 1 &
\end{tabular}

Centro Cirúrgico

Sala: 06

Equipamentos

\begin{tabular}{|c|c|c|}
\hline & 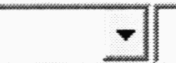 & Incluir \\
\hline Carrinho de anestesia & Takaoka & Fuji \\
\hline Monitor FC + ECG + PANI + oxímetro & Dixtal & DX2010 \\
\hline Bisturi elétrico & Deltronix & B-6600 A \\
\hline
\end{tabular}


Centro Cirúrgico

Sala: 07

Equipamentos

\begin{tabular}{ccccc}
\hline Carrinho de anestesia & Takaoka & 674 & 1 \\
Monitor FC + ECG + PANI + oxímetro & Dixtal & DX2010 & 1 \\
Bisturi elétrico & Deltronix & B-6600 S & 1 \\
Balança digital & Filizola & BPIS & 1 \\
Lipoaspirador & All Cap & & 1 \\
Microscópio cirúrgico & DFVasconcellos MC-M92 & 1 \\
Microscópio cirúrgico & Kaps & 1
\end{tabular}

Centro Cirúrgico

Sala: 08

Equipamentos

\begin{tabular}{ccccc}
\hline Carrinho de anestesia & Takaoka & Origami & 1 \\
Monitor de FC + oxímetro + PANI & Tatung & TMD-100B & 1 \\
Monitor FC + oxicapnógrafo + PANI & Dixtal & DX2010 & 1 \\
Bisturi elétrico & WEM & SS-501 & 1 \\
Videolaparoscópio & Storz & 1 & 1 \\
Videohisteroscópio & Storz & 1
\end{tabular}

Centro Cirúrgico

Sala: 09

Equipamentos

\begin{tabular}{|c|c|c|c|}
\hline & 7 & Incluir & \\
\hline Carrinho de anestesia & Takaoka & Fuji & \\
\hline Monitor de FC + oxímetro + PANI & Tatung & TMD-100B & 1 \\
\hline Monitor FC + oxicapnógrafo + PANI & Dixtal & DX2010 & 1 \\
\hline Bisturi elétrico & Valley Lab & Force 2 & \\
\hline Videolaparoscópio & Storz & & \\
\hline
\end{tabular}




\section{Centro Cirúrgico}

Sala: 10

Equipamentos

\begin{tabular}{|ccccc|}
\hline & & & & \\
Carrinho de anestesia & Takaoka & Origami & 1 \\
Oxímetro & Dixtal & DX 2405 & 1 & \\
Monitor FC + ECG & Dixtal & 920 & 1 & \\
Monitor de PANI & Dixtal & DX2710 & 1 & \\
Bisturi elétrico & Deltronix & B-6600 A & 1
\end{tabular}

\section{Centro Cirúrgico}

Sala: 11

Equipamentos

\begin{tabular}{|c|c|c|c|}
\hline & & - & Incluir \\
\hline Carrinho de anestesia & Takaoka & Origami & (4) \\
\hline Monitor multiparâmetro & Dixtal & DX2010 & 9 \\
\hline Bisturi elétrico & WEM & SS-501 & 8 \\
\hline
\end{tabular}

\section{Centro Cirúrgico}

Sala: 12

Equipamentos

\begin{tabular}{ccccc}
\hline & & & Incluir \\
\cline { 3 - 5 } Carrinho de anestesia & Takaoka & 674 & 1 \\
Monitor multiparâmetro & Dixtal & DX2010 & 1 \\
Bisturi elétrico & Deltronix & B-6600 S & 1 \\
Videolaparoscópio & Storz & Calcusplit & 1 \\
$\begin{array}{c}\text { Monitor de FC + oxímetro }+ \\
\text { PANI }\end{array}$ & Tatung & TMD-100B & 1
\end{tabular}


Centro Cirúrgico

Sala: 13

Equipamentos

\begin{tabular}{|cccc|}
\hline Carrinho de anestesia & Ohmeda & Datex Aestiva 3000 & 1 \\
Monitor multiparâmetro & Dixtal & DX2010 & 1 \\
Bisturi elétrico & Deltronix & B-6600 S & 1
\end{tabular}

\section{Centro Cirúrgico}

Sala: 14

\section{Equipamentos}

\begin{tabular}{|ccccc}
\hline & & & \\
& & & \\
Carrinho de anestesia & Takaoka & Shogun Pró & 1 \\
Monitor multiparâmetro & Dixtal & DX2010 & 1 \\
Bisturi elétrico & Valley Lab & Force 2 & 1 \\
Colchão térmico & Gaymar Med & Therm II & 1 \\
Desfibrilador & FAJ & FAJ 200 & 1 \\
Bomba de CEC & Braile & BEC 2000 & 1 \\
Foco de luz frontal de cabeça & Kom Lux & & 1
\end{tabular}

\section{Centro Cirúrgico}

Sala: 15

Equipamentos

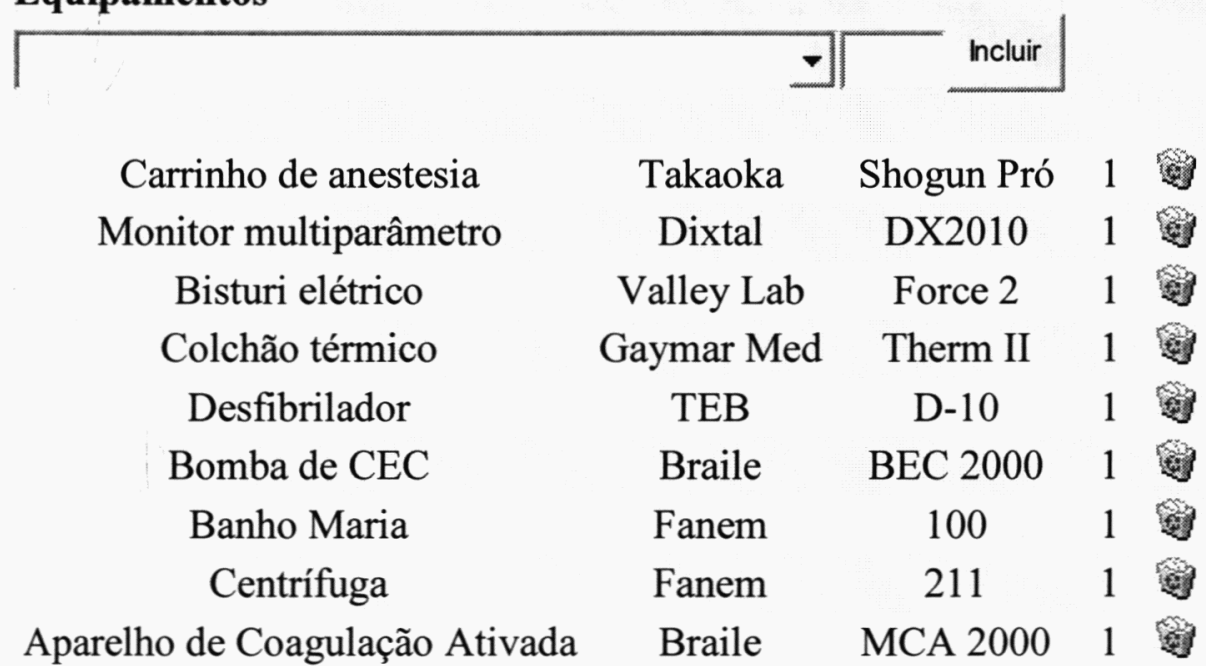




\section{Centro Cirúrgico}

\section{Sala: 16}

\section{Equipamentos}

\begin{tabular}{|c|c|c|c|}
\hline & & Incluir & \\
\hline Carrinho de anestesia & Takaoka & Shogun Pró & 1 \\
\hline Monitor multiparâmetro & Dixtal & DX2010 & 1 \\
\hline Bisturi elétrico & Valley Lab & Force 2 & 1 \\
\hline Colchão térmico & Gaymar Med & Therm II & 1 \\
\hline Desfibrilador & TEB & D-10 & 1 \\
\hline Bomba de CEC & Braile & BEC 2000 & 1 \\
\hline
\end{tabular}

Centro Cirúrgico

Sala: 17

\section{Equipamentos}

\begin{tabular}{ccccc}
\hline Carrinho de anestesia & Takaoka & 674 & 1 & \\
Monitor FC + ECG + PANI + oxímetro & Dixtal & DX2010 & 1 & \\
Bisturi elétrico & Deltronix & B-6600 A & 1 & Incluir \\
Foco auxiliar & & & 1
\end{tabular}

\section{Centro Cirúrgico}

Sala: 18

Equipamentos

\begin{tabular}{|c|c|c|c|}
\hline & & 7 & Incluir \\
\hline Carrinho de anestesia & Takaoka & Fuji & 㮘 \\
\hline Bisturi elétrico & Deltronix & B-6600 A & is \\
\hline Bisturi bipolar & Deltronix & C $200 \mathrm{~T}$ & (2) \\
\hline Monitor multiparâmetro & Dixtal & DX2010 & 1 㻢 \\
\hline
\end{tabular}




\section{Centro Cirúrgico}

Sala: 19

\section{Equipamentos}

\begin{tabular}{|c|c|c|c|}
\hline & 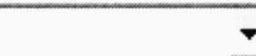 & Incluir & \\
\hline Carrinho de anestesia & Ohmeda & Modulus SE & 1 \\
\hline Aparelho de Autotransfusão & Fresenius & C.A.T.S. & 1 \\
\hline Banho Maria & Fanem & 146 & 1 \\
\hline Foco auxiliar & & & 1 \\
\hline Capnógrafo & Dixtal & DX7100 & 1 \\
\hline Colchão térmico & Gaymar Med & Therm II & 1 \\
\hline Desfibrilador & FAJ & FAJ 200 & 1 \\
\hline Monitor multiparâmetro & HP & 685 & 1 \\
\hline Oxímetro & Dixtal & DX 2405 & 1 \\
\hline Monitor de PANI & Dixtal & DX2710 & 1 \\
\hline Bisturi elétrico & Valley Lab & Force 2 & 1 \\
\hline Bisturi Argônio & Valley Lab & force argon & 1 \\
\hline Aspirador ultrasônico & Cusa & System 200 & 1 \\
\hline Pressurizador & Ranger & 90032 & 1 \\
\hline
\end{tabular}

\section{Centro Cirúrgico}

Sala: 20

\section{Equipamentos}

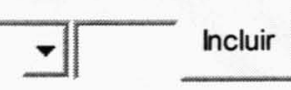

$\begin{array}{ccccc}\text { Carrinho de anestesia } & \text { Ohmeda } & \text { Modulus SE } & 1 \\ \text { Monitor de FC + oxímetro + PANI } & \text { Tatung } & \text { TMD-100B } & 1 \\ \text { Monitor multiparâmetro } & \text { Dixtal } & \text { DX2010 } & 1 \\ \text { Bisturi elétrico } & \text { Valley Lab } & \text { Force 2 } & 1 \\ \text { Microscópio cirúrgico } & \text { Olympus } & \text { OME-5000 } & 1 \\ \text { Microscópio cirúrgico } & \text { DFVasconcellos } & \text { MC-M92 } & 1\end{array}$


Centro Cirúrgico

Sala: 21

Equipamentos

\begin{tabular}{|c|c|c|c|}
\hline & & $\nabla$ & Incluir \\
\hline Carrinho de anestesia & Takaoka & Samurai III & 1 \\
\hline Oxímetro & Dixtal & DX 2405 & 1 \\
\hline Monitor FC + ECG & Dixtal & 920 & 1 \\
\hline Monitor de PANI & Dixtal & DX2710 & 1 \\
\hline Bisturi elétrico & Deltronix & B-6600 S & 1 \\
\hline
\end{tabular}

Centro Cirúrgico

Sala: Recuperação

Equipamentos

\begin{tabular}{|cccc|}
\hline & & & \\
\cline { 3 - 4 } Monitor de PANI & Dixtal & $\mathrm{DX} 2710$ & 2 \\
Monitor FC + ECG & Dixtal & 920 & 8 \\
Desfibrilador & TEB & $\mathrm{D}-10$ & 1 \\
Oxímetro & Dixtal & DX2405Oxypleth & 12 \\
Respirador & Intermed & Inter 5 & 2
\end{tabular}

\section{Centro Cirúrgico}

Sala: Reserva

Equipamentos

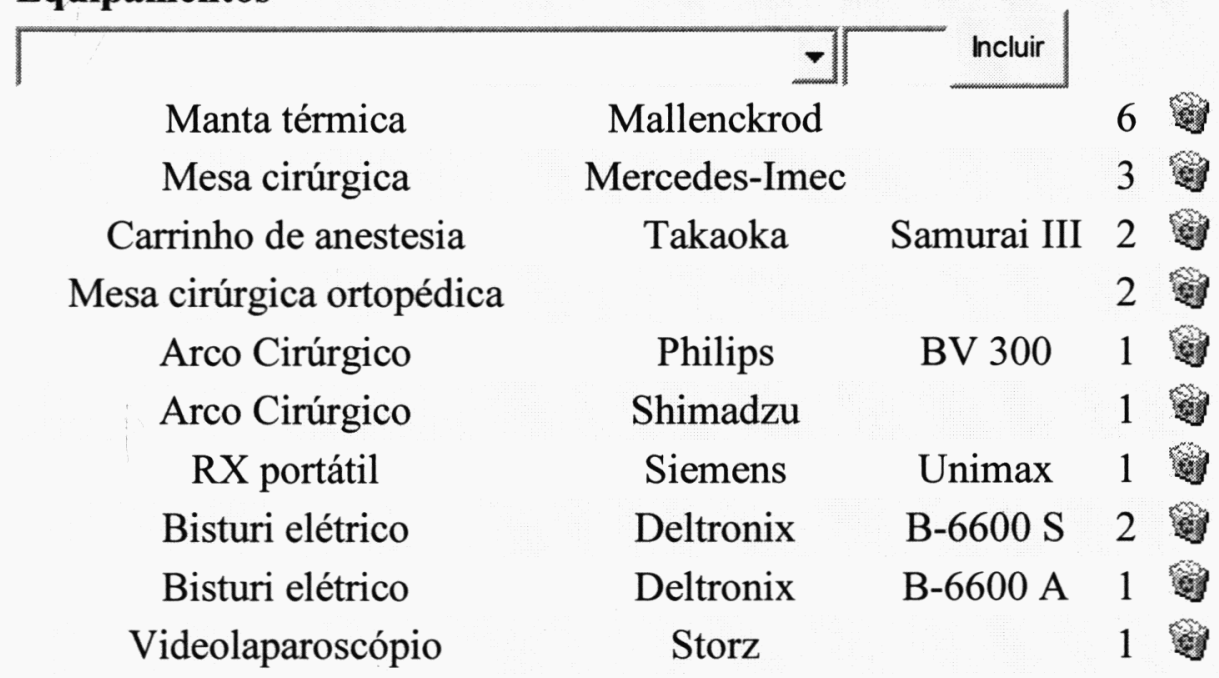




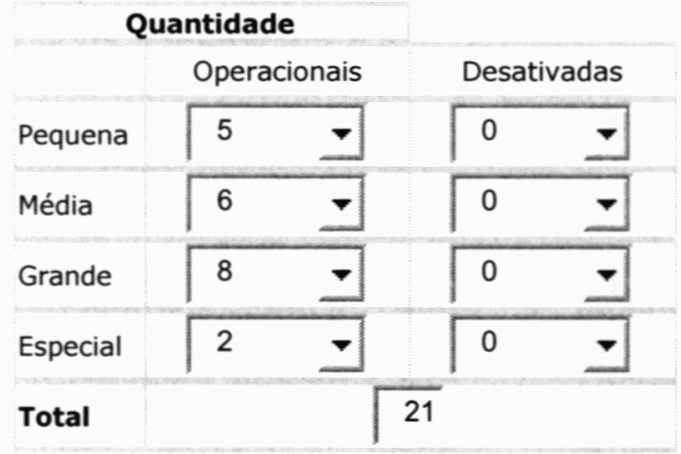

\section{RPA}

$\begin{array}{ccc}\text { Área Física } & \text { Incluir } \\ \mathrm{RH} & \mathrm{sim} \\ \text { Desfibrilador } & \mathrm{sim} & \mathrm{sim} \\ \text { Monitor de FC } & \mathrm{sim} & \mathrm{sim} \\ \text { Oxímetro } & \mathrm{sim} & \end{array}$


Apoio Diagnóstico e Terapia

\section{SADT}

Incluir

\begin{tabular}{|c|c|c|c|}
\hline Patologia Clínica & $\operatorname{sim}$ & Aparelhos & adequados \\
\hline Anatomia Patológica & $\operatorname{sim}$ & Aparelhos & adequados \\
\hline $\mathrm{ECG}$ & $\operatorname{sim}$ & Aparelhos & adequados \\
\hline $\mathrm{RX}$ & $\operatorname{sim}$ & com seriógrafo & $\operatorname{sim}$ \\
\hline USG & $\operatorname{sim}$ & & \\
\hline Hemoterapia & $\operatorname{sim}$ & onforme Legislação & $\operatorname{sim}$ \\
\hline
\end{tabular}




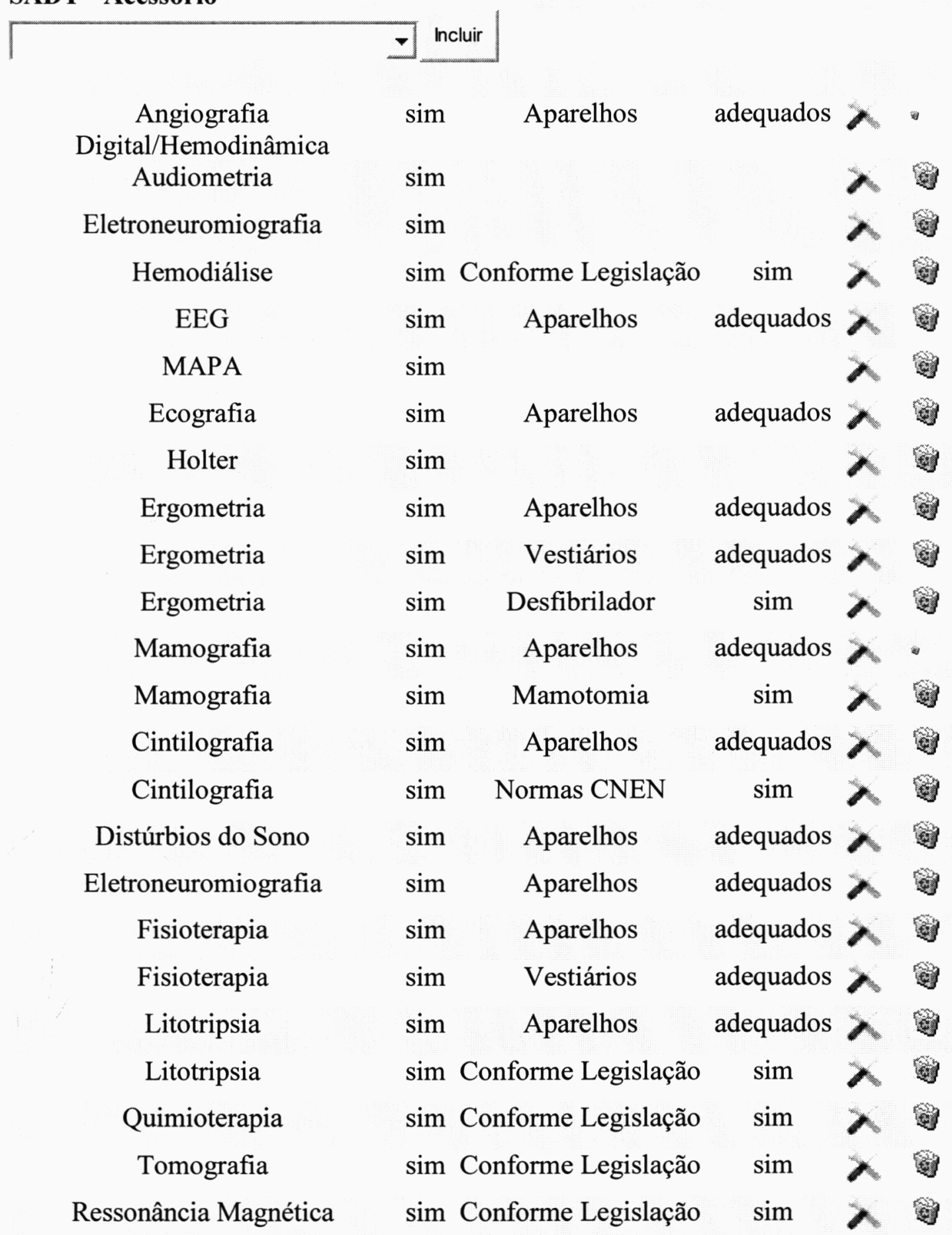




\section{Equipamentos Patologia Clínica}

\begin{tabular}{|c|c|c|c|}
\hline & $\nabla$ & Incluir & \\
\hline Hematologia & Pentra & 60 Plus ABX & 1. \\
\hline Hematologia & Coulter & 890 & 1 \\
\hline Hematologia & Sysmex & 400 & 1 \\
\hline Coagulação & Dade Behring & DXT & 1 \\
\hline Microhematócrito & & & 1 \\
\hline Espectrofotômetro & Espectra & & 1 \\
\hline Bioquímica & COBAS & Mira & 1 \\
\hline Bioquímica & Radiometer & ABL 700 & 1 \\
\hline Eletrólitos $\mathrm{Na}, \mathrm{K} \mathrm{e} \mathrm{Ca}$ & AVL & 9180 electrolyte & 1 \\
\hline Eletrólitos $\mathrm{Na}, \mathrm{K}, \mathrm{Ca}$ e $\mathrm{Cl}$ & Omni & & 1 \\
\hline Eletrólitos $\mathrm{Na}, \mathrm{K}, \mathrm{Ca}$ e $\mathrm{Cl}$ & Hitachi & Automatic analyser & 1 \\
\hline Hemogasômetro & AVL & Compact 2 & 1 \\
\hline Hemogasômetro & Radiometer & ABL 5 & 1 \\
\hline Sorologia & Behring & Mefilometro 100 & 1 \\
\hline Sorologia & Behring & Opus 6 & 1 \\
\hline Leitora de ELISA & Sorin & & 1 \\
\hline Leitora de ELISA & Bartels & & 1 \\
\hline ELISA & Roche & Elecsys & 1 \\
\hline ELISA & Organon & Tectwrel & 1 \\
\hline Radioimunoensaio & Abbott & & 1 \\
\hline Rast & Pharmacia & Unicap 100 & 1 \\
\hline Leitora de Proteína & CELM & DS 35 & 1 \\
\hline Leitora de Proteína & Sunrise & & 1 \\
\hline Microbiologia & Bio Mérieux & Mini API & 1 \\
\hline Cintilador líquido & Packard & & 1 \\
\hline Osmômetro & Fiske Mark & & 1 \\
\hline Espectrofotômetro & CELM & & 1 \\
\hline Microanalisador & & & 1 \\
\hline Cromatógrafo gasoso & & & 1 \\
\hline
\end{tabular}


Equipamentos ECG

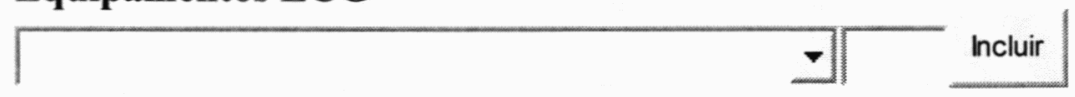

ECG Dixtal EP $3 \quad 1$

\section{Equipamentos RX}

\begin{tabular}{|clcc|}
\hline & & & \\
RX com seriógrafo & Philips & Super $80 \mathrm{CP}$ & 1 \\
RX com seriógrafo & Philips & $80 \mathrm{CP}$ & 1 \\
RX & Philips & Challenge Super $80 \mathrm{CT}$ & 1 \\
Reveladora & Imation & & 1 \\
Reveladora & Kodak & RPX omat & 2
\end{tabular}

\section{Equipamentos USG}

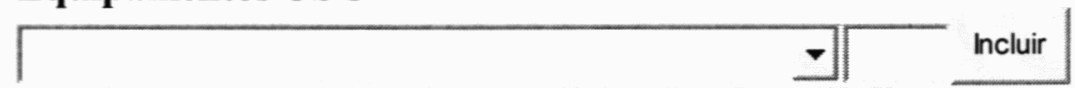

$\begin{array}{ccccc}\text { USG } & \text { ATL } & \text { HTI } & 1 \\ \text { USG com Doppler e 3D } & \text { Philips } & \text { SD 800 } & 1 \\ \text { USG } & \text { GE } & \text { Logiq 200 } & 1 \\ \text { USG } & \text { GE } & \text { Logiq 100 } & 1 \\ \text { USG com scan Vascular } & \text { Toshiba } & \text { Sonolayer } & 1\end{array}$

\section{Equipamentos Angiografia/Hemodinâmica}

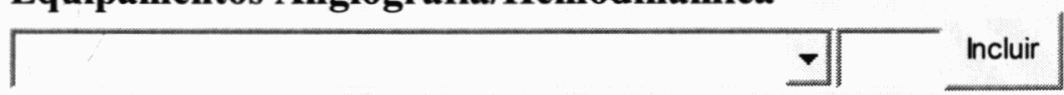

Angiografia Digital Philips Integris 1

Hemodinâmica Shimadzu Digitex 24001 웡

\section{Equipamentos Audiometria}

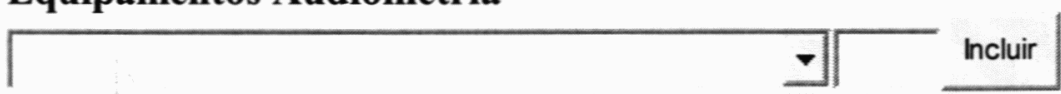

Potencial evocado - BERA

1 解 
Equipamentos Hemodiálise

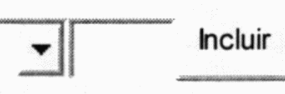

Máquina de Hemodiálise Fresenius

31

Equipamentos EEG

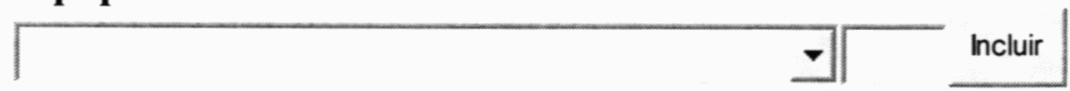

$\begin{array}{lllll}\text { EEG } & \text { Dantec } & \text { Cantata } & 1 \\ \text { EEG } & \text { Berger } & \text { TP119 } & 2\end{array}$

Potencial Evocado + EEG Nikon Kohda Neuro fax 1

Equipamentos Eco

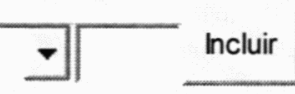

Ecocardiógrafo ATL c/scan vascular e doppler

Equipamentos MAPA

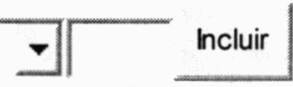

MAPA SpaceLab 4 嗮

Equipamentos Holter

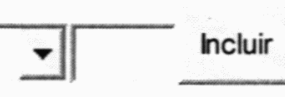

Holter Dynamis

9 铇

'quipamentos Ergometria

Ergometria Inbramed $1020 \quad 2$ Incluir

quipamentos Ergometria

)esfibrilador EMAI $\quad \mathrm{DX}-10$ Incluir

quipamentos Mamografia

\begin{tabular}{ccccc|c|c}
\hline $\begin{array}{ccc}\text { Mamógrafo } \\
\text { Tamógrafo com mamotomia }\end{array}$ & GE & Senographe DMR & 1
\end{tabular}


Equipamentos Tomografia

चा Incluir

Tomografia convencional Shimadzu SCT $300 \mathrm{TE} 1$

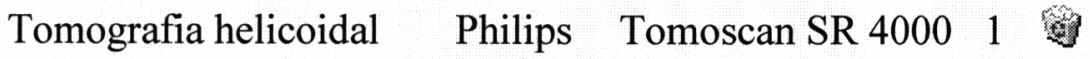

\section{Equipamentos Ressonância Magnética}

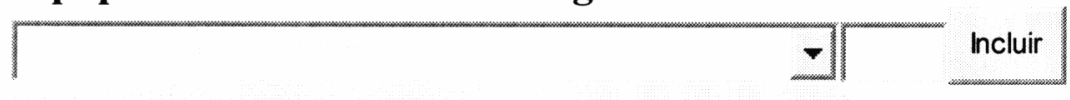

Ressonância Magnética Philips Integris 1 ? 


\section{Apoio Técnico e Administrativo}

\section{Farmácia}

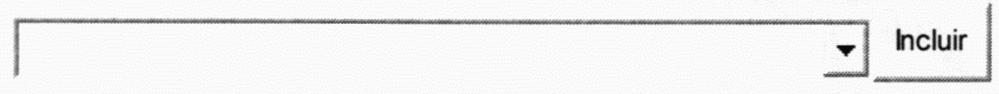

Há controle dos medicamentos Port 344

A farmácia manipula NPP

$\begin{array}{ccc}\operatorname{sim} & 0 \\ \text { não } & 0 \\ \text { não } & 0 \\ \operatorname{sim} & 0 \\ \operatorname{sim} & \text { Quantos } \\ \text { sim } & 3 \\ \text { Individualizada } & 0\end{array}$

Há capela de fluxo laminar

Há local adequado para dispensação

Há farmacêutico no local

Há padronização de medicamentos

Dispensação

Individualizada

0 近

SND

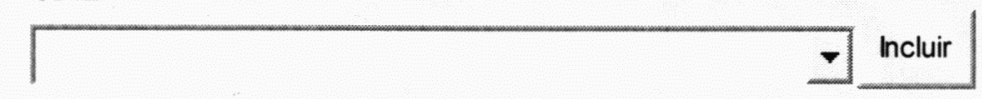

Circulação adequada

$\operatorname{sim}$

0 迎

Equipamentos necessários e conservados

$\operatorname{sim}$

0 解

Área adequada com boa iluminação e aeração

$\operatorname{sim}$

0 웡

Existe bancada para manipulação dos alimentos

$\operatorname{sim}$

0 的

Há cardápio afixado

$\operatorname{sim}$

0 近

Há Nutricionista

$\operatorname{sim}$

Quantas

4 制

\section{Limpeza/Higiene}

Incluir

Há normas e rotinas para limpeza da unidade sim

Utilizam produtos próprios para limpeza sim

A CCIH participa na elaboração de normas do setor sim

Há coleta seletiva do lixo sim

Funcionários utilizam equipamentos de proteção sim 


\section{Lavanderia}

\begin{tabular}{cc}
\hline Máquina de lavar modelo profissional & sim \\
Centrífugas apropriadas & $\operatorname{sim}$ \\
Calandras & $\operatorname{sim}$ \\
Há barreiras físicas & $\operatorname{sim}$ \\
Há cruzamento limpo/contaminado & $\operatorname{sim}$ \\
Área física apropriada & não \\
Equipamentos em boas condições & $\operatorname{sim}$ \\
Funcionários com equipamentos de proteção & $\operatorname{sim}$ \\
Serviço de Costura/Rouparia & $\operatorname{sim}$
\end{tabular}

\begin{tabular}{|cc|}
\hline Almoxarifado & \\
Área apropriada & $\mathrm{sim}$ \\
Estoques suficientes & $\mathrm{sim}$ \\
Setor informatizado & $\mathrm{sim}$
\end{tabular}

Manưtenção

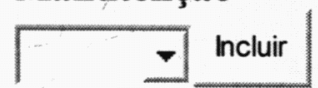

sim Própria

की

\section{Vigilância}

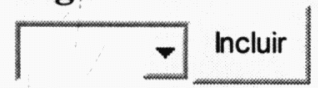

Sim Própria

(2)

SAME sim Informatizado sim

Prontuários conforme Legislação sim 


\section{Central Esterilização}

Central Esterilização:

Encontra-se instalado em área física adequada

Tem área para expurgo do material

Tem área para preparo/esterilização

Tem área para estocagem/distribuição

não
sim
sim
sim
sim
sim
não
sim
não
sim
não

Há enfermeira responsável

Há normatização de procedimentos na área

Há cruzamento de fluxo de circulação entre as áreas

Funcionários paramentados adequadamente

Possui estufas

Possui Autoclave horizontal

Possui Autoclave vertical

Há manutenção preventiva de equipamentos

É utilizado Controle Biológico

\section{Periodicidade}

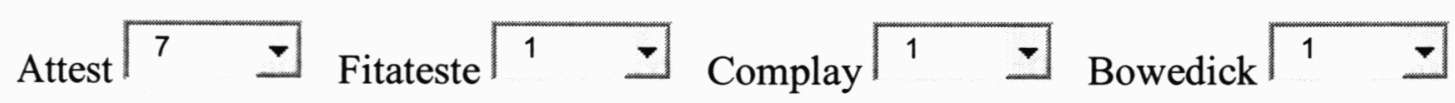




\section{Parecer:}

- Hospital geral filantrópico (Fundação), Universitário, com 700 leitos, sendo 60 para convênios, com nível de atendimento terciário e quaternário. Realiza transplantes: cardíaco, renal, medula óssea, fígado, ossos e córnea.

- Estrutura física: vertical, planejada, com sinalização adequada e em boas condições de higiene e limpeza, iluminação adequada. Com pronto-socorro geral, UTI geral, Cardiológica, Adulto, Pediátrica e Neonatal, Centro Cirúrgico com 21 salas, RPA, Centro Obstétrico, Maternidade, Hemodinâmica, Hemodiálise, Hemocentro, Unidades de Internação.

- Estrutura básica: 03 geradores que dão suporte a todas as áreas críticas, cabine primária de força, central de gases, sistema de prevenção de incêndios com hidrantes e extintores, ar condicionado central, 05 poços artesianos, 12 elevadores, pára-raios e posto de abastecimento de diesel.

- Hotelaria: suítes e apartamentos confortáveis com TV, telefone, frigobar, ar condicionado central, com 01 bico de oxigênio, 01 de ar comprimido e 01 de vácuo. Suítes e apartamentos com pias para lavagem das mãos. Sanitários: portas abrindo para dentro, contrariando a RDC_50/02, com box e barras de apoio. Enfermarias com o mesmo padrão, porém sem telefone. Enfermarias SUS simples.

- Serviços de apoio: farmácia com 03 farmacêuticos, dispensação por sistema individualizado. SND com 04 nutricionistas. Serviço de Limpeza terceirizado para os usuários de convênios. Lavanderia com fluxos incorretos, Serviços de Segurança, Manutenção e Almoxarifado próprios e organizados. Central de Esterilização de Materiais em área pequena para dar suporte às necessidades, em fase inicial de reforma e ampliação.

- SADT: Anatomia Patológica, Angiografia Digital, Audiometria, Cintilografia, ECG, EEG, Eletromiografia, Endoscopia, Ergometria, Fisioterapia, Hemodiálise, Hemodinâmica, Hemoterapia, Holter, Litotripsia, Mamografia, Patologia Clínica, Quimioterapia, Ressonância Magnética, RX Simples e Contrastados, Tomografia e USG.

- Organização e funcionamento: Regulamento Interno, Normas, Rotinas, Setor de Recrutamento e Seleção de Pessoal, Programas de Educação Continuada, Indicadores Hospitalares, Relatórios Gerenciais, Informatização em rede, exceto 
o prontuário eletrônico, Serviço Social, Psicologia Hospitalar e Setor de Saúde Ocupacional. Todas as Comissões existentes e funcionantes.

- Recursos Humanos

- Servidores/ leito: 3,93

- Funcionários da Enfermagem/Total de Leitos: 1,55

- Enfermeiros/Leito: 0,19

- Técnicos e Auxiliares de Enfermagem/ Leito: 1,32

- Atendentes/ Leito: 0,03

- Indicadores de Qualidade

- Taxa de Mortalidade Institucional: $0,46 \%$

- Taxa de Cesárea: $89,33 \%$

- Indicadores de Produtividade

- Taxa de Ocupação: $72,36 \%$

- Taxa de Permanência: 3,0 dias

- Giro de Rotatividade: 7,33 pacientes/mês

Parecer: $\mathrm{O}$ Hospital $\mathrm{A}$ apresenta condições para atendimento em nível terciário $\mathrm{e}$ quaternário.

Para tanto deverá:

1. Adequar a Central de Esterilização de Materiais à RDC_50/02.

2. Adequar a Lavanderia à RDC_50/02.

3. Adequar sanitários das enfermarias e apartamentos à RDC_50/02.

4. Implantar sistema de tratamento de resíduos e esgoto.

5. Contratar mais técnicos de enfermagem para alterar a composição da equipe e melhorar a assistência prestada ao paciente.

6. Contratar Recursos Humanos para compor a equipe de enfermagem da UTI.

7. Rever indicações de cesáreas. 


\section{ANEXO 5 - Vistoria Técnica Hospitalar - Hospital B}

\section{Identificação do Estabelecimento}

Nome:

B

Diretor Clínico: CRM:

Data da Vistoria: 23/ janeiro/ 2003

Acompanhantes:

Adrana Valéria Penha

Adrana (secretária da Diretoria)

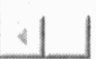

$\mathrm{N}^{\mathrm{o}}$ Total de Leitos:

Total de Leitos Operacionais:

220

$\mathrm{N}^{\mathrm{o}}$ de Leitos Convênio:

\section{Classificação do Estabelecimento}

Tipo de Hospital:

Lista de Especializações:

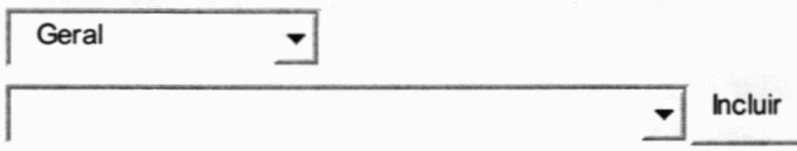

\section{Tipo de Serviço}

Tipo de serviço:

Abrangência do serviço

Abrangência do serviço:

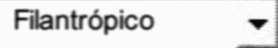

Regional - 
Organização e Funcionamento

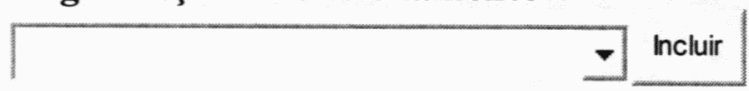

\begin{tabular}{|c|c|c|c|}
\hline Normas e Rotinas e Manuais & $\operatorname{sim}$ & Do conhecimento das partes & $\operatorname{sim}$ \\
\hline Regime Interno/regulamento & $\operatorname{sim}$ & Do conhecimento das partes & $\operatorname{sim}$ \\
\hline Recrutamento e Seleção de Pessoal & $\operatorname{sim}$ & & \\
\hline Programas de Treinamento & $\operatorname{sim}$ & & \\
\hline Educação Continuada & $\operatorname{sim}$ & & \\
\hline Indicadores Hospitalares & $\operatorname{sim}$ & & \\
\hline Relatórios Gerenciais & $\operatorname{sim}$ & & \\
\hline Informatização & $\operatorname{sim}$ & Em Rede & $\operatorname{sim}$ \\
\hline Serviço Social & $\operatorname{sim}$ & & \\
\hline Psicologia Hospitalar & $\operatorname{sim}$ & & \\
\hline Saúde Ocupacional & $\operatorname{sim}$ & & \\
\hline Comissão de Ética Médica & $\operatorname{sim}$ & Reuniões Regulares / Atas & $\operatorname{sim}$ \\
\hline $\mathrm{CCIH}$ & $\operatorname{sim}$ & Reuniões Regulares / Atas & $\operatorname{sim}$ \\
\hline Revisão de Prontuários & $\operatorname{sim}$ & Reuniões Regulares / Atas & não \\
\hline Revisão de Óbitos & $\operatorname{sim}$ & Reuniões Regulares / Atas & não \\
\hline CIPA & $\operatorname{sim}$ & Reuniões Regulares / Atas & $\operatorname{sim}$ \\
\hline Farmácia e Medicamentos & $\operatorname{sim}$ & & \\
\hline Controle e Gestão de Qualidade & $\operatorname{sim}$ & & \\
\hline Ensino e Pesquisa & $\operatorname{sim}$ & & \\
\hline Residência Médica/Pós-Graduação & $\operatorname{sim}$ & & \\
\hline
\end{tabular}


Recursos Humanos de todo o Hospital (Ano de $\sqrt{2003}$ )

Profissionais

Médicos contratados

Enfermeiros

Técnicos de enfermagem

Auxiliares de enfermagem

Atendentes de enfermagem

Outros Funcionários

Total

Quantidade

\begin{tabular}{|l}
66 \\
\hline 29 \\
\hline 56 \\
\hline 307 \\
\hline 05 \\
\hline 676
\end{tabular}

1139

Informações Gerais (Ano de

2002

Levantamento de dados anual

Número de óbitos após 48 horas

Números de saídas (Altas e Óbitos)

Números de óbitos por causas maternas

Número de pacientes atendidos em Obstetrícia

Número de nascidos vivos

Número de nascidos mortos

Número de óbitos neonatais após 48 horas

Número de óbitos operatórios até 10 dias pós-cirurgia

Número de atos cirurgicos

Número de cesáreas

Número de partos normais

Número total de partos

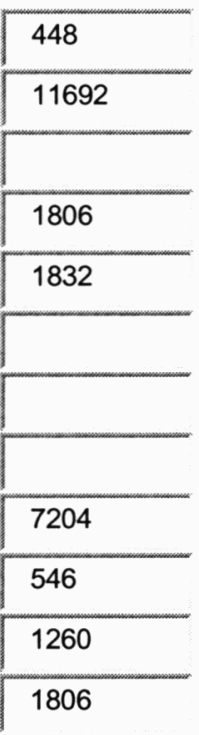

Número de infecções atribuíveis ao hospital

Número de supurações de feridas cirúrgicas em cirurgias limpas

Número de cirurgias limpas do período

Número de pacientes/dia

Número de leitos/dia

Número de leitos disponíveis no período

\begin{tabular}{|l}
\hline 338 \\
\hline 96 \\
\hline 6994 \\
\hline 52156 \\
\hline
\end{tabular}


Indicadores de Qualidade (Ano de $\sqrt{2002}$ )

Taxa de mortalidade institucional

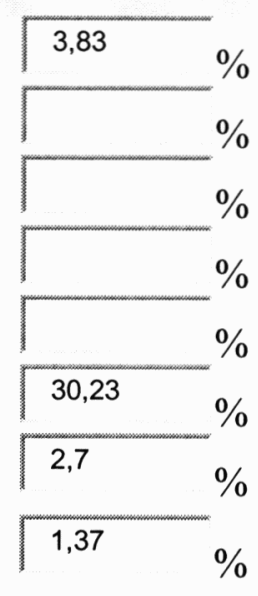

Taxa de mortalidade materna

Taxa de natimortalidade

Taxa de mortalidade neonatal

Taxa de mortalidade operatória

Taxa de cesáreas

Taxa de infecção hospitalar

Taxa de supuração de ferida cirúrgica em cirurgia limpa

Indicadores de produtividade (Ano de $\sqrt{2002}$ )

Taxa de ocupação

Taxa de permanência

Giro de rotatividade

\begin{tabular}{ll}
\hline 64,9 & $\%$ \\
44,46 & dias \\
& vezes
\end{tabular}




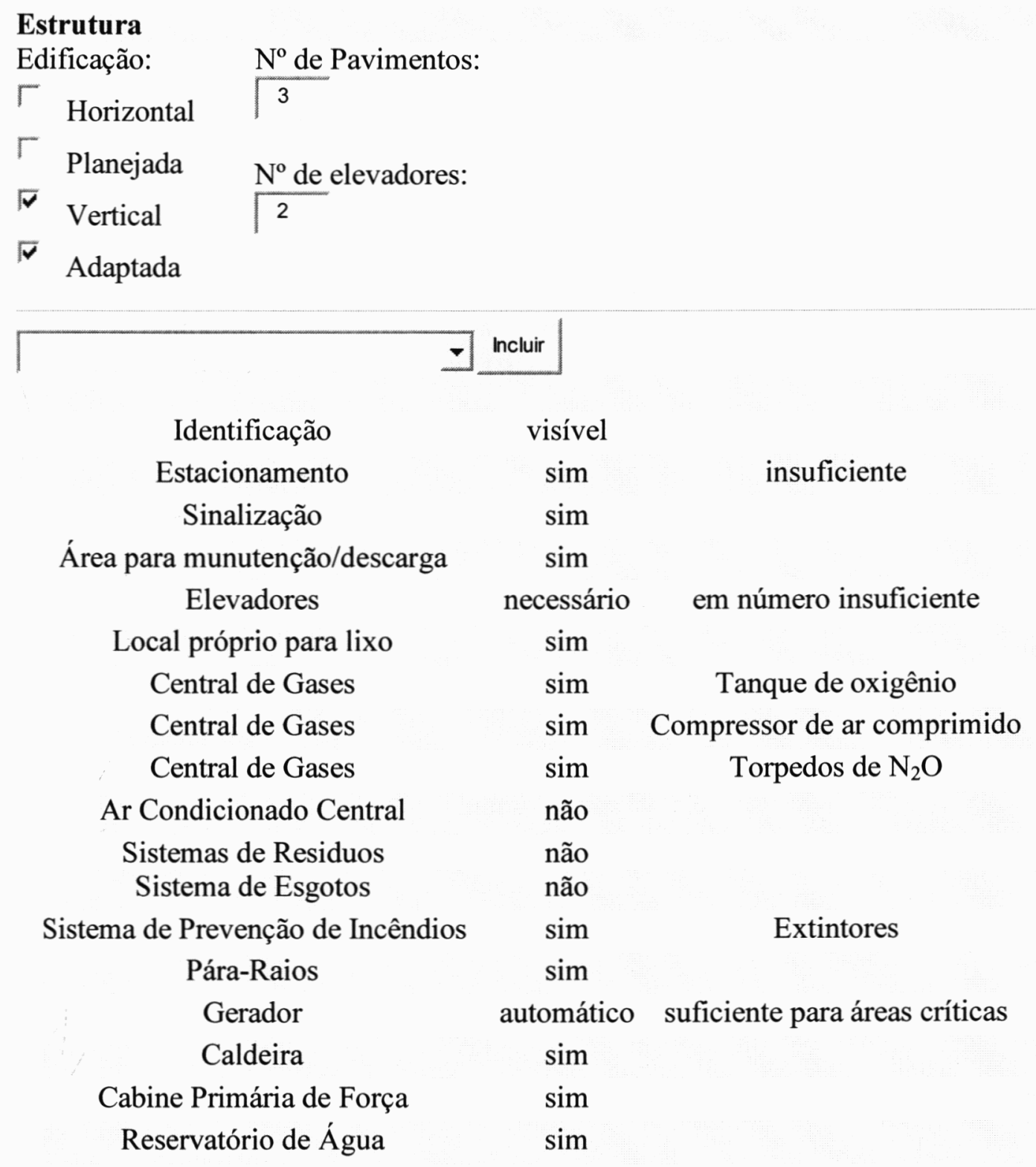


Organização e Atenção ao Paciente

\section{Hotelaria}

\begin{tabular}{|c|c|c|c|c|c|c|}
\hline & - & & & & & \\
\hline Recepção & & Confortável & & & 0 & . \\
\hline Recepção & & Adequada & & & 0 & 。 \\
\hline Recepção & & Sanitários & $\operatorname{sim}$ & cada sexo & 0 & 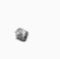 \\
\hline Recepção & & informatizada & $\operatorname{sim}$ & & 0 & . \\
\hline Limpeza & & boa & & & 0 & . \\
\hline Higiene & & boa & & & 0 & 8 \\
\hline Conservação Pre & lial & boa & & & 0 & 3 \\
\hline
\end{tabular}

Unidades de Internação

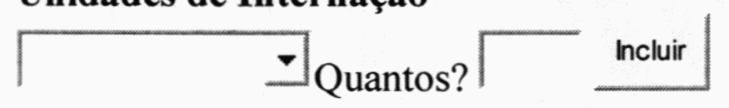

Apartamentos - Quantos?

Carrinho de emergência

Não

Torpedo de oxigênio na unidade

Não

cadeira de descanso

sofá/cama acompanhante

Sanitário

Sanitário

bico de vácuo

bico de ar

bico de oxigênio

telefone

ar condicionado

TV

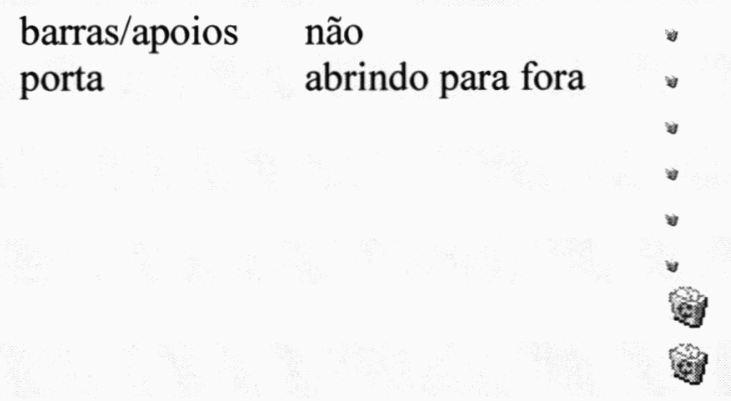

\section{Apartamentos \\ Instalações Hidráulicas \\ Instalações Elétricas \\ Ventilação \\ Iluminação}

Corredores Livres

$\begin{array}{ll}\text { Adequada } & 0 \\ \text { Adequada } & 0 \\ \text { Adequada } & 0 \\ \text { Adequada } & 0 \\ \operatorname{sim} & 0\end{array}$


Enfermaria

$\longrightarrow$ Quantos? Incluir

Enfermarias 2 Leitos - Quantos?

Carrinho de emergência

Não

Torpedo de oxigênio na unidade

Não

Distância mínima entre os leitos cadeira de descanso

Sanitário

Sanitário

bico de vácuo

Barras/Apoios não

Porta

Abrindo para fora

bico de ar

bico de oxigênio

telefone

ar condicionado

TV 


\section{Pronto Socorro}

Tipo:

\begin{tabular}{|c|c|c|c|}
\hline & Incluir & & \\
\hline Tipo & Geral & 0 & $\cdot$ \\
\hline Entrada bem localizada, fácil acesso & $\operatorname{sim}$ & 0 & * \\
\hline Sala exclusiva para urgências & $\operatorname{sim}$ & 0 & * \\
\hline Sala exclusiva para urgências & $N^{\circ}$ de Leitos & 6 & * \\
\hline 1 Bico de Oxigênio/leito & $\operatorname{sim}$ & 0 & $\because$ \\
\hline 1 Ar Comprimido/leito & $\operatorname{sim}$ & 0 & $\because$ \\
\hline 1 Vácuo/leito & $\operatorname{sim}$ & 0 & . \\
\hline Ambulância para remoção & $\operatorname{sim}$ & 0 & v \\
\hline Possui UTI Móvel & $\operatorname{sim}$ & 0 & * \\
\hline Equipe Médica conforme legislação & não & 0 & \% \\
\hline Enfermeira nos turnos & não & 0 & . \\
\hline Medicamentos de urgência & $\operatorname{sim}$ & 0 & * \\
\hline Sala de Inalação & $\operatorname{sim}$ & 0 & \% \\
\hline Sala de curativos & $\operatorname{sim}$ & 0 & . \\
\hline Sala de gesso & $\operatorname{sim}$ & 0 & 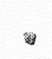 \\
\hline Sala de pequenas cirurgias & $\operatorname{sim}$ & 0 & 㫨 \\
\hline
\end{tabular}

\section{Equipamentos da Urgência}

\begin{tabular}{lllll}
\hline & & & & \\
& & & \\
Desfibrilador & Ecafix & MDF-03 & 2 \\
Oxímetro & Takaoka & & 1 \\
Respirador & Bird & Mark-7 & 1
\end{tabular}

\section{Consultórios:}

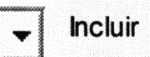

$\begin{array}{lcc}\text { Sim } & \text { Geral } & 0 \\ \text { Sim } & \text { Ortopedia } & 0 \\ \text { Sim } & \text { Psiquiatria } & 0 \\ \text { Sim } & \text { Cardiologia / Cirurgia Cardiovascular } & 0\end{array}$


Outras Salas

\begin{tabular}{lllr}
\hline Sala & Incluir \\
Cirurgia Ambulatorial & Pequena & Equips. Excluir
\end{tabular}

Outras Salas

Sala: Cirurgia Ambulatorial

Equipamentos

-

Mesa cirúrgica Mercedes-Imec 1 g

Bisturi elétrico Deltronix $6500 \quad 1 \quad$ 鞄 


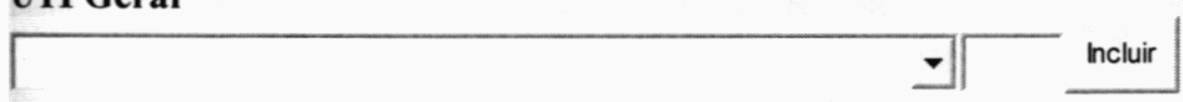

Número de Leitos

01 médico para cada 10 leitos

13.

Há normas e rotinas para a área

A UTI participa da CCIH

Há programas de acompanhamento de visita com orientação

Encontra-se em área física adequada

De acordo com a legislação vigente

0 posto de enfermagem permite boa visão dos leitos

Há boa circulação de funcionários e pacientes

Possui médico diarista

Possui equipe médica em todos os turnos

Equipe de enfermagem treinada e completa

Enfermeira em todos os turnos

Há leitos para isolamento

Quarto para médico plantonista

Área de descanso para enfermagem

2 bicos de oxigênio/leito

1 bico de ar comprimido/leito

1 bico de vácuo/leito

10 tomadas elétricas

$\begin{array}{ll}\text { sim } & 13 \\ \text { sim } & 0 \\ \text { sim } & 0 \\ \text { sim } & 0 \\ \text { não } & 0 \\ \text { não } & 0 \\ \text { não } & 0 \\ \text { sim } & 0 \\ \text { sim } & 0 \\ \text { sim } & 0 \\ \text { sim } & 0 \\ \text { sim } & 0 \\ \text { sim } & 3 \\ \text { sim } & 0 \\ \text { não } & 0 \\ \text { sim } & 0 \\ \text { sim } & 0 \\ \text { sim } & 0 \\ \text { sim } & 0\end{array}$

\section{Equipamentos}

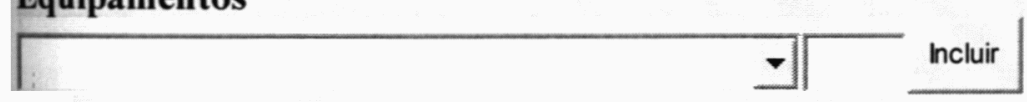

$\begin{array}{cccc}\text { Respirador } & \text { Bird } & 6400 & 4 \\ \text { Respirador } & \text { Intermed } & \text { Inter 5 } & 2 \\ \text { Respirador } & \text { Takaoka } & \text { Monterey } & 3 \\ \text { Monitor de FC + oxímetro + PANI } & \text { Dixtal } & \text { DX2010 } & 7 \\ \text { Monitor multiparâmetro } & \text { Dixtal } & \text { DX2010 } & 1 \\ \text { Bomba de Infusão } & \text { BBraun } & \text { Nutrimat II } & 33 \\ \text { RX portátil } & \text { Philips } & \text { MCD 105 } & 1 \\ \text { Monitor de PIC } & \text { Coleman } & \text { ICP express } & 1 \\ \text { Hemodializador portátil de proporção } & & & 2\end{array}$


Número de Leitos

01 médico para cada 10 leitos

Há normas e rotinas para a área

A UTI participa da CCIH

Há programas de acompanhamento de visita com orientação

Encontra-se em área física adequada

$\begin{array}{ll} & 13 \\ \text { sim } & 0 \\ \text { sim } & 0 \\ \text { sim } & 0 \\ \text { sim } & 0 \\ \text { não } & 0 \\ \text { não } & 0 \\ \text { não } & 0 \\ \text { sim } & 0 \\ \text { sim } & 0 \\ \text { sim } & 0 \\ \text { sim } & 0 \\ \text { sim } & 0 \\ \text { sim } & 1 \\ \text { sim } & 0 \\ \text { não } & 0 \\ \text { sim } & 0 \\ \text { sim } & 0 \\ \text { sim } & 0 \\ \text { sim } & 0\end{array}$

De acordo com a legislação vigente

$\mathrm{O}$ posto de enfermagem permite boa visão dos leitos

Há boa circulação de funcionários e pacientes

Possui médico diarista

Possui equipe médica em todos os turnos

Equipe de enfermagem treinada e completa

Enfermeira em todos os turnos

Há leitos para isolamento

Quarto para médico plantonista

Área de descanso para enfermagem

2 bicos de oxigênio/leito

1 bico de ar comprimido/leito

1 bico de vácuo/leito

10 tomadas elétricas

\section{Equipamentos}

\begin{tabular}{|cccc}
\hline & & \\
Monitor multiparâmetro & Dixtal & DX2010 & 4 \\
Monitor FC + ECG + PANI + oxímetro & Dixtal & DX2010 & 13 \\
Bomba de Infusão & BBraun & Infusomat & 20 \\
Desfibrilador & Marquette & Cardioserv & 1 \\
Respirador & Bird & 6400 & 2 \\
Respirador & Intermed & Inter 5 & 2 \\
Respirador & Takaoka & Monterey & 2 \\
Balão Intra-Aórtico & Kontron & 7000 & 1 \\
ECG & Dixtal & EP 3 & 1
\end{tabular}




\section{UTI Neonatal}

\section{Incluir}

Número de Leitos

01 médico para cada 10 leitos

Há normas e rotinas para a área

$\operatorname{sim}$

A UTI participa da CCIH

Há programas de acompanhamento de visita com orientação

Encontra-se em área física adequada

De acordo com a legislação vigente

$O$ posto de enfermagem permite boa visão dos leitos

$\operatorname{sim}$

$0 \%$

$\operatorname{sim} \quad 0$.

$\operatorname{sim} \quad 0$ \&

$\operatorname{sim} \quad 0$

$\operatorname{sim} \quad 0$.

Há boa circulação de funcionários e pacientes

$\operatorname{sim} \quad 0$.

Possui médico diarista

Possui equipe médica em todos os turnos

Equipe de enfermagem treinada e completa

Enfermeira em todos os turnos

2 bicos de oxigênio/leito

1 bico de ar comprimido/leito

1 bico de vácuo/leito

10 tomadas elétricas

Há leitos para isolamento

$\operatorname{sim} \quad 0$.

$\operatorname{sim} \quad 0$.

$\operatorname{sim} \quad 0$.

$\operatorname{sim} \quad 0$.

$\operatorname{sim} \quad 0$.

$\operatorname{sim} \quad 0$.

$\operatorname{sim} \quad 0$.

$\operatorname{sim} \quad 0$.

$\operatorname{sim} \quad 0$.

não $\quad 0$ \& 


\begin{tabular}{|c|c|c|c|c|}
\hline & $\nabla$ & Incluir & & \\
\hline Bomba de Infusão & BBraun & Nutrimat II & 15 & \\
\hline Bomba de infusão por seringa & BBraun & Perfusor Compact & 3 & - \\
\hline Berço aquecido calor irradiante & Fanem & AQ-50 & 5 & 。 \\
\hline Berço aquecido calor irradiante & Fanem & BA-51 TS & 1 & - \\
\hline Berço aquecido por insuflação & Olidef CZ & & 2 & 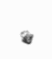 \\
\hline Bilispot & Olidef CZ & & 2 & . \\
\hline Bilispot & Hosp Serv & & 2 & . \\
\hline Biliberço & Olidef CZ & & 4 & 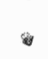 \\
\hline Oxímetro & Ecafix & Active & 1 & \% \\
\hline Oxímetro & Dixtal & DX 2515 & 4 & 。 \\
\hline Oxímetro & Takaoka & $9504 / 0 x$ & 5 & 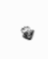 \\
\hline Respirador & Intermed & Inter 3 & 8 & . \\
\hline Respirador & Intermed & Inter 5 & 2 & 。 \\
\hline Capnógrafo & Dixtal & DX1265 & 1 & . \\
\hline Monitor FC + oxímetro & Dixtal & DX2010 & 4 & - \\
\hline Monitor FC + ECG & Dixtal & 5DM 2000 & 1 & . \\
\hline Desfibrilador & EMAI & DX-10 & 1 & 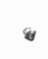 \\
\hline Incubadora & Olidef CZ & SCTILine 3 & 6 & 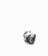 \\
\hline Incubadora & Hosp Serv & DSI-2000 & 3 & 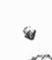 \\
\hline Incubadora & Fanem & C186-TS/ST & 1 & 究 \\
\hline Incubadora de Transporte & Olidef CZ & & 1 & 远 \\
\hline
\end{tabular}




$\begin{array}{cc}\text { Tem sala de admissão } & \text { não } \\ \text { Sala/leitos de pré-parto } & \text { sim } \\ \text { Sala de parto normal } & \text { sim } \\ \text { Sala de parto cirúrgico } & \text { sim } \\ \text { Vestiário com sanitário para ambos os sexos } & \text { não } \\ \text { Sala de estar e repouso para funcionários e médicos } & \text { sim } \\ \text { Recuperação pós-anestésica (RPA) } & \text { não } \\ \text { O parto é realizado por: } & \text { Médico } \\ \text { Há disponibilidade de médico obstetra no local durante 24 horas } & \text { sim } \\ \text { O neonatologista recepciona todos os RNs } & \text { sim } \\ \text { Há neonatologista no local durante 24 horas } & \text { sim } \\ \text { Há disponibilidade de anestesista durante 24 horas } & \text { sim } \\ \text { Há sala de reanimação e identificação do RN } & \text { não } \\ \text { Há pia com água corrente na sala de reanimação } & \text { não } \\ 1 \text { bico de oxigênio/sala } & \text { sim } \\ 1 \text { bico de ar comprimido/sala } & \text { sim } \\ 1 \text { bico de vácuo/sala } & \text { sim } \\ \text { Torpedo de oxigênio } & \text { não } \\ \text { aspirador elétrico } & \text { não }\end{array}$

Salas

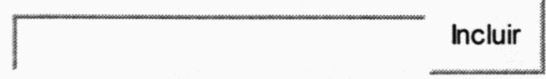

Parto Normal

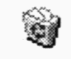

Área: Maternidade

Sala: Parto Normal

\section{Equipamentos}

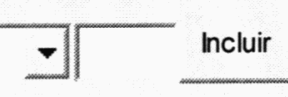
Berço aquecido calor irradiante Hosp Serv BA-R 1 .
Mesa de parto
Foco Central de Teto $\quad 1$ 㮘




\section{Berçário}

Incluir

Há berçário de primeiros cuidados Área Física

Há berçário de patológicos

Há alojamento conjunto

Há UTI neonatal

$\operatorname{sim}$
adequada
não
$\operatorname{sim}$
$\operatorname{sim}$




\section{Centro Cirúrgico}

\begin{tabular}{ccc}
\hline & sim \\
Área de recepção de paciente com passa maca & Area de Escovação & sim \\
Posto de Enfermagem e Serviços & sim \\
Vestiários com sanitários para funcionários com barreira & não \\
Sala de preparo de equipamentos e material & sim \\
Depósito de equipamentos e materiais & sim \\
Sala administrativa & sim \\
Expurgo & sim \\
Depósito de Material de Limpeza & sim \\
Sala de estar para funcionários & sim \\
Sala de Espera com sanitário para acompanhantes & não \\
Área para guarda de macas e cadeira de rodas & sim \\
Sala de Biópsia de congelação (Anatomia Patológica) & não \\
Fluxos pacientes/funcionários por entradas diferentes & sim \\
Há Sala de Conforto Médico no Centro Cirúrgico & sim \\
2 bicos de oxigênio/sala & sim \\
1 bico de ar comprimido/sala & sim \\
1 bico de vácuo/sala & sim \\
Desfibrilador ligado no CC & sim
\end{tabular}

Centro Cirúrgico/Salas

\begin{tabular}{|c|c|c|c|}
\hline 1 & $\nabla$ incluir & & \\
\hline Sala & Tamanho & Equips. & Excluir \\
\hline 01 & Grande & $\lambda$ & 得 \\
\hline Arsenal & Média & $\lambda$ & 通 \\
\hline 08 Neurocirurgia & Especial & $\lambda$ & 约 \\
\hline 07 & Grande & $\lambda$ & 绝 \\
\hline 06 & Média & $\lambda$ & 矐 \\
\hline 10 Cesárea & Pequena & $\lambda$ & 㲅 \\
\hline 04 & Pequena & $\lambda$ & (i) \\
\hline 03 & Média & $\lambda$ & ? \\
\hline Cardíaca & Especial & $\lambda$ & ig \\
\hline Vídeo & Média & $\lambda$ & (9) \\
\hline
\end{tabular}




\section{Centro Cirúrgico}

Sala: 01

\section{Equipamentos}

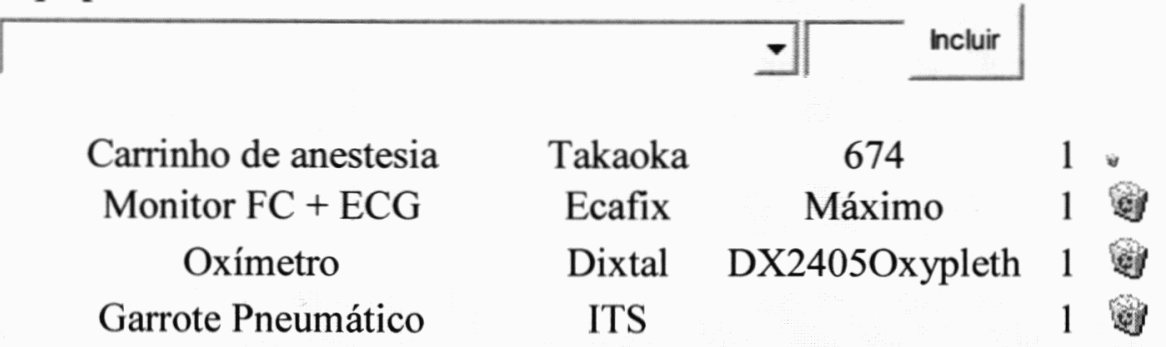

\section{Centro Cirúrgico}

Sala: Arsenal

\section{Equipamentos}

\begin{tabular}{|c|c|c|c|}
\hline & & $\nabla$ & Inclui \\
\hline Mesa cirúrgica ortopédica & & & 2 \\
\hline Arco Cirúrgico & Philips & BV 25 & 1 \\
\hline Oxímetro & Nellcor & N 180 & 1 \\
\hline Bisturi elétrico & Deltronix & В 3500 & 1 \\
\hline Berço aquecido calor irradiante & Fanem & AQ-50 & 1 \\
\hline Berço aquecido calor irradiante & Hosp Serv & BA-R & 1 \\
\hline RX portátil & Philips & MCD 105 & 1 \\
\hline
\end{tabular}




\section{Centro Cirúrgico \\ Sala: 08 Neurocirurgia}

\section{Equipamentos}

\begin{tabular}{|ccccc}
\hline & & & & \\
Carrinho de anestesia & Takaoka & Origami & 1 & \\
Monitor FC + ECG + PANI + oxímetro & Ecafix & Máximo & 1 & \\
Capnógrafo & Dixtal & DX1265 & 1 & \\
Microscópio cirúrgico & Zeiss & 240 FOPM & 1 & 0 \\
Bisturi elétrico & WEM & SS-500 & 1 & 1
\end{tabular}

\section{Centro Cirúrgico}

Sala: 07

\section{Equipamentos}

\begin{tabular}{ccccc}
\hline & & & \\
Carrinho de anestesia & Takaoka & 674 & 1 \\
Monitor FC + ECG + PANI + oxímetro & Dixtal & DX2010 & 1 & \\
Oxímetro & Dixtal & DX2405Oxypleth & 1 & Buir \\
Bisturi elétrico & Deltronix & B-6600 S & 1
\end{tabular}

\section{Centro Cirúrgico}

Sala: 06

\section{Equipamentos}

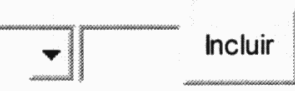

$\begin{array}{ccccc}\text { Carrinho de anestesia } & \text { Takaoka } & \text { Shogun Pró } & 1 \\ \text { Monitor FC + PANI } & \text { Dixtal } & \text { DX 2405 } & 1 \\ \text { Oxímetro } & \text { Dixtal } & \text { DX 2405 } & 1 \\ \text { Bisturi elétrico } & \text { WEM } & \text { SS-500 } & 1\end{array}$




\section{Centro Cirúrgico}

Sala: 10 Cesárea

\section{Equipamentos}

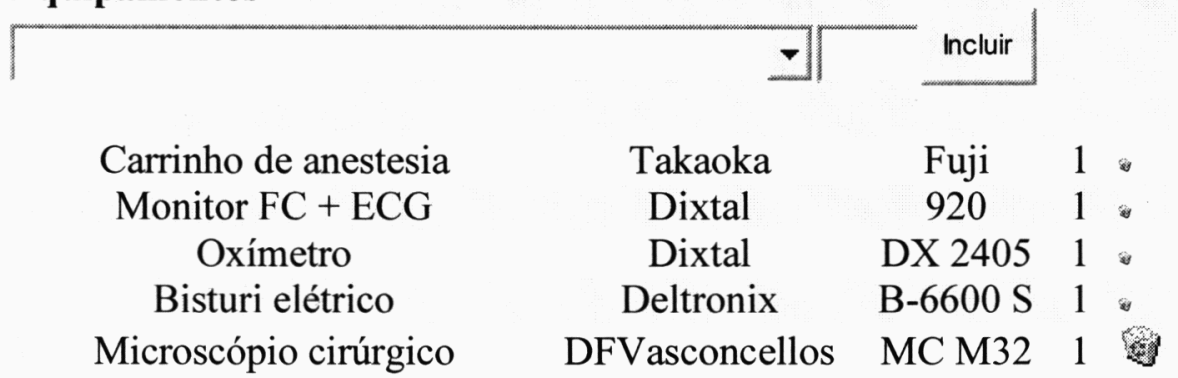

\section{Centro Cirúrgico}

Sala: 04

\section{Equipamentos}

\begin{tabular}{|c|c|c|c|}
\hline & & 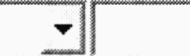 & Incluir \\
\hline Carrinho de anestesia & Takaoka & 674 & \\
\hline Monitor FC + oxímetro & Ecafix & Máximo & 18 \\
\hline Bisturi elétrico & Deltronix & B-6600 S & 18 \\
\hline
\end{tabular}

\section{Centro Cirúrgico}

Sala: 03

\section{Equipamentos}

\begin{tabular}{|ccccc|}
\hline & & & & \\
Carrinho de anestesia & Takaoka & Origami & 1 \\
Desfibrilador & Ecafix & MDF-03 & 1 & \\
Oxímetro & Dixtal & DX 2405 & 1 \\
Balança pesa-bebê & Filizola & Baby & 1
\end{tabular}


Centro Cirúrgico

Sala: Cardíaca

Equipamentos

\begin{tabular}{|c|c|c|c|}
\hline & & 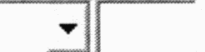 & Incluir \\
\hline Carrinho de anestesia & Takaoka & Origami & \\
\hline Monitor multiparâmetro & Dixtal & DX2010 & 1. \\
\hline Bomba de Infusão & BBraun & Nutrimat II & 1 \\
\hline Bomba de CEC & Braile & BEC 2000 & 1 \\
\hline Bomba de cardioplegia & DMG & & 1 \\
\hline
\end{tabular}

\section{Centro Cirúrgico}

Sala: Vídeo

Equipamentos

\begin{tabular}{|cccc}
\hline & & -7 \\
Monitor multiparâmetro & Dixtal & DX2010 & 1 \\
Bisturi elétrico & WEM & SS-500 & 1 \\
Videolaparoscópio & & & 1 \\
Videoartroscópio & & & 1
\end{tabular}

\begin{tabular}{|c|c|c|c|c|}
\hline \multicolumn{3}{|c|}{ Quantidade } & \multirow{2}{*}{\multicolumn{2}{|c|}{ Desativadas }} \\
\hline & \multicolumn{2}{|c|}{ Operacionais } & & \\
\hline Pequena & 1 & $\nabla$ & 0 & $\nabla$ \\
\hline Média & 4 & $=$ & 0 & $=$ \\
\hline Grande & 2 & \pm & 0 & -1 \\
\hline Especial & 1 & $=$ & 0 & - \\
\hline Total & & & & \\
\hline
\end{tabular}

\section{RPA}

\begin{tabular}{ccc}
\hline Área Física & inadequada \\
in $H$ & Inclequados \\
Desfibrilador & $\operatorname{sim}$ \\
Monitor de FC & $\operatorname{sim}$ \\
Oxímetro & $\operatorname{sim}$
\end{tabular}


Serviços de Apoio Diagnóstico e Terapia

SADT

\begin{tabular}{ccccc}
\hline & Aparelhos & adequados & \\
Eatologia Clínica & $\operatorname{sim}$ & Aparelhos & adequados \\
Endoscopia & $\operatorname{sim}$ & Aparelhos & adequados \\
Endoscopia & $\operatorname{sim}$ & Salas & adequadas \\
Endoscopia & $\operatorname{sim}$ & Repouso & adequadas \\
Hemoterapia & $\operatorname{sim}$ & Conforme Legislação & $\operatorname{sim}$ \\
RX & $\operatorname{sim}$ & com seriógrafo & $\operatorname{sim}$ \\
RX & $\operatorname{sim}$ & & & \\
RX Portátil & $\operatorname{sim}$ & & & \\
USG & $\operatorname{sim}$ & &
\end{tabular}

\section{Equipamentos}

\begin{tabular}{|cccc|}
\hline & & & \\
& & & \\
Bioquímica & COBAS & Mira Plus & 1 \\
Coagulação & Bio Mérieux & Option 2 & 1 \\
Eletrólitos Na, K e Ca & AVL & 9180 electrolyte & 1 \\
Hormônios & Bio Mérieux & Mini-Vidas & 1 \\
Hematologia & Coulter & 890 & 2 \\
Hemogasômetro & Drake & AGS-21 & 1 \\
Hemogasômetro & Radiometer & ABL 5 & 1
\end{tabular}

Equipamentos

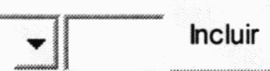

ECG Ecafix ECG 61 \%

Equipamentos

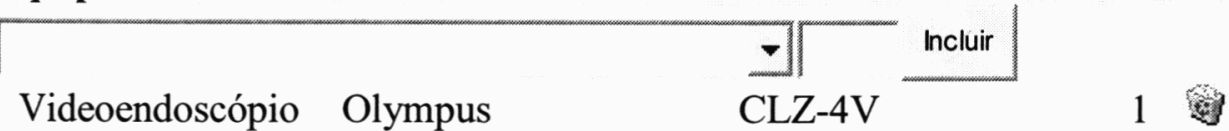




\section{Equipamentos}

\begin{tabular}{|c|c|c|c|c|}
\hline & & $\nabla$ & Incluir & \\
\hline RX com seriógrafo & Picker & HF 1500 & & (a) \\
\hline RX com seriógrafo & Philips & Diagnost 15 & & (⿰⿺⿻一𠃋十斤丶 \\
\hline
\end{tabular}

\section{Equipamentos}

\begin{tabular}{|c|c|c|c|}
\hline & & 7 & Incluir \\
\hline RX digital & Philips & Direct View CR 800 & 1 \\
\hline $\mathrm{RX}$ & Picker & HF 500 & 1 \\
\hline $\mathrm{RX}$ & Picker & Clinix HFE & 1 \\
\hline
\end{tabular}

\section{Equipamentos}

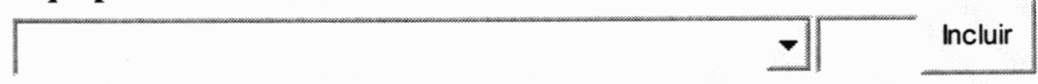

RX portátil Philips

1 政

\section{Equipamentos}

\begin{tabular}{|ccccc}
\hline & & & \\
USG & GE & Logiq 200 & 1 & \\
USG com Doppler e 3D & Acuson & $128 \mathrm{XP} / 10$ & 1 & \\
USG com scan Vascular + ECO doppler & GE & Logiq 200 & 1 & \\
USG & GE & Sinergy & 1
\end{tabular}


SADT - Acessório

\begin{tabular}{|c|c|c|c|c|}
\hline- & Incluir & & & \\
\hline Angiografia Digital/Hemodinâmica & $\operatorname{sim}$ & Aparelhos & adequados & 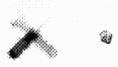 \\
\hline Cintilografia & $\operatorname{sim}$ & Aparelhos & adequados & $>$ \\
\hline Cintilografia & $\operatorname{sim}$ & Normas CNEN & $\operatorname{sim}$ & 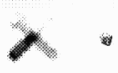 \\
\hline Audiometria & $\operatorname{sim}$ & Aparelhos & adequados & 入 \\
\hline EEG & $\operatorname{sim}$ & Aparelhos & adequados & 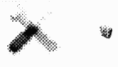 \\
\hline Ergometria & $\operatorname{sim}$ & Aparelhos & adequados & n \\
\hline Ergometria & $\operatorname{sim}$ & Vestiários & adequados & n. \\
\hline Fisioterapia & $\operatorname{sim}$ & & & $\lambda$ \\
\hline Holter & $\operatorname{sim}$ & & & 2 \\
\hline MAPA & $\operatorname{sim}$ & & & $\lambda$ \\
\hline Ecografia & $\operatorname{sim}$ & Aparelhos & adequados & $\lambda$ \\
\hline Litotripsia & $\operatorname{sim}$ & Aparelhos & adequados & $\infty$ \\
\hline Litotripsia & $\operatorname{sim}$ & Conforme Legislação & $\operatorname{sim}$ & 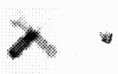 \\
\hline Quimioterapia & $\operatorname{sim}$ & Conforme Legislação & não & $\lambda$ \\
\hline Tomografia & $\operatorname{sim}$ & Conforme Legislação & $\operatorname{sim}$ & $x$ \\
\hline Ressonância Magnética & $\operatorname{sim}$ & Conforme Legislação & $\operatorname{sim}$ & \\
\hline
\end{tabular}

Equipamentos

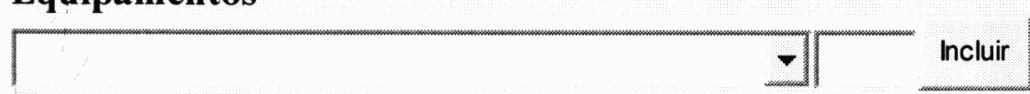

$\begin{array}{cccc}\text { Angiografia Digital } & \text { Philips } & \text { Poly Diagnost C2 } & 1 \\ \text { Desfibrilador } & \text { TEB } & \text { D-10 } & 1 \\ \text { Infusor digital } & \text { Angiomat } & 6000 & 1 \\ \text { Estudo eletrofisiológico } & \text { TEB } & & 1\end{array}$

\section{Equipamentos}

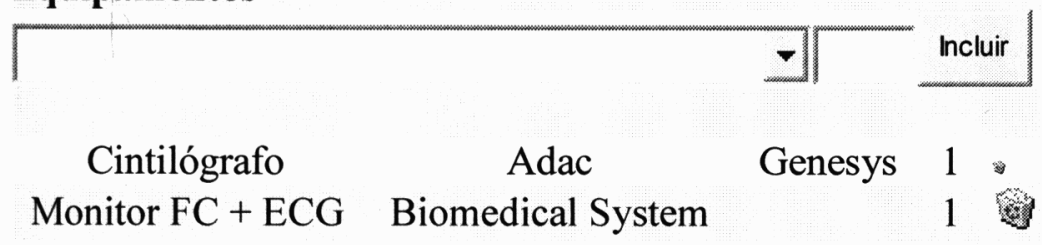


Equipamentos

\begin{tabular}{llll}
\hline EEG Dantec Cantata & & 1 \\
Equipamentos & &
\end{tabular}

Ecocardiógrafo HP Image Point 1 의

Ecocardiógrafo Toshiba Sonolayer 1 क्ष

Equipamentos

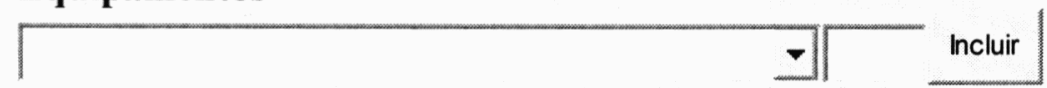

$\begin{array}{cccc}\text { Ergometria } & \text { Inbramed } & 1020 & 1 \\ \text { Ergometria } & \text { Inbramed } & \text { Inbrasport } & 1 \\ \text { Desfibrilador } & \text { TEB } & \text { D-10 } & 1 \\ \text { Desfibrilador } & \text { Intramed } & \text { HS-01 } & 1 \\ \text { Monitor FC + ECG } & \text { FAJ } & & 1 \\ \text { Monitor FC + ECG } & \text { TEB } & \text { M-10 C } & 1\end{array}$

Equipamentos

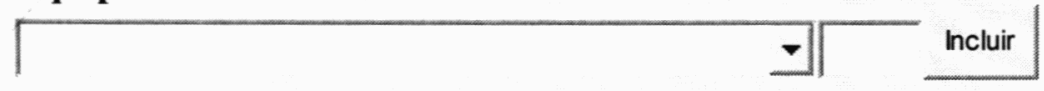

$\begin{array}{cccc}\text { Litotripsia } & \text { Tripter } & \mathrm{X} & 1 \\ \text { Monitor FC + ECG } & \text { Ecafix } & \text { ACL } 07 & 1\end{array}$

Equipamentos

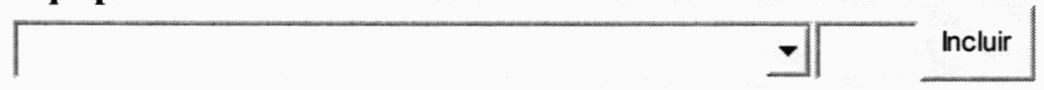

$\begin{array}{ccccc}\text { Tomografia convencional } & \text { GE } & 640 & 1 \\ \text { Tomografia helicoidal } & \text { Picker } & \text { PQ 5000 } & 1\end{array}$

\section{Equipamentos}

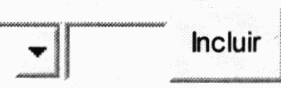

Ressonância Magnética Picker Edge 1,5 1 g의 


\section{Apoio Técnico e Administrativo}

\section{Farmácia}

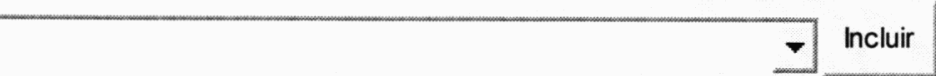

Há controle dos medicamentos Port 344

$\begin{array}{cc}\operatorname{sim} & 0 \\ \text { não } & 0 \\ \text { sim } & 0 \\ \operatorname{sim} & \text { Quantos } \\ \text { sim } & 0 \\ \text { Individualizada } & 0\end{array}$

A farmácia manipula NPP

Há local adequado para dispensação

Há farmacêutico no local

Há padronização de medicamentos

Dispensação

Individualizada

0 劉

\section{SND}

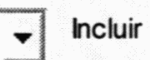

Circulação adequada

Equipamentos necessários e conservados

Área adequada com boa iluminação e aeração

Existe bancada para manipulação dos alimentos

Há cardápio afixado

Há Nutricionista

$\begin{array}{ll}\operatorname{sim} & 0 \\ \operatorname{sim} & 0 \\ \operatorname{sim} & 0 \\ \operatorname{sim} & 0 \\ \operatorname{sim} & 0 \\ \operatorname{sim} & 0\end{array}$

Incluir
Há normas e rotinas para limpeza da unidade

Utilizam produtos próprios para limpeza

A CCIH participa na elaboração de normas do setor

Há coleta seletiva do lixo

Funcionários utilizam equipamentos de proteção

$\operatorname{sim}$
$\operatorname{sim}$
$\operatorname{sim}$
$\operatorname{sim}$
$\operatorname{sim}$




\section{Lavanderia}

$\begin{array}{cc}\text { Máquina de lavar modelo profissional } & \operatorname{sim} \\ \text { Centrífugas apropriadas } & \operatorname{sim} \\ \text { Calandras } & \operatorname{sim} \\ \text { Há barreiras físicas } & \text { não } \\ \text { Área física apropriada } & \text { não } \\ \text { Há cruzamento limpo/contaminado } & \text { sim } \\ \text { Equipamentos em boas condições } & \text { não } \\ \text { Funcionários com equipamentos de proteção } & \text { sim } \\ \text { Serviço de Costura/Rouparia } & \text { sim }\end{array}$

Almoxarifado

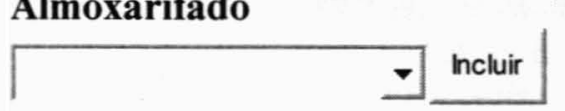

Área apropriada não

Estoques suficientes sim

Setor informatizado sim

(9)

\section{Manutenção

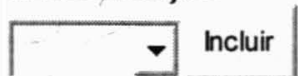

sim Própria

Vigilancia

- Incluir

Sim Própria

迩

SAME

Prontuários conforme Legislação sim Informatizado sim

sim
角 


\section{Central Esterilização}

Central Esterilização:

\begin{tabular}{|c|c|c|}
\hline$\nabla$ & Incluir & \\
\hline Encontra-se instalado em área física adequada & não & \\
\hline Tem área para expurgo do material & $\operatorname{sim}$ & \\
\hline Tem área para preparo/esterilização & $\operatorname{sim}$ & \\
\hline Tem área para estocagem/distribuição & $\operatorname{sim}$ & \\
\hline Há enfermeira responsável & não & \\
\hline Há normatização de procedimentos na área & não & \\
\hline Há cruzamento de fluxo de circulação entre as áreas & $\operatorname{sim}$ & \\
\hline Funcionários paramentados adequadamente & $\operatorname{sim}$ & \\
\hline Possui estufas & $\operatorname{sim}$ & 1 \\
\hline Possui Autoclave horizontal & $\operatorname{sim}$ & 2 \\
\hline Possui Autoclave vertical & não & 0 \\
\hline Há manutenção preventiva de equipamentos & não & \\
\hline É utilizado Controle Biológico & $\operatorname{sim}$ & \\
\hline
\end{tabular}

\section{Periodicidade}

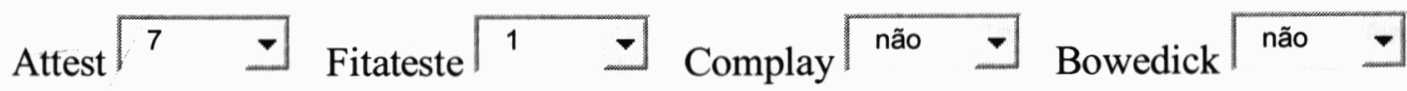




\section{Parecer:}

- Hospital: geral privado sem fins lucrativos, com 220 leitos operacionais, com nível de atendimento terciário.

- Estrutura física: vertical, adaptada, com sinalização adequada, sem estacionamento, em boas condições de higiene e limpeza. Pronto-socorro geral, Maternidade, UTI geral com isolamento sem antecâmara, UTI cardiológica e UTI neonatal sem isolamento. Centro Cirúrgico com 16 salas, 07 operacionais. RPA em área física inadequada, com recursos humanos e materiais inadequados.

- Estrutura básica: gerador com suporte às áreas críticas, 02 cabines primárias de força, central de gases, sistema de prevenção de incêndios com extintores e hidrantes, pára-raios e 03 elevadores.

- Hotelaria: apartamentos que podem ser transformados em enfermarias de 02 leitos, confortáveis, com TV, telefone, ar condicionado, cadeira de descanso, 01 bico de oxigênio, 01 de ar comprimido e 01 de vácuo. Sanitários: porta abrindo para fora, box, sem barras/apoios, contrariando a RDC no 50/02. 04 apartamentos com frigobar. Posto de enfermagem central com área de prescrição. Enfermarias SUS simples.

- Serviços de apoio: farmácia com 02 farmacêuticos, dispensação por sistema individualizado e padronização de medicamentos. SND com 02 nutricionistas, cardápio afixado semanalmente. Serviço de limpeza próprio com normas e rotinas e participação da CCIH. Manutenção própria. Lavanderia em área fisica inadequada, com fluxo cruzado e equipamentos inadequados. Central de Esterilização de Materiais em reforma, área física inadequada.

- SADT: Audiometria, Cintilografia, EEG, ECG, Endoscopia, Fisioterapia, Angiografia Digital/Hemodinâmica, Holter, Quimioterapia, Ecografia, Ergometria, Litotripsia, Patologia Clínica, Mamografia, Ressonância Magnética, RX Simples e Contrastado, Tomografia e USG.

- Organização e funcionamento: Normas, Rotinas e Manuais, Regimento/Regulamento Interno, Recrutamento e Seleção de Pessoal, Educação Continuada, Indicadores Hospitalares, Relatórios Gerenciais, Informatização em rede exceto prontuário eletrônico, Saúde Ocupacional. Comissões de Ética Médica, 
CCIH, Revisão de Prontuários e de Óbitos, CIPA, Ensino, Residência Médica, Farmácia e Medicamentos e Controle de Gestão de Qualidade.

- Recursos Humanos:

o Servidores/leito: 5,17

o Proporção de funcionários de enfermagem/ leito: 1,8

o Enfermeiros/ leito: 0,13

$\circ$ Técnicos e Auxiliares de Enfermagem/ leito: 1,65

o Atendentes/ leito: 0,02

- Indicadores de Qualidade:

- Taxa de Mortalidade Institucional: $3,83 \%$

- Taxa de Cesárea: $30,23 \%$

○ Taxa de Infecção Hospitalar: $2,7 \%$

- Indicadores de Produtividade:

○ Taxa de Ocupação: $64,9 \%$

- Taxa de permanência: 4,46 dias

- Giro de Rotatividade: 4,42 pacientes/mês

\section{Parecer:}

Consideramos o Hospital B apto.

Deverá:

1. Resolver problemas estruturais:

- Adequar sanitários à RDC no 50/02.

- Adequar sala de aplicação de quimioterápicos à RDC n ${ }^{\circ}$ 50/02 e Portarias MS $n^{\circ} 3535 / 98$ e no $113 / 99$.

- Instalar sala de reanimação de RN.

- Instalar Berçário de Patológicos/ Prematuros.

- Instalar isolamento na UTI neonatal.

- Adequar vestiários do Centro Cirúrgico à $\mathrm{RDC} \mathrm{n} \mathrm{n}^{\circ}$ 50/02.

- Mudar a entrada do Centro Cirúrgico Cardiológico (entrada através da UTI), adequando-a à RDC n ${ }^{\circ}$ 50/02.

- Adequar Central de Esterilização de Materiais à RDC n n $^{\circ}$ 50/02. 
- Adequar UTI à RDC n ${ }^{\circ}$ 50/02, bem como à Portaria 3432/98.

- Adequar Lavanderia à RDC n $n^{\circ} 50 / 02$.

2. Implantar sistema de tratamento de resíduos e esgoto.

3. Reequipar sala de emergência/ urgência para dar condições de sustentação de vida, com instalação imediata de respirador adequado.

4. Equipar RPA.

5. Equipar unidade de internação com carrinho de emergência e torpedo de oxigênio.

6. Contratar recursos humanos para compor a equipe médica e de enfermagem do Pronto Socorro (Resoluções n 1451/95 do CFM e n 189/2003 do COFEN)

7. Contratar recursos humanos da área de enfermagem: Enfermeiros e Técnicos de Enfermagem para comporem equipe e melhorar o atendimento. 


\section{ANEXO 6 - Vistoria Técnica-Hospitalar - Hospital C}

\section{Identificação do Estabelecimento}

Nome:

$\mathrm{C}$

Diretor Clínico:

CRM:

Data da Vistoria: 27/ Novembro/ 2003

Acompanhantes:

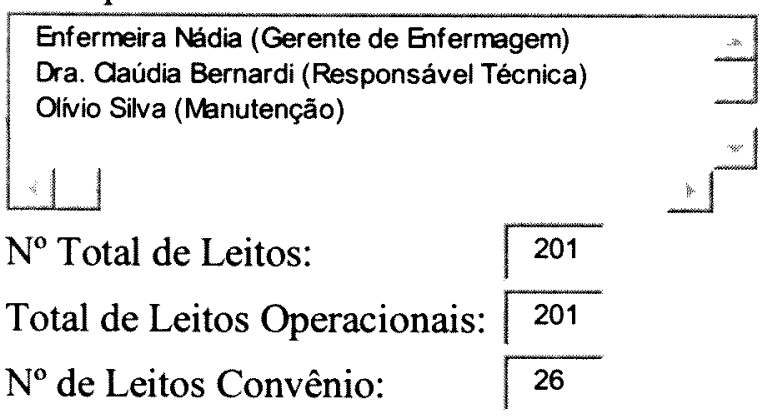

\section{Classificação do Estabelecimento}

Tipo de Hospital:

Lista de Especializações:

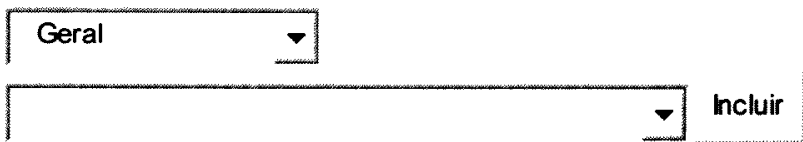

\section{Tipo de Serviço}

Tipo de serviço:

Abrangência do serviço

Abrangência do serviço:

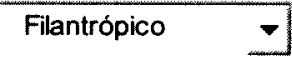

Regional 


\section{Organização e Funcionamento}

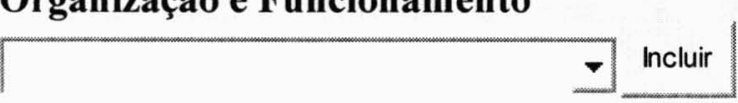

\begin{tabular}{|c|c|c|c|}
\hline Normas e Rotinas e Manuais & $\operatorname{sim}$ & Do conhecimento das partes & $\operatorname{sim}$ \\
\hline Regime Interno/regulamento & $\operatorname{sim}$ & Do conhecimento das partes & $\operatorname{sim}$ \\
\hline Recrutamento e Seleção de Pessoal & $\operatorname{sim}$ & & \\
\hline Programas de Treinamento & $\operatorname{sim}$ & & \\
\hline Educação Continuada & $\operatorname{sim}$ & & \\
\hline Indicadores Hospitalares & $\operatorname{sim}$ & & \\
\hline Relatórios Gerenciais & $\operatorname{sim}$ & & \\
\hline Informatização & $\operatorname{sim}$ & Em Rede & $\operatorname{sim}$ \\
\hline Serviço Social & $\operatorname{sim}$ & & \\
\hline Psicologia Hospitalar & $\operatorname{sim}$ & & \\
\hline Saúde Ocupacional & $\operatorname{sim}$ & & \\
\hline Comissão de Ética Médica & $\operatorname{sim}$ & Reuniões Regulares / Atas & $\operatorname{sim}$ \\
\hline $\mathrm{CCIH}$ & $\operatorname{sim}$ & Reuniões Regulares / Atas & $\operatorname{sim}$ \\
\hline Revisão de Prontuários & $\operatorname{sim}$ & Reuniões Regulares / Atas & $\operatorname{sim}$ \\
\hline Revisão de Óbitos & $\operatorname{sim}$ & Reuniões Regulares / Atas & $\operatorname{sim}$ \\
\hline CIPA & $\operatorname{sim}$ & Reuniões Regulares / Atas & $\operatorname{sim}$ \\
\hline Farmácia e Medicamentos & $\operatorname{sim}$ & & \\
\hline Controle e Gestão de Qualidade & & & \\
\hline Ensino e Pesquisa & & & \\
\hline Residência Médica/Pós-Graduação & & & \\
\hline
\end{tabular}


Recursos Humanos de todo o Hospital (Ano de $\sqrt{2003}$ )

Profissionais

Quantidade

Médicos contratados

Enfermeiros

Técnicos de enfermagem

Auxiliares de enfermagem

Atendentes de enfermagem

Outros Funcionários

Total

142

41
76
$\frac{142}{322}$
$\frac{1}{481}$
1063

Informações Gerais (Ano de 2002)

Levantamento de dados anual

Número de óbitos após 48 horas

Números de saídas (Altas e Óbitos)

Números de óbitos por causas maternas

Número de pacientes atendidos em Obstetrícia

Número de nascidos vivos

Número de nascidos mortos

Número de óbitos neonatais após 48 horas

Número de óbitos operatórios até 10 dias pós-cirurgia

Número de atos cirurgicos

Número de cesáreas

Número de partos normais

Número total de partos

Número de infecções atribuíveis ao hospital

Número de supurações de feridas cirúrgicas em cirurgias limpas

Número de cirurgias limpas do período

Número de pacientes/dia

Número de leitos/dia

Número de leitos disponíveis no período

\begin{tabular}{|l}
\hline 659 \\
\hline 12342 \\
\hline 01 \\
\hline 1076 \\
\hline 5026 \\
\hline 41 \\
\hline 13 \\
\hline 156 \\
\hline 5892 \\
\hline 323 \\
\hline 427 \\
750 \\
\hline
\end{tabular}

\begin{tabular}{|l}
\hline 3761 \\
\hline 61463 \\
\hline 252 \\
\hline 82116
\end{tabular}


Indicadores de Qualidade (Ano de 2002 )

Taxa de mortalidade institucional

Taxa de mortalidade materna

Taxa de natimortalidade

Taxa de mortalidade neonatal

Taxa de mortalidade operatória

Taxa de cesáreas

Taxa de infecção hospitalar

Taxa de supuração de ferida cirúrgica em cirurgia limpa

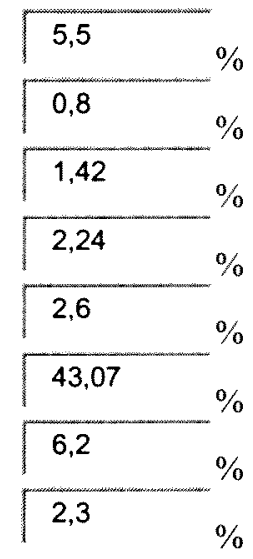

\section{Indicadores de produtividade (Ano de 2002)}

Taxa de ocupação

Taxa de permanência

Giro de rotatividade

\begin{tabular}{ll}
\hline 74,8 & $\%$ \\
5.1 & dias \\
61,2 & vezes
\end{tabular}




\section{Estrutura}

Edificação:

$\frac{N^{\circ} \text { de Pavimentos: }}{2}$

Horizontal

Planejada

$\checkmark$ Vertical

$\mathrm{N}^{\circ}$ de elevadores:

Adaptada

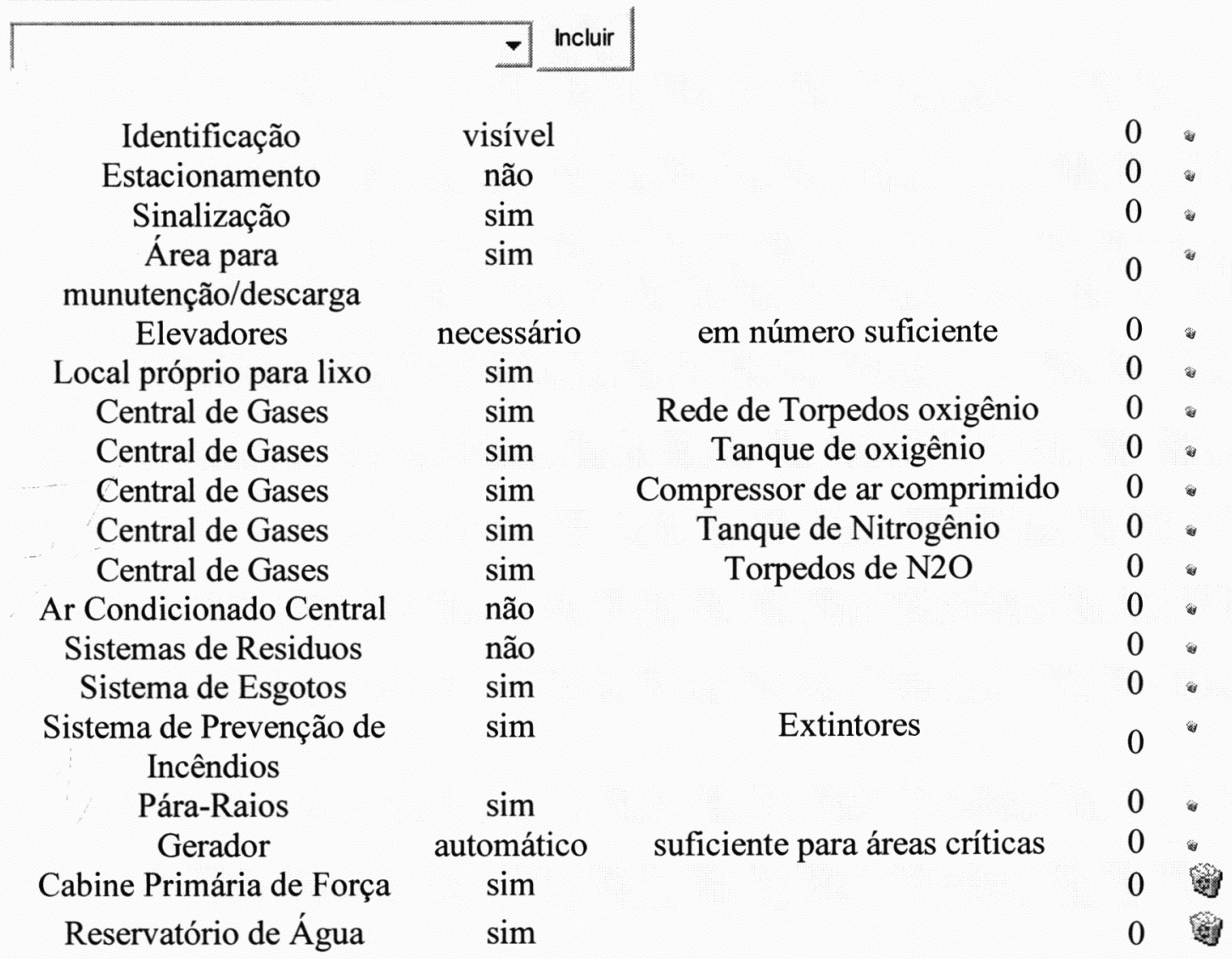


Não apresenta recepção

$\begin{array}{ccc}\text { Apartamentos - Quantos? } & \\ \text { Carrinho de emergência } & \text { sim } & \\ \text { Torpedo de oxigênio na unidade } & \text { sim } \\ \text { cadeira de descanso } & \text { sim } & \\ \text { sofá/cama acompanhante } & \text { sim } & \text { naros } \\ \text { Sanitário } & \text { porta } & \text { abrindo para fora } \\ \text { Sanitário } & & \\ \text { bico de ar } & & \\ \text { bico de oxigênio } & & \\ \text { telefone } & & \\ \text { frigobar } & & \\ \text { TV } & \end{array}$

\section{Apartamentos}

Instalações Hidráulicas

Adequada

Instalações Elétricas

Ventilação

Iluminação

Corredores Livres

Adequada

Adequada

Adequada

sim

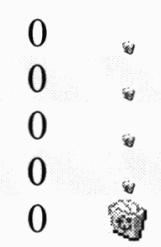


Enfermarias 2 Leitos - Quantos?

Carrinho de emergência

Torpedo de oxigênio na unidade

Distância mínima entre os leitos cadeira de descanso

Sanitário

Sanitário

bico de ar

bico de oxigênio

telefone

frigobar

TV

\section{Enfermarias 2 Leitos}

Instalações Hidráulicas
Instalações Elétricas
Ventilação
Iluminação
Corredores Livres

Sim
Sim
Barras/Apoios
Porta Abrimdo para fora




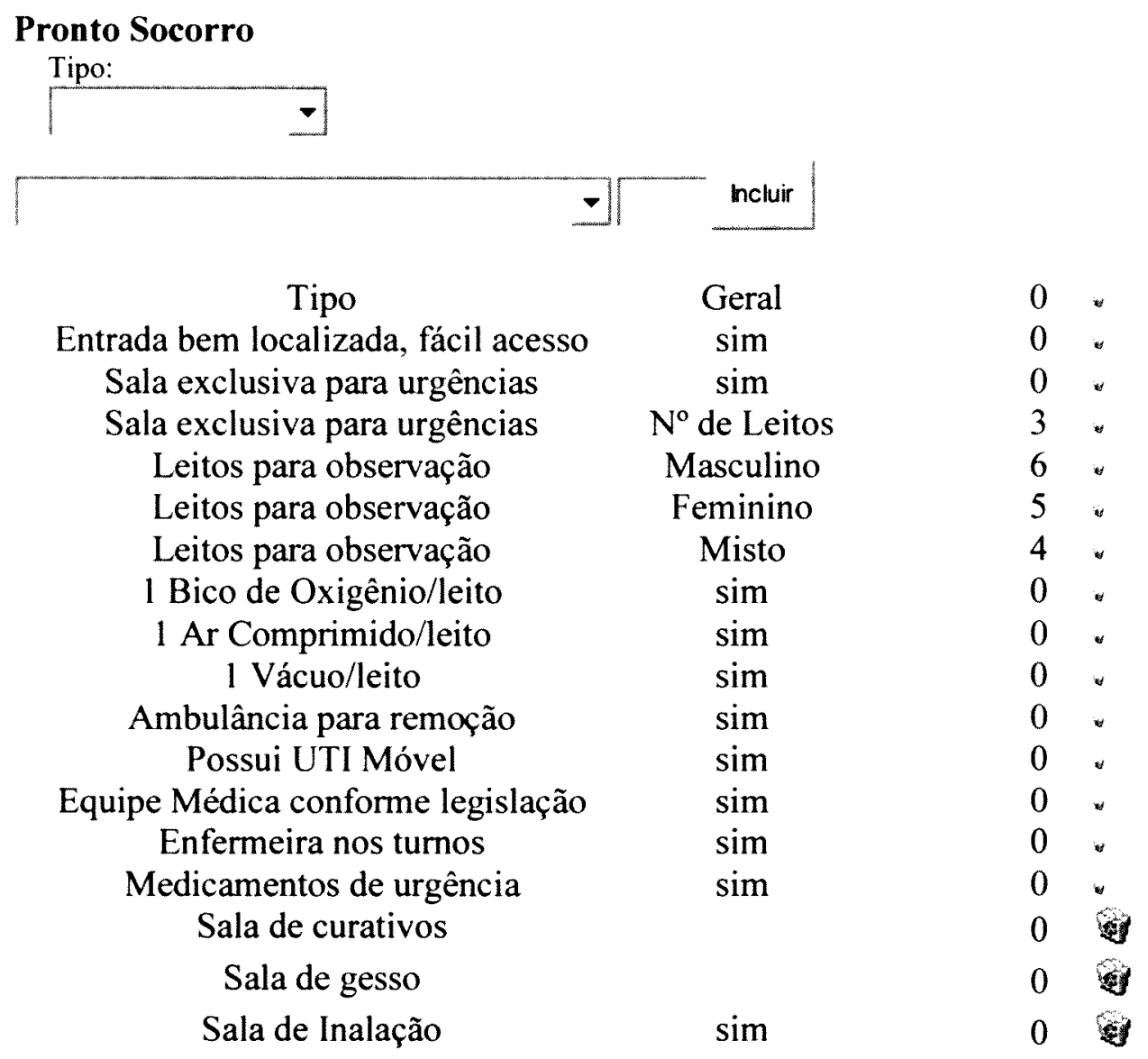

\section{Equipamentos da Urgência}

\begin{tabular}{cccc}
\hline & & \\
Desfibrilador & Ecafix & MDF-03 & 1 \\
Desfibrilador & Anamed & Vital Line & 1 \\
Respirador & Bird & Mark-7 & 1 \\
Carrinho de Emergência com desfibrilador & & & 2 \\
Bomba de Infusão & Samtronic & ST 550T2 & 1 \\
ECG & Ecafix & ECG 6 & 1
\end{tabular}




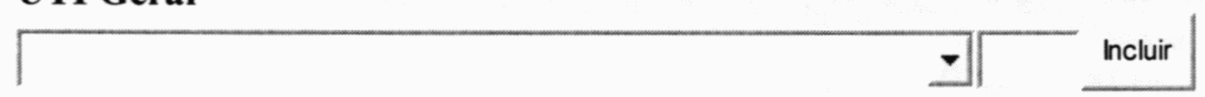

Número de Leitos

Há normas e rotinas para a área

A UTI participa da CCIH

01 médico para cada 10 leitos

Há programas de acompanhamento de visita com orientação

Encontra-se em área física adequada

De acordo com a legislação vigente

$\mathrm{O}$ posto de enfermagem permite boa visão dos leitos

Há boa circulação de funcionários e pacientes

Possui médico diarista

Possui equipe médica em todos os turnos

Equipe de enfermagem treinada e completa

Enfermeira em todos os turnos

Há leitos para isolamento

Quarto para médico plantonista

Área de descanso para enfermagem

2 bicos de oxigênio/leito

$\begin{array}{ll} & 16 \\ \text { sim } & 0 \\ \text { sim } & 0 \\ \text { sim } & 0 \\ \text { sim } & 0 \\ \text { sim } & 0 \\ \text { sim } & 0 \\ \text { sim } & 0 \\ \text { sim } & 0 \\ \text { sim } & 0 \\ \text { sim } & 0 \\ \text { sim } & 0 \\ \text { sim } & 0 \\ \text { sim } & 2 \\ \text { sim } & 0 \\ \text { não } & 0 \\ \text { sim } & 0 \\ \text { sim } & 0 \\ \text { sim } & 0 \\ \text { sim } & 0\end{array}$

1 bico de ar comprimido/leito

1 bico de vácuo/leito

0 광

10 tomadas elétricas 


\section{Equipamentos}

\begin{tabular}{|c|c|c|c|c|}
\hline & & Incluir & & \\
\hline Monitor multiparâmetro & Dixtal & DX2010 & 11 & \\
\hline Monitor FC + ECG & Anamed & & 3 & 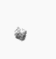 \\
\hline Carrinho de parada & Ecafix & & 1 & 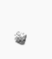 \\
\hline Carrinho de parada & Lanco & & 1 & 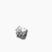 \\
\hline Desfibrilador & Zoll & & 1 & . \\
\hline Desfibrilador & Ecafix & DF-03 & 1 &. \\
\hline Oxímetro & Moriya & M 1000 & 2 & 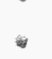 \\
\hline Bisturi elétrico & Medcir & MBJ II & 1 & 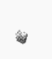 \\
\hline Bisturi elétrico & Deltronix & B $3300 \mathrm{~S}$ & 1 & . \\
\hline Hemogasômetro & AVL & Compact 2 & 1 & . \\
\hline Respirador & Bird & Mark-7 & 1 & 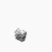 \\
\hline Respirador & Bird & 6400 & 1 & 。 \\
\hline Respirador & Takaoka & Monterey & 7 & 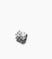 \\
\hline Respirador & Takaoka & Vent Care & 2 & 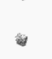 \\
\hline Respirador & Intermed & Inter 5 & 14 & * \\
\hline Monitor FC + ECG & BESE & Biomonitor 4 & 1 & . \\
\hline Bomba de Infusão & JMS & OT-601 & 2 & . \\
\hline Bomba de Infusão & Samtronic & Infusion Pump 400 & 11 & - \\
\hline Balão Intra-Aórtico & Datascope & System 90 & 1 & . \\
\hline ECG & Funbec & ECG 5 & 1 & - \\
\hline Monitor FC + ECG & Anamed & & 6 & $\cdot$ \\
\hline Hemodialisador portátil & BBraun & FAD 100 & 1 & . \\
\hline Hemodialisador portátil & BBraun & Dialog & 1 & 8 \\
\hline Almofada térmica & Ioyama & & 0 & \\
\hline
\end{tabular}




\section{UTI Neurológica}

Número de Leitos

12 *

Há normas e rotinas para a área

A UTI participa da CCIH

01 médico para cada 10 leitos

$\operatorname{sim}$

$\operatorname{sim}$

$\operatorname{sim}$

Há programas de acompanhamento de visita com orientação

$\operatorname{sim}$

Encontra-se em área física adequada

De acordo com a legislação vigente

$O$ posto de enfermagem permite boa visão dos leitos

$\operatorname{sim}$

$\operatorname{sim}$

$\operatorname{sim}$

$\operatorname{sim}$

Há boa circulação de funcionários e pacientes

Possui médico diarista

Possui equipe médica em todos os turnos

$\operatorname{sim}$

$\operatorname{sim}$

$\operatorname{sim}$

$\operatorname{sim}$

Enfermeira em todos os turnos

Há leitos para isolamento

Quarto para médico plantonista

$\operatorname{sim}$

$\operatorname{sim}$

$\operatorname{sim}$

Área de descanso para enfermagem

$\operatorname{sim}$

$\operatorname{sim}$

1 bico de ar comprimido/leito

1 bico de vácuo/leito

$\operatorname{sim}$

10 tomadas elétricas

$\operatorname{sim}$

0 。

0 \%

0 \%

0 .

0 ช

0 *

0 .

0 *

0 .

0 .

0 *

0 *

1 \%

0 \%

0 姆

0 ํํㄴ

0 난

0 खै

0 㪍 


\section{Centro Cirúrgico}

\begin{tabular}{ccc}
\hline Área de recepção de paciente com passa maca & não \\
Área de Escovação & sim \\
Posto de Enfermagem e Serviços & sim \\
Vestiários com sanitários para funcionários com barreira & sim \\
Sala de preparo de equipamentos e material & sim \\
Depósito de equipamentos e materiais & sim \\
Sala administrativa & sim \\
Expurgo & sim \\
Depósito de Material de Limpeza & sim \\
Sala de estar para funcionários & sim \\
Sala de Espera com sanitário para acompanhantes & não \\
Área para guarda de macas e cadeira de rodas & sim \\
Sala de Biópsia de congelação(Anatomia Patológica) & não \\
Fluxos pacientes/funcionários por entradas diferentes & sim \\
Há Sala de Conforto Médico no Centro Cirúrgico & sim \\
2 bicos de oxigênio/sala & não \\
1 bico de ar comprimido/sala & sim \\
1 bico de vácuo/sala & sim
\end{tabular}

\section{Centro Cirúrgico/Salas}

\begin{tabular}{|c|c|c|c|}
\hline & $\nabla$ Incluir & & \\
\hline Sala & Tamanho & Equips. & Excluir \\
\hline 01 & Pequena & $\lambda$ & $\theta$ \\
\hline 04 & Média & $\lambda$ & $\theta$ \\
\hline 06 (Urgência) & Grande & $\lambda$ & . \\
\hline 07 & Grande & $\lambda$ & . \\
\hline 08 & Média & $\lambda$ & . \\
\hline 09 & Grande & $\lambda$ & . \\
\hline 05 & Grande & $\lambda$ & 进 \\
\hline
\end{tabular}




\section{Centro Cirúrgico}

Sala: 01

\section{Equipamentos}

\begin{tabular}{|c|c|c|c|}
\hline & & 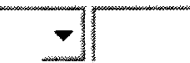 & Incluir \\
\hline Carrinho de anestesia & Takaoka & Sansei & \\
\hline Broncoscópio & Circon & & $\theta$ \\
\hline Monitor FC + ECG & Anamed & Vital Line & 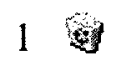 \\
\hline
\end{tabular}

\section{Centro Cirúrgico}

Sala: 04

\section{Equipamentos}

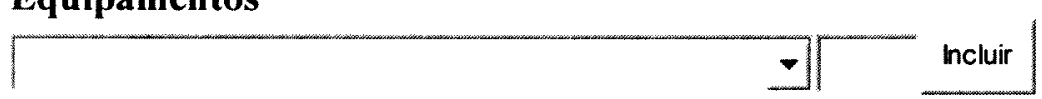

Carrinho de anestesia

$\begin{array}{cccc}\text { Takaoka } & \text { Fuji } & 1 & \\ \text { DFVasconcellos } & \text { MC M32 } & 1 & \\ \text { WEM } & \text { SS -701 } & 1\end{array}$

Bisturi elétrico

\section{Centro Cirúrgico}

Sala: 06 (Urgência)

\section{Equipamentos}

\begin{tabular}{|c|c|c|c|}
\hline & 7 & Incluir & \\
\hline Carrinho de anestesia & Takaoka & Origami & \\
\hline Berço aquecido calor irradiante & Fanem & AQ-50 & 1. \\
\hline Arco Cirúrgico & National Electric & & \\
\hline Monitor FC + ECG & Dixtal & 920 & 1 \\
\hline
\end{tabular}




\section{Centro Cirúrgico}

Sala: 07

\section{Equipamentos}

\begin{tabular}{cccc|}
\hline & & & \\
Carrinho de anestesia & Takaoka & Shogun Pró & 1 \\
Mesa cirúrgica ortopédica & & & 2 \\
Bisturi elétrico & WEM & SS -701 & 1 \\
Monitor FC + ECG & Dixtal & 920 & 1 \\
Videolaparoscópio & Storz & & 1
\end{tabular}

\section{Centro Cirúrgico}

Sala: 08

\section{Equipamentos}

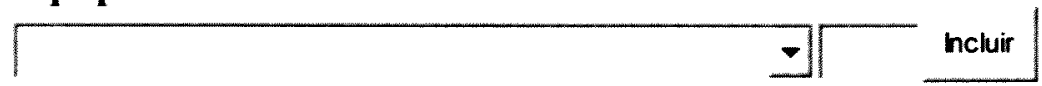

Carrinho de anestesia Takaoka Fuji 1 得

\section{Centro Cirúrgico}

Sala: 09

\section{Equipamentos}

\begin{tabular}{|cccc|}
\hline & & - & \\
Carrinho de anestesia & Takaoka & Origami & 1 \\
Arco Cirúrgico & Siemens & Siremobil & 1 \\
Monitor FC + ECG & Anamed & Vital Line & 1 \\
Videoartroscópio & & & 1
\end{tabular}




\section{Centro Cirúrgico}

Sala: 05

\section{Equipamentos}

\begin{tabular}{|ccc|c|}
\hline & & \\
Carrinho de anestesia & Takaoka & Origami & 1 \\
Microscópio cirúrgico & DFVasconcellos & MC M32 & 1 \\
Bisturi elétrico & Deltronix & B-6600 A & 1
\end{tabular}

Quantidade

\begin{tabular}{|c|c|c|c|}
\hline \multirow[b]{2}{*}{ Pequena } & Operacionais & \multicolumn{2}{|c|}{ Desativadas } \\
\hline & 1 & 0 & $\nabla$ \\
\hline Média & 2 & 0 & - \\
\hline Grande & 4 & 0 & $\nabla$ \\
\hline Especial & 0 & 0 & $\boldsymbol{\nabla}$ \\
\hline Total & & & \\
\hline
\end{tabular}

RPA

\begin{tabular}{cc|} 
Área Física & $\begin{array}{c}\text { adequada } \\
\text { adequados }\end{array}$ \\
Desfibrilador & sim \\
Monitor de FC & $\operatorname{sim}$ \\
Oxímetro & $\operatorname{sim}$ \\
01 bico de oxigênio/leito & $\operatorname{sim}$ \\
01 bico ar comprimido/leito & $\operatorname{sim}$ \\
01 bico de vácuo/leito & $\operatorname{sim}$
\end{tabular}


Serviços de Apoio Diagnóstico e Terapia

SADT

\begin{tabular}{|cccc}
\hline & Ancluir & \\
Eatologia Clínica & $\operatorname{sim}$ & Aparelhos & adequados \\
ECG & $\operatorname{sim}$ & Aparelhos & adequados \\
Endoscopia & $\operatorname{sim}$ & Aparelhos & adequados \\
Endoscopia & $\operatorname{sim}$ & Salas & adequadas \\
Endoscopia & $\operatorname{sim}$ & Repouso & adequadas \\
Hemoterapia & $\operatorname{sim}$ & Conforme Legislação & $\operatorname{sim}$ \\
RX & $\operatorname{sim}$ & com seriógrafo & $\operatorname{sim}$ \\
RX & $\operatorname{sim}$ & &
\end{tabular}

\section{Equipamentos}

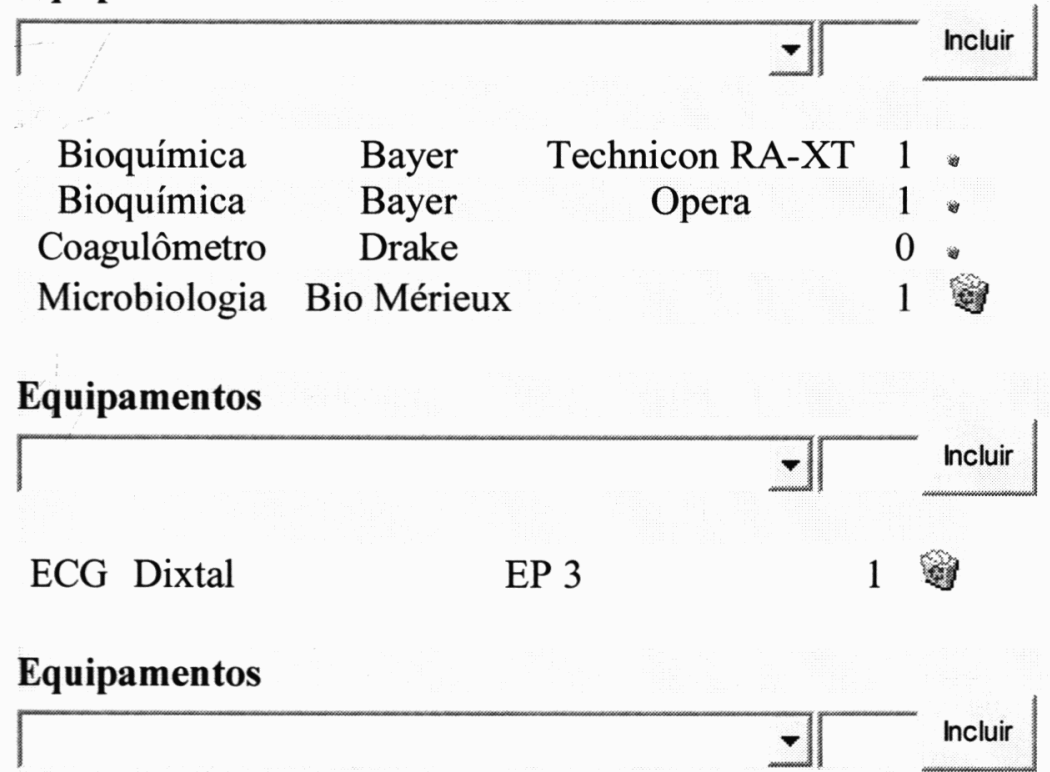

RX com seriógrafo Philips Super 80 CP 1 
Equipamentos

\begin{tabular}{|ccccc|}
\hline & & & & \\
RX & Emic Limex $100 \mathrm{~mA}$ & MKT 100 & 1 & \\
RX & Intecal $500 \mathrm{~mA}$ & & 1 & \\
Reveladora & Macrotec & MX-2 & 3
\end{tabular}

\section{Equipamentos}

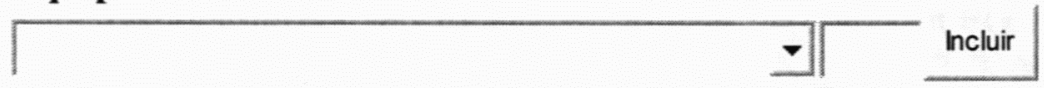

USG com scan Vascular + ECO doppler ATL HDI $3000 \quad 1 \quad 5$

\section{SADT - Acessorio}

\begin{tabular}{cccc}
\hline Angiografia Digital/Hemodinâmica & $\operatorname{sim}$ & Aparelhos & adequados \\
Mamografia & $\operatorname{sim}$ & Aparelhos & adequados \\
Tomografia & $\operatorname{sim}$ & Conforme Legislação & $\operatorname{sim}$ \\
Ergometria & $\operatorname{sim}$ & Aparelhos & adequados \\
Ergometria & $\operatorname{sim}$ & Desfibrilador & $\operatorname{sim}$ \\
Ecografia & $\operatorname{sim}$ & Aparelhos & adequados \\
Holter & $\operatorname{sim}$ & $\operatorname{sim}$ & \\
MAPA & $\operatorname{sim}$ & Conforme Legislação & $\operatorname{sim}$ \\
Quimioterapia & $\operatorname{sim}$ & Conforme Legislação & $\operatorname{sim}$ \\
Radioterapia & &
\end{tabular}

\section{Equipamentos}

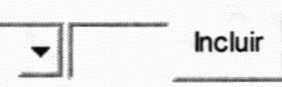

$\begin{array}{cccc}\text { Angiografia Digital } & \text { GE } & \text { Advant X } & 1 \\ \text { Monitor de FC + oxímetro } & \text { EMAI } & \text { RX-300 A } & 1 \\ \text { Desfibrilador } & \text { Biotronik } & \text { DP-1B } & 1 \\ \text { Desfibrilador } & \text { EMAI } & \text { DX-10 } & 1 \\ \text { Polígrafo } & \text { TEB } & \text { SP12/32 } & 1 \\ \text { Infusor digital } & \text { Angiomat } & 6000 & 1 \\ \text { Bomba de Infusão } & \text { JMS } & \text { OT-601 } & 3 \\ \text { Bomba de Infusão } & \text { Lifemed } & \text { LF-2001 } & 2\end{array}$




\section{Equipamentos}

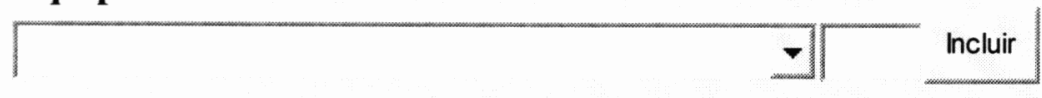

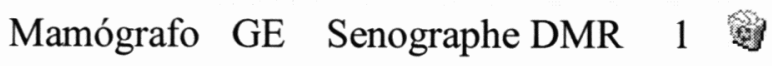

\section{Equipamentos}

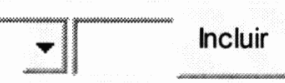

Tomografia convencional Philips Tomoscan EG 1 (2) 


\section{Apoio Técnico e Administrativo}

Farmácia

Há controle dos medicamentos Port 344

$\begin{array}{cl}\operatorname{sim} & 0 \\ \text { não } & 0 \\ \operatorname{sim} & 0 \\ \operatorname{sim} \text { Quantos } & 2 \\ \operatorname{sim} & 0 \\ \text { Unitária } & 0\end{array}$

A farmácia manipula NPP

Há local adequado para dispensação

Há farmacêutico no local

Há padronização de medicamentos

Dispensação

Unitária

Incluir

SND

- Incluir

Circulação adequada

Equipamentos necessários e conservados

Área adequada com boa iluminação e aeração

Existe bancada para manipulação dos alimentos

Há cardápio afixado

Há Nutricionista

$\begin{array}{ll}\operatorname{sim} & 0 \\ \operatorname{sim} & 0 \\ \operatorname{sim} & 0 \\ \operatorname{sim} & 0 \\ \operatorname{sim} & 0 \\ \operatorname{sim} & 0\end{array}$

Limpeza/Higiene
Há normas e rotinas para limpeza da unidade

Utilizam produtos próprios para limpeza

A CCIH participa na elaboração de normas do setor

Há coleta seletiva do lixo

Funcionários utilizam equipamentos de proteção $\operatorname{sim}$

$\operatorname{sim}$

$\operatorname{sim}$

$\operatorname{sim}$

$\operatorname{sim}$
(20)

劉

迎

a 


\section{Lavanderia}

$\begin{array}{cc}\text { Máquina de lavar modelo profissional } & \operatorname{sim} \\ \text { Centrífugas apropriadas } & \operatorname{sim} \\ \text { Calandras } & \operatorname{sim} \\ \text { Há barreiras físicas } & \text { sim } \\ \text { Há cruzamento limpo/contaminado } & \text { não } \\ \text { Área física apropriada } & \text { não } \\ \text { Equipamentos em boas condições } & \text { não } \\ \text { Funcionários com equipamentos de proteção } & \operatorname{sim} \\ \text { Serviço de Costura/Rouparia } & \operatorname{sim}\end{array}$

Almoxarifado

\begin{tabular}{|cc|}
\hline Ancluir & \\
Área apropriada & $\operatorname{sim}$ \\
Estoques suficientes & $\operatorname{sim}$ \\
Setor informatizado & $\operatorname{sim}$
\end{tabular}

\section{Manutenção}

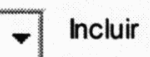

sim Própria

㮘

\section{Vigilancia}

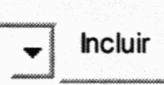

Sim Própria

(2)

SAME

Prontuários conforme Legislação sim Informatizado sim $\operatorname{sim}$
(9) 


\section{Central Esterilização}

Central Esterilização:

$\begin{array}{cc}\text { Encontra-se instalado em área física adequada } & \text { não } \\ \text { Tem área para expurgo do material } & \text { sim } \\ \text { Tem área para preparo/esterilização } & \operatorname{sim} \\ \text { Tem área para estocagem/distribuição } & \text { sim } \\ \text { Há enfermeira responsável } & \text { não } \\ \text { Há normatização de procedimentos na área } & \text { sim } \\ \text { Há cruzamento de fluxo de circulação entre as áreas } & \text { sim } \\ \text { Funcionários paramentados adequadamente } & \text { sim } \\ \text { Possui estufas } & \text { não } \\ \text { Possui Autoclave horizontal } & \text { sim } \\ \text { Possui Autoclave vertical } & \text { não } \\ \text { Há manutenção preventiva de equipamentos } & \text { sim }\end{array}$

\section{Periodicidade}

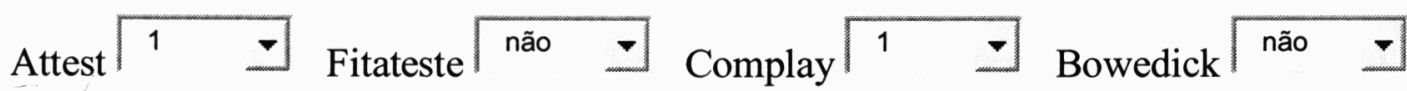




\section{Parecer:}

- Hospital geral privado sem fins lucrativos, com 201 leitos operacionais, 26 leitos para convênios, com nível de atendimento terciário.

- Estrutura física: vertical, adaptada, com sinalização adequada e em boas condições de higiene e limpeza. Pronto-socorro geral, UTI geral, UTI Neurológica, Centro Cirúrgico com 07 salas cirúrgicas, RPA com 06 leitos e recursos adequados e Unidades de Internação.

- Estrutura básica: 02 geradores automáticos para suporte às áreas críticas, cabine primária de força, central de gases, sistema de prevenção de incêndios com extintores, pára-raios e 04 elevadores.

- Hotelaria: não há recepção diferenciada para pacientes de convênios. Apartamentos e ou enfermarias de 02 leitos confortáveis com TV, telefone, frigobar, com 02 bicos de oxigênio e 02 de ar comprimido. Sanitários: porta de correr, sem barras/apoios, contrariando a RDC $n^{\circ}$ 50/02. Sofá-cama para acompanhantes, cadeira de descanso. Enfermaria SUS simples.

- Serviços de apoio: farmácia com 02 farmacêuticos, dispensação por dose unitária, com padronização dos medicamentos. SND com 01 nutricionista e cardápio afixado semanalmente. Serviço de limpeza com normas e rotinas e participação da CCIH. Manutenção própria. Lavanderia necessitando trocar piso, com fluxos corretos, equipamentos em regular estado de conservação. Central de Esterilização de Materiais com fluxo cruzado

- SADT: Ecografia, Endoscopia, Mamografia, ECG, Quimioterapia, Radioterapia. Terceirizados: Anatomia Patológica, Patologia Clínica, RX Simples e Contrastado, USG, Hemodinâmica, Ergometria, Holter, MAPA, Tomografia.

- Organização e funcionamento: Regimento Interno, Regulamento, Normas, Rotinas, Setor de Recrutamento e Seleção de Pessoal, Indicadores Hospitalares, Relatórios Gerenciais, Informatização em Rede exceto prontuário eletrônico, Serviço Social, Psicologia Hospitalar e Setor de Saúde Ocupacional. Comissões de Ética Médica, CCIH, Revisão de Prontuários e Óbitos, Ensino e Pesquisa, Residência Médica, CIPA, Farmácia e Medicamentos.

- Recursos Humanos 
- Servidores/ leito: 5,28

○ Proporção funcionários de enfermagem/ leito: 2,18

○ Enfermeiros/ leito: 0,20

- Técnicos e Auxiliares de Enfermagem/ leito: 1,97

- Atendentes/ leito: 0,004

Observamos a necessidade de reduzir o número de auxiliares de enfermagem, aumentandose o número dos demais membros que compõem a equipe de enfermagem a fim de melhorar a assistência prestada ao paciente.

- Indicadores de Qualidade

- Taxa de Mortalidade Institucional: $5,5 \%$

- Taxa de Cesáreas: 43,07\%

- Taxa de Mortalidade Operatória: $2,6 \%$

- Taxa de Infecção Hospitalar: 6,2\%

Observação: A Maternidade, Berçário e UTI neonatal foram transferidos para outro Hospital em outubro de 2003.

- Indicadores de Produtividade

- Taxa de Ocupação: $74,8 \%$

- Taxa de Permanência: 5,1 dias

- Giro de Rotatividade: 5,1 pacientes/mês 
Parecer: Consideramos o Hospital C apto.

Para tanto deverá:

1. Reduzir o número de auxiliares de enfermagem aumentando-se o número dos demais membros da equipe de enfermagem a fim de melhorar a assistência prestada ao paciente

2. Resolver problemas estruturais:
a. Adequar sanitários à RDC_n $n^{\circ} 50 / 02$, instalando barras de apoio.
b. Instalar passa-maca no Centro Cirúrgico em atendimento à $\mathrm{RDC}_{-} \mathrm{n}^{\circ} 50 / 02$.
c. Trocar piso da Lavanderia em cumprimento à RDC_n $n^{\circ} 50 / 02$.
d. Instalar Sistema de Tratamento de resíduos e esgoto.
e. Adequar Central de Esterilização de Materiais à RDC_n $n^{\circ} 50 / 02$.

3. Equipar lavanderia com novos equipamentos

4. Reequipar sala de emergência/urgência do pronto-socorro para dar condições de sustentação de vida, instalando respirador adequado.

5. Analisar o processo assistencial em função das altas taxas de infecção hospitalar e de cesáreas. 


\section{ANEXO 7 - Vistoria Técnica-Hospitalar - Hospital D}

\section{Identificação do Estabelecimento}

Nome:

D

Diretor Clínico:

CRM:

Data da Vistoria: 24/ Janeiro/ 2003

Acompanhantes:

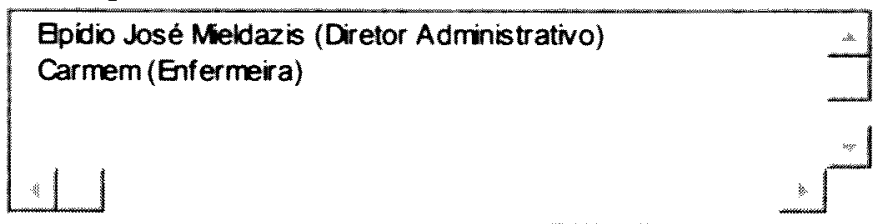

$\mathrm{N}^{\mathbf{o}}$ Total de Leitos:

Total de Leitos Operacionais: $\longdiv { 9 5 }$

$\mathrm{N}^{\mathrm{o}}$ de Leitos Convênio:

\section{Classificação do Estabelecimento}

Tipo de Hospital:

Geral

Lista de Especializações:

\section{Tipo de Serviço}

Tipo de serviço:

Abrangência do serviço

Abrangência do serviço:

Regional $\rightarrow$


Organização e Funcionamento

\begin{tabular}{|c|c|c|c|}
\hline & Incluir & & \\
\hline Recrutamento e Seleção de Pessoal & sim & & \\
\hline $\begin{array}{l}\text { Programas de Treinamento } \\
\text { Educação Continuada }\end{array}$ & $\begin{array}{l}\text { sim } \\
\text { sim }\end{array}$ & & \\
\hline Indicadores Hospitalares & sim & & \\
\hline Relatórios Gerenciais & $\operatorname{sim}$ & & \\
\hline Informatização & $\operatorname{sim}$ & Em Rede & $\operatorname{sim}$ \\
\hline Serviço Social & $\operatorname{sim}$ & & \\
\hline Psicologia Hospitalar & não & & \\
\hline Saúde Ocupacional & $\operatorname{sim}$ & & \\
\hline Ensino e Pesquisa & não & & \\
\hline Residência Médica/Pós-Graduação & não & & \\
\hline Farmácia e Medicamentos & $\operatorname{sim}$ & & \\
\hline Controle e Gestão de Qualidade & $\operatorname{sim}$ & & \\
\hline Regime Interno/regulamento & $\operatorname{sim}$ & Do conhecimento das partes & $\operatorname{sim}$ \\
\hline Comissão de Ética Médica & $\operatorname{sim}$ & Reuniões Regulares / Atas & $\operatorname{sim}$ \\
\hline $\mathrm{CCIH}$ & sim & Reuniões Regulares / Atas & $\operatorname{sim}$ \\
\hline Revisão de Prontuários & $\operatorname{sim}$ & Reuniões Regulares / Atas & $\operatorname{sim}$ \\
\hline Revisão de Óbitos & $\operatorname{sim}$ & Reuniões Regulares / Atas & $\operatorname{sim}$ \\
\hline CIPA & $\operatorname{sim}$ & Reuniões Regulares / Atas & sim \\
\hline Normas e Rotinas e Manuais & $\operatorname{sim}$ & Do conhecimento das partes & $\operatorname{sim}$ \\
\hline
\end{tabular}


Recursos Humanos de todo o Hospital (Ano de $\sqrt{2003}$ )

Profissionais

Quantidade

Médicos contratados

07

Enfermeiros

Técnicos de enfermagem

Auxiliares de enfermagem

Atendentes de enfermagem

Outros Funcionários

Total

\begin{tabular}{|l}
\hline 24 \\
\hline 105 \\
\hline 87 \\
\hline 0 \\
\hline 167 \\
390
\end{tabular}

Informações Gerais (Ano de $\longdiv { 2 0 0 2 }$

Levantamento de dados anual

Número de óbitos após 48 horas

Números de saídas (Altas e Óbitos)

Números de óbitos por causas maternas

Número de pacientes atendidos em Obstetrícia

Número de nascidos vivos

Número de nascidos mortos

Número de óbitos neonatais após 48 horas

Número de óbitos operatórios até 10 dias pós-cirurgia

Número de atos cirurgicos

Número de cesáreas

Número de partos normais

Número total de partos

Número de infeç̧ões atribuiveis ao hospital

Número de supurações de feridas cinúrgicas em cirurgias limpas

Número de cirurgias limpas do período

Número de pacientes/dia

Número de leitos/dia

Número de leitos disponíveis no periodo

\begin{tabular}{|l}
\hline 17 \\
\hline 612 \\
\hline 0 \\
\hline 40 \\
\hline 480 \\
\hline 2 \\
\hline 3 \\
\hline 0 \\
\hline 582 \\
\hline 36 \\
\hline 04 \\
\hline 40 \\
\hline
\end{tabular}

\begin{tabular}{l}
380 \\
\hline 1753 \\
\hline 2321 \\
\hline 95
\end{tabular}


Indicadores de Qualidade (Ano de $\sqrt{2002}$ )

Taxa de mortalidade institucional

Taxa de mortalidade materna

Taxa de natimortalidade

Taxa de mortalidade neonatal

Taxa de mortalidade operatória

Taxa de cesáreas

Taxa de infecção hospitalar

Taxa de supuração de ferida cirúrgica em cirurgia limpa

\begin{tabular}{|c|}
\hline 0,9 \\
\hline 0 \\
\hline 0,6 \\
\hline 0,7 \\
\hline 0,1 \\
\hline 89 \\
\hline 2,96 \\
\hline 0,79 \\
\hline
\end{tabular}

Indicadores de produtividade (Ano de $\sqrt{2002}$ )

Taxa de ocupação

$83,18 \%$

Taxa de permanência

$2,76 \quad$ dias

Giro de rotatividade

$77,30 \quad$ vezes




\section{Estrutura}

Edificação:

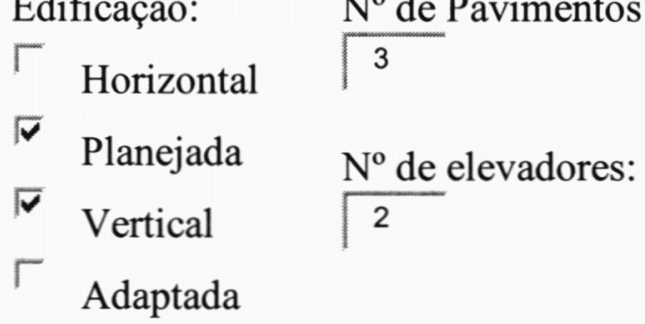

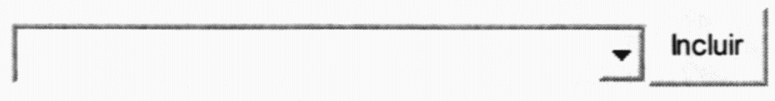

\begin{tabular}{|c|c|c|c|}
\hline Identificação & visível & & 0 \\
\hline Sinalização & $\operatorname{sim}$ & & 0 \\
\hline Área para munutenção/descarga & $\operatorname{sim}$ & & 0 \\
\hline Local próprio para lixo & $\operatorname{sim}$ & & 0 \\
\hline Reservatório de Água & $\operatorname{sim}$ & & 0 \\
\hline Caldeira & $\operatorname{sim}$ & & 0 \\
\hline Cabine Primária de Força & $\operatorname{sim}$ & & 0 \\
\hline Gerador & automático & suficiente para áreas críticas & 0 \\
\hline Prevenção de incêndios & $\operatorname{sim}$ & extintores & 0 \\
\hline Ar Condicionado Central & não & & 0 \\
\hline Sistemas de Resíduos & não & & 0 \\
\hline Sistema de Esgotos & não & & 0 \\
\hline Pára-Raios & $\operatorname{sim}$ & & 0 \\
\hline Estacionamento & $\operatorname{sim}$ & insuficiente & 0 \\
\hline Elevadores & necessário & em número insuficiente & 0 \\
\hline Central de Gases & $\operatorname{sim}$ & Tanque de oxigênio & 0 \\
\hline Central de Gases & $\operatorname{sim}$ & Compressor de ar comprimido & 0 \\
\hline Central de Gases & $\operatorname{sim}$ & Tanque de Nitrogênio & 0 \\
\hline Central de Gases & $\operatorname{sim}$ & Torpedos de $\mathrm{N}_{2} \mathrm{O}$ & 0 \\
\hline
\end{tabular}




\section{Organização e Atenção ao Paciente}

\section{Hotelaria}

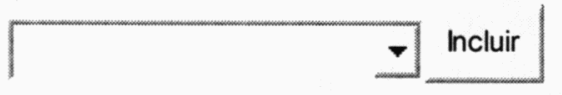

$\begin{array}{ccccc}\text { Recepção } & \text { informatizada } \operatorname{sim} & 0 \\ \text { Limpeza } & \text { ótima } & & 0 \\ \text { Higiene } & \text { ótima } & & 0 \\ \text { Conservação Predial } & \text { boa } & & 0 \\ \text { Recepção } & \text { Sanitários } & \text { sim cada sexo } & 0 \\ \text { Recepção } & \text { Adequada } & \text { sim } & \\ \text { Recepção } & \text { Confortável } & \text { sim } & \end{array}$

Unidades de Internação

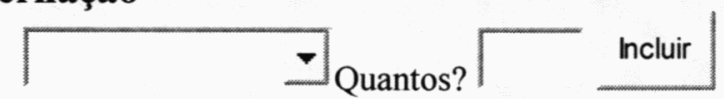

\section{Apartamentos}

cadeira de descanso

sofá/cama acompanhante

Sanitário

Sanitário

barras/apoios

não

porta abrindo para fora

bico de vácuo

bico de oxigênio

frigobar

ar condicionado

telefone

TV

\section{Apartamentos}

$$
\begin{gathered}
\text { Instalações Hidráulicas } \\
\text { Instalações Elétricas } \\
\text { Ventilação } \\
\text { Iluminação } \\
\text { Corredores Livres }
\end{gathered}
$$

Carrinho de emergência

Torpedo de oxigênio na unidade
Adequada

Adequada

Adequada

Adequada

sim

sim

sim

0
0
0
0
0
0
0


Enfermaria

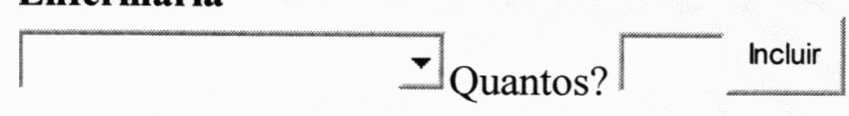

Enfermarias 2 Leitos - Quantos?

bico de vácuo

bico de oxigênio

एक

ar condicionado

telefone

Ventilador

$\operatorname{sim}$

TV

Sanitário

Sanitário

barras/apoios não
porta abrindo para fora

\title{
Enfermarias 2 Leitos
}

\author{
Instalações Hidráulicas \\ Carrinho de emergência \\ Torpedo de oxigênio na unidade
}

Adequada

Adequada

Adequada

Adequada

sim

sim

$\operatorname{sim}$

0 㮘

0 解

0 铯

0 解

0 包

0 通

0 ชู 


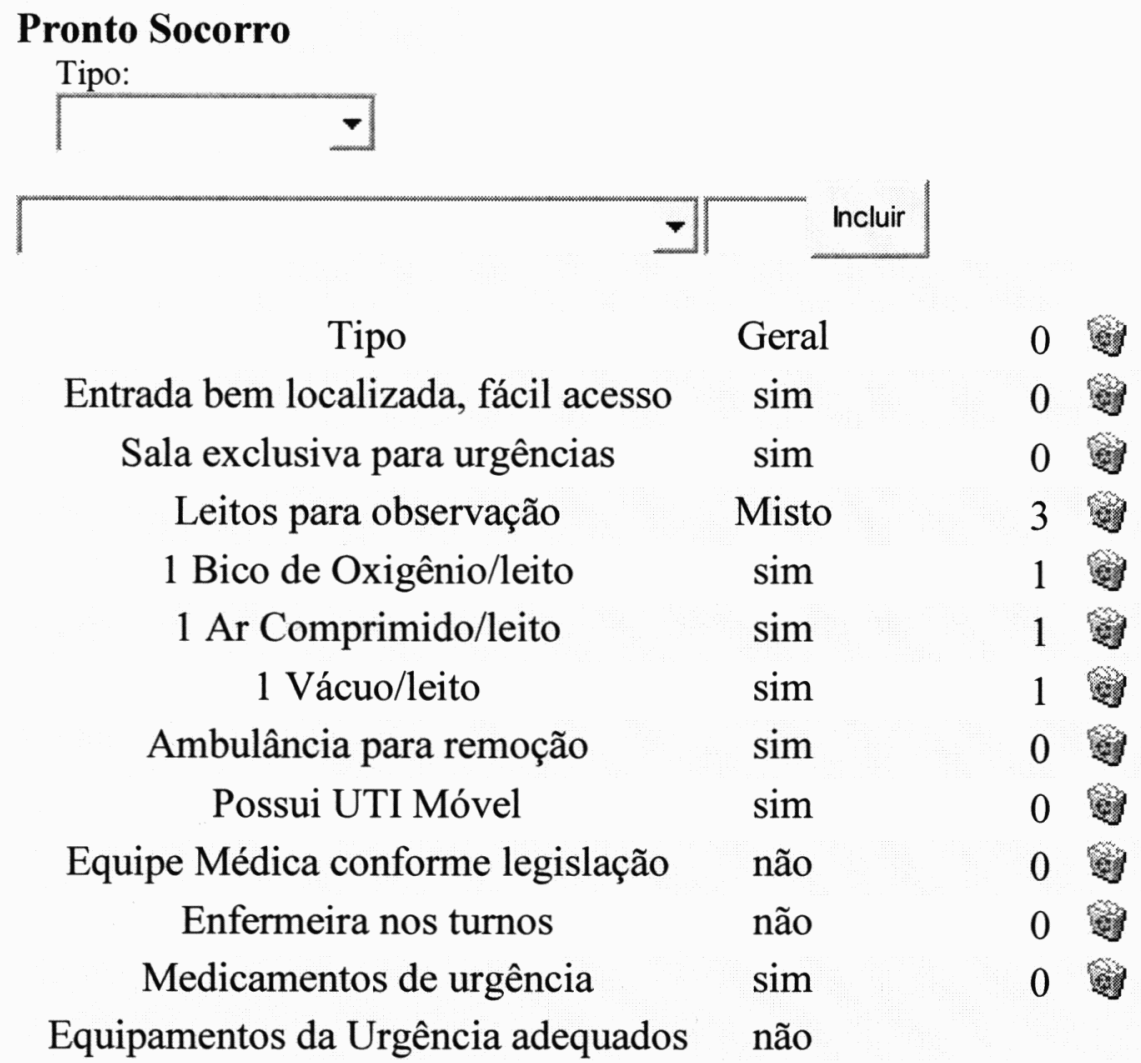

\section{Equipamentos da Urgência}

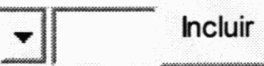

$\begin{array}{ccccc}\text { Desfibrilador } & \text { Ecafix } & \text { MDF-03 } & 1 \\ \text { ECG } & \text { Ecafix } & \text { ECG 6 } & 1 \\ \text { Respirador } & \text { Bird } & \text { Mark-7 } & 1 \\ \text { Monitor FC + ECG } & \text { Ecafix } & \text { TC 500 } & 1\end{array}$

\section{Outras Salas}

\begin{tabular}{llll}
\hline Sala & Tamanho Incluir & \\
Cirurgia & Pequena & & Equips. Excluir
\end{tabular}




\section{UTI Geral}

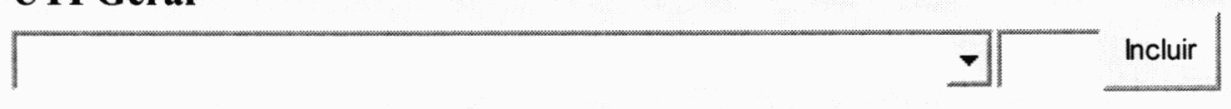

Número de Leitos

01 médico para cada 10 leitos

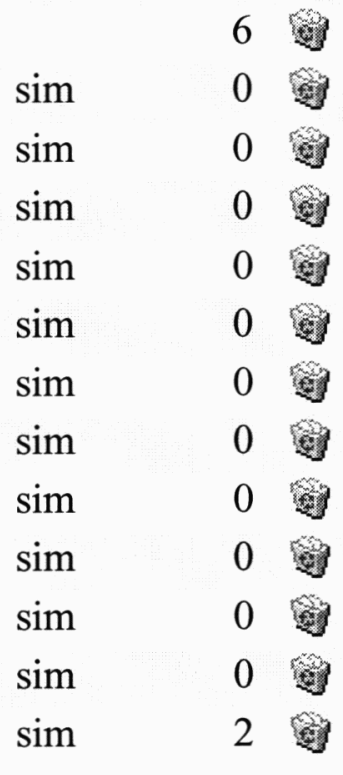

Há normas e rotinas para a área

A UTI participa da CCIH

$\operatorname{sim}$

Há programas de acompanhamento de visita com orientação

Encontra-se em área física adequada

De acordo com a legislação vigente

O posto de enfermagem permite boa visão dos leitos

Há boa circulação de funcionários e pacientes

$\operatorname{sim}$

02 bicos de ar comprimido por leito

02 bicos de vácuo por leito

$\operatorname{sim}$

10 tomadas elétricas por leito

$\operatorname{sim}$

\section{Equipamentos}

\begin{tabular}{ccccc}
\hline & & & & \\
& & Incluir \\
Respirador & Intermed & Inter 5 & 6 \\
Respirador & Newport & Breeze & 1 \\
Respirador & Bird & Mark-7 & 2 \\
Monitor multiparâmetro & Intermed & Tracer 5 & 1 \\
Capnógrafo & EMAI & & 1 \\
Monitor de PIC & Coleman & ICP express & 1 \\
ECG & Ecafix & ECG 6 & 1 \\
Bomba de Infusão & Nikkiso & PFA-06 & 12
\end{tabular}




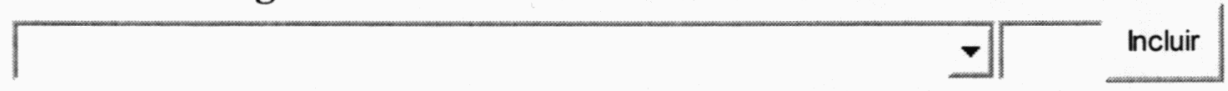

Há normas e rotinas para a área

A UTI participa da $\mathrm{CCIH}$

$\begin{array}{ll}\operatorname{sim} & 0 \\ \operatorname{sim} & 0 \\ \operatorname{sim} & 0 \\ \operatorname{sim} & 0 \\ \operatorname{sim} & 0 \\ \operatorname{sim} & 0 \\ \operatorname{sim} & 0 \\ \operatorname{sim} & 0 \\ \operatorname{sim} & 0 \\ \operatorname{sim} & 0 \\ \operatorname{sim} & 0 \\ \operatorname{sim} & 0 \\ \operatorname{sim} & 4 \\ \operatorname{sim} & 1 \\ \operatorname{sim} & \\ \operatorname{sim} & \end{array}$

\section{Equipamentos}

\begin{tabular}{cccc|}
\hline & & & \\
Respirador & Bird & 6400 & 4 \\
Monitor multiparâmetro & SpaceLab & & 4 \\
Capnógrafo & EMAI & Capnocheck & 1 \\
Desfibrilador & Ecafix & DF-03 & 1 \\
Marca-Passo externo & Biotronik & EDP20A & 2 \\
ECG & Ecafix & ECG 6 & 1 \\
Bomba de Infusão & Lifemed & LF-2001 & 9 \\
Bomba de Infusão & BBraun & Nutrimat II & 3 \\
Bomba de Infusão & Digibomb & & 6 \\
Bomba de Infusão & Baxter & & 12 \\
Bomba de infusão por seringa & BBraun & Perfusor Compact & 4 \\
Bomba de infusão por seringa & Samtronic & ST MS & 4 \\
Hemofiltrador lento & BBraun & FAD 100 & 1
\end{tabular}


चा Incluir

Há normas e rotinas para a área

A UTI participa da CCIH

$\operatorname{sim}$

$\operatorname{sim}$

0.

Há programas de acompanhamento de visita com orientação

$\operatorname{sim}$

0 จ

Encontra-se em área física adequada

$\operatorname{sim}$

0 ig

De acordo com a legislação vigente

$\operatorname{sim}$

0 歇

O posto de enfermagem permite boa visão dos leitos

$\operatorname{sim}$

0 क्षे

Há boa circulação de funcionários e pacientes

$\operatorname{sim}$

0 辇

Possui médico diarista

$\operatorname{sim}$

0 迎

Possui equipe médica em todos os turnos

Equipe de enfermagem treinada e completa

$\operatorname{sim}$

0 绗

Enfermeira em todos os turnos

sim

0 (2)

$\operatorname{sim}$

0 行

Número de Leitos

Há leitos para isolamento

02 bicos de oxigênio por leito

02 bicos de ar comprimido por leito

02 bicos de vácuo por leito

10 tomadas elétricas por leito

$\operatorname{sim}$

0 एक

\section{Equipamentos}

\begin{tabular}{|c|c|c|c|}
\hline & 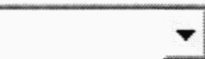 & Incluir & \\
\hline Respirador & Intermed & Inter 3 & 4 \\
\hline Incubadora & Fanem & C186-TS/ST & 2 \\
\hline Bomba de Infusão & Nikkiso & PFA-06 & 4 \\
\hline Monitor multiparâmetro & SpaceLab & & 4 \\
\hline Berço aquecido calor irradiante & Fanem & BA-51 TS & 4 \\
\hline Monitor de FC + oxímetro & Criticare & 504 & 1 \\
\hline Monitor FC + ECG & Ecafix & Active & 2 \\
\hline Oxímetro & Ecafix & Active & 2 \\
\hline Bomba de infusão por seringa & Samtronic & ST 670 infantil & 4 \\
\hline Hemofiltrador lento & BBraun & FAD 100 & 1 \\
\hline
\end{tabular}


Sala de admissão $\operatorname{sim}$

Sala/leitos de pré-parto

$\operatorname{sim}$

Sala de parto normal

Sala de parto cirúrgico

Vestiário com sanitário para ambos os sexos

$\operatorname{sim}$

$\operatorname{sim}$

$\operatorname{sim}$

Sala de estar e repouso para funcionários e médicos

$\operatorname{sim}$

Recuperação pós-anestésica (RPA)

$\operatorname{sim}$

$O$ parto é realizado por:

Médico

Há disponibilidade de médico obstetra no local durante 24 horas

$\operatorname{sim}$

O neonatologista recepciona todos os $\mathrm{RNs}$

$\operatorname{sim}$

$\operatorname{sim}$

$\operatorname{sim}$

Há disponibilidade de anestesista durante 24 horas

$\operatorname{sim}$

$\operatorname{sim}$

Há pia com água corrente na sala de reanimação

$\operatorname{sim}$

02 bicos de ar comprimido por leito

$\operatorname{sim}$

02 bicos de vácuo por leito

sim

10 tomadas elétricas por leito

$\operatorname{sim}$

\section{Salas}

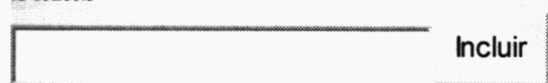

Parto normal

Reanimação do RN

Parto cirúrgico

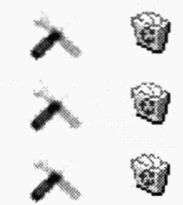

Área: Maternidade

Sala: Parto normal

\section{Equipamentos}

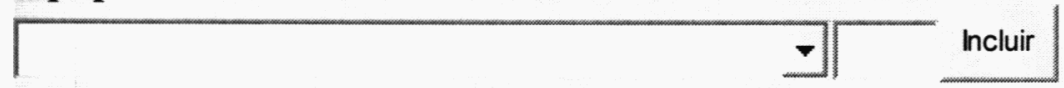

Mesa de parto

Foco Central de Teto

Área: Maternidade

Sala: Reanimação do RN 


\section{Equipamentos}

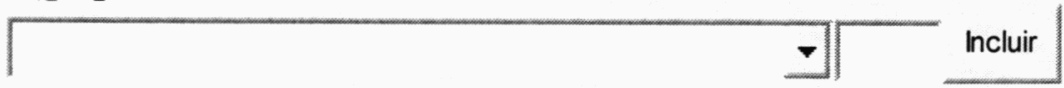

Berço aquecido calor irradiante Fanem BA-51 TS 2 \%

Área: Maternidade

Sala: Parto cirúrgico

\section{Equipamentos}

\begin{tabular}{|c|c|c|c|}
\hline & & & 7 \\
\hline Carrinho de anestesia & Takaoka & Fuji & 1 \\
\hline Bisturi elétrico & WEM & SS-500 & 1 \\
\hline Oxímetro & Ohmeda & & 1 \\
\hline Monitor FC + ECG & Funbec & TC 500 & 1 \\
\hline
\end{tabular}

\section{Berçário}

Incluir

Há berçário de primeiros cuidados sim

Há berçário de patológicos

$\operatorname{sim}$

Há alojamento conjunto

$\operatorname{sim}$

Há UTI neonatal

2 bicos de oxigênio/leito

$\operatorname{sim}$

2 bicos de ar comprimido/leito

sim

Incluir

2 bicos de vácuo/leito

sim

$\operatorname{sim}$ 


\section{Centro Cirúrgico}

Área de recepção de paciente com passa maca

Área de Escovação

$\operatorname{sim}$

Posto de Enfermagem e Serviços

$\operatorname{sim}$

$\operatorname{sim}$

Vestiários com sanitários para funcionários com barreira

$\operatorname{sim}$

Sala de preparo de equipamentos e material

$\operatorname{sim}$

Depósito de equipamentos e materiais

$\operatorname{sim}$

Sala administrativa

$\operatorname{sim}$

Depósito de Material de Limpeza

$\operatorname{sim}$

Sala de estar para funcionários

Sala de Espera com sanitário para acompanhantes

Área para guarda de macas e cadeira de rodas

Sala de Biópsia de congelação(Anatomia Patológica)

Fluxos pacientes/funcionários por entradas diferentes

$\operatorname{sim}$

$\operatorname{sim}$

$\operatorname{sim}$

$\operatorname{sim}$

$\operatorname{sim}$

sim

$\operatorname{sim}$

2 bicos de oxigênio/leito

$\operatorname{sim}$

2 bicos de ar comprimido/leito

$\operatorname{sim}$

2 bicos de vácuo/leito

\section{Centro Cirúrgico/Salas}

\begin{tabular}{|c|c|c|c|}
\hline & $\nabla$ Incluir & & \\
\hline Sala & Tamanho & Equips. & Excluir \\
\hline 01 & Especial & $\lambda$ & (9) \\
\hline 02 & Média & $\lambda$ & \\
\hline 03 & Média & $\lambda$ & \\
\hline 04 & Grande & $\lambda$ & \\
\hline 05 & Média & $\lambda$ & 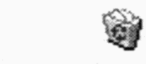 \\
\hline 06 & Grande & $\lambda$ & 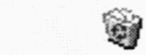 \\
\hline 07 & Média & $\lambda$ & 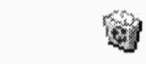 \\
\hline Reserva & Grande & $\lambda$ & \\
\hline
\end{tabular}




\section{Centro Cirúrgico}

Sala: 01

\section{Equipamentos}

\begin{tabular}{|c|c|c|c|}
\hline & 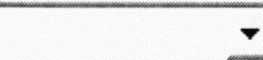 & Incluir & \\
\hline Carrinho de anestesia & Takaoka & Origami & 1 의 \\
\hline Bisturi elétrico & WEM & SS-500 & 1 \\
\hline Oxicapnógrafo & Ohmeda & Oxicap X 700 & 1 \\
\hline Monitor FC + ECG & Funbec & TC 500 & 1 \\
\hline Bomba de CEC & Braile & BEC 2000 & 1 \\
\hline Bomba de CEC & Macchi & & 1 㮘 \\
\hline $\begin{array}{c}\text { Aparelho de Coagulação } \\
\text { Ativada }\end{array}$ & Braile & MCA 2000 & 1 (3) \\
\hline Cell Saver & Haemonetics & & 1 \\
\hline Desfibrilador & Ecafix & MDF-03 & 1 \\
\hline Balão Intra-Aórtico & Datascope & System 90 & 1 \\
\hline Balão Intra-Aórtico & Arrow & Acat 1 & 1 \\
\hline Monitor multiparâmetro & SpaceLab & & 1 gु \\
\hline
\end{tabular}

\section{Centro Cirúrgico}

Sala: 02

\section{Equipamentos}

\begin{tabular}{|ccccc|}
\hline & & & & \\
Carrinho de anestesia & Takaoka & Fuji & 1 & Incluir \\
Bisturi elétrico & WEM & SS-500 & 1 & 1 \\
Oxicapnógrafo & Ohmeda & Oxicap X 700 & 1 \\
Monitor FC + ECG & Funbec & TC 500 & 1
\end{tabular}


Centro Cirúrgico

Sala: 03

Equipamentos

\begin{tabular}{|c|c|c|c|}
\hline & & $=$ & cluir \\
\hline Carrinho de anestesia & Takaoka & Fuji & 1 \\
\hline Bisturi elétrico & WEM & SS-500 & 1 \\
\hline Oxicapnógrafo & Ohmeda & Oxicap X 700 & 1 \\
\hline Monitor FC + ECG & Funbec & TC 500 & 1 \\
\hline
\end{tabular}

\section{Centro Cirúrgico}

Sala: 04

\section{Equipamentos}

\begin{tabular}{ccccc}
\hline & & & & \\
Carrinho de anestesia & Takaoka & Sansei & 1 \\
Bisturi elétrico & WEM & SS-500 & 1 \\
Oxímetro & Ohmeda & & 1 \\
Capnógrafo & Ohmeda & & 1 \\
Monitor FC + ECG & Funbec & TC 500 & 1
\end{tabular}

Centro Cirúrgico

Sala: 05

\section{Equipamentos}

\begin{tabular}{cccc}
\hline & & Fuji & 1 \\
Carrinho de anestesia & Takaoka & SS-500 & 1 \\
Bisturi elétrico & WEM & & 1 \\
Oxímetro & Ohmeda & TC 500 & 1 \\
Monitor FC + ECG & Funbec &
\end{tabular}




\section{Centro Cirúrgico}

Sala: 06

\section{Equipamentos}

\begin{tabular}{ccccc}
\hline & & & & \\
Carrinho de anestesia & Takaoka & Fuji & 1 \\
Bisturi elétrico & WEM & SS-500 & 1 & 1 \\
Oxímetro & Ohmeda & & 1 & 1 \\
Monitor FC + ECG & Funbec & TC 500 & 1
\end{tabular}

\section{Centro Cirúrgico}

Sala: 07

\section{Equipamentos}

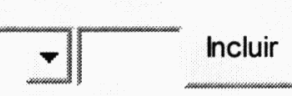

$\begin{array}{ccccc}\text { Bisturi elétrico } & \text { WEM } & \text { SS-500 } & 1 \\ \text { Monitor FC + ECG } & \text { Funbec } & \text { TC 500 } & 1\end{array}$

\section{Centro Cirúrgico}

Sala: Reserva

\section{Equipamentos}

\begin{tabular}{|c|c|c|c|}
\hline & 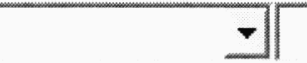 & Incluir & \\
\hline Carrinho de anestesia & Takaoka & Origami & 2 \\
\hline Bisturi elétrico & WEM & SS-500 & 4 \\
\hline Oxímetro & Ohmeda & & 1 \\
\hline Bomba de Infusão & Nikkiso & PFA-06 & 1 \\
\hline Bomba de infusão por seringa & Samtronic & ST MS & 2 \\
\hline Monitor FC + ECG & Funbec & TC 500 & 2 \\
\hline Microscópio cirúrgico & DFVasconcellos & MC M32 & 1 \\
\hline Arco Cirúrgico & Siemens & Siremobil & 1 \\
\hline Colchão térmico & BioTherm & BT200 & 1 \\
\hline Berço aquecido calor irradiante & Fanem & BA-51 TS & 1 \\
\hline Mesa cirúrgica ortopédica & & & 2 \\
\hline Garrote Pneumático & Gerar & & 1 \\
\hline
\end{tabular}




\begin{tabular}{|c|c|c|c|c|}
\hline \multicolumn{5}{|c|}{ Quantidade } \\
\hline \multirow[b]{2}{*}{ Pequena } & \multicolumn{2}{|c|}{ Operacionais } & \multicolumn{2}{|c|}{ Desativadas } \\
\hline & 0 & 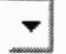 & 0 & $F$ \\
\hline Média & 4 & $\nabla$ & 0 & 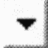 \\
\hline Grande & 2 & $\nabla$ & 0 & $\nabla$ \\
\hline Especial & 1 & $\nabla$ & 0 & $\nabla$ \\
\hline Total & & & & \\
\hline
\end{tabular}

RPA

\begin{tabular}{cc|} 
Área Física & adequada \\
Monitor de FC & $\operatorname{sim}$ \\
Oxímetro & $\operatorname{sim}$ \\
01 bico de oxigênio/leito & $\operatorname{sim}$ \\
01 bico ar comprimido/leito & $\operatorname{sim}$ \\
01 bico de vácuo/leito & $\operatorname{sim}$ \\
Desfibrilador & $\operatorname{sim}$ \\
$\mathrm{RH}$ & adequados
\end{tabular}


Serviços de Apoio Diagnóstico e Terapia

SADT

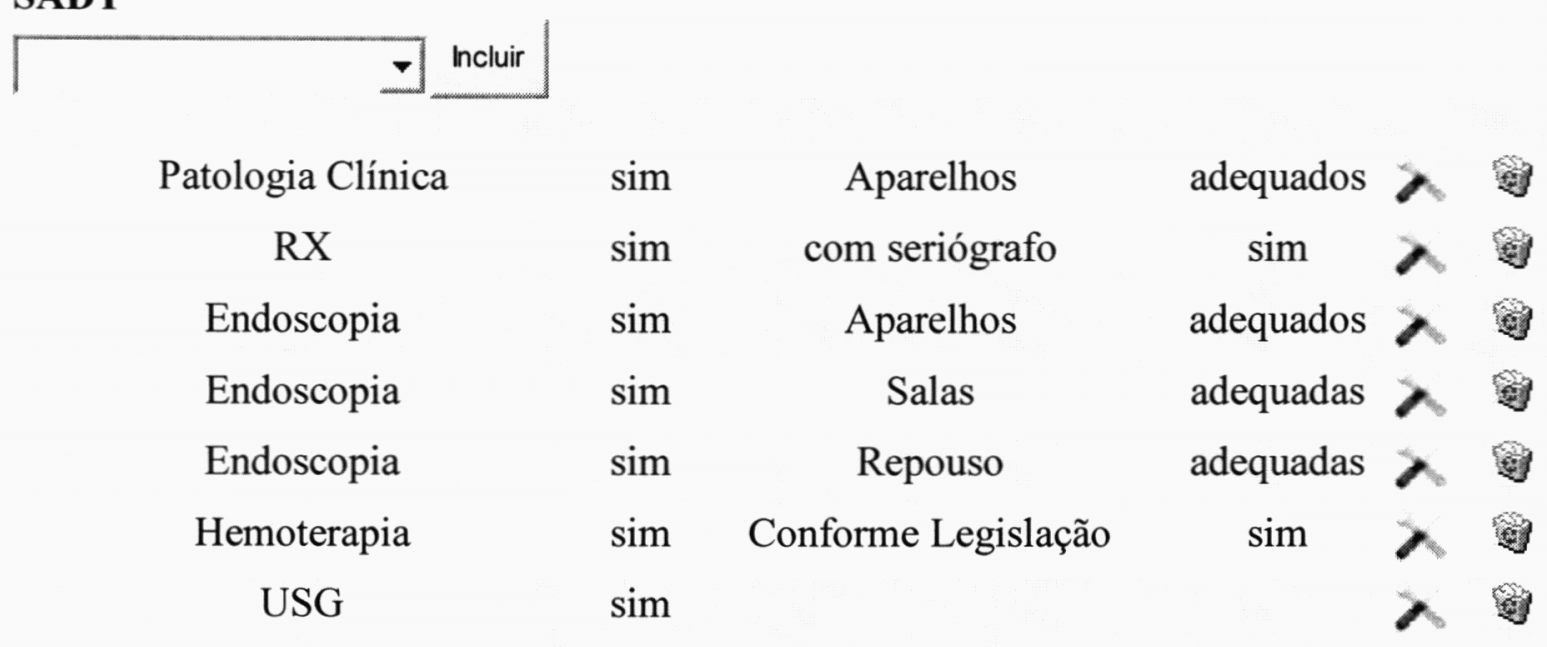

\section{Equipamentos}

\begin{tabular}{|cccc|}
\hline & & & \\
Bioquímica & Bayer & Technicon RA-XT & 1 \\
Hemogasômetro & Radiometer & ABL 5 & 1 \\
Eletrólitos Na, $\mathrm{K}, \mathrm{Ca}$ e Cl & Radiometer & EML 100 & 1 \\
Coagulação & Dade Behring & Fibrintimer II & 1 \\
Espectrofotômetro & CELM & $210-\mathrm{D}$ & 1 \\
Urina & Bayer & Clintek & 1 \\
Hematologia & Coulter & ACT & 1
\end{tabular}

\section{Equipamentos}

\begin{tabular}{ccccc}
\hline & & & \\
RX com seriógrafo & Siemens $800 \mathrm{~mA}$ & Polymat 3050 & 1 \\
RX & CGR & Triplunix & 1 \\
RX panorâmico de mandíbula & Siemens & Namodor 2 PO & 1 & 1 \\
Reveladora & Kodak & RPX omat & 1 \\
RX & Siemens & Pleophoss 4S & 1 \\
RX & Spitzer & & 1
\end{tabular}

Equipamentos

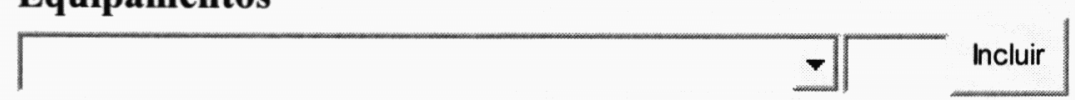

$\begin{array}{ccccc}\text { USG } & \text { Toshiba com } 03 \text { transdutores } & \text { Tosbee } & 1 & 1 \\ \text { USG } & \text { Envision } & \text { AI 5200S } & 1\end{array}$


SADT - Acessório

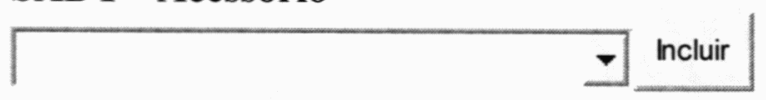

Angiografia Digital/Hemodinâmica sim

Ecografia

Mamografia

Mamografia

Tomografia $\operatorname{sim}$

$\operatorname{sim}$

$\operatorname{sim}$

sim Conforme Legislação adequados

adequados

adequados

não

$\operatorname{sim}$

Incluir

\section{Equipamentos}

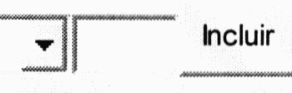

$\begin{array}{ccccc}\text { Angiografia Digital } & \text { Philips } & \text { Integris } & 1 \\ \text { Bomba injetora } & \text { Angiomat } & 1 & \text { Siemens } & 1\end{array}$

\section{Equipamentos}

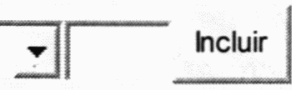

Mamógrafo Philips Mammodiagnostic BC 1 is

\section{Equipamentos}

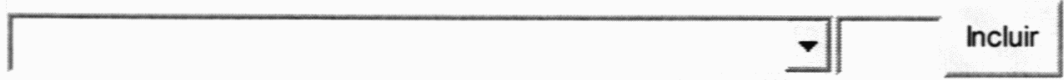

Tomografia helicoidal Toshiba Auklet 1 원 


\section{Apoio Técnico e Administrativo}

\section{Farmácia}

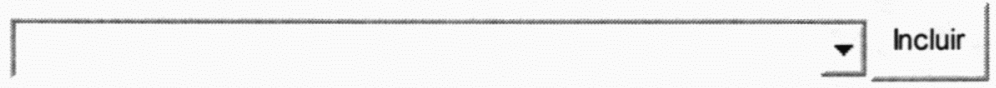

Há controle dos medicamentos Port 344

$\operatorname{sim}$

A farmácia manipula NPP

não

Em área adequada conforme legislação

não

Há local adequado para preparo dos medicamentos

não

Há local adequado para dispensação

Há farmacêutico no local

$\operatorname{sim}$

Há padronização de medicamentos

Dispensação

Há capela de fluxo laminar $\operatorname{sim}$

sim

Individualizada

$\operatorname{sim}$

SND

\section{$\nabla$ Incluir}

Circulação adequada

Equipamentos necessários e conservados

Área adequada com boa iluminação e aeração

Existe bancada para manipulação dos alimentos

Há cardápio afixado

Há Nutricionista

$\begin{array}{ll}\operatorname{sim} & 0 \\ \operatorname{sim} & 0 \\ \operatorname{sim} & 0 \\ \operatorname{sim} & 0 \\ \operatorname{sim} & 0 \\ \operatorname{sim} & \text { Quantas }\end{array}$

\section{Limpeza/Higiene}

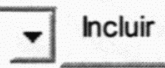

Há normas e rotinas para limpeza da unidade sim

Utilizam produtos próprios para limpeza sim

A CCIH participa na elaboração de normas do setor sim

Há coleta seletiva do lixo sim

Funcionários utilizam equipamentos de proteção sim

Lavanderia - terceirizada e externa

$\nabla$ Incluir

\section{Almoxarifado}

$\nabla$ Incluir

Área apropriada

$\operatorname{sim}$

Estoques suficientes

$\operatorname{sim}$

Setor informatizado

$\operatorname{sim}$ 


\section{Manutenção}

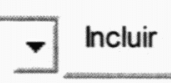

$\operatorname{sim}$

Própria

Vigilancia

$\nabla$ Incluir

$\operatorname{sim}$

Própria

SAME

Informatizado sim

Prontuário conforme Legislação sim

\section{Central Esterilização}

Central Esterilização:

Encontra-se instalado em área física adequada

Tem área para expurgo do material

Tem área para estocagem/distribuição

Há enfermeira responsável

Há normatização de procedimentos na área

$\operatorname{sim}$

$\operatorname{sim}$

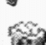

$\operatorname{sim}$

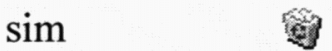

$\operatorname{sim}$

Há cruzamento de fluxo de circulação entre as áreas

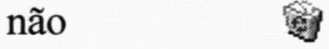

Funcionários paramentados adequadamente

$\operatorname{sim}$

Possui estufas

não

0 约

Possui Autoclave vertical

Há manutenção preventiva de equipamentos

não

0 解

É utilizado Controle Biológico

$\operatorname{sim}$

ชู

Possui Autoclave horizontal

$\operatorname{sim}$

if

$\operatorname{sim} 2$

\section{Periodicidade}

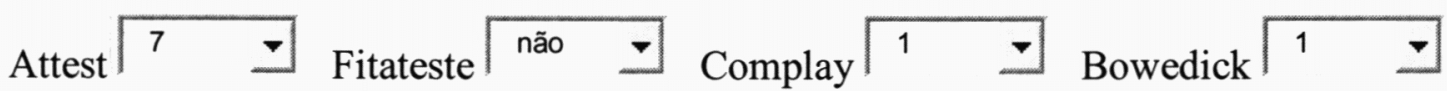




\section{Parecer:}

- Hospital geral privado com 95 leitos operacionais, com nível de atendimento secundário.

- Estrutura física: vertical, adaptada, com sinalização adequada e em boas condições de higiene e limpeza. Pronto-atendimento geral com sala de urgência montada, necessitando de respirador adequado. Maternidade, Berçário, UTI geral, Pediátrica e Neonatal, Centro Cirúrgico com 07 salas, RPA com 10 leitos com recursos adequados e Unidades de Internação.

- Estrutura básica: gerador para suporte às áreas críticas, cabine primária de força, central de gases, sistema de prevenção de incêndios com extintores e hidrantes, pára-raios e 02 elevadores.

- Hotelaria: apartamentos confortáveis com TV, telefone, frigobar, ar condicionado, com 01 bico de oxigênio, 01 de ar comprimido e 01 de vácuo. Sanitários: porta abrindo para fora, box/cortina, sem barras/apoios, contrariando a RDC_50/02. Enfermarias confortáveis com TV, telefone e ventilador, com 01 bico de oxigênio e 01 de vácuo. Sanitários: porta abrindo para fora, box/cortina, sem barras/apoios, contrariando a RDC_50/02.

- Serviços de apoio: farmácia com 01 farmacêutico, dispensação por sistema individualizado, com padronização dos medicamentos. SND com 01 nutricionista e cardápio afixado semanalmente. Serviço de limpeza com normas e rotinas e participação da CCIH. Manutenção Própria. Lavanderia terceirizada. Manutenção própria. Central de Esterilização de Materiais adequada.

- SADT: Angiografia Digital, Ecocardiografia, ECG, Hemoterapia, Quimioterapia, Mamografia, Patologia Clínica, Radiologia, Tomografia e USG.

- Organização e funcionamento: Regulamento Interno, Normas, Rotinas, Setor de Recrutamento e Seleção de Pessoal, Indicadores Hospitalares, Relatórios Gerenciais, Informatização em Rede (exceto o prontuário eletrônico), Setor de Saúde Ocupacional, Serviço Social. Comissões de Ética Médica, CCIH, Ensino e Pesquisa, CIPA, Farmácia e Medicamentos, Controle e Gestão de Qualidade, Marketing, Informática e Plano Diretor. Hospital acreditado pela ONA.

- Recursos Humanos

o Servidores/ leito: 4,10

o Proporção funcionários de enfermagem/ leito: 2,27

o.Enfermeiros/ leito: 0,25 
o Técnicos e Auxiliares de Enfermagem/ leito: 2,02

- Indicadores de Qualidade

○ Taxa de Mortalidade Institucional: 0,9\%

o Taxa de Cesáreas: $89 \%$

o Taxa de Infecção Hospitalar: 2,96\%

- Indicadores de Produtividade

O Taxa de Ocupação: $83,18 \%$

- Taxa de Permanência: 2,76 dias

o Giro de Rotatividade: 6,44 pacientes/mês

\section{Parecer:}

Consideramos o Hospital D apto.

Para tanto há a necessidade de:

1. Resolver problemas estruturais:

- Adequar área física da UTI neonatal à RDC no 50/02.

- Adequar sanitários à RDC no 50/02 (instalação de barras/apoios).

2. Implantar sistema de tratamento de resíduos e esgoto.

3. Reequipar sala de emergência/urgência do pronto-atendimento para dar condições de sustentação de vida (imediato), com instalação de respirador adequado. 


\section{ANEXO 8 - Vistoria Técnica-Hospitalar - Hospital E}

\section{Identificação do Estabelecimento}

Nome:

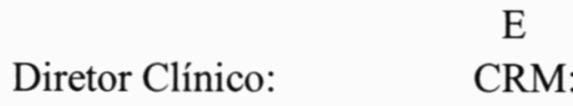

Data da Vistoria: $\begin{array}{lll}16 & \square\end{array}$

Acompanhantes:

\begin{tabular}{ll}
\hline A parecida Giselda C. Fanelli \\
\\
$\mathrm{N}^{\circ}$ Total de Leitos: & 70 \\
Total de Leitos Oper: & 70 \\
$\mathrm{~N}^{\circ}$ de Leitos Convênio: & 70
\end{tabular}

\section{Classificação do Estabelecimento}

Tipo de Hospital:

Geral $\quad \square$

Lista de Especializações:

Geral

ชิ

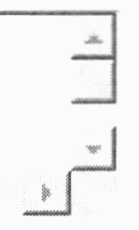

\section{Tipo de Serviço}

Tipo de serviço:

Privado

Abrangência do serviço

Abrangência do serviço:

Regional


Organização e Funcionamento

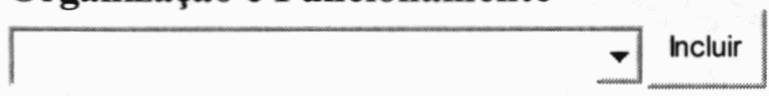

Farmácia e Medicamentos
Controle e Gestão de Qualidade
Ensino e Pesquisa
Residência Médica/Pós-Graduação
Normas e Rotinas e Manuais
Regime Interno/regulamento
Recrutamento e Seleção de Pessoal
Programas de Treinamento
Educação Continuada
Indicadores Hospitalares
Relatórios Gerenciais
Informatização
Serviço Social
Psicologia Hospitalar
Saúde Ocupacional
Comissão de Ética Médica
CCIH
Revisão de Prontuários
Revisão de Óbitos
CIPA

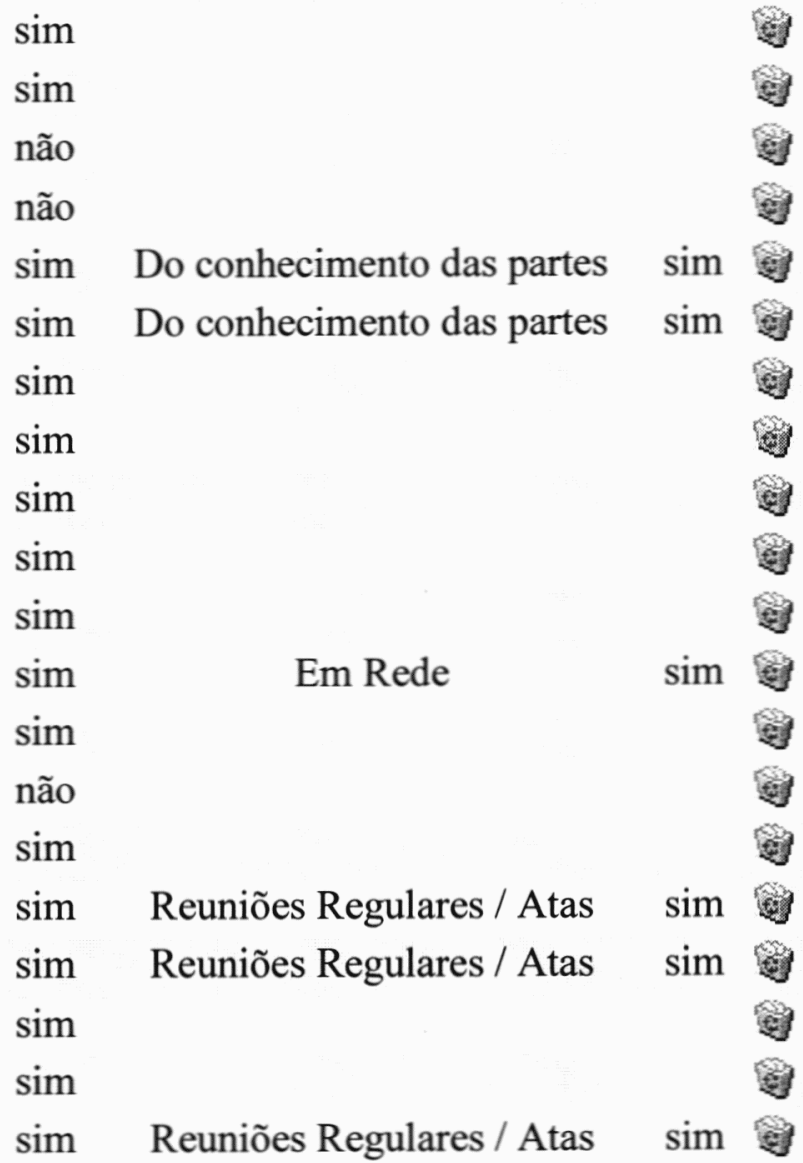


Recursos Humanos de todo o Hospital (Ano de $\sqrt{2003}$ )

Profissionais

Médicos

Enfermeiros

Técnicos de enfermagem

Auxiliares de enfermagem

Atendentes de enfermagem

Outros Funcionários

Total

\section{Corpo clinico aberto}

\begin{tabular}{l}
\hline 16 \\
\hline 59 \\
\hline 55 \\
\hline 0 \\
139 \\
269
\end{tabular}

Informações Gerais (Ano de $\longdiv { 2 0 0 2 }$

Levantamento de dados anual

Número de óbitos após 48 horas

Números de saidas (Altas e Óbitos)

Números de óbitos por causas maternas

Número de pacientes atendidos em Obstetrícia

Número de nascidos vivos

Número de nascidos mortos

Número de óbitos neonatais após 48 horas

Número de óbitos operatórios até 10 dias pós-cirurgia

Número de atos cirurgicos

Número de cesáreas

Número de partos normais

Número total de partos

\begin{tabular}{|l}
\hline 69 \\
\hline 6122 \\
\hline 1 \\
\hline 604 \\
\hline 595 \\
\hline 2 \\
\hline 0 \\
\hline 5 \\
\hline 6003 \\
\hline 450 \\
\hline 139 \\
\hline 589 \\
\hline
\end{tabular}

Número de infecções atribuíveis ao hospital

Número de supurações de feridas cirúrgicas em cirurgias limpas

Número de cirurgias limpas do período

Número de pacientes/dia

Número de leitos/dia

Número de leitos disponíveis no período 
Indicadores de Qualidade (Ano de $\sqrt{2002}$ )

Taxa de mortalidade institucional

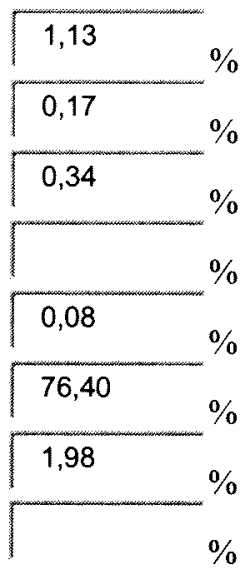

Indicadores de produtividade (Ano de $\sqrt{5902}$ )
Taxa de ocupação
$\begin{aligned} & \text { Taxa de permanência } \\ & \text { Giro de rotatividade }\end{aligned}$




\section{Estrutura}

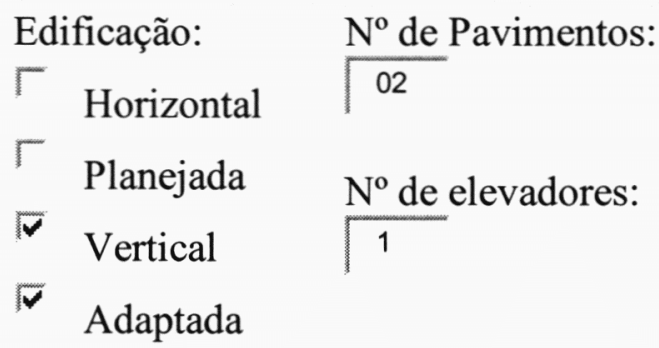

\begin{tabular}{|c|c|c|c|c|}
\hline- & Incluir & & & \\
\hline Identificação & visível & & 0 & 崭 \\
\hline Estacionamento & $\operatorname{sim}$ & suficiente & 0 & 20 \\
\hline Sinalização & $\operatorname{sim}$ & & 0 & (3) \\
\hline Área para munutenção/descarga & $\operatorname{sim}$ & & 0 & (2) \\
\hline Elevadores & necessário & em número insuficiente & 0 & 通 \\
\hline Local próprio para lixo & $\operatorname{sim}$ & & 0 & • \\
\hline Reservatório de Água & $\operatorname{sim}$ & & 0 & $\cdot$ \\
\hline Caldeira & não & & 0 & 8 \\
\hline Gerador & automático & suficiente para áreas críticas & 0 & 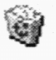 \\
\hline Cabine Primária de Força & $\operatorname{sim}$ & & 0 & 泡 \\
\hline Central de Gases & $\operatorname{sim}$ & Tanque de oxigênio & 0 & 约 \\
\hline Central de Gases & $\operatorname{sim}$ & Compressor de ar comprimido & 0 & (6) \\
\hline $\begin{array}{c}\text { Central de Gases } \\
\text { Ar Condicionado Central }\end{array}$ & $\begin{array}{l}\text { sim } \\
\text { não }\end{array}$ & Torpedos de $\mathrm{N}_{2} \mathrm{O}$ & 0 & 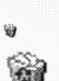 \\
\hline Sistemas de Tratamento de Resíduos & não & & 0 & 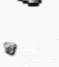 \\
\hline Sistema de Esgotos & não & & 0 & (2) \\
\hline Pára-Raios & $\operatorname{sim}$ & & 0 & 8 \\
\hline Sistema de Prevenção de Incêndios & $\operatorname{sim}$ & Extintores & 0 & - \\
\hline Sistema de Prevenção de Incêndios & $\operatorname{sim}$ & Hidrantes & 0 & (2) \\
\hline Sistema de Prevenção de Incêndios & $\operatorname{sim}$ & Brigada de incêndio & 0 & 6 \\
\hline
\end{tabular}


Organização e Atenção ao Paciente

\section{Hotelaria}

\begin{tabular}{|ccc|}
\hline & Adequada & \\
Recepção & Incluir & \\
Recepção & Confortável & \\
Recepção & informatizada & sim \\
Recepção & Sanitários & sim \\
Limpeza & ótima & \\
Higiene & ótima & \\
Conservação Predial & ótima &
\end{tabular}

Unidades de Internação

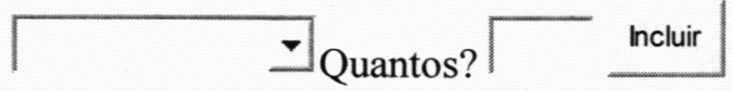

Apartamentos - Quantos? 1

bico de vácuo

bico de ar

bico de oxigênio

Sanitário

Sanitário

porta abrindo para fora

cadeira de descanso

barras/apoios sim

cada sexo

$\begin{array}{ll}0 & 0 \\ 0 & 0 \\ 0 & 0 \\ 0 & 0 \\ 0 & 0 \\ 0\end{array}$

sofá/cama acompanhante

frigobar

ar condicionado

telefone

TV

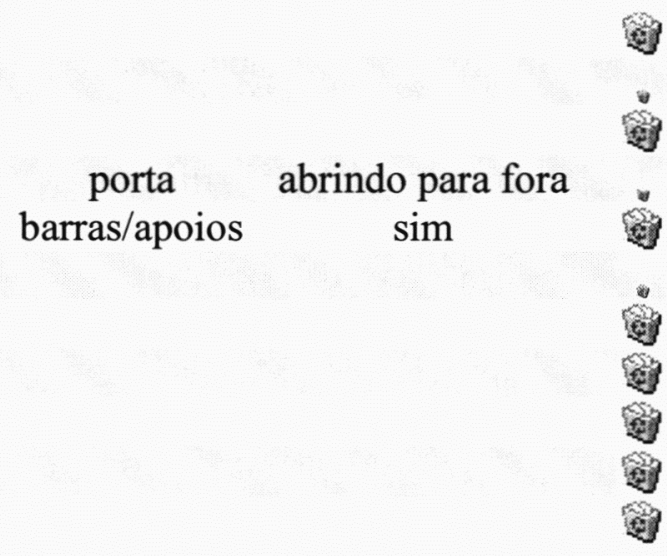

\section{Apartamentos}

$\begin{array}{ccc}\text { Instalações Hidráulicas } & \text { Adequada } & 0 \\ \text { Instalações Elétricas } & \text { Adequada } & 0 \\ \text { Ventilação } & \text { Adequada } & 0 \\ \text { Iluminação } & \text { Adequada } & 0 \\ \text { Corredores Livres } & \operatorname{sim} & 0 \\ \text { Carrinho de emergência } & \operatorname{sim} & 2 \\ \text { Torpedo de oxigênio na unidade } & \operatorname{sim} & 0\end{array}$




\section{Enfermaria}

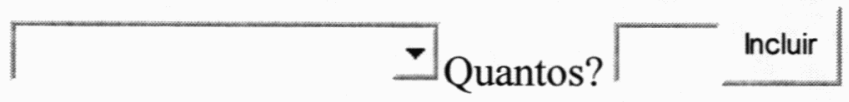

Enfermarias 2 Leitos - Quantos? 1

$\begin{array}{ccc}\text { Sanitário } & \text { Barras/Apoios } & \text { sim } \\ \text { Sanitário } & \text { Porta } & \text { Abrindo para fora } \\ \text { bico de vácuo } & & \\ \text { bico de ar } & & \\ \text { bico de oxigênio } & & \\ \text { ar condicionado } & \\ \text { telefone } & & \\ \text { TV } & & \end{array}$

\section{Enfermarias 2 Leitos}

$\begin{array}{ccc}\text { Instalações Hidráulicas } & \text { Adequada } & 0 \\ \text { Instalações Elétricas } & \text { Adequada } & 0 \\ \text { Ventilação } & \text { Adequada } & 0 \\ \text { Iluminação } & \text { Adequada } & 0 \\ \text { Corredores Livres } & \text { sim } & 0 \\ \text { Carrinho de emergência } & \text { sim } & 2 \\ \text { Torpedo de oxigênio na unidade } & \text { não } & 0\end{array}$




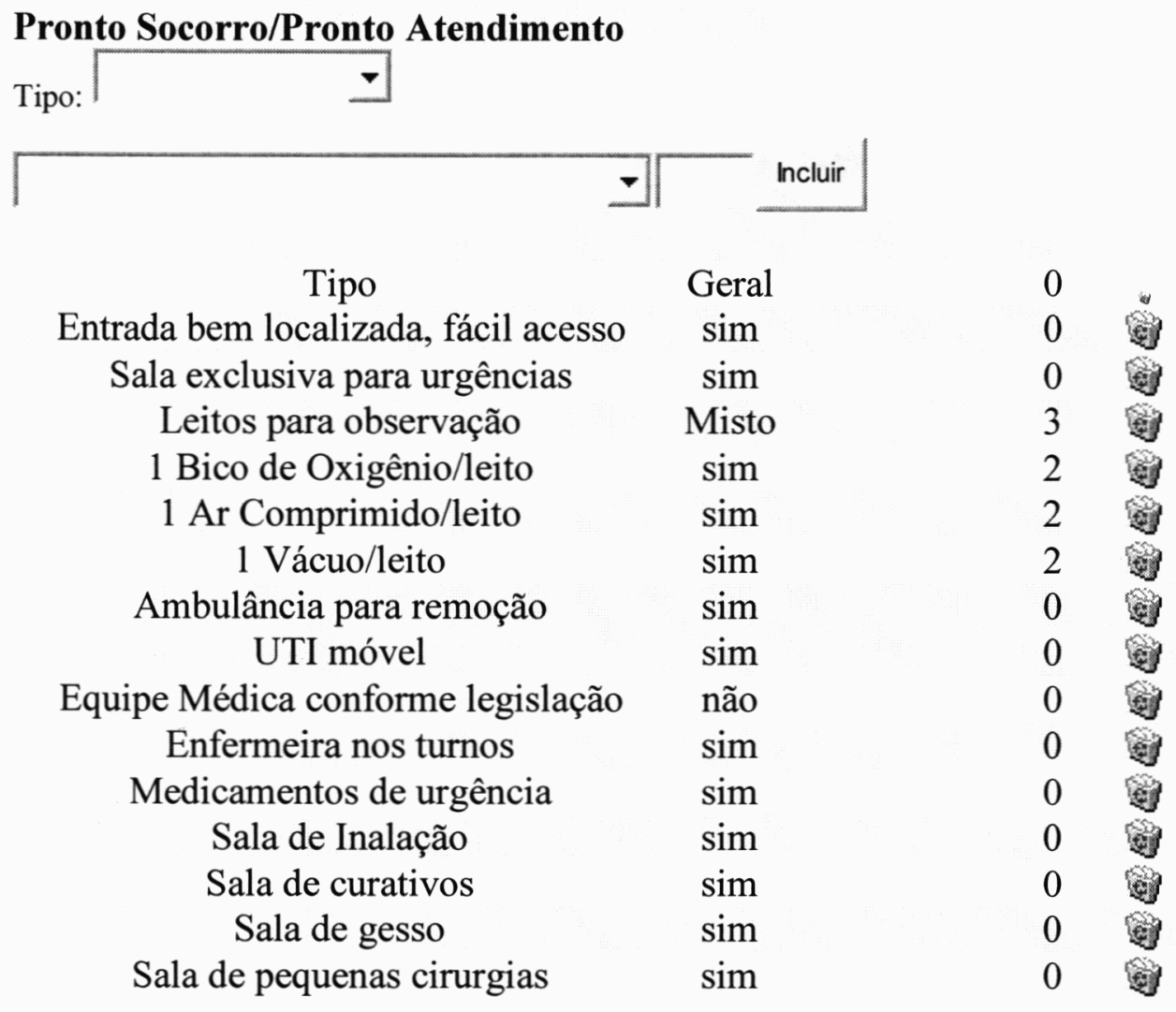

\section{Consultórios:}

\begin{tabular}{lcc|}
\hline & Incluir & \\
$\operatorname{sim}$ & Pediatria & 0 \\
$\operatorname{sim}$ & GO & 0 \\
$\operatorname{sim}$ & Geral & 0
\end{tabular}

Equipamentos da Urgência

\begin{tabular}{cccc|c|}
\hline & & & Mark-7 & 2 \\
Respirador & Bird & Mncluir \\
Oxímetro & Nellcor & N 180 & 2 \\
ECG & Cardiofax & ECAPS 12 & 1 \\
Monitor FC + ECG & Takaoka & Cardiotak & 1 \\
Desfibrilador & Scopia & Cardiolife & 1 \\
Bomba de Infusão & JMS & OT-701 & 1 \\
Bomba de Infusão & Uniset & & 1
\end{tabular}


Outras Salas

Incluir

Sala

Pequena Cirurgia Pequena
Equips. Excluir

in

\section{Outras Salas}

Sala: Pequena Cirurgia

\section{Equipamentos}

\begin{tabular}{cc|}
\hline & -1 \\
Mesa cirúrgica & 1 \\
Foco Central de Teto & 1 \\
Foco auxiliar & 1
\end{tabular}




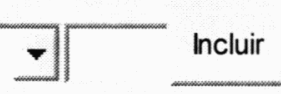

Número de Leitos

\begin{tabular}{|c|c|}
\hline & 5 \\
\hline $\operatorname{sim}$ & 0 \\
\hline $\operatorname{sim}$ & 0 \\
\hline $\operatorname{sim}$ & 0 \\
\hline $\operatorname{sim}$ & 0 \\
\hline $\operatorname{sim}$ & 0 \\
\hline não & 0 \\
\hline $\operatorname{sim}$ & 0 \\
\hline $\operatorname{sim}$ & 0 \\
\hline $\operatorname{sim}$ & 0 \\
\hline $\operatorname{sim}$ & 0 \\
\hline $\operatorname{sim}$ & 0 \\
\hline $\operatorname{sim}$ & 0 \\
\hline $\operatorname{sim}$ & 1 \\
\hline $\operatorname{sim}$ & 0 \\
\hline não & 0 \\
\hline $\operatorname{sim}$ & 0 \\
\hline $\operatorname{sim}$ & 0 \\
\hline $\operatorname{sim}$ & 0 \\
\hline & 0 \\
\hline
\end{tabular}

01 médico para cada 10 leitos

Há normas e rotinas para a área

A UTI participa da CCIH

Há programas de acompanhamento de visita com orientação

Encontra-se em área física adequada

De acordo com a legislação vigente

O posto de enfermagem permite boa visão dos leitos

Há boa circulação de funcionários e pacientes

Possui médico diarista

Possui equipe médica em todos os turnos

Equipe de enfermagem treinada e completa

Enfermeira em todos os turnos

Há leitos para isolamento

Quarto para médico plantonista

Área de descanso para enfermagem

2 bicos de oxigênio/leito

1 bico de ar comprimido/leito

1 bico de vácuo/leito

$\operatorname{sim}$ 


\section{Equipamentos}

\begin{tabular}{cccc}
\hline & Patrol & 5 \\
Bomba de Infusão enteral & Incluir & \\
Oxímetro & Abbott & & \\
Carrinho de Emergência com desfibrilador & Nellcor & Metro Lifeline & \\
Hemogasômetro & Drake & AGS-21 & 1 \\
RX portátil & Emic Limex & MKT - 100 & 1 \\
Oxicapnógrafo & Criticare & Poet TE plus & 1 \\
Bomba de Infusão & JMS & OT-701 & 18 \\
Bomba de Infusão & Nikkiso & PFA-06 & 6 \\
Monitor FC + ECG + PANI + oxímetro & Nikon Kolden & Lifescope & 1 \\
Monitor FC + ECG + PANI + oxímetro & Welch Allyn & & 1 \\
Cardioversor & & & 1 \\
Respirador & Hamilton & Galileo & 2 \\
Respirador & Newport & Wave 2000 & 2 \\
Respirador & Newport & E 1001 & 1 \\
Monitor de PANI & Colin & Press Mate & 1 \\
Monitor de PAI & Dynascope & DS 3300 & 1
\end{tabular}


Maternidade

Tem sala de admissão
Sala/leitos de pré-parto
O parto é realizado por:

\section{Berçário}

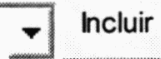

$\begin{array}{cc}\text { Há berçário de primeiros cuidados } & \text { sim } \\ \text { Há berçário de patológicos } & \text { não } \\ \text { Há alojamento conjunto } & \text { sim } \\ \text { Área Física } & \text { adequada } \\ \text { Há UTI neonatal } & \text { não }\end{array}$

Salas

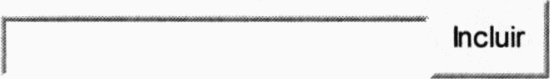

Berçário de Primeiros Cuidados 
Área: Bercario

Sala: Berçário de Primeiros Cuidados

\section{Equipamentos}

\begin{tabular}{|c|c|c|c|}
\hline & 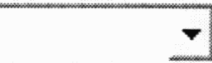 & Incluir & \\
\hline Berço comum & & & 8 \\
\hline Incubadora & Fanem & C186-TS/ST & 1 \\
\hline Incubadora & Olidef CZ & RW plus & 1 \\
\hline Bilispot & Fanem & & 1 \\
\hline Fototerapia & & & 2 \\
\hline Berço aquecido por insuflação & Olidef CZ & & 2 \\
\hline Incubadora & Fanem & C186-TS/ST & 1 \\
\hline
\end{tabular}




\section{Centro Cirúrgico}

\begin{tabular}{cc}
\hline Área de Escovação & sim \\
Área de recepção de paciente com passa maca & $\operatorname{sim}$ \\
Posto de Enfermagem e Serviços & $\operatorname{sim}$ \\
Vestiários com sanitários para funcionários com barreira & $\operatorname{sim}$ \\
Sala de preparo de equipamentos e material & não \\
Depósito de Material de Limpeza & sim \\
Sala administrativa & $\operatorname{sim}$ \\
Depósito de Material de Limpeza & $\operatorname{sim}$ \\
Sala de estar para funcionários & $\operatorname{sim}$ \\
Sala de Espera com sanitário para acompanhantes & não \\
Área para guarda de macas e cadeira de rodas & $\operatorname{sim}$ \\
Sala de Biópsia de congelação (Anatomia Patológica) & sim \\
Fluxos pacientes/funcionários por entradas diferentes & sim \\
Há Sala de Conforto Médico no Centro Cirúrgico & sim \\
Expurgo & $\operatorname{sim}$ \\
2 bicos de oxigênio/sala & $\operatorname{sim}$ \\
1 bico de ar comprimido/sala & sim \\
1 bico de vácuo/sala & sim
\end{tabular}

\section{Centro Cirúrgico/Salas}

\begin{tabular}{|c|c|c|c|c|}
\hline & & 7 & Incluir & \\
\hline Sala & Tamanho & & Equips. & Excluir \\
\hline 01 & Média & & $\lambda$ & (2) \\
\hline 02 & Grande & & $\alpha$ & 第 \\
\hline Parto & Média & & $\lambda$ & (2) \\
\hline 03 & Grande & & $\lambda$ & (2) \\
\hline Arsenal & Média & & $\lambda$ & 94 \\
\hline 04 & Grande & & $\lambda$ & ชิ \\
\hline 06 & Grande & & $\alpha$ & (9) \\
\hline
\end{tabular}


Centro Cirúrgico

Sala: 01

\section{Equipamentos}

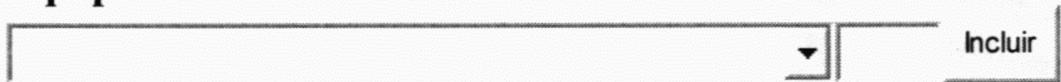

$\begin{array}{ccccc}\text { Carrinho de anestesia } & \text { Takaoka } & \text { Samurai III } & 1 \\ \text { Oxímetro } & \text { Nellcor } & \text { N } 180 & 1 \\ \text { Monitor FC + ECG } & \text { Ecafix } & \text { Active } & 1\end{array}$

\section{Centro Cirúrgico}

Sala: 02

\section{Equipamentos}

\begin{tabular}{|c|c|c|c|}
\hline & & $\nabla$ & Incluir \\
\hline Carrinho de anestesia & Takaoka & Origami & 1 \\
\hline Berço aquecido calor irradiante & Gigante & BA-UTI & 1 \\
\hline Balança pesa-bebê & Filizola & Baby & 1 \\
\hline Monitor FC + ECG & Dixtal & 920 & 1 \\
\hline Oxímetro & Nellcor & N 180 & \\
\hline
\end{tabular}

\section{Centro Cirúrgico}

Sala: Parto

\section{Equipamentos}

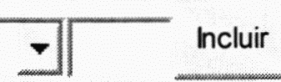

Carrinho de anestesia Takaoka Origami 1 a Berço aquecido calor irradiante Gigante BA-UTI 1 ig

\section{Centro Cirúrgico}

Sala: 03

\section{Equipamentos}

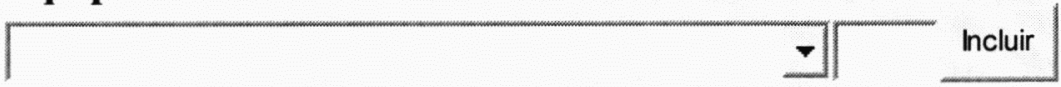

$\begin{array}{ccccc}\text { Carrinho de anestesia } & \text { Dräger } & \text { Cícero } & 1 \\ \text { Bisturi elétrico } & \text { Deltronix } & \text { B-6600 S } & 1\end{array}$




\section{Centro Cirúrgico}

Sala: Arsenal

\section{Equipamentos}

\begin{tabular}{|c|c|c|c|}
\hline & $\nabla$ & Incluir & \\
\hline Arco Cirúrgico & Toshiba & & 1 \\
\hline Microscópio cirúrgico & Zeiss & 240 FOPM & 1 \\
\hline Microscópio cirúrgico & DFVasconcellos & MC 900 & 1 \\
\hline Facoemulsificador & Alcon Universal & & 1 \\
\hline Videofibrorinolaringoscópio & Smith Nephew & & 1 \\
\hline Videohisteroscópio & & & \\
\hline Bisturi elétrico & WEM & SS-501 & \\
\hline Videoartroscópio & Endoview & & \\
\hline
\end{tabular}

\section{Centro Cirúrgico}

Sala: 04

\section{Equipamentos}

\begin{tabular}{ccccc}
\hline & & & \\
Carrinho de anestesia & Takaoka & Samurai III & 1 & Incluir \\
Monitor FC + ECG + PANI + oxímetro & Dixtal & DX2010 & 1 \\
Capnógrafo & Criticare & Poet TE plus & 1 \\
Bisturi elétrico & Valley Lab & Force 40 & 1
\end{tabular}

\section{Centro Cirúrgico}

Sala: 06

\section{Equipamentos}

\begin{tabular}{ccccc}
\hline & Takaoka & Samurai III & 1 \\
Carrinho de anestesia & Criticare & 508 & 1 & Incluir \\
Monitor de FC + oxímetro + PANI & Valley Lab & Force 2 & 1 \\
Bisturi elétrico & & & 1 \\
Mesa cirúrgica ortopédica & & 1
\end{tabular}




\begin{tabular}{l|lll|}
\multicolumn{3}{c}{ Quantidade } \\
\multicolumn{1}{c}{ Operacionais } & \multicolumn{1}{c|}{ Desativadas } \\
Pequena & 0 & & 0 \\
\hline Média & 3 & & 0 \\
\hline Grande & 4 & & 0 \\
Especial & 0 & & 0 \\
\hline Total & & & \\
\hline
\end{tabular}

\section{RPA}

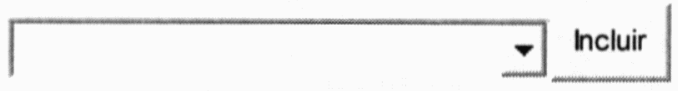

Área Física adequada

$\mathrm{RH}$ adequados

Desfibrilador sim

Monitor de FC sim

Oxímetro sim 
Serviços de Apoio Diagnóstico e Terapia

SADT

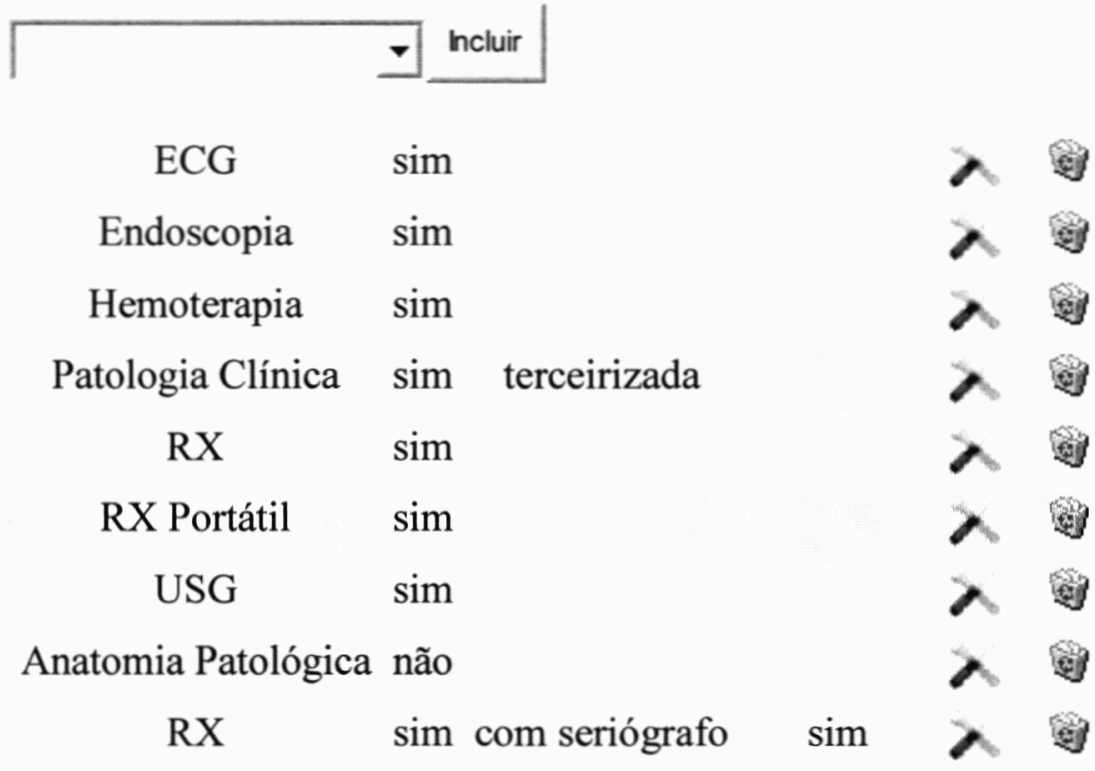

Equipamentos

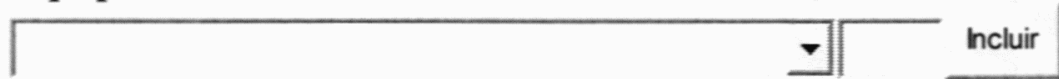

ECG Dixtal EP $6 \quad 1$ 의

Equipamentos

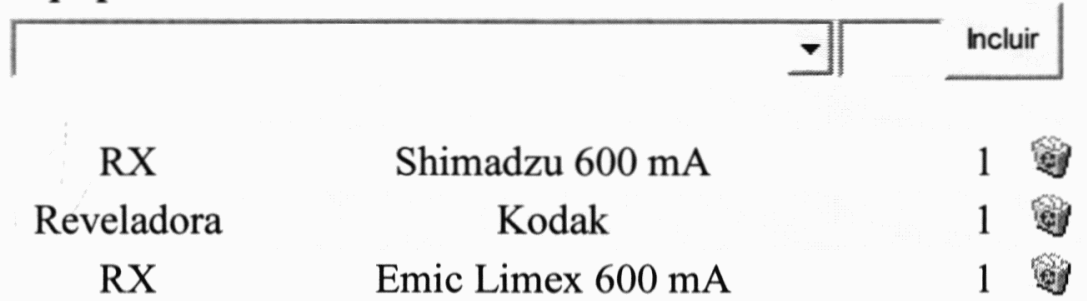

\section{Equipamentos}

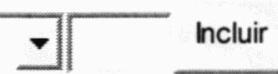

$\begin{array}{lll}\text { RX portátil Emic Limex } & \text { MKT }-100 & 1\end{array}$ 
SADT - Acessório

\begin{tabular}{|c|c|c|c|c|}
\hline \pm & - Incluir & & & \\
\hline Audiometria & não & & & $\lambda$ \\
\hline Cintilografia & não & & & $\lambda$ \\
\hline EEG & não & & & $\lambda$ \\
\hline Fisioterapia & $\operatorname{sim}$ & terceirizada & Unimed & $\lambda$ \\
\hline Hemodiálise & $\operatorname{sim}$ & & & $\lambda$ \\
\hline Holter & não & & & 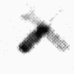 \\
\hline Litotripsia & não & & & 2 \\
\hline Mamografia & não & & & $\lambda$ \\
\hline Quimioterapia & não & & & $\lambda$ \\
\hline Radioterapia & não & & & n \\
\hline Ressonância Magnética & não & & & $\lambda$ \\
\hline Ressonância Magnética & não & & & $\geqslant$ \\
\hline \multicolumn{4}{|c|}{ Angiografia Digital/Hemodinâmica não } & $\lambda$ \\
\hline Ergometria & não & & & $>$ \\
\hline Ecografia & $\operatorname{sim}$ & terceirizada & & $\lambda$ \\
\hline Eletroneuromiografia & não & & & $\lambda$ \\
\hline Distúrbios do Sono & não & & & $\lambda$ \\
\hline Tomografia & $\operatorname{sim}$ & Conforme Legislação & $\operatorname{sim}$ & $\lambda$ \\
\hline Tilt Table Test & não & & & N. \\
\hline
\end{tabular}

\section{Equipamentos}

\begin{tabular}{|c|c|c|c|}
\hline & & Incluir & \\
\hline Tomografia helicoidal & Toshiba & $X$ Vision EY & 1 \\
\hline Carrinho de anestesia & Takaoka & & \\
\hline Bomba de Infusão & BBraun & Infusomat & 1 \\
\hline
\end{tabular}

\section{Equipamentos}

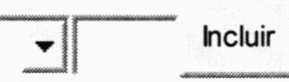

Ecocardiógrafo Siemens Cypress 1 (9) 


\section{Apoio Técnico e Administrativo}

\section{Farmácia}

$\square$ Incluir

Há controle dos medicamentos Port 344

A farmácia manipula NPP

Em área adequada conforme legislação

Há capela de fluxo laminar

$\begin{array}{lll}\text { sim } & 0 \\ \text { não } & 0 \\ \text { não } & 0 \\ \text { não } & 0 \\ \text { sim } & 0 \\ \text { sim } & 0 \\ \text { sim Quantos } & 1 \\ \text { Unitária } & 0 & 0 \\ \text { sim } & 0\end{array}$

SND

Circulação adequada

Equipamentos necessários e conservados

Área adequada com boa iluminação e aeração

Existe bancada para manipulação dos alimentos

Há cardápio afixado

Há Nutricionista $\operatorname{sim}$

$\operatorname{sim}$

$\operatorname{sim}$

$\operatorname{sim}$

$\operatorname{sim}$

$\operatorname{sim}$
0 实

0 邹

0 第

0

0 过

Quantas 1 解

\section{Limpeza/Higiene}

Há normas e rotinas para limpeza da unidade

Utilizam produtos próprios para limpeza

A CCIH participa na elaboração de normas do setor

Há coleta seletiva do lixo
Funcionários utilizam equipamentos de proteção

Incluir

$\operatorname{sim}$
$\operatorname{sim}$
$\operatorname{sim}$
$\operatorname{sim}$




\section{Lavanderia}

\begin{tabular}{cc}
\hline Máquina de lavar modelo profissional & $\operatorname{sim}$ \\
Centrífugas apropriadas & $\operatorname{sim}$ \\
Calandras & $\operatorname{sim}$ \\
Há barreiras físicas & $\operatorname{sim}$ \\
Há cruzamento limpo/contaminado & não \\
Área física apropriada & não \\
Equipamentos em boas condições & $\operatorname{sim}$ \\
Funcionários com equipamentos de proteção & $\operatorname{sim}$ \\
Serviço de Costura/Rouparia & $\operatorname{sim}$
\end{tabular}

Almoxarifado

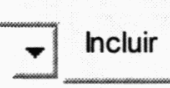

$\begin{array}{ccc}\text { Área apropriada } & \operatorname{sim} \\ \text { Estoques suficientes } & \operatorname{sim} \\ \text { Setor informatizado } & \operatorname{sim}\end{array}$

\section{Manutenção}

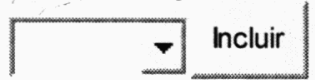

sim Própria

눈

Vigilância

- Incluir

sim Própria

gิ

SAME

$\operatorname{sim}$

Informatizado

$\operatorname{sim}$

Prontuários conforme Legislação sim 


\section{Central Esterilização}

Central Esterilização:

Encontra-se instalado em área física adequada

Tem área para expurgo do material

Tem área para preparo/esterilização

Tem área para estocagem/distribuição

Há enfermeira responsável

Há normatização de procedimentos na área

Há manutenção preventiva de equipamentos

Há cruzamento de fluxo de circulação entre as áreas

Funcionários paramentados adequadamente

Possui estufas

Possui Autoclave horizontal

É utilizado Controle Biológico

$\begin{array}{ll}\operatorname{sim} & \\ \operatorname{sim} & \\ \operatorname{sim} & \\ \operatorname{sim} & \\ \operatorname{sim} & \\ \operatorname{sim} & \\ \text { não } & \\ \operatorname{sim} & \\ \text { não } & 0\end{array}$

\section{Periodicidade}

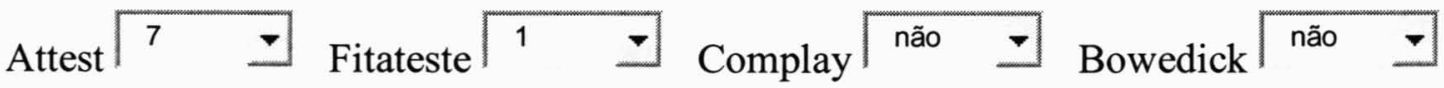




\section{Parecer:}

- Hospital geral privado com 70 leitos operacionais, com nível de atendimento secundário.

- Estrutura física: vertical, adaptada (2 pavimentos), com sinalização adequada, estacionamento, em boas condições de higiene e limpeza. Pronto atendimento geral, Maternidade, Berçário, UTI Geral, Centro Cirúrgico com 07 salas cirúrgicas, RPA com 07 leitos e recursos adequados e Unidades de Internação.

- Estrutura básica: gerador para suporte às áreas críticas, cabine primária de força, central de gases, sistema de prevenção de incêndios com extintores e hidrantes, pára-raios e 01 elevador.

- Hotelaria: apartamentos com cama elétrica, campainha viva-voz, TV, ar condicionado, telefone e frigobar, 01 bico de oxigênio, 01 de ar comprimido e 01 de vácuo. Sanitários: porta abrindo para fora e com barras/apoios. Enfermarias com TV, telefone e ar condicionado, 01 bico de oxigênio, 01 de ar comprimido e 01 de vácuo. Sanitários: porta abrindo para fora e com barras/apoios.

- Serviços de apoio: farmácia com 01 farmacêutico, dispensação por sistema unitário, com padronização dos medicamentos. SND com 01 nutricionista e cardápio afixado semanalmente. Serviço de limpeza próprio com normas e rotinas e participação da $\mathrm{CCIH}$. Lavanderia terceirizada, porém ainda lavando roupas novas, local sem ventilação. Almoxarifado próprio em área adequada. Manutenção própria (operacional) e terceirizada através de engenheiro clínico e técnico para equipamentos e coordenação geral. Central de Esterilização de Materiais adequada.

- SADT: ECG, Hemodiálise (01 máquina), Densitometria Óssea, Ecocardiografia, Patologia Clínica, Radiologia, RX Simples e Contrastado, USG, ECO, Tomografia e Hemoterapia.

- Organização e funcionamento: Regulamento Interno, Normas e Rotinas, Recrutamento e Seleção de Pessoal, Treinamento, Educação Continuada, Indicadores Hospitalares, Relatórios Gerenciais, 
Informatização em Rede exceto o prontuário eletrônico, Serviço Social e Saúde Ocupacional. Comissões de Ética Médica, CCIH, Revisão de Prontuários, Revisão de Óbitos, CIPA, Farmácia e Medicamentos e Controle e Gestão de Qualidade, visando receber Selo do Programa APM/CREMESP-CQH.

- Recursos Humanos

○ Servidores/ leito: 3,84

○ Proporção funcionários de enfermagem/ leito: 1,86

○ Enfermeiros/ leito: 0,22

o Técnicos e Auxiliares de Enfermagem/ leito: 1,62

- Indicadores de Qualidade

○ Taxa de Mortalidade Institucional: 1,13\%

- Taxa de Mortalidade Operatória: 0,08\%

○ Taxa de Infecção Hospitalar: 1,98 \%

○ Taxa de Cesáreas: $76,40 \%$

- Indicadores de Produtividade

○ Taxa de Ocupação: $59 \%$

o Taxa de Permanência: 2,38 dias

o Giro de Rotatividade: 4,25 pacientes/mês 


\section{Parecer:}

Consideramos o Hospital E apto.

Para tanto há a necessidade de:

1. Resolver problemas estruturais:

a. Adequar área física da UTI à RDC $\mathrm{n}^{\circ} 50 / 02$.

b. Adequar salas de gesso e curativo do PA à RDC n $n^{\circ}$ 50/02 (leito encostado na parede).

2. Organizar leitos da observação do pronto-atendimento, separando-os em masculinos, femininos e pediátricos.

3. Reequipar sala de emergência/ urgência do pronto-atendimento para dar condições de sustentação de vida (imediato), com instalação de respirador adequado.

4. Equipar Unidades de Internação com torpedo de oxigênio reserva, aspirador elétrico e cardioversor com carga elétrica.

5. Retirar berços aquecidos por insuflação do Berçário

6. Contratar recursos humanos para compor a equipe médica do Pronto Socorro (Resolução 1.451/95 do Conselho Federal de Medicina).

7. Avaliar processo assistencial em função da alta Taxa de Cesáreas. 


\section{ANEXO 9 - Vistoria Técnica-Hospitalar - Hospital F}

\section{Identificação do Estabelecimento}

Nome:

\section{$\mathrm{F}$}

Diretor Clínico:

CRM:

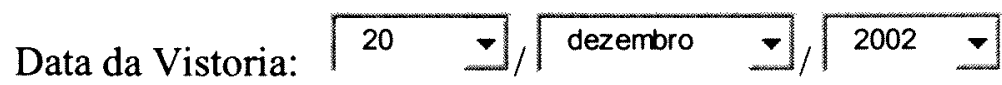

Acompanhantes:

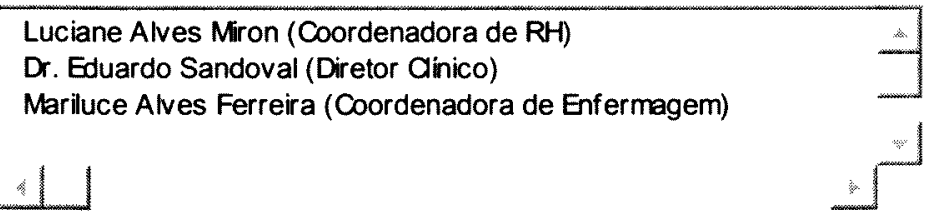

$N^{o}$ Total de Leitos:

130

Total de Leitos Operacionais:

$N^{o}$ de Leitos Convênio:

\section{Classificação do Estabelecimento}

Tipo de Hospital:

Geral $\quad \square$

Lista de Especializações:

\section{Tipo de Serviço}

Tipo de serviço:

Abrangência do serviço

Privado

Abrangência do serviço:

Regional 
Organização e Funcionamento

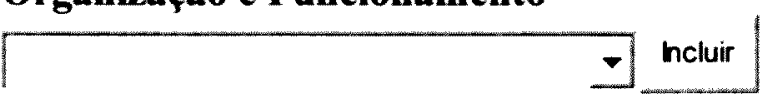

Normas e Rotinas e Manuais sim Recrutamento e Seleção de Pessoal sim

Programas de Treinamento sim Educação Continuada sim

Indicadores Hospitalares sim

Relatórios Gerenciais

Informatização

Serviço Social

Psicologia Hospitalar

Saúde Ocupacional

Revisão de Prontuários

Ensino e Pesquisa

Residência Médica/Pós-Graduação

Farmácia e Medicamentos

Controle e Gestão de Qualidade

Comissão de Ética Médica

CIPA

Revisão de Óbitos

Regime Interno/regulamento

$\mathrm{CCIH}$
Do conhecimento das partes sim .

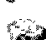

$\operatorname{sim}$

$\operatorname{sim}$

sim

Em Rede

não

$\operatorname{sim}$

não

não

não

não

$\operatorname{sim}$

sim

$\operatorname{sim}$

sim

$\operatorname{sim}$

$\operatorname{sim}$
Reuniões Regulares / Atas

Reuniões Regulares / Atas

Reuniões Regulares / Atas

Do conhecimento das partes

Reuniões Regulares / Atas $\operatorname{sim}$

9

ब의

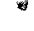

9

(2)

3

(1)

(2)

$\operatorname{sim}$

$\operatorname{sim}$

$\operatorname{sim}$

não

$\operatorname{sim}$ 


\begin{tabular}{|c|c|c|}
\hline Recursos Humanos de & odo o Hospital (Ano de & 2002 \\
\hline Profissionais & Quantidade & \\
\hline Médicos & Corpo Clínico aberto & \\
\hline Enfermeiros & 15 & \\
\hline Técnicos de enfermagem & 46 & \\
\hline Auxiliares de enfermagem & 186 & \\
\hline Atendentes de enfermagem & 0 & \\
\hline Outros Funcionários & 223 & \\
\hline Total & 470 & \\
\hline
\end{tabular}

Informações Gerais (Ano de $\longdiv { 2 0 0 2 }$

Levantamento de dados anual

Número de óbitos após $\mathbf{4 8}$ horas

Números de saídas (Altas e Óbitos)

Números de óbitos por causas maternas

Número de pacientes atendidos em Obstetrícia

Número de nascidos vivos

Número de nascidos mortos

Número de óbitos neonatais após 48 horas

Número de óbitos operatórios até 10 dias pós-cirurgia

Número de atos cirurgicos

Número de cesáreas

Número de partos normais

Número total de partos

Número de infecções atribuiveis ao hospital

Número de supurações de feridas cirúrgicas em cirurgias limpas

Número de cirurgias limpas do período

Número de pacientes/dia

Número de leitos/dia

Número de leitos disponíveis no período

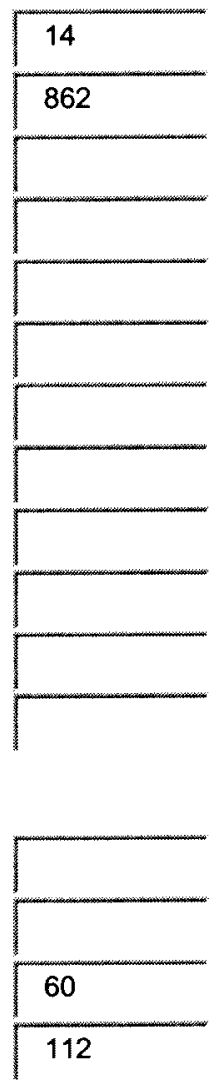


Indicadores de Qualidade (Ano de $\sqrt{2002}$ )

Taxa de mortalidade institucional

Taxa de mortalidade materna

Taxa de natimortalidade

Taxa de mortalidade neonatal

Taxa de mortalidade operatória

Taxa de cesáreas

Taxa de infecção hospitalar

Taxa de supuração de ferida cirúrgica em cirurgia limpa

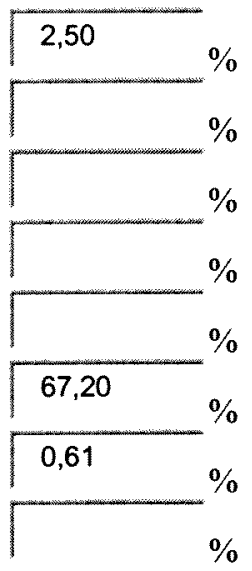

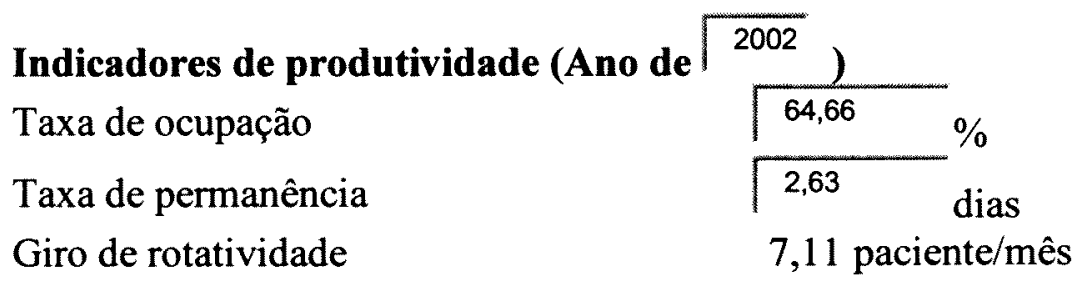




\section{Estrutura}

Edificação:

$\Gamma$ Horizontal

$\frac{\mathrm{N}^{\mathrm{o}} \text { de Pavimentos: }}{2}$

$\sqrt{\nabla}$ Planejada

$\sqrt{\checkmark}$ Vertical

$\Gamma$ Adaptada

$N^{0}$ de elevadores:

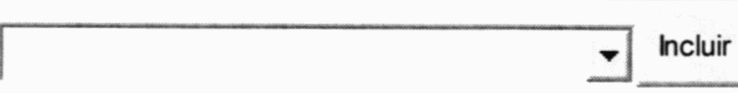

\section{Identificação \\ Sinalização \\ Área para munutenção/descarga \\ Elevadores \\ Local próprio para lixo \\ Reservatório de Água \\ Caldeira \\ Gerador \\ Cabine Primária de Força \\ Ar Condicionado Central \\ Sistema de Esgotos \\ Pára-Raios}

Sistemas de Tratamento de Resíduos

Sistema de Prevenção de Incêndios

Estacionamento

Central de Gases

Central de Gases

Central de Gases

Sistema de Prevenção de Incêndios

visível
sim
sim
desnecessário
sim
sim
não
automático
sim
não
não
sim
não
sim
sim
sim
sim
sim
sim




\section{Organização e Atenção ao Paciente}

\section{Hotelaria}

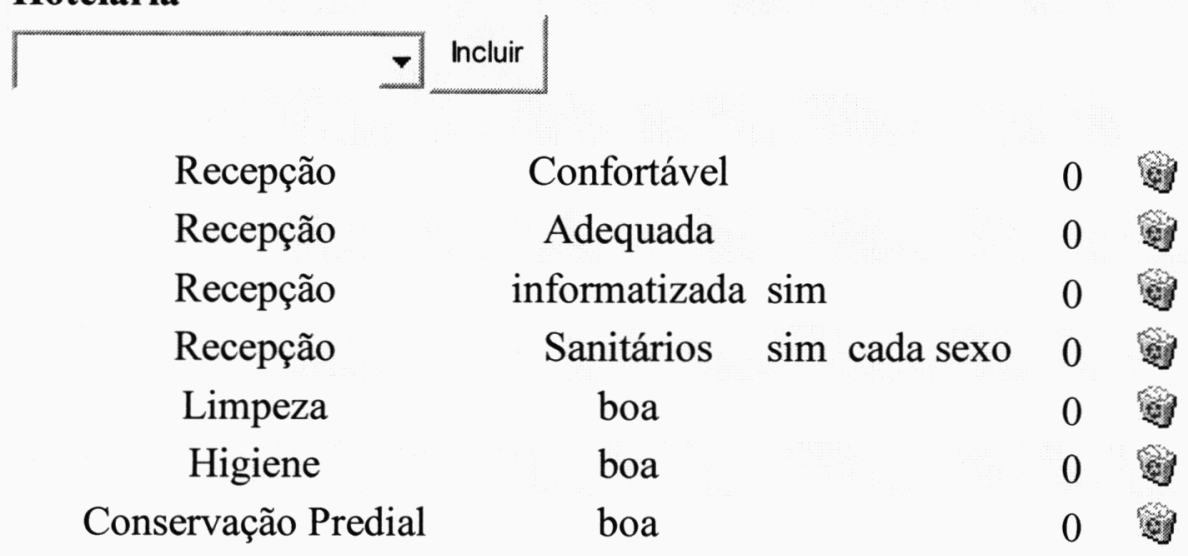

Suítes - Quantos? 1

bico de oxigênio

Carrinho de emergência

$\operatorname{sim}$

bico de vácuo

bico de ar

Sanitário

Sanitário

telefone

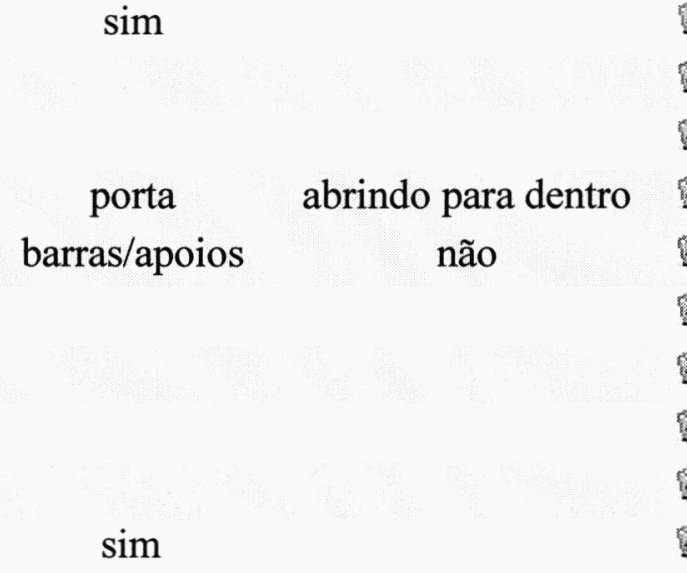

TV

frigobar

sofá/cama acompanhante

Torpedo de oxigênio na unidade

$\operatorname{sim}$

\section{Suítes}

$\begin{array}{cccc}\text { Instalações Hidráulicas } & \text { Adequada } & 0 \\ \text { Instalações Elétricas } & \text { Adequada } & 0 \\ \text { Ventilação } & \text { Adequada } & 0 \\ \text { Iluminação } & \text { Adequada } & 0 \\ \text { Corredores Livres } & \text { sim } & 0\end{array}$


Apartamentos - Quantos? 24

bico de oxigênio

(4)

bico de vácuo

cadeira de descanso

sofá/cama acompanhante

bico de ar

Sanitário

Sanitário

TV

porta abrindo para dentro

\section{Apartamentos}

Instalações Hidráulicas

Adequada

0 4

Instalações Elétricas

Adequada

0 嗮

Ventilação

Adequada

0 क्ष

Iluminação

Adequada

0 疑

Corredores Livres

Carrinho de emergência

Torpedo de oxigênio na unidade

$\operatorname{sim}$

0 鈿

$\operatorname{sim}$

0 约

$\operatorname{sim} 1$ क्ष 


\section{Enfermaria}

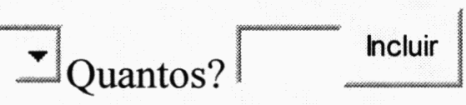

Enfermarias 2 Leitos - Quantos?

Distância mínima entre os leitos Sanitário

Sanitário

bico de vácuo

bico de ar

bico de oxigênio

Barras/Apoios não
Porta

\section{Enfermarias 2 Leitos}

$\begin{array}{ccc}\text { Instalações Hidráulicas } & \text { Adequada } & 0 \\ \text { Instalações Elétricas } & \text { Adequada } & 0 \\ \text { Ventilação } & \text { Adequada } & 0 \\ \text { Iluminação } & \text { Adequada } & 0 \\ \text { Corredores Livres } & \operatorname{sim} & 0 \\ \text { Carrinho de emergência } & \operatorname{sim} & 0 \\ \text { Torpedo de oxigênio na unidade } & \operatorname{sim} & 0\end{array}$




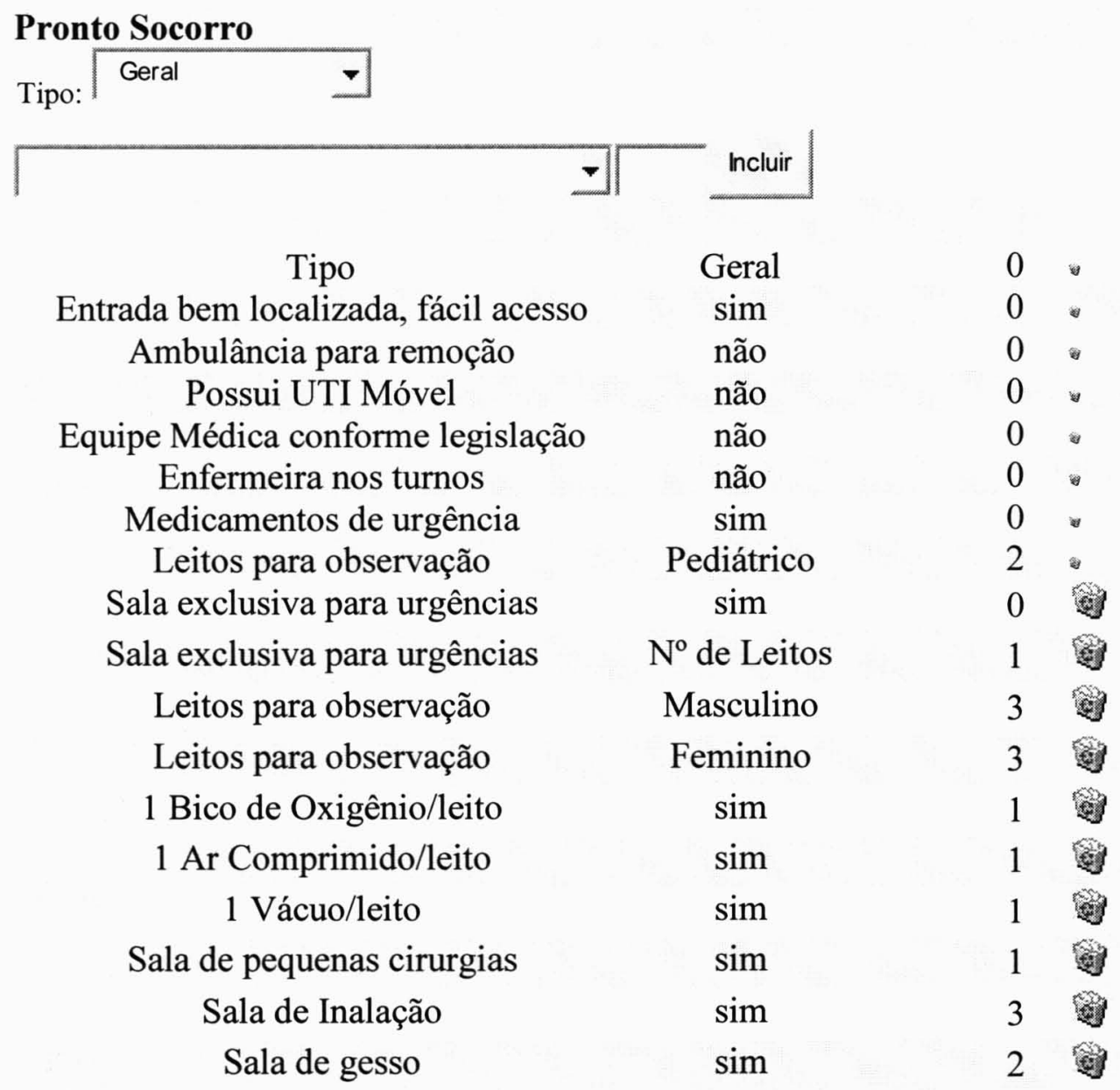

\section{Equipamentos da Urgência}

\begin{tabular}{|ccccc|c|}
\hline & & & \\
Desfibrilador & Ecafix & MDF-03 & 1
\end{tabular}

\section{Consultórios:}

\begin{tabular}{|c|c|c|}
\hline & $\exists$ Incluir & \\
\hline $\operatorname{sim}$ & Geral & 0 \\
\hline $\operatorname{sim}$ & GO & 0 \\
\hline & Pediatria & 0 \\
\hline $\operatorname{sim}$ & Ortopedia & 0 \\
\hline
\end{tabular}

\section{Outras Salas}




\begin{tabular}{llll}
\hline Sala & Tamanho & \\
Pequena Cirurgia & Pequena & Excluir \\
Sutura & Pequena & Média &
\end{tabular}

Outras Salas

Sala: Pequena Cirurgia

\section{Equipamentos}

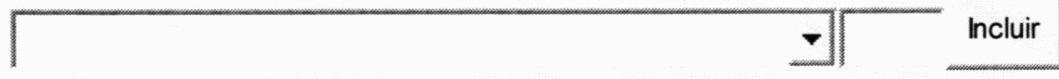

$\begin{array}{cccc}\text { Mesa cirúrgica } & \text { Mercedes-Imec } & 1 \\ \begin{array}{c}\text { Foco Central de Teto } \\ \text { Bisturi elétrico }\end{array} & \text { Deltronix } & \text { B 3500 } & 1\end{array}$

\section{Outras Salas}

Sala: Sutura

\section{Equipamentos}

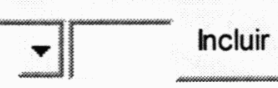

Foco auxiliar

1 解 


\section{UTI Geral}

चा Incluir

Número de Leitos

\begin{tabular}{|c|c|c|}
\hline & 10 & (9) \\
\hline $\operatorname{sim}$ & 0 & (4) \\
\hline não & 0 & 通 \\
\hline sim & 0 & (9) \\
\hline $\operatorname{sim}$ & 0 & 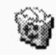 \\
\hline $\operatorname{sim}$ & 0 & \\
\hline $\operatorname{sim}$ & 0 & \\
\hline sim & 0 & \\
\hline $\operatorname{sim}$ & 0 & \\
\hline não & 0 & \\
\hline $\operatorname{sim}$ & 0 & \\
\hline sim & 0 & \\
\hline $\operatorname{sim}$ & 0 & \\
\hline sim & 2 & \\
\hline sim & 0 & \\
\hline $\operatorname{sim}$ & 0 & \\
\hline sim & 0 & \\
\hline
\end{tabular}

\section{Equipamentos}

\begin{tabular}{ccccc}
\hline & \multicolumn{3}{c}{ Incluir } \\
\cline { 2 - 5 } Respirador & Bird & $6400 \mathrm{ST}$ & 1 \\
Respirador & Intermed & Inter 5 & 4 \\
ECG & Ecafix & ECG 6 & 1 \\
Hemodialisador portátil & Althin & & 1 \\
Respirador & Bird & $8400 \mathrm{ST}$ & 2 \\
Monitor FC + ECG + PANI + PAI & Ecafix & Máximo & 1 \\
Monitor multiparâmetro & Ecafix & Máximo & 1 \\
Monitor FC + ECG + PANI + oxímetro & Ecafix & Máximo & 6 \\
Desfibrilador com marca-passo externo & Ecafix & MDF-03 & 2 \\
Desfibrilador & Zoll & & 1 \\
Bomba de Infusão & BBraun & Infusomat & 10 \\
Bomba de Infusão & Lifemed & LF-2001 & 10 \\
BEEPAP & Respironic & & 1 \\
& & &
\end{tabular}




\section{UTI Pediátrica}

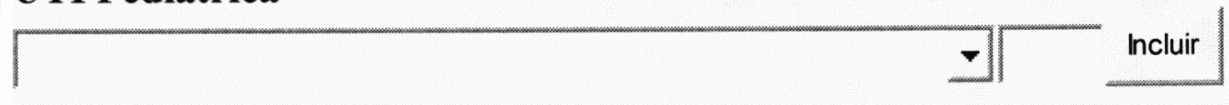

01 médico para cada 10 leitos

$\operatorname{sim}$

Há normas e rotinas para a área

não

A UTI participa da CCIH

$\operatorname{sim}$

Há programas de acompanhamento de visita com orientação

$\operatorname{sim}$

Encontra-se em área física adequada

$\operatorname{sim}$

De acordo com a legislação vigente

$O$ posto de enfermagem permite boa visão dos leitos

$\operatorname{sim}$

$\operatorname{sim}$

Há boa circulação de funcionários e pacientes

$\operatorname{sim}$

não

Possui médico diarista

Possui equipe médica em todos os turnos

Equipe de enfermagem treinada e completa

Enfermeira em todos os turnos

Há leitos para isolamento

Quarto para médico plantonista

$\operatorname{sim}$

$\operatorname{sim}$

$\operatorname{sim}$

$\operatorname{sim}$

$\operatorname{sim}$

não

$\operatorname{sim}$

2 bicos de oxigênio/leito

1 bico de ar comprimido/leito

$\operatorname{sim}$

1 bico de vácuo/leito

$\operatorname{sim}$

10 tomadas elétricas

$\operatorname{sim}$

Número de Leitos

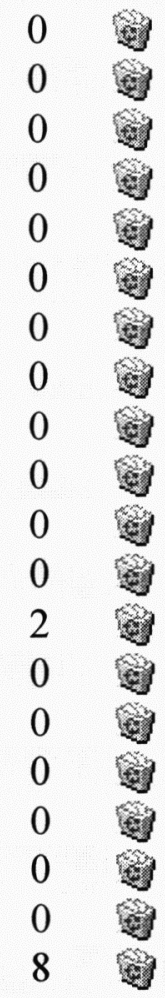

\section{Equipamentos}

\begin{tabular}{|cccc|}
\hline & Intermed & Inter 3 & 4 \\
Respirador & Gigante & Lux & 6 \\
Incubadora & Ecafix & MDF-03 & 2 \\
Desfibrilador & Lifemed & LF-2001 & 1 \\
Bomba de Infusão & Newport & & 1 \\
Respirador & Ecafix & Máximo & 8 \\
Monitor FC + ECG + PANI + oxímetro \\
Respirador & Intermed & Inter 5 & 2 \\
Berço aquecido calor irradiante & Gigante & BA-UTI & 1 \\
Bilispot & Gigante & & 4
\end{tabular}




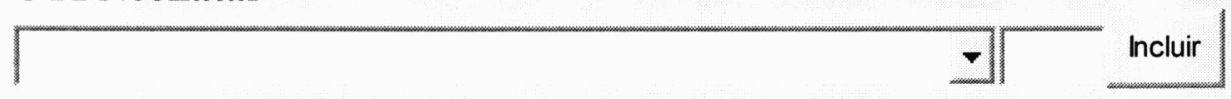

01 médico para cada 10 leitos

$\begin{array}{ll}\text { sim } & 8 \\ \text { não } & 0 \\ \text { sim } & 0 \\ \text { sim } & 0 \\ \text { sim } & 0 \\ \text { sim } & 0 \\ \text { sim } & 0 \\ \operatorname{sim} & 0 \\ \operatorname{sim} & 0 \\ \operatorname{sim} & 0 \\ \operatorname{sim} & 0 \\ \operatorname{sim} & 0 \\ \operatorname{sim} & 0 \\ \operatorname{sim} & 2 \\ \operatorname{sim} & 0 \\ \operatorname{sim} & 0 \\ \operatorname{sim} & 0\end{array}$

\section{Equipamentos}

Há normas e rotinas para a área

A UTI participa da $\mathrm{CCIH}$

Há programas de acompanhamento de visita com orientação

Encontra-se em área física adequada

De acordo com a legislação vigente

O posto de enfermagem permite boa visão dos leitos

Há boa circulação de funcionários e pacientes

Possui médico diarista

Possui equipe médica em todos os turnos

Equipe de enfermagem treinada e completa

Equipe de enfermagem treinada e completa

Enfermeira em todos os turnos

Há leitos para isolamento

1 bico de ar comprimido/leito

1 bico de vácuo/leito

10 tomadas elétricas

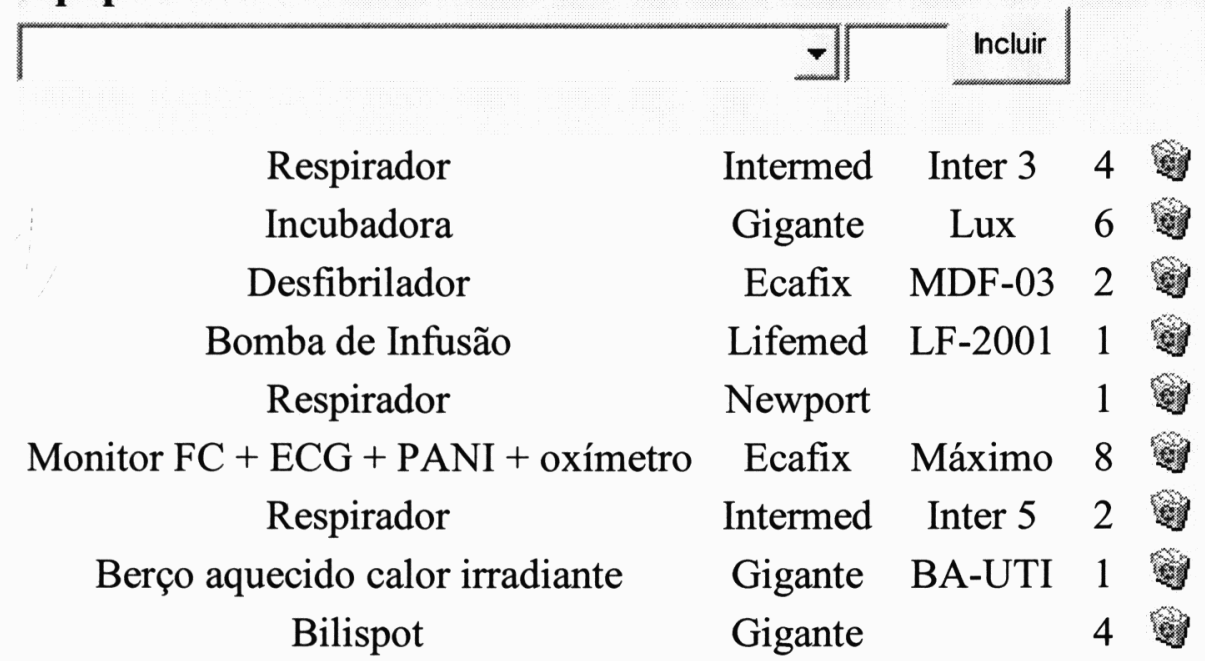




\section{Maternidade}

Tem sala de admissão
Sala/leitos de pré-parto
Sala de parto normal

Salas

${ }^{\text {Incluir }}$

Sala de Reanimação neonatal >

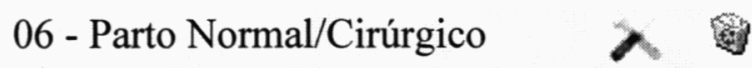

05 - Parto Normal/Cirúrgico $>$ 入

Área: Maternidade

Sala: Sala de Reanimação neonatal

\section{Equipamentos}

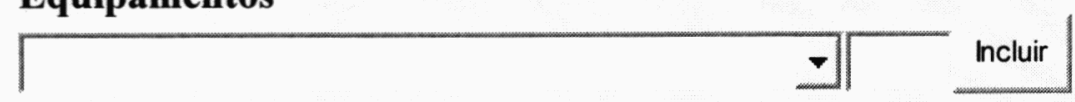
Berço aquecido calor irradiante
Gigante
BA-UTI 1 致
Balança pesa-bebê
Toledo
1 解 
Área: Maternidade

Sala: 06 - Parto Normal/Cirúrgico

\section{Equipamentos}

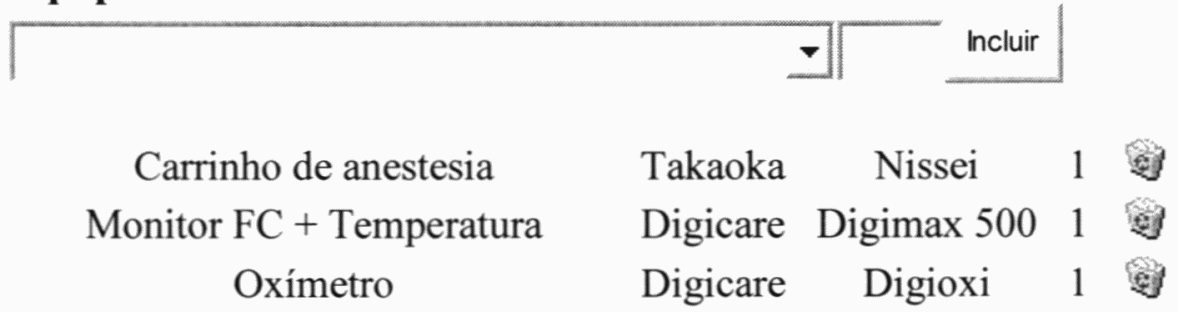

Área: Maternidade

Sala: 05 - Parto Normal/Cirúrgico

\section{Equipamentos}

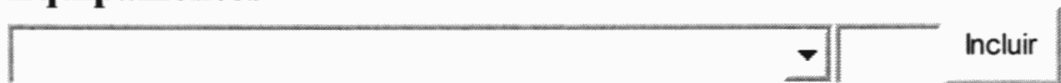

Carrinho de anestesia

Monitor de FC + oxicapnógrafo

Takaoka Nissei 1 ?

Bisturi elétrico

Dixtal DX2010 1 酐

Deltronix B 3600 S 1 ?

Área: Maternidade

Sala: 05 - Parto Normal/Cirúrgico

Equipamentos

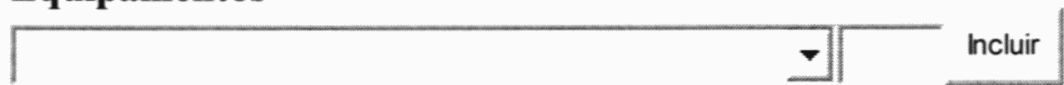

Carrinho de anestesia Takaoka Nissei 1 役

Monitor de FC + oxicapnógrafo Dixtal DX2010 1 (9

Bisturi elétrico

Deltronix B $3600 \mathrm{~S} 1$ 


\section{Berçário}

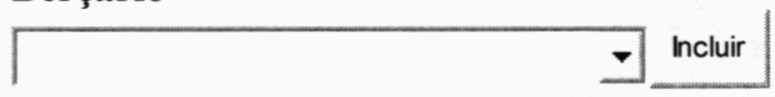

Há berçário de primeiros cuidados sim

Há berçário de patológicos sim

2 bicos de oxigênio/leito sim

1 bico de vácuo/leito sim

Há alojamento conjunto sim

Há UTI neonatal

$$
\operatorname{sim}
$$

03 过

Salas

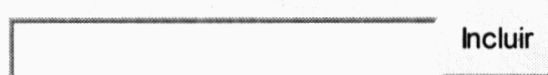

Berçário de Primeiros Cuidados

Berçário de Intermediários/Patológicos/Prematuros

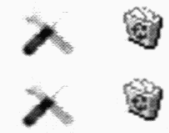

Área: Bercário

Sala: Berçário de Primeiros Cuidados

\section{Equipamentos}

\begin{tabular}{|cll|}
\hline & & \\
Incubadora & Olidef CZ & 1 \\
Berço aquecido por insuflação & Olidef CZ & 3
\end{tabular}

Área: Bercário

Sala: Berçário de Intermediários/Patológicos/Prematuros

\section{Equipamentos}

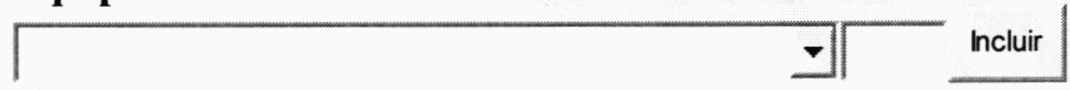

\begin{tabular}{|c|c|c|}
\hline Incubadora & Gigante & $\mathrm{I}$ \\
\hline Berço comum & & \\
\hline Fototerapia & Gigante & 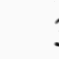 \\
\hline Fototerapia & Olidef CZ & \\
\hline Bilispot & Gigante & \\
\hline
\end{tabular}




\section{Centro Cirúrgico}

\begin{tabular}{cl}
\hline Área de Escovação & sim \\
Área de recepção de paciente com passa maca & sim \\
Posto de Enfermagem e Serviços & $\operatorname{sim}$ \\
Vestiários com sanitários para funcionários com barreira & $\operatorname{sim}$ \\
Sala de preparo de equipamentos e material & $\operatorname{sim}$ \\
Sala administrativa & $\operatorname{sim}$ \\
Depósito de Material de Limpeza & $\operatorname{sim}$ \\
Sala de estar para funcionários & $\operatorname{sim}$ \\
Sala de Espera com sanitário para acompanhantes & $\operatorname{sim}$ \\
Área para guarda de macas e cadeira de rodas & $\operatorname{sim}$ \\
Sala de Biópsia de congelação(Anatomia Patológica) & não \\
Fluxos pacientes/funcionários por entradas diferentes & sim \\
Há Sala de Conforto Médico no Centro Cirúrgico & $\operatorname{sim}$ \\
2 bicos de oxigênio/sala & $\operatorname{sim}$ \\
1 bico de ar comprimido/sala & $\operatorname{sim}$ \\
1 bico de vácuo/sala & $\operatorname{sim}$ \\
carrinho de anestesia em todas as salas & sim \\
Monitor de FC em todas as salas & sim
\end{tabular}

\section{Centro Cirúrgico/Salas}

\begin{tabular}{|c|c|c|c|}
\hline & $\nabla$ Incluir & & \\
\hline Sala & Tamanho & Equips. & Excluir \\
\hline 01 & Grande & $\lambda$ & กู \\
\hline 02 & Média & $\lambda$ & (4) \\
\hline 03 & Média & $\lambda$ & (9) \\
\hline 04 & Média & $\lambda$ & 9 \\
\hline
\end{tabular}




\section{Centro Cirúrgico}

Sala: 01

\section{Equipamentos}

\begin{tabular}{|cccc|}
\hline & & & \\
Carrinho de anestesia & Takaoka & Origami & 1 \\
Bisturi elétrico & WEM & SS-601 MC & 1 \\
Monitor FC + oxicapnógrafo & Dixtal & DX2010 & 1 \\
Arco Cirúrgico & Philips & BV 25 & 1 \\
Videolaparoscópio & Storz & Hamou micro & 1 \\
Videoartroscópio & Storz & Hamou micro & 1
\end{tabular}

\section{Centro Cirúrgico}

Sala: 02

\section{Equipamentos}

\begin{tabular}{|c|c|c|c|}
\hline & 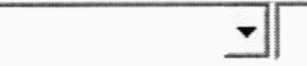 & Incluir & \\
\hline Carrinho de anestesia & Takaoka & Origami & 1 . \\
\hline Bisturi elétrico & WEM & SS-601 MC & 1 \\
\hline Monitor de FC + oxicapnógrafo & Dixtal & DX2010 & 1 \\
\hline Microscópio cirúrgico & DFVasconcellos & MC-M92 & 1 \\
\hline
\end{tabular}

\section{Centro Cirúrgico}

Sala: 03

\section{Equipamentos}

\begin{tabular}{cccc|}
\hline & & & \\
Carrinho de anestesia & Takaoka & Origami & 1 \\
Bisturi elétrico & WEM & SS-601 MC & 1 \\
Monitor de FC + oxicapnógrafo & Dixtal & DX2010 & 1 \\
Microscópio cirúrgico & DFVasconcellos & MC-M92 & 1
\end{tabular}




\section{Centro Cirúrgico}

Sala: 04

\section{Equipamentos}

\begin{tabular}{|cccc|c|}
\hline & & & & \\
Carrinho de anestesia & Takaoka & Origami & 1 & Incluir \\
Bisturi elétrico & WEM & SS-601 MC & 1 & \\
Monitor de FC + oxicapnógrafo & Dixtal & DX2010 & 1 & \\
Videofibrorinolaringoscópio & & & 1 &
\end{tabular}

\begin{tabular}{|c|c|c|c|c|}
\hline \multicolumn{3}{|c|}{ Quantidade } & \multirow{2}{*}{\multicolumn{2}{|c|}{ Desativadas }} \\
\hline \multirow[b]{2}{*}{ Pequena } & \multicolumn{2}{|c|}{ Operacionais } & & \\
\hline & 0 & $\nabla$ & 0 & $\nabla$ \\
\hline Média & 5 & $\nabla$ & 0 & $\nabla$ \\
\hline Grande & 1 & $\boldsymbol{\nabla}$ & 0 & $\nabla$ \\
\hline Especial & 0 & $\boldsymbol{\nabla}$ & 0 & 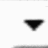 \\
\hline Total & & & & \\
\hline
\end{tabular}

RPA

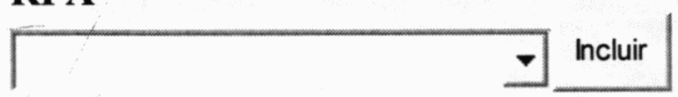

01 bico de oxigênio/leito sim

01 bico ar comprimido/leito

$\operatorname{sim}$

01 bico de vácuo/leito

$\operatorname{sim}$

Desfibrilador

$\operatorname{sim}$

Monitor de FC

$\operatorname{sim}$

Oxímetro

não 
Serviços de Apoio Diagnóstico e Terapia

SADT

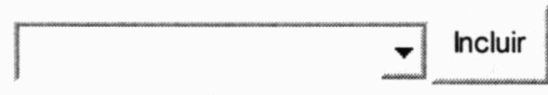

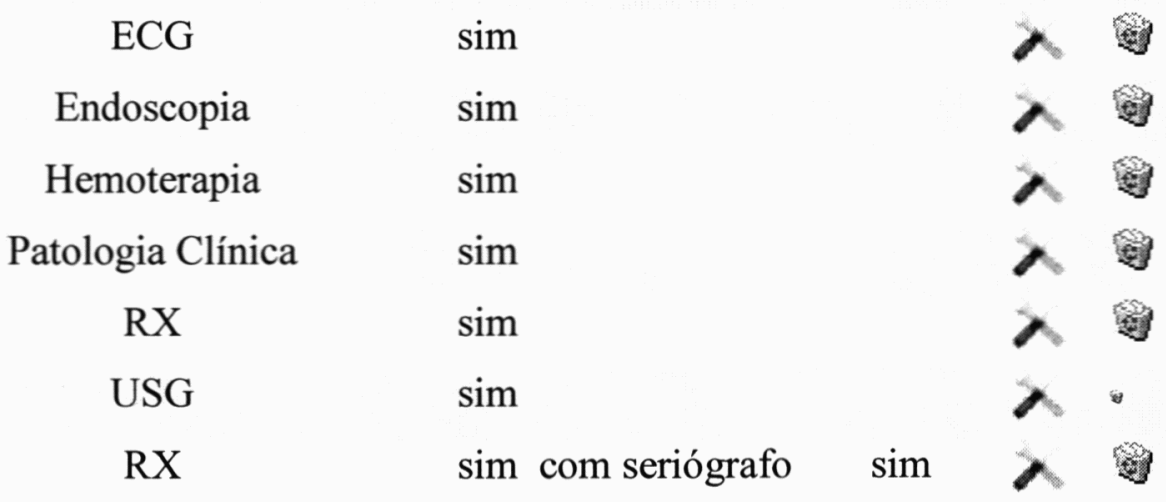

Equipamentos

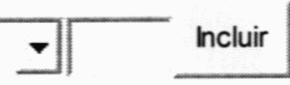

ECG Dixtal EP 31 个

Equipamentos

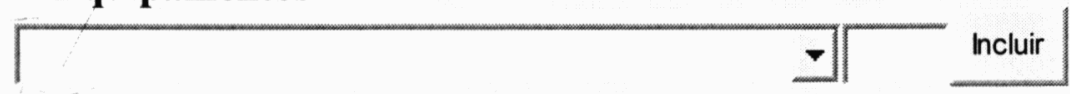

$\begin{array}{clll}\text { Endoscópio para colangiografia } & \text { Olympus } & 1 \\ \text { Endoscópio } & \text { Olympus } & 1 & 1 \\ \text { Endoscópio para colonoscopia } & \text { Olympus } & 1\end{array}$

\section{Equipamentos}

\begin{tabular}{|cccc|c}
\hline & & Mira & 1 \\
Bioquímica & COBAS & FC-180 & 1 \\
Bioquímica & CELM & Incluir \\
Bioquímica & Abbott & Super System & 1 \\
Hormônios & Immulite & $2000 \mathrm{TM}$ & 1 \\
Hemogasômetro & Drake & AGS-21 & 1 \\
Hematologia & Coulter & 890 & 1 \\
Espectrofotômetro & Bausch & & 1 \\
Agitador Orbital & & 255 & 1 \\
Capela de fluxo laminar & VECO & MicroBactek 9050 & 1 \\
Microscópio de imunoflorescência & & & 1 \\
Urina & Clintek & 200 & 1
\end{tabular}




\section{Equipamentos}

\begin{tabular}{|c|c|c|c|}
\hline & & -1 & Incluir \\
\hline Reveladora & Macrotec & MX-2 & 1 \\
\hline RX portátil & & & 1 \\
\hline $\mathrm{RX}$ & Siemens $500 \mathrm{~mA}$ & Heliophos & 1 \\
\hline $\mathrm{RX}$ com seriógrafo & Siemens & Heliophos 4B & 1 \\
\hline
\end{tabular}

\section{Equipamentos}

II Incluir

USG GE Logiq alfa $100 \mathrm{MP} \quad 1$ 蚫


SADT - Acessorio

\begin{tabular}{|c|c|c|c|}
\hline & $\mp$ Incluir & & \\
\hline Audiometria & não & & $\lambda$ \\
\hline Cintilografia & não & & $\lambda$ \\
\hline Ergometria & $\operatorname{sim}$ & & $\lambda$ \\
\hline Fisioterapia & não & & $\lambda$ \\
\hline Hemodiálise & não & & $\lambda$ \\
\hline Holter & $\operatorname{sim}$ & & $\lambda$ \\
\hline Litotripsia & $\operatorname{sim}$ & & $\lambda$ \\
\hline Mamografia & não & & $\lambda$ \\
\hline Quimioterapia & não & & $\lambda$ \\
\hline Radioterapia & não & & $\lambda$ \\
\hline Ressonância Magnética & não & & $\lambda$ \\
\hline Tomografia & não & & \\
\hline Angiografia Digital/Hemodinâmica & ca não & & \\
\hline EEG & não & & \\
\hline Ecografia & $\operatorname{sim} A$ & Aparelhos adequados & \\
\hline
\end{tabular}

\section{Equipamentos}

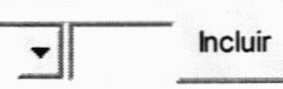

Ecocardiógrafo GE Vivid 31 解

Equipamentos

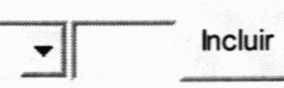

Ergometria Inbramed UT-4000 1 ตी 


\section{Apoio Técnico e Administrativo}

\section{Farmácia}

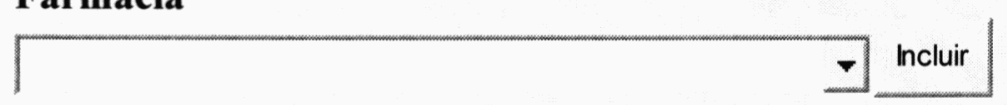

Há controle dos medicamentos Portaria 344

\begin{tabular}{|c|c|c|}
\hline $\operatorname{sim}$ & & \\
\hline não & & \\
\hline não & & \\
\hline não & & 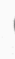 \\
\hline $\operatorname{sim}$ & & \\
\hline $\operatorname{sim}$ & & \\
\hline $\operatorname{sim}$ & Quantos & \\
\hline $\operatorname{sim}$ & & \\
\hline Individualizada & & \\
\hline
\end{tabular}

SND

A farmácia manipula NPP

Em área adequada conforme legislação

Há capela de fluxo laminar

Há local adequado para preparo dos medicamentos

Há local adequado para dispensação

Há farmacêutico no local

Há padronização de medicamentos

Dispensação

Individualizada

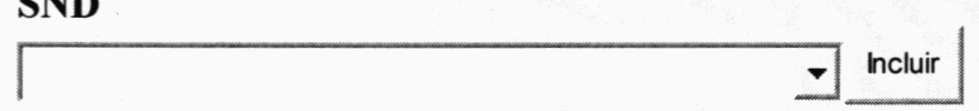

Circulação adequada

Equipamentos necessários e conservados

não

0 通

sim

Área adequada com boa iluminação e aeração

não

0 เ

Existe bancada para manipulação dos alimentos

$\operatorname{sim}$

0 泡

Há cardápio afixado

$\operatorname{sim}$

0 迎

Há Nutricionista

sim Quantas

2 题

\section{Limpeza/Higiene}

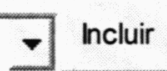

Há normas e rotinas para limpeza da unidade

$\operatorname{sim}$
$\operatorname{sim}$
$\operatorname{sim}$
$\operatorname{sim}$
$\operatorname{sim}$




\section{Lavanderia}

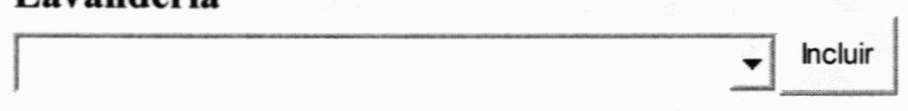

$\begin{array}{cl}\text { Máquina de lavar modelo profissional } & \text { sim } \\ \text { Centrífugas apropriadas } & \text { sim } \\ \text { Calandras } & \text { sim } \\ \text { Há barreiras físicas } & \text { sim } \\ \text { Há cruzamento limpo/contaminado } & \text { não } \\ \text { Área física apropriada } & \text { não } \\ \text { Equipamentos em boas condições } & \text { sim } \\ \text { Serviço de Costura/Rouparia } & \text { sim }\end{array}$

\begin{tabular}{|cc|c|}
\hline Almoxarifado & incluir \\
Área apropriada & $\operatorname{sim}$ \\
Estoques suficientes & $\operatorname{sim}$ \\
Setor informatizado & $\operatorname{sim}$
\end{tabular}

\section{Manutenção}

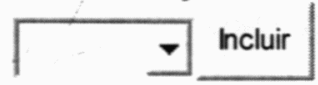

sim Própria

\section{Vigilancia}

- Incluir

sim Própria

(4)

SAME

sim informatizado

Prontuários conforme a Legislação

$\operatorname{sim}$ 


\section{Central Esterilização}

Central Esterilização:

\begin{tabular}{|cl}
\hline & sim \\
Encontra-se instalado em área física adequada & $\operatorname{sim}$ \\
Tem área para expurgo do material & $\operatorname{sim}$ \\
Tem área para preparo/esterilização & sim \\
Tem área para estocagem/distribuição & $\operatorname{sim}$ \\
Há enfermeira responsável & sim \\
Há normatização de procedimentos na área & não \\
Há cruzamento de fluxo de circulação entre as áreas & sim \\
Funcionários paramentados adequadamente & não \\
Possui estufas & sim \\
Possui Autoclave horizontal & não \\
Possui Autoclave vertical & sim \\
Há manutenção preventiva de equipamentos & sim
\end{tabular}

\section{Periodicidade}

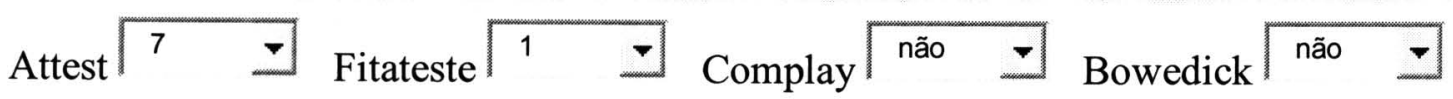




\section{Parecer:}

- Hospital geral privado com 130 leitos, 112 leitos operacionais, nível de atendimento secundário.

- Estrutura física: vertical, adaptada, com sinalização adequada e em boas condições de higiene e limpeza. Pronto-socorro geral, Maternidade, Berçário, UTI Geral, Pediátrica e Neonatal, Centro Cirúrgico com 06 salas cirúrgicas, RPA com 07 leitos e Unidades de Internação.

- Estrutura básica: gerador automático para suporte às áreas críticas, cabine primária de força, central de gases, sistema de prevenção de incêndios com extintores e hidrantes, pára-raios.

- Hotelaria: suíte: 01 sofá - cama, 01 mesa com 02 cadeiras, 01 bico de ar comprimido e 01 de vácuo. Ante-sala, frigobar, TV e telefone. Sanitário: porta abrindo para dentro, com box, sem barras/apoio.

- Apartamentos/Enfermarias: com TV, 01 bico de ar comprimido e 01 de vácuo. Sanitário: porta abrindo para dentro, com box, sem barras/ apoio. Concentrador portátil de oxigênio (Millenium Respironics) em todas as unidades.

- Serviços de apoio: farmácia com 01 farmacêutico, dispensação por sistema individualizado e unitário, com padronização dos medicamentos. SND com 02 nutricionistas e cardápio afixado semanalmente, em reforma, com área física e fluxos inadequados. Serviço de limpeza terceirizado com normas e rotinas e participação da $\mathrm{CCIH}$. Manutenção própria e terceirizada para equipamenos. Lavanderia em reforma. Central de Esterilização de Materiais adequada.

- SADT: ECG, Endoscopia, Patologia Clínica, Hemoterapia, RX Simples e Contrastado, Ecografia, Ergometria, Holter, Litotripsia.

- Organização e funcionamento: Regulamento Interno, Normas, Rotinas, Setor de Recrutamento e Seleção de Pessoal, Programa de Treinamento, Educação Continuada, Indicadores Hospitalares, Relatórios Gerenciais, Informatização em Rede exceto prontuário eletrônico, Saúde Ocupacional, Serviço Social. Comissões de Ética Médica, CCIH, Revisão de Óbitos, CIPA, Controle e Gestão de Qualidade, visando a acreditação pela ONA.

- Recursos Humanos 
○ Servidores/ leito: 4,19

o Proporção funcionários de enfermagem/ leito: 2,20

o Enfermeiros/ leito: 0,13

o Técnicos e Auxiliares de Enfermagem/ leito: 2,07

Observamos a necessidade de contratação de mais enfermeiros para alterar a composição da equipe de enfermagem e melhorar a assistência de enfermagem prestada ao paciente.

- Indicadores de Qualidade

○ Taxa de Mortalidade Institucional: 1,6\%

○ Taxa de Cesárea: 67,20\%

○ Taxa de Infecção Hospitalar: 0,61\%

- Indicadores de Produtividade

○ Taxa de Ocupação: 64,66\%

o Taxa de Permanência: 2,63 dias

o Giro de Rotatividade: 2,57 pacientes/mês 
Parecer: Consideramos o Hospital F apto.

Para tanto deverá:

1. Resolver problemas estruturais:

a. Adequar sanitários à $\mathrm{RDC} \mathrm{n}^{\circ} 50 / 02$.

b. Adequar Serviços de Nutrição e Lavanderia à RDC n ${ }^{\circ} 50 / 02$.

2. Reequipar sala de emergência/ urgência para dar condições de sustentação de vida (imediato), com instalação de respirador adequado.

3. Retirar berço aquecido por insuflação do berçário

4. Instalar Comissões de Revisão de Prontuários.

5. Estabelecer normas e rotinas para a UTI.

6. Contratar médico diarista para UTI (Portaria MS n 3432/98).

7. Contratar recursos humanos para compor a equipe médica e de enfermagem do Pronto Socorro (Resolução $n^{\circ} 1451 / 95$ do CFM e nº 189/2003 do COFEN).

8. Contratar mais enfermeiros para alterar a composição da equipe e melhorar a assistência prestada ao paciente.

9. Analisar indicadores de qualidade e produtividade em relação às taxas de cesáreas e de ocupação. 


\section{ANEXO 10 - Vistoria Técnica-Hospitalar - Hospital G}

\section{Identificação do Estabelecimento}

Nome:

\section{G}

Diretor Clínico:

CRM:

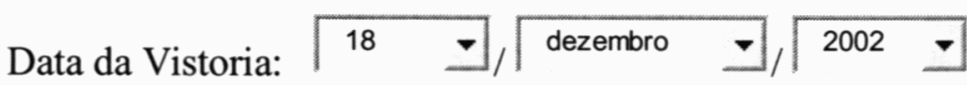

Acompanhantes:

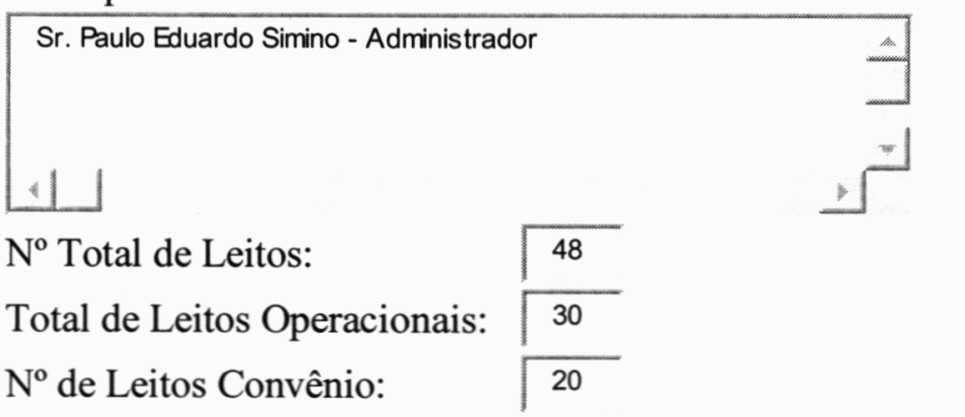

\section{Classificação do Estabelecimento}

Tipo de Hospital:

Geral 구

Lista de Especializações:

Geral

逋

\section{Tipo de Serviço}

Tipo de serviço: Privado

Abrangência do serviço

Abrangência do serviço: 
Organização e Funcionamento

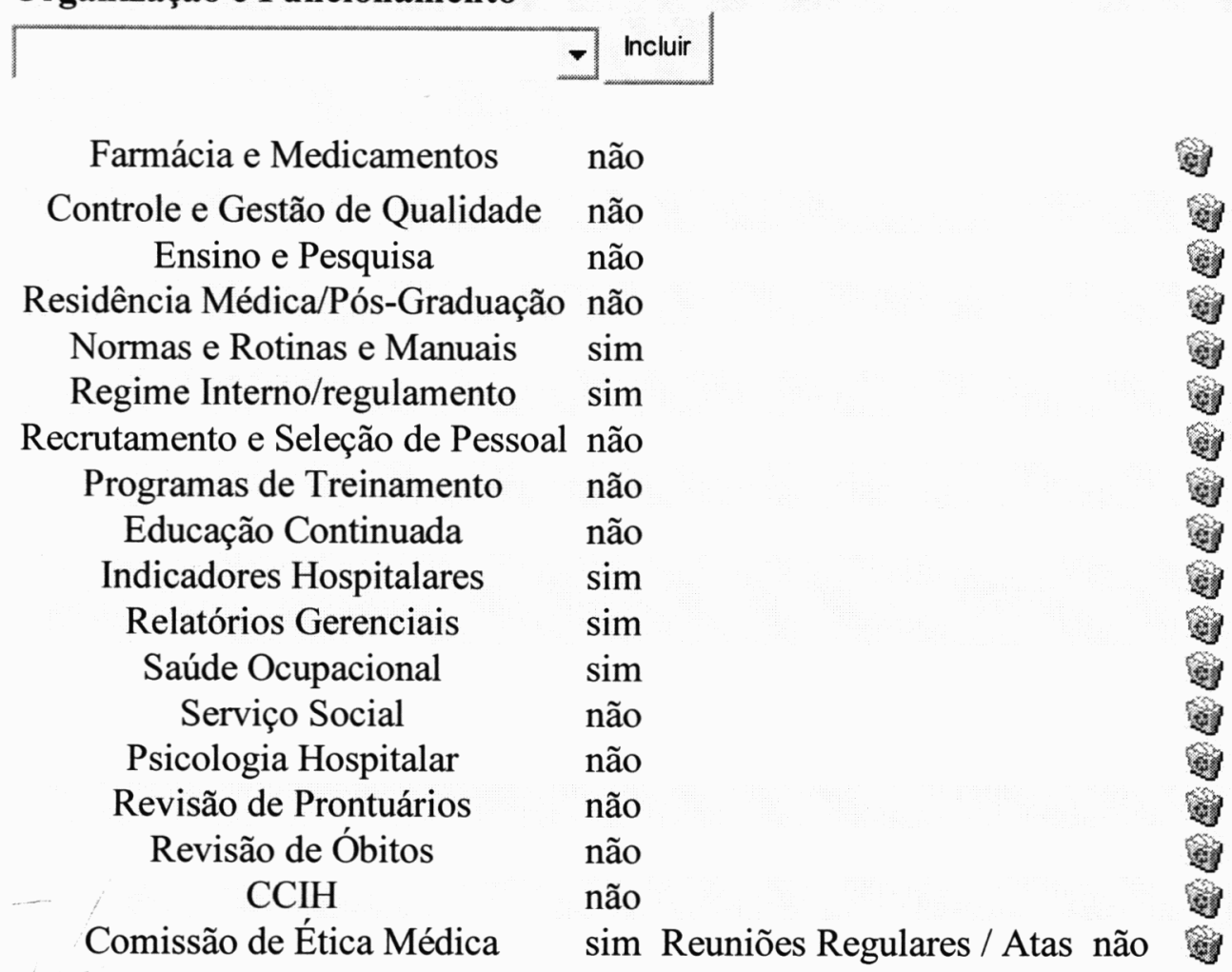


Recursos Humanos de todo o Hospital (Ano de 2002 )

Profissionais

Quantidade

Médicos

Enfermeiros

Técnicos de enfermagem

Auxiliares de enfermagem

Atendentes de enfermagem

Outros Funcionários

Total

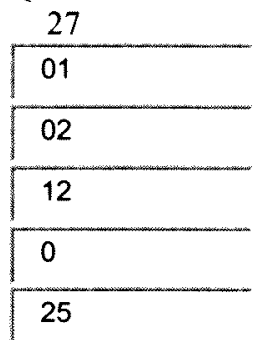

67

Informações Gerais (Ano de $\longdiv { 2 0 0 1 }$

Levantamento de dados anual

Número de óbitos após 48 horas

Números de saídas (Altas e Óbitos)

Números de óbitos por causas maternas

Número de pacientes atendidos em Obstetrícia

Número de nascidos vivos

Número de nascidos mortos

Número de óbitos neonatais após 48 horas

Número de óbitos operatórios até 10 dias pós-cirurgia

Número de atos cirurgicos

Número de cesáreas

Número de partos normais

Número total de partos

Número de infecções atribuiveis ao hospital

Número de supurações de feridas cirúrgicas em cirurgias limpas

Número de cirurgias limpas do período

Número de pacientes/dia

Número de leitos/dia

Número de leitos disponíveis no período

\begin{tabular}{l}
\hline 271 \\
\hline 4671 \\
\hline 0 \\
6279
\end{tabular}


Indicadores de Qualidade (Ano de $\sqrt{2001}$ )

Taxa de mortalidade institucional

Taxa de mortalidade materna

Taxa de natimortalidade

Taxa de mortalidade neonatal

Taxa de mortalidade operatória

Taxa de cesáreas

Taxa de infecção hospitalar

Taxa de supuração de ferida cirúrgica em cirurgia limpa

\begin{tabular}{|c|}
\hline 1,01 \\
\hline 0 \\
\hline 0 \\
\hline 1,69 \\
\hline 0 \\
\hline 91 \\
\hline 0 \\
\hline 0 \\
\hline
\end{tabular}

Indicadores de produtividade (Ano de $\sqrt{2001}$ )

Taxa de ocupação

Taxa de permanência

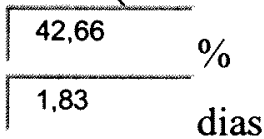

Giro de rotatividade $\quad 6,63$ pacientes/mês 


\section{Estrutura \\ Edificação: \\ $\mathrm{N}^{\mathrm{o}}$ de Pavimentos: \\ IV Horizontal \\ r \\ Planejada \\ $\mathrm{N}^{\mathrm{o}}$ de elevadores: \\ V Vertical \\ $\checkmark$ Adaptada}

Identificação

Estacionamento

Sinalização

Área para munutenção/descarga

Local próprio para lixo

Reservatório de Água

Elevadores

Caldeira

Gerador

Cabine Primária de Força

Ar Condicionado Central

Sistemas de Residuos

Sistema de Esgotos

Pára-Raios

Sistema de Prevenção de Incêndios

Central de Gases

Central de Gases visível

sim

sim

sim

$\operatorname{sim}$

$\operatorname{sim}$

desnecessário

não

não

sim

não

não

não

não

sim

Extintores

$\operatorname{sim}$

Tanque de oxigênio

sim Compressor de ar comprimido

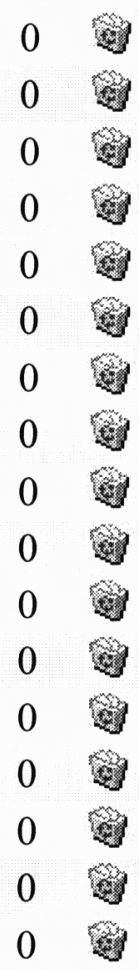


Organização e Atenção ao Paciente

\section{Hotelaria}

Incluir

\begin{tabular}{|c|c|c|c|c|}
\hline Recepção & Confortável & $\operatorname{sim}$ & & \\
\hline Recepção & Adequada & $\operatorname{sim}$ & & \\
\hline Recepção & Sanitários & $\operatorname{sim}$ & cada sexo & 0 \\
\hline Recepção & informatizada & $\operatorname{sim}$ & & 0 \\
\hline Limpeza & boa & & & 0 \\
\hline Higiene & boa & & & 0 \\
\hline Conservação Predial & boa & & & 0 \\
\hline
\end{tabular}

Unidades de Internação

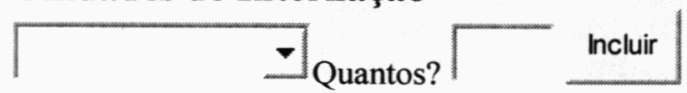

Apartamentos - Quantos?

cadeira de descanso

sofá/cama acompanhante

bico de oxigênio

Sanitário

Sanitário

ventilador

telefone

ar condicionado

frigobar

TV

$\begin{array}{cc}\operatorname{sim} & \\ \operatorname{sim} & \\ 01 & \\ \text { porta } & \text { abrindo para dentro } \\ \text { barras/apoios } & \text { não } \\ \operatorname{sim} & \\ \operatorname{sim} & \\ \operatorname{sim} & \\ \operatorname{sim} & \\ \operatorname{sim} & \end{array}$

\section{Apartamentos}

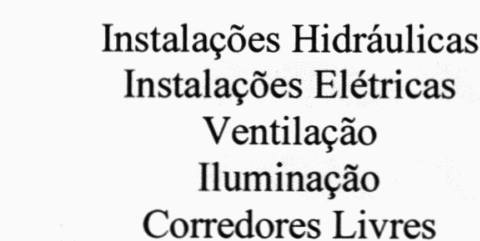

Carrinho de emergência

Torpedo de oxigênio na unidade

$\begin{array}{cl}\text { Adequada } & 0 \\ \text { Adequada } & 0 \\ \text { Adequada } & 0 \\ \text { Adequada } & 0 \\ \operatorname{sim} & 0 \\ \operatorname{sim} & 0 \\ \operatorname{sim} & 0\end{array}$




\section{Enfermaria}

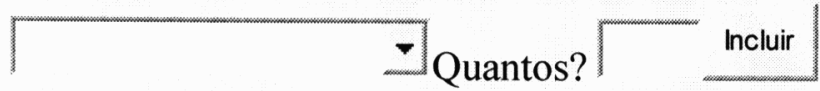

Enfermarias 4 Leitos - Quantos?

Carrinho de emergência

Torpedo de oxigênio na unidade

Distância mínima entre os leitos

Sanitário

Sanitário

bico de oxigênio

$\begin{array}{cc}\operatorname{sim} \\ \operatorname{sim} \\ \text { Barras/Apoios } \\ \text { Porta } & \text { Abrindo para dentro }\end{array}$

\section{Enfermarias 4 Leitos}

Instalações Hidráulicas
Instalações Elétricas
Ventilação
Iluminação
Corredores Livres

Adequada

Adequada

Adequada

Adequada

sim

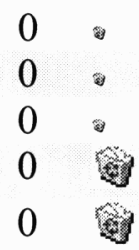


Pronto Socorro / Pronto Atendimento

Tipo: Geral Incluir

Entrada bem localizada, fácil acesso sim

Sala exclusiva para urgências sim

Leitos para observação

1 Bico de Oxigênio/leito

1 Ar Comprimido/leito

1 Vácuo/leito

Ambulância para remoção

Possui UTI Móvel

Equipe Médica conforme legislação

Enfermeira nos turnos

Medicamentos de urgência

$\begin{array}{ll}\text { sim } & 0 \\ \text { sim } & 0 \\ \text { sim } & 0 \\ \text { não } & 0 \\ \text { sim } & 0 \\ \text { não } & 0 \\ \text { não } & 0 \\ \text { não } & 0 \\ \text { não } & 0 \\ \text { sim } & 0\end{array}$

Equipamentos da Urgência

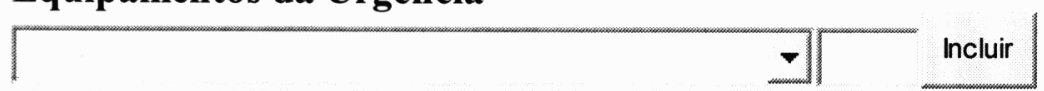

Foco auxiliar

Aspirador elétrico Fanem

12

Consultórios:

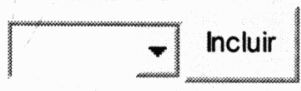

sim Geral

sim Pediatria

0 第

sim Ortopedia

0 辇

sim GO

0 嗮

0 翚 


\section{Outras Salas}

\begin{tabular}{lllr}
\hline Sala & Tamanho Incluir & \\
Sutura & Pequena & Equips. Excluir
\end{tabular}

Outras Salas

Sala: Sutura

\section{Equipamentos}

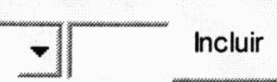

Foco auxiliar

Aspirador elétrico Fanem

Dia Pump

1 约

1 约 


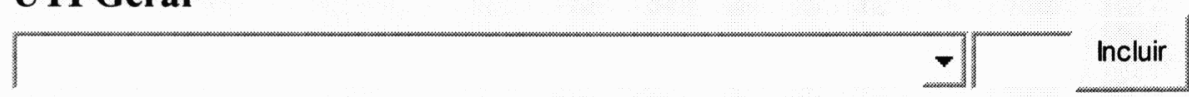

Número de Leitos

Há normas e rotinas para a área

A UTI participa da CCIH

Há programas de acompanhamento de visita com orientação

Encontra-se em área física adequada

De acordo com a legislação vigente

$\mathrm{O}$ posto de enfermagem permite boa visão dos leitos

Há boa circulação de funcionários e pacientes

Possui médico diarista

Possui equipe médica em todos os turnos

Há leitos para isolamento

Quarto para médico plantonista

Área de descanso para enfermagem

2 bicos de oxigênio/leito

1 bico de ar comprimido/leito

1 bico de vácuo/leito

$\begin{array}{ll} & 2 \\ \text { não } & 0 \\ \text { não } & 0 \\ \text { não } & 0 \\ \text { não } & 0 \\ \text { não } & 0 \\ \text { não } & 0 \\ \text { não } & 0 \\ \text { não } & 0 \\ \text { não } & 0 \\ \text { não } & 0 \\ \text { não } & 0 \\ \text { não } & 0 \\ \text { não } & 0 \\ \text { não } & 0 \\ \text { não } & 0\end{array}$

\section{Equipamentos}

\section{-}

$\begin{array}{ccccc}\text { Respirador } & \text { Bird } & \text { Mark-7 } & 1 & \text { a } \\ \text { Desfibrilador } & \text { Funbec } & \text { DF-02 } & 1 & \\ \text { Monitor de FC } & \text { Funbec } & \text { 4-HC/FT } & 1 & \text { g }\end{array}$




Tem sala de admissão
Sala/leitos de pré-parto
Sala de parto normal
Sala de parto cirúrgico

Salas

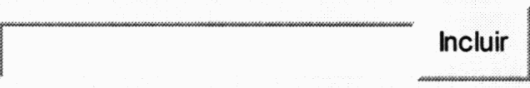

Reanimação do RN 入 
Berçário

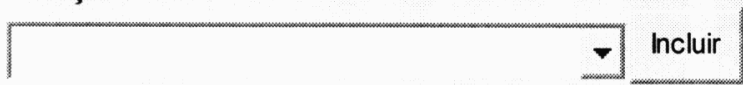

Há berçário de primeiros cuidados

Há UTI neonatal

Há alojamento conjunto

$$
\text { Área Física }
$$

Há berçário de patológicos

sim
não
sim
adequada
$\operatorname{sim}$

Salas

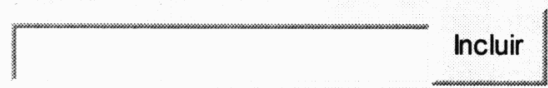

Intermediário/Patológico/ Prematuro

Isolamento

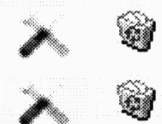

Área: Bercario

Sala: Intermediário/Patológico/ Prematuro

\section{Equipamentos}

\begin{tabular}{|c|c|c|c|}
\hline & 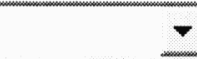 & & Incluir \\
\hline Incubadora & Olidef CZ & & \\
\hline Berço aquecido por insuflação & Olidef $\mathrm{CZ}$ & & 1 \\
\hline Bilispot & Fanem & & 8 \\
\hline Oxímetro & Nellcor & N 180 & 1 䈱 \\
\hline
\end{tabular}

Área: Bercário

Sala: Isolamento

\section{Equipamentos}

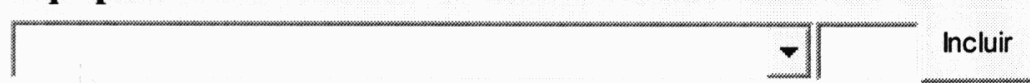

Aspirador elétrico

Gigante Lux 2




\section{Centro Cirúrgico}

Área de recepção de paciente com passa maca

$\operatorname{sim}$

(8)

Área de Escovação

$\operatorname{sim}$

की

Posto de Enfermagem e Serviços

não

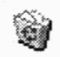

Vestiários com sanitários para funcionários com barreira não

Sala de preparo de equipamentos e material não

Depósito de equipamentos e materiais não

Sala administrativa

não

Depósito de Material de Limpeza

não

Sala de estar para funcionários

$\operatorname{sim}$

Sala de Espera com sanitário para acompanhantes

não

Área para guarda de macas e cadeira de rodas

$\operatorname{sim}$

Sala de Biópsia de congelação(Anatomia Patológica)

não

(a)

Fluxos pacientes/funcionários por entradas diferentes

$\operatorname{sim}$

Há Sala de Conforto Médico no Centro Cirúrgico

$\operatorname{sim}$

$\operatorname{sim}$

2 bicos de oxigênio/sala

$\operatorname{sim}$

1 bico de ar comprimido/sala

$\operatorname{sim}$

1 bico de vácuo/sala

\section{Centro Cirúrgico/Salas}

\begin{tabular}{|c|c|c|c|}
\hline & & - Incluir & \\
\hline Sala & Tamanho & Equips. & Excluir \\
\hline 01 & Média & $\lambda$ & 蚂 \\
\hline 02 & Pequena & $\lambda$ & 微 \\
\hline
\end{tabular}




\section{Centro Cirúrgico}

Sala: 01

\section{Equipamentos}

\begin{tabular}{|c|c|c|c|}
\hline & & - & Incluir \\
\hline Carrinho de anestesia & Narcosul & AUTS 3800 & 1 \\
\hline Bisturi elétrico & WEM & SS-500 & 1 \\
\hline Oxímetro & Ohmeda & Biox 3700 & 1 \\
\hline Capnógrafo & Dixtal & Capnogard & 1 \\
\hline Aspirador elétrico & Narcosul & & 1 \\
\hline RX portátil & Philips & MCD 105 & 1 \\
\hline
\end{tabular}

\section{Centro Cirúrgico}

Sala: 02

\section{Equipamentos}

\begin{tabular}{|c|c|c|c|}
\hline & $\rightarrow$ & Incluir & \\
\hline Carrinho de anestesia & Narcosul & Modulus 3000 & 1 \\
\hline Bisturi elétrico & Medsystem & BE-150 & 1 \\
\hline Microscópio cirúrgico & DFVasconcellos & MC 900 & 1 \\
\hline Microscópio cirúrgico & Opto & SM 2001 & 1 \\
\hline Aspirador elétrico & Fanem & Dia Pump & 1 \\
\hline
\end{tabular}

\begin{tabular}{|c|c|c|c|c|}
\hline \multicolumn{3}{|c|}{ Quantidade } & & \\
\hline & & hais & \multicolumn{2}{|c|}{ Desativadas } \\
\hline Pequena & 1 & - & 0 & - \\
\hline Média & 1 & - & 0 & $\nabla$ \\
\hline Grande & 0 & 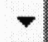 & 0 & 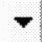 \\
\hline Especial & 0 & 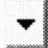 & 0 & $\nabla$ \\
\hline Total & & & & \\
\hline
\end{tabular}


Serviços de Apoio Diagnóstico e Terapia

\section{SADT}

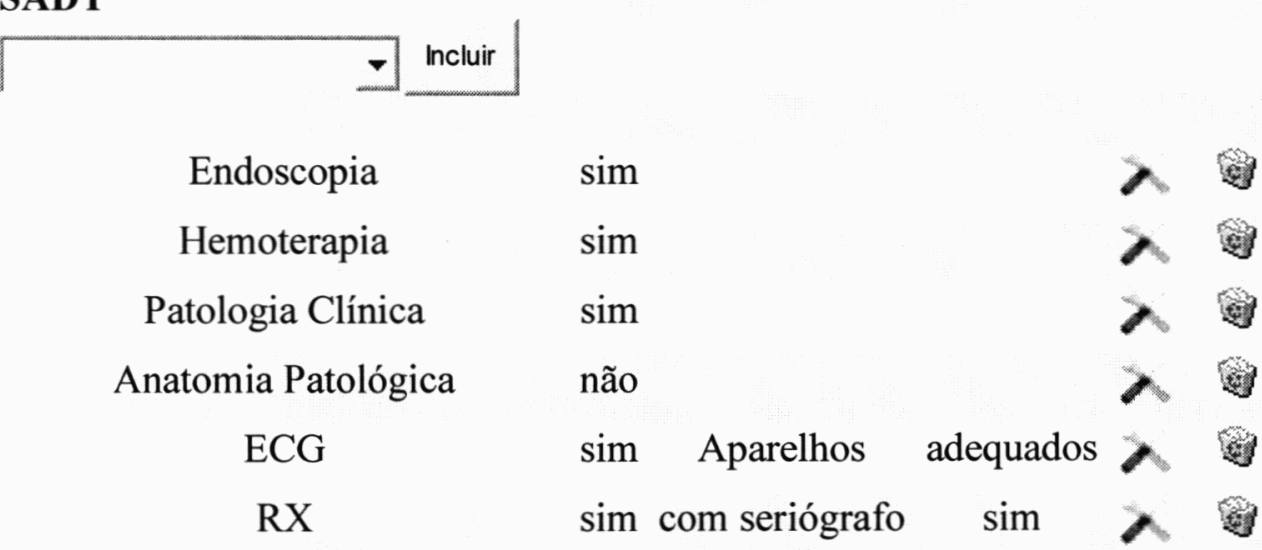

\section{Equipamentos}

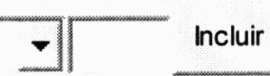

Videoendoscópio Endoview 1 跑

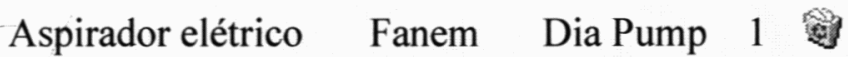

Aspirador elétrico Nevoni 1 这

\section{Equipamentos}

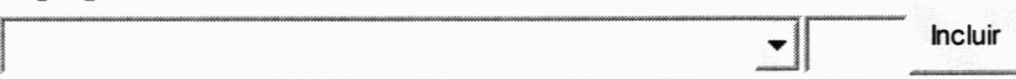

RX com seriógrafo Toshiba DC-12 MB 1 의

Reveladora Macrotec MX-2 1 解 
SADT - Acessório

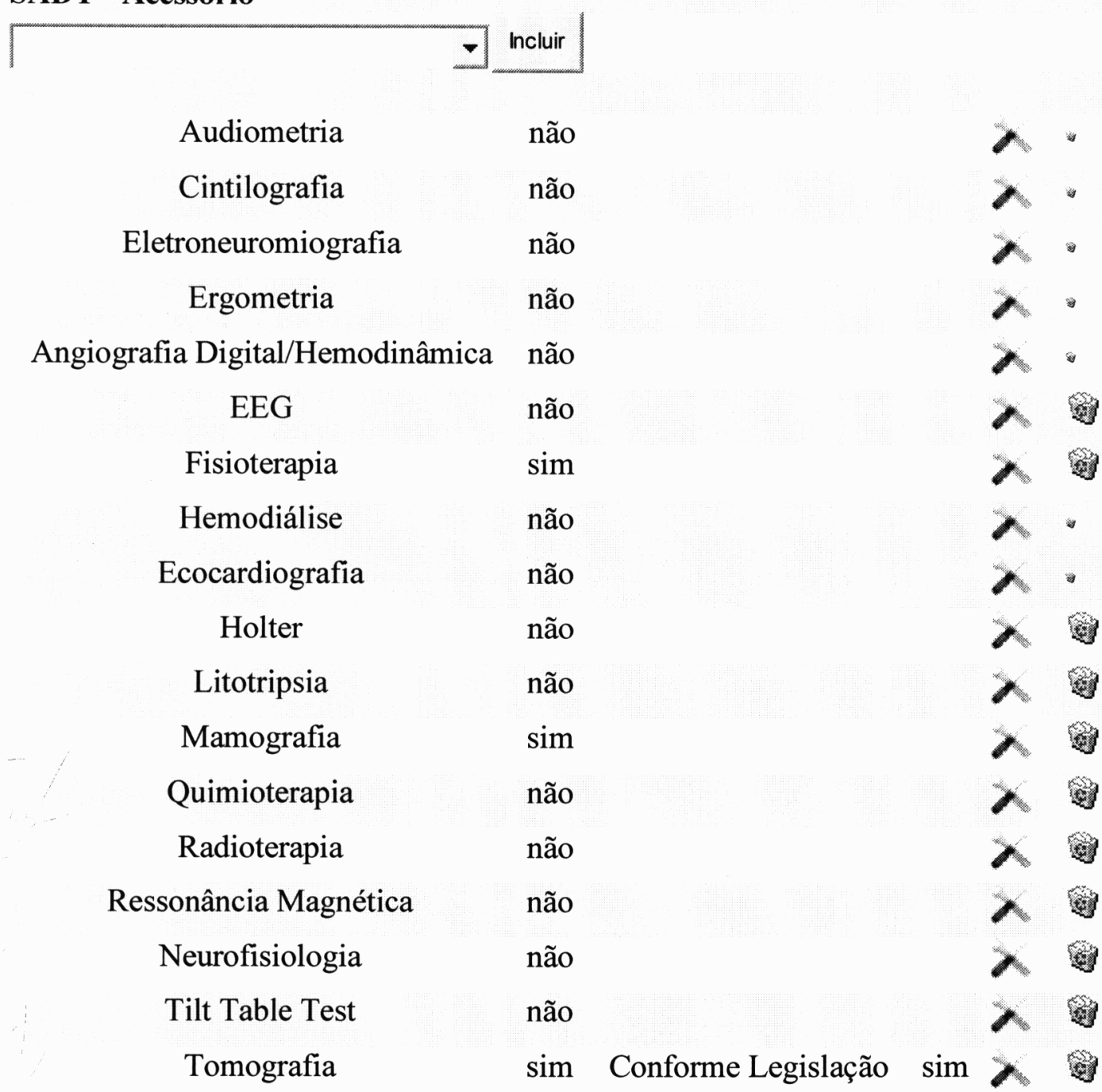

\section{Equipamentos}

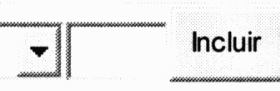

Mamógrafo Emitron EM 4351 \$

\section{Equipamentos}

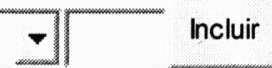

Tomografia helicoidal Siemens Somatom 1 ? 


\section{Apoio Técnico e Administrativo}

Farmácia

Há controle dos medicamentos Port 344

A farmácia manipula NPP

Em área adequada conforme legislação

Há capela de fluxo laminar

Há padronização de medicamentos

Há local adequado para dispensação

Há farmacêutico no local

Há padronização de medicamentos

Dispensação

\section{- Incluir}

$\operatorname{sim} \quad 0$.

não 0 .

não 0 .

não 0 .

$\operatorname{sim} \quad 0$.

$\operatorname{sim} \quad 0$.

sim Quantos 1.

$\operatorname{sim} 0$ 。

Convencional 0

SND

Incluir

Circulação adequada

Equipamentos necessários e conservados

$\operatorname{sim} \quad 0$.

Área adequada com boa iluminação e aeração

$\operatorname{sim} \quad 0$.

Existe bancada para manipulação dos alimentos

$\operatorname{sim} \quad 0$.

Há cardápio afixado

$\operatorname{sim} \quad 0$ 。

Há Nutricionista

$\operatorname{sim} \quad 0$.

não 0 嗮

\section{Limpeza/Higiene}

Há normas e rotinas para limpeza da unidade

$\operatorname{sim}$

Utilizam produtos próprios para limpeza

$\operatorname{sim}$

A CCIH participa na elaboração de normas do setor

Há coleta seletiva do lixo

não

$\operatorname{sim}$

Funcionários utilizam equipamentos de proteção

$\operatorname{sim}$ 


\section{Lavanderia}

$\begin{array}{cc}\text { Máquina de lavar modelo profissional } & \text { sim } \\ \text { Centrífugas apropriadas } & \text { sim } \\ \text { Calandras } & \operatorname{sim} \\ \text { Há barreiras físicas } & \text { sim } \\ \text { Há cruzamento limpo/contaminado } & \text { não } \\ \text { Área física apropriada } & \text { sim } \\ \text { Equipamentos em boas condições } & \operatorname{sim} \\ \text { Funcionários com equipamentos de proteção } & \operatorname{sim} \\ \text { Serviço de Costura/Rouparia } & \operatorname{sim}\end{array}$

\section{Almoxarifado}

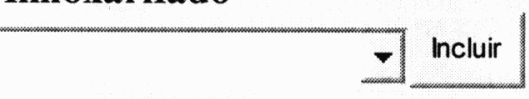

Área apropriada

sim

Estoques suficientes

$\operatorname{sim}$

Setor informatizado

$\operatorname{sim}$

\section{Manutenção}

\section{- Incluir}

sim Própria

Vigilancia

- Incluir

não

(9)

SAME

Informatizado

Prontuário único

Prontuários conforme a Legislação

$\operatorname{sim}$ 


\section{Central Esterilização}

Central Esterilização:

\begin{tabular}{|c|c|c|}
\hline 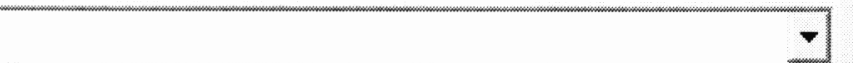 & Incluir & \\
\hline Encontra-se instalado em área física adequada & não & \\
\hline Tem área para expurgo do material & $\operatorname{sim}$ & \\
\hline Tem área para preparo/esterilização & $\operatorname{sim}$ & \\
\hline Tem área para estocagem/distribuição & não & \\
\hline Há enfermeira responsável & não & \\
\hline Há normatização de procedimentos na área & $\operatorname{sim}$ & \\
\hline Há cruzamento de fluxo de circulação entre as áreas & $\operatorname{sim}$ & \\
\hline Funcionários paramentados adequadamente & $\operatorname{sim}$ & \\
\hline Possui Autoclave vertical & não & 0 \\
\hline Há manutenção preventiva de equipamentos & não & \\
\hline É utilizado Controle Biológico & $\operatorname{sim}$ & \\
\hline Possui estufas & $\operatorname{sim}$ & 1 \\
\hline Possui Autoclave horizontal & $\operatorname{sim}$ & 1 \\
\hline
\end{tabular}

\section{Periodicidade}

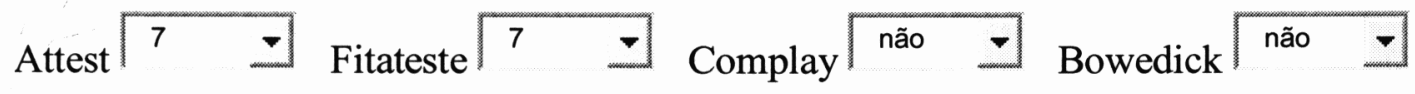




\section{Parecer:}

- Hospital geral privado, com 48 leitos, 30 leitos operacionais, com nível de atendimento primário.

- Estrutura física: horizontal, adaptada, com sinalização adequada e em boas condições de higiene e limpeza. Pronto-atendimento de adulto e Pediatria, Maternidade, Berçário, Sala erroneamente denominada UTI geral com 02 leitos, Centro Cirúrgico com 02 salas cirúrgicas, sem RPA. Unidades de Internação.

- Estrutura básica: sem gerador para suporte às áreas críticas, cabine primária de força, central de gases, sistema de prevenção de incêndios com extintores, sem pára-raios.

- Hotelaria: apartamentos confortáveis com TV, telefone, frigobar, ar condicionado, com 01 bico de oxigênio. Sanitários: porta abrindo para dentro, com box, sem barras/apoios, contrariando a RDC_50/02. Isolamento com 02 apartamentos, com sanitários privativos com portas abrindo para dentro, com box, sem barras/ apoio e sala de paramentação comum aos dois apartamentos. Enfermaria com 04 leitos. Para cada 02 leitos, 01 bico de oxigênio. Sanitário: 01 para os 04 leitos, com porta abrindo para dentro, com box, sem barras/apoios contrariando a RDC_50/02.

- Serviços de apoio: farmácia com 01 farmacêutico, dispensação por sistema convencional, com padronização dos medicamentos. SND sem nutricionista e cardápio afixado semanalmente. Limpeza própria com normas e rotinas, a CCIH não participa da elaboração de normas. Lavanderia própria, com área física e fluxos corretos. Serviço de Manutenção próprio para o hospital e terceirizado para os equipamentos. Sem Serviço de Vigilância. Central de Esterilização de Materiais em área física inadequada com fluxo cruzado.

- SADT: ECG, Mamografia, RX Simples e Contrastado e Tomografia, Endoscopia, Fisioterapia. Patologia Clínica externa e terceirizada.

- Organização e funcionamento: Regulamento Interno, Normas, Rotinas, Indicadores Hospitalares, Relatórios Gerenciais, Informatização em Rede 
exceto prontuário eletrônico e Saúde Ocupacional. Comissões: de Ética Médica (sem Livro Ata) e CIPA.

- Recursos Humanos

○ Servidores/leito: 2,23

- Proporção funcionários de enfermagem/ leito: 0,5

- Enfermeiros/ leito: 0,03

- Técnicos e Auxiliares de Enfermagem/ leito: 0,46

Observamos a necessidade de contratação de mais enfermeiros para alterar a composição da equipe de enfermagem e melhorar a assistência de enfermagem prestada ao paciente.

- Indicadores de Qualidade

- Taxa de Mortalidade Institucional: 1,01\%

- Taxa de Cesárea: 91\%

- Indicadores de Produtividade

○ Taxa de Ocupação: $42,66 \%$

- Taxa de Permanência: 1,83 dias

- Giro de Rotatividade: 6,63 pacientes/mês 


\section{Parecer:}

Consideramos o Hospital G apto.

Para tanto deverá:

1. Contratar Recursos Humanos de enfermagem para alterar a composição da equipe e melhorar a assistência prestada ao paciente.

2. Instalar Comissões de: CCIH, Revisão de Prontuários e de Óbitos. Colocar em funcionamento a Comissão de Ética Médica.

3. Instalar e equipar RPA.

4. Resolver problemas estruturais:

a. Instalar gerador para dar suporte às áreas críticas

b. Adequar sala de endoscopia: centralizar mesa e equipar com material de emergência.

c. Adequar sanitários dos apartamentos e enfermarias à $\mathrm{RDC} \mathrm{n}^{\circ}$ 50/02.

d. Adequar vestiários do $\mathrm{CC}$ à $\mathrm{RDC} \mathrm{n}^{\circ}$ 50/02.

e. Adequar Central de Esterilização de Materiais à $R D C n^{\circ} 50 / 02$.

f. Adequar enfermarias à RDC n ${ }^{\circ} 50 / 02$.

5. Reequipar sala de emergência do PA para dar condições de sustentação de vida, com instalação imediata de respirador adequado.

6. Retirar de utilização berços aquecidos por insuflação do berçário.

7. O serviço denominado de UTI não obedece à legislação vigente, não atendendo nenhum critério técnico preestabelecido.

8. Contratar nutricionista para o SND.

9. Contratar Recursos Humanos para compor equipe médica e de enfermagem do PA, conforme Resoluções CFM n $1451 / 95$ e COFEN n $189 / 2003$. 


\section{ANEXO 11 - Vistoria Técnica-Hospitalar - Hospital H}

\section{Identificação do Estabelecimento}

Nome:

$\begin{array}{ll} & \mathrm{H} \\ \text { Diretor Clínico: } & \mathrm{CRM} \text { : }\end{array}$

Data da Vistoria: $\begin{array}{ll}23 & -\end{array}, \sqrt{\text { outubro }} \quad \sqrt{2003}=$

Acompanhantes:

Rita Mattar (Psicóloga)
Alessandra Fimiko (Enfermeira)
Lucimeire Ravelli Peixoto (Gerente)
Sidnei David gual (Estágiário da Área Administrativa)

$N^{o}$ Total de Leitos:

38

Total de Leitos Operacionais:

38

$\mathrm{N}^{\circ}$ de Leitos Convênio:

38

\section{Classificação do Estabelecimento}

Tipo de Hospital:

Geral

Lista de Especializações:

Incluir

\section{Tipo de Serviço}

Tipo de serviço:

Privado

Incluir

Abrangência do serviço

Abrangência do serviço: 


\section{Organização e Funcionamento}

\begin{tabular}{|c|c|c|c|}
\hline & Incl & & \\
\hline Farmácia e Medicamentos & não & & \\
\hline Controle e Gestão de Qualidade & não & & \\
\hline Ensino e Pesquisa & não & & \\
\hline Residência Médica/Pós-Graduação & não & & \\
\hline Normas e Rotinas e Manuais & $\operatorname{sim}$ & & \\
\hline Regime Interno/regulamento & $\operatorname{sim}$ & & \\
\hline Recrutamento e Seleção de Pessoal & $\operatorname{sim}$ & & \\
\hline Programas de Treinamento & $\operatorname{sim}$ & & \\
\hline Educação Continuada & não & & \\
\hline $\begin{array}{l}\text { Indicadores Hospitalares } \\
\text { Relatórios Gerenciais }\end{array}$ & $\begin{array}{l}\operatorname{sim} \\
\operatorname{sim}\end{array}$ & & \\
\hline $\begin{array}{l}\text { Informatização } \\
\text { Serviço Social }\end{array}$ & $\begin{array}{l}\text { não } \\
\text { sim }\end{array}$ & & \\
\hline Psicologia Hospitalar & $\operatorname{sim}$ & & \\
\hline Saúde Ocupacional & $\operatorname{sim}$ & & \\
\hline $\mathrm{CCIH}$ & $\operatorname{sim}$ & Reuniões Regulares / Atas & não \\
\hline Revisão de Prontuários & não & & \\
\hline Revisão de Óbitos & não & & \\
\hline CIPA & $\operatorname{sim}$ & Reuniões Regulares / Atas & $\operatorname{sim}$ \\
\hline Comissão de Ética Médica & $\operatorname{sim}$ & Reuniões Regulares / Atas & $\operatorname{sim}$ \\
\hline
\end{tabular}


Recursos Humanos de todo o Hospital (Ano de $\sqrt{2003}$ )

Profissionais

Médicos

Enfermeiros

Técnicos de enfermagem

Auxiliares de enfermagem

Atendentes de enfermagem

Outros Funcionários

Total

Quantidade

Corpo Clínico aberto

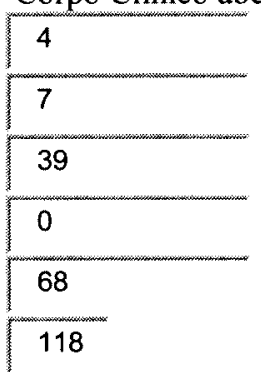

Informações Gerais (Ano de

2002

Levantamento de dados anual

Número de óbitos após 48 horas

Números de saídas (Altas e Óbitos)

Números de óbitos por causas maternas

Número de pacientes atendidos em Obstetrícia

Número de nascidos vivos

Número de nascidos mortos

Número de óbitos neonatais após 48 horas

Número de óbitos operatórios até 10 dias pós-cirurgia

Número de atos cirurgicos

Número de cesáreas

Número de partos normais

Número total de partos

Número de infecções atribuiveis ao hospital

Número de supurações de feridas cirúrgicas em cirurgias limpas

Número de cirurgias limpas do período

Número de pacientes/dia

Número de leitos/dia

Número de leitos disponíveis no período

\begin{tabular}{l}
25 \\
$\frac{12320}{18}$ \\
$\frac{181}{185}$ \\
\hline 04 \\
2 \\
\hline 0 \\
1540 \\
166 \\
19 \\
185
\end{tabular}

$\frac{0}{474}$
$\frac{1140}{13870}$


Indicadores de Qualidade (Ano de $\sqrt{2002}$ )

Taxa de mortalidade institucional

Taxa de mortalidade materna

Taxa de natimortalidade

Taxa de mortalidade neonatal

Taxa de mortalidade operatória

Taxa de cesáreas

Taxa de infecção hospitalar

Taxa de supuração de ferida cirúrgica em cirurgia limpa

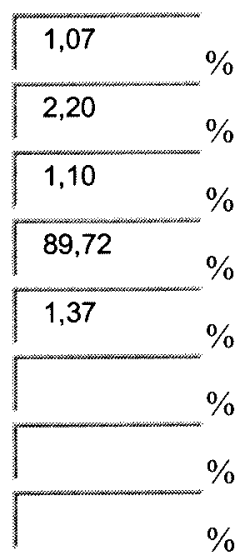

Indicadores de produtividade (Ano de

2002

Taxa de ocupação

Taxa de permanência

\begin{tabular}{ll}
41,81 & $\%$ \\
\hline 2,5 & dias
\end{tabular}

Giro de rotatividade

5,08 pacientes/mês 


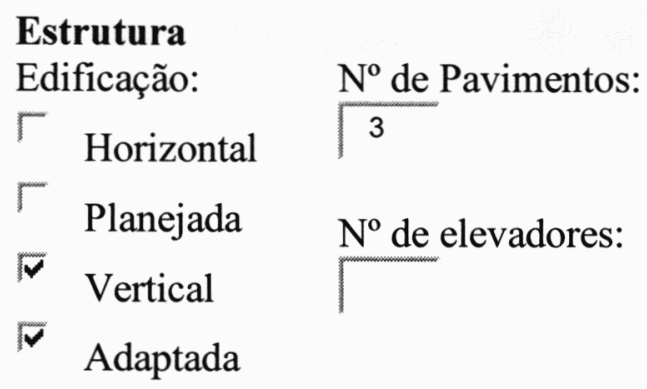

\begin{tabular}{|c|c|c|c|}
\hline & Incluir & & \\
\hline Identificação & visível & & 0 \\
\hline Sinalização & não & & 0 \\
\hline Área para munutenção/descarga & $\operatorname{sim}$ & & 0 \\
\hline Local próprio para lixo & $\operatorname{sim}$ & & 0 \\
\hline Reservatório de Água & $\operatorname{sim}$ & & 0 \\
\hline Caldeira & não & & 0 \\
\hline Gerador & automático & suficiente para o hospital & 0 \\
\hline Cabine Primária de Força & $\operatorname{sim}$ & & 0 \\
\hline Ar Condicionado Central & não & & 0 \\
\hline Sistemas de Residuos & não & & 0 \\
\hline Sistema de Esgotos & não & & 0 \\
\hline Pára-Raios & não & & 0 \\
\hline Sistema de Prevenção de Incêndios & $\operatorname{sim}$ & Extintores & 0 \\
\hline Estacionamento & $\operatorname{sim}$ & insuficiente & 0 \\
\hline Elevadores & desnecessário & & 0 \\
\hline Central de Gases & $\operatorname{sim}$ & Rede de Torpedos oxigênio & 0 \\
\hline Central de Gases & $\operatorname{sim}$ & Torpedos de $\mathrm{N} 2 \mathrm{O}$ & 0 \\
\hline Central de Gases & $\operatorname{sim}$ & Compressor de ar comprimido & 0 \\
\hline
\end{tabular}


Organização e Atenção ao Paciente

\section{Hotelaria}

\begin{tabular}{|ccc}
\hline & Incluir & \\
Recepção & Confortável & \\
Recepção & Adequada & \\
Recepção & informatizada & sim \\
Recepção & Sanitários & sim \\
Limpeza & boa & \\
Higiene & boa & \\
Conservação Predial & boa &
\end{tabular}

Unidades de Internação

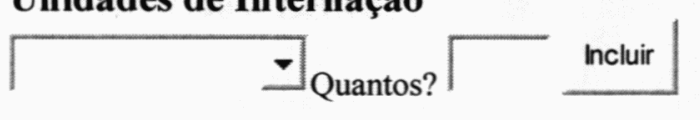

Apartamentos - Quantos? 7

cadeira de descanso Sanitário

Sanitário

bico de ar comprimido

bico de oxigênio

sofá/cama acompanhante

telefone

ar condicionado

TV

sim abrindo para dentro
porta
barras/apoios
01
01
$\operatorname{sim}$
Sim
Sim
$\operatorname{sim}$

\section{Apartamentos}

$\begin{array}{ccc}\text { Instalações Hidráulicas } & \text { Adequada } & 0 \\ \text { Instalações Elétricas } & \text { Adequada } & 0 \\ \text { Ventilação } & \text { Adequada } & 0 \\ \text { Iluminação } & \text { Adequada } & 0 \\ \text { Corredores Livres } & \text { sim } & 0 \\ \text { Carrinho de emergência } & \text { não } & 0 \\ \text { Torpedo de oxigênio na unidade } & \text { não } & 0\end{array}$




\section{Enfermaria}

\section{$\beth_{\text {Quantos? }}$ Incluir}

Enfermarias 2 Leitos - Quantos? 3

$\begin{array}{ccc}\text { Sanitário } & \text { Barras/Apoios } & \text { não } \\ \text { Sanitário } & \text { Porta } & \text { Abrindo para dentro } \\ \text { bico de ar } & \operatorname{sim} & \\ \text { bico de oxigênio } & \operatorname{sim} & \\ \text { ventilador } & \operatorname{sim} & \\ \text { TV } & \operatorname{sim} & \end{array}$

\section{Enfermarias 2 Leitos}

$\begin{array}{ccc}\text { Instalações Hidráulicas } & \text { Adequada } & 0 \\ \text { Instalações Elétricas } & \text { Adequada } & 0 \\ \text { Ventilação } & \text { Adequada } & 0 \\ \text { Iluminação } & \text { Adequada } & 0 \\ \text { Corredores Livres } & \text { sim } & 0 \\ \text { Carrinho de emergência } & \text { não } & 0 \\ \text { Torpedo de oxigênio na unidade } & \text { não } & 0\end{array}$


Enfermaria

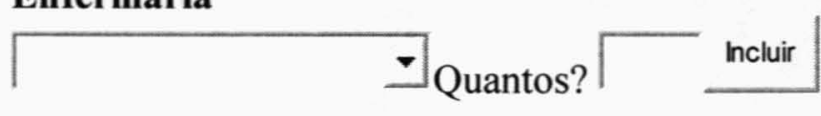

Enfermarias 5 Leitos - Quantos?

$\begin{array}{ccc}\text { Sanitário } & \text { Barras/Apoios } & \text { não } \\ \text { Sanitário } & \text { Porta } & \text { Abrindo para dentro } \\ \text { bico de ar } & \operatorname{sim} & \\ \text { co de oxigênio } & \operatorname{sim} & \\ \text { ventilador } & \operatorname{sim} & \\ \text { TV } & \operatorname{sim} & \end{array}$

\section{Enfermarias 5 Leitos}

$\begin{array}{ccc}\text { Instalações Hidráulicas } & \text { Adequada } & 0 \\ \text { Instalações Elétricas } & \text { Adequada } & 0 \\ \text { Ventilação } & \text { Adequada } & 0 \\ \text { Iluminação } & \text { Adequada } & 0 \\ \text { Corredores Livres } & \text { sim } & 0 \\ \text { Carrinho de emergência } & \text { não } & 0 \\ \text { Torpedo de oxigênio na unidade } & \text { não } & 0\end{array}$




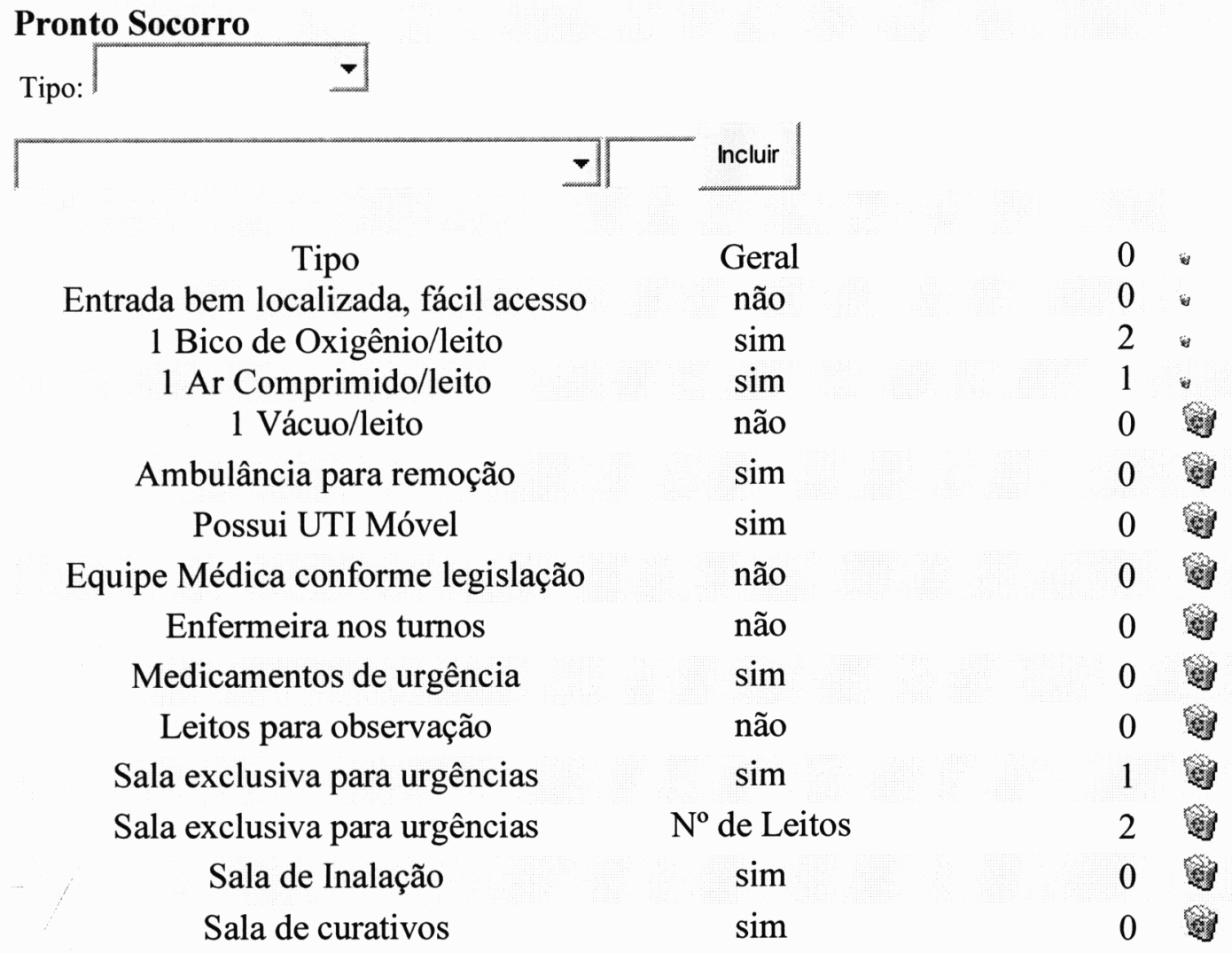

Equipamentos da Urgência

\begin{tabular}{lllll}
\hline & & & \\
Desfibrilador & EMAI & DX-10 & 1 & \\
Cardioversor & EMAI & RX-20 & 1 & \\
AMBU & & & 1 &
\end{tabular}

\section{Consultórios:}

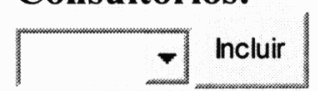

Sim GO

Sim Pediatria

0 吹

Sim Geral 


\section{Outras Salas}

$\square$ Incluir

Sala

Tamanho

Pequena Cirurgia

Gabinete Dentário

Pequena

Pequena
Equips. Excluir

媇

(2)

\section{Outras Salas}

Sala: Pequena Cirurgia

\section{Equipamentos}

$\begin{array}{ccc}\text { Mesa cirúrgica } & \text { Incluir } \\ \text { Foco Central de Teto } & 1 & 1\end{array}$




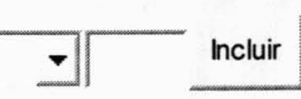

Número de Leitos

Há normas e rotinas para a área

Há programas de acompanhamento de visita com orientação

Encontra-se em área física adequada

De acordo com a legislação vigente

O posto de enfermagem permite boa visão dos leitos

Há boa circulação de funcionários e pacientes

Possui médico diarista

Possui equipe médica em todos os turnos

Equipe de enfermagem treinada e completa

Enfermeira em todos os turnos

Há leitos para isolamento

\begin{tabular}{|c|c|}
\hline & 2 \\
\hline não & 0 \\
\hline não & 0 \\
\hline não & 0 \\
\hline não & 0 \\
\hline $\operatorname{sim}$ & 0 \\
\hline $\operatorname{sim}$ & 0 \\
\hline não & 0 \\
\hline não & 0 \\
\hline não & 0 \\
\hline não & 0 \\
\hline não & 0 \\
\hline
\end{tabular}

Equipamentos

\begin{tabular}{|cccc|c|}
\hline & & & & \\
Monitor de FC & Funbec & TC-500 & 1 \\
Oxímetro & Criticare & 504 & 1 & \\
Monitor FC + ECG & Funbec & $4-1$ TC FC & 2 & \\
Monitor FC + ECG & Ecafix & ACL 07 & 1 & \\
Desfibrilador & EMAI & DX-10 & 1 \\
Cardioversor & EMAI & RX-20 & 1 \\
Respirador & Takaoka & Memphis & 1
\end{tabular}




Tem sala de admissão
Sala/leitos de pré-parto
Sala de parto normal
Sala de parto cirúrgico
Vestiário com sanitário para ambos os sexos

\section{Berçário}

$\begin{array}{ccc}\text { Há berçário de patológicos } & \text { não } \\ \text { Há alojamento conjunto } & \text { sim } & \text { não } \\ \text { Há UTI neonatal } & \text { sim }\end{array}$


Salas

${ }^{\text {Incluir }}$

Berçário de Primeiros Cuidados

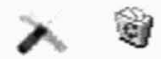

Área: Bercario

Sala: Berçário de Primeiros Cuidados

Equipamentos

\begin{tabular}{|c|c|c|c|}
\hline & T & Incluir & \\
\hline Respirador & Intermed & Inter 3 & 1 \\
\hline Respirador & Sechrist & IV-100 B & 1 \\
\hline Incubadora & Olidef CZ & RW plus & 1 \\
\hline Incubadora & Fanem & C186-TS/TS & 1 \\
\hline Berço aquecido calor irradiante & Fanem & AQ-50 & 2 \\
\hline Balança pesa-bebê & Filizola & Baby & 1 \\
\hline Monitor FC + oxímetro & Ecafix & Active & 1 \\
\hline Bilispot & Fanem & & 1 \\
\hline
\end{tabular}


Centro Cirúrgico

\begin{tabular}{cc}
\hline 2 bicos de oxigênio/sala & sim \\
Área de Escovação & sim \\
Árecepc̃o de paciente com passa maca & sim \\
Posto de Enfermagem e Serviços & não \\
Vestiários com sanitários para funcionários com barreira não \\
Sala de preparo de equipamentos e material & não \\
Depósito de equipamentos e materiais & não \\
Sala administrativa & não \\
Expurgo & não \\
Depósito de Material de Limpeza & sim \\
Sala de estar para funcionários & não \\
Sala de Espera com sanitário para acompanhantes & não \\
Área para guarda de macas e cadeira de rodas & sim \\
Sala de Biópsia de congelação(Anatomia Patológica) & não \\
Fluxos pacientes/funcionários por entradas diferentes & sim \\
Há Sala de Conforto Médico no Centro Cirúrgico & não \\
Número total de salas cirúgicas & \\
Número de salas de média cirurgia & \\
Número de salas de pequena cirurgia & sim \\
1 bico de ar comprimido/sala & sim de vácuo/sala
\end{tabular}

\section{Centro Cirúrgico/Salas}

\begin{tabular}{|c|c|c|c|}
\hline & - Incluir & & \\
\hline Sala & Tamanho & Equips. & Excluir \\
\hline Urologia & Pequena & $\lambda$ & 约 \\
\hline 01 & Média & $\lambda$ & giv \\
\hline 02 & Média & $\lambda$ & 2 \\
\hline
\end{tabular}


Centro Cirúrgico

Sala: Urologia

Equipamentos

\begin{tabular}{|ccc|c|}
\hline & & -1 & Incluir \\
Mesa Ginecológica & & 1 & 1 \\
Foco auxiliar & & MC 900 & 1 \\
Microscópio cirúrgico & DFVasconcellos \\
Uroscópio & Storz & & 1
\end{tabular}

\section{Centro Cirúrgico}

Sala: 01

\section{Equipamentos}

\begin{tabular}{|c|c|c|c|}
\hline & - & Incluir & \\
\hline Carrinho de anestesia & Takaoka & Samurai III & 1 \\
\hline Monitor FC + oxímetro & EMAI & MX 300 & 1. \\
\hline Bisturi elétrico & Union Medical & UMD 3000 & 1 \\
\hline $\begin{array}{c}\text { Berço aquecido calor irradiante } \\
\text { Videolaparoscópio }\end{array}$ & Fanem & AQ-50 & \\
\hline
\end{tabular}

\section{Centro Cirúrgico}

Sala: 02

Equipamentos

\begin{tabular}{|ccc|c|}
\hline & & \\
Berço aquecido calor irradiante & Takaoka & \\
Foco auxiliar & & 1 & 1 \\
Mesa cirúrgica ortopédica & & 1 \\
Bisturi elétrico & EMAI & BP-400 & 1 \\
RX portátil & Siemens & Unimax GV & 1
\end{tabular}

Quantidade

\begin{tabular}{|c|c|c|c|c|}
\hline \multicolumn{3}{|c|}{ Quantidade } & & \\
\hline & \multicolumn{2}{|c|}{ Operacionais } & \multicolumn{2}{|c|}{ Desativadas } \\
\hline Pequena & 1 & $\boldsymbol{\nabla}$ & 0 & $\nabla$ \\
\hline Média & 2 & $\nabla$ & 0 & $\nabla$ \\
\hline Grande & 0 & $\nabla$ & 0 & $\nabla$ \\
\hline Especial & 0 & $\boldsymbol{\nabla}$ & 0 & $\nabla$ \\
\hline Total & & & & \\
\hline
\end{tabular}


Serviços de Apoio Diagnóstico e Terapia

\section{SADT}

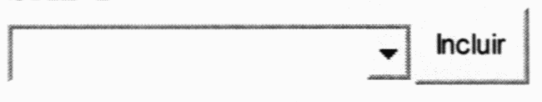

\begin{tabular}{|c|c|c|}
\hline ECG & sim & \\
\hline Endoscopia & $\operatorname{sim}$ & \\
\hline Hemoterapia & sim & \\
\hline Patologia Clínica & $\operatorname{sim}$ & \\
\hline $\mathrm{RX}$ & sim & \\
\hline RX Portátil & $\operatorname{sim}$ & \\
\hline USG & $\operatorname{sim}$ & \\
\hline Anatomia Patológica & não & \\
\hline $\mathrm{RX}$ & $\operatorname{sim}$ & com seriógrafo sim \\
\hline
\end{tabular}

\section{Equipamentos}

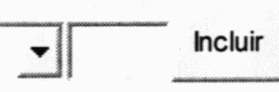

ECG Ecafix ECG $6 \quad 1$ \%

Equipamentos

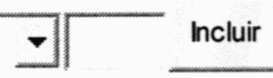

Videoendoscópio

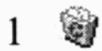

Equipamentos

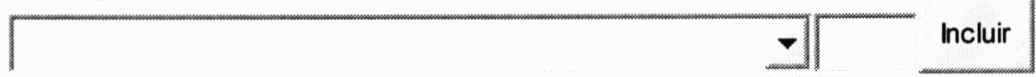

Fotômetro de chama Corning EEL 1 *

Espectrofotômetro CELM E-225 D 1 (

Bioquímica CELM SB 190 1 通 


\section{Equipamentos}

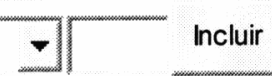

RX portátil Siemens Unimax GV 1 (

\section{Equipamentos}

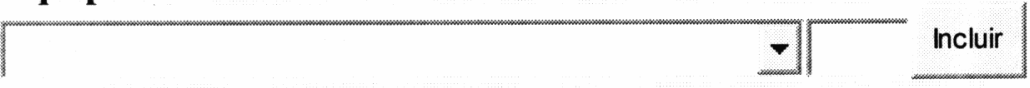

\begin{tabular}{|c|c|c|}
\hline RX com seriógrafo & Toshiba & DC-12 MB \\
\hline USG & Toshiba & EUB 315 \\
\hline Reveladora & Eletromédica & Runsamatic \\
\hline
\end{tabular}

\section{Equipamentos}

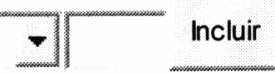

USG Toshiba EUB $315 \quad 1$ 원 
SADT - Acessório

\begin{tabular}{|c|c|c|}
\hline 7 & Incluir & \\
\hline Angiografia Digital/Hemodinâmica & não & 2 \\
\hline Audiometria & não & 2 \\
\hline Cintilografia & não & $\lambda$ \\
\hline Eletroneuromiografia & não & $\lambda$ \\
\hline Ergometria & não & $\lambda$ \\
\hline Fisioterapia & não & $\lambda$ \\
\hline Hemodiálise & não & $>$ \\
\hline Ecocardiografia & não & $\lambda$ \\
\hline Holter & não & r. \\
\hline Litotripsia & não & $\lambda$ \\
\hline Mamografia & não & 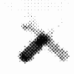 \\
\hline Quimioterapia & não & $\lambda$ \\
\hline Radioterapia & não & $\lambda$ \\
\hline Ressonância Magnética & não & $\lambda$ \\
\hline Tomografia & não & $\lambda$ \\
\hline Neurofisiologia & não & $\lambda$ \\
\hline EEG & não & $>$ \\
\hline
\end{tabular}




\section{Apoio Técnico e Administrativo}

\section{Farmácia}

Incluir

Há controle dos medicamentos Port 344

$\operatorname{sim}$

0 .

A farmácia manipula NPP

não

0 疑

Em área adequada conforme legislação

não 0

Há capela de fluxo laminar

não

0

Há local adequado para preparo dos medicamentos

$\operatorname{sim} \quad 0$

Há local adequado para dispensação

$\operatorname{sim}$

0 约

Há farmacêutico no local

$\operatorname{sim}$

Quantos 1

Há padronização de medicamentos

não

0 (2)

Dispensação

Individualizada

0 证

\section{SND}

Circulação adequada

Equipamentos necessários e conservados

Área adequada com boa iluminação e aeração

Existe bancada para manipulação dos alimentos

Há cardápio afixado

Há Nutricionista $\operatorname{sim}$

$\operatorname{sim}$

0 敏

$\operatorname{sim}$

0 约

$\operatorname{sim}$

0 约

0 行

$\operatorname{sim}$

0 绳

sim Quantas 1 疑

\section{Limpeza/Higiene}

Há normas e rotinas para limpeza da unidade sim

Utilizam produtos próprios para limpeza sim

A CCIH participa na elaboração de normas do setor sim

Há coleta seletiva do lixo

$\operatorname{sim}$

Funcionários utilizam equipamentos de proteção sim 


\section{Lavanderia}

\begin{tabular}{cc}
\hline Máquina de lavar modelo profissional & $\operatorname{sim}$ \\
Centrífugas apropriadas & $\operatorname{sim}$ \\
Calandras & $\operatorname{sim}$ \\
Há barreiras físicas & $\operatorname{sim}$ \\
Há cruzamento limpo/contaminado & não \\
Área física apropriada & $\operatorname{sim}$ \\
Equipamentos em boas condições & $\operatorname{sim}$ \\
Funcionários com equipamentos de proteção & $\operatorname{sim}$ \\
Serviço de Costura/Rouparia & $\operatorname{sim}$
\end{tabular}

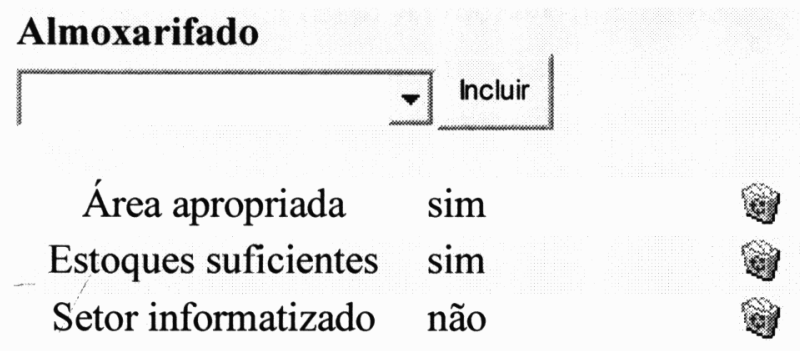

\section{Manutenção}

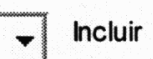

sim Própria

\section{Vigilancia}

\section{- Incluir}

Não

SAME

$\operatorname{sim}$

0 约

Informatizado

não

0 납

Prontuário conforme a Legislação

$\operatorname{sim}$

0 通 
Central Esterilização

Central Esterilização:

\begin{tabular}{|cl}
\hline Encontra-se instalado em área física adequada & não \\
Tem área para expurgo do material & sim \\
Tem área para preparo/esterilização & sim \\
Tem área para estocagem/distribuição & sim \\
Há enfermeira responsável & não \\
Há normatização de procedimentos na área & não \\
Há cruzamento de fluxo de circulação entre as áreas & sim \\
Funcionários paramentados adequadamente & sim \\
Possui estufas & não \\
Possui Autoclave horizontal & sim \\
Possui Autoclave vertical & não
\end{tabular}

\section{Periodicidade}

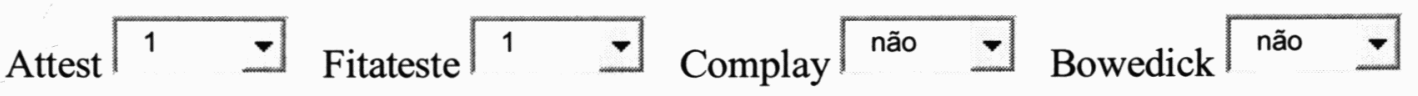




\section{Parecer:}

- Hospital geral com 38 leitos, com nível de atendimento primário.

- Estrutura física: vertical (3 pavimentos), adaptada, com sinalização adequada e em boas condições de higiene e limpeza. Pronto-Socorro Geral, Maternidade, Berçário de baixo risco, Sala de Sustentação de Vida (erroneamente chamada de Semi-Intensiva), Centro Cirúrgico com 03 salas, sem RPA. Unidades de Internação.

- Estrutura básica: gerador para suporte às áreas críticas, cabine primária de força, central de gases (torpedos), sistema de prevenção de incêndios com extintores, sem pára-raios e sem elevadores.

- Hotelaria: enfermarias masculina e feminina com divisórias entre os leitos. Sanitário: 03 boxes para banho, 03 boxes com vasos sanitários, TV, Ventilador, 01 bico de oxigênio e 01 de ar comprimido/leito. Pediatria: 01 enfermaria com 03 leitos e 03 berços. 01 bico de oxigênio e 01 de ar comprimido/leito. Utilizam o banheiro coletivo da enfermaria feminina. Copa para preparo de refeições.

Maternidade: 02 enfermarias de 02 leitos com sanitário coletivo. Sanitário: porta abre para dentro, sem barras de apoio. 03 apartamentos com 01 leito, 01 sofá-cama, TV, 01 bico de oxigênio, 01 de ar comprimido. Sanitário porta abrindo para dentro, com barra de apoio no chuveiro.

Unidade de Internação Geral: 07 apartamentos com 02 leitos, 01 bico de oxigênio com 02 saidas. TV e Ar condicionado em 06 apartamentos. Telefone em 01 apartamento. Sanitário: porta abrindo para dentro com barras de apoio no chuveiro, sem box.

- Serviços de apoio: farmácia com 01 farmacêutico, dispensação por sistema individualizado, sem padronização dos medicamentos. SND com 01 nutricionista e cardápio afixado mensalmente. Serviço de Limpeza próprio com normas e rotinas e participação da CCIH. Manutenção própria. Lavanderia com fluxos corretos. Central de Esterilização de Materiais em área física inadequada com fluxo cruzado.

- SADT: Hemoterapia, USG, Tomografia em instalação, Endoscopia, RX Simples e Contrastado e Patologia Clínica.

- Organização e funcionamento: Regulamento Interno, Normas, Rotinas, Setor de Recrutamento e Seleção de Pessoal, Programa de Treinamento, Indicadores 
Hospitalares, Relatórios Gerenciais, Informatização parcial, Serviço Social, Psicologia Hospitalar e Saúde Ocupacional. Comissões de Ética Médica, CCIH e CIPA.

- Recursos Humanos

- Servidores/ leito: 3,11

- Proporção funcionários de enfermagem/ leito: 1,32

- Enfermeiros/ leito: 0,11

- Técnicos e Auxiliares de Enfermagem/ leito: 1,21

- Indicadores de Qualidade

- Taxa de Mortalidade Institucional: $1,07 \%$

- Taxa de Cesáreas: $89,72 \%$

- Taxa de Infecção Hospitalar: 1,37\%

- Indicadores de Produtividade

- Taxa de Ocupação: $41,81 \%$

- Taxa de Permanência: 2,5 dias

○ Giro de Rotatividade: 5,08 pacientes/mês 


\section{Parecer:}

Consideramos o Hospital $\mathrm{H}$ apto.

Para tanto deverá:

1. Resolver problemas estruturais:

a. Adequar sanitários à $\mathrm{RDC} \mathrm{n}^{\circ} 50 / 02$.

b. Melhorar sinalização interna.

c. Instalar pára-raios.

d. Adequar área física do PS (entrada e sala de Observação) à RDC n ${ }^{\circ}$ 50/02.

e. Adequar sala de endoscopia à $\mathrm{RDC} \mathrm{n}^{\circ}$ 50/02.

f. Adequar unidades de internação à $R D C n^{\circ} 50 / 02$.

g. Adequar vestiários do $\mathrm{CC}$ à $\mathrm{RDC} \mathrm{n}^{\circ} 50 / 02$.

h. Adequar salas cirúrgicas à $\mathrm{RDC} \mathrm{n}^{\circ} 50 / 02$.

i. Instalar RPA.

j. Adequar área física da Central de Esterilização de Materiais à RDC n ${ }^{\circ} 50 / 02 .$.

2. Reequipar sala de emergência/ urgência do pronto-socorro para dar condições de sustentação de vida (imediato), com instalação de respirador adequado.

3. Registrar em ata as reuniões da Comissão de Ética Médica.

4. Instalar Comissões de Revisão de Prontuários e Revisão de Óbitos.

5. Alterar periodicidade da realização do controle biológico (Attest).

6. Padronizar medicamentos.

7. Contratar recursos humanos para compor a equipe médica e de enfermagem do Pronto Socorro (Resolução n 1451/95 do CFM e n 189/2003 do COFEN).

8. Contratar recursos humanos para agência transfusional, no período noturno.

9. Contratar enfermeiros e técnicos de enfermagem para alterar a composição da equipe e melhorar a assistência prestada ao paciente.

10. O serviço denominado UTI não obedece à legislação, não atendendo nenhum critério técnico preestabelecido. 


\section{ANEXO 12 - Vistoria Técnica Hospitalar - Hospital I}

\section{Identificação do Estabelecimento}

Nome:

Diretor Clínico: $\quad$ I

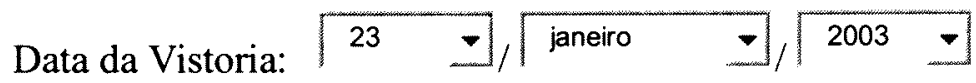

Acompanhantes:

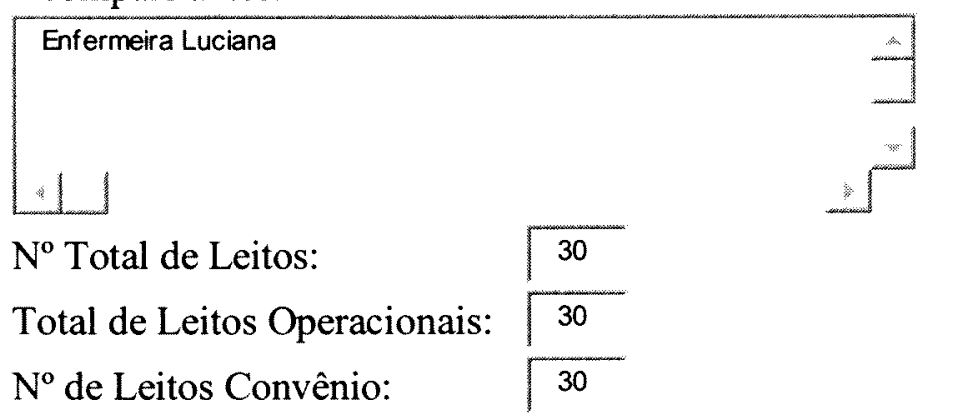

\section{Classificação do Estabelecimento}

Tipo de Hospital:

Geral

Lista de Especializações:

ncluir

\section{Tipo de Serviço}

Tipo de serviço:

Abrangência do serviço

Abrangência do serviço:

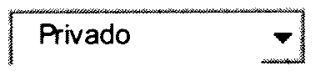

Regional 


\section{Organização e Funcionamento}

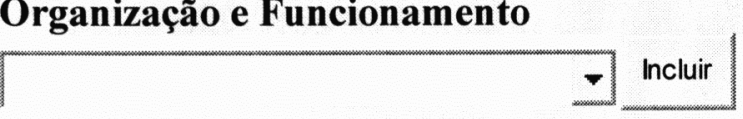

\section{Normas e Rotinas e Manuais}

Regime Interno/regulamento

Recrutamento e Seleção de Pessoal

Programas de Treinamento

Educação Continuada

Indicadores Hospitalares

Relatórios Gerenciais Informatização

Serviço Social

Psicologia Hospitalar

Saúde Ocupacional

Comissão de Ética Médica

$$
\mathrm{CCIH}
$$

Revisão de Prontuários

Revisão de Óbitos

CIPA

Farmácia e Medicamentos

Controle e Gestão de Qualidade

Ensino e Pesquisa

Residência Médica/Pós-Graduação $\operatorname{sim}$

$\operatorname{sim}$

$\operatorname{sim}$

não

não

$\operatorname{sim}$

$\operatorname{sim}$

não

não

não

$\operatorname{sim}$

$\operatorname{sim}$

$\operatorname{sim}$

não

não

$\operatorname{sim}$

não

não

não

não
Do conhecimento das partes não

Do conhecimento das partes não

Reuniões Regulares / Atas sim 


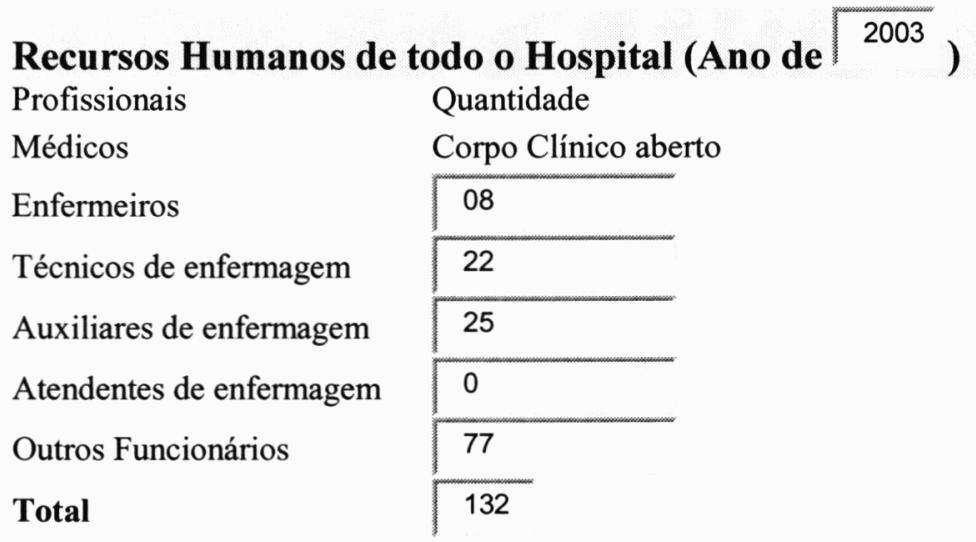

Informações Gerais (Ano de

2002

Levantamento de dados anual

Número de óbitos após 48 horas

Números de saídas (Altas e Óbitos)

Números de óbitos por causas maternas

Número de pacientes atendidos em Obstetrícia

Número de nascidos vivos

Número de nascidos mortos

Número de óbitos neonatais após 48 horas

Número de óbitos operatórios até 10 dias pós-cirurgia

Número de atos cirurgicos

Número de cesáreas

Número de partos normais

Número total de partos

Número de infecções atribuíveis ao hospital

Número de supurações de feridas cirúrgicas em cirurgias limpas

Número de cirurgias limpas do período

Número de pacientes/dia

Número de leitos/dia

Número de leitos disponíveis no período

\begin{tabular}{|l}
\hline 42 \\
\hline 2844 \\
\hline 0 \\
\hline 193 \\
\hline 182 \\
\hline 0 \\
\hline 0 \\
\hline 01 \\
\hline 1388 \\
\hline 159 \\
\hline 22 \\
\hline 181 \\
\hline
\end{tabular}

\begin{tabular}{|l}
\hline 1025 \\
\hline 8,15 \\
\hline 28,10 \\
\hline 30
\end{tabular}


Indicadores de Qualidade (Ano de $\sqrt{2002}$ )

Taxa de mortalidade institucional

\begin{tabular}{|c|}
\hline 1,47 \\
\hline 0 \\
\hline 0 \\
\hline 0 \\
\hline 0,07 \\
\hline 87,84 \\
\hline 0,35 \\
\hline 0,09 \\
\hline
\end{tabular}

Taxa de mortalidade materna

Taxa de natimortalidade

Taxa de mortalidade neonatal

Taxa de mortalidade operatória

Taxa de cesáreas

Taxa de infecção hospitalar

Taxa de supuração de ferida cirúrgica em cirurgia limpa

2002

Indicadores de produtividade (Ano de

Taxa de ocupação

$\longdiv { 2 9 } \%$

Taxa de permanência

1,04 dias

Giro de rotatividade

7,84 pacientes/mês 


\section{Estrutura}

Edificação:

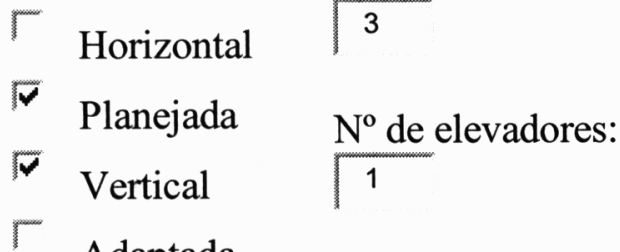

$\mathrm{N}^{\mathrm{o}}$ de Pavimentos:

Adaptada

\section{- Incluir}

\begin{tabular}{|c|c|c|c|}
\hline Identificação & visível & & 0 \\
\hline Estacionamento & não & & 0 \\
\hline Sinalização & $\operatorname{sim}$ & & 0 \\
\hline Área para munutenção/descarga & sim & & 0 \\
\hline Elevadores & necessário & em número insuficiente & 0 \\
\hline Local próprio para lixo & $\operatorname{sim}$ & & 0 \\
\hline Central de Gases & $\operatorname{sim}$ & Rede de Torpedos oxigênio & 0 \\
\hline Central de Gases & $\operatorname{sim}$ & Compressor de ar comprimido & 0 \\
\hline Central de Gases & $\operatorname{sim}$ & Torpedos de $\mathrm{N} 2 \mathrm{O}$ & 0 \\
\hline Ar Condicionado Central & não & & 0 \\
\hline Sistemas de Residuos & não & & 0 \\
\hline Sistema de Esgotos & não & & 0 \\
\hline Sistema de Prevenção de Incêndios & $\operatorname{sim}$ & Extintores & 0 \\
\hline Pára-Raios & $\operatorname{sim}$ & & 0 \\
\hline Gerador & automático & suficiente para áreas críticas & 0 \\
\hline Caldeira & não & & 0 \\
\hline Cabine Primária de Força & $\operatorname{sim}$ & & 0 \\
\hline Reservatório de Água & $\operatorname{sim}$ & & 0 \\
\hline
\end{tabular}


Organização e Atenção ao Paciente

\section{Hotelaria}

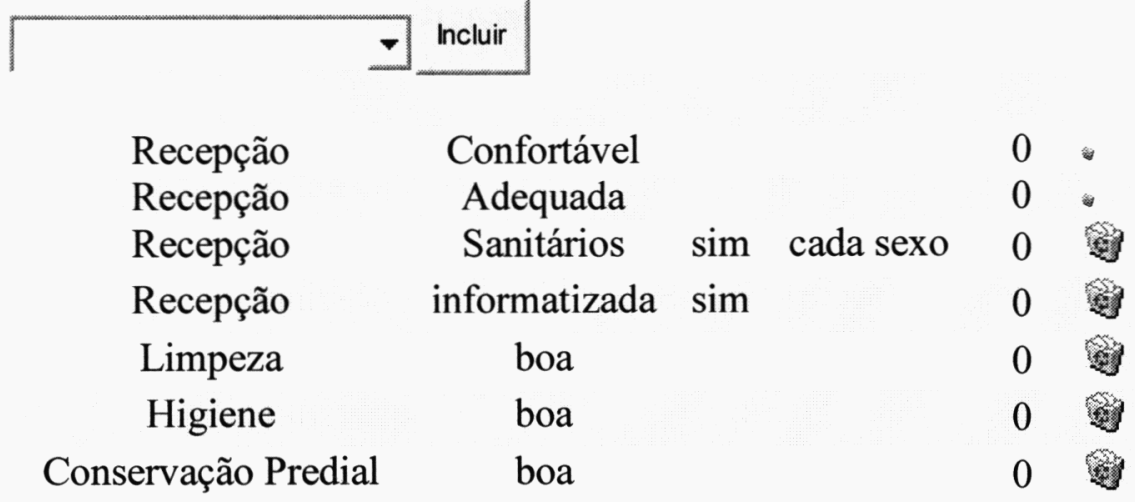

\section{Unidades de Internação}

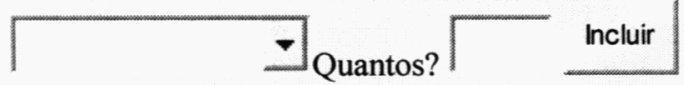

Apartamentos - Quantos?

cadeira de descanso
sofá/cama acompanhante
bico de vácuo
bico de ar
bico de oxigênio
Sanitário
Sanitário
telefone
ar condicionado
frigobar
TV

$\operatorname{sim}$
$\operatorname{sim}$
$\operatorname{sim}$
$\operatorname{sim}$

\section{Apartamentos}

Instalações Hidráulicas
Instalações Elétricas
Ventilação
Iluminação
Corredores Livres

Carrinho de emergência

Torpedo de oxigênio na unidade

$\begin{array}{cl}\text { Adequada } & 0 \\ \text { Adequada } & 0 \\ \text { Adequada } & 0 \\ \text { Adequada } & 0 \\ \text { sim } & 0 \\ \text { sim } & \\ \text { não } & \end{array}$


Enfermaria

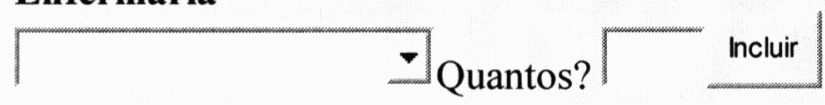

Enfermarias 2 Leitos - Quantos? 1

Distância mínima entre os leitos cadeira de descanso

Sanitário

Sanitário

bico de vácuo

bico de ar

bico de oxigênio
Instalações Hidráulicas Instalações Elétricas
Ventilação
Iluminação
Corredores Livres

Carrinho de emergência

Torpedo de oxigênio na unidade

$\begin{array}{cc}\operatorname{sim} & \\ \operatorname{sim} & \text { não } \\ \text { Barras/Apoios } & \text { Abrindo para dentro } \\ \text { Porta } & 01 \\ \operatorname{sim} & 01 \\ \operatorname{sim} & 01\end{array}$

$\begin{array}{cl}\text { Adequada } & 0 \\ \text { Adequada } & 0 \\ \text { Adequada } & 0 \\ \text { Adequada } & 0 \\ \text { sim } & 0 \\ \text { não } & \\ \text { não } & \end{array}$




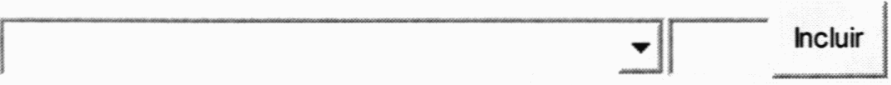

$\begin{array}{ccc}\text { Entrada bem localizada, fácil acesso } & \text { sim } & 0 \\ \text { Sala exclusiva para urgências } & \text { sim } & 0 \\ \text { Sala exclusiva para urgências } & \mathrm{N}^{\circ} \text { de Leitos } & 1 \\ \text { Leitos para observação } & \text { Masculino } & 4 \\ \text { Leitos para observacão } & \text { Feminino } & 4 \\ \text { 1 Bico de Oxigênio/leito } & \operatorname{sim} & 0 \\ \text { 1 Ar Comprimido/leito } & \operatorname{sim} & 0 \\ \text { 1 Vácuo/leito } & \operatorname{sim} & 0 \\ \text { Ambulância para remoção } & \operatorname{sim} & 0 \\ \text { Possui UTI Móvel } & \operatorname{sim} & 0 \\ \text { Equipe Médica conforme legislação } & \text { não } & 0 \\ \text { Enfermeira nos turnos } & \text { não } & 0 \\ \text { Medicamentos de urgência } & \text { sim } & 0 \\ \text { Sala de curativos } & & 0 \\ \text { Sala de Inalação } & \text { sim } & 0\end{array}$

\section{Equipamentos da Urgência}

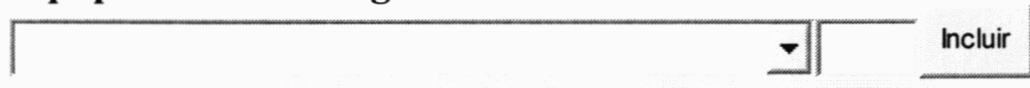

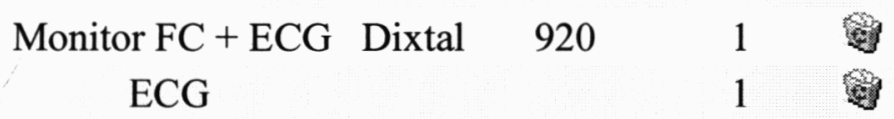




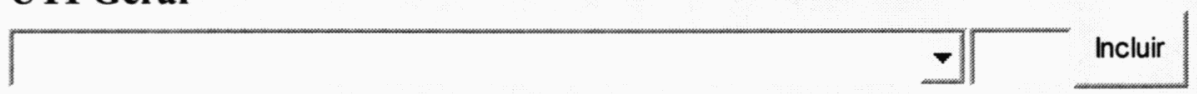

Número de Leitos

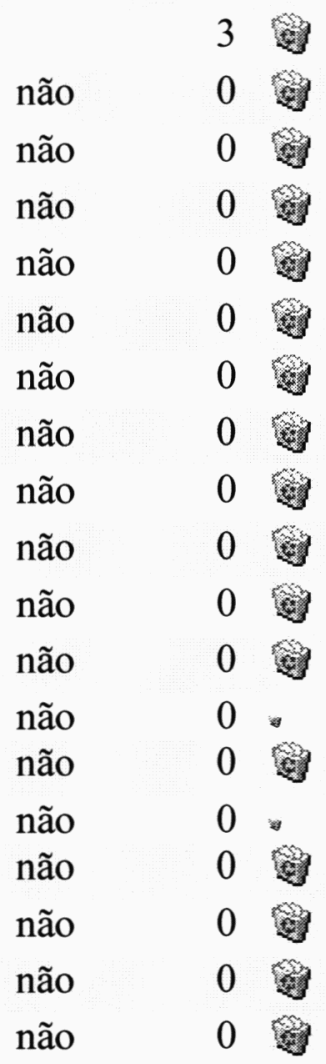

\section{Equipamentos}

\begin{tabular}{|cccc|}
\hline & & & \\
Monitor FC + ECG & TEB & M-10 C & 4 \\
Desfibrilador & TEB & D-10 & 1 \\
Respirador & Takaoka & Vent Care & 1 \\
Respirador & Takaoka & & 1 \\
Oxímetro & Criticare & 504 & 1 \\
Bomba de Infusão & BBraun & Nutrimat II & 5
\end{tabular}




\begin{tabular}{cc}
\hline 2 bicos de oxigênio/sala & sim \\
Sala/leitos de pré-parto & não \\
Tem sala de admissão & sim \\
O parto é realizado por: & Médico \\
O neonatologista recepciona todos os RNs & não \\
Há neonatologista no local durante 24 horas & não \\
Há disponibilidade de médico obstetra no local & sim \\
durante 24 horas & sim \\
Há disponibilidade de anestesista durante 24 horas & não \\
Há sala de reanimação e identificação do RN & não \\
Vestiário com sanitário para ambos os sexos & não \\
Sala de estar e repouso para funcionários e médicos & não \\
Recuperação pós-anestésica (RPA) & não \\
Há pia com água corrente na sala de reanimação & sim \\
1 bico de ar comprimido/sala & sim \\
1 bico de vácuo/sala &
\end{tabular}

\section{Berçário}

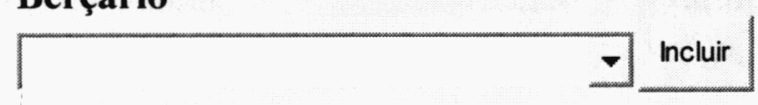

Há berçário de primeiros cuidados sim

Área: Bercário

Sala: Primeiros Cuidados

\section{Equipamentos}

\begin{tabular}{|cccc|}
\hline & \multicolumn{2}{|c|}{ Incluir } \\
Berço aquecido por insuflação & Olidef CZ & 1 \\
Incubadora & Olidef CZ & RW plus & 1 \\
Balança pesa-bebê & Filizola & Baby & 1
\end{tabular}




$\begin{array}{cc}\text { Área de recepção de paciente com passa maca } & \text { não } \\ \text { Área de Escovação } & \text { sim } \\ \text { Posto de Enfermagem e Serviços } & \text { sim } \\ \text { Vestiários com sanitários para funcionários com barreira } & \text { não } \\ \text { Sala de preparo de equipamentos e material } & \text { não } \\ \text { Sala administrativa } & \text { não } \\ \text { Depósito de Material de Limpeza } & \text { não } \\ \text { Sala de estar para funcionários } & \text { não } \\ \text { Sala de Espera com sanitário para acompanhantes } & \text { não } \\ \text { Área para guarda de macas e cadeira de rodas } & \text { não } \\ \text { Sala de Biópsia de congelação (Anatomia Patológica) } & \text { não } \\ \text { Fluxos pacientes/funcionários por entradas diferentes } & \text { sim } \\ 2 \text { bala de Conforto Médico no Centro Cirúrgico } & \text { não } \\ 1 \text { bico de ar comprimido/sala } & \text { não } \\ 1 \text { bico de vácuo/sala } & \text { sim }\end{array}$

\section{Centro Cirúrgico/Salas}

\begin{tabular}{cccc}
\hline Sala & Tamanho & Equips. Excluir \\
01 & Média & Média &
\end{tabular}


Centro Cirúrgico

Sala: 01

\section{Equipamentos}

\begin{tabular}{|cccc|}
\hline & Takaoka & 674 & 1 \\
Carrinho de anestesia & Dixtal & DX 7100 & 1 \\
Oxicapnógrafo & TEB & M-10 C & 1 \\
Monitor FC + ECG & WEM & SS-501 & 1 \\
Bisturi elétrico & & & 1 \\
Mesa cirúrgica ortopédica & TEB & MED 1 & 1 \\
Oxímetro & DFVasconcellos & MC-M92 & 1 \\
Microscópio cirúrgico & & & 1 \\
Foco auxiliar & Funbec & DF-02 & 1 \\
Desfibrilador & KSS & & 1 \\
Berço aquecido calor irradiante & Filizola & Baby & 1 \\
Balança pesa-bebê & & &
\end{tabular}

\section{Centro Cirúrgico}

Sala: 02

\section{Equipamentos}

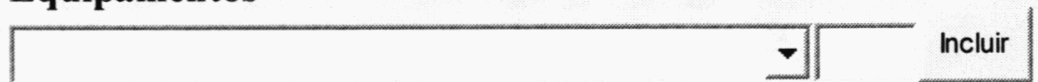

\begin{tabular}{|c|c|c|}
\hline Carrinho de anestesia & Takaoka & 674 \\
\hline Monitor FC + ECG & TEB & $\mathrm{M}-10 \mathrm{C}$ \\
\hline Bisturi elétrico & WEM & SS-501 \\
\hline
\end{tabular}

\begin{tabular}{|c|c|c|c|c|}
\hline \multicolumn{3}{|c|}{ Quantidade } & \multirow{2}{*}{\multicolumn{2}{|c|}{ Desativadas }} \\
\hline \multirow[b]{2}{*}{ Pequena } & \multicolumn{2}{|c|}{ Operacionais } & & \\
\hline & 0 & - & 0 & - \\
\hline Média & 2 & $\nabla$ & 0 & - \\
\hline Grande & 0 & $\nabla$ & 0 & $\boldsymbol{r}$ \\
\hline Especial & 0 & - & 0 & - \\
\hline Total & & & & \\
\hline
\end{tabular}


Serviços de Apoio Diagnóstico e Terapia

\section{SADT}

\begin{tabular}{|cc|}
\hline RX & $\operatorname{sim}$ \\
USG & $\operatorname{sim}$ \\
Patologia Clínica & $\operatorname{sim}$
\end{tabular}

\section{Equipamentos}

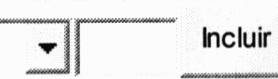

\begin{tabular}{|c|c|c|}
\hline $\mathrm{RX}$ & Siemens & Unimax \\
\hline Revela & Macrotec & MX-2 \\
\hline XX portátil & Salgado Herman & $100 \mathrm{~mA}$ \\
\hline
\end{tabular}

\section{Equipamentos}

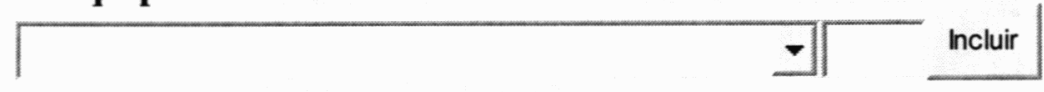

USG Toshiba Sonolayer 1 월 
SADT - Acessorio

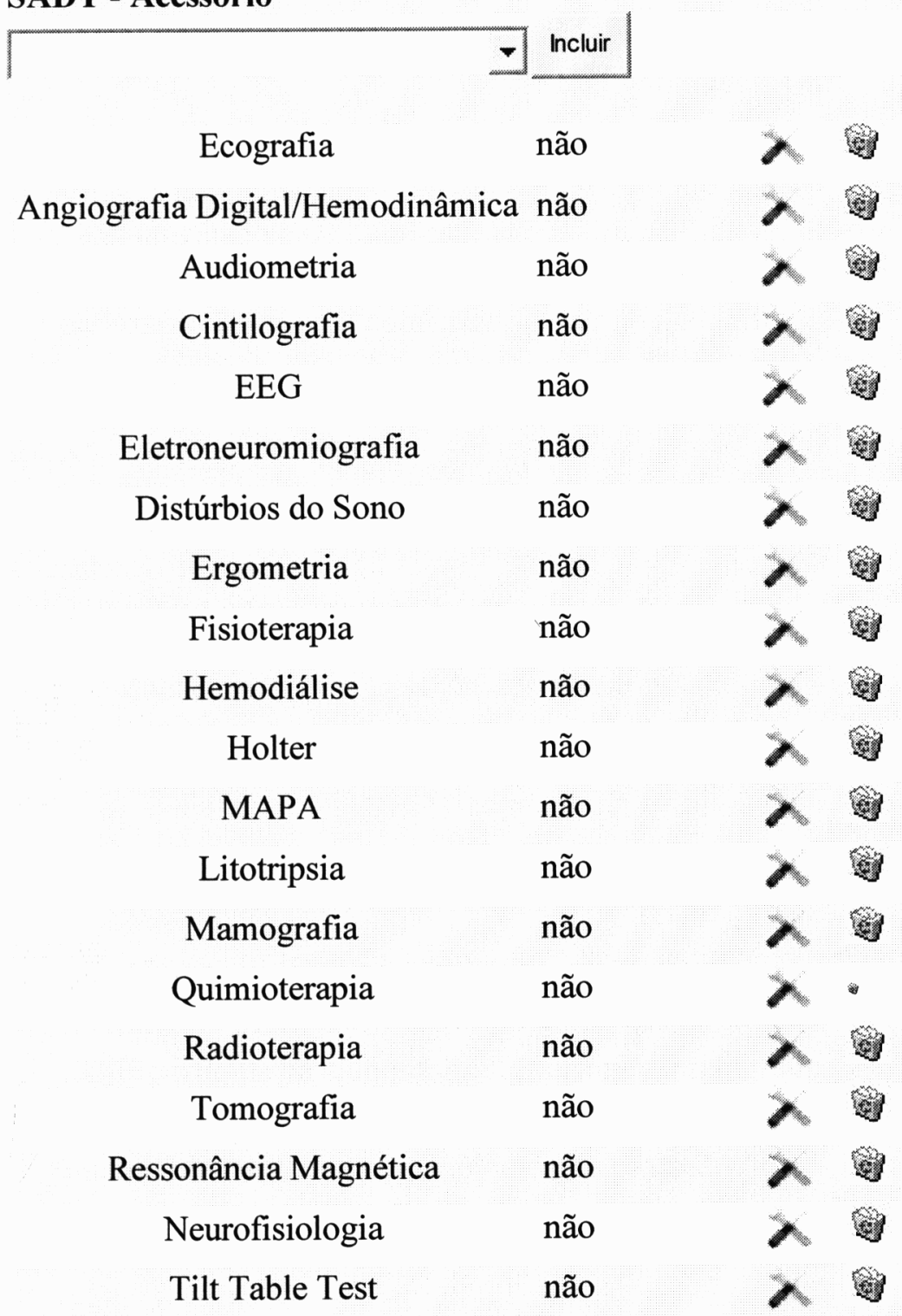




\section{Apoio Técnico e Administrativo}

\section{Farmácia}

\begin{tabular}{|c|c|c|c|}
\hline & - & Incluir & \\
\hline Há controle dos medicamentos Portaria 344 & & $\operatorname{sim}$ & \\
\hline A farmácia manipula NPP & & não & \\
\hline Há local adequado para dispensação & & não & \\
\hline Há farmacêutico no local & & $\operatorname{sim}$ & Quantos \\
\hline Há padronização de medicamentos & & não & \\
\hline Dispensação & Indivi & idualiz & \\
\hline
\end{tabular}

SND

\begin{tabular}{lll}
\hline Circulação adequada & não & Incluir \\
\cline { 2 - 3 } Equipamentos necessários e conservados & sim & 0 \\
Área adequada com boa iluminação e aeração & não & 0 \\
Existe bancada para manipulação dos alimentos & sim & 0 \\
Há cardápio afixado & $\operatorname{sim}$ & 0 \\
Há Nutricionista & $\operatorname{sim}$ Quantas & 1
\end{tabular}

\section{Limpeza/Higiene}

Há normas e rotinas para limpeza da unidade

Utilizam produtos próprios para limpeza

7 Incluir

sim

$\operatorname{sim}$

A CCIH participa na elaboração de normas do setor sim

Há coleta seletiva do lixo

$\operatorname{sim}$

$\operatorname{sim}$

\section{Lavanderia Terceirizada}

\section{Almoxarifado}

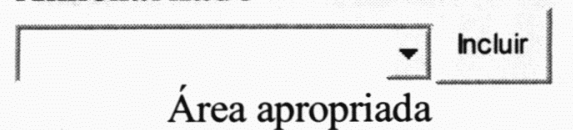

Estoques suficientes

Setor informatizado

$$
\begin{aligned}
& \text { não } \\
& \text { sim } \\
& \text { sim }
\end{aligned}
$$

SAME

sim Informatizado não

Prontuários conforme Legislação sim Único 
Manutenção

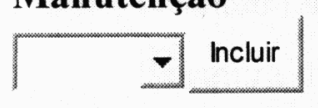

sim Própria

(2)

Vigilância

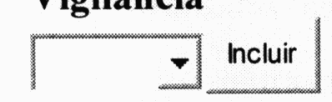

não

野

Central Esterilização

Central Esterilização:

Incluir

Encontra-se instalado em área física adequada

Tem área para expurgo do material

Tem área para preparo/esterilização

Tem área para estocagem/distribuição

Há enfermeira responsável

Há normatização de procedimentos na área

Há cruzamento de fluxo de circulação entre as áreas

Funcionários paramentados adequadamente

Possui estufas

Possui Autoclave horizontal

Possui Autoclave vertical

Há manutenção preventiva de equipamentos

É utilizado Controle Biológico

não
sim
não
não
não
sim
sim
sim
não
sim
não
não
sim

\section{Periodicidade}

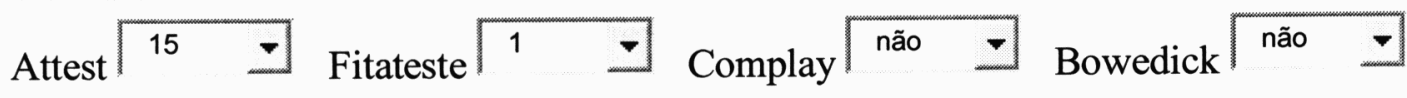




\section{Parecer:}

- Hospital Geral privado, com 28 leitos, nível de atendimento primário.

- Estrutura física: vertical, planejada, identificação e sinalização adequadas e em boas condições de higiene e limpeza. Pronto Socorro sem condições de suporte de vida, local erroneamente denominado UTI com 03 leitos em área inadequada, Centro Cirúrgico com 02 salas, sem RPA. Unidades de Internação.

- Estrutura básica: 01 elevador, gerador manual, cabine primária de força, central de gases, local exclusivo para lixo, pára-raios e reservatório de água.

- Hotelaria: sala de espera com TV e som ambiente, rouparia, expurgo. 09 apartamentos com TV, telefone, ar condicionado, frigobar e secretária eletrônica, com 02 bicos de oxigênio, 01 de ar comprimido e 01 de vácuo. Sanitários: portas abrindo para dentro, sem barras/apoios.

- Serviço de apoio: farmácia com 01 farmacêutico, dispensação por sistema individualizado e em área inadequada. SND com 01 nutricionista, em área inadequada, equipamentos necessários e conservados, cardápio afixado. Serviço de limpeza próprio com normas e rotinas. Manutenção própria. Lavanderia terceirizada. Almoxarifado em área inadequada. Central de Esterilização de Materiais em área física inadequada, com fluxo cruzado.

- SADT: ECG, Fisioterapia, Radiologia, Ultra-sonografia, Endoscopia. Patologia Clínica externa e terceirizada.

- Organização e funcionamento: Normas, Rotinas, Regulamento Interno, Recrutamento e Seleção de Pessoal, Indicadores Hospitalares. Comissões de Ética Médica, CCIH e CIPA.

- Recursos Humanos

- Servidores/leito: 4,4

- Funcionários de enfermagem/leito: 1,83

- Enfermeiros/leito: 0,26

- Técnicos e Auxiliares de enfermagem/ leito 1,56

- Indicadores de Qualidade:

- Taxa de mortalidade Institucional: $1,47 \%$

- Taxa de Mortalidade Operária: $0,07 \%$

- Taxa de Cesáreas: $87,84 \%$

○ Taxa de Infecção Hospitalar: $0,35 \%$ 
- Indicadores de Produtividade:

○ Taxa de ocupação: $29 \%$

- Média de Permanência: 1,04 dias

- Giro de Rotatividade: 7,84 pacientes/mês 


\section{Parecer:}

O Hospital I está apto.

Para tanto deverá:

1. Resolver problemas estruturais

2. Adequar sanitários à $\operatorname{RDC} \mathrm{n}^{0} 50 / 02$.
a. Instalar gerador automático para suporte às áreas críticas.
b. Adequar Centro Cirúrgico e RPA à RDC n ${ }^{\circ}$ 50/02.
c. Adequar Farmácia à RDC n ${ }^{\circ} 50 / 02$.
d. Adequar SND à RDC n ${ }^{\circ}$ 50/02.
e. Adequar Almoxarifado à $\operatorname{RDC} n^{\circ} 50 / 02$.

3. Retirar berços aquecidos por insuflação do berçário.

4. Reequipar sala de emergência do PS para sustentação de vida, com instalação imediata de respirador adequado.

5. Instalar Comissões de Revisão de Prontuários e Óbitos.

6. Padronizar medicamentos.

7. Organizar prontuários conforme legislação.

8. Contratar equipe médica e de enfermagem para o PS (Resoluções $n^{\circ} 1451 / 95$ do CFM e $n^{\circ}$ 189/2003 do COFEN).

9. O serviço denominado UTI não obedece à legislação, não atendendo nenhum critério técnico preestabelecido.

Observação: O Hospital I passa por uma grande reforma e ampliação. Foi construída nova unidade de internação atendendo aos padrões legais e de conforto ao usuário. Está em fase final de construção a UTI para 06 leitos, o novo Centro Cirúrgico e o Novo Centro de Esterilização de Materiais. 
ANEXO 13 - Execução Orçamentária e Financeira - Ministério da Saúde - 2002

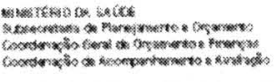

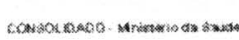

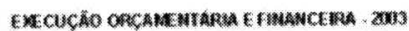

\begin{tabular}{|c|c|c|c|c|c|c|c|c|c|}
\hline \multirow{2}{*}{ 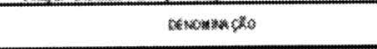 } & & & atarti & 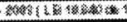 & 5012063 & & क & (4) & 4 \\
\hline & ams & 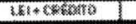 & 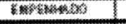 & $p \times 60$ & sencosen & 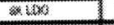 & 䢁 & & \\
\hline 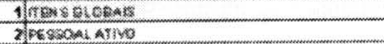 & sest.s20.281 & 6.452 .582 .492 & $6.304 \times 18.444$ & 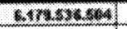 & $261.245 \times 44$ & 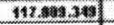 & ag, 18 & 25,80 & 9.84 \\
\hline 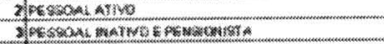 & 2573584548 & 2385.37asa1 & 2M3SESyser] & 2.914 .815 .563 & 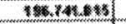 & 22.746 .534 & 92332] & 20,al & est: \\
\hline 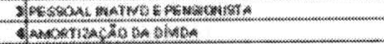 & 2162589.391 & 2.58652544 & 2624146158 & 2891542783 & 4595.885 & 1475est & 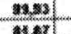 & $38 \times$ & sar \\
\hline 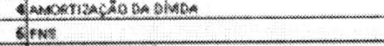 & 372.08 .358 & 584.182,845] & 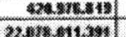 & 4ascents & of & cosicisz & 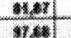 & ant & $\frac{16,83]}{693}$ \\
\hline 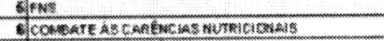 & 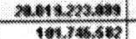 & $\frac{23.264 .25857}{272800}$ & 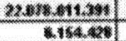 & $\frac{2082404 a 46 e}{1551,13 s}$ & $\frac{9.454901 .245}{4503.295}$ & 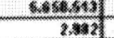 & 30,24 & $24 \times 1$ & eag \\
\hline 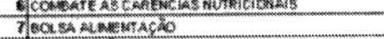 & 154568586 & 300.6000 & 36866010 & 118.474.265 & 63.52173 & & $10 \mathrm{net}$ & s7,31 & s.se \\
\hline 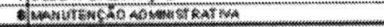 & 927.386 .364 & 132387.000 & $157.3 \times 6 \times 2$ & 524081352 & $932 \times 2 \times 99$ & & 330 & 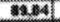 & Bat \\
\hline Thosertass prodersoses & 19750220 & zrascosed & 728.920 .558 & 1007stil & n.4.3.189 & & 3823 & 3730 & 600 \\
\hline 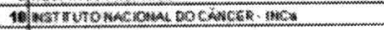 & $02.458 .8 \%$ & 33385.607 & 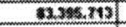 & 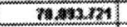 & $13.30 \% .328$ & & $100 \mathrm{an}$ & anas & 600 \\
\hline 11 howkens socas & 745 aceased & 245600000 & 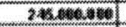 & $x+5,500.606$ & -1 & & 1asen & teanel & 200 \\
\hline 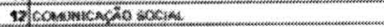 & 4091238 & risse.ene & $r e x 4.532$ & 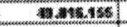 & $20.45 x, m$ & 1. & 322 & s.2. & (axt) \\
\hline 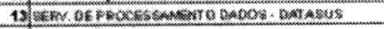 & 34712,352 & 24.636 .000 & 2087.004 & 49200.12 & Asas.a24 & & m358 & anos: & 3.800 \\
\hline 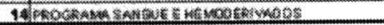 & 26.312.68s & 28851.001 & $2812 \times 10$ & 1.441344 & 1.53.834 & & mas & 3.44 & $\mathrm{aco}$ \\
\hline 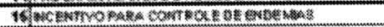 & 554664533 & 505.560 .800 & B1458ed49 & $399.7 \times 3.265$ & $2459 n$ & in & 92. & जक्य & 600 \\
\hline 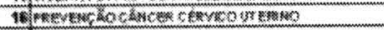 & 86.762 .865 & 7367.60 & $M \times 6 \times 120$ & 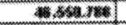 & 24714 361 & -6 & * 673 & 83,20 & 20.6) \\
\hline 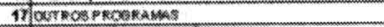 & 128524923 & $197.788 .55 \mathrm{set}$ & $156+58384$ & $500 \times 20780$ & 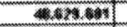 & $6 \mathbf{6 7 5 3}$ & 7058 & 3400 & ens \\
\hline 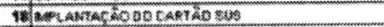 & 6486. .44 & s3eceses & \$1.166.780 & 28.272 .272 & 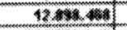 & & s5,34 & 440 & 60 \\
\hline 15prosses & TH4ละS16 & 335670.360 & 222418.145 & 112.4\%8. 488 & $\operatorname{sen} 22284$ & 200 & 44.12 & 4736 & 2,00 \\
\hline zcaosil $-m-m$ & 13238413 & 13asse ated & 132858286 & 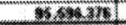 & 6.92.24 & & 102.60 & 622 & $\mathrm{~mol}$ \\
\hline गी & $=013.00$ & 6000100 & -3.7606 & 362.60 & 0.37 .64 & & 12816 & 5,21 & 2.0 \\
\hline 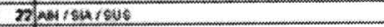 & 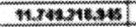 & 513.268 .260 .158 & 43253642039 & 11.074 & 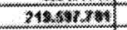 & 4227286 & 3ne1 & and & eas \\
\hline 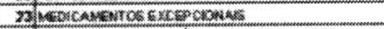 & 459727254 & $518 \mathrm{senane}$ & sт6. & $504128 x$ & 11.14 & & 19exe & 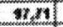 & eate \\
\hline 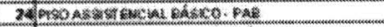 & $206400 \times 191$ & 1.383 .350040 & $161.5 \times 348$ & 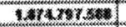 & 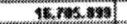 & & 39s4 & 3nese & ead \\
\hline 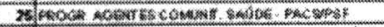 & 63121125854 & nsucsenes & 0.674148 .798 & 1508848270 & 18.984.599 & & 976 & 56.54 & 0.40 \\
\hline 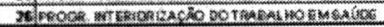 & - of & sacenesel & 41318. erre & 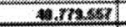 & 1.1936.524 & & 8084 & anks & a.e. \\
\hline 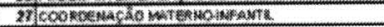 & .166 .640 & oneme & 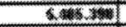 & 2.843 .84 & $3.3 n .941$ & & 6186 & $23, n$ & (2001) \\
\hline 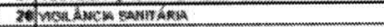 & 76.461 .312 & 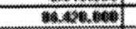 & 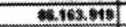 & 78.53350 & 46.300 .675 & & कore & का720 & eance \\
\hline 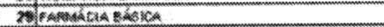 & 165.568 .694 & Traserabe & $178 \times 84868$ & 56412458 & 1.225 .470 & & s981 & 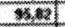 & sar \\
\hline 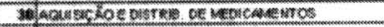 & 63533326 & 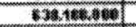 & 633974se6 & 484242726 & 45.782 .19 & 76,28 & 3234 & 3434 & 0.00 \\
\hline 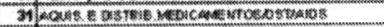 & 542568.976 & sstivesabet & ssisecten & cotosis 65 & 38.524 .438 & & 100 & 90,12 & 60 \\
\hline 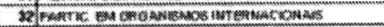 & 26.72 .60 & $35.456 .6 n$ & 35.17 .60 & 32.364 .360 & $2 \times 3 \times 50$ & & 5000 & $m, n$ & 600 \\
\hline 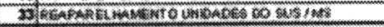 & $420.27 .5 \%$ & 124605.367 & wrsatise & 53.096 & 14.536. & TEesest & rase & (10.5) & 6.19 \\
\hline 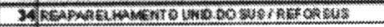 & 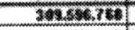 & 10160.80 & TExकe4t & 6.smaser & $0.513+185$ & 90.72 & 3034 & ase & 8,30 \\
\hline 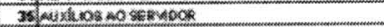 & askEs. 158 & sazse.6ee & 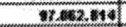 & 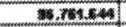 & 301.379 & & 322 & $n \times 1$ & Bat \\
\hline 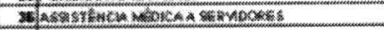 & 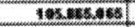 & 1er swe.abe & 197.134.3394 & 95.rnAns & $11,357,602$ & & nses & $n, x$ & oot \\
\hline 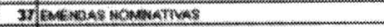 & 360.155 .76 & 876.86:917 & 420445114 & $42.7 a 44$ & 378.581749 & . 0.74 & $5+24$ & sas & $\mathbf{3 , a t}$ \\
\hline selasnats & 132044,42 & 109271806 & 145685869 & \$18328s:1 & 26.562 .641 & gesens & sove & $20 \times$ & s.40. \\
\hline 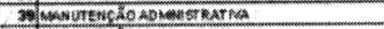 & 33538.768 & $58 x 51,500$ & 3832.66 & 45.518 .66 & C.44.453 & 111521 & \$6.18 & $=0$ & 321 \\
\hline 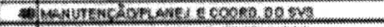 & 2065.122 & 31283.558 & 3285682 & 6.76468 & 14132.727 & 58.391 & 2063. & 322 & 619 \\
\hline 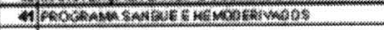 & $0.00 \mathrm{ks}$ & $830 \times 5$ & crasen & 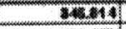 & 5.50 .018 & & $1 \mathrm{ma}$ & 53.28 & (ad) \\
\hline 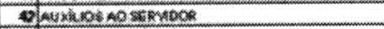 & 2.244 .444 & $2,584,200$ & 2603.00 & $2,403.00$ & & 1808791 & 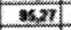 & $\%, 27$ & (4,2) \\
\hline 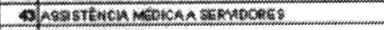 & 72378 & 1.238600 & Easaser & *21.537 & 1804 & seensas & neel & 6150! & 2269 \\
\hline cfleukata & 2629438158 & 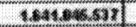 & (347.3124) & 682.26164 & 46eses.set & \%585644 & 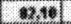 & 497 & 150 \\
\hline 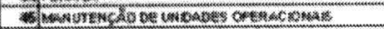 & 4854682 & $28.1 \mathrm{k} .60$ & 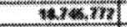 & $54+11400$ & $8 \times 34.469$ & 6.36220 & 746 & 5201 & 8,22 \\
\hline 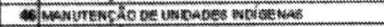 & 124227.436 & $138 \times 320 \times 60$ & 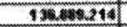 & 120.27.258 & 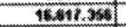 & 1341,728 & 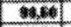 & $=0 \times 3$ & 1,40 \\
\hline 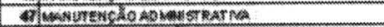 & s460.4 & 72.62 .600 & 67.586 .42 & 6. & 1.322 .601 & & 3270 & 20 & 20 \\
\hline selackes braciencto & anders 5 & 413200.300 & 40402458 & Toserkers & $632 \times 2+8 \times 2$ & 3.586 .518 & (2) & $6 \times$ & ent \\
\hline 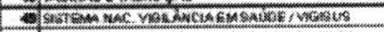 & 6.x.10.389 & resered & Eases. & Bansel & 27,54642 & - Aint & 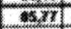 & ses: & .91 \\
\hline 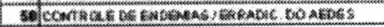 & $2314582,5=18$ & $3 \times 5303.500$ & 285651167 & Yas: 15.574 & $91,278,580$ & 3arkstate & naro & 5,56 & 3,00 \\
\hline 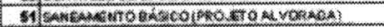 & 441.032454 & of & & & & & ant & 001 & .00 \\
\hline 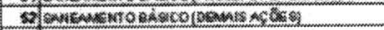 & 12840640 & 15876e.s34 & 104.785.524 & 24 acsessts & T.2.76:\%? & ตnพm) & n271 & 22,4 & exte \\
\hline 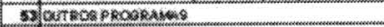 & sciter.63z & 52128.000 & atcks:s & $30.35 \times 3 \times 0$ & 19512r8st & 3.20864 & nes & 5,33 & Eall \\
\hline 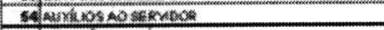 & 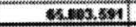 & reses.ent & 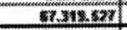 & 53mase & aste & 28584281 & now & ows & 2,50 \\
\hline 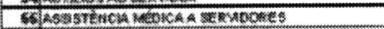 & 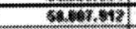 & 6.486 & 58685.854 & 35.232 .54 & 207570 & & 9ober & Q243 & $\mathrm{cm}$ \\
\hline 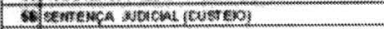 & 16.365 & 102686 & 162.656 & $n a * 4$ & $\$ 1.8 \pi$ & 36.93 & $70 \times 3$ & ant & 20,37 \\
\hline 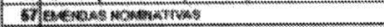 & 8936.634 & 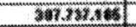 & 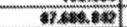 & & 626280 & & 20.60 & 0,00 & 20 \\
\hline setcocksy: & 158cestar & 202.58 .300 & 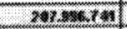 & 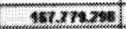 & ex.247.49 & 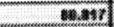 & a128 & enese & eas \\
\hline 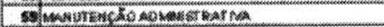 & $34 \times 03.110$ & 38. 534 sae & 38.383 .178 & 32,xasset & 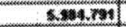 & & nasm & *40) & axe \\
\hline 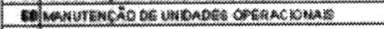 & $45.501,044$ & 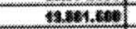 & 12080.04 & 18.585 .62 & 2.271 .649 & & 3972 & 33.20 & a.ae \\
\hline 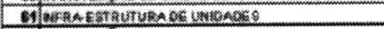 & 15.390 .311 & uses sed & $\$ 4 \times 28.154$ & 48.327 .232 & 29196.934 & 132 & 100.10 & n.,1 & Gat \\
\hline 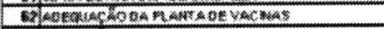 & 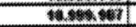 & 20100.60 & 200ent & 7omateon & & & 180, se & 16000 & Eat \\
\hline 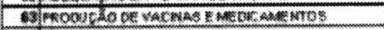 & किखिए। & 2006 & rasmem & 58.762 .183 & 11502खा & $\$$ & भा11 & 800 & $\mathrm{Bat}$ \\
\hline 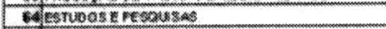 & 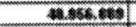 & 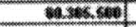 & 51852.12 & 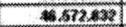 & 13.352 .305 & 6ens & 908 & 7619 & 64 \\
\hline SGEUTESBPRCBRAMRS & 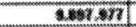 & 0.517 .360 & $\$ 22612.2364$ & 10.902 .324 & wemset & & 980 & 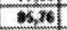 & see \\
\hline 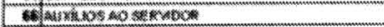 & s.surket & 16060 & 7.563236 & 7.405 .130 & 7,408 & & 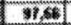 & $\$ \pi$ & 60 \\
\hline 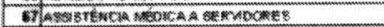 & $45+16 \mathrm{an}$ & 5.3212.160 & knizated & $6.212+100$ & & & 1 tatent & 1000 & 206 \\
\hline 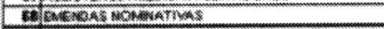 & का & sacese & काm & $\$ 94115$ & 8.76 & 423 & कsषा & का,22 & 6.2. \\
\hline 6 ans: & Aressen & 85.465em & matims & 57341622 & 2280.47 & 1,124582 & 202 & ar & 1,72 \\
\hline 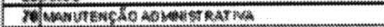 & 6 6er.ers & $2767 \mathrm{cos}$ & xwrent & 26:32.663 & Exas & & s.84 & 5648] & 6 \\
\hline 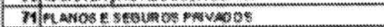 & $22 \times 16 \times 14$ & 347000 & 3060.001 & 20.205 .584 & 1.335 .394 & 1.1360631 & as4. & 242 & 2,28 \\
\hline 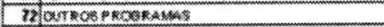 & 2.346 .539 & 2306000 & Q⿻1 & 1277.66 & 28223 & & 7949 & 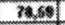 & 000 \\
\hline 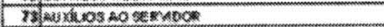 & 63636 & 128460 & 822685 & 52268 & -1 & & 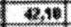 & (210) & 200 \\
\hline 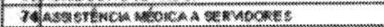 & & 28610 & 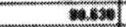 & 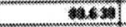 & a & & 30 & 20 & 600 \\
\hline reanc & 208500400 & 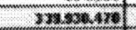 & 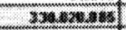 & $328 \times 38 \times 620$ & 6200.450 & $2916 \times 185$ & 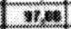 & 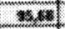 & 2,28 \\
\hline 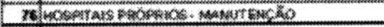 & & $8 \pi 5,5020$ & 5.560 .5003 & & 3703.384 & & zus & 32.01 & 26,32 \\
\hline T7Persoalatino & $269 \mathrm{~cm}$ & 331224.45 & 322.510523 & $32 \times 41541$ & 19mem? & 3.76459 & का & 37.35 & $\frac{13}{232}$ \\
\hline 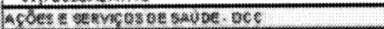 & 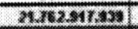 & 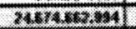 & 20686.409 .2001 & 21038x219 & 1.286.7882933 & 36202.79 & iste & asest & 3 \\
\hline 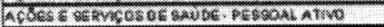 & 2973.2659 & 335232421 & 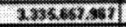 & 2.4ว1518.58? & 18.7181013 & 22.76504 & 9232 & \$3a! & 60 \\
\hline 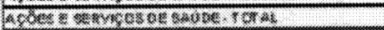 & 24730.042528 & 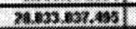 & nz:164.158.24! & 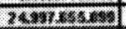 & 2.2133 .3014 .89 & 8322.32 & 980 & a17! & का \\
\hline 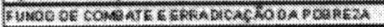 & 693082422 & 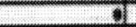 & 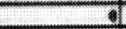 & & & & ane & था & 620 \\
\hline Outkos custedos ecaptab. Total & $22456 \times 6361$ & 2464662.944 & 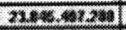 & $21.53 \times 2784$ & 1.886.768193 & 36302.76 & 364 & ass & 0.45 \\
\hline 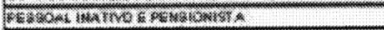 & $202 \operatorname{scs} x \sin$ & 2626.625949 & 282410354 & $2514 \times 2 \times 23$ & 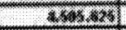 & 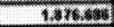 & (30) & 9010 & 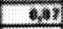 \\
\hline A. & 3720.08 .158 & S14.152.94 & $484 \sin 10$ & 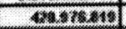 & & 8321840 & *in & (19) & 18,13 \\
\hline & 20263366021 & 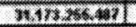 & 3026.20641 & xems?tex & $2 \times 180957$ & 152127.43 & 36.81 & asal & Q.43 \\
\hline
\end{tabular}


ANEXO 14 - Execução Orçamentária e Financeira - Ministério da Saúde - 2003

Mustraio OA SALOE

Catbs ecrer aria de Planejamento o Orcramento

Co ordenaça Geral de Orçanento * Fina

EXECUCAAO ORCAMENTARIA E FWANCEIRA - 2004

CONSOL UDADO - Ministerie da Saide

POSIC KO: MANO (EECHADO)

*

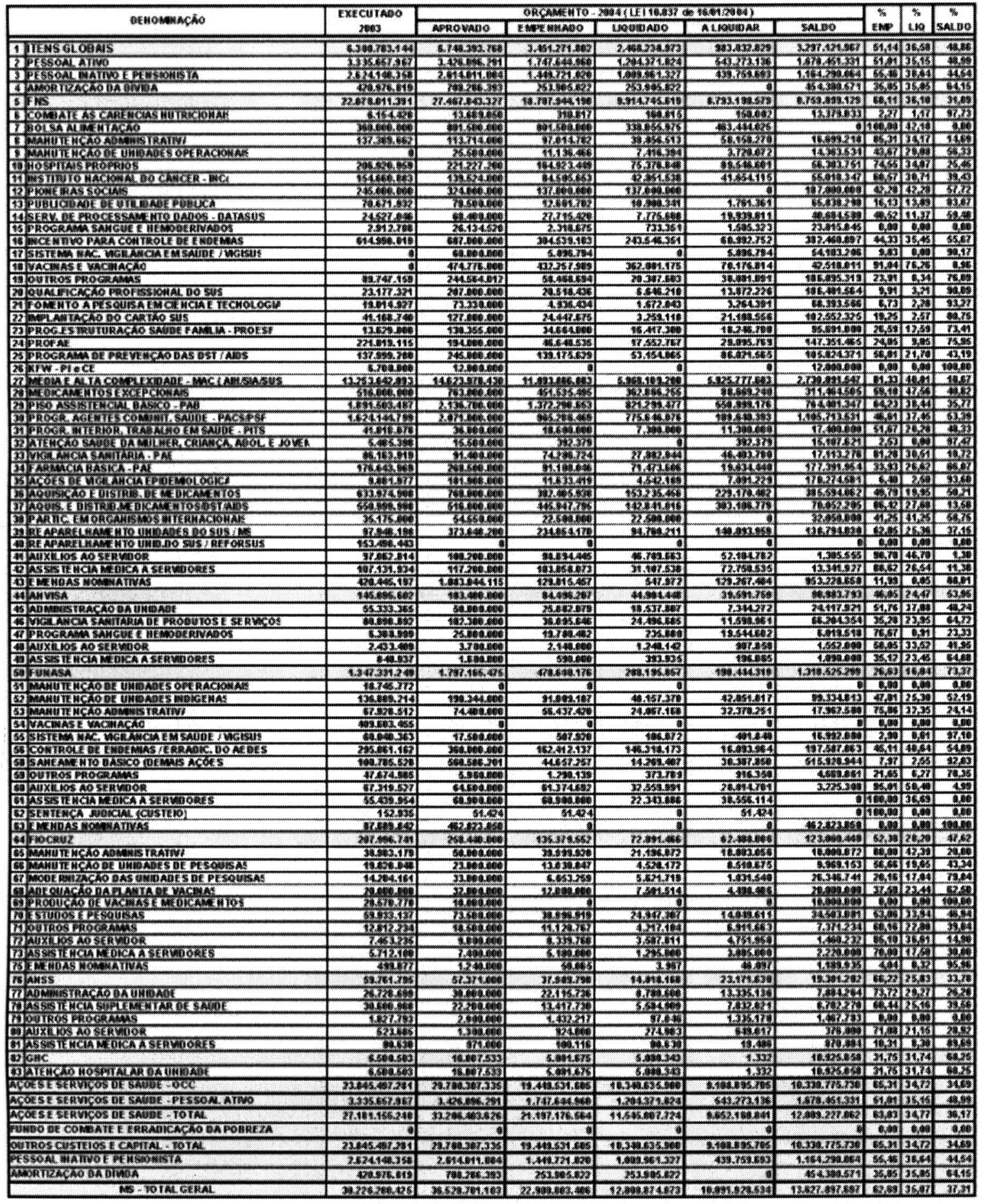

